\title{
Exploring Quality of Learning and Teaching Experiences in Higher Education using the Theory of Constraints: \\ Kenya and New Zealand
}

\author{
By \\ Sarah Wambui Kimani
}

\begin{abstract}
A thesis
submitted to Victoria University of Wellington

in fulfilment of the requirements for the degree of

Doctor of Philosophy
\end{abstract}

Victoria University of Wellington

2015 


\begin{abstract}
The purpose of this study is to examine the quality of learning and teaching (L\&T) experiences in higher education (HE) and the effect of undesirable factors on the achievement of L\&T goals with an aim of assisting key stakeholders to improve the quality of L\&T.
\end{abstract}

As a qualitative study, the theory of constraints (TOC) methodology is espoused as a suitable framework that guided the construction of the interview guide and the analysis of data. The research is conducted in two business schools, one in Kenya and another in New Zealand (NZ). Three different groups of stakeholders were involved in each business school: students, lecturers and senior administrators. To collect data from students, focus group discussions were used, while personal interviews were used to collect data from lecturers and senior administrators.

Findings indicate that the goals of L\&T are not commonly understood within the two business schools, and that there are very few critical root causes that cause many undesirable factors that impact on the quality of experiences of L\&T. In Kenya, two critical root causes were identified: bureaucratic structure of the university and limited government funding. In NZ one critical root cause was identified: research is given more priority than teaching.

Since the study only explored quality of L\&T in two business schools, collection of more data in other faculties is required to provide more general findings. The use of TOC methodology in HE sector is limited. It therefore produces a platform for further studies. Nevertheless, the findings have practical implications to key stakeholders who could explore resolutions to one or two critical root causes of undesirable factors that impact on quality of L\&T experiences specific to their business school as a way to improve quality of L\&T.

This study also makes theoretical and methodological contributions. At a theoretical level, the work connects with research on L\&T in the HE literature which has pointed to the importance of goals and/or learning outcomes, but does so by providing an alternative systems perspective, TOC. TOC places high importance on first understanding the goal of a system. This goal then becomes the benchmark against which efforts are measured. The study has demonstrated, in particular, the negative effects of a lack of clear and common understanding and communication of the L\&T goals to the learning outcomes. The study also contributes to the literature through identifying the critical factors of less than desirable effects that impact the quality of experiences of L\&T in HE institutions. Its major contribution is the identification of one or two critical root causes that are specific to each business school. The use of TOC methodology in exploring quality of experiences of L\&T has identified many factors that impact on L\&T experiences, which are similar to those identified in other quality studies in HE. Relatedly, this study has shown that the TOC models, particularly the goal tree and the current reality tree models, embed assumptions, variables, and relationships that are in harmony/consonant with existing HE models of L\&T experiences. In particular this study has used Biggs 3P model to map out the cause-effect relationships of the undesirable effects of L\&T experiences and concludes that integration of the TOC models with the 3P model provides a comprehensive analysis of the L\&T system. Moreover by exploring L\&T experiences with a seemingly negative lens this study has exposed many 'critical' views that would otherwise not have surfaced. Furthermore, the use of two diverse cases brings to the fore an international perspective of the experiences of L\&T in HE sector.

With regard to the methodology, this study has undertaken a rigorous application of the TOC methodology to explore the experiences of $L \& T$ in two diverse HE sectors. The study is the first of its kind in Kenya and NZ to address these L\&T issues using the TOC-Thinking Processes (TOCTP). The use of the TOC methodology in HE has broadened the TOC body of knowledge which has been predominantly practice-led. The results of this study have demonstrated the value of the 
TOC methodology in producing useful insights about perceived quality of L\&T in the HE sector. The use of TOC methodological tools has proven to be effective in identifying very few critical factors where management could focus attention. Moreover, TOC goes beyond this identification, with recommendations focused on these key root causes rather than treating causes and effects as unrelated, focusing on symptoms rather than root causes, and providing general exhortations to do everything better. Contributions are also made in the manner of usage of the TOC-TP tools within a qualitative research framework, by using the TP tools to capture/convey/communicate the causeeffect interrelationships between factors in the L\&T system. The analysis of individual stakeholder views within each case, as well as their combined views, and cross-case analysis, is further aided by the use of TP. By weaving together the TOC's system thinking approach and the qualitative approach, this study has demonstrated that the two approaches can complement each other to enhance trustworthiness and rigor of study. 


\section{Acknowledgements}

A number of people were instrumental in the completion of this thesis.

My first thanks go to my lovingly devoted husband Elias Kiarie Kagira. You funded my PhD study whole-heartedly. You took up the roles of father and mother. Thank you for your wisdom, emotional support, and great encouragement. A man of your virtue is rare to find. Words cannot express who you really are in my life!

I am most grateful to my first supervisor, Professor Vicky Mabin. Your patience in allowing me to find my direction, your encouragement, and great advice are immeasurable. Thanks for the freesias. They were exhilarating. Thanks for the Christmas fruit cake, and Easter egg chocolate, they were delicious! Thanks for the moments we spent together it was always lovely. You mentored me all the way. Thanks for always being there for me. You are my role model. Thanks to you Professor John Davies, my second supervisor. You always re-assured me with confidence while I was in doubt. Your feedback particularly on academic writing was thrilling. I acknowledge your special dedication and perseverance to go through my thesis, word by word, not once, but repeatedly. You inspired me with these special talents.

I thank NACOSTI for giving me the national permit to carry out this study in Kenya. I also thank the University of Nairobi, office of the deputy Vice Chancellor (research, production \& extension) for giving me permission to carry out this study at the School of Business. My special thanks to Mr. Bernard Mwangi for your great support during data collection in Kenya.

Thanks to the Dean of Victoria Business School, Professor Bob Buckle for your approval to conduct this study at VBS.

I am truly indebted to all my participants from Kenya and New Zealand who took part in this study. Thank you for your willingness to participate, your honesty, and openness that you shared with me. Thank you also for your feedback at different stages of this study.

I also wish to thank the academic and administrative staff at VBS who provided me with important input or support during this study. Thanks to you Emeritus Professor Lawrie Corbett for taking me through the quality management course. My special thanks to Dr. Sally Riad, Dr. Arun Elias, Dr. Todd Bridgman, and Megan Key. Many thanks to Sue Robinson for proofreading this thesis.

Many thanks go to the Catholic University of Eastern Africa (CUEA) for granting me study leave. Special thanks to Victoria University of Wellington, Victoria Business School, and the School of Management for the various forms of funding and grants that you offered at various stages of my $\mathrm{PhD}$ (data collection funding, conferences funding, equity grants \& thesis submission scholarship). Without this support, I would not have been able to complete this study.

Hearty thanks to my wonderful family for your prayers and unfailing support. Special thanks to my lovely daughters, Shirleen and Zawadi. Thank you Shirleen for always saying to me, 'and mum, remember to always be happy' and Zawadi you always said amidst tears on skype 'I love you mummy'. Sorry Zawadi for your tantrums at JKIA airport. Thanks to dad and mum, the Kiome's, and Kagira's family for your prayers. Special thanks to you Dr. Diana and your family 
for the social support you offered to my family. You always stepped in for me. Thanks Olpha and Patroba of CUEA, for being true friends to me. Shukrani.

To my Elim church life-group members: Naomi, Chinee, Irese, Diane, and Lola. Thank you all for your prayers and social support throughout my PhD journey. To Sarah Pinto, thank you for your wonderful company, prayers, and social support at Stafford House. Thanks too for your company during prayers at St. Gerard's Monastery, Mt. Victoria.

My special thanks to Maryam, Ali, and Tuba, my NZ family. You have a special place in my heart. Thanks for all your social and emotional support during my stay in NZ.

Thanks to my PhD fellows-Jay Newdick, Simon Scott, Sandra Goh, Rubeena, Gloria, Thao, Zuraida, Lien, Hongxia, and Jessicah. Thanks for your wonderful great smiles, they kept me going. And Eli Mada, you are one girl I will never forget. Thanks for the Bilum. To you Mele Pea, we will remain friends forever, thanks for the Tupenu. And to you Kiri Te Hiko, thanks for educating me about Māori culture.

Finally, to all of you who have in one way or another contributed towards my completion of this study, I say, THANK YOU VERY MUCH. 


\section{Table of contents}

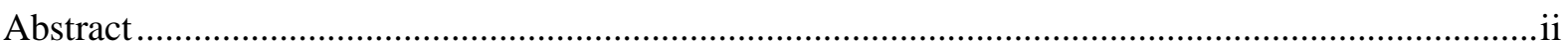

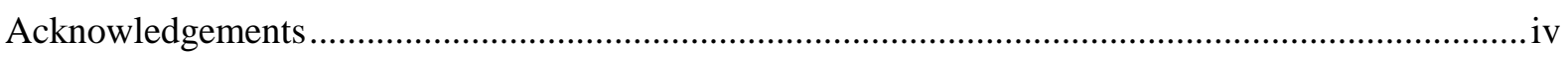

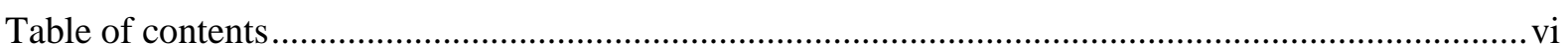

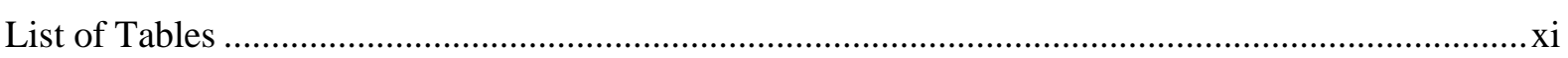

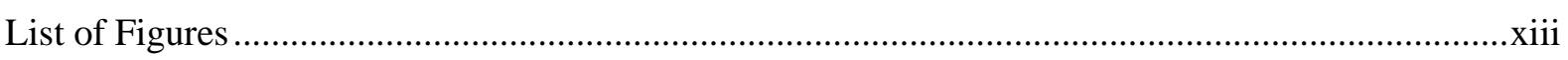

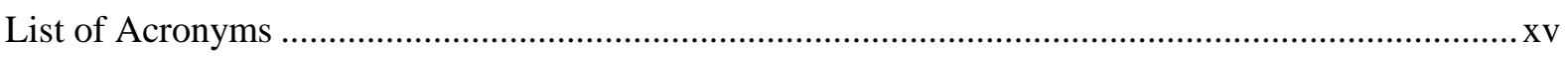

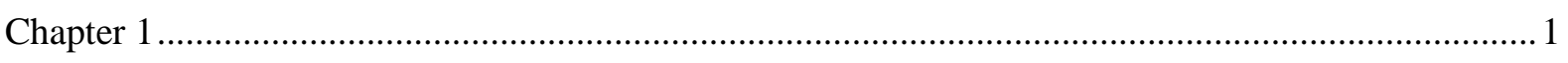

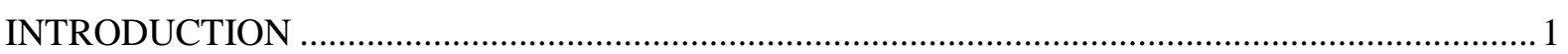

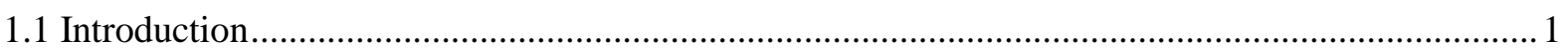

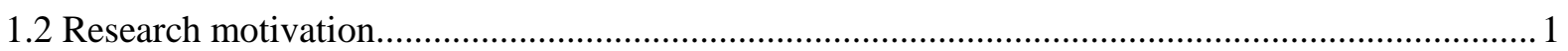

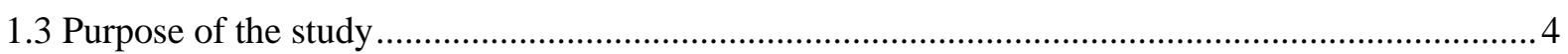

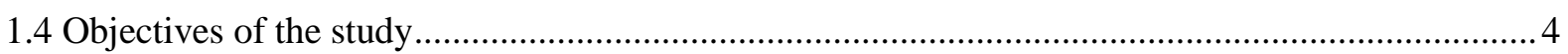

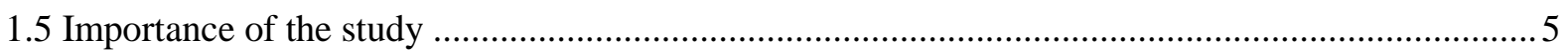

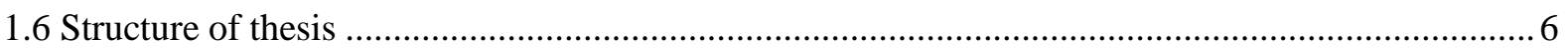

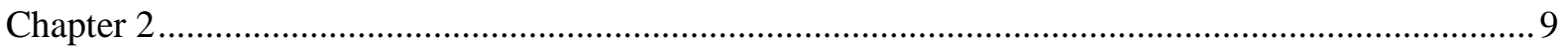

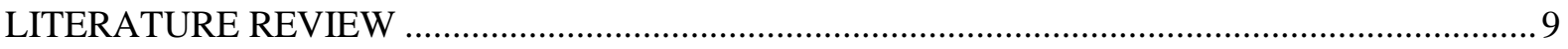

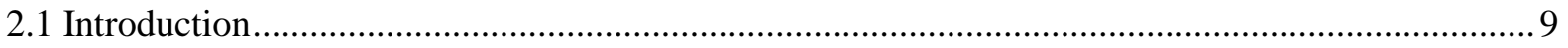

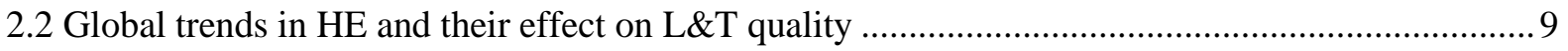

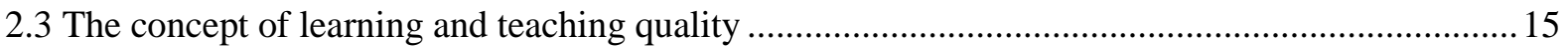

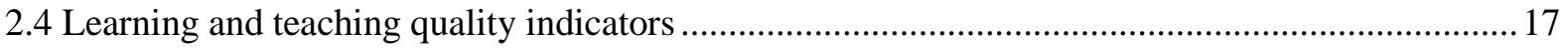

2.5 The quality of learning and teaching (L\&T) experiences: students' perspective............................21

2.6 The quality of teaching and learning: lecturers' perspective .........................................................24

2.7 Quality management models and their applications to HE: insights and limitations......................26

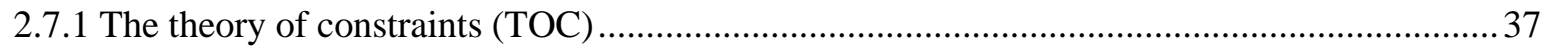

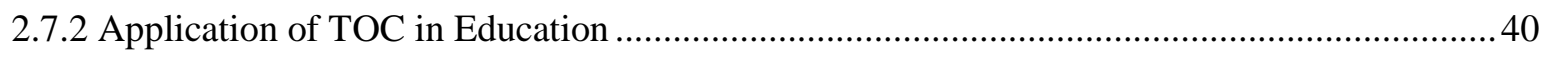

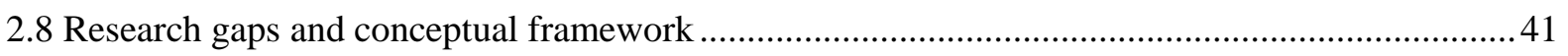

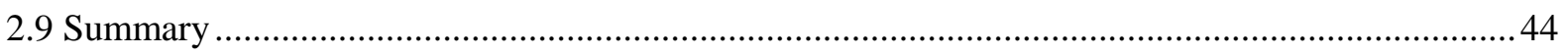

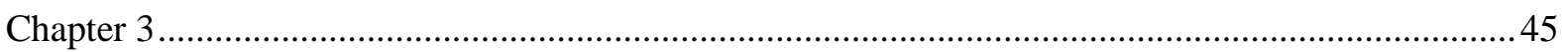

THEORY OF CONSTRAINTS AS A RESEARCH METHODOLOGY …....................................... 45

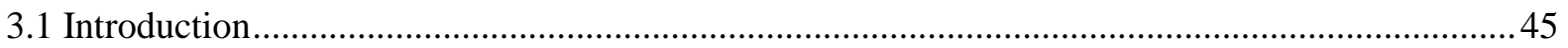

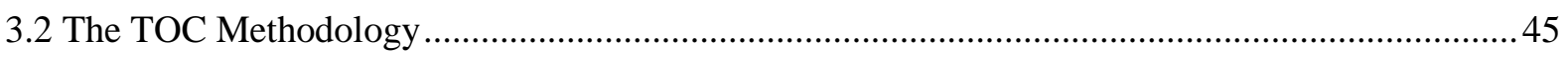

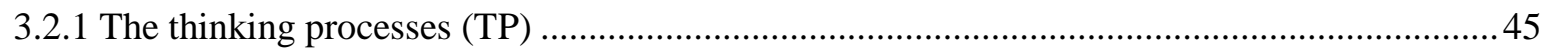

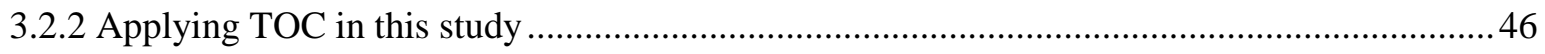

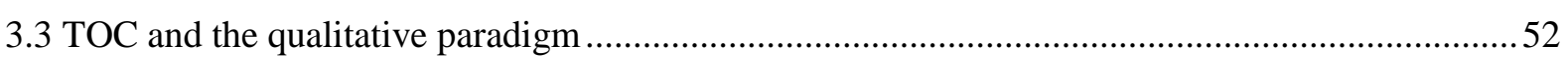




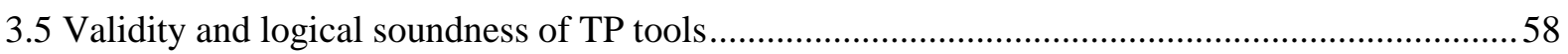

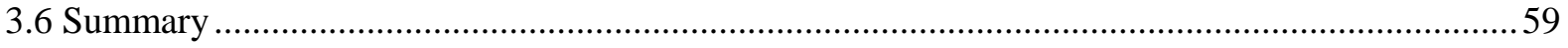

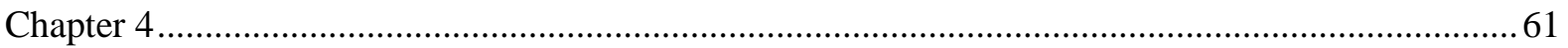

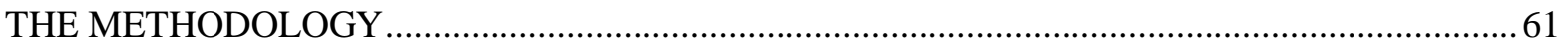

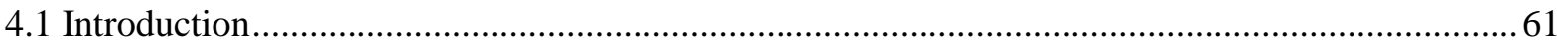

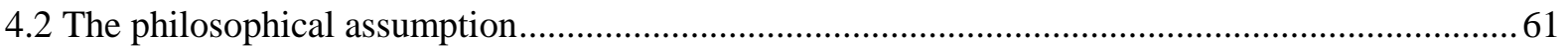

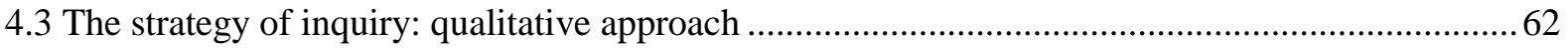

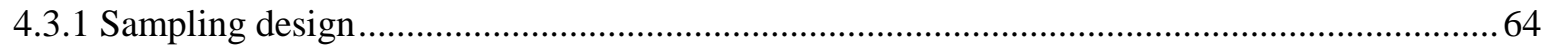

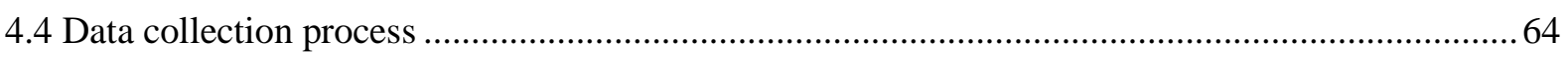

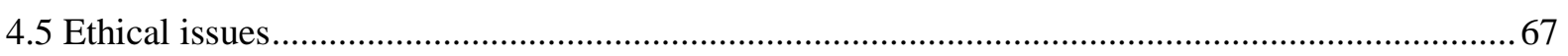

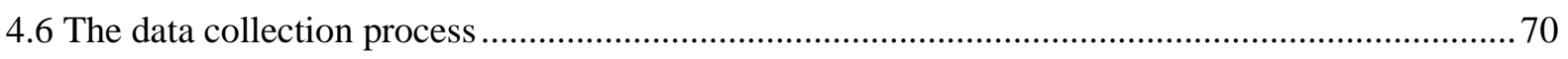

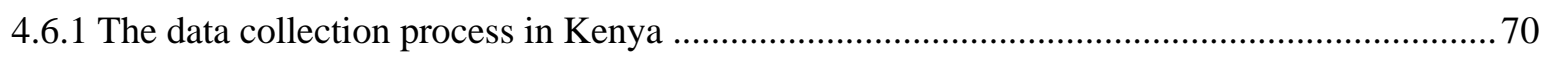

4.6.2 The data collection process in New Zealand......................................................................... 79

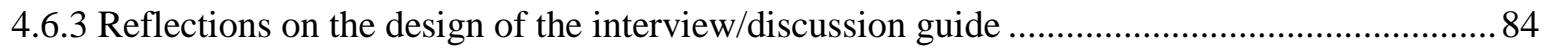

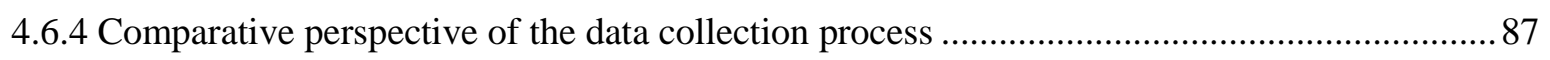

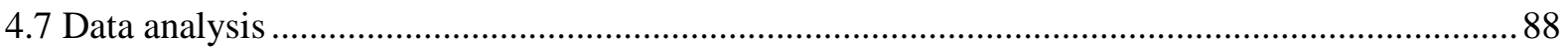

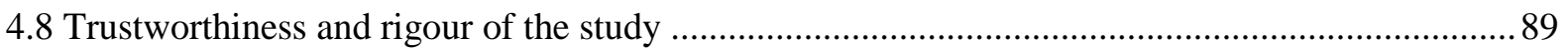

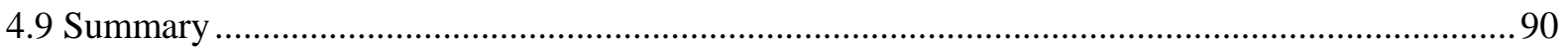

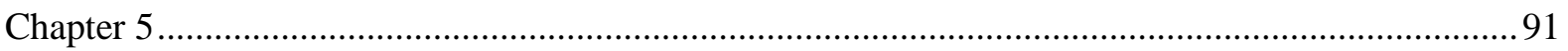

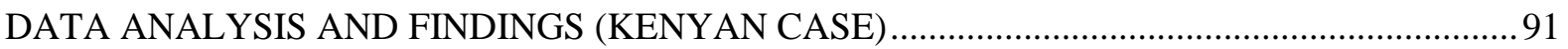

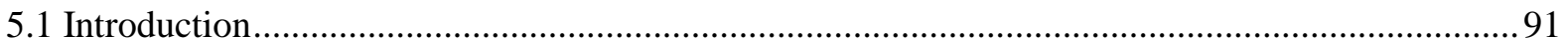

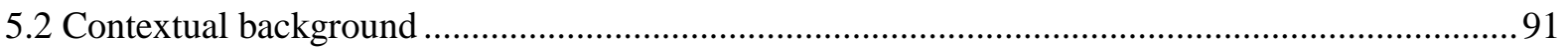

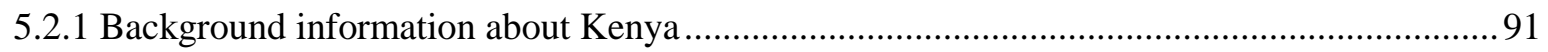

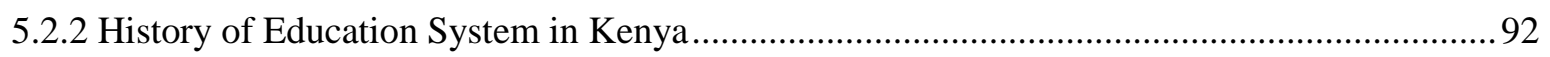

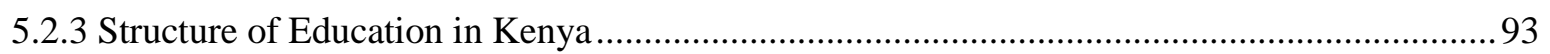

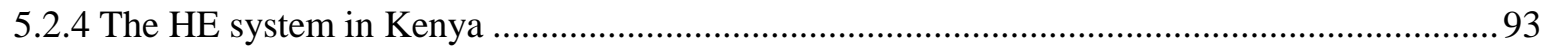

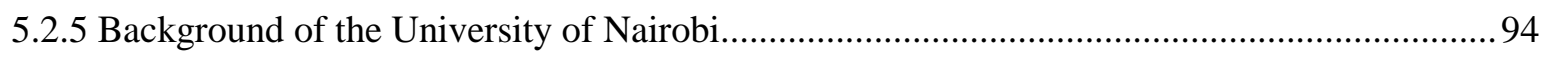

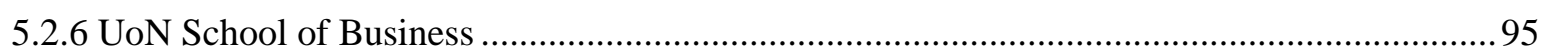

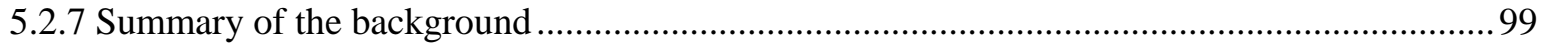

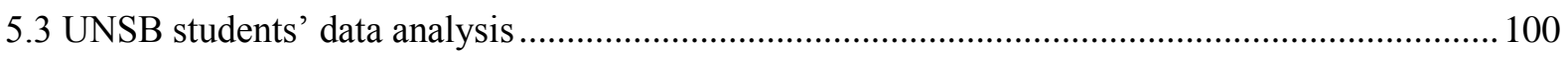

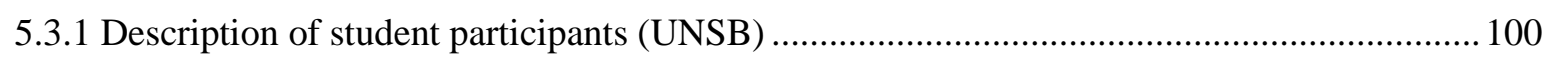

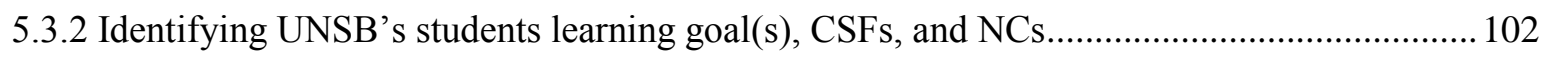

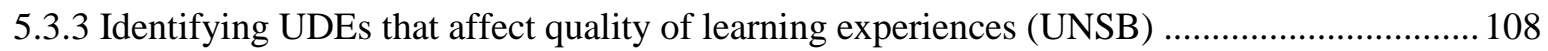

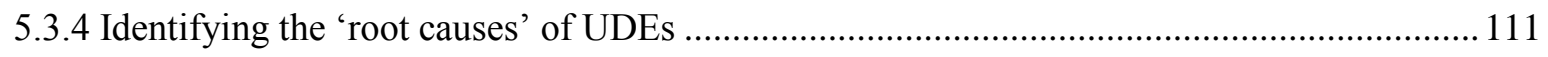

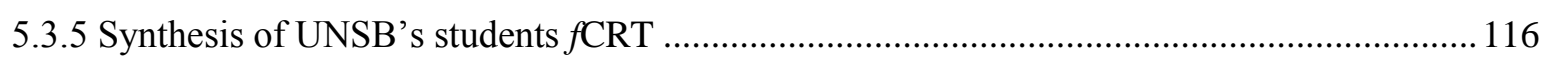

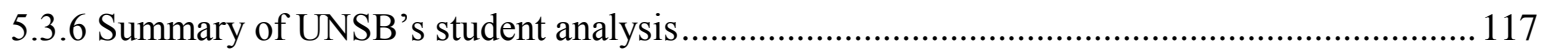


5.4 UNSB lecturers data analysis

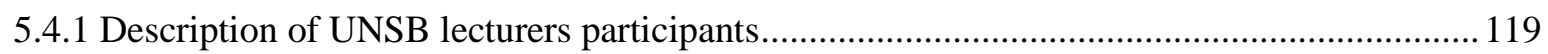

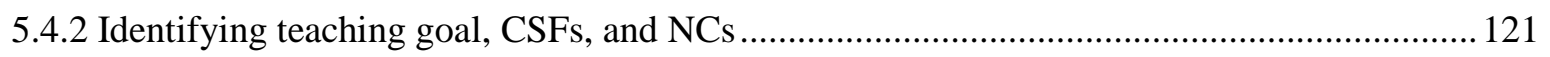

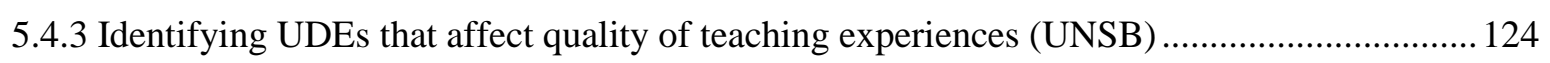

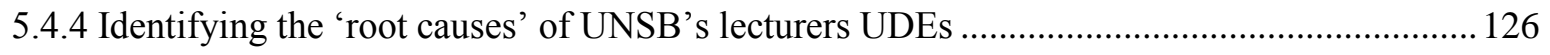

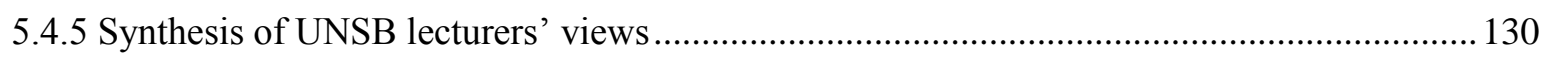

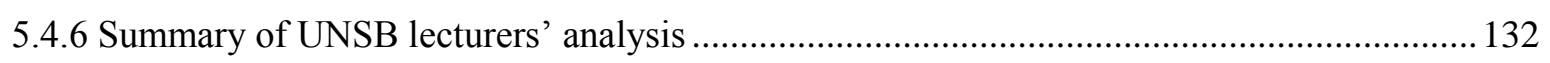

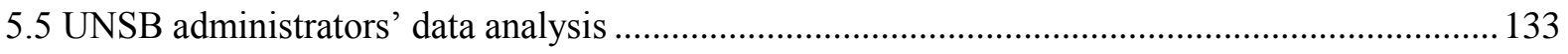

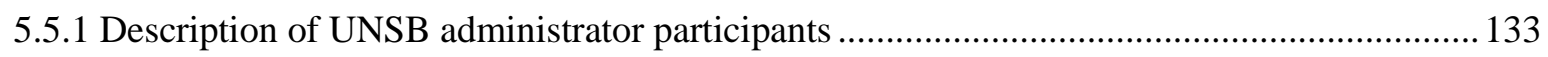

5.5.2 Identifying UNSB administrators goal, CSFs, and NCs .............................................. 134

5.5.3 Identifying UDEs that affect quality of L\&T experiences of UNSB administrators ............. 137

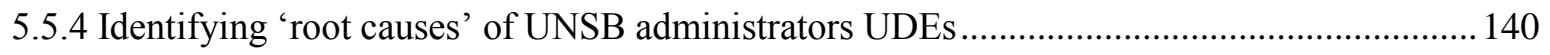

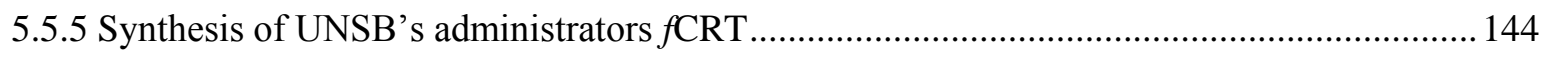

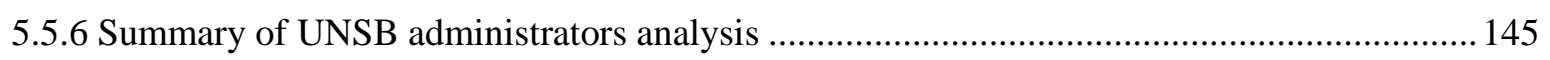

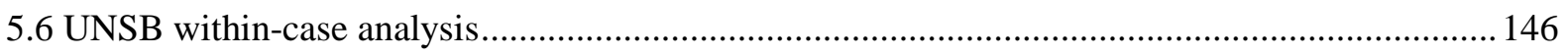

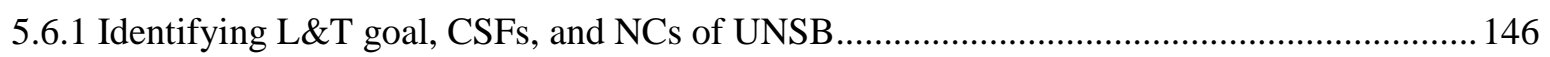

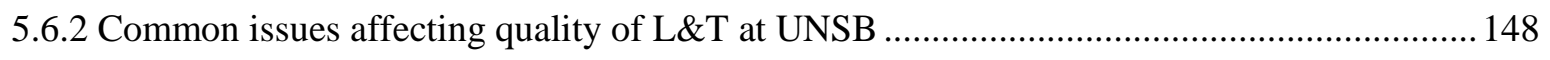

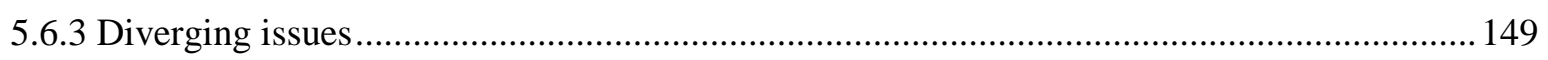

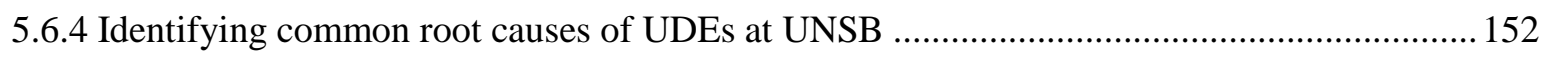

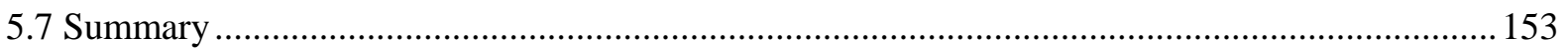

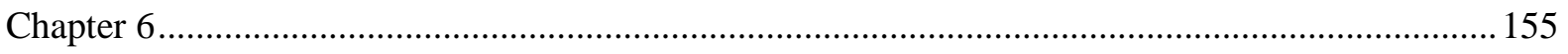

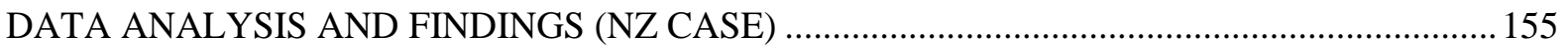

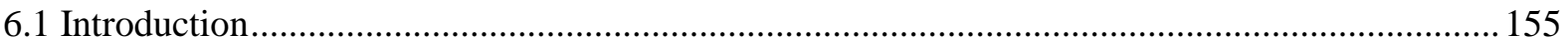

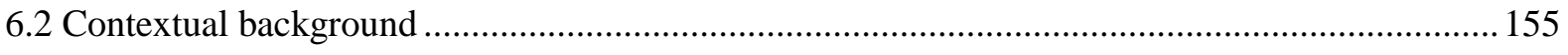

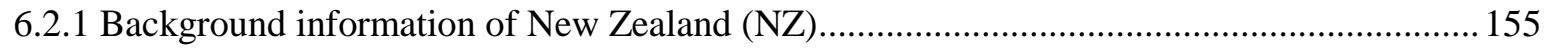

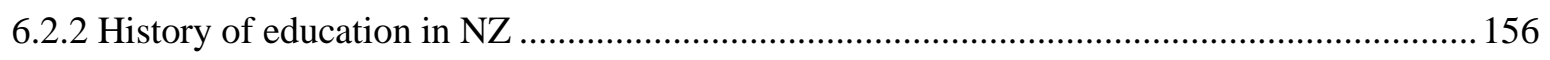

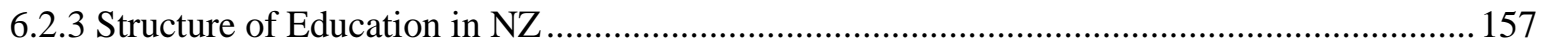

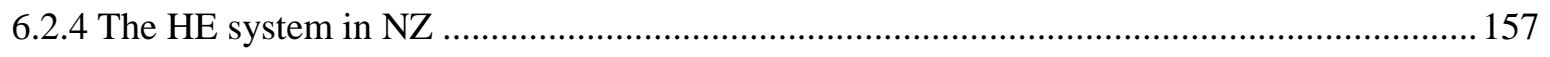

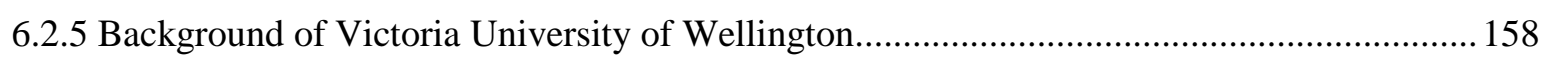

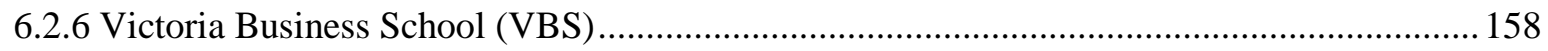

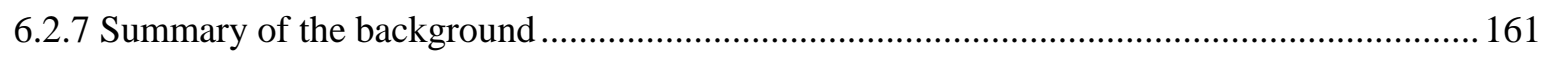

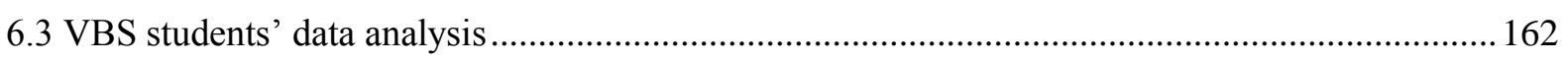

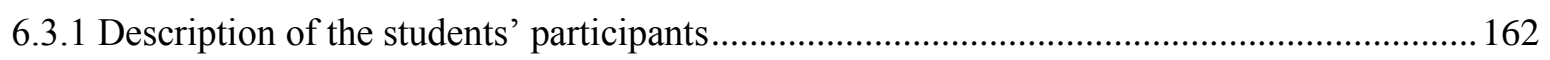

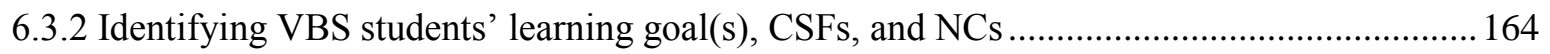

6.3.3 Identifying UDEs that affect the quality of learning experiences (VBS) ............................... 169

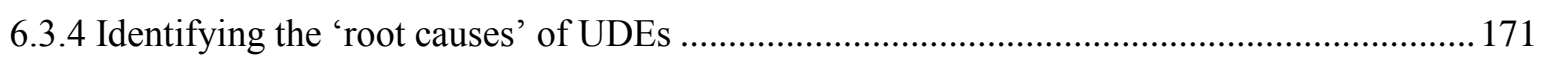

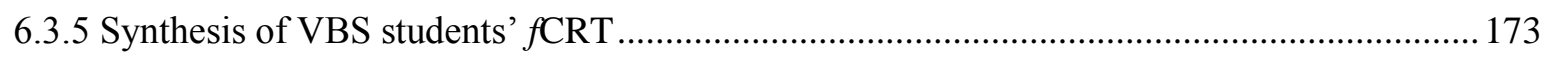

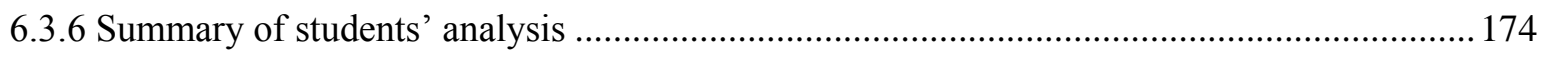


6.4 VBS lecturers' data analysis

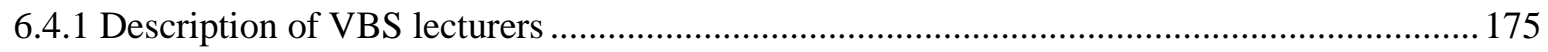

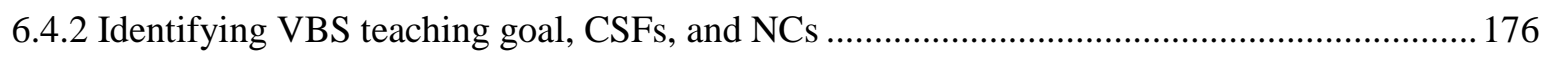

6.4.3 Identifying UDEs that affect quality of teaching experiences (VBS) .................................... 182

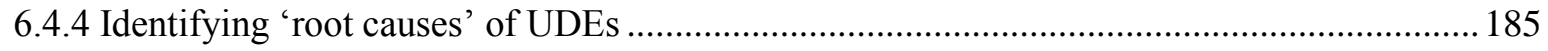

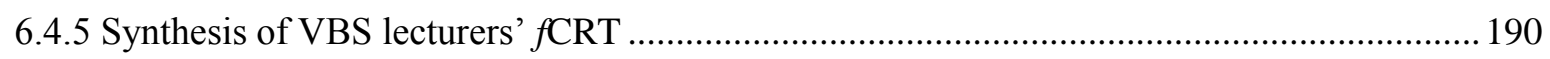

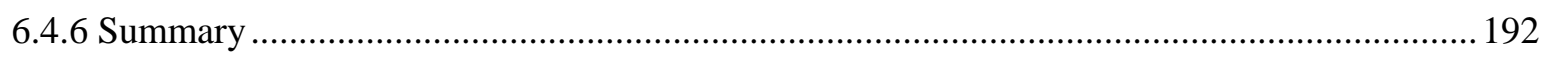

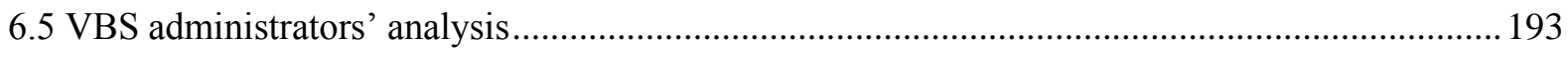

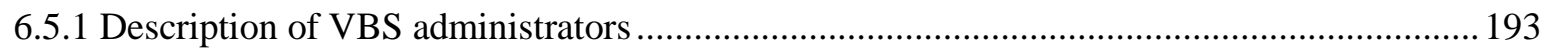

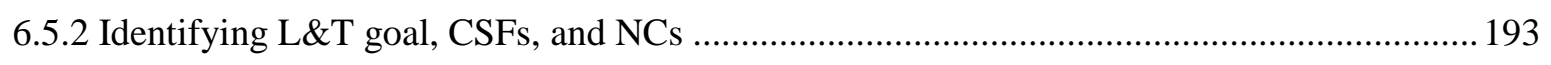

6.5.3 Identifying UDEs that affect quality of L\&T experiences of VBS administrators ................ 197

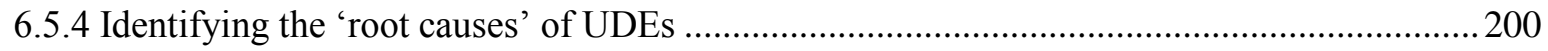

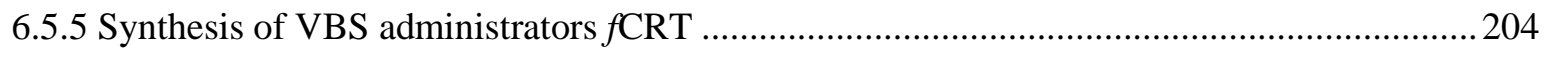

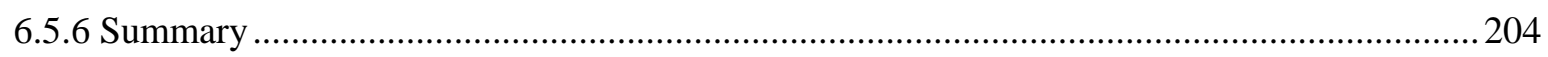

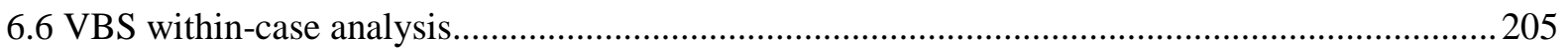

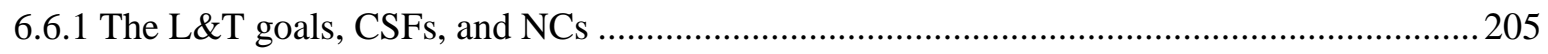

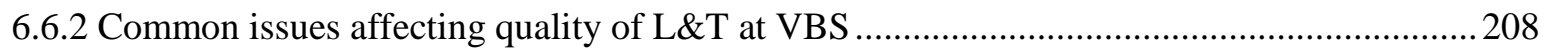

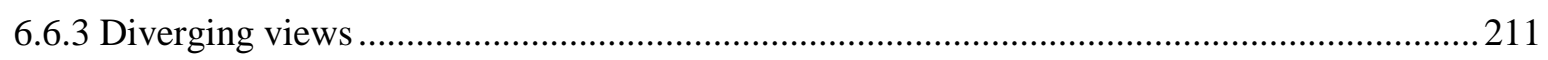

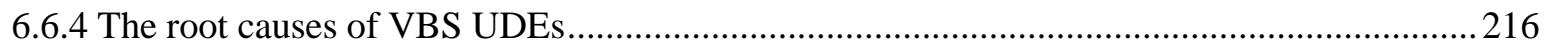

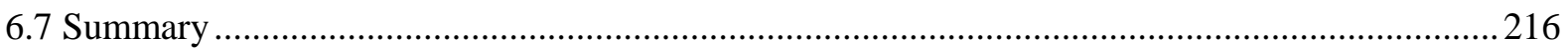

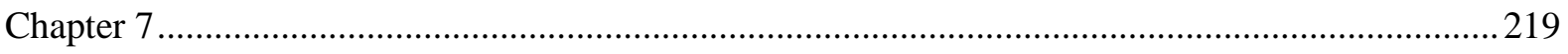

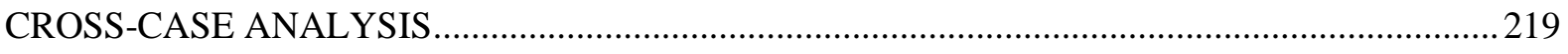

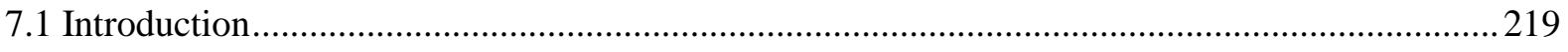

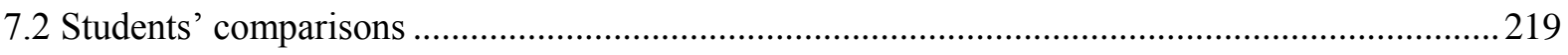

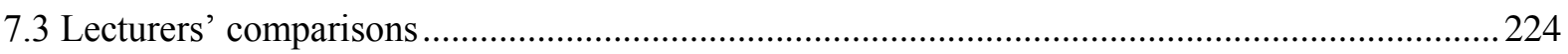

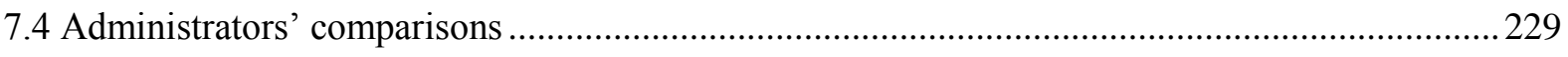

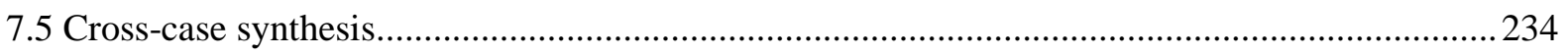

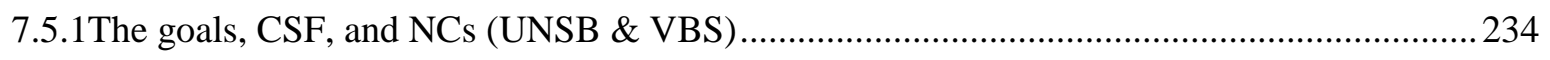

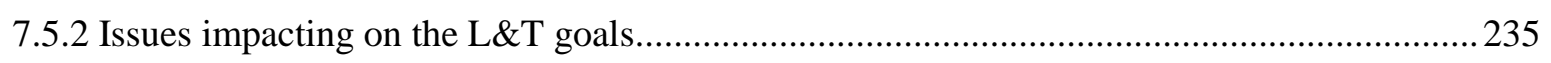

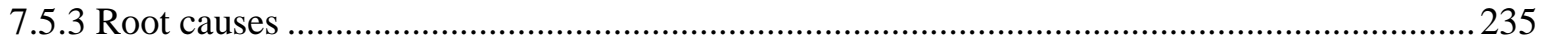

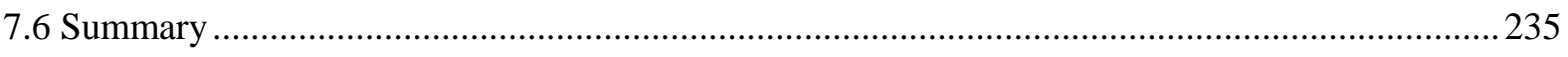

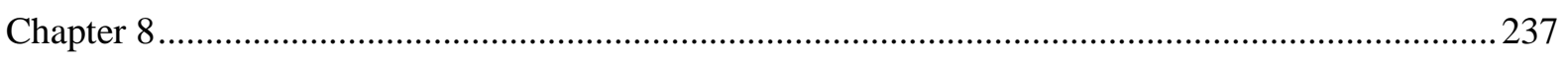

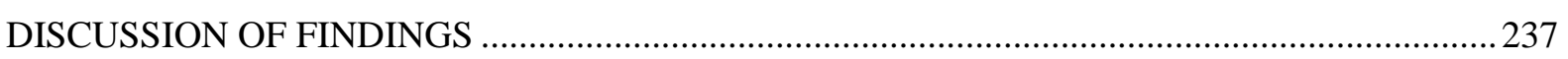

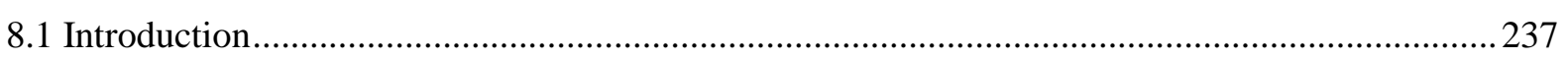

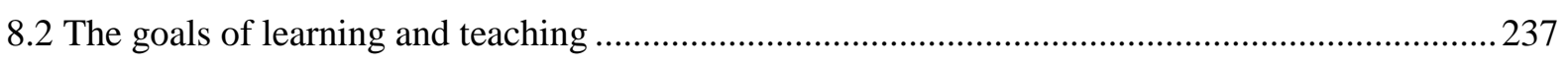

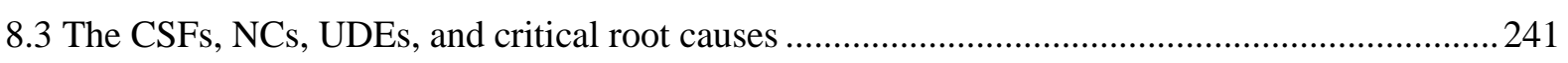

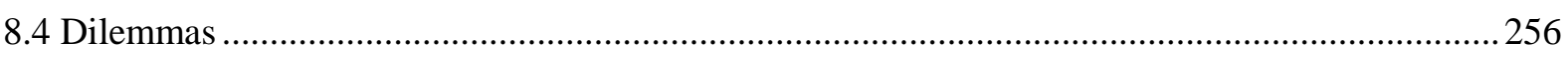




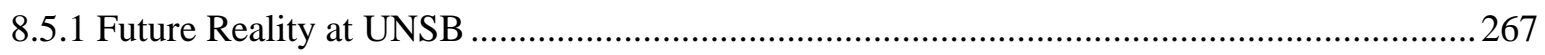

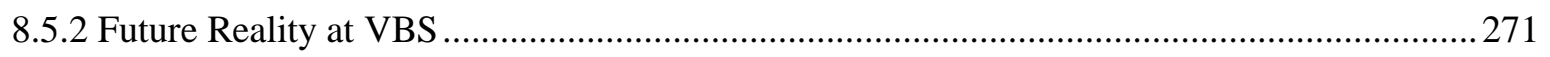

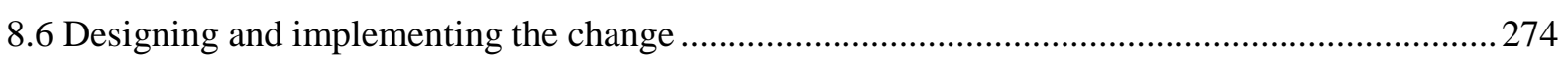

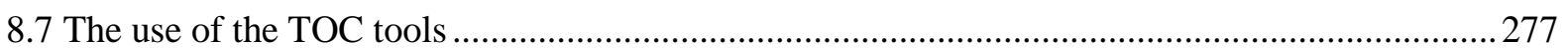

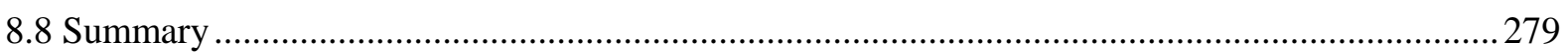

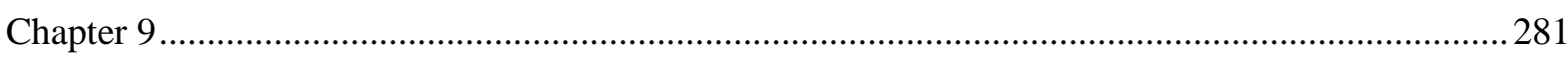

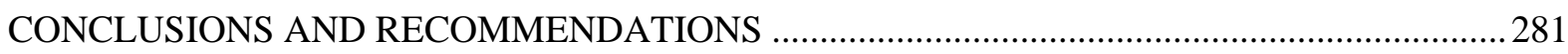

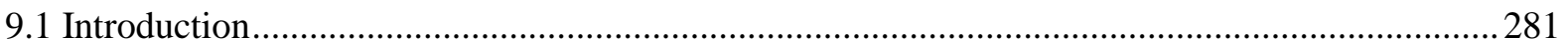

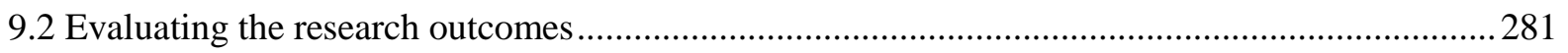

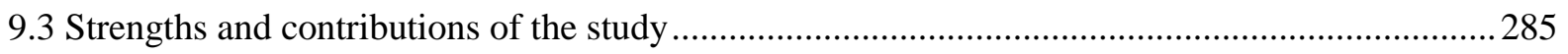

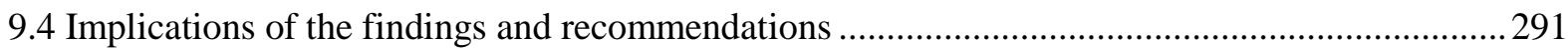

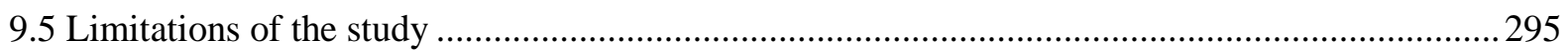

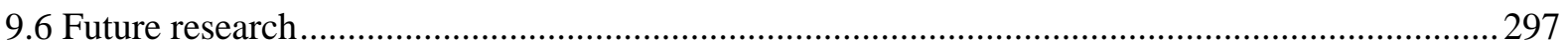

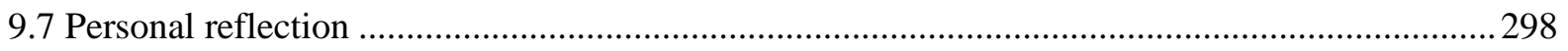

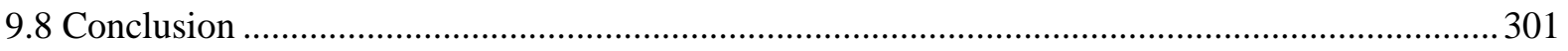

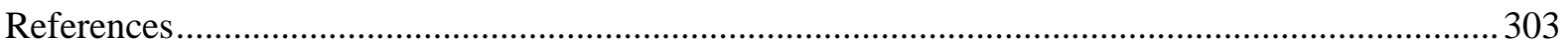

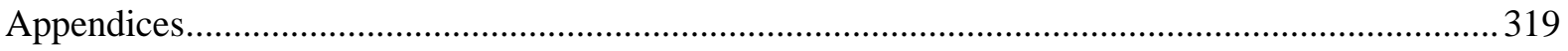

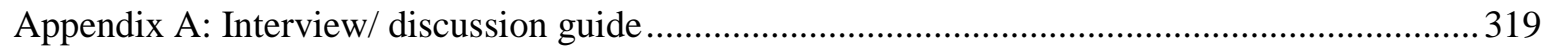

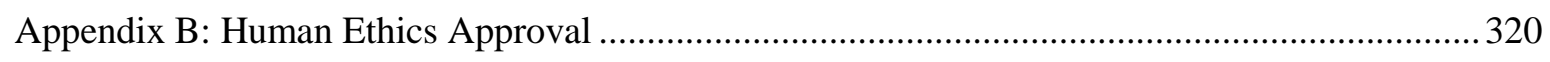

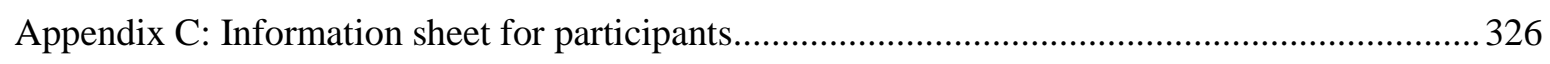

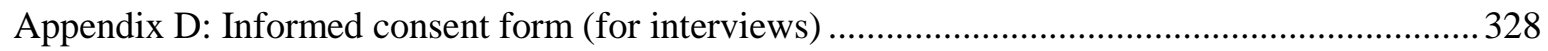

Appendix E: Research Authorisation \& Clearance Permit ............................................................ 329

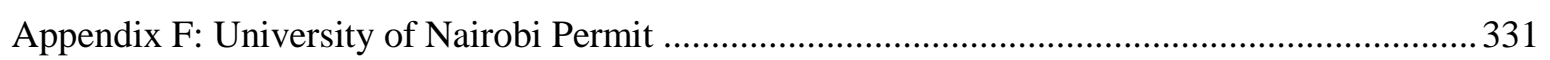

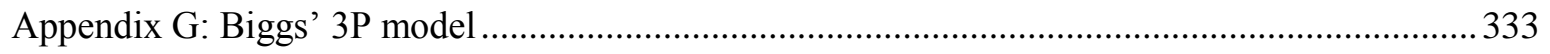

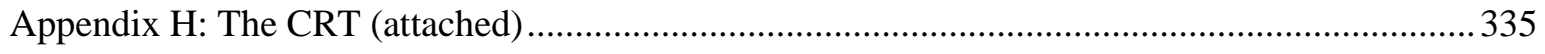




\section{List of Tables}

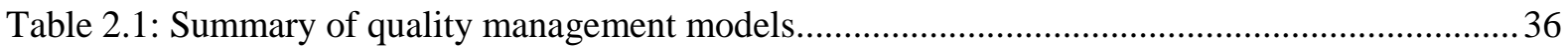

Table 3.1: Relating the change sequence questions to logic trees ....................................................51

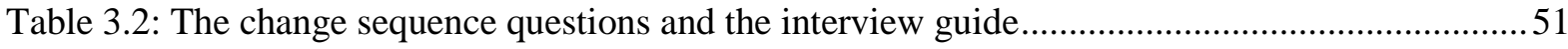

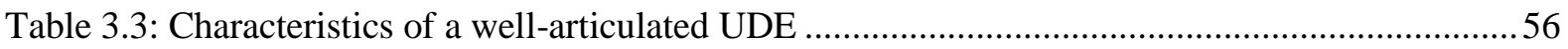

Table 3.4: Summary table showing data collection methods, data forms and validity checks .............58

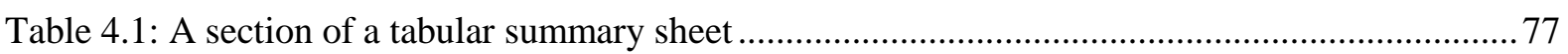

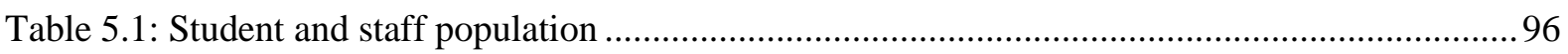

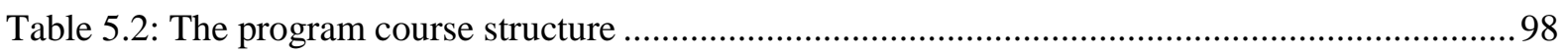

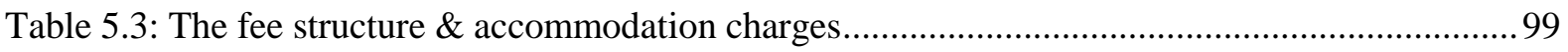

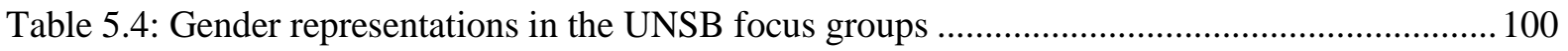

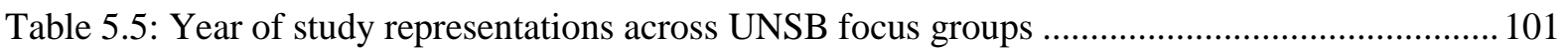

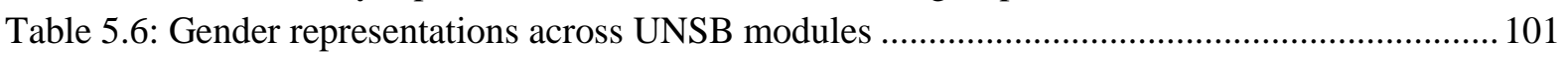

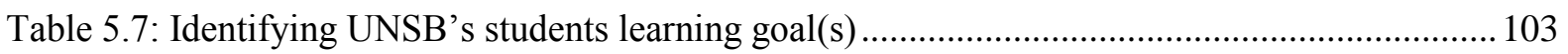

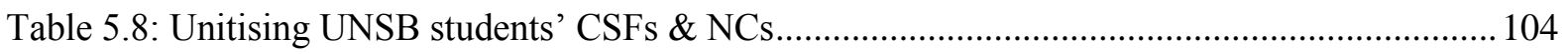

Table 5.9: Issues impacting on UNSB students' quality of learning experiences .............................. 108

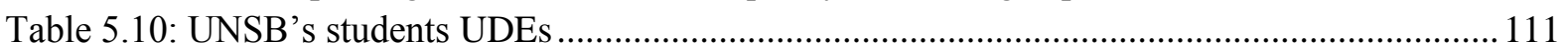

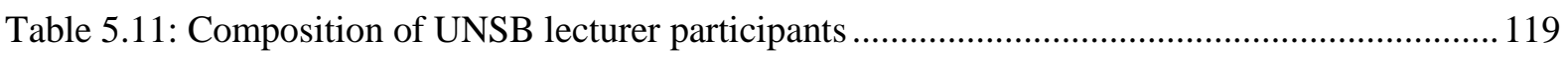

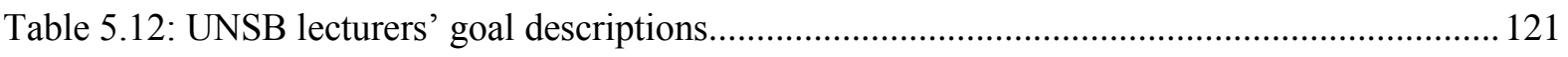

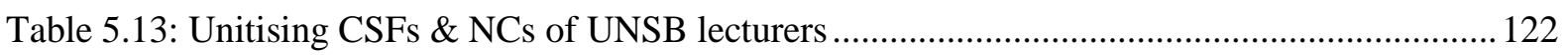

Table 5.14: Issues impacting on UNSB lecturers' quality of L\&T experiences ................................. 124

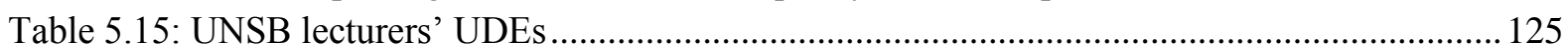

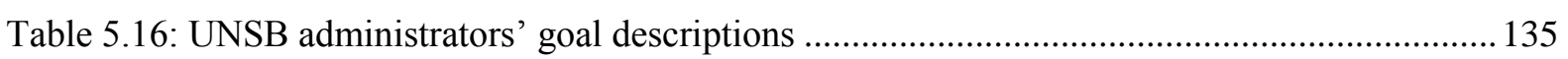

Table 5.17: Identifying CSFs and NCs of UNSB administrators .................................................. 136

Table 5.18: Issues impacting on quality of L\&T experiences of UNSB administrators.................... 138

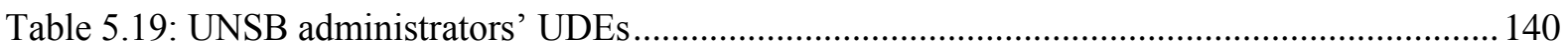

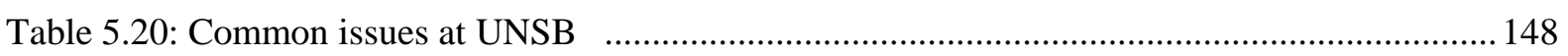

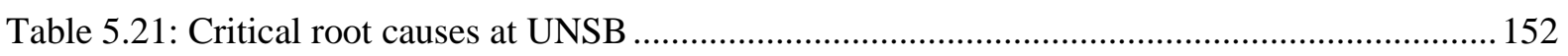

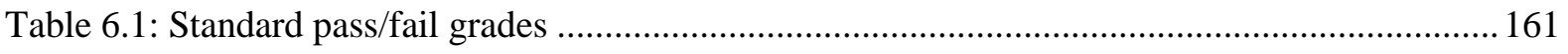

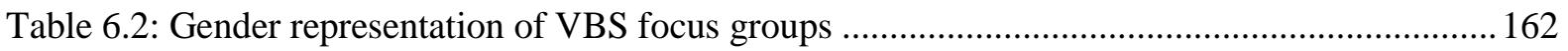

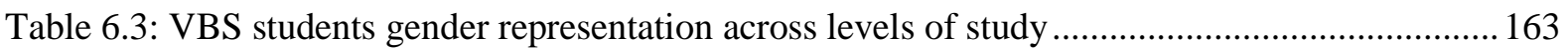

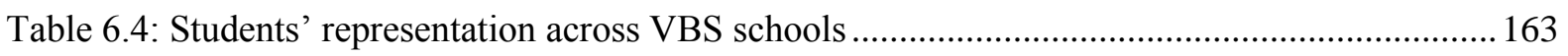

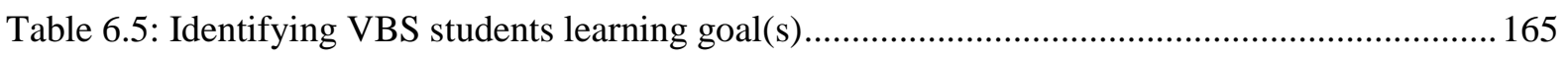

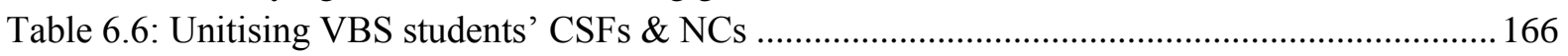

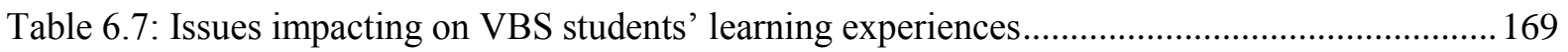

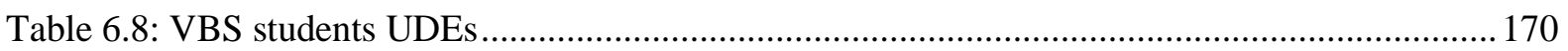

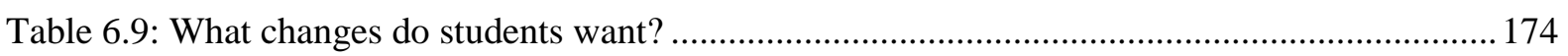

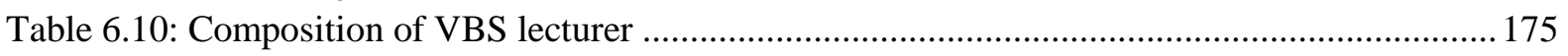

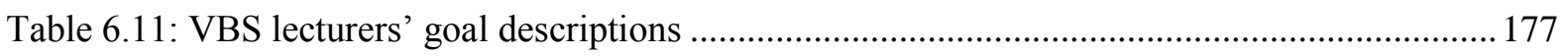

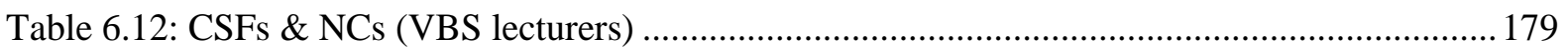

Table 6.13: Issues impacting on VBS lecturers' quality of experiences of L\&T ................................ 182

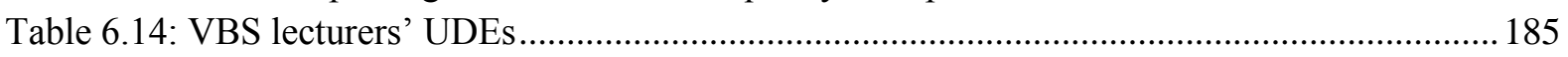

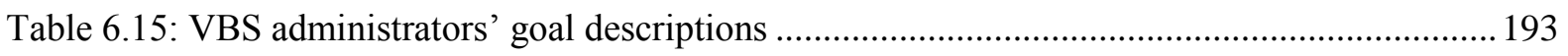




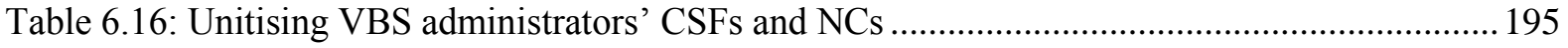

Table 6.17: Issues impacting on quality of L\&T experiences of VBS administrators........................... 197

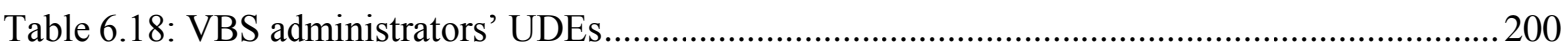

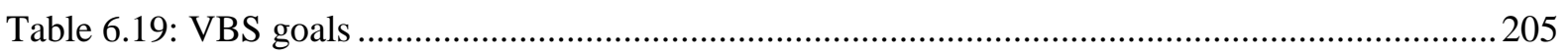

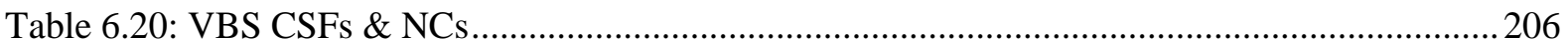

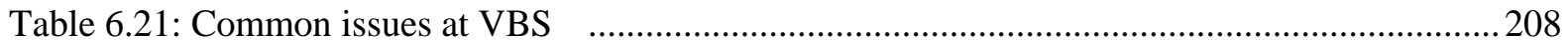

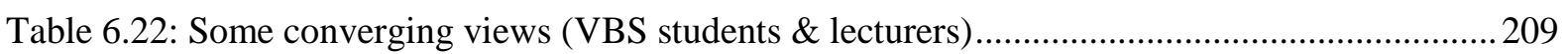

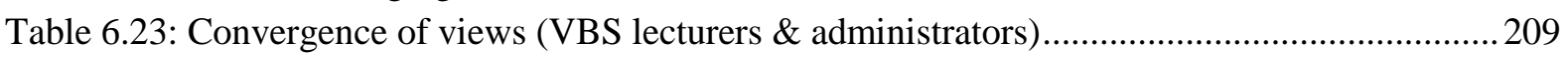

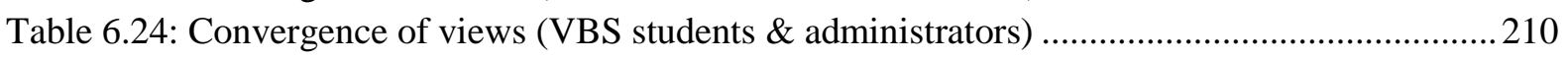

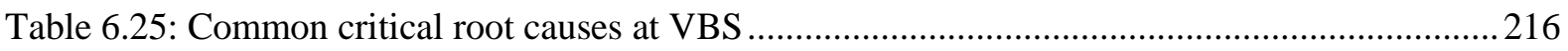

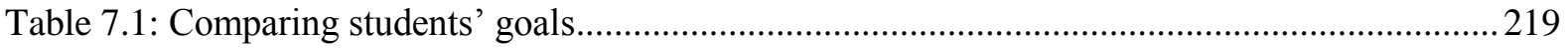

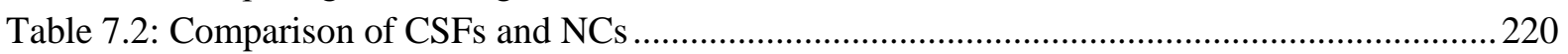

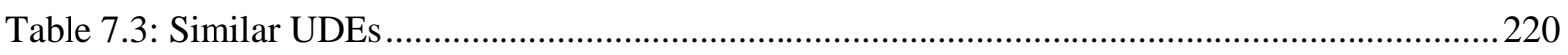

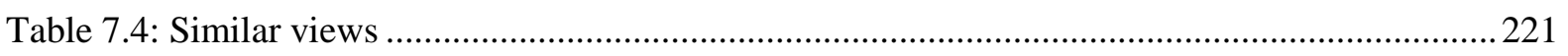

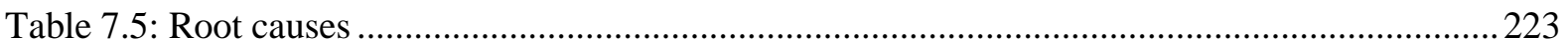

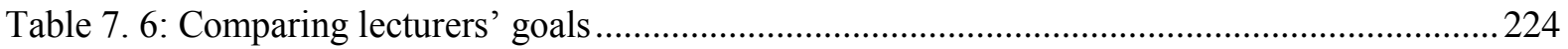

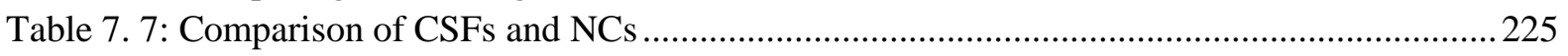

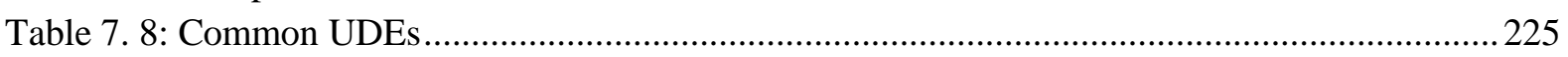

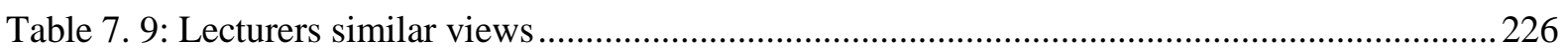

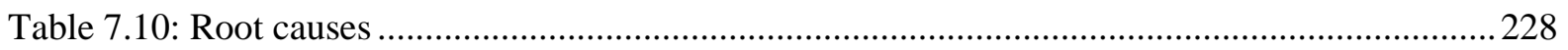

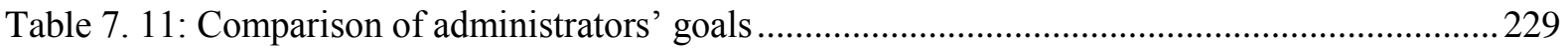

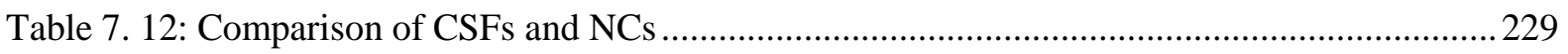

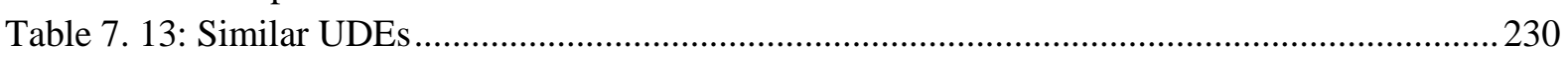

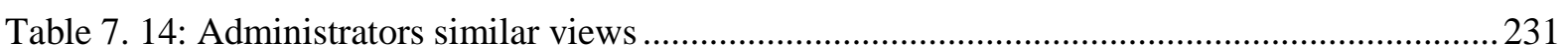

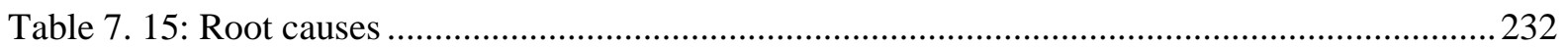

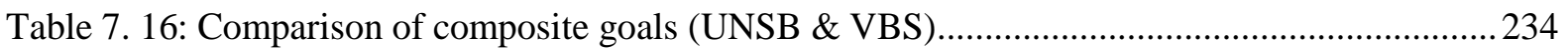

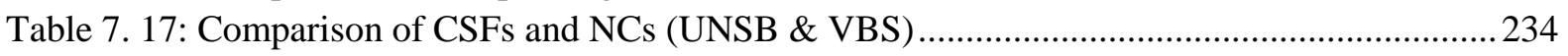

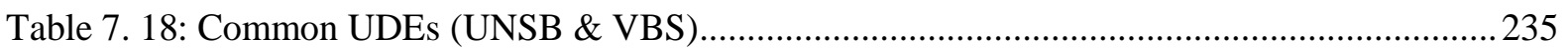

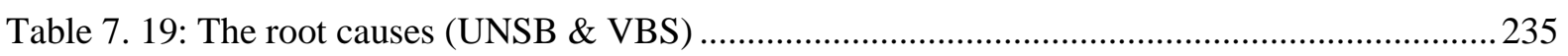

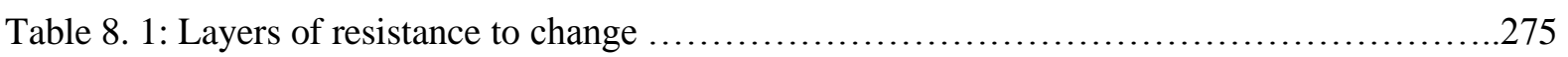

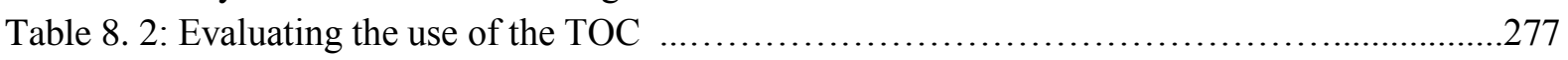




\section{List of Figures}

Figure 2.1: Conceptual model indicating gaps that are addressed by this study ..................................43

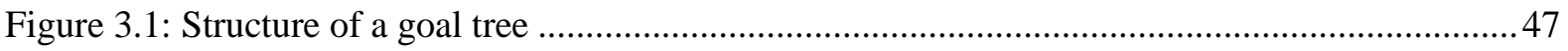

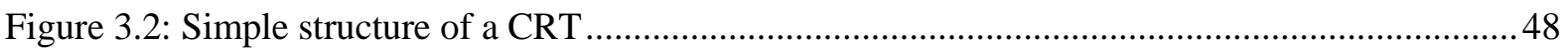

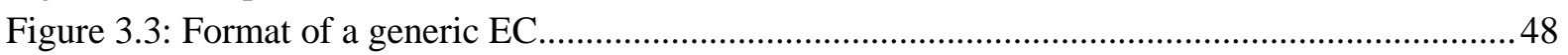

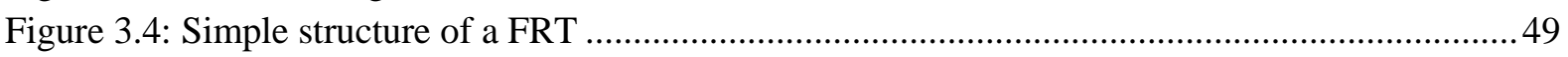

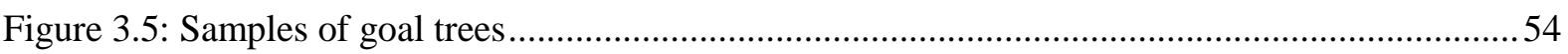

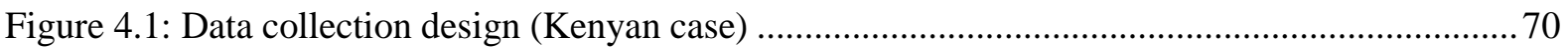

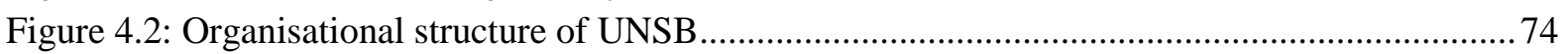

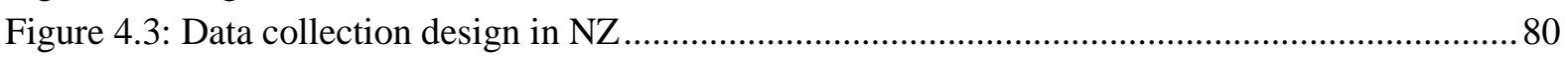

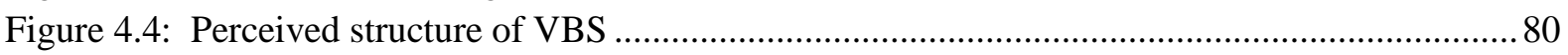

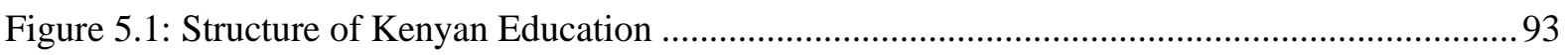

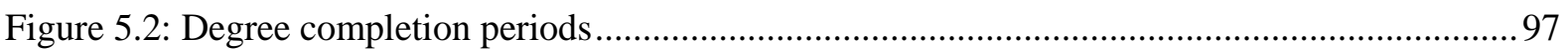

Figure 5.3: UNSB focus group discussion interview time

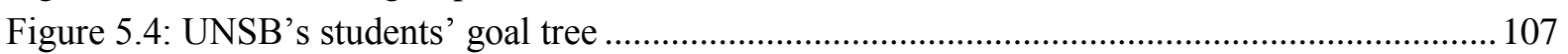

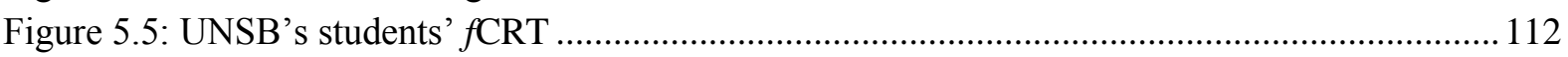

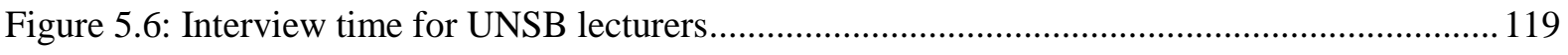

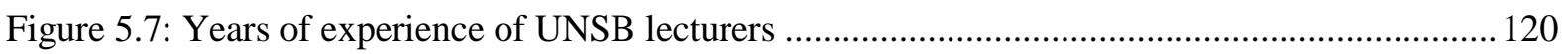

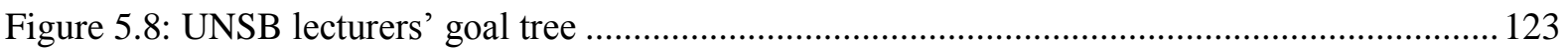

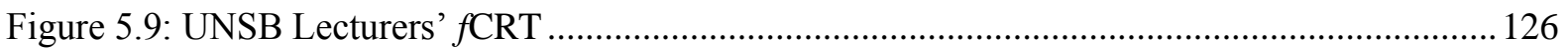

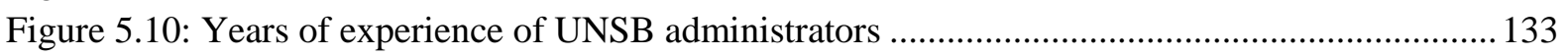

Figure 5.11: Interview time in Minutes for UNSB administrators ................................................ 134

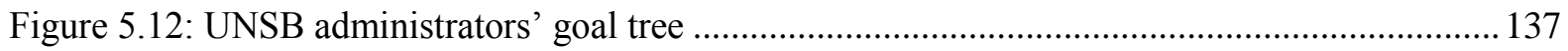

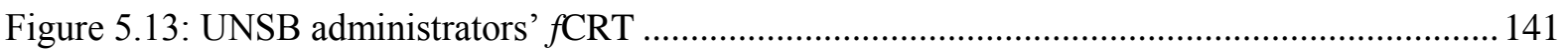

Figure 5.14: Combined goal tree of UNSB ................................................................................... 147

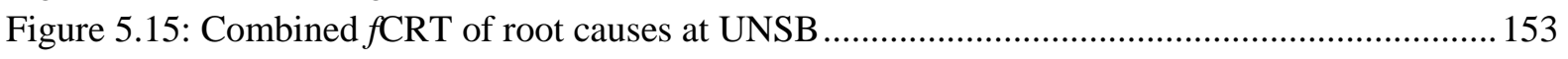

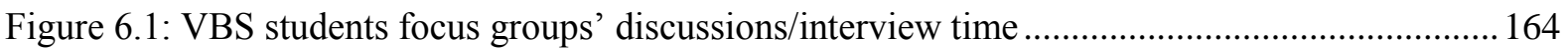

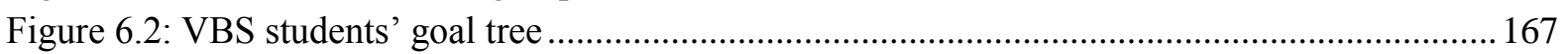

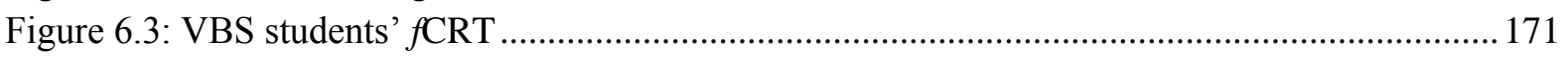

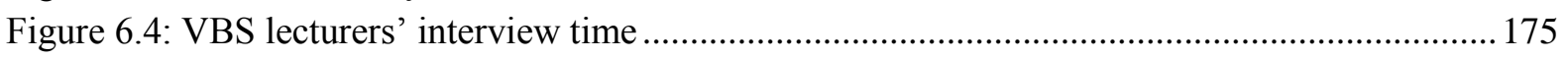

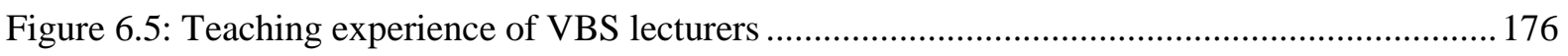

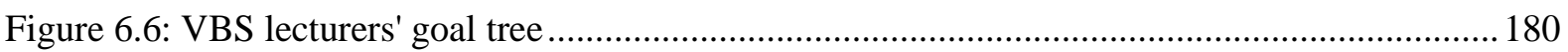

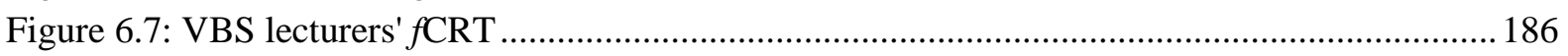

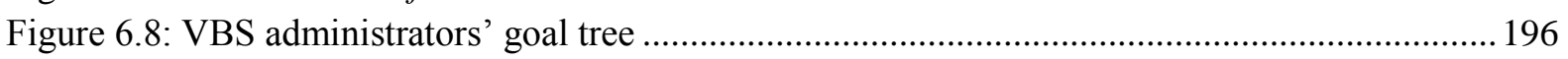

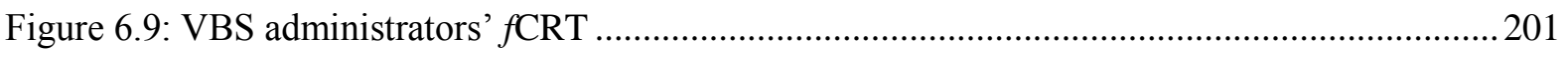

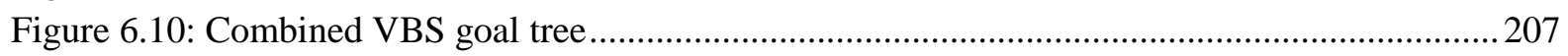

Figure 8. 1: Integration of goal tree (Dettmer), and fCRT (Ronen) with the 3P model (Biggs).........242

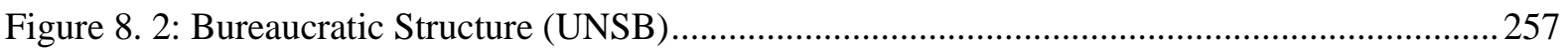

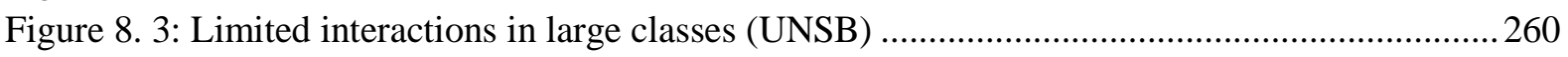




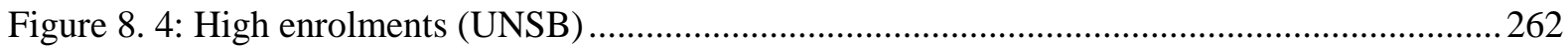

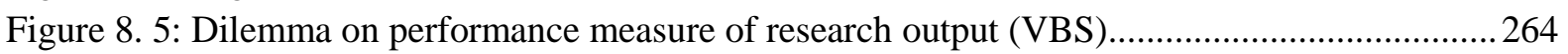

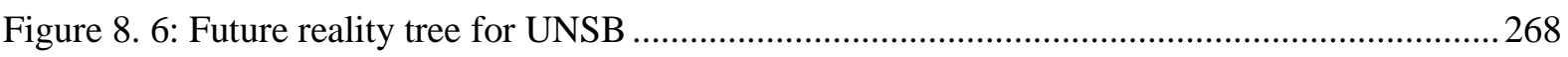

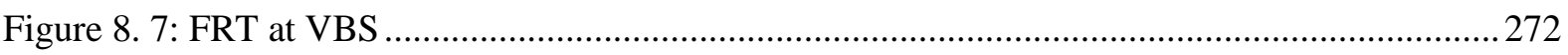




\section{List of Acronyms}

AoL Assurance of Learning

BCom Bachelor of Commerce

CLR Categories of Legitimate Reservations

CRT Current Reality Tree

CSF Critical Success Factor

CUEA Catholic University of Eastern Africa

EC Evaporating Cloud

fCRT focused Current Reality Tree

FG Focus Group

FRT Future Reality Tree

HE Higher Education

HEIs Higher Education Institutions

L\&T Learning and Teaching

MoU Memorandum of Understanding

NACOSTI National Commission for Science, Technology and Innovation

NC Necessary Condition

NZ New Zealand

PASS Peer assisted study sessions mentoring schemes,

PBRF Performance based research fund

PHELT Postgraduate Certificate on Higher Education Learning and Teaching

SC Sufficiency Condition

SLSS Student learning support services

TOC Theory of Constraints

TOC-TP Theory of Constraints-Thinking Processes

TP Thinking Processes

UDE Undesirable Effects

UNSB University of Nairobi School of Business

UoN University of Nairobi

VBS Victoria Business School

VUW Victoria University of Wellington 


\section{Chapter 1}

\section{INTRODUCTION}

In order to answer the question 'Where do we go from here?' ..., we must first honestly recognise where we are now (Martin Luther King).

\subsection{Introduction}

This chapter starts with a description of motivation for the study. It then provides the purpose, the objectives, and importance of the study. Finally, an outline of the structure of the thesis is provided.

\subsection{Research motivation}

My interest in exploring the quality of L\&T experiences in higher education (HE) arose from over ten years of teaching experience in two universities in Kenya and also from my reflection of my own university learning experience. My undergraduate learning experience was not particularly pleasant. Often, I got lost in the crowd. Even after four years of university experience and with an honours degree, upper second class, I still lacked the confidence and courage to argue my case. Nevertheless, I still managed to join an MBA program soon after finishing a BCom program.

After graduating with Masters in Business Administration (MBA), I worked with a multinational bank where I enjoyed serving bank clients. The issue of customer care was highly emphasised. After 2 years, I joined academia. The issue of customer care was not always emphasised. Which customers anyway? However, with a background of marketing, one of the courses that I regularly taught was 'marketing of services'. This course emphasised the need for quality customer service, which was related to the customer care training that I had earlier encountered in the bank. It was while teaching this course that I had my first encounter with various service quality models. The service quality (SERVQUAL) model, also known as the Gaps model (Bitner, Zeithaml \& Gremler in Maglio, Kieliszewski, \& Spohrer, 2010), was particularly fascinating to me, especially when I related it to the HE context, to my own undergraduate experience, and to those of the students that I was teaching.

In simple terms, the SERVQUAL model identifies potential gaps that form within service organisations as a result of the differences between what customers expect to experience and 
what they actually experience (Lovelock \& Wirtz, 2007, p.424). As a service quality improvement model, its ultimate goal is to recognise then close the gaps as much as possible. In relating this model to the HE environment, I was particularly curious to know how students judged the quality of the service that they received. This led me to conduct a survey (in 2008) on students' perception of service quality offered in Kenyan universities. The survey used a modified form of Higher Education PERFormance-only (HEdPERF) model that is specifically designed for higher education (Abdullah, 2006).

The results of the study indicated, contrary to my expectations, that the overall students' satisfaction in the four universities where the study was conducted was positive (Kimani, Kagira, \& Kendi, 2011). I attributed the findings to the user-based quality imperative or what user/customers perceive quality to be. But, it could also have been attributed to not explicitly understanding quality standards, against which students based their ratings. Since the study was based on a performance model, it did not indicate any gaps between expectations/desired states and actual states. It only indicated the actual experiences.

Around the same time that I was conducting the above study, the Inter-University Council of East Africa had embarked on a regional quality assurance initiative with support from the German Academic Exchange Services (DAAD) and the German Rectors Conference (HRK). I was appointed to chair internal self-assessment in the Faculty of Commerce at Catholic University of Eastern Africa (CUEA), where I worked. This two-year long project not only exposed me to local and regional workshops on quality in $\mathrm{HE}$, but heightened my interest in understanding how quality in HE could be improved.

Indeed, in Kenya, around the same period, there were some warning signals about the quality of graduates. On 8th July 2011, the Engineers Registration Board of Kenya was reported to have refused to recognise degrees from three leading public universities in Kenya and had rejected some courses from many private universities (Nganga, 2011; Nganga \& Kigotho, 2011). Likewise, on 28th August 2011, the Kenya Medical Laboratory and Technicians Board and the Council for Legal Education of Kenya had also refused to recognise degree qualifications from some universities (Ngigi, 2011). Other organisations such as the Institute of Surveyors of Kenya, Chartered Institute of Accountants, Pharmacy and Poisons Board, Medical Practitioners and Dentistry Board, Nursing Council, and Veterinary Board were also reported to have been pushing universities to improve the quality of their degrees (Nganga, 2011). In all these cases, the professional bodies bemoaned the low quality of curricula, lack 
of qualified lecturers, duplicated courses, and a lack of professional focus on teaching. These professional bodies also argued that some institutions had failed to meet accreditation guidelines and lacked adequate facilities to cope with high student numbers (Nganga, 2011; Nganga \& Kigotho, 2011). The failure to accredit these degrees led to legal battles between these professional bodies, the accreditation body (then Commission for Higher Education, now Commission for Universities Education), universities, and students (Lucheli, 2012). Meanwhile, as an African proverb goes, 'when elephants fight, it is the grass that suffers', employers continued to be frustrated with the quality of the graduates.

With a growing conviction of a need for an in-depth understanding of the quality of service offered in HE, and with an offer to study the same at VUW, I decided to focus on quality of learning and teaching (L\&T) experiences targeting students, lecturers, and administrators (referring to senior academic managers/administrators) of HE institutions from two different international contexts. I fathomed that exploring HE quality issues in two different contexts would give me a global perspective of L\&T issues. And since I had an opportunity to do so, I took it up gladly. This is what provided the direction of my $\mathrm{PhD}$ research. Moreover, on realising that my supervisors are experts in theory of constraints (TOC), which was totally a new concept to me at the beginning of my PhD journey, I became curious to understand what TOC was all about. On learning that TOC is not just a theory but also a meta-methodology, I set out to investigate how this theory could be applied to HE context to explore quality of L\&T experiences.

From the preceding discussion there is need to explore quality in HE institutions. In particular this study's purpose is to explore the quality of L\&T experiences in business schools and, how those experiences may be improved.

But before we proceed to examine the purpose of the study, let us first understand why this thesis emphasises learning and teaching (L\&T) rather than teaching and learning which may seem more logical. The answer rests with the changing trend in education where the objective of education today emphases learning over teaching. Barr and Tagg (2000) in DeZure (ed.) express a need for a paradigm shift, 'From teaching to learning - a new paradigm for undergraduate education'. In this article, they argue for a shift from a traditional dominant paradigm of teaching centred to a learning paradigm whose mission is not to provide instruction but rather produce learning (p.199). This view is corroborated by Hattie (2003) who conceptualised visible learning as "when teachers see learning through the eyes of the student 
and when students see themselves as their own teachers' (p.25). This paradigm shift seems to be embraced by accreditation bodies such as AACSB whose revised standards (2013) emphasise learning and teaching ( $\underline{\text { www.aacsb.edu})}$ and many universities whose programs (e.g. Harvard Graduate School of Education have programs labelled L\&T_www.gse.harvard.edu) and centres of learning and teaching (e.g. Binghamton centre for learning and teachingwww.binghamton.edu). A number of post graduate courses in higher education are nowadays labelled L\&T(www.education.ox.ac.uk). Relatedly, the Victoria University of Wellington offers Postgraduate Higher Education Learning and Teaching (PHELT) programmes (www.cad.vuw.ac.nz). Administrative titles have often followed this trend and Victoria has been no exception with its Learning and Teaching Strategy Committee, and within VBS, the Associate Dean (Teaching and Learning) was renamed the Associate Dean (Learning and Teaching) in 2014.

\subsection{Purpose of the study}

The purpose of this study is to explore the quality of learning and teaching (L\&T) experiences in HE institutions and how those experiences may be improved, using the theory of constraints (TOC).

\subsection{Objectives of the study}

The general objective of this study is to explore the quality of learning and teaching experiences in HE institutions and how those experiences may be improved. To achieve this general objective, the study is guided by four specific objectives. To gain deeper insights of the quality of learning and teaching experiences in HE institutions, two diverse case situations are involved: Kenya and New Zealand. These two cases allow the identification of the similarities and differences to emerge for each of the four objectives:

1. To identify the L\&T system goal(s) with a view to identifying critical success factors and necessary conditions for goal achievement.

2. To identify the factors that affect the quality of L\&T experiences with a view to identifying the critical root causes of less-than-desirable L\&T experiences.

3. To determine the impact of L\&T experiences on the performance of the L\&T systems with a view to understanding what currently limits effective performance of L\&T systems. 
4. To propose improvements to enhance the quality of L\&T experiences and the performance of L\&T systems.

The TOC methodology is espoused as a suitable framework to help in exploring the above objectives.

\subsection{Importance of the study}

The importance of this study is justified via four veins of reasoning:

The first concerns the current trends in HE and the impact of those trends on meeting the learning goals. This study provides timely and relevant insights about the impact of such trends on L\&T practices and experiences, and ultimately on the achievement (or not) of learning goals.

Secondly, the literature on the quality of L\&T experiences in undergraduate programs in HE indicates limitations in two fundamental areas: a lack of a holistic approach to understanding L\&T experiences and the under-or non-achievement of $L \& T$ system goals. In relation to a holistic approach, much research work on experiences of L\&T relates to students' experiences or to teaching experiences but not both. Findings from these studies provide a list of factors that determine satisfaction or dissatisfaction without indicating relationships between these factors. This thesis applies a systems approach to understand the L\&T system from the perspective of three major stakeholders (namely the students, teachers, and administrative staff). It then maps the interrelationships of the factors that impact L\&T experiences with an aim of identifying a few critical factors that have the greatest impact on the whole L\&T system.

Review of the current literature suggests gaps in research relating to $L \& T$ goal $(s)$ in HE. The need for exploring L\&T goals is justified by a basic argument within the theory of constraints that any quality improvement initiative requires an understanding of the systems goal, to which, collective effort of a system is directed. A system's goal then serves as a benchmark to measure system performance (Goldratt, 1990). This study proposes that undesirable experiences of L\&T limit effective achievement of L\&T system goals. Yet, few studies relate the effect of undesirable factors on quality of experiences of L\&T or on achievement of the goal of L\&T. Although a number of studies have investigated students' perceptions of various phenomena, they largely focus on quantitative measurements, which are largely satisfaction based (Gamage et al., 2008; Owlia \& Aspinwall, 1998). Such studies fail to consider how dissatisfying or 
undesirable experiences impact on the performance of L\&T systems or on the achievement of the L\&T goal. Exploring how undesirable factors impact on experiences of L\&T, and identifying critical root causes of those undesirable factors, may point to key areas where university leadership should focus attention.

Thirdly, this study applies the TOC methodology beyond its predominant domain of application in industrial settings, into the HE sector. Applying TOC methodology in two diverse HE contexts provides broader perspectives of the application of a TOC-based quality model. Moreover, analysing data using TOC tools provides a different approach to qualitative data analysis, thus making a broader contribution to qualitative research methods.

Finally, the use of TOC methodological tools provides theoretical insights into goals of L\&T, and to the causal relationships of factors that impact on L\&T systems. In addition, the application and evaluation of TOC tools in this study adds to the methodological development

of TOC by exploiting the strengths and addressing shortcomings of their application. For example, the study demonstrates the effectiveness of the goal tree and the focused current reality tree (fCRT), two lesser known tools, and complements the tools with recognised qualitative research methods.

\subsection{Structure of thesis}

This thesis is divided into nine chapters:

Chapter one has discussed the motivation of the study and also outlines the aims and objectives. The importance of the study is also explained.

In the second chapter, a review of literature is provided, which includes a discussion of global trends in HE and their impact on L\&T. It also explores the concept of L\&T quality, indicators of L\&T quality as well as studies that discuss quality of experiences of L\&T. An evaluation of seven globally recognised quality models that have been applied in HE is also provided. The aim of this chapter is to highlight research gaps. Then TOC methodology is espoused as a suitable approach with which to explore quality of L\&T systems and provide guidance on quality improvement. 
Chapter three provides a detailed discussion on the TOC methodology and provides a justification of why and how TOC tools are applied in this study. Validity checks for the TOC tools are also explored.

Chapter four describes the research methodology. It sheds light on the philosophical assumptions of the study and on the mode of enquiry. It then provides detailed descriptions of data collection processes in Kenya and NZ. The nature of data analysis is then briefly described, accompanied by a personal reflection of the data collection process. Finally, the chapter discusses trustworthiness and rigour of study.

Chapter five provides an analysis of data and presents findings based on the Kenyan case. This analysis is guided by research objectives. Using a 'funnel' approach, the chapter first provides separate analysis of each of the three groups of participants namely: the students, lecturers, and senior academic administrators ${ }^{1}$. Then, it provides a within-case comparison across three groups of participants before drawing conclusions on the whole case study.

Chapter six uses the same approach as chapter five to analyse the NZ case. Chapter seven then provides cross-case comparisons across similar group of participants (such as Kenyan students and NZ students) guided by research objectives.

Chapter eight provides a discussion of findings guided by research objectives, and in relation to gaps identified in the literature review. The chapter also offers possible resolutions and directions on how university leadership could deal with particular issues that surface as findings.

Finally, chapter nine concludes the thesis with a summary of key findings and an outcome of the strengths and contributions of thesis. Then, implications, recommendations, limitation, and directions for future research are suggested. Chapter nine provides opportunity to outline the personal reflections of the researcher, before final concluding remarks are made.

\footnotetext{
${ }^{1}$ In this thesis, the term 'administrator(s)' implies senior academic managers who hold various senior administrative positions (e.g. an Associate Dean) in a business school.
} 
Chapter 1: Introduction 


\section{Chapter 2}

\section{LITERATURE REVIEW}

Education's purpose is to replace an empty mind with an open one (Malcolm Forbes).

\subsection{Introduction}

This chapter presents a review of the literature on issues that impact on L\&T experiences in HE. In order to provide a broad understanding of L\&T phenomena within globalised economies, literature on global trends in HE is first reviewed. Secondly, conceptualisations of L\&T quality are reviewed to provide insights of various perspectives of quality of L\&T. Then, literature on L\&T experiences from the perspective of students and teachers is provided so as to offer deeper understanding of how students and teachers perceive L\&T experiences. In order to understand the quality models that have been applied in higher education institutions (HEIs) to improve quality, an evaluation of seven models and frameworks that have been applied internationally in HE is provided. Finally, based on gaps identified in this literature review, a conceptual framework that depicts the gaps that this study addresses is provided.

\subsection{Global trends in HE and their effect on L\&T quality}

For many years, universities in many countries have experienced global trends that have affected the academic landscape in many ways, with some posing as opportunities and others as challenges to students' and teachers' experiences. These trends constitute a milieu of challenges and include a shift from elite to mass education, and increased student enrolment; the declining morale of academic staff and divided loyalty; new approaches of learning and teaching; poor coordination and integration of academic practices; and commodification of academic knowledge.

\section{1) Democratisation of knowledge and access}

There has been a massive increase in the access to HE. Trow (2000) indicates that this access has brought about a shift from elite to mass $\mathrm{HE}$, and that quantum increases in student enrolment have led to an expansion of part-time non-tenured teachers on contracts, who often cannot develop genuine mentoring relationships with the students and institutions, and are weighed down by heavy workloads (Trow, 1997; 2000). Increased workloads have led to a serious decline in morale among academic staff (Trow, 2000). Indeed, Winter, Taylor, and 
Sarros (2000) opine that low morale among academic staff has led to low creativity in teaching and stifled learning. In support of this, Coates (2010) notes that students lack or have only a low level of engagement in effective educational practices such as asking questions in class, co-working with teaching staff, class presentations, exchange programs, community based projects, and internships.

The growth in student numbers has also increased pressure to put in place new systems for academic support and innovative approaches to pedagogy so as to deal with a diverse student body and ensure that these students complete their programs with appropriate knowledge and skills (Altbach, Reisberg, \& Rumbley, 2009). However, Rae (2007) opines that the higher enrolment has massively increased the supply of graduates seeking to enter job markets, raising employability concerns. He argues that not only have there been long-standing debates about the nature of degrees and the extent of development of intellectual, creative and other higher level skills; but also their relevance in the job market (Rae, 2007).

\section{2) Government under-funding}

The massification of HE has been accompanied by funding shortages. Government support has not kept pace with high student numbers (Altbach et al., 2009; Trow, 2000). This has resulted in funding for research becoming increasingly contestable in some HE contexts including Australia and New Zealand (Berg \& Roche, 1997; Ernst \& Young, 2012; Jongbloed \& Vossensteyn, 2001; Middleton, 2009). The contestability for research funding has in some ways, impacted on L\&T experiences negatively as discussed under teaching and research (7) below. Funding shortages have driven HEIs towards what has been described as the marketisation of knowledge and internationalisation of curricula (Altbach et al., 2009; Sayers, 2013). Such marketisation is outlined below.

\section{3) Marketisation and internationalisation of curricula}

The marketisation of courses has facilitated internationalisation of curriculum. Marketisation, in this case implies that education has become a commodity to be bought, sold, traded, and consumed in the local or global educational market place (Roberts, 1999). Such a market place is characterised by stiff competition where students are regarded as consumers (and not cocreators) of course offerings, making choices about which programs to accept or reject from various providers (competitors) (Dill, Massy, Williams, \& Cook, 1996; Sayers, 2013). It is not 
surprising then, that HE institutions have adopted an entrepreneurial/corporate model in order to compete effectively in the market (Dill et al., 1996; Gill, 2011).

\section{4) Entrepreneurialism and corporatisation}

Mok (2000) suggests that the entrepreneurial model has brought about a shift from collegial to managerial forms of governance, and to a new discourse that relies on mission statements, system outputs, audits, strategic plans, cost centres, public relations (PR), research outputs, teaching scores, and a general academic capitalism. Unfortunately, these aspects of governance and managerialism have brought about dilemmas between administrative leadership and faculty leadership, between corporate leadership and departmental leadership, between autonomous collegiality and controlling managerialism, and between academic loyalty to a discipline and loyalty to an institution (Gill, 2011). This managerialism has contributed to the de-professionalisation of academic careers (Dill, et al., 1996).

\section{5) Academic de-professionalisation}

Many factors may be attributed to what has been called the de-professionalisation of academic teaching and learning. Trow (2000) points to a weakening identification of academics and scholars with their institutions, and their growing reluctance to serve for example, on academic senate or faculty committees. Tensions exist in the form of fragmented communication within departments that have led to atomisation and isolation of faculty members (Dill, 2000; Fielden \& Malcolm, 2005; Rowland, 2002). In addition, defensive forms of professional autonomy are noted, where academic courses are perceived as private property, and where there is a lack of faculty interest, for example, in peer review of teaching (Dill, et al., 1996). Indeed, Gill (2011) has observed that managing academics is like 'herding cats' (p.54) that are notoriously independent, uncontrollable, and selfish creatures.

\section{6) Departmental fragmentation}

According to Knight and Trowler, (2000), faculty dis-engagement in teaching, hard managerialism, and the loss of collegiality has intensified disciplinary fragmentation. Moreover, course and programs proliferation have contributed to poor coordination and integration (Dill, 2000; Mok; 2000). There is now less emphasis on taking courses in the 'proper' sequence, and greater emphasis on students' ability to plan their degree programs (Dill, Massy, Williams, \& Cook, 1996). Further, Dill et al. (1996) indicate that the expansion and fragmentation of HE knowledge has brought about a 'lack of consensuses' on what should 
constitute academic curricula at university level. Indeed, despite the Association of American Colleges' (AAC) proposal for curricula to be organised to allow the development of critical thinking, coherence, and connecting learning with other fields, life and career, its (AAC) task force's (that comprised teaching scholars) findings indicate high variability in integrating them (critical thinking, coherence, and connectivity) within different academic disciplines (Lattuca \& Stark, 1994).

\section{7) Research versus teaching}

It has been noted in recent decades that research expectations from university academic staff have been rising to the extent that research productivity in many universities is the main criterion for hiring, tenure, and promotions (Prince, Felder, \& Brent, 2007). Biggs (2001) has noted that even in those universities that place equal emphasis on teaching and research, research tends to enjoy greater prestige, and is rewarded more than teaching. The reasons for the prestigious position of research is regarded by some as due to its perceived contribution to external funding, future grants, future earnings for the faculty member, and national rankings (Dill, 2000; Prince et al., 2007).

However, according to Dill (2000), such emphasis on research has brought about negative effects to L\&T. Dill argues that this emphasis has led to less commitment to undergraduate teaching with less time devoted to students, on the one hand, and to academic committees on the other hand. The underpinning assumption is that there has been a decline in time spent on teaching-related activities, which affects other critical functions such as curriculum coordination, student assessment, program review, and teaching improvement (Dill et al., 1996).

Research examining relationships between research and teaching is divided. Some empirical evidence indicates that there is no relationship between research and teaching practice or effectiveness (Hattie \& Marsh, 1996; Jenkins, 2004). Elsewhere, a US study reported negative correlation between research and teaching indicating that 'attending a college whose faculty is heavily research-oriented increases student dissatisfaction and impacts negatively on most measures of cognitive and affective development' (study quoted by Prince et al., 2007, p.284). But the negative effect of emphasis on research is also apparent among lecturers. In NZ for instance, Middleton, (2009) indicates that classification of academic staff by PBRF (Performance Based Research Fund) as A, B, C or R (fail) has brought to some \{academics $\}$ a 
'sense of crisis and loss in cherished identities and commitments' while others experienced it as 'an assault on their professionalism' (p.203). Similarly, Willis (2009) indicates that NZ's emphasis on PBRF has made scholarship of teaching and learning increasingly invisible. She argues that this emphasis has discouraged some academic staff from using theories and methods 'that makes sense to them, and to their students' (p.5).

In developing countries including Kenya, research and publication among academic staff is comparatively low due to academic staff holding dual teaching jobs and limitation of resources (Lim, 1999). In Kenya, for instance, until recently, a lecturer would remain in one job position for many years because of concentrating on his/her effort on teaching rather than research. Promotion systems in Kenya tend to reward research more than teaching as in other HE settings and academics are starting to realise this. This implies that a lecturer who concentrated on teaching would be disgruntled about the promotion system that would seem not to recognise his/her teaching effort.

\section{8) Information Technology (IT)}

Another important trend that continues to transform HEIs in many ways is Information Technology (IT). As a basic driver of HE transformation (Trow, 2000), IT has changed the way education is delivered, supported, and accessed in both the developed and developing countries (Ernst \& Young, 2012). IT and innovation has brought about changes to quality of L\&T experiences through what is referred to as the learning centre approach, which integrates information resources, computing facilities, multimedia production, educational research, and e-learning, to develop synergies through a mix of people, resources and facilities (Bulpitt, 2012). This approach, which has some aspects of blended learning ${ }^{2}$ has transformed L\&T experiences and outcomes (Davis \& Fill, 2007). These blended experiences are, however, different in different HE contexts. Africa, in particular, remains relatively underserved with IT access (Altbach et al., 2009), therefore, traditional approaches to L\&T tend to flourish.

Despite advances in technology, a technological divide is apparent among university lecturers and the Net-generation ${ }^{3}$ students (Skiba \& Barton, 2006). As a result of this divide, the adoption of teaching approaches have not kept pace with the change in the technological levels that the Net-generation students might expect. Such limited uptake of technology in L\&T is

\footnotetext{
${ }^{2}$ A combination of traditional methods of teaching with online learning activities ((Davis \& Fill, 2007)

${ }^{3}$ Also referred to as millennials, describes a generation born after 1982 (Feiertag \& Berge, 2008; Skiba \& Barton, 2006)
} 
reported as due to limited resources, limited pedagogical training on new technologies, inertia, and inadequate social and institutional support (Bennett, 2004; Gedera, 2014; Koehler \& Mishra, 2009).

The use of IT in HEIs has facilitated collaborative learning practices that use groups or teams to achieve learning objectives (Smit, 1994). Many benefits have been associated with collaborative learning. They include building self-esteem, reducing anxiety and competition, encouraging cooperation and understanding diversity, fostering relationships and stimulating critical thinking (Harasim, 2012, p.72 ; Roberts, 2004; Smit, 1994). Relatedly, Bennett (2004) observes that collaborative learning not only distributes knowledge, but also workload among group members and can provide motivational support. It also provides learners with exposure to other points of view/interpretations thus broadening their perspectives. Despite these benefits, collaborative learning approaches are not well practised in HEIs (Bennett, 2004). This is perhaps due to associated disadvantages that include the free-rider effect, freeloading, and much effort in designing good group activities (Bennett, 2004; Bower \& Richards, 2006).

In summary, the above literature reveals that global trends in HE have impacted on L\&T in many ways, mostly negative. We therefore wonder, is there any point in caring about L\&T? Should we just give up amidst this tide running against L\&T? Is there something we can do? If we truly care, we need to do something, if we can. But what can we do? Thus, although there appears to be no suggestion about how to deal with the negative effects of global trends on quality of experiences of L\&T, there is strong evidence of a genuine need to care about or address experiences of L\&T. Literature on global trends also fails to tell us what aspects of these trends are evident in a specific HE context or how a particular global trend has impacted on any specific L\&T system of a particular HEI. By exploring the negative effects of quality experiences of L\&T in diverse HE contexts, it is hoped that this study will shed some light on how particular global trends affect specific HEIs.

The above discussion has highlighted how global trends in HE have impacted negatively on quality of L\&T experiences. However, we have not provided an understanding of what constitutes quality of L\&T. The next subsection explores the concept of L\&T quality with an aim of broadening understanding of the interrelationships of the factors that impact on the L\&T experiences. 


\subsection{The concept of learning and teaching quality}

There exist different views of what constitutes quality learning and quality teaching. We choose to view quality teaching as a casual antecedent of learning quality. This view is in line with Chickering and Gamson (1999) who observed that quality teaching drives quality learning. The view is also corroborated by Hattie (2009, p.22) who argues that what teachers do affects learning. Within this line of argument, we start by exploring the concepts of learning and teaching, first, with the concept of teaching quality.

The concept of teaching quality can be approached from different perspectives. Kulski and Groombridge (2004) for instance approach the concept from two levels: the individual level and the institutional level. At the individual level, Kulski and Groombridge (2004) argue that insights about teaching quality can be gained by studying teachers who have been identified as excellent, and by describing their characteristics or attributes such as mastery of subject matter, the appropriateness of the assessment tasks, and contributions to curriculum development. Kulski and Groombridge (2004) argument, however, tend to focus more on the teacher than how the teaching quality may be enhanced. Indeed, their view tends focus on what has been referred to as an instructional paradigm (Barr \& Tagg, 2010) that tends to be teacher-centred and would therefore rely on excellence of instructors. Such a view tends to ignore the fact that learning is also achieved through other ways and means outside what an excellent teacher may offer. Anecdotal evidence indicates that some professors, with great mastery of their subject are very poor teacher. Such professors may also have great contributions to curriculum. Therefore possessing the above characteristics may not necessarily bring about quality learning. Yilmaz (2008), for instance, opines that learning is socially and culturally mediated with the learner taking an active role, and the teacher taking a facilitative role. Thus, the opponents of a teacher-centred approach might not necessarily be concerned with excellent teachers but those who may provide a platform for discussion or facilitation. Other have identified characteristics of excellent teachers that would include clarity of course requirements, clarity of explanations, respect for students and encouragement of independent thought, pedagogical knowledge and full command of the curriculum, empathy with students, openness and quality of assessment procedures, clarity of goals, choice in assignments, sensitivity to class level and progress, appropriate pace in lecturing, and enthusiasm (Henard \& Leprince-Ringuet, 2008; Healey, 2000). Although these characteristics share some similarity 
with those of Kulski and Groombridge (2004) in that they tend to focus more on the teaching process than the learning process, they recognise to some extent, need for independent thought.

Nevertheless, to support the idea of excellent/expert teachers, Hattie (2003) argues that students who have been taught by expert teachers exhibit a clearer understanding of the concepts in a more integrated, more coherent way and at a higher level of abstraction than other students. Although the compendium of these characteristics might explain the concept of individual teaching quality, the limitation is in terms of how to measure and assess teaching quality. Kulski and Groombridge (2004) indicate that one limitation is due to a multiplicity of data sources while Neumann and Becher (2002) indicate another limitation is how to evaluate teaching in different knowledge and social domains.

At an institutional level, factors related to teaching quality would include a scholarly approach to teaching, a provision of appropriate induction programs, modelling and dissemination of good teaching, regular evaluation of teaching, opportunities for staff development and an appropriate course establishment process (Kulski \& Groombridge, 2004). Indeed, as Biggs (2001) suggests, the focus should not be on the teacher but on the teaching that would enhance satisfaction of both the teacher and the learner (Biggs, 2001). The problem with the institutional approach to teaching quality is that different institutions will emphasise different scholarly approaches to teaching quality and different characteristics of teachers. While some may emphasis research-informed teaching experience, intensive induction programs, and offer many opportunities for staff development, others may emphasis excellence in high impact methods of teaching (LEAP, 2015) and may offer limited opportunities for staff development. Similarly, the missions shaping different institutions may tend to emphasis particular characteristics of teachers that are in line with their mission statements. For instance, secular institutions may emphasis on a good teacher (as judged by their teaching philosophies) while religious institutions may emphasis on the character of the teacher (such as moral principles and beliefs).

Turning over the leaf to learning quality, it is perceived as a wider concept that embraces the teaching environment as well as the learners' perspectives. Indeed, it not only involves an evaluation of what teaching means, and an analysis of what is important to teach, but also determines how to know that learning is taking place (Weigert, 1998). Writing in the same vein, Hattie (2009) conceptualised visible learning as 'when teachers see learning through the eyes of the students, and when students see themselves as their own teachers' (p. 268). Indeed, 
Hattie, (2009) theorised that feedback should come from students to teachers in terms of what students know, what they understand, where they make mistakes, where they have misconceptions, and when student engagement lacks. This nature of feedback is what brings about visible learning, in Hattie's view. Although this view of learning quality tends to be more integrative in that it embraces the learner in the L\&T environments, this view is yet to be appreciated and embraced in many HE institutions. From my observation and experience, many teachers of HEIs have limited time to evaluate the learners or even to reflect on whether learning is taking place.

To sum up the relationship between learning and teaching quality, Martens and Prosser (1998) indicate that high quality teaching is fundamentally about affording high quality student learning. But providing high quality student learning is relative and may be viewed differently by different stakeholders. Indeed, even within a similar group of stakeholders, say teachers, they may not agree of what really constitute high quality learning. For instance, some may view providing students with adequate learning materials as high quality learning while another may view such as 'limiting students' ability to search for knowledge'. Martens and Prosser (1998) further emphasise that quality teaching is about keeping a focus on how and what students are learning and how that can be improved. But this view lends itself to different interpretations. While some may, for instance, interpret it as focusing on how the learning and teaching functions may be improved, others may interpret it as need to improve research so that it can inform teaching. Such kind of interpretations may therefore impact on how HEIs ascertain high quality learning. What measures do and can they use? Although the next sub-section may fail to provide answers to this question, it provides perspectives of L\&T quality indicators that are used to measure quality of L\&T in HEIs.

\subsection{Learning and teaching quality indicators}

It has been argued that understanding learning quality and teaching is complex and often uses subjective measures that take a variety of forms (Kulski \& Groombridge, 2004). This subsection briefly reviews measures of quality learning and teaching based on dimensional frameworks, and quality assurance.

Chalmers (2008) provides a learning and teaching quality dimensional framework drawn from empirical research in Australia. She identified four key dimensions of teaching quality, which she claims can be broken down at institutional, faculty, departmental/program, and 
individual/teacher levels. These dimensions which address students' learning issues relate to (p.12):

- Institutional climate and systems: Include adopting a student-centred learning perspective and ensuring desired teacher characteristics, qualifications, and professional development are in place. It also involves use of current research findings to inform teaching and curriculum/course content, community engagement and partnerships.

- Diversity: Involves valuing and accommodating student and staff diversity, and providing adequate support services and multiple pathways for rewarding and recognising staff.

- Assessment: Involves assessment policies that address issues of pedagogy such as an evidence-based approach to assessment and formative assessment.

- Engagement and learning community: Includes engaging student and staff, and fostering and facilitating (academic) learning communities.

Chalmers indicates that such a framework provides universities with a tool that they can use to review their systems, and implement changes. Indeed, the framework has been piloted in eight Australian universities allowing them to focus on the substance of the dimension that is most relevant to it. As a result, different universities have assessed different elements such as inputs into teaching, academic policy development, and student engagement. Implementation using this framework does not necessarily take a holistic and systemic approach to quality assessment and enhancement. Without a holistic and systemic approach, it may be less likely that a university can achieve its quality enhancement goal.

Another dimensional framework for examining teaching quality in HE is provided by Owlia and Aspinwall (1998), who through empirical testing determined that teaching quality may be measured in the following dimensions:

- Academic resources: Relates to sufficient and modern equipment/facilities, ease of access to the equipment, visually appealing environment, and support services (accommodation, sports).

- Competence: Relates to the extent to which academic staff possess relevant theoretical and practical knowledge, the extent to which staff are up to date in their subjects, and have expertise in teaching and communicating. 
- Attitude: Relates to the extent to which academic staff understand students' needs, are willing to help, are available to guide and advise students, and to give personal attention.

- Content: Relates to relevance of the program to the future jobs of students and the applicability of knowledge learnt to other fields. It also relates to the extent to which a program contains primary and ancillary knowledge and skills; and to which students learn communication skills and team working.

The above dimensions of teaching quality relates to learning quality in that they address students learning needs. To operationally define the above four quantitatively derived dimensions, Owlia and Aspinwall (1998) used a revised SERVQUAL model (see section 2.7 (8)). Unlike the SERVQUAL's 22-item Likert scale, their model was adapted to a 30-item scale based on a prior theoretical framework (Owlia \& Aspinwall, 1996) earlier developed to examine quality in HE. Although Owlia and Aspinwall (1998) recommend that this framework can be used for quality improvement in HE, it is noted that their framework was tested in engineering education, and that some variables, though found to have content validity or theoretical relevance on HE quality, were not empirically valid. Therefore, they recommend more refined measures to be developed. Moreover, though Owlia and Aspinwall (1998) provide a valuable list of important quality dimensions, these dimensions can be difficult to interpret because they do not usually indicate how a 'visually appealing environment', for example, contributes to or determines quality of teaching and learning. Indeed, Chalmers (2008) claims that there is limited empirical support for quantitatively derived dimensions or indicators as enhancers of teaching and learning quality. She therefore recommends the use of qualitative measures. This study aims to explore the quality of experiences of L\&T in a more deeper way than would be achieved using a quantitative approach. It therefore adopts a qualitative approach.

Other forms of quality indicators in HE have been identified through quality assurance (QA) approaches. Kis (2005) identifies three forms of approaches to quality assurance in HE: accreditation, assessments and audits. Moreover, various organisations and agencies are involved in QA. They include governments, autonomous agencies, and other stakeholders (students, graduates, staff, employers, and other budget providers) (Kis, 2005). For instance, the European Association for Quality Assurance in Higher Education (ENQA) is an umbrella organisation which represents quality assurance organisations from European Higher 


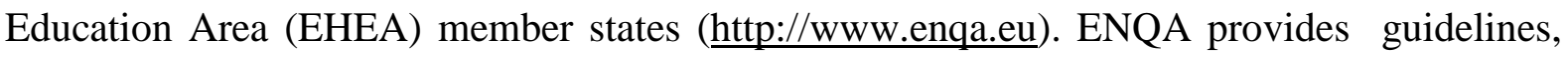
policies and procedures for QA used in monitoring the effectiveness of their QA systems; formal mechanisms for approval, monitoring and periodic review of programs and awards, published criteria, regulations and procedures for students' assessments, quality assurance of teaching staff, learning resources and student support, and information systems, and public information (ENQA, 2003).

Within business schools, various external accreditation bodies such as the Association to Advance Collegiate Schools of Business (AACSB) (http://www.aacsb.edu) and the European Quality Improvement System (EQUIS), [the quality assurance arm of the European Foundation for Management Development (EFMD)] (https://www.efmd.org) are involved in QA. Such bodies also provide guidelines for standards and criteria relating to the quality of operations and processes in business schools all of which are contextual to the issues of the business schools.

Not surprisingly, there are different forms of QA frameworks and performance measures, each withtheir own strengths and limitations. Chalmers and Johnson (2012) observe that these frameworks employ a variety of performance indicators, which are also contextualised. They offer an Australian-based categorisation as follows:

- Input: Measures quantity of human, financial and physical resources involved in supporting institutional programs, activities, and services.

- Output: Measures quantity of outcomes produced.

- Outcome: Measures complex processes and results in terms of quality and impact. Focuses on quality of educational program.

- Process: Measures the means used to deliver the educational programs, activities, and services.

Chalmers and Johnson (2012) further indicate that each of these categories has different characteristics and objectives. Despite the perceived importance of these indicators and performance measures, a survey of Australian universities' policies and practices by Ramsden and Martin (1996) indicate that only about half the universities have developed criteria/measures for identifying levels of teaching competence/excellence. Some authors such as Barnett (1994) (as cited by Tam, 2001) perceive these performance indicators as neither proposing any improvement strategies nor providing insights into the future. However, it has been observed that QA performance indicators can serve the purpose of either improvement or 
accountability (Kis, 2005). Kis further observes that the purpose and focus can vary according to different stakeholders. This view is corroborated by Chalmers and Johnson (2012) who observe that in reality, the more powerful stakeholder's perspective is usually the one that prevails.

What is clear from the above discussion is that indicators, dimensions and performance measures for quality are diverse, and that there are different approaches aiming to assure quality in HE. Although each type of indicator or performance measure is found to yield valuable insights or information regarding quality, seemingly inherent differences can be attributed to different stakeholders' positions and perspectives (Chalmers \& Johnson, 2012). Indeed, Chalmers and Johnson observe that while governments may be interested in efficiency and cost-effectiveness, for instance, institutions may be concerned with improving quality of their courses, learning processes, and outcomes, while students may be more concerned about costs. Thus, according to Chalmers and Johnson (2012), QA requires that different stakeholder's viewpoints be considered. The next two subsections explore literature on how students and lecturers as stakeholders perceive quality of L\&T and its effect on their satisfaction/dissatisfaction.

\subsection{The quality of learning and teaching (L\&T) experiences: students' perspective}

Studies that have sought to evaluate students' satisfaction with their HE experiences have identified various factors causing satisfaction/dissatisfaction. These factors may be attributed to different contexts, to different student groups, to different measures used or attributes, or to the various analytical procedures followed. The purpose of this section is to highlight factors that cause satisfaction/dissatisfaction and are perceived as critical to students' learning experiences.

An empirical survey on student satisfaction conducted in private universities in Japan and Thailand to ascertain students' perceptions of quality of services, identified a total of ten L\&T factors, that were grouped into three major categories (Gamage et al., 2008). The first was an academic category where students considered the quality of academic staff, quality of programs, and university reputation as important factors that influenced their perceptions. Second was a non-academic category that included financial assistance and tuition fees, counselling and support services, job placement services, and grievance procedures. Third was 
a facilities category where students considered physical plants and facilities, library and computing facilities, and student organisations as important factors. A study conducted in Kenya among university students similarly identified academic quality, program quality, administrative quality, student support, and availability of resources as important factors affecting their satisfaction (Kimani et al., 2011). A NZ study conducted by Retna, Chong and Cavana (2009), identified potential for intellectual growth, the learning environment, and students' participation rates as three critical factors that affected students' overall satisfaction with learning, in a university setting.

In an effort to develop a conceptual model of student satisfaction with their HE experience Douglas, McClelland and Davies (2008) conducted a UK based study aimed at identifying determinants of students' perceived quality and their impact on students' satisfaction or dissatisfaction with the overall student experience. Their findings indicated that responsiveness, communication, and access were the critical areas for managerial focus. Similar findings were identified by Tsinidou, Gerogiannis and Fitsilis (2010) among business and economics students in Greece. They determined that the main factors of importance were the communication skills of academic staff, clear guidelines and advice from administrators, and availability of text-books and journals for staff and students. On curriculum structure, students valued practical or hands-on experiential approaches to learning. Other factors included convenient university location, high quality classrooms and laboratories (infrastructure), and professional career prospects.

The above studies identify a variety of factors deemed to contribute to students'satisfaction. My opinion is that these studies are essentially correlation studies, not necessarily an indication of causality. Indeed, Gamage et al. (2008) and Kimani et al. (2011) used factor analysis to identify important satisfaction factors. Retna et al (2009) on the other hand used quantitative and qualitative methods to analyse students' satisfaction with learning. The quantitative aspect was based on factor analysis while the qualitative aspect was based on two open questions which were analysed under the factors that emerged from their quantitative analysis. Their results supported their initial hypotheses that the learning environment, positive and constructive feedback and stimulating tutorials improve student learning and led to higher levels of student satisfaction with their learning experiences at university. We therefore find that Retna et al (2009) study tend to lean more towards quantitative with a focus on correlation. None of these studies explore the network of causal interrelationships explicitly. 
Moreover, the literature does not indicate whether the satisfaction factors are necessary and sufficient for students' satisfaction and/or success in their learning, or whether without them students cannot succeed. There is also an implicit assumption that if satisfaction factors are missing, they cause dissatisfaction. But logically speaking, factors causing satisfaction are not necessarily the same as those which, if missing, cause dissatisfaction and vice versa. In line with this view, Chalmers (2008) observes that without examining those factors that can also cause dissatisfaction, a critical and holistic perspective of what might need to be improved cannot be achieved. Douglas et al (2008) corroborates Chalmer's view and argues that by enhancing satisfaction factors and trying to reduce the number of dissatisfaction factors, learning experiences could improve. Unlike the above correlation studies, Douglas et al (2008) study identified important factors (satisfiers \& dissatisfiers) through frequency of occurrence (for quantitative data) and through thematic analysis (for qualitative data). Although their study highlights important satisfiers and dissatisfiers that influenced loyalty behaviours in a learning institution in UK, the study was based on a small number of students in a faculty. To provide a holistic perspective it would be better to focus on both satisfying and dissatisfying factors, and understand these factors from other perspectives (other than students).

Studies that discuss students' dissatisfaction issues are scant and focus on limited aspects of learning experiences. For instance, Abouchedid and Nasser (2002) conducted a study specifically on registration and advising, in a Lebanon private university, and found that students portrayed the registration process as frustrating with regard to time taken to complete registration, the space provided for registration and the fees settlement processes. Moreover, in this study, different faculties were perceived to provide better quality (on registration and advising) than others. Another study in Australia by Boyd, Herrmann and Fox (in Black \& Stanley, 1998) indicated students' frustrations about the length of assignment turnaround time, difficulty in contacting tutors, heavy workload (especially readings), feelings of isolation, and frustrations in the use of various technologies in their learning.

Whilst these studies highlight important dissatisfying issues that management could pay attention to, they fail to provide a causal and systemic relationship linking those dissatisfying factors to impact on the learning outcomes or the goals of L\&T. Therefore, it still remains unclear how the dissatisfying factors impact on the achievement of the overall L\&T goal(s). The studies on dissatisfaction also fail to provide solutions on how those dissatisfying factors could be ameliorated. As a result, their findings do not assist university leadership by providing viable solutions for improving students' experiences. Furthermore, these studies are based on 
students' views and perceptions. Yet, within a HE environment, as Harvey and Green (1993) indicate, students might not always be in the best position to understand or even judge quality of L\&T. It is therefore important to understand how teacher satisfaction is impacted by students, as well as their own teaching experiences. Moreover, research evidence also suggests that learning outcomes are influenced by the learning approaches that students adopt, which tend to be influenced by teaching approaches (Trigwell \& Prosser, 1991). Although this study is not concerned about examining L\&T approaches per se, these approaches tend to impact on L\&T experiences. It therefore seems appropriate to explore lecturers' perspectives of their teaching experiences.

\subsection{The quality of teaching and learning: lecturers' perspective}

Lea and Callaghan (2008) indicate that research on lecturers' satisfaction/dissatisfaction with their teaching experiences is scant. They, however, conducted an exploratory study in UK based on lecturers' perceptions and experiences of their teaching. Using grounded theory to analyse data, they categorised their findings into two themes:

- Understanding HE context: This theme embraces both government and university level factors. These factors were perceived to place pressure on, and create barriers to teaching. They include a perceived low value placed on L\&T compared to research, erosion of state funding leading to financial constraints, widening participation due to government policy to increase and widen access to $\mathrm{HE}$, the nature of secondary education that was perceived as inadequate to prepare students for independent learning and critical thinking, and increased external control over curricula.

- Dealing with HE context: This theme concerns how lecturers manage the dynamic L\&T process. They include an awareness of and articulation of complex pressures that impinged upon teaching and learning, responsiveness or ways of dealing with the complex pressures and reflectiveness or a full cycle of evaluating and reworking in the light of that evaluation.

Although Lea and Callaghan's (2008) study highlights important constraints that impact on L\&T, their study was based on a small number (22) of participants holding a range of academic positions (there were 13 interviews with 'module' leaders and two focus groups comprising four and five participants) who were drawn from a mix of disciplines including humanities, 
science and engineering, business studies, and food, land use and leisure studies. Moreover, their study used interviews and focus group discussions, both of which centred on different issues. Indeed, their interviews addressed issues of rationale for the design of a learning 'module' in terms of content, teaching methods and assessments, evaluation of how well a module achieved stated learning objectives, participant's general philosophies of teaching and personal objectives for a module, participants understanding of how students learn, constraints and benefits in teaching a module, and the role of evaluation in the design and delivery of a module. Focus group schedules, on the other hand, addressed conceptions of learners and how students learn, conceptions of HE lecturers and activity of teaching, and L\&T environment. Because of these equivocal findings, a broad mix of disciplines and a very small sample, the study fails to provide coherent or holistic findings of L\&T in disciplinary contexts. As a consequence, Lea and Callaghan (2008, p. 186) have proposed more rigorous studies being conducted. This thesis tries to capture this rigour through causal mapping of the factors that impact on L\&T experiences as will be explained later in chapter 3.

Other studies, such as that of Winter et al. (2000) have investigated quality of academic life and found restraining factors that include disenchantment and demoralisation of academic staff. Theirs was a correlation study/survey of 189 academic staff of an Australian university from humanities and social sciences, sciences, and business related disciplines. Although Winter et al.'s study identifies some positive and negative aspects of the quality of academic work-life, the reliance on correlation fails to identify what causes things to happen or what causes, for instance, disenchantment and demoralisation of academic staff. More precisely, Chalmers (2008) notes that studies relying on quantitative measures of quality of L\&T fail to effectively and accurately measure quality. Maxwell (2004) corroborates this view arguing that quantitative studies often fail to provide adequate explanations of a phenomenon. Instead, he advocates qualitative studies which he argues can offer more meaningful understanding, particularly if based on causal explanations. Thus, to provide a deeper understanding of L\&T experiences, this study uses a qualitative approach.

We find that although studies on teachers' perspectives have identified factors that may cause dissatisfaction, these factors are viewed in isolation, independently, and might not indicate where university leadership could focus improvement effort.

In summary, many studies on quality in HE tend to focus on identifying a general list of important factors that impact on quality but do not provide adequate explanations of 
relationships between those factors or directions of how to address the quality challenges (Gibbs, 2010; Owlia \& Aspinwall, 1996, 1998). The critical factors that impact on a specific institution's quality of L\&T experiences remain largely unexplored. Most of these studies either provide students' or teachers' perspectives, but not both. Yet, quality issues in L\&T are influenced collectively by teachers' factors, students' factors, departmental issues and policies, institutions' policies or even specific country policies (Chalmers, 2008). However, such studies do not provide a holistic perspective on L\&T quality issues. To address this gap, this study takes a systemic approach to explore the quality of experiences of L\&T from the perspectives of major stakeholders: students, lecturers and senior administrators/or managers of HEIs.

\subsection{Quality management models and their applications to HE: insights and limitations}

Regardless of how quality is measured and defined, the desire to improve the quality of L\&T experiences has become evident. The issue is how? Many have turned for inspiration to quality improvement methods developed and employed in other contexts, primarily in industry. Indeed, there have been a variety of quality management models that have been implemented in different HEIs in an attempt to be comprehensive in the coverage of factors that measure performance and provide tangible applications to improving quality (Abdullah, 2006; Hides, Davies, \& Jackson, 2004; Srikanthan \& Dalrymple, 2003).

In addition, Becket and Brookes (2008) identified seven different models or frameworks that have been applied internationally in HE institutions to evaluate and manage quality. These models are drawn from the total quality management (TQM) movement, the European Framework for Quality Management (EFQM) excellence model, the balanced score card (BSC) framework, the Malcolm Baldrige National Quality Award (MBNQA), the ISO 9000 series, the Business Process Reengineering (BPR) and the service quality (SERVQUAL) framework. Other models applied in HE are SERVPERF and HEdPERF. The following subsection provides a brief discussion of these models and frameworks.

\section{Total Quality Management (TQM)}

Total quality management (TQM) is a management philosophy that was developed for industrial or manufacturing purposes. Sahney, Banwet and Karunes (2004) argue that the term first appeared in 1961 when it was devised by Feigenbaum, but who named it as total quality control (TQC). Witcher (1990) (as cited by (Crawford \& Shutler, 1999) on the other hand, 
defined TQM by deconstructing the phrase: 'total' implying every person's involvement including customers and suppliers, 'quality' implying meeting customers' requirements and 'management' implying commitment of senior management. While the literature evidence draws no consensus on the definition of the TQM, it has generally been viewed as a customer oriented process of continuous improvement of quality (Ross, 1993).

However, whereas the proponents of the TQM claim that the TQM principles can be implemented in any organisation, its opponents claim that its implementation is associated with high costs of training, consumption of management time, increase in paperwork and formality, and high levels of employee commitment (Bolton, 1995; Elmuti, Kathawala, \& Manippallil, 1996; Powell, 1995).

A number of TQM studies have been conducted in the educational sector. These studies, which have been either empirical, theoretical or both, have focused on performance indicators, and performance measures, assessment of quality, and quality of learning (Sahney et al., 2004). Venkatraman (2007) evaluated the use of a proposed TQM framework for a course evaluation process and theorised that the framework provided systematic guidelines for implementation of TQM in HE, but cautioned that TQM philosophies have to be adapted for successful implementation in HE. Similarly, Crawford and Shutler (1999) examined the application of TQM in education comparing Crosby's model (to produce a product with 'zero defects) with Deming's model (never-ending cycle of improvement). They theorised that in the context of education, Deming's model may lead to continuous improvement of quality of instruction, and is likely to encourage students to become critical and creative thinkers.

However, the use of TQM in HE has been criticised for a variety of reasons that relate to the implementation challenges, which are seen to be impracticable and ideological (ignoring organisational diversity and complexity), while its language is perceived to fit inappropriately within the HE contexts (Bolton, 1995; Elmuti et al., 1996; Houston, 2007).

Others have advocated for cautious implementation of TQM, citing that the number of institutions that have successfully implemented TQM in a meaningful way is small and the associated gains are not worthy of the time and effort expended (Koch \& Fisher, 1998). Relatedly, Mehralizadeh and Safaeemoghaddam (2010) indicate that TQM has ignored critical and contributory academic matters such as faculty tenure, curricula, tuition and fee levies, scholarship assistance, and overall weakening of the academic culture. Indeed, Koch, (2003) strongly argues that TQM has failed to address the "most important challenges facing the 
institutions of HE that relate to the curricula (what should be taught), the viability of faculty tenure, the use of faculty time, the propriety of technological innovations in instruction, the impact and validity of distance learning, whether students actually learn in any situation, the division of resources and attention between undergraduate and graduate education, involvement of HE in economic development ventures, tuition and fee levels, campus diversity, and alcohol and drug abuse' (p.328). Such failures could perhaps be addressed by querying the goal or purpose of HEIs, and understanding any critical constraints that may limit the goal attainment.

\section{European Foundation for Quality Management (EFQM)}

The EFQM excellence framework (initially called the European Model for Business Excellence) was formed in 1988 by 14 founders who were all presidents of world-class organisations. These organisations were endorsed by the European commission. The framework was then introduced in 1991, with the first award being awarded in 1992 (Hides et al., 2004). EFQM provide a non-prescriptive framework comprising of a set of three integrated components namely; the fundamental concepts of excellence, the criteria, and the RADAR described below (EFQM, 2012, p.2-6, retrieved from www.efqm.org).

i) The fundamental concepts of excellence: define the underlying principles that form the foundation for achieving sustainable excellence in any organisation. There are eight fundamental concepts, which are:
a) Achieving balanced results
b) Adding value for customers
c) Leading with vision, inspiration and integrity
d) Managing by processes
e) Succeeding through people
f) Nurturing creativity and innovation
g) Building partnerships
h) Taking responsibility for a sustained future.

ii) The criteria: provide a framework to help organisations to convert the fundamental concepts and RADAR thinking into practice. There are nine criteria, which are consistent with TQM principles in assessment of progress towards an organisation's goals, and define what organisations should do in order to achieve excellence. The nine 
criteria are then categorised into five enablers and four results: Enablers comprise leadership, policy and strategy, people, resources and partnerships, and processes, while results comprise customer satisfaction, people satisfaction, societal impact and key performance results (Davies, Hides, \& Casey, 2001).

iii) The RADAR process, encompass Results, Approaches, Deploy, Assess and Refine, is a powerful tool for driving systemic improvement in all areas of the organisation. It is a logical assessment framework that provides a structured approach to assessing the performance of an organisation. RADAR helps determine the results that an organisation aims to achieve; plans and develops an integrated set of sound approaches to deliver required results now and in the future; deploys the approaches in systematic ways that ensure implementation; and then assesses and refines the deployed approaches based on monitoring and analysis of the results achieved and on-going learning activities (EFQM, 2012).

The EFQM framework has been identified by Davies et al. (2001) as an excellent process framework for improving leadership in HE. Calvo-Mora, Leal, and Roldán (2006) indicate that enablers (particularly, partnership and resources) play important roles in the process management of universities. Furthermore, a study by Osseo-Asare and Longbottom (2002) of six HEI in UK indicated that the EFQM framework is better able to identify areas for improvement compared to the Quality Assurance Agency (QAA) model.

Nevertheless, the use of the EFQM framework in HE has limitations. Osseo-Asare and Longbottom (2002) suggest that using the EFQM framework for self-assessment within HE has major limitations of being too prescriptive (to the nine criteria), time consuming, requiring adequate resources, and is highly biased on scoring the EFQM criteria due to lack of rigor in verification. The lack of rigor in verification is corroborated by Calvo-Mora, Leal and Roldán (2006) who argue that the evaluative nature of EFQM hides useful information on possible relationships or influences among criteria, and that the implementation, development and improvement of the criteria is not produced independently.

A related study in UK by Hides et al. (2004) indicated that the use of the EFQM framework in HE has lagged behind that in the private sector due to a lag in adapting the framework in the public sector as well as a lag in pressure to respond to customers' needs through continuous improvements. They identified senior management commitment and a focus on customer 
delivery as two major issues to address within the UK HE consortium implementation of EFQM. This view was supported by Calvo-Mora et al. (2006) who similarly recommended strong leadership and commitment of senior management of HEIs together with a well-defined policy and strategy, for successful implementation of EFQM.

\section{Balanced Scorecard (BSC)}

The Balanced Scorecard (BSC) is a general and flexible approach to performance measurement that was developed by Kaplan and Norton in 1992. BSC involves balancing objectives and measures of performance; isolating the system of cause and effect relationships required to attain strategic purpose (Nair, 2004). That is, the performance measures should be linked together on a cause-and-effect basis (Garrison, Noreen, \& Brewer, 2012). Thus, BSC's emphasis on building integration and synergy between four important dimensions namely: financial, customer, internal business processes, and learning and growth (Kaplan \& Norton, 2001). However, Kaplan and Norton do not argue that effectiveness in each of the four dimensions are necessary and/or sufficient conditions for success. Indeed, they suggest that organisations can add dimensions or reflect perspectives that are more relevant to them (Nair, 2004, p.20).

The BSC has been widely adopted in USA and European businesses, but less so in HE (Umashankar \& Dutta, 2007). Although Umashankar and Dutta support the use of BSC in HE, they contend that academic measures should be emphasised, in comparison to financial measures. They also proposed that BSC be used in HEIs for reinforcement of the importance of managing, rather than just monitoring performance. Taking a different stance, Lawrence and Sharma (2002) argue that applying BSC in HE may jeopardise the essence of education, and can result in commodifying students and academic labour. They also indicate that the BSC language is very business focused, priviledging the 'customer' as one of the four dimensions or measures.

However, and interestingly, the emphasis on cause-effect within the BSC resembles TOC's use of causal maps (discussed later). As Nair (2004, p.26) points out, in BSC, the art of understanding relationships among all key dimensions is done using strategy mapping, a technique of drawing cause and effect relationships among all dimensions including their contributing parts. 


\section{Malcolm Baldrige National Quality Award (MBNQA)}

The MBNQA was established in the US in 1987 to promote the diffusion of TQM practices. It was initially designed to recognise US organisations that excelled in quality management practices and their high performance. Today MBNQA is used in over 25 countries including NZ, with awards offered on an annual basis. The purpose of the award is to promote quality awareness as a competitive tool, and an understanding of performance excellence and information sharing (Rao et al., 1996). The MBNQA examination criteria have seven categories with specified factor weights: leadership (90 points), information and analysis (75 points), strategic and quality planning (55 points), human resources development and management (140 points), Process management (140 points), quality and operational results (250 points), customer focus and satisfaction (250 points) cumulating to a score of 1000 points (Winn \& Cameron, 1998).

In HE, it is suggested that MBNQA offers such benefits as highlighting strengths and priorities for improvement, creating baseline measures, providing a platform for sharing effective practices, broadening participation in leadership and problem solving as well as complementing new accrediting models (Ruben, Russ, Smulowitz, \& Connaughton, 2007). Despite such benefits, Vesper \& Gartner (1997) observed that the application of criteria for determining the constitution of high quality in MBNQA was rather fluid, while Mehralizadeh and Safaeemoghaddam (2010) opined more strongly that MBNQA was unfair, superficial and publicity-oriented.

Writing in the same vein, Osseo-Asare and Longbottom (2002) note that there is little published on successful applications of MBNQA within HE. This is further echoed by Kanji and Tambi (1999) who indicate that the MBNQA neither utilises suitable statistical methods to determine factor weights, factor scores and total evaluation score, nor shows structural relationships among the seven factors and how these factors contribute to business excellence. Similarly, Winn and Cameron's (1998) study of the relationship of MBNQA categories at a midwestern university (USA) indicated that the assumed structural relationship among the seven dimensions does not match the relationship in the actual data set. However, a study of the relationships amongst the MBNQA categories by Pannirselvam and Ferguson (2001) confirmed its validity as a construct. Notwithstanding, the study's sample (69 organisations out of which only 4 were educational institutions) and the data collection processes were different from those of Winn and Cameron (1998). 
To contextualise MBNQA in HE, Ruben developed an Excellence in Higher Education (EHE) model in 1994. The model also consists of seven categories, which he described as relevant to any educational institution: leadership, strategic planning, beneficiaries and constituents, programs and services, faculty/staff and workplace, assessment and information use, and outcomes and achievements (Ruben, 2007). However, its efficacy in evaluating L\&T has not been tested.

\section{ISO 9000}

ISO is an acronym for the International Organisation for Standardisation, an international organisation made up of representatives from the standards boards of 91 countries including the USA (Rao et al, 1996). In 1987, the European Committee for Standardisation (ECS) adopted ISO 9000 standards but revised them in 1994 (Cox, Blackstone \& Schleier, 2003). The purpose of ISO 9000 is to promote global standardisation of processes in order to facilitate global business.

ISO 9000 is seen as a quality system that is defined in terms of organisational structure, procedures, processes and resources (Lundquist, 1997). In HE, ISO 9000 has been seen as an imposition of bureaucratic standards derived from industry on academic departments with an effect that the translation of the standards have created confusion and anxiety when applied in HE (Kanji \& Tambi, 1999). Unfortunately, these standards have been perceived as a minimal level, rather than a facilitating process of continuous improvement. While fears exist that the minimalist perspective might cause complacency within HE systems, Harvey and Newton (2004) have cautioned over the risk of procedural emphasis rather than an innovation emphasis within HE quality systems.

Moreover, ISO 9000 system has been seen to be manufacturing-oriented and that the language and structure is less suitable in other types of organisations (Lundquist, 1997). While this view might be true, complying with ISO 9000 documentation processes does not always require that a company belongs to manufacturing or otherwise (ISO 9001:2008 Management Systems certification is common in HE). If anything, all companies are involved in documentation, which should be taken as an integral part of on-going quality improvement. Nevertheless, Mehralizadeh and Safaeemoghaddam (2006) noted the slow rate of its acceptance within HE with the first university getting it in 2002, the University of Wisconsin-Stout. 


\section{Business process re-engineering (BPR)}

Business process reengineering has been defined by Hammer and Champy (in Abdous, 2011) as the fundamental re-thinking and radical redesign of business processes to achieve dramatic improvements in critical temporary measures of performance including cost, service, quality and speed. Its goal is to improve efficiency and effectiveness by radically rethinking the existing processes.

According to Davenport and Stoddard (1994), there are five primary tenets that make up BPR: (1) a clean slate approach to organisational design and change, (2) an orientation to broad, cross-functional business processes, or how work is done, (3) the need for, and possibility of, radical change in process performance, (4) information technology as an enabler of change in how work is done, and (5) changes in organisational and human arrangements that accompany change in technology.

A review of the literature indicates that that there is high rate of failure of BPR implementation in HE (Abdous, 2011). Its implementation failure has been blamed on factors that include managers' arrogance, resistance, lack of process perspective, inflexibility, focus on cost reduction and downsizing, and weak teams and communication problems (Ahmad, Francis, \& Zairi, 2007). Similarly, Abdous (2011) claims that the overall effectiveness and outcomes of BPR in HE are unclear, and proposed a creative framework for implementing BPR in HE. Allen and Harrison's (1999) analysis of research data on BPR of five universities in the UK revealed more of a business process improvement rather than radical redesign of processes. They, however, noted high resistance to change in HE, unlike other organisations, and recommended that BPR's potential be weighed against the cultural, political, and management structures in the HEIs in determining whether to implement BPR related change.

\section{SERVQUAL}

The SERVQUAL construct or model was developed by Parasuraman, Zeithaml and Berry (1985) and later improved in 1991 (Parasuraman, Zeithaml, \& Berry, 1985, 1994). SERVQUAL can be considered as a scale that was originally developed to measure service quality by computing the differences between customers' desired expectations and their perceptions of a service organisation's performance across five service dimensions namely: reliability, responsiveness, assurance, empathy, and tangibles. 
SERVQUAL has been applied within HE. Cuthbert (1996) has used a SERVQUAL model based on the initial elements of service quality developed by Parasuraman et al. (1985) and the factors considered to be relevant in the measurement of students' course experience. A version of the SERVQUAL was successfully used by Rigotti and Pitt (1992) to evaluate an MBA program. Although SERVQUAL has been successfully adapted within the education context, it has been criticised on the potential inappropriateness of the ability of expectations of its five dimensions to remain constant over time, lack of prior knowledge and experience with university education, and unrealistic expectations of incoming university students (Ford, Joseph, \& Joseph, 1999).

Other criticisms (Buttle, 1996) span theoretical and operational issues such as reflecting a disconfirmation paradigm (of actual vs expected) rather than an attitudinal paradigm; there being little evidence that customers evaluate service quality in terms of PerformanceExpectations gaps; and a relative focus on the process of service delivery and not the outcomes of the service encounter. Moreover, SERVQUAL's five dimensions are not universal. Indeed, recent application of SERVQUAL in Iran suggests that three (tangibles, reliability, and empathy) of the five SERVQUAL dimensions reported negative quality gaps (Abili, Thani, Mokhtarian, \& Rashidi, 2011). SERVQUAL has also been criticised for varied meanings of the term 'expectation', that it fails to measure absolute service quality (SQ) expectations, and that it suffers from variations in customers' assessments of SQ from time to time as well as variance in the scale administration (Buttle, 1996). Nevertheless, SERVQUAL, as a de facto gaps model, depicts differences between expectations and actual performance. By comparison, when using TOC, the first step in any improvement initiative is the identification of the gap between the 'actual' and 'desired' states of any system (Dettmer, 2007, p.11). In TOC, these gaps are labelled as undesirable effects (UDEs). Unlike SERVQUAL, however, TOC depicts the linkages from gaps through to UDEs as causal maps/configurations (Dettmer, 2007, p116; Mabin, Davies, \& Cox, 2006).

To address the limitations of SERVQUAL, other models such as SERVPERF and HEdPERF have been proposed. These models are discussed next.

\section{SERVPERF model}

This model was developed by Cronin and Taylor (1992) to address the limitations of the SERVQUAL model. SERVPERF makes use of the original SERVQUAL scale items and also requires the customer to rate a provider's performance (on a Likert scale extending from 
strongly disagree to strongly agree). Unlike SERVQUAL, however, it does not seek to estimate difference scores and addresses post-consumption perceptions only. The instrument requires the consumers to rate only the performance of a particular service encounter. Further, it eliminates the need to measure expectations on the grounds that customer expectations change when the consumer experiences a service. SERVPERF assumes that directly measuring performance expectations is unnecessary. Cronin and Taylor (1992) empirically built an argument for the superiority of SERVPERF over SERVQUAL by focusing on overall sevice quality. However, a recent meta-analysis of validity of SERVQUAL and SERVPERF, by Carrillat, Jaramillo and Mulki (2007), indicates that they are equally valid predictors of overall service quality. Bayraktaroglu and Atrek (2010) also found SERVQUAL and SERVPERF measurements to have similar convergent validity and reliability scores and recommended that both be used in measuring service quality in higher-education services. These models, as indicated earlier, use quantitative data and have the drawback of providing correlation findings, which do not offer adequate explanations of causal relationships.

\section{HEdPERF model}

In an effort to develop a measuring instrument for the HE sector, Abdullah (2006) developed a higher education PERFormance-only (HEdPERF) model that he tested and compared against SERVPERF in order to determine whether either instrument had a superior measuring capability. He found out that in terms of uni-dimensionality, reliability and validity, HEdPERF explained variance within the HE setting to a greater extent than SERVPERF. He concluded that measurement of service quality using the HEdPERF method resulted in more reliable estimates, greater criterion and construct validity, greater explained variance, and consequently better fit than the SERVPERF and HEdPERF-SERVPERF scales. Using the HEdPERF scale, Abdullah (2006) confirmed that six dimensions are important in determining students' perceptions of service quality: academic aspects, non-academic aspects, reputation, access, program, and understanding. A study by Brochado (2009) using SERVQUAL, SERVPERF, and HEdPERF concluded that SERVPERF and HEdPERF present the best measurement capability, but did not identify the best. Although there is limited application of HEdPERF in HE studies, Abdullah's work is well cited.

Table 2.1 provides a summary of the above nine quality management models and frameworks in terms of the key definition variables, applicability, and their weaknesses in HE. 
Table 2.1: Summary of quality management models

\begin{tabular}{|c|c|c|c|c|}
\hline Model & $\begin{array}{l}\text { Some studies } \\
\text { conducted with the } \\
\text { model }\end{array}$ & $\begin{array}{l}\text { Key definition variables of } \\
\text { model/criteria }\end{array}$ & Applicability in HE & Weaknesses of the approach in HEL\&T \\
\hline $\begin{array}{l}\text { TQM (developed } \\
\text { in early 1950s by } \\
\text { Deming) }\end{array}$ & $\begin{array}{l}\text { Venkatraman (2007); } \\
\text { Koch \& Fisher } \\
\text { (1998); Powell } \\
\text { (1995); Koch (2003); } \\
\text { Crawford \& Shutler, } \\
\text { (1999); Sahney, } \\
\text { Banwet and Karunes } \\
\text { (2004); Ross, (1993) } \\
\text { Koch, (2003). }\end{array}$ & \begin{tabular}{|l|} 
(1) Commitment to TQM \& \\
continous improvement \\
process (2) Customer focus \\
(3) Teamwork (total \\
involvement) (4) Leadership \\
support (5) Communication \\
(6) Education \& training (7) \\
Performance appraisal (8) \\
Reward \& recognition (Elmuti, \\
et al., 1996).
\end{tabular} & $\begin{array}{l}\text { (1) Teaching and learning } \\
\text { with adaptation of TQM (2) } \\
\text { Curriculum redesign } \\
\text { (Columbia University), (3) } \\
\text { Class scheduling (Edinburgh } \\
\text { University) (4) Graduate } \\
\text { placement \& acceptance of } \\
\text { college credits (Fox Valley } \\
\text { Technical college-US) (5) } \\
\text { Assessment processes- has } \\
\text { been used in the US and UK } \\
\text { institutions (Elmuti, et al., } \\
\text { 1996; Kanji, Malek, \& Tambi, } \\
\text { 1999) registration process } \\
\text { (Koch, 2003). }\end{array}$ & $\begin{array}{l}\text { (1) Ignores complexity and diversity, process based (not results } \\
\text { oriented) time and effort consuming (Houston, 2007; Emulti et al. } \\
\text { 1996) (2) Little academic improvements, incongruent with tenure } \\
\text { system and autonomy in HE (Emulti et al. 1996; Koch \& Fisher, } \\
\text { 1998; Koch, 2003) (3) TQM interferes with HE culture, academic } \\
\text { freedom, time constraints, research responsibilities \& irregular } \\
\text { teaching schedules fails to deal with cultural \& attitudinal } \\
\text { problems (Koch, 2003), (4) Fragmented degree of integration (lacks } \\
\text { entire HE integration) \& Lack of 'total system approach (Emulti, et } \\
\text { al. 1996) (5) Cost benefit analysis is universally lacking, additional } \\
\text { costs of setting quality procedures (Bolton, 1995;Elmuti et al., 1996) } \\
\text { (6) Customer priority of TQM is not a form of HE excellence; } \\
\text { performance measures \& quality assurance are not properly } \\
\text { addressed by TQM; TQM language; quality control (uniformity) vs } \\
\text { diversity; TQM advocates for reduction in variability (Bolton, } \\
\text { 1995). }\end{array}$ \\
\hline $\begin{array}{l}\text { EFQM (formed in } \\
1988 \text { by } 14 \\
\text { founders of world } \\
\text { class companies) }\end{array}$ & \begin{tabular}{|l|} 
Osseo-Asare \& \\
Longbottom, 2002; \\
Calvo-Mora, Leal \& \\
Roldan, 2006; Hides, \\
Davies \& Jackson \\
(2004).
\end{tabular} & \begin{tabular}{|l|} 
1) Consists of 3 integrated \\
components (EFQM, 2012) (2) \\
Fundamental concepts \\
(3)Five enablers and four \\
results (4) RADAR
\end{tabular} & $\begin{array}{l}\text { 1)Largely in UK HEIs 2) } \\
\text { Developing leadership in HE } \\
\text { (Davies, Hides \& Casey, } \\
\text { 2001) }\end{array}$ & $\begin{array}{l}\text { (1)Time consuming, (2) Requires adequate resources (3) biased in } \\
\text { scoring, (4) lacks rigor in verification (5) Provides a European } \\
\text { context, yet few UK HEIs have adopted it (Kanji \& Tambi, 1999). }\end{array}$ \\
\hline $\begin{array}{l}\text { BSC (developed } \\
\text { by Kaplan \& } \\
\text { Norton, 1992) }\end{array}$ & $\begin{array}{l}\text { Lawrence \& Sharma } \\
\text { (2002) Kaplan \& } \\
\text { Norton, (1992); Nair } \\
\text { (2004); Umashankar } \\
\text { \& Dutta (2007). }\end{array}$ & $\begin{array}{l}\text { (1) Four important } \\
\text { perspectives are customer, } \\
\text { internal perspective, } \\
\text { innovation \& learning and } \\
\text { financial perspective (2) } \\
\text { Strategy map. }\end{array}$ & $\begin{array}{l}\text { (1) HEI in USA- in academic } \\
\text { program \& planning process } \\
\text { (2)Theoretical implications in } \\
\text { Indian HE (3) Administrative } \\
\text { service in University of } \\
\text { California }\end{array}$ & $\begin{array}{l}\text { (1) Current performance measures do not reflect the many } \\
\text { stakeholders of HE and are not closely linked to strategic } \\
\text { management of HE (2) Commodifies students and academic labour } \\
\text { with an emphasis on financial measures rather than academic } \\
\text { measures. (3) Should be used in HE for reinforcement of importance } \\
\text { of management rather than monitoring (4) The four perspectives do } \\
\text { not provide CSF for any organization and it also lacks the 'how' of } \\
\text { doing things }\end{array}$ \\
\hline $\begin{array}{l}\text { MBNQA } \\
\text { (developed in } \\
1987 \text { with input } \\
\text { from over } 200 \\
\text { experts) }\end{array}$ & $\begin{array}{l}\text { Vesper \& Gartner } \\
\text { (1997); Osseo-Asare } \\
\text { \& Longbottom, } \\
\text { (2002); Kanji \& } \\
\text { Tambi, (1999) }\end{array}$ & \begin{tabular}{|l|} 
(1)Weighted seven basic \\
categories or dimensions \\
(leadership, information \& \\
analysis, strategic planning, \\
HR development \& \\
management, process quality, \\
operational results, customer \\
focus \& satisfaction) (2) core \\
values consistent with TQM \\
(Winn \& Cameron, 1998; \\
Izadi, Kashef, \& Stadt, 1996)
\end{tabular} & $\begin{array}{l}\text { (1) HEIs in USA, Canada } \\
\text { (Vesper \& Gartner, 1997; } \\
\text { Winn \& Cameron, 1998; } \\
\text { Ruben, 2007) }\end{array}$ & $\begin{array}{l}\text { (1) Conceptualisation of high quality is fluid (Vesper \& Gartner } \\
\text { (1997); (2) Little empirical evidence in HE (Osseo-Asare \& } \\
\text { Longbottom (2002) (3) unfair, superficial and publicity-related } \\
\text { (Mehralizadeh and Safaeemoghaddam, 2006) (4) The assumed } \\
\text { relationship among the dimensions is not significantly related } \\
\text { (Winn \& Cameron, 1998) (5) Eligible USA companies only (Izadi, } \\
\text { Kashef, \& Stadt, 1996). }\end{array}$ \\
\hline $\begin{array}{l}\text { ISO } 9000 \\
\text { (developed in } \\
1987 \text { by ECS) }\end{array}$ & \begin{tabular}{|l|} 
Lundquist (1997) \\
Kanji \& Tambi, (1999)
\end{tabular} & $\begin{array}{l}\text { Set of standards for quality } \\
\text { systems }\end{array}$ & $\begin{array}{l}\text { Belgium, US, UK, Hong } \\
\text { Kong, Australia (Lundquist, } \\
1997)\end{array}$ & $\begin{array}{l}\text { (1) Imposition of bureaucratic procedures and high costs of } \\
\text { certification (Lundquist, 1997) (2) Defines what should be done but } \\
\text { offers little guidance on how to do it (Izadi, Kashef, \& Stadt, 1996). }\end{array}$ \\
\hline $\begin{array}{l}\text { BPR (developed } \\
\text { by Hammer \& } \\
\text { Champy, 1992) }\end{array}$ & $\begin{array}{l}\text { Ahmad, Francis \& } \\
\text { Zairi (2007) Abdous } \\
\text { (2011) Allen } \\
\text { \&Harrison (1999) }\end{array}$ & \begin{tabular}{|l|} 
(1) Fundamental rethinking \\
and radical redesign of \\
business processes (Abdous \\
(2011) (2) Discontinuous \\
thinking \& a change \\
management strategy (Allen \\
$\&$ Harrison, 1999)
\end{tabular} & $\begin{array}{l}\text { UK, administrative functions } \\
\text { (Ahmad, Francis \& Zairi, } \\
\text { 2007; Abdous 2011) }\end{array}$ & $\begin{array}{l}\text { Academic resistance to change, requires cultural, political, and } \\
\text { management structural change in HE. }\end{array}$ \\
\hline $\begin{array}{l}\text { SERVQUAL } \\
\text { (developed by } \\
\text { Parasuraman, } \\
\text { Zeithaml \& Berry, } \\
\text { 1985;1994) }\end{array}$ & \begin{tabular}{|l|} 
Parasuraman, \\
Zeithaml \& Berry, \\
1985;1994) Cuthbert, \\
$(1996)$
\end{tabular} & $\begin{array}{l}5 \text { component model (RATER) } \\
\text { reliability, as surance, } \\
\text { tangibility, empathy and } \\
\text { responsiveness }\end{array}$ & $\begin{array}{l}\text { Wide application including } \\
\text { USA, NZ (Ford et al. 1999) } \\
\text { USA, Abili et al. (2011) Iran }\end{array}$ & $\begin{array}{l}\text { (1) Not contextualised for HE (2) Different SQ dimensions in HE (3) } \\
\text { Unrealistic expectations, is disconfirmation paradigm rather than } \\
\text { an attitudinal paradigm, little evidence that customers evaluate } \\
\text { service quality in terms of Performance-Expectations gaps, and a } \\
\text { focus on the process of service delivery and not the outcomes of } \\
\text { the service encounter. }\end{array}$ \\
\hline $\begin{array}{l}\text { The SERVPERF } \\
\text { model (developed } \\
\text { by Cronin \& } \\
\text { Taylor, 1992) }\end{array}$ & $\begin{array}{l}\text { Carrillat, Jaramillo \& } \\
\text { Mulki (2007) } \\
\text { Bayraktaroglu } \\
\text { \&Atrek (2010) }\end{array}$ & $\begin{array}{l}\text { Captures customers' } \\
\text { performance perceptions in } \\
\text { comparison to their } \\
\text { expectations of the service } \\
\text { encounter. An improvement } \\
\text { of SERVQUAL.RATER } \\
\text { factors but based on } \\
\text { performance only. }\end{array}$ & $\begin{array}{l}\text { Brochado, (2009) (Empirical } \\
\text { work in Portugal) Carrillat, } \\
\text { Jaramillo \& Mulki (2007) } \\
\text { (research paper) }\end{array}$ & $\begin{array}{l}\text { Are designed as generic measures of SQ and require modification } \\
\text { to fit specific application situations such as HE (Abdulla, 2006). }\end{array}$ \\
\hline $\begin{array}{l}\text { The HEdPERF } \\
\text { model, developed } \\
\text { by Abdullah, } \\
\text { (2006) }\end{array}$ & Abdullah, (2006) & $\begin{array}{l}\text { Five factor structure: Non- } \\
\text { academic aspects, academic } \\
\text { aspects, } \\
\text { reputation, } \\
\text { Access, } \\
\text { Program aspects }\end{array}$ & $\begin{array}{l}\text { Brochado, (2009) (Portugal) } \\
\text { Abdullah, (2006) (Malaysia) }\end{array}$ & Limited applications in HEIs. \\
\hline
\end{tabular}


The frameworks and models suggest that many quality change initiatives have been applied within HE sector in an effort to understand and improve quality. Recently, Barnard (2010) conducted an analysis of a representative sample of research studies using TQM, Six Sigma, Lean, BSC, BPR, Organisational Transformation, Outsourcing Initiatives, New Product Launches, MRP/ERP, TOC, and other IT projects. His results indicated that 50-80 percent of the quality initiatives conducted using these models either failed to meet the original objectives, stopped before completion or even caused organisation performance to decay (p.408). Although Barnard's findings relate to industrial applications of the models, they corroborate with the above discussions on the quality models in HE about their failure to enhance quality. Indeed, Becket and Brookes (2008) also indicate that within HE, the models have been applied with only partial success.

Barnard (2010) also points that his analysis found that the only quality implementations where research reported no failures were those that used the theory of constraints (TOC). For example, Mabin and Balderstone (2003) present a meta-analysis of over 80 successful applications of TOC, where companies reported considerable improvements in lead time, cycle-time, and revenue. Indeed, Mabin and Balderstone indicate that despite extensive searches, the study of literature relating to TOC found no reports of failures. However, whilst none of these studies extended to the HE sector, a consideration of TOC, its methodology and advantages is worthwhile and is provided in the subsequent section.

\subsubsection{The theory of constraints (TOC)}

The advent of the theory of constraints (TOC) dates back to the 1970s when Dr. Eliyahu Goldratt, then a physicist, developed a scheduling program that tripled the chicken houses output of his neighbour's plant. In 1980, Goldratt introduced Optimised Production Timetables (OPT), which was later called Optimised Production Technology (OPT), as a scheduling solution (Watson, Blackstone, \& Gardiner, 2007). OPT gained quick market acceptance, and by 1995 , over 100 companies worldwide used it.

Goldratt further developed 'nine OPT rules' or the 'global rules' (Goldratt \& Fox, 1986). These rules are discussed in his book, 'The Goal', as a means to addressing the scheduling and performance measurement problems facing manufacturing plant managers (Goldratt \& Cox, 1992). Seeking to achieve the 'goal' of an organisation is the raison d'être for TOC. It has led to the conceptual development of problem identification and problem-solving tools such as 'five focussing steps', and 'drum-buffer-rope'. In addition, it has led to the development of 
alternative 'performance measurements', 'thinking processes', 'a process of on-going improvement (POOGI)', and 'critical chain project management (CCPM)'. These have evolved to develop a broader TOC body of knowledge that has three main branches namely: the operational strategy tools (logistics), performance measurement systems (global performance measures) and the thinking processes (TP) (Mabin \& Balderstone, 2000; Kim, Mabin, \& Davies, 2008). Indeed, TOC has evolved from scheduling software into a management philosophy of continuous improvement. In seeking to achieve the goal of an organisation, TOC's major contributions have been in successful communication of the importance of the notion of bottlenecks, the development of an effective scheduling approach, and the importance of education/training with a focus on changing top management attitudes (Cheng, Trietsch, \& Balakrishnan, 2008). Similary, Ronen and Pass, contend that the TOC's contribution to quality has been identifying where to focus efforts for improvements (in Cox \& Schleier, 2010).

As indicated earlier, several studies have reported significant benefits from the use of TOC compared to, use of other methods in terms of increased output, decreased inventory and cycletime (Watson et al., 2007), increased due date performance, financial performance and throughput performance, and reduced lead time (Mabin \& Balderstone, 2003). Other significant benefits have been realised in diverse sectors such as manufacturing, services (airlines, hospitals, banking, and education) not-for-profit organisations and government bodies. These benefits in a manufacturing and service context include reduced operating expenses, recovering major customers, reduced customer returns, achievement of planned results ahead of schedule, better management, improved supply chain distribution and general effectiveness, reduction in new product introduction intervals, reduced multi-tasking and improved task focus, and increased savings (www.goldratt.com).

Using TOC is however not straight forward. A number of difficulties and limitations have been raised in the literature. Ronen (2005) observes that TOC has a low profile in academic research journals and offers the following reasons for this:

- TOC is heuristic oriented, or satisficing. Many academic journals prefer processoptimizing, quantitative approaches, while the goal of TOC is simplicity.

- TOC processes are cause-effect driven. Academic journals prefer field studies with empirical data.

- TOC originated in practice - not enough academics have been exposed to its full contribution.

- TOC is often misperceived as a simplistic toolkit that does not need thorough research. 
Ronen (2005) called on academics to apply academic methodologies to TOC concepts and confirm or improve its methods as well as apply academic rigor to research in TOC.

Watson et al. (2007) identified two common problems with thinking processes (TP). One is that reliance on subjective interpretation of perceived reality and the qualitative nature of the subject matter makes the diagrams produced using the tools inherently unreliable, which leads to a perceived lack of reliability and validity in TP analyses. Two, the TP tools are criticised for not being user friendly. But subjectivity is not uncommon within qualitative paradigms (Guba \& Lincoln, 1994). For instance, constructivism and critical theory paradigms assume subjective relationships between a researcher and respondents (Guba \& Lincoln, 1994). Nevertheless, judgement of reliability in qualitative paradigms tends to differ from that of qualitative enquiry. In quantitative paradigms reliability is measured by the consistency with which a measuring instrument measures what it is intended to measure while in qualitative paradigms, reliability is established through methodological trustworthiness (Guba \& Lincoln, 1994). The criteria for establishing the trustworthiness are credibility, transferability, dependability, and confirmability (Lincoln \& Guba, 1982). These issues are discussed in section 4.8. The TOC tools are constructed guided by rules of logic known as categories of legitimate reservations (CLR). The use of the CLR, while increasing rigour of analysis on the one hand, may not always be user friendly on the other hand. Nevertheless, the use of CLR and causal logic increase rigour and makes the chain of logic clearer as called for by Mahoney (2008).

Mabin and Davies (2010) indicate that TOC methods have yet to be fully understood or appreciated by mainstream disciplines such as the operations research (OR)/management science (MS), community in terms of their philosophical underpinnings, their systemic nature as a multi-methodological set, and their multi-methodological use with other OR/MS and systems methodologies. They suggest future research not just in multi-methodological issues, but also in assessing and clarifying the philosophical and methodological assumptions that would underpin methodological consistency and rigor in using TOC-TP tools.

This research combines TOC-TP analysis with established qualitative research methods in complementary fashion thus aiming to raise the academic rigour of both research methodologies. 


\subsubsection{Application of TOC in Education}

The TOC-TP tools have been applied in education environments due to their simplicity, ease of integration in academic programs and their use in building cognitive skills, improving student behaviour, academic learning and school governance with non-zero sum win-win solutions (www.TOCFE, Inc). As a result of these benefits, TOC for Education (TOCFE) (a not-for-profit organisation) has initiated successful programs in Singapore, Malaysia and the Philippines, with the support of their governments, and has reported improved curriculum delivery and student conduct. Other TOC for Education testimonies come from other nations such as Colombia, the United States, Singapore, Israel, Mexico, Serbia, Philippines, Venezuela, the United Kingdom, Malaysia, Russia, and the Republic of South Africa. Most of these applications, however, have been in primary and secondary schools (www.TOCFE, Inc), and their communities.

A program of TOCFE in Medelin and Envigado (South America) aimed at empowering disadvantaged women involved 140 teachers and 1200 students in 6 institutions using two TOC-TP tools (the evaporating cloud and the negative branch) identified a lack of future vision as the major undesirable factor among the youths. Whilst the results were qualitative in nature, they demonstrate that all students agreed that they had a good experience with the use TOC tools, and had developed ability to apply these tools in their daily lives (www.tocforeducation.com).

A more strategic application of TOC in education is related to a longitudinal research carried out in Israel (at Reut High School) where changes were implemented in the administration of matriculation exams using TOC's TP tools and project management principles. The changes resulted in remarkable improvement in student performance without the need for additional resources (R. Goldratt \& Weiss, 2005). In addition, the issue of student performance in HE in terms of course and qualification completions are a key concern. More specifically, Scott (2009) reports that within the OECD, New Zealand has one of the lowest reported HE qualification completion rates.

In HE, TOC has been applied at Medgar Evers College University in New York to address the problem of attrition in its mathematics program. In addition, more than 100 universities and schools, including the University of Michigan, Ohio State University, and Wayne State University in the US use a cross-section of TOC-TP tools. Many 'Ivy League' business schools use concepts of constraint management to run their operations (http://tocforcollege.com). The 
Washington State University offers several courses on TOC relating to constraints management (www.wsu.edu). TOC is also a pre-requisite course in US business graduate courses including MBA (Nagarkatte \& Oley, 2010; www.goldratt.com). Other related applications of TOC in HE include the development of management information systems (MIS) mini cases using TOC's conflict resolution process, and the development of graphic organisers using the prerequisite tree (PRT) to enhance cooperative learning and improve teaching of business statistics at Saginaw Valley State University (Danilo, 2002a, 2002b). A study by Cooper and Loe (2000) using TOC tools has led to enhanced students' problem solving skills.

At Victoria University of Wellington, TOC has been used in setting up an Assurance of Learning system (AoL) (Mabin, 2010) and the TOC-TP has for many years been taught in undergraduate 'systems thinking and decision making' course. Pongsart (2005) investigated postgraduate students' constraints in completing a master's degree thesis using TOC, and identified keeping deadlines, keeping healthy, knowing how to get started and feeling supported as the major constraints to be addressed. He carried out further research comparing the effectiveness of improving performance of master's thesis students using TOC and appreciative inquiry and found that the two methods could effectively be used (in combination) to improve the performance of master's students (Pongsart, 2015).

Despite the foregoing, the application and research of the TOC in the HE sector has been limited. Nevertheless, justified by empirical evidence of the perceived high success rates of TOC applications on quality improvements and its ability to take a systemic view of causeeffect relationships, this study uses the TOC methodology to explore ways of improving the quality of learning and teaching.

\subsection{Research gaps and conceptual framework}

Extant literature on quality of L\&T in HE tends to overlook L\&T goals. Moreover, although many studies (such as Lea \& Callaghan, 2008; Owlia \& Aspinwall, 1996; Winter et al., 2000) highlight important factors that impact on the quality of experiences of L\&T, these studies do not indicate whether these factors are sufficient or necessary for the achievement of learning outcomes or satisfaction of students and teachers. Similarly, although studies such as Lea and Callaghan (2008) and Winter et al. (2000) highlight negative factors that impact on L\&T, the causal relationships between these factors are not examined. Yet, a focus on causality can provide a logical, sequential mode of explanation of the causes of particular outcomes 
(Mahoney, 2008). In turn, it implies that causation can help us to establish the root causes of the negative factors that affect L\&T experiences.

The review of literature did not identify any studies that have explored undesirable factors that impact on students', teachers' and academic administrators' experiences of L\&T, the causal interrelationships between these factors, and the impact of the less than desirable experiences of L\&T on the achievement (or otherwise) of L\&T system goal(s). Previous studies have been predominantly students, few teachers and administrators and few if any on the three.

In summary, literature on global trends in HE imply that there are many factors that impact negatively on quality of L\&T in many HE institutions (HEIs). But the specific factors that affect particular institutions in different HE contexts are not apparent. Moreover, there exist different views of what constitutes quality of L\&T. Similarly there seems to be no agreement on the different indicators of L\&T quality in different HEIs. Indeed, perspectives from key stakeholders (such as students and lecturers) indicate various factors that they perceive as important enhancers of quality. It is no wonder that different quality models have been applied in different HEIs in an effort to improve quality of L\&T. Studies evaluating the use of these quality models in HEIs indicate that their use in HE have only been partially successful (Brookes \& Becket, 2008).

In particular, this study explores the goals of L\&T, the critical success factors (CSFs) needed to achieve the goal(s) and the necessary conditions supporting those critical success factors. Rockart (1979, p.85) defines CSFs as 'the limited number of areas in which results, if they are satisfactory, will ensure successful competitive performance for the organisation. They are very few key areas where things business to flourish. If results in these areas are not adequate, the organisation's efforts for the period will be less than desired'. Rockart further notes that CSFs should receive constant and careful attention from management. Although CSF methodology has been used in a HEI in UK to identify and define the management information needs of academic heads of departments (Greene \& Loughridge 1996), extant literature does not explicitly indicate the CSFs and NCs for quality of L\&T experiences from students and lecturers. The use of goal tree then provide a focus on the satisfying factors that are needed to achieve the L\&T goals. 
This study also investigates the undesirable effects (UDEs) or the dissatisfying factors that limit effective achievement of the goal(s) and using cause-effect logic seeks to establish the root cause(s) of the UDEs, to identify ways of redressing the issues.

Given this situation, the Figure 2.1 depicts a conceptual framework of the logic-based causality approach that this study takes to explore the knowledge gaps using the TOC methodology.

Figure 2.1: Conceptual model indicating gaps that are addressed by this study

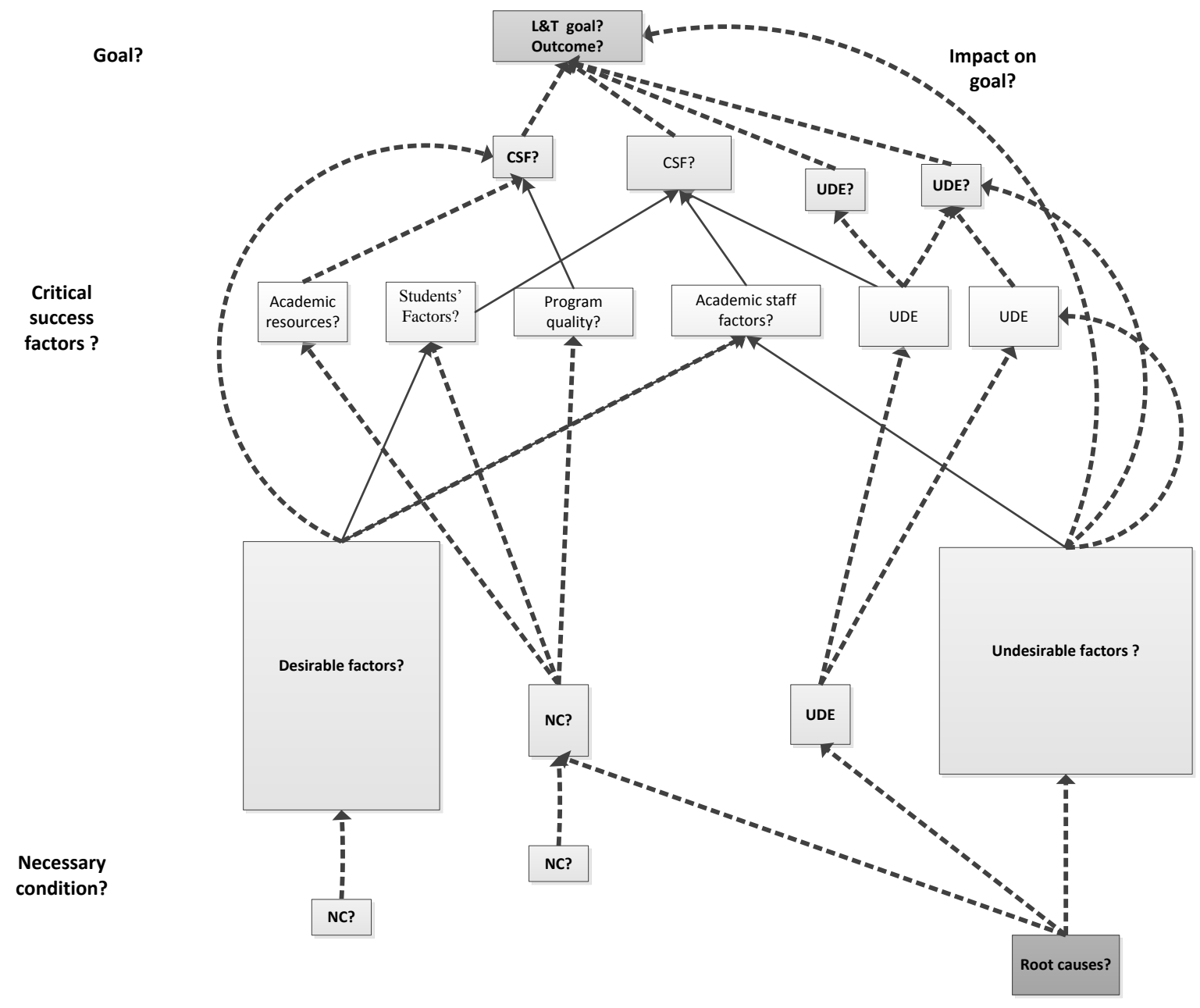

Key: CSF-critical success factor; NC-necessary condition; UDE-undesirable effects

The conceptual definitions of the terms used in the conceptual framework are provided here below.

- The goal: The ultimate purpose for which a system exists or the end to which a system's collective effort is directed (Dettmer, 2011). This study aims to identify the goal(s) of L\&T. In this case, L\&T is a system. 
- Critical success factors (CSFs): The limited (between 3-5 factors) number of high-level terminal outcomes without which the system's goal cannot be achieved. Each CSF requires the satisfaction of necessary conditions that reside at a lower level (Dettmer, 2011). In order to achieve the L\&T goal(s), the study identifies a few CSFs.

- Necessary conditions (NCs): More discrete and specific factors, tasks or activities that must be successfully completed to support the high level CSFs (Dettmer, 2011). For each CSF, 2-3 tasks or activities to support that CSF are identified.

- Undesirable effects (UDEs): A negative aspect of a current reality that is undesirable relative to the system goal (i.e. it had negative implications on the performance of a system) (Cohen, 2010, p.697). Those factors that impact negatively in the effective achievement of the L\&T goals are identified. Then, through cause and effect logic, critical root cause(s) are identified.

\subsection{Summary}

This chapter presents a review of literature highlighting the multitude of factors that appear to impact on the quality of experiences of L\&T and the inadequacies of the studies to date, thus establishing research gaps related to experiences of L\&T. A discussion of the global trends indicates many undesirable effects that impact on the experiences of L\&T. The review of the conceptualisation of L\&T quality, and indicators of quality of L\&T suggest that there is no common conceptualisation or agreement on measures of quality of L\&T. Furthermore, evaluations of models of quality that have been applied in HE sector suggest that the application of these models in HEIs have not been of benefit to HE. As a result, the TOC model is espoused as one that can be used to explore the interrelationships between factors that affect the quality of L\&T experiences in HE, and one that could be used to lead quality improvements. The chapter concludes with a conceptual model that depicts various gaps that are addressed by this study. 


\section{Chapter 3}

\section{THEORY OF CONSTRAINTS AS A RESEARCH METHODOLOGY}

I smile and start to count on my fingers: One, people are good. Two, every conflict can be removed. Three, every situation, no matter how complex it initially looks, is exceedingly simple. Four, every situation can be substantially improved; even the sky is not the limit. Five, every person can reach a full life. Six, there is always a win-win solution. Shall I continue to count? (Eli Goldratt).

\subsection{Introduction}

The purpose of this chapter is to describe the TOC methodology, justifying its use in this study as a research methodology. The chapter also describes the construction of the four TOC tools used in this study as well as their purpose.

\subsection{The TOC Methodology}

As described in section 2.7.1, the Theory of Constraints (TOC) is a system-based management philosophy (Kim et al., 2008). It is based on the premise that every system has a goal and that in practice very few factors or constraints limit a system's performance at any given time (Goldratt, 1990). Therefore, TOC focuses on identifying those constraint(s) that prevent a system from achieving its goal, focusing efforts on the critical factors that can improve performance of the whole system. This methodology [which uses cause and effect logic can be able to isolate and focus on a few critical factors] is important because as Houston (2007) observes, it helps to deal with the wholeness and interconnectedness of complexities inherent in systems.

TOC now constitutes a systems-based meta-methodology, with various sets of tools that may be used to work through the stages of problem structuring, diagnosis, solution development and implementation (Davies, Mabin, \& Balderstone, 2005). The set of tools, collectively known as the Thinking Processes, comprise logic-tree mapping processes and a conflict resolution process (see Dettmer, 2007).

\subsubsection{The thinking processes (TP)}

According to Scheinkopf $(1999, \mathrm{p} .4)$ the thinking processes (TP) were developed to provide a systemic way of determining the constraints that hinder the achievement of desired goals, 
understand why constraints exist, define the steps to elevate the constraints, and the logical manner in which, the steps should be taken to bring about improvement. In other words, Mabin and Davies (2010) observe that TP guides the decision-making process as well as representing the logic. Indeed, Davies, Mabin, and Balderstone (2005) argue that TPs exist to guide the process of managing change.

\subsubsection{Applying TOC in this study}

There are three basic aspects of TOC that apply in this study. In the first aspect, TOC takes a system view rather than dealing with symptoms one by one. A system comprises many interdependent parts connected via cause and effect relationships (Dettmer, 2007). In this study the use of theTOC methodology provides views of the L\&T as a system.

A major concern for this study is identifying factors that adversely affect L\&T experiences in HE. Therefore, as the second aspect, TOC methodology is used to identify the causal relationships between these factors as well as the critical root causes of any undesirable experiences in L\&T. TOC then provides possible solutions through its 'change sequence'.

This brings us to the third aspect, TOC's approach to change. Unlike conventional approaches to change management that focus on behaviour change, TOC's approach is focused on whatever should be changed to reach the system goal (Ricketts, 2008). TOC promotes this change using the change sequence framework, originally three, now five fundamental questions: Why change? What to change? What to change to? How to cause the change to happen? How to measure and sustain change? (Cox et al., 2012). The first and the last are later additions.

In addressing 'why change', TOC methodology identifies the actual and desired states of a system. This process reveals an improvement gap, which, if addressed effectively and continuously, can make a system achieve its goal - the desired state (Barnard, 2010; Dettmer, 2007, p.71). The process of understanding 'why change' then involves identifying the system goal, the critical success factors (CSFs) for achieving these goals, and the necessary conditions (NCs) bringing about the critical success factors (Dettmer, 2011). In TOC, 'why change' is depicted in the form of a goal tree $(\mathrm{GT})^{4}$, a visual hierarchy that reveals the CSFs and the NCs

\footnotetext{
${ }^{4}$ Initially called intermediate objectives map (IOM) (Dettmer, 2007, p.72), later named goal tree (Dettmer, 2011)
} 
that underlie a system goal (Dettmer, 2011) (Figure 3.1). In this study, this process helps to answer the first research objective of identifying CSFs and NCs for L\&T goal achievement.

Figure 3.1: Structure of a goal tree

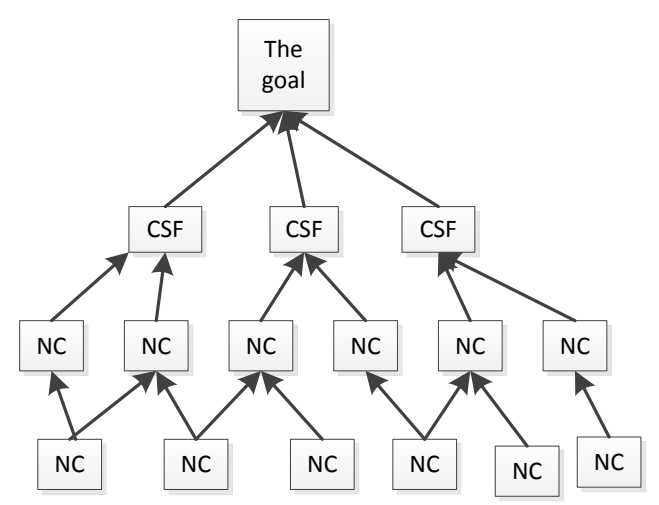

Source: (Dettmer, 2011)

To address the 'what to change' within the L\&T system, TOC will be used to identify and locate the constraint that limits the achievement of the L\&T system goal. As previously stated, the central idea behind TOC is that every system is limited by its constraint(s) (Cox \& Schleier, 2010; Goldratt \& Cox, 1992). In this view, the L\&T system is perceived by the researcher to be limited by constraints in the form of undesirable effects (UDEs). UDEs are gaps, or negative aspects of a current reality. They are undesirable relative to the goal of the system (Cox, Boyd, Sullivan, Reid, \& Cartier, 2012; E. Goldratt, 2010). The literature on L\&T experiences has revealed many factors that impact adversely on L\&T experiences. TOC enables a systematic and systemic analysis of these factors, diagnoses them into undesirable effects and depicts them in the form of a current reality tree (CRT) (Figure 3.2), a logic-based tool for determining cause and effect relationships of a current situation (Cox, Mabin \& Davies, 2005). 
Figure 3.2: Simple structure of a CRT

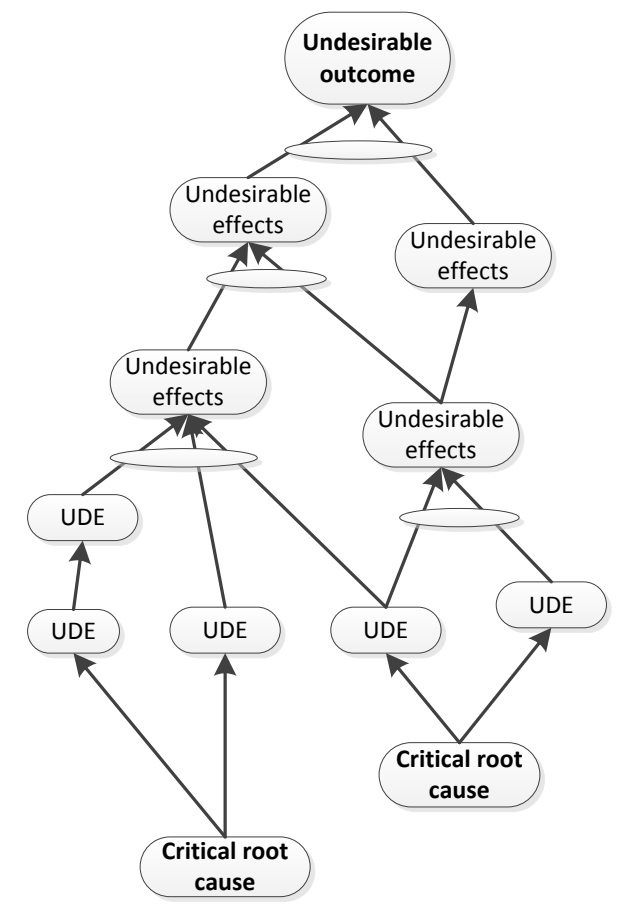

Source: Dettmer, 2007, p.117

The TOC approach to addressing 'what to change' not only identifies the undesirable experiences through the CRT, but also helps in surfacing the assumptions behind the L\&T practices that impact the UDEs. More specifically, TOC helps in surfacing assumptions related to L\&T conflicts or dilemmas and then depicting them in the form of an evaporating cloud (EC) (Figure 3.3).

Figure 3.3: Format of a generic EC

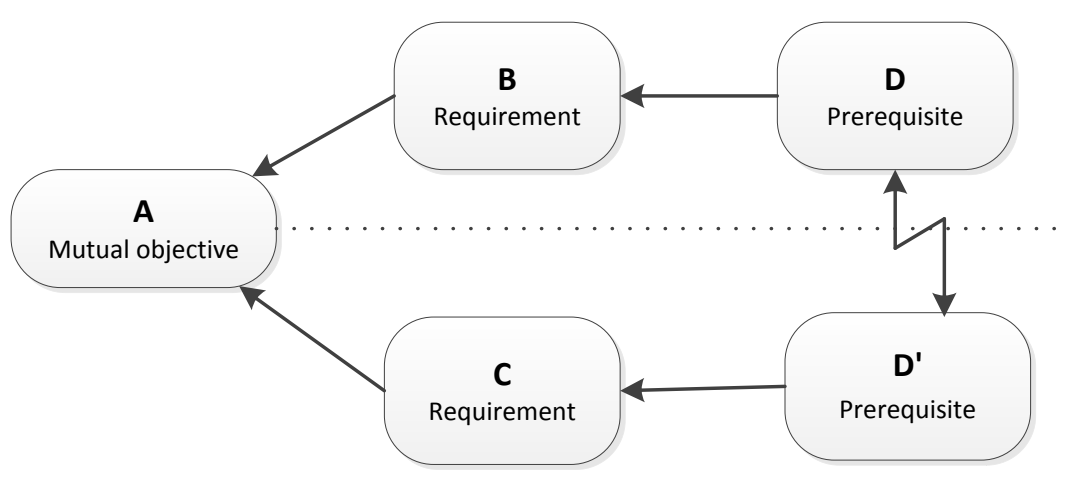

Source: Cox, et al. (2003, p.95); Fedurko (2013 p. 51).

The EC is a five box diagram which has an imaginary line depicting two different viewpoints. It is read from left to right as follows. In order to have objective A, we must have requirement B. And in order to have requirement B, we must have prerequisite $\mathrm{D}$. On the other hand, in order to have objective $\mathrm{A}$, we must have requirement $\mathrm{C}$. And in order to have requirement $\mathrm{C}$, 
we must have prerequisite $\mathrm{D}^{\prime}$ ( $\mathrm{D}$ prime). The $\mathrm{D}^{\prime}$ is always opposite of $\mathrm{D}$ and often cannot coexist, hence the conflict (Fedurko, 2013 p. 51). In order to resolve the conflict, assumptions of each side are surfaced and to evaporate the cloud/dilemma/conflict, ideas (called injections in TOC) are generated which could resolve the conflict leaving the two sides in a win-win situation (Cox, Mabin \& Davies, 2005) (see Chapter 8). It is important to note that verbalising assumptions through the EC in this manner not only helps in better understanding of a current situation but may also help ease tensions and conflicts that are often brought about by misunderstandings resulting from wrong assumptions.

In addition to verbalisation of assumptions, the TOC-EC process also generates ideas or possible solutions for addressing the undesirable issues affecting L\&T experiences using the 'what to change to' question. The analysis of this question checks for possible unintended negative effects or overlooked problems or issues that are likely to block the implementation of proposed solution(s). TOC uses the future reality tree (FRT) (Figure 3.4), a logical tool that shows the effects of implementing a proposed solution.

Figure 3.4: Simple structure of a FRT

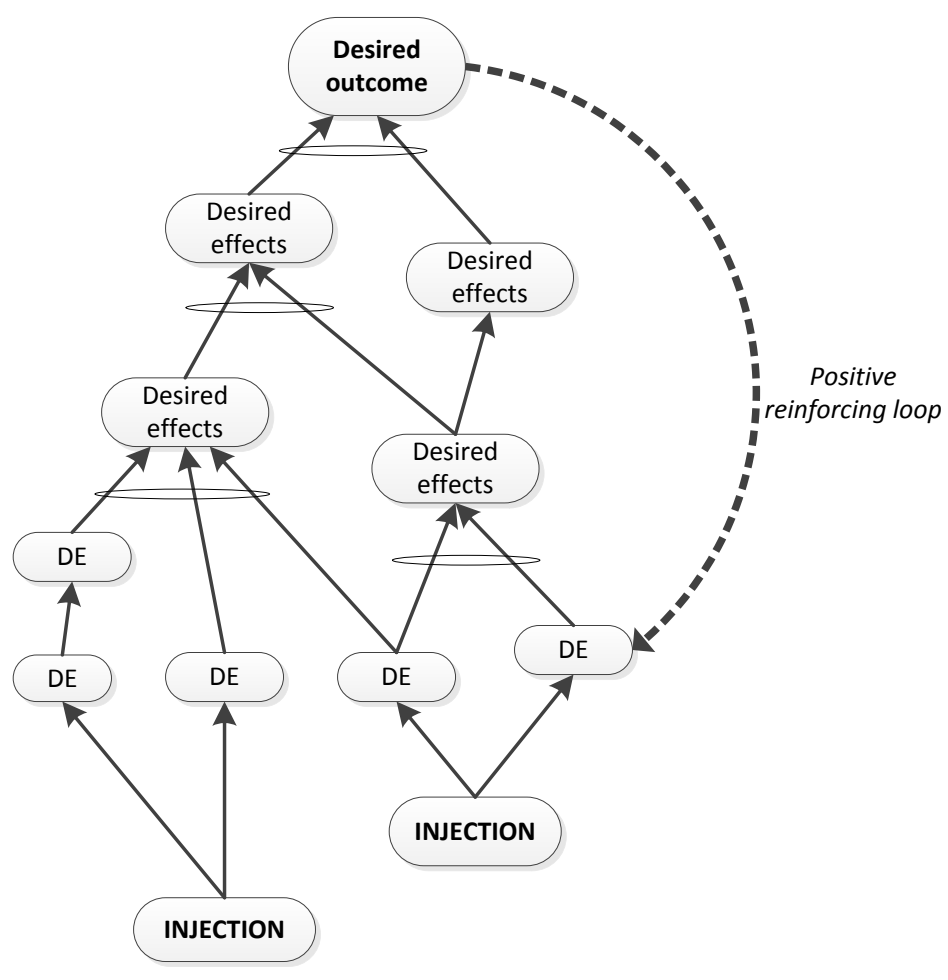

Source: Dettmer, 2007, p.207

As part of the FRT development, the negative branch reservation (NBR) process is used to map out why the proposed idea might actually work, might fail to work, or might work but 
bring about negative consequences (Cox, Mabin \& Davies, 2005). While a tentative FRT is provided for each case in Chapter 8 , it has not been fully worked through, and further negative branches are expected to be surfaced during implementation.

Therefore, the process of identifying and surfacing assumptions, and the generation of possible solutions might not only enhance the clarity of common L\&T purpose and flow of information, but might also improve the relationships within the L\&T system (Scheinkopf, 1999). As the relationships improve, L\&T experiences might also be assumed to improve.

This study does not address the implementation question of "how to cause the change to happen' at this stage but hopes to do so in a future study. In addressing this question, the TOC approach would help the L\&T system to further identify any obstacles to implementation of the proposed solution(s). The analysis of this question would help to identify the elements that might be needed to implement the proposed solution and the required sequence of actions needed to realise the desired outcomes (Davies \& Mabin, 2009). The TOC prerequisite tree (PRT) offers a logical process to identify all the obstacles that would block the successful implementation of the proposed solution or impede the ability to solve the problem. A resulting set of 'intermediate objectives' identify the intermediate steps that might be taken to overcome those obstacles. In doing so, the TOC approach further addresses the tensions (conflicts) and resistance to change within a system (Davies \& Mabin, 2009).

As suggested in the previous chapter, the global literature on L\&T experiences suggests tensions and/or dilemmas in areas that include teaching and research (Hattie \& Marsh, 1996; Healey, \& Jenkins, 2006); and approaches to HE management (Davies, 2001; Mok, 2000). In addition, Abdous (2011) notes a general high resistance to change in HE. TOC methodology provides a framework to analyse and resolve these tensions and/dilemmas, identifying the desired change while striving to overcome resistance to change (Mabin, Forgeson, \& Green, 2001).

This study thus sets out to answer three of the five change sequence questions of TOC's thinking processes (Cox, Boyd, Sullivan, Reid, \& Cartier, 2012) depicted in Table 3.1. 
Table 3.1: Relating the change sequence questions to logic trees

\begin{tabular}{|c|c|c|c|}
\hline & State of change & $\begin{array}{l}\text { Applicable logic } \\
\text { tree }\end{array}$ & Purpose \\
\hline 1 & $\begin{array}{l}\text { What is the desired } \\
\text { state? Why change? }\end{array}$ & Goal Tree & $\begin{array}{l}\text { Identify the goal, critical success factors \& necessary } \\
\text { conditions }\end{array}$ \\
\hline 2 & What to change? & $\begin{array}{l}\text { Current Reality Tree } \\
\text { (CRT) }\end{array}$ & Identify the UDEs and the core problem(s) \\
\hline 3 & What to change to? & $\begin{array}{l}\text { Evaporating Cloud } \\
\text { (EC), Future Reality } \\
\text { Tree (FRT) }\end{array}$ & $\begin{array}{l}\text { EC resolves dilemma by surfacing assumptions \& proposing } \\
\text { ideas (injections) while FRT tests the effectiveness of proposed } \\
\text { injections }\end{array}$ \\
\hline
\end{tabular}

(Adapted from Dettmer, 2007, p. 29)

In order to answer the research problem, an interview guide (see Appendix A) was constructed based on the above three change sequence questions. The first change question on 'what is the desired state' was adapted from Dettmer (2007: Ch 3) and Dettmer (2011), while the other two were adapted from Cox, et al. (2003, p. 90). Table 3.2 shows how the interview protocol fitted within the change sequence. The purpose is to show the pre-coded nature of the interview guide.

Table 3.2: The change sequence questions and the interview guide

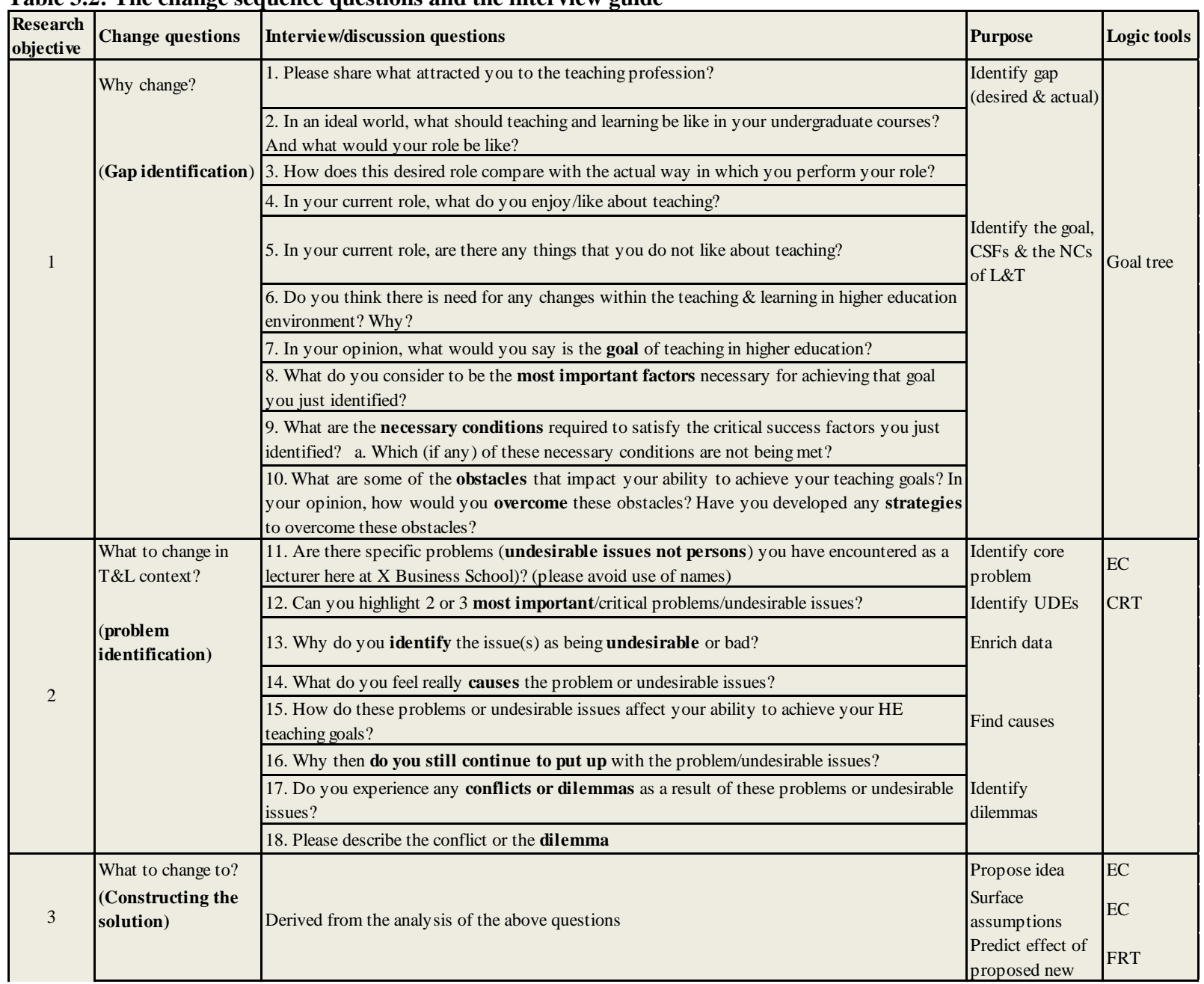




\subsection{TOC and the qualitative paradigm}

Beyond the prior evidence from the literature of the efficacy of the TOC methodology, the use of TOC in this study is justified by the identified need to use a different approach from other reported studies on quality in HE: a systemic approach rather than a piecemeal or fragmented approach. The TOC methodology is 'fit' to answer the research problem within the qualitative inquiry. The purpose of this study was to: (1) identify the L\&T system goal(s) with a view to identifying the critical success factors and necessary conditions for goal achievement, (2) identify the less than desirable factors that affect the experiences of L\&T with a view to identifying their critical root causes, and (3) determine their impact on the performance of the L\&T systems, and (4) to propose improvement ideas to resolve dilemmas associated with the critical root causes that could enhance the quality of experiences of L\&T and the performance of L\&T systems. In the following sections, we provide additional rationale for why TOC may provide an appropriate methodological approach to meeting the study objectives.

\section{i) Identifying the L\&T goal(s)}

The goal of any qualitative research is to offer valid explanations of the outcomes (Mahoney, 2008). In order to explain the outcomes of specific cases, Mahoney and Goertz (2006) assert that qualitative researchers often think about causation in terms of necessary and/or sufficient causes. They argue that the assessment of necessary and/or sufficient causation is consistent with logic and good science in qualitative research.

Consistent with qualitative studies, TOC uses necessity-based logic to construct a goal tree. Dettmer (2007, p.6) defines a necessary condition 'as a circumstance indispensable to some result or that upon which everything is contingent'. He also defines critical success factors as necessary conditions for goal achievement and argues that the relationship between CSFs and NCs is interdependent (Dettmer, 2007, p.7).

\section{ii) Identifying the critical root causes}

A central purpose of qualitative research is to identify the causes of specific outcomes. Subsequently, qualitative researchers offer explanation of outcomes using causes-of-effects approaches, moving backwards towards the causes (Mahoney \& Goertz, 2006). Similarly, TOC methodology uses cause-effect logic to identify the core causes of undesirable effects (Davies et al., 2005). In TOC, this is depicted in the form of a current reality tree (CRT) as mentioned earlier. To identify the causes using TOC methods, a top-down approach is used where a 
leading UDE (Ronen \& Pass, 2008, p.118), which represents deficiency in achievement of the goal, is first identified. Then the process moves backward downwards connecting to other UDEs that help answer the 'why?' of the effect, forming a CRT. To verify the sufficiency of the logic of CRT, a bottom-up approach is used with 'if...then' logic (Cox, Mabin, \& Davies, 2005).

\section{iii) Propose solutions for improvements}

In general, questions are often posed about whether research should lead to development of a theory or to solutions of practical problems (Mahoney \& Goertz, 2006). Based on a pragmatic perspective, this study aims to produce theoretical knowledge leading to enhancement of the TOC body of knowledge and to suggest solutions to identified problems. In order to propose solutions, this study uses an evaporating cloud (EC). The TOC approach presumes that root causes are often perpetuated by an underlying conflict (Dettmer, 2007, p. 13). Therefore, in resolving the problems, the TOC-EC process is used to analyse the underlying necessary conditions and assumptions causing the conflict and proposes possible resolutions. Then, the FRT tests the proposed ideas to ensure that the contemplated changes will help to bring about the desired improvements (Dettmer, 2007, p. 207).

\subsection{Constructing the logic trees}

The construction of TOC logic trees follows TOC protocol in presenting and testing logic relationships. This subsection highlights how the four types of logic trees and EC diagrams that are used in this study are constructed and linked in a manner that establishes problem identification, and works through problem structuring to problem-solving and implementation.

\section{1) The goal tree}

Within the TOC philosophy, establishing a common understanding of the goal and its critical success factors is the first stage of setting an organisation in the Process Of Ongoing Improvements (POOGI). Dettmer (2011) argues that 'a well-defined goal and its critical success factors provide the benchmarks for deciding the parts of the system that needed attention.' In this study, the construction of goal trees involved the following steps:

\section{(a) Articulating the goal(s)}

In order to establish an understanding of the learning (students), teaching (lecturers) and L\&T (admin) goals and the important factors that were needed for the achievement of those goals, 
academic staff and groups of students were asked about their goals of learning, teaching or both. During the individual/personal interviews, respondents verbalised the goal, then I restated it, and then wrote it at the back of one page of the interview protocol guide. I then moved on to the next question that enquired about the most important factors necessary for achieving that goal. I demonstrated 'how to respond' using a hand drawn diagram (Figure 3.5, Note that this figure is merely for demonstrative purposes and the reader is not expected to bother reading the contents) The graphical presentation made it easy to move to the next question on the necessary conditions required to satisfy the critical success factors already identified. This process was repeated in all the individual/personal interviews. In the case of the focus group (FG) discussions, each student was given an opportunity to verbalise his/her own goal within the group. Unsurprisingly, some students' goals were the same.

Figure 3.5: Sample of a goal tree constructed during data collection

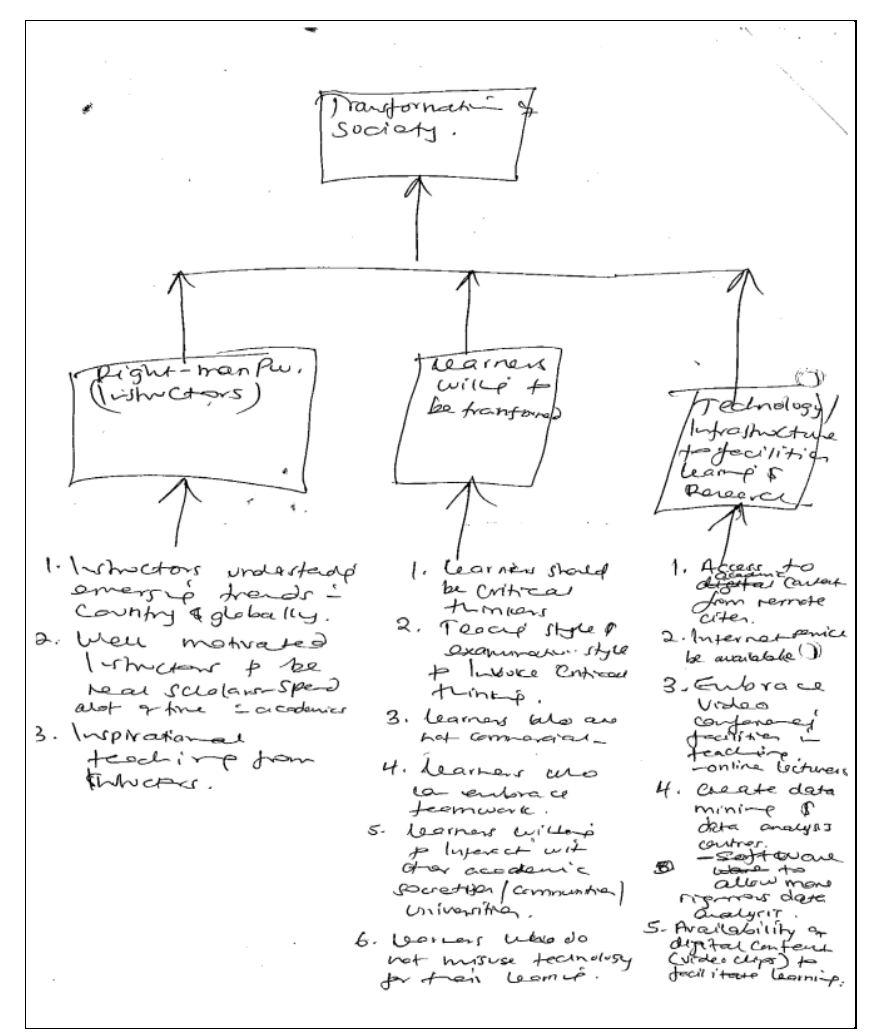

(b) Identifying a consensus goal via unitisation

To identify a consensus goal for staff, all participants' goals in each category were presented and analysed in a table format. Then 'unitisation' of common words, a sentence or a line of script was formed to construct a common goal. According to Saunders et al. (2007, p. 480) unitisation is an analytical process that attaches units of data into appropriate categories or labels with the aim of reducing the data into comprehensible form. A unit of data may be a 
number of words, a line of transcript, a sentence, a number of sentences, a complete paragraph that fits the defined category.

The process of unitisation involved coding of the already available data from the 'field goal trees'. Since the data had already been categorised by participants in their respective goal trees as either critical success factors (CSFs) or necessary conditions (NCs), the process of unitisation involved combining or unitising the categories identified as CSFs and NCs through coding. Any sentence, a verb-object sequence, or a single word, that communicated one idea was unitised and coded under a particular CSF or NC. Thus the process of unitisation started with a first CSF as mentioned by, for instance, FG KM1 - up to date learning resources is CSF1. The researcher went through all the other CSFs and NCs of all the groups searching for phrases that are related or implied learning resources. Then specific equipment or learning resources mentioned or related tasks or activities would then fall under the NCs under CSF1. Such NCs would include phrases that mention specific learning resources such as computer facilities, and finance labs. This process continued until most phrases were unitized and coded into either CSFs or NCs. Then further analysing was performed on the data guided by necessity logic so as to construct the goal trees.

In the case of a FG, in order to proceed to identify the CSFs and the NCs, consensus on a common goal in each group was first sought. Often individual goals tended to dovetail, and consensus was achieved by merging common aspects into one acceptable goal by the group members.

\section{(c) Identifying the CSF \& NCs}

After identifying the goal, the next step involved determining CSFs, which are the minimal requirements that are needed in order to achieve the goal (Dettmer, 2011). The CSFs and the NCs identified by the different groups of participants (students, staff) are presented in tables (see Chapters $5 \&$ 6). Some CSFs turned out to be NCs and vice versa. To determine the common CSFs, 'unitisation' of the identified CSFs (by the participant groups) was performed on a phrase, a sentence or a line of script that fitted or could be accommodated within a labelled CSF. If for instance, the first CSF was identified as 'L\&T facilities \& resources', then any sentence, phrase or words that implied this factor, was unitised under CSF1 (others would be CSF2, CSF3). This process was repeated for the other CSFs, reducing this data into three or 
less CSFs in a category. After identifying the CSFs, the NCs factors were determined for each CSF. Again, the unitisation process led the cross-examination of the constructs and phrases related to a particular CSF and labelled as NC under that particular CSF. For instance, for CSF1, the phrases related to it would be labelled NC1. Similarly, for CSF2, the related NCs would be labelled NC2, etc. In some cases, further unitisations of the NCs led to another level/category of NCs.

\section{2) The current reality tree}

After the construction of a goal tree, achievement gaps were identified by participants along with other symptoms or problems, referred to as 'undesirable effects' (UDE's). The CRT was used to depict a chain of effect-cause-effect relationships between the factors that limited the achievement of participants' L\&T goals leading down to the root causes of those limiting or constraining factors (Davies et al., 2005).

To construct the CRT, in practice, factors that negatively impacted on L\&T goals or were symptoms of not meeting the goals, were first identified. From these factors, a set of undesirable effects (UDEs) were determined using the protocol described by Cox et al., (2012) (Table 3.3).

Table 3.3: Characteristics of a well-articulated UDE

\section{Characteristics of a well-articulated UDE}

1. It is a complaint about an on-going problem that exists in reality and because of this problem, you cannot perform better.

2. It should be a complete sentence written in the present tense.

3 . It is a description of the state of the system, not an action.

4. It is within your area of responsibility or influence.

5. Something can be done about it.

6. It must not blame someone.

7. It must not be a speculated cause.

8. It must not be a hidden solution to the problem.

9. It must contain only one entity.

10. It should not include a cause in its verbalisation.

11. It should be factual and not subjective.

Source: Cox et al. (2012, p.130) 
The UDEs were then connected together through a logical chain of cause and effect to the root cause $(s)^{5}$ guided by use of a logic-testing process invoking use of the Categories of Legitimate Reservations (CLRs) (see section 3.5). The CLRs consist of rules that test the cause-effect logic in terms of challenging the clarity, and/or existence of the cause-effect; if...then relationships; the sufficiency of the cause to produce the effect; the possibility of cause-effect reversal; or the existence of circular logic.

Completed CRTs are used to provide a narrative of logical explanation and diagrammatic representation of how the root causes lead to under-achievement of the goals of L\&T. It is important to note that full CRTs were initially created for the Kenyan case. Later on, a reduced or focused CRT (fCRT) that emphasises only a few core UDEs (Ronen \& Pass, 2008), was adopted because it is not only easier to construct but also easier to explain. This issue of use of full CRT and focused CRT is discussed in Chapter 9, section 9.3.

The flying logic software as an aid to capturing and presenting the logic trees
Flying Logic software, specifically designed for constructing the thinking
processes logic trees, was used to construct both the CRT and fCRT logic
diagrams. Well-articulated UDEs, are factored in the Flying Logic Software using
cause-effect linkages. Once all data is factored in, the entities at the bottom of the
tree are usually identified as the root cause $(s)$. The user determine the logical
linkages between causes and effects but has no control over the layout, which is
automatically adjusted for best display by the software. Notably, Flying Logic's
'AND' is not the same as 'AND' in CLRs (section 3.5). Flying Logic does not
differentiate between magnitudinal 'AND', which implies that each cause
contributes to the effect in an additive way, and where several independent causes
can produce the same effect (Dettmer, 2007, p.46) (see section 3.5 on additional
cause). The software is quick to learn and friendly to use with immediate output.
However, while working with a large amount of data, its visual advantages get
compromised.

\section{3) The evaporating cloud}

In line with Krause's call for alternative frames for analysing the wicked problem that exist in HE (Krause, 2012), this study has adopted a systemic yet systematic TOC approach, from the goal tree (that identifies critical factors success), to CRT (that identifies the less desirable factors) followed by a EC process. Resolving conflict situations and dilemmas using the EC process acknowledges the social complexity of a system, and so necessarily raises/surfaces

\footnotetext{
${ }^{5}$ To verify the validity of the root causes, total number of participants/groups who mentioned the root cause(s) were double-checked and this information is provided in the within-case synthesis of root causes for each of the two cases (see section $5.6 .4 \&$ 6.6.4).
} 
various assumptions (valid and invalid) that people might hold concerning the conflict. The intent is always to lead to a win-win solution (Dettmer, 2007).

\section{4) The future reality tree (FRT)}

The FRT logic tree tests whether changes to the status quo will improve the current situation and bring about the desired effects without creating negative side-effects (Dettmer, 2007, p. $206 \&$ 207). It therefore serves as a framework for attempting to change the future (p. 210). Dettmer argues that the FRT is intended to build on the CRT and the EC in the problem-solving process. In this study, the construction of the FRT was underpinned by the construction of the goal tree, which provided the expected performance/outcome, the CSFs and NCs; the CRT which identified the undesirable effects (which needed to be turned into desirable effects); and the ECs that provided solutions to be injected and tested. Although the FRT may also depict a positive reinforcing loop (see Figure $8.6 \& 8.7$ ), to test the effect of changes, the FRT would further be refined by examining negative branch reservations that arose during discussion of the FRT.

Table 3.4: Summary table showing data collection methods, data forms and validity checks

\begin{tabular}{|c|c|c|c|c|c|}
\hline $\begin{array}{l}\text { Research } \\
\text { question }\end{array}$ & $\begin{array}{l}\text { Method of data } \\
\text { collection }\end{array}$ & Purpose & $\begin{array}{l}\text { Data forms/ confirmability } \\
\text { strategies }\end{array}$ & $\begin{array}{l}\text { Analysis } \\
\text { TOC-TP } \\
\text { tools } \\
\end{array}$ & Validity checks \\
\hline $\begin{array}{l}\text { Why change } \\
\text { L\&T context? } \\
\text { (Identifying } \\
\text { the gap) }\end{array}$ & $\begin{array}{l}\text { (1) Focus group } \\
\text { discussions } \\
\text { (students) } \\
\text { (2) Personal } \\
\text { interviews (staff) }\end{array}$ & $\begin{array}{l}\text { (1) Identify gap } \\
\text { (desired \& actual) } \\
\text { (2) Identify the goal, } \\
\text { CSFs \& the NCs of } \\
\text { L\&T }\end{array}$ & $\begin{array}{l}\text { (1) Flip charts for note taking } \\
\text { (2) Raw logic trees (diagrams) } \\
\text { (3) Tape recording }\end{array}$ & Goal tree & $\begin{array}{l}\text { (1) CLR (2) Multiple data } \\
\text { sources (MDS) (3) Participants' } \\
\text { review of the transcripts (4) } \\
\text { Necessary condition (NC) logic }\end{array}$ \\
\hline $\begin{array}{l}\text { What to change } \\
\text { in L\&T context? } \\
\text { (Identifying } \\
\text { the problem) }\end{array}$ & \begin{tabular}{|l|} 
(1) Focus group \\
discussions \\
(students) \\
(2) Personal \\
interviews (staff)
\end{tabular} & $\begin{array}{l}\text { (1) Identify core } \\
\text { problem (2) Identify } \\
\text { UDEs (3) Enrich data }\end{array}$ & $\begin{array}{l}\text { (1) Flip charts for note taking } \\
\text { (2) Raw logic trees (diagrams) } \\
\text { (3) Tape recording }\end{array}$ & $\begin{array}{l}\text { (1) EC (2) } \\
\text { CRT (3) } \\
f \text { CRT }\end{array}$ & $\begin{array}{l}\text { (1)Sufficient condition (SC) logic } \\
\text { (2) CLR (3) NC logic (4) MDS } \\
\text { (5) Linkages between } f \text { CRT \& } \\
\text { EC }\end{array}$ \\
\hline $\begin{array}{l}\text { What to change } \\
\text { to? } \\
\text { (Constructing } \\
\text { the solution) }\end{array}$ & $\begin{array}{l}\text { (1) Focus group } \\
\text { discussions } \\
\text { (students) } \\
\text { (2) Personal } \\
\text { interviews (staff) }\end{array}$ & $\begin{array}{l}\text { (1) Prioritise } 3 \text { key } \\
\text { UDEs } \\
\text { (2) Develop EC } \\
\text { (3) Surface } \\
\text { assumptions } \\
\text { (4) Propose injections } \\
\text { (5) Map future reality }\end{array}$ & $\begin{array}{l}\text { (1) Flip charts for note taking } \\
\text { (2) Raw logic trees (diagrams) } \\
\text { (3) Tape recording }\end{array}$ & $\begin{array}{l}\text { (1) EC } \\
\text { (2) FRT }\end{array}$ & (1) CLR (2) MDS (3) SC logic \\
\hline
\end{tabular}

\subsection{Validity and logical soundness of TP tools}

TOC diagrams can be constructed using two types of logic. First is necessity condition logic that describes the requirement(s) or prerequisites that are needed to have a desired outcome. The goal tree and the EC are constructed using necessity logic. Second is the sufficient condition logic that describes effects as being the logical outcome of causes in such a way that 
the cause(s) are sufficient to cause the effect (Dettmer, 2007). The CRT is constructed using the sufficiency logic (Cox et al., 2005; Fedurko, 2013).

In order to scrutinise the logic of the TOC diagrams/trees, the categories of legitimate reservation (CLRs) or the rules of logic are used. The CLRs consist of a framework of 8 specific tests (Dettmer, 2007, p 32). These are:

1. Clarity: Checks the accuracy or completeness of an idea in communication, to ensure statements are clear in meaning within the context.

2. Entity existence: An entity is a complete idea expressed as a statement. Any entity (cause or effect) should be grammatically correct, contain no more than one idea, and avoid embedded 'if-then' statements. The content of the statement should be sound or have real meaning and be reasonably acceptable to the listener.

3. Causality existence: Addresses concerns such as 'does the stated cause actually lead to the stated effect?', 'does the 'if-then' connection exist?', and 'is it a tangible/observable cause?'

4. Cause insufficiency: Addresses concerns of 'is the cause enough to produce the stated effect? Or are there conditions that are required for the stated cause to lead to the effect? This signifies a missing 'and' condition.

5. Additional cause: Concerned with 'could another completely independent cause produce or add to the effect? This addresses the 'either/or' conditions. This signifies a missing 'or' condition.

6. Cause-effect reversal: Concerned with distinction between 'why an effect exists vs how we know it exists. Could the stated cause be an indicator rather than the cause?

7. Predicted effect existence: This means that if a proposed cause-effect relationship is valid, some other unstated effect would be expected, and can be tested for.

8. Tautology (circular logic): The effect is offered erroneously as a rationale for the existence of the cause.

\subsection{Summary}

This chapter establishes the authenticity of the TOC methodology in helping managers develop a systemic and holistic view of their organisational/system goals. The TOC-TP tools are espoused as a legitimate set of methodological tools that can help in systemic change management for the purpose of quality improvement. The TP tools systemically and systematically embrace logic processes and logic trees, labelled as the goal tree, the CRT, the EC, and the FRT. These logic trees are constructed using necessity-logic, and sufficiency-logic. A set of logic rules, in the form of CLRs guides the construction process. These tools of analysis are used in Chapters 5 and 6 whereby they are posited as valuable tools for conducting qualitative research to express cause-effect relationships more transparently than via narrative or text alone. The next chapter provides a rich description of the data collection processes in Kenya and New Zealand. 
Chapter 3: Theory of constraints as a research methodology 


\section{Chapter 4}

\section{THE METHODOLOGY}

Not everything that can be counted counts and not everything that counts can be counted (Albert Einstein).

\subsection{Introduction}

This chapter explains how the researcher's philosophical view underpins first the research strategy and then the methods adopted to fit that strategy. This is followed by a detailed description of the field procedures, data collection, pre-analysis and analysis.

\subsection{The philosophical assumption}

In the conduct of any research study, researchers make certain philosophical assumptions. Philosophical assumptions refer to the stance that a researcher adopts, knowingly or unknowingly, towards the nature of reality or the world view that $\mathrm{s} / \mathrm{he}$ tries to understand (ontology), the development and the nature of that knowledge (epistemology), and the methods used in the process of research (methodology) (Creswell, 2007, p.16). The discussions surrounding the choice of philosophical stance continue. While acknowledging the importance of situating oneself and the inquiry within a certain philosophical position, the nature of this study does not prioritise that. Instead, this study prioritises the research question/objective as the most important determinant of the research philosophy. This leads to a pragmatic perspective.

\section{The pragmatic paradigm}

Within the pragmatic paradigm, individuals focus on the outcomes of the research with concern for applications (what works) and solutions to the problem (Creswell, 2007, p. 22). Indeed, pragmatism not only focuses on the importance of the research question(s)/objectives but also allows the researcher to study what interests him/her, and what is of value to him/her, using different ways that s/he deems appropriate, and to then use the results in ways that can bring about improvements within the value system (Saunders, Lewis \& Thornhill, 2007, p.110). This worldview is consistent with Kuhn's (1962 as cited by Denyer, Tranfield, \& Aken, 2008) broad interpretation of a paradigm as: 
A combination of research questions asked, research methodologies accepted as appropriate to answer them, and the nature of resulting research products (p.395).

In a pragmatic paradigm a researcher may therefore use one or a combination of methods as long as they are best suited to answering the research question (or achieving the research objective). The use of different methods in pragmatism may also imply that at some point the researcher and the researched would be interactive while at other times the researcher would easily stand apart from the researched (Saunders, Lewis, \& Thornhill, 2007, p.110) .

Thus, while valuing the interactions with the participants and their subjective experiences of L\&T, the researcher sought to use an objective science to explore and analyse those experiences. As explained in chapter 3, the TOC methodology that applies cause and effect logic to analyse data is used. In order to factually report about the choice of strategy of inquiry, sampling design and the data collection process, the researcher now prefers to use first person singular, ' $I$ ' to make the work more readable.

\subsection{The strategy of inquiry: qualitative approach}

I adopted a qualitative approach as a research method for collecting and analysing data. In this approach, factors that participants perceive as important in the achievement of their L\&T goals are first explored. Secondly, factors that are perceived to cause less than desirable experiences of L\&T are then explored with an aim of identifying the critical root causes. Thirdly, improvement practices that could enhance the quality of L\&T experiences and the performance of L\&T systems are proposed.

In order to understand the above three issues, I adopted a case study design. Why? First, the case study is best suited to answer the research problem, which is 'to explore the L\&T experiences in HEIs' by generating an in-depth understanding of the L\&T experiences of the students, lecturers, and senior administrative staff (Saunders, Lewis, \& Thornhill, 2007; Darke et al., 1998). Moreover, case studies are considered particularly useful where research and theory are at early stages and are considered as valid means of testing theory (Darke, Shanks, \& Broadbent, 1998). The application of the TOC to explore the L\&T experiences in HE is considered relatively new, which makes case study suitable in this study. Furthermore, this study uses multiple case-study design, which not only allows theoretical replication and crosscase comparisons, but also provides multiple measures of the same phenomenon. These 
multiple sources do strengthen the findings through the convergence or corroboration of information (Darke et al., 1998).

Case selection: I selected two business schools (see section 4.4): the University of Nairobi School of Business (UNSB) (Kenya), and the Victoria Business School (NZ).

Why explore L\&T experiences from two diverse cases?

The rationale for this is twofold. Firstly, exploring the two cases satisfies my curiosity, as a researcher, for knowledge of solving L\&T problems prevalent in my home country (Kenya) and in my study country (NZ). Exploring the two cases enriches my understanding of L\&T systems globally. In my view, the two cases provide deeper insights of L\&T issues.

Secondly, the two cases allow identification of common and different features, which can be compared to global trends. Indeed, the use of two cases might allow generalisation of common L\&T issues. This generalisation cannot be achieved with one case.

\section{Why explore business schools in particular?}

First, the importance of business schools should not be underrated. Business schools make greater contribution to the management and leadership of many corporations compared to other schools. This contribution is through their business graduates and affiliations to the corporate sector. The performance of the business schools might therefore affect the performance of the corporates and the general economies of the world (Adler, 2002). Indeed, reflecting on current corporate scandals and their impact on stakeholders, Adler called for 'a reflection of business school policies' (p. 149).

Second, the quality of L\&T experiences in business schools is likely to be different from other schools such as medicine and law, which engage to a great extent with their professional bodies and with practice, and therefore are better able to measure their quality in terms of competence of their graduates. In business schools, it is not unusual to find faculty who have little or no practical experience, engaged with educating students to make decisions relating to practice (Bennis \& O’Toole, 2005).

Third, I have been working in a business school for the last ten (10) years and have experienced conflicts and dilemmas within the L\&T context. Therefore, I have a keen interest as well as capability to explore how the experiences of L\&T in business schools could be improved. 


\subsubsection{Sampling design}

I selected the two cases for this study because they could purposively inform the research problem (Creswell, 2007, p. 125) and were also conveniently accessible to me. Moreover, the two cases shared similarities in that they are public universities, are capital city universities and are typical cases within their contexts.

To select students and academic staff, I used stratified purposeful sampling and convenience sampling to fit participants in different categories. Within this case-study design that relies on cause-effect process to explain the outcomes, I was not particularly concerned with finding large numbers of participants but with a diverse group of participants in each case. Indeed, Mahoney and Goertz (2006) argue that in case studies there is substantial leverage even when the population $(N)$ is equal to 1 . Section 4.6.1 and 4.6.2 provides detailed selection procedures of participants in Kenya and NZ respectively.

\subsection{Data collection process}

To embark on the data collection process, I first developed an interview guide. This interview guide was constructed guided by a TOC change sequence framework (Chapter 3). It was only after the interview guide was approved by the Human Ethics Committee (Appendix B) that I embarked on the data collection process.

I used two data collection methods: face-to-face interviews and focus group interviews. The use of these methods is consistent with qualitative case studies (Creswell, 2007, p.129) and with other TOC applied studies (Kelly-Weekes, 2012; Nagarkatte \& Oley, 2010; Van Gelder \& Urban, 2010).

i) Face-to-face interviews: senior administrative and academic staff

To deepen exploration of the experiences of L\&T, I used an open ended interview guide with senior administrative and academic staff in the two business schools. A similar set of interview guides was used for all participants with minor adjustments based on the role/position of the participants (see Appendix A). But this does not mean that I asked the questions in exactly the same way or in the same order. This is because many times a participant responded to a particular question in a broader way thus answering another question in the guide. Other times, a participant answered a question in a way that required further probing of the question. Further 
probing could sometimes lead to an answer of another question in the interview guide. The main focus was on getting answers to the research problem.

The face-to-face interviews created rapport and a sense of trust. This is probably because I assured participants of anonymity in reporting their responses. As such, participants were particularly open to me in their discussions. Perhaps that openness would have been compromised if I used another method, say a focus group. This interview method also allowed me to observe the changes in participant's body language as they engaged deeper in the discussion. Indeed, on a few occasions, participants demonstrated to me by show of documents what they referred to in their discussions. For instance, one participant showed me Bloom's Taxonomy hanging on a wall, another a print-out of an email from a student recommending him/her for good teaching done many years back, another a model s/he used in a class, another showed a book that contained contextualised cases of teaching, yet another demonstrated to me how s/he was literally shaking in his/her first lecture at a university.

During each interview, in addition to tape recording, I used an interview protocol (a replica of an interview guide but with ample spaces between questions to write responses from a participant) recommended by Creswell (2007, p. 133). The interview protocol was particularly useful in assigning serialised codes for each interview and for recording basic information (date, place, interviewee, and interviewer). More importantly the protocol helped me to illustrate and clarify in a graphical form the response expected from three sequence questions (asking about the goal, the critical success factors and the necessary conditions). But most importantly, in the last interview, least unexpectedly, the participant declined to be tape recorded and so I used the interview protocol to write all the responses. In all the interviews, I carried a folder complete with all the relevant field documents (information sheets, consent forms, interview guides, interview protocols, permits).

\section{ii) Focus group interviews: students}

I used focus group (FG) interviews to collect data from all students. The relevance of focus group discussions in this study is exemplified by Wilkinson (in Silverman, 2004 p. 180) who indicates that the 'naturalistic' nature of a FG can provide a synergistic effect that allows participants to react to, and build upon responses of other group members leading to a more detailed discussion. However, FGs may create high morale of group members through involvement and interactions which may create an impression that an organisation is listening, while in actual fact, it is not (McLafferty, 2004). Another downside is that those individuals who 
may have different opinions from the rest of group members may be silenced (McLafferty, 2004). Relatedly, the moderator must be proactive to ensure the voices of all members are heard.

The focus groups (FGs) sizes ranged from 3 to 9 in a group. This is perceived to be within the normal FG range as noted by Wilkinson (in Silverman, 2004, p. 178) of between two to twelve depending on the context. Other studies that have used FGs include Lea and Callaghan (2008) who used two FGs comprising 4 and 5 key staff involved in L\&T (such as chairs of Faculty learning \& teaching committees) in addition to personal interviews with lecturers. Relatedly, Lea, Stephenson, \& Troy (2003) used 8 FGs comprising of 6 students each (totaling to 48 students) to explore issues of L\&T in a HE environment as well as specific student-centered learning issues in UK. McLafferty (2004) used six FGs to explore methodological issues arising from using focus group interviews. She used one group of nursing lecturers (6), two groups of students (9 and 8), two groups of nurses from care of older adults' areas (5 and 4) and one group from the acute clinical areas (4). Nevertheless, the aim of using FG discussions is to generate rich, detailed and contextual data (Lea \& Callaghan, 2008). Indeed, through FG interactions, students provided rich information within a short period of time.

The process of conducting FGs involved several steps. Specific steps undertaken in Kenya and NZ are explained in section. 4.6.1 and 4.6.2 respectively. First, at the start of the group discussions, soft drinks and snacks were served in order to facilitate a relaxed environment the discussions. Secondly, in each of the FGs, I introduced myself to the group members and provided a brief introduction of the purpose of the study. In the case of Kenya, I then distributed the information sheet forms, discussion guides, and the consent forms. (In NZ, by the time students got into the discussion room, the sitting positions were well labelled in the table with their names together with the information sheet forms, discussion guides, and the consent forms). Thirdly, I allowed some time for the students to go through the forms. Before starting the FG discussions, I sought verbal approval to record the discussions. I assured students of anonymity of their verbatim quotes in the write up. I then placed the audio recorder in a central position. Fourthly, I went through each question in the discussion guide and as the students engaged well with the questions, I 'bulleted' their responses in flip charts (particularly in Kenya). In NZ, because of time limitation, I included few aspects (such as the goal tree) of the discussion guide in the flip charts and relied more on tape recording. At the end of the discussions, I gave each student a small token of appreciation as I thanked students for participating in the discussion. 


\section{Familiarising with the research setting}

In an attempt to understand participants' experiences of L\&T particularly in the NZ case, I purposively and actively interacted with L\&T activities in order to familiarise myself with the research setting. Often, researchers immerse themselves in a research setting with the objective of sharing people's lives (Saunders et al., 2007, p. 284). In the Kenyan case this was easy. I only needed to observe a few changes in a new tuition block that had recently been built; otherwise it was a familiar context. In NZ, it was daunting. To familiarise myself with the L\&T context, during the pre-analysis period (of the Kenyan case) and particularly in March and April 2014, I attended two workshops from the Centre for Academic Development (CAD) on online assessment with the Blackboard (Learning management system-LMS), and on marking and feedback for tutors. From April 2014 until December 2014, I served as a postgraduate student representative on the Faculty of Commerce Academic Board. Other L\&T engagements were with Ako Victoria 2014 (also 2013) and in several Vic Teach seminars. Other involvements in $\mathrm{PhD}$ workshops and seminars also provided me with a broader understanding of L\&T issues at Victoria University of Wellington. This familiarisation was useful in that some concepts, which would otherwise have been unfamiliar, became familiar in such a way that when participants mentioned them, I could easily understand them.

\subsection{Ethical issues}

There are many ethical issues that I addressed at different stages of this research. They relate to ethical approval, research authorisation, privacy of participants, informed consent, and confidentiality in report writing.

\section{i) Ethical approval and authorisation}

The first step in this stage involved seeking ethical approval from the Human Ethics Committee of Victoria University of Wellington. This ensured that the ethical principles for conducting this research were in accordance with the university statutes. In order to obtain access to Victoria Business School (VBS), I sought authority from the Dean. Likewise, in order to access participants in Kenya, I first sought authority at national level (Appendix E), and then at institutional level (Appendix F). This process is elucidated in section 4.6.2.

It is important to note that in Kenya, many participants insisted on seeing a copy of the national permit and/or institutional authority at the point of recruitment or during the interviews. The 
permit assured participants of the legitimacy of the research and this gave them the confidence to participate.

In NZ, the first email contact to participants indicated that the VBS Dean had consented to the research.

\section{ii) Privacy of participants' contacts}

To obtain first contacts and subsequent correspondence with the participants there were varied privacy concerns. In the first case (Kenyan), access to people's contacts was easy through their mobile phones. Culturally people give out other people's mobile phone numbers and that is acceptable. It is not perceived as breach of privacy. Thus, to establish first contacts I got the participants' mobile phone numbers either from the registrar or the secretaries, the participant themselves or from my friends. To contact the Kenyan participants, I first sent them a mobile text message, explaining who gave me their number (if they didn't do it themselves) and a brief purpose of why I was contacting them. For the students' contact person, I called him/her directly.

In NZ, giving out people's personal information such as mobile phone numbers is considered a breach of privacy. Therefore, there was no way I could get students' contacts in the form of emails or mobile phone numbers. For lecturers and senior administrators, their emails are available in the VUW website.

These privacy issues had implications for how I contacted and corresponded with the students. For instance, in Kenya, I could email a document to all students in one FG. In NZ, I always emailed myself and then Bcc to students in a FG so that they did not get the other students' email addresses.

\section{iii) Voluntary participation, informed consent and confidentiality}

Upon getting the first contacts and upon agreement to voluntary participation, I emailed participants the details of the study in the form of the information sheet (Appendix C), the interview guide (Appendix A) and the consent form (Appendix D). I also gave the same documents to them during the interviews. And during the interview, I always explained the purpose of the research to all participants and assured them of confidentiality of their responses. [It is important to note here that although this study is not confidential, anonymity of participants' verbatim responses in writing is provided by use of pseudonyms]. Moreover, I allowed ample time for the participants to go through the documents themselves. I also 
addressed any questions that they had and always sought verbal approval to record the interviews. In addition to their verbal confirmation, the signing of the consent form also served as a further confirmation to proceed with recording and interviewing. On one occasion, a participant signed the consent form but declined to be recorded.

Two participants raised ethical concerns related to reporting. One concern was about the description of specific participants and whether that would include their job titles and/or their host schools/departments. The other concern was whether my reporting will include the specific courses a particular lecturer taught (say a marketing lecturer, an accounting lecturer), which might help to identify participants more closely. In response I assured the participants that descriptions and verbatim quotes would use pseudonyms and would not be specific (e.g. DKto denote accounting student, LK- to denote Marketing lecturer). I further assured them that other forms of attributions of a lecturer with a particular course, for example, would be avoided if deemed prejudicial.

\section{iv) Privacy of data}

During data transcription I took care not to reveal the identity of the participants (lecturers \& students) and any information that could easily identify them. Thus, where participants talked about a course or mentioned names, these were given codes to maintain anonymity of their responses. These changes were explained to the participants when their transcripts were emailed to them for member checking.

To ensure privacy of data, all hard copy documents for field-work were stored in a locked filing cabinet. The soft copies and the interview recordings were saved in a password protected computer and laptop. Other publications (such as conference papers) related to this study have consistently ensured that participants remain un-identified as in this thesis.

\section{v) Publication of the findings}

This study is largely about undesirable issues impacting on the experiences of L\&T. Although the study is neither anonymous nor confidential, doesn't publishing such findings put the respective business schools in a bad light? Is it fair to the business schools? To mitigate this, reasonable care is taken to generalise the names of the schools in present and future publications (e.g. A Kenyan business school has been used in conference paper publications instead of the specific business school). 


\subsection{The data collection process}

Data for this study were collected in two phases. The first phase was the Kenyan case that is described below.

\subsubsection{The data collection process in Kenya}

The data collection process in Kenya is depicted in Figure 4.1.

Figure 4.1: Data collection design (Kenyan case)

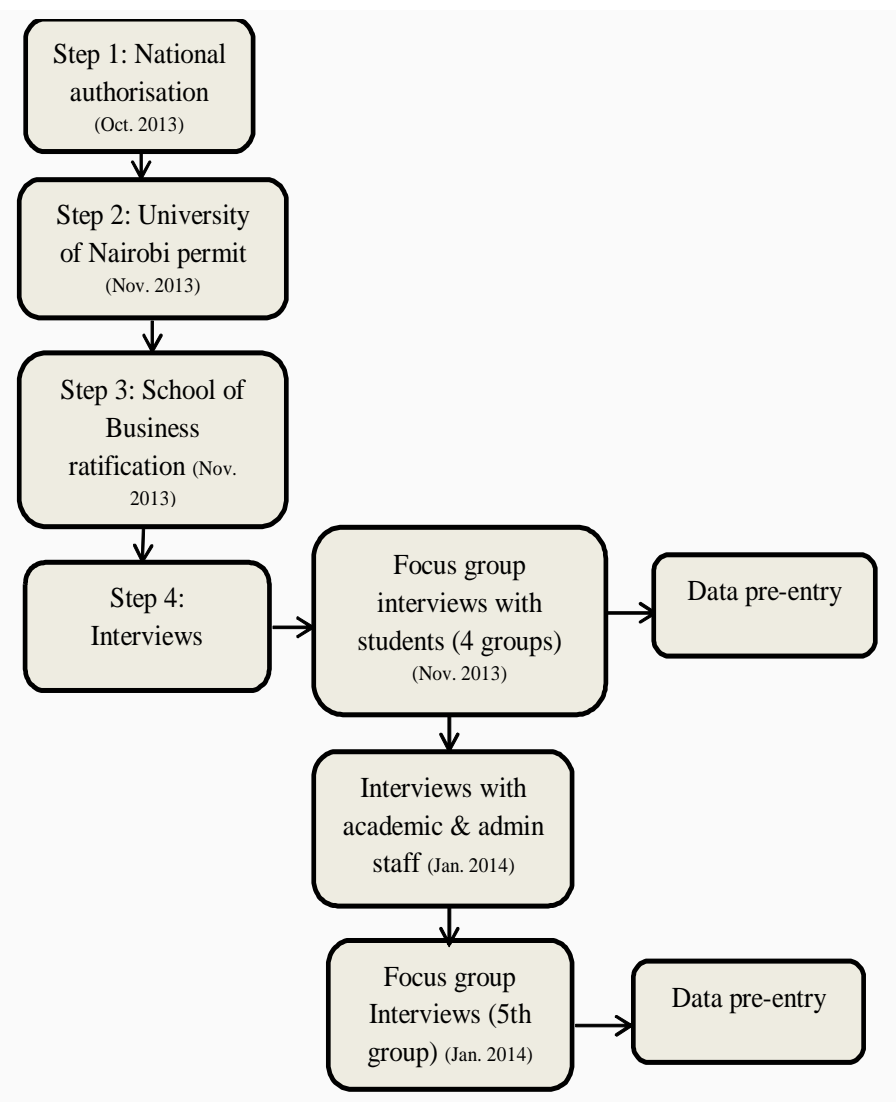

In order to collect data in Kenya, the first step involved applying for a national research and authorisation permit (Appendix E). A national research permit is a statutory requirement under the Science and Technology Act, Chapter 250 of the Laws of Kenya that stipulates that, no systematic research can be conducted in Kenya without authorisation or clearance from the National Commission for Science, Technology and Innovation (NACOSTI) (www.nacosti.go.ke). The NACOSTI's purpose is to advise and regulate matters of research, among other functions, in the country. The process of obtaining the national research permit for this study involved filling in an application form signed by the applicant and both supervisors, attaching relevant documents (copy of research proposal, copy of ethical approval, letter from Vice Chancellor VUW, curriculum vitae, copy of passport and a passport size photograph) and the payment of an application fee. This process took one week. Upon receipt 
of the Research Authorisation \& Clearance Permit, I was required to report to the County Commissioner and the County Director of Education for stamping of the permit before embarking on the study.

The second step involved application for permission to carry out the study at University of Nairobi (UoN). I submitted an application letter to the Vice Chancellor (VC) together with a copy of the national permit. The permission was granted from the office of deputy VC (Research, production \& extension). This permit was copied to the relevant university bodies including the Dean, School of Business (see Appendix F).

In the School of Business, further ratification (step three) was granted by the school assistant registrar and copied to the security officers and administrators in different campuses that host the school of business courses and/or programs. In order to have a clearer understanding of the data collection in the University of Nairobi-School of Business (UNSB), the reader is first referred to UNSB background information in Chapter 5.

\section{Building Samples, contacting participants and conducting interviews}

This study was designed to collect data from three different samples: students, lecturers and senior academic administrators. I envisaged the need to start with the students' focus group discussions because it was an appropriate time of the semester to get their cooperation.

\section{(i) Focus Group (FG) Samples (students)}

The assistant registrar was very instrumental in building initial contacts. He provided me with a list of four students and their telephone numbers that I could call to help me build samples for the focus groups. As indicated earlier, giving out people's mobile phone numbers in Kenya is an acceptable practice. The same day I was given the numbers, while still in Lower Kabete campus (where UNSB is located), I simply picked one number from the list, called one student who happened to be on campus and we met. I explained to him the purpose of the research. The student confirmed his cooperation in arranging four different focus groups. We agreed to diversify gender and years of study as much as was possible. The student also agreed to arrange for the venues (classes) within the campus where we could hold the FG interviews. The four groups comprised:

- Module I students

- Module II students (Full-time)

- International students

- Student leaders 
The fifth group (Module II students-Part-time) was held at a later date. This group comprised evening students who undertake their program from $5.30 \mathrm{pm}-8.30 \mathrm{pm}$. The evening program is designed for employed students who work from $8.00 \mathrm{am}-5.00 \mathrm{pm}$. This group is taught from a different campus (called Chiromo campus), about $3 \mathrm{~km}$ from the main campus, which is in the capital city, Nairobi. Despite being separated (in location) from the other modules, this group had already entered into an exam period by the time I finished collecting data with the first four groups of students. Upon showing the endorsed authorisation by the UNSB Assistant Registrar, an officer (at the UoN Main campus where the UNSB evening program coordination office is located) provided me with a list of five students and their telephone numbers that I could call. Similar to the first process of developing initial contacts, I picked one number and called the student. I explained to him the purpose of the study and promised to email him other details (discussion guide and information sheet). The student took about two weeks to gather students for the FG. The student also arranged the venue. The focus group discussion meeting was held on a Saturday at Chiromo campus.

The process of conducting the FGs is explained earlier in sec 4.4 whereby in each of the FGs, I introduced myself to the group members and provided a brief introduction of the purpose of the study. I then distributed the information sheet forms, discussion guides, and the consent forms. Then I allowed some time for the students to go through them. At the start of the FG discussions, I sought verbal approval to record the discussions. I assured students of anonymity of their verbatim quotes in the write up. Then, I went through each question in the discussion guide and as the students engaged well with the questions, I 'bulleted' their responses in flip charts. At the start of the group discussions, soft drinks and snacks were served in order to facilitate a relaxed environment the discussions. At the end of the discussions, I gave each student a small token of appreciation.

Reflection of UNSB FG discussions:

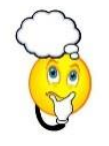
interview questions. It appeared to me that they appreciated listening to their 'own voices' and truly being involved in the discussion. That is perhaps how they preferred to learn: to participate fully in the discussion and have someone to listen, acknowledge and appreciate their views. They indicated that they enjoyed the discussions with me and wished that they could attend my classes. They assumed that my classes were always like that.

\section{(ii) Personal interviews (Lecturers)}

Initial contacts for the lecturers were obtained through telephones calls or from the lecturers at Lower Kabete campus. This did not always work. Some lecturers did not keep their promised 
interview dates, while others ignored the follow-up calls or texts. The assistant registrar was again very helpful in drawing up a list from each of the three departments (see Figure 4.2) of those lecturers who were more likely to cooperate and provide the information that I sought. This list worked well. Thus, upon agreement with a lecturer, we scheduled an interview date. In most cases, lecturers were given hard copies, before or on the interview date. It is important to note that hard copies were more convenient for lecturers than emailing the documents. Indeed there was only one case where I emailed a lecturer the information sheet form and the consent form before the interview date. In Kenya, the use of mobile phone calls and text messages is more common than emails. Thus, calls were made or texts were sent to the lecturers a day or two before the interview. During the interview, I sought verbal approval to record the interview. As with student participants, lecturers were assured of anonymity of their verbatim quotes in the write up. I then went through each question in the interview guide. During the interviews, I wrote some notes on the interview protocol sheets as the audio recording went on.

\section{(iii) Personal interviews (senior administrators)}

I selected the senior administrators based on the relevance of their positions within the structure of the UNSB (Figure 4.2). They included the Dean, the Associate Dean (undergraduate), three chairs of departments, and the coordinator of the BCom program. Others, whose positions were not explicit in the structure (for reasons unknown to me), but were deemed instrumental in this study, were the Director of Quality Assurance (DQA), the Assistant Registrar and the Dean of Students. Six interviews were conducted. In all six interviews, I made the initial contacts through an initial visit to the administrator's office. In four interviews, I left the information sheet and the interview guide (often together with a note) with the secretary to pass over to the administrator. The note also included my mobile phone number. The administrators or their secretaries then contacted me to arrange for an interview date.

For the other two interviews, I handed the information sheet and the interview guide to the administrators personally some days before the interview date. Before each interview, I called or sent a reminder text to the interviewee a day or two before. During the interview, I sought verbal approval to record the interview. I then went through each question in the interview guide. I wrote notes on the interview protocol sheets. 


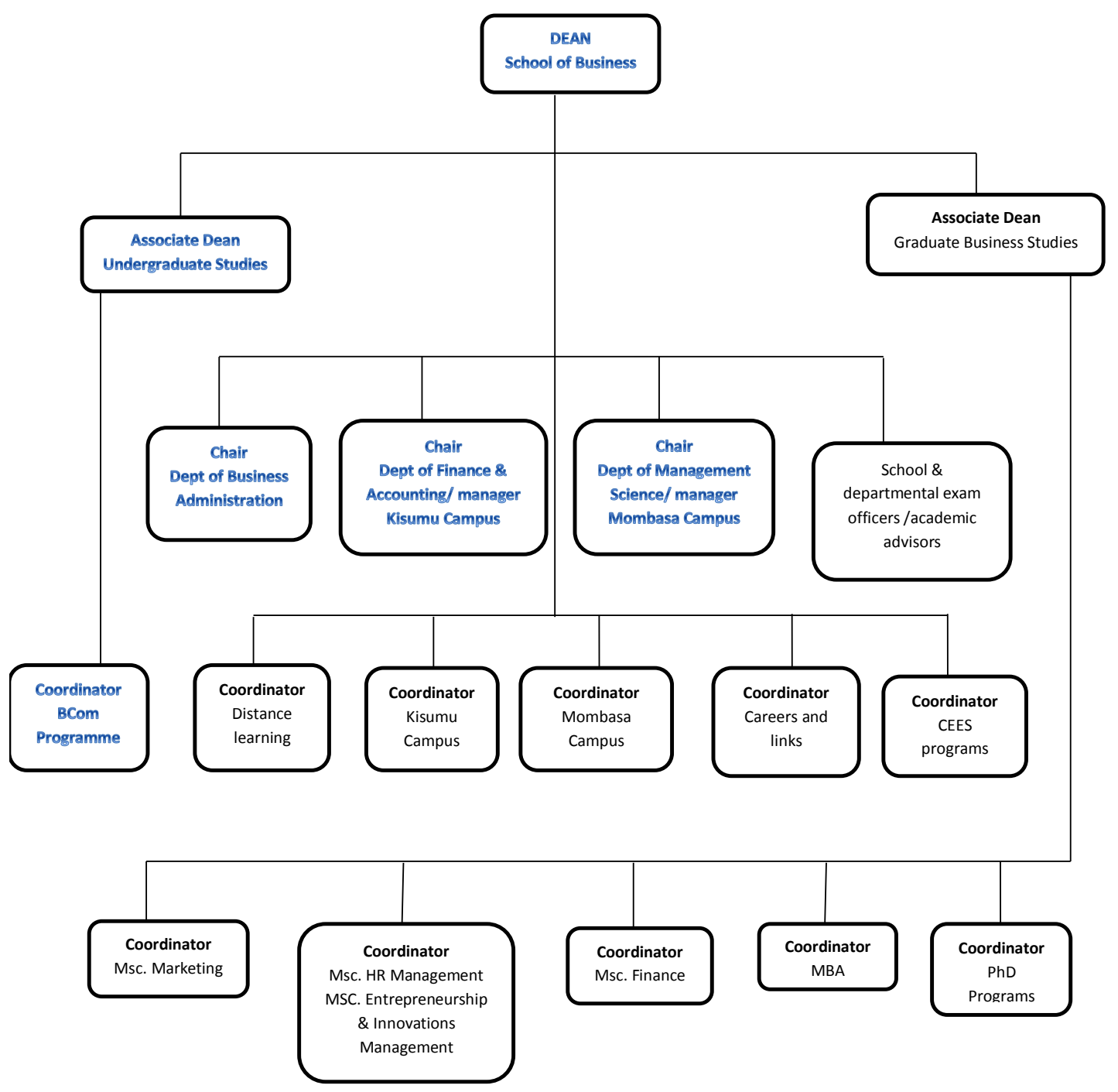

Source: http://business.uonbi.ac.ke/

Although eight administrators were envisioned for the study, two administrators were not interviewed. One was in transition to another senior office and so he proposed that I interview the person who had previously acted in his capacity. I had already interviewed the proposed person as a lecturer and I did not find it needful to re-interview him. If anything, this particular person had provided additional information on the 'anything else?' part of the interview guide that he felt could help improve the experiences of L\&T. The other administrator was simply not committed and on two occasions did not turn up for interview as agreed. Since a senior person in that role volunteered to participate, I deemed that information as adequate. 


\section{vi) Time frames of focus group and interviews}

After conducting the first four FG discussions, there was a three-week student strike from $14^{\text {th }}$ December 2013. The data collection process was therefore halted until the university re-opened on $6^{\text {th }}$ January 2014. Interviews for the lecturers and administrators were run concurrently. Except for the Director, Quality Assurance (DQA), all administrators' interviews were held in Lower Kabete. For lecturers, some interviews were held in Lower Kabete and others on the Main campus and Chiromo campus.

\section{vii) Saturation}

Many qualitative studies follow the concept of saturation where collecting additional data do not necessarily lead to more information (Mason, 2010). Mason goes further to indicate that many qualitative researchers claim saturation without appropriately describing how it was achieved. In this study as the data collection progressed, it became clear how well the TOC methodological themes such as the 'goal', 'critical success factors', 'necessary conditions', and 'undesirable issues' that were considered in the construction of the interview guide were being addressed and a saturation point was reached where little if any new information was emerging.

\section{viii) Categories of participants}

In this study some categories of participants (such as academic administrators) were definite in that they were defined by the structure of the school. The student categories were also definite in terms of years of study and modules. Although I could have conducted additional focus group discussions with replica groups, five groups generated an enormous amount of data, which tended to converge highly around the pre-coded themes, and was deemed to be sufficient. Lecturers were categorised based on their departments. The process of interviewing lecturers also generated large volumes of data. Indeed, the multiple samples enriched the data, allowing similarities and differences within the case to emerge as data were collected.

\section{Data pre-analysis strategy in Kenya}

This sub-section describes the steps in coding the data for the focus group discussions and for the personal interviews in Kenya. It is important to note that the TOC methodology that guided the construction of the interview guide also provided a general data analysis strategy that is supported by the following steps. 
Steps in coding the FG discussion data

1) The flip chart notes

I collected initial data from each of the five focus groups using an audio recorder and bulleted notes on flip charts. The flip charts were fixed on blackboards with masking tape and were all numbered to ease the process of re-pasting them on the wall and transferring the data contents into an initial tabular Word document.

2) The tabular summary sheet

After every FG interview, I transferred the bulleted notes into a pre-prepared table. The table contained basic information about each focus group in terms of date, time, and venue in the first row. The second row contained data related to the characteristics of the group members in terms of gender, year of study, country of origin or representative leadership position. The third and subsequent rows addressed the discussion questions and the bulleted responses of each group to that particular question. Table 4.1 shows a portion of the tabular summary sheet.

3) Transcribing the focus group (FG) discussions

Table 4.1 provides a snippet of FG discussions. However, for in-depth information, I transcribed each of the five FG discussions into an interview protocol Word document that was saved in separate files for each group. I then filed the five Word files in the same folder for ease of retrieval. 
Table 4.1: A section of a tabular summary sheet

\begin{tabular}{|c|c|c|c|c|c|}
\hline $\begin{array}{l}\text { Student } \\
\text { groups }\end{array}$ & $\begin{array}{l}\text { Module I: } \\
\text { 18/11/2013 } \\
\text { Time: } \\
\text { 2pm-4.30pm } \\
\text { Venue: G04 }\end{array}$ & $\begin{array}{l}\text { Module II: } \\
\text { 19/11/2013 Time: } \\
\text { 11am-1.20pm } \\
\text { Venue: G01 }\end{array}$ & $\begin{array}{l}\text { International } \\
\text { students: } \\
\text { 21/11/2013: } \\
\text { Time: } 11.30- \\
\text { 2.30pm } \\
\text { Venue: G01 }\end{array}$ & $\begin{array}{l}\text { Student leaders: } \\
\text { 22/11/13: Time } \\
\text { 11.45am-2pm Venue: } \\
\text { G01 }\end{array}$ & $\begin{array}{l}\text { Evening } \\
\text { students: } 25 / 1 / 14 \\
\text { Time: } 12 \mathrm{pm}- \\
\text { 2.30pm Venue: } \\
\text { Chiromo Campus }\end{array}$ \\
\hline $\begin{array}{l}\text { Characteristics } \\
\text { of students }\end{array}$ & $\begin{array}{l}\text { Total no. } 7 \\
\text { Males: } 4 \\
\text { Females: } 3 \\
\text { Yr. of Study } \\
\text { Yr. 1=2 } \\
\text { students } \\
\text { (1male, } 1 \\
\text { female) } \\
\text { Yr. } 2=2 \\
\text { students } \\
\text { (1male, } 1 \\
\text { female) } \\
\text { Yr. } 3=0 \\
\text { Yr. } 4=3 \\
\text { students } \\
\text { (2males, } 1 \\
\text { female) }\end{array}$ & $\begin{array}{l}\text { Total no. } 9 \\
\text { Males: } 5 \\
\text { Females: } 4 \\
\text { Yr. of Study } \\
\text { Yr. } 1=0 \text { students } \\
\text { Yr. } 2=0 \text { students } \\
\text { Yr. } 3=3 \text { (2males, } \\
1 \text { female) } \\
\text { Yr. } 4=6 \\
\text { students( } 3 \text { males, } \\
3 \text { females) }\end{array}$ & $\begin{array}{l}\text { Total no. } 3 \\
\text { Males : } 3 \\
\text { Females: } 0 \\
\text { Yr. of Study: } \\
\text { All in fourth } \\
\text { year of study } \\
\text { Countries: } \\
\text { 1. South Sudan } \\
\text { 2. Uganda } \\
\text { 3. Somalia }\end{array}$ & $\begin{array}{l}\text { Total no. } 5 \\
\text { Males: } 5 \\
\text { Females: } 0 \\
\text { Yr. of Study } \\
\text { Yr. 1= } 0 \text { students } \\
\text { Yr. } 2=1 \\
\text { Yr. } 3=0 \\
\text { Yr. } 4=4 \text { students } \\
\text { 1. School of Business } \\
\text { organisation (SOBO) } \\
\text { Secretary general } \\
\text { 2. Students of UoN } \\
\text { Organisation (SONU) } \\
\text { faculty representative } \\
\text { for module } 2 \\
\text { 3. SONU faculty } \\
\text { representative for } \\
\text { module } 1 \\
4 \text {. SOBO Vice } \\
\text { Chairman } \\
\text { 5. SOBO secretary for } \\
\text { sports \& entertainment }\end{array}$ & $\begin{array}{l}\text { Total no. } 9 \\
\text { Males : } 4 \\
\text { Females: } 5 \\
\text { Yr. of Study: } \\
\text { All in second year } \\
\text { of study }\end{array}$ \\
\hline $\begin{array}{l}\text { Motivation to } \\
\text { do degree in } \\
\text { business }\end{array}$ & $\begin{array}{l}\text { 1. Believes } \\
\text { that business } \\
\text { drives } \\
\text { economy } \\
\text { 2. Needed } \\
\text { knowledge } \\
\text { about business } \\
\text { 3. Application } \\
\text { in business is } \\
\text { wide... }\end{array}$ & $\begin{array}{l}\text { 1. Had learnt } \\
\text { business studies } \\
\text { in high school and } \\
\text { liked the course } \\
2 . \text { Had business } \\
\text { background } \\
\text { experience in } \\
\text { running parents } \\
\text { business... }\end{array}$ & $\begin{array}{l}\text { 1. To contribute } \\
\text { to the } \\
\text { development of } \\
\text { the country } \\
2 \text {. To benefit the } \\
\text { society } \\
\text { Motivation from } \\
\text { high school } \\
\text { where the } \\
\text { director ... }\end{array}$ & $\begin{array}{l}\text { 1. Broadness of the } \\
\text { business field \& } \\
\text { diversity of its } \\
\text { application } \\
\text { 2. A belief that all } \\
\text { organisations need .... }\end{array}$ & $\begin{array}{l}\text { 1. Mother acted as } \\
\text { role model as a } \\
\text { business woman } \\
\ldots . \\
2 . \text { Had interest in } \\
\text { numbers since } \\
\text { high school ... }\end{array}$ \\
\hline
\end{tabular}

4) Excel data sheet

I designed the Excel data sheet exactly as the Word tabular summary sheet. The difference was that the Excel sheet had the ability to hold all the transcribed data for all the FGs. Indeed, the matrix format of Excel allowed the thematic questions to be captured on one axis and the Five FGs on the other. Thus, after every transcription I transferred data into the Excel sheet that I had structured according to the discussion questions. This process involved copying and pasting specific data from a specific part of the Word document into the appropriate boxes of the Excel document. The consolidated spread-sheet allowed for ease of comparison of particular themes across the five FGs. Arranging data in such a way allowed for a systematic and thematic approach to analysis. The Excel data sheet acted as a master file. 


\section{Steps in coding the face-to-face interview data}

The face-to-face interviews were recorded using an audio recorder and on paper. I found writing the main points in spaces within the interview protocol guide particularly useful in restating and confirming the issues raised by participants during the interview. Writing in the protocol was also very useful where, in a subsequent question, I needed to refer to responses raised in an earlier question. These write ups also acted as a good back-up in case the recorder ran out of space, as it did in one interview. Next, I followed two basic steps that were similar to number $3 \& 4$ above:

1) Transcribing the interviews

I transcribed the interviews in the spaces of a protocol document and filed them separately using pseudonyms within the same folder for related groups of participants in each case. For instance, file LK 09, was filed together with all other LK files under the folder 'LK transcribes'.

2) Excel data sheet

Data from the interview protocol guide were then pasted to particular boxes in the Excel sheet. The Excel sheet for each group of participants contained basic information about the participants in the form of gender, years of experience, specialisations, departments or schools that they belonged and awards or recognition. The interview questions that were similar to the ones in the protocol guide were all pasted in the Excel sheet. Then I copied the transcribed information from the interview protocol guide and pasted to the particular column in the Excel sheet. Thus, the columns specified the particular participant while the rows indicated the interview questions and responses of each participant to a particular question. As in the case of the FGs, arranging data in such a way allowed easy comparison of responses across a particular question or theme.

3) Member checking of the transcript

All participants were sent their respective transcripts for confirmation. However, very few participants responded. Indeed only two administrators, two lecturers and one student responded. 


\subsubsection{The data collection process in New Zealand}

I had intended starting data collection at Victoria Business School (VBS) in October 2013, immediately after the proposal stage of my research. Thus, upon Human Ethics (HE) approval of the research, the Dean VBS gave me approval to commence the data collection process. But soon after, before the commencement of data collection, I changed plans and decided to travel to Kenya to start the data collection there.

Upon return to NZ in March 2014, with overwhelming data from Kenya, it made sense first to analyse those data before embarking on further data collection from VBS. Thus, during the period of March 2014 to July 2014, I embarked on data transcription and pre-analysis of the Kenyan case. Reflecting on this, I find that the experience of data collection in Kenya and the pre-analysing period did provide me with ample time to understand VBS L\&T context better. Indeed, it provided me with more confidence to face $\mathrm{NZ}$ participants with less apprehension particularly of the 'Kiwi' accent.

a) Building Samples, contacting participants and conducting interviews

This case study emphasised the exploration of experiences of L\&T of VBS students, lecturers and senior academic administrators/managers. As a qualitative study, the objective was not to maximise the number of participants but to get information that could adequately address the research problem. Nevertheless, I used a criterion to match the categories of participants of the first phase (Kenyan case) while taking into account the structure of VBS, the diversity of the target population and participants' willingness to participate in the study. Moreover, the trimester dates were not ignored due to their influence on the students' and lecturers' ability and willingness to participate.

Since approval had already been granted (Figure 4.3), I decided to start the interviews with the senior academic administrators/managers as I continued to organise students into focus groups. 
Figure 4.3: Data collection design in NZ

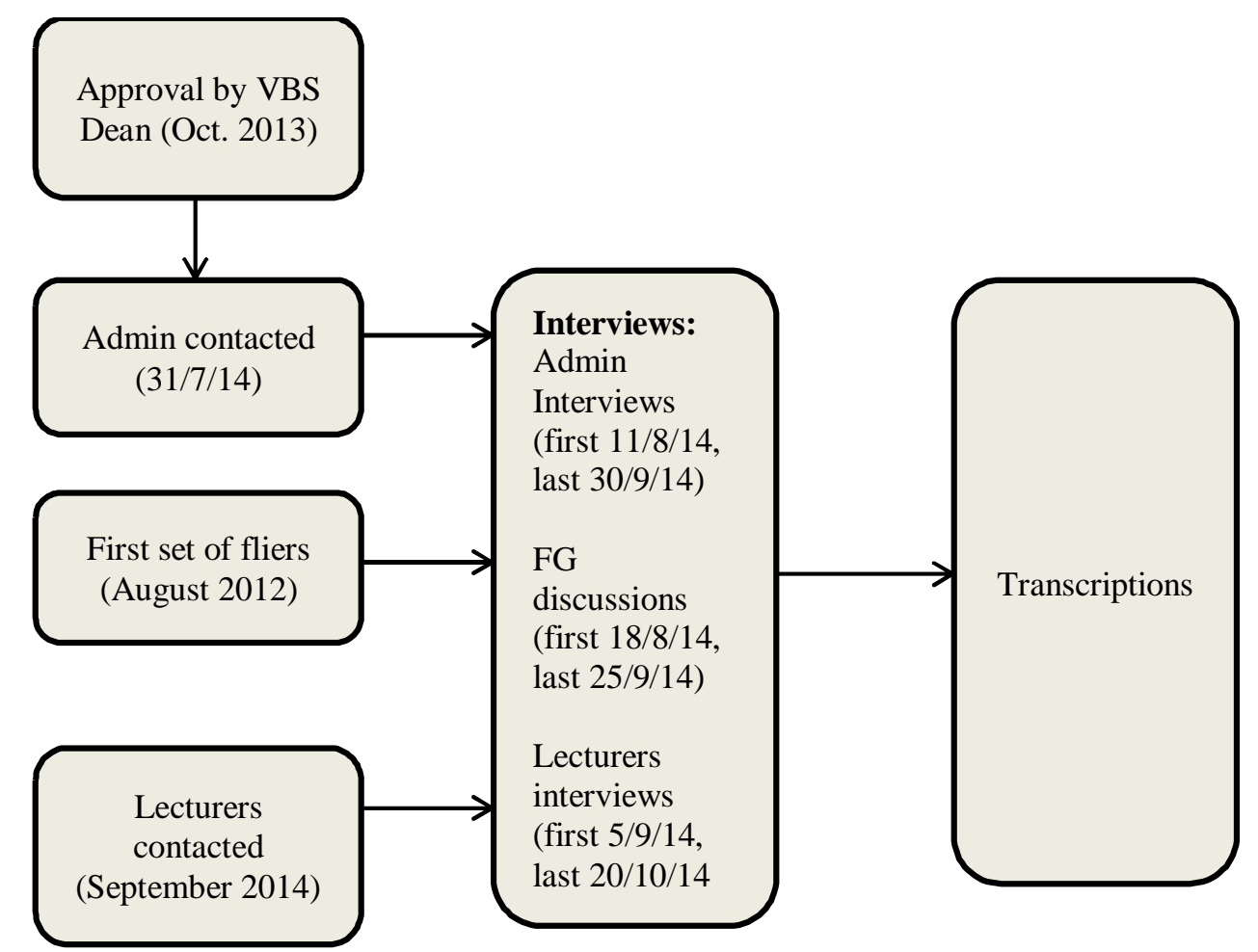

(i) Selection and interviews with senior administrators

As indicated earlier on the sampling design, I based the selection of senior academic administrators/managers of VBS on the relevance of their positions in the study (see Figure 4.4).

Figure 4.4: Perceived structure of VBS

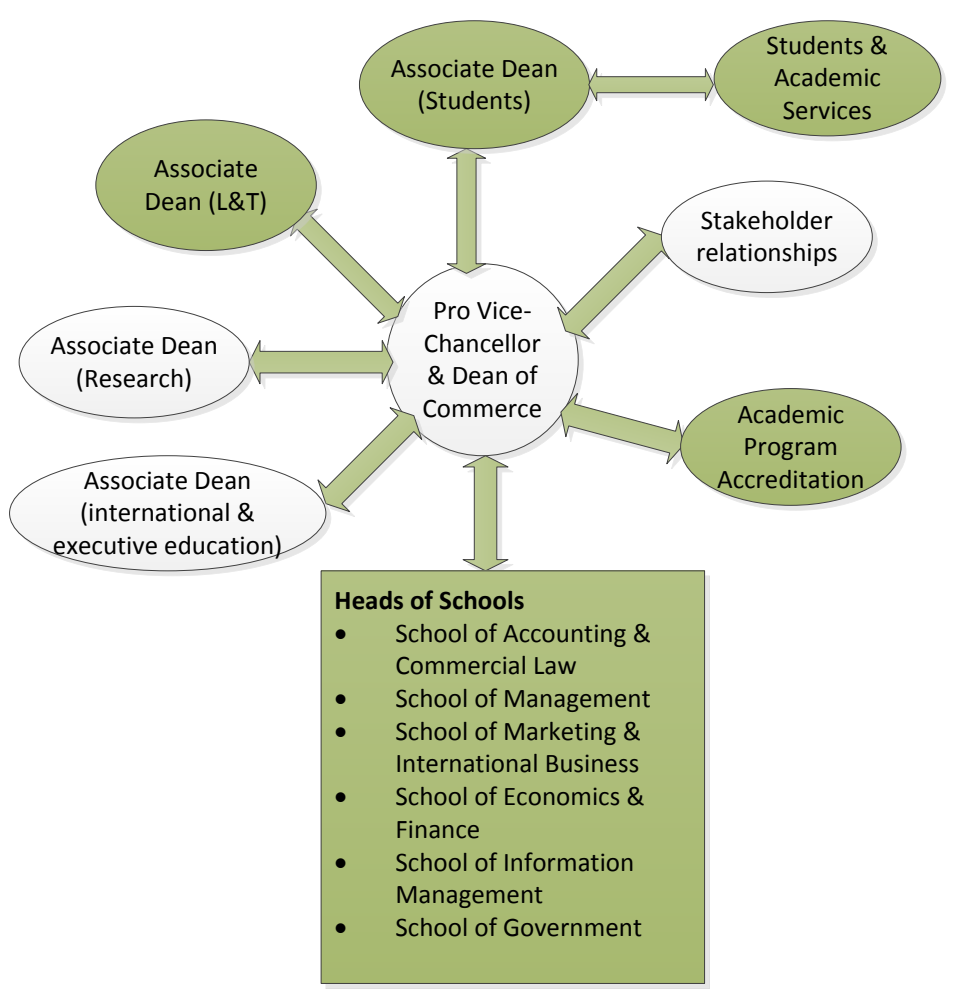


The first emails were sent to senior managers/administrators or to the administrators of their calendars on $31^{\text {st }}$ July 2014 , requesting appointments for interview. The administrators targeted for this study were in the offices of Academic Program ${ }^{6}$ Accreditation, Associate Dean Learning \& Teaching (ADLT), Associate Dean of Students, and Student Academic Services, and the Heads of Schools (except the School of Government, which did not closely match the characteristics of the Kenyan case). Some administrators/managers responded quickly giving appointment dates while others did not. I followed-up with them as I worked through other field schedules. All interviews were held in the administrators' offices. A total of 8 interviews were conducted.

\section{(ii) Focus Group (FG) Samples (students)}

To arrange the recruitment process of students to participate in the study, I held a consultative meeting with the Deputy Associate Dean of Students. We discussed the different categories of students that I wanted to participate in my study. As indicated in section 4.5, I could not get students' contact details due to privacy reasons. To progress, I embarked on an aggressive advertisement campaign of my study using fliers that I pinned on VBS student notice boards. The first batch of fliers indicated that the focus group meeting would take $1.30 \mathrm{hrs}$ to $2 \mathrm{hrs}$. This did not work despite an incentive of \$20 supermarket voucher. I quickly changed the time to 1hour and decided to reduce the group size to 4-5 students. One student advised me to use the bathrooms to put up the fliers, which meant I was able to overcome the clutter on notice boards.

In addition to fliers, I did five short personal presentations in two separate 100 level classes on the Kelburn campus, two 200 level tutorial presentations and one 300 level class presentation (on Pipitea campus that houses VBS). I made effort to recruit students through intra-net in two university halls (Joan Stevenson \& Stafford house-UniLodge). The Te Putahi Atawhai placed the flier on Facebook targeting the Māori \& Pasifika students. The response was gradual and by mid-semester break, I had conducted four FGs. The other three FGs were conducted after the break, bringing the total to seven FGs.

\footnotetext{
${ }^{6}$ With permission from supervisor, this thesis uses the word program to imply programme
} 


\section{a. The flier}

The flier simply advertised for VBS undergraduate students interested in participating in a $\mathrm{PhD}$ research study to contact me through an email address that I provided therein. Interested students were asked to respond giving their year of study (year I, II or III) and the category that they belonged to (Domestic students, international students or Māori \& Pasifika). I included an incentive of $\$ 20$.

\section{b. The recruitment into the groups}

The recruitment process started when a student sent me an email expressing their interest to participate in the study. Before replying to the email, I opened a doodle-scheduling link for the particular group the student belonged to (if it was a first student in that category). I then replied to each by providing each with full information about the research and by attaching all the necessary information (information sheet, discussion guide, and consent form). I also informed the student that I would provide the same information documents as hard copies during the FG meeting. Within the same email, I advised each student to click to a google-doodle scheduling link. This link enabled the student to vote the most appropriate/preferred time for the group discussion. In the email, I also advised students that they could invite their friends to contact me. Upon voting in a particular group, I selected the time that majority of the students voted for the meeting and I communicated to all who voted. I then closed the link. After booking a meeting room with the school administrator, I communicated the venue to the students.

The process of recruiting students turned out to be very demanding mentally and physically, and a very slow process. Despite the difficulty of getting interested students, not all those who expressed interest finally participated because the allotted times did not suit everyone. Moreover, each voting process needed constant vigilance, and a constant update of students of the voting progress.

In the final group, there were two students who preferred not to vote through the doodle link despite referring them there. They specified their preferred times, then I simply included them in the doodle schedule and coincidentally, others chose that time. There were also some students who expressed interest immediately after the last focus group. In reply, I advised these students that the process of collecting data was over but I thanked them for expressing their interest. All the fliers were removed from the notice boards a few days after the last FG. This also helped to stop other students emailing about the study. 
Categorising the groups into year I, II, and III (level 100, 200, and 300), international, and Māori \& Pasifika worked relatively well probably because of the scheduling of their classes and tutorials. Moreover, requesting them to encourage their friends to participate in the study also worked in some ways. On few occassions, after a FG meeting I got other interested participants who emailed me.

\section{c. Focus group meetings}

About 30 minutes before the start of the FG meeting, I arranged the meeting room ready for the students. I arranged the labels of participants' names (mostly first) together with information sheet, discussion guide, and consent forms on the table. In each of the seven FGs, I first introduced myself to the group and provided a brief introduction of the purpose of the study including its scope. I assured students of confidentiality of their responses in the write up. Then I sought verbal approval to record the discussions. The signing of the consent form further confirmed their approval. Then, I went through the discussion guide as the FG members responded. Due to limitation of time, I only used the flip charts while discussing the questions related to the goal of learning, the critical success factors, and the necessary conditions. During the discussions, some drinks and snacks were provided. At the end of the discussions, I gave each participant a $\$ 20$ supermarket voucher as a token of my appreciation.

\section{(iii) Selection and interviews with lecturers}

Using VBS web page lists of lecturers from each of the five schools, and with the help of a VBS insider; we identified lecturers based on their perceived willingness and availability to participate. In the next step, I personally approached some of the identified lecturers in their offices to make personal contact and to briefly highlight to them my study and assess their interest. I did not want to send blind emails. And since I did not know most of the lecturers, I hoped that this first contact would help to cut through the clutter of emails people have to deal with on daily basis. Then, on agreement, I sent them a request for an appointment for an interview, attaching the relevant documents (information sheet and interview guide). I kept a record of the email dates. On a few occasions, I got an appointment during the first personal contact and on one occasion, I got an immediate appointment (with an allowance of 20 minutes) for an interview. But most appointments were confirmed after participants received the first email. I made a deliberate effort to have participants from each of the five schools. A few lecturers did not respond but when I got the desired number of participants I informed those that I could that the data collection process was over. 


\section{(iv) Transcriptions and member checking}

I transcribed all the interviews literally. The process took a long time but it was personally satisfying because I developed a 'clear voice' of my participants in my mind. This made my analysis easy. Initially, I did not have an appropriate order of transcribing the interviews because I started transcribing while still collecting data. Then, when I finished with FGs, I decided to finish transcribing all of them (FG discussions). Thus, I started with transcripts for senior managers/admin, before switching to FGs, then to lecturers and back to senior admin.

Whenever I finished transcribing a particular script, I immediately sent it to the group or participant for checking. Many transcriptions came back from lecturers with clarifications. And on one occasion we replayed the recorder with a lecturer to get the facts right. The administrators also responded well to transcriptions. Again on one occasion we replayed the recorder while another administrator requested the audio record to use while going through the transcript. Only one student responded.

\subsubsection{Reflections on the design of the interview/discussion guide}

The design of the interview/discussion guide brought many issues to the fore.

(i) The first question that asked participants what attracted them to their position sometimes elicited mixed answers and questions in NZ. A few participants indicated that they were not attracted to their positions and explained how they got there. Others indicated that the question was difficult to answer; 'That is a very difficult question, do a lot of people find it very difficult? VL10'.

(ii) Asking for 3 factors? I felt that I was putting some participants under undue pressure when I asked for '3 factors' and some did not easily seem to get the three. One participant asked 'Why three?' (VAD 04). Well, I could answer that the TOC thinking is that only a few key leverage points influence the overall system performance at any one time (Goldratt, 1990, p.4), but few is not three, it is relative. But some felt that the predetermined questions did not allow them to give their experiences within their own frame of reference but was rather imposed on them. Following up on those three factors that participants identified, some took heavy breaths and long pauses. One participant indicated, 'Oh, this seems a difficult one ?' (VAD 03). 
(iii) Emphasis or repetition? As we moved down the interview guide often times participants asked me, 'Are you sure they are not among those we have discussed?' (LK 09). To some, some of the issues that they mentioned as 'did not like' tended to be repeated under 'undesirable issues'.

(iv) Some terms? A few of the participants in NZ tended to be uncomfortable with 'don't like'. One participant said, I do not like that term 'like'. Was that a contextual issue or the use of English language? Likewise, some participants were not comfortable with the term 'obstacles'. In Kenya they preferred to use 'challenges'. Could the pilot testing of the interview guide (in each of the two cases) have made any positive difference?

(v) Design of the guide? The design of the guide tended to disrupt a few participants' lines of thinking/thought. One participant indicated, 'I do not like this way of questioning' (VAD 04). It tended to interfere with his/her line of thought. S/he tended to prefer a less structured guide. However, each of the question was included for a purpose in order to construct the diagrams.

(vi) Conflicts or dilemma? One question that asked, 'Have you experienced any conflicts or dilemmas?' elicited mixed responses. Incidentally, some Kenyan participants did not seem to 'experience any dilemma'. One participant indicated:

No. We have very clear rules on how to operate at the university. The university has put things very clearly, so unless you want to put yourself in a dilemma situation, dilemmas are not there. ... If you do the right things you will never come across these dilemmas. If a student has failed, he has failed! What's dilemma? If the student has passed, he has passed. Bring your marks on time, who is going to put you to challenge? (LK10).

In this university I don't think I have had any conflicts or dilemmas. Anything that comes up we are able to deal with it, there are systems, and I don't think there are student dilemmas that I can think of. At UoN, systems are that when you have a problem, you deal with it. Report to the chairman, when I feel there is an ethical issue or what, I deal with this guy. If we are not able to do that we have a Dean. If not the Dean, then there is the principal, we are able to deal with these cases. So that we won't say it is a conflict. You know a conflict or a dilemma comes in if like your bosses are causing you to do something you don't know what to do or something like that. Personally if there is anything, then I will try to find a way out. Otherwise that is why I am here to get a way out \{solution\} (LK09).

At this school, I really can't say there are any conflicts. It's really a very free place (LK06).

Honestly no, because you find that, like our department, if you are not happy with a situation, usually the chairman is very receptive and you will find changes will be made (LK07).

One student group indicated two opposing positions on dilemmas:

No there are no conflicts or dilemmas, unless at a personal issue (KIS)

This dilemma is very common and all of us go through it. Sometimes you do course work and get 25/30. The last paper, you do it very well but at the end of the day you find yourself getting a grade C or a D. The final 
exam you guess that you could get something like $40 / 70$, which adds to a B $(25+40=65$ or B). But you end up getting a $\mathrm{D}$ grade. To make it worse you cannot do anything, you cannot report to anyone, the scripts are not brought back, and you can't petition anyone (KIS).

In NZ, one participant indicates 'No, I mean in what sense? What sort of conflicts? (VAD 06). Thus, this question was not always obvious.

(vii) Mere speculation? I sometimes felt that the question on 'What really causes the problem or undesirable issues? ' was largely a matter of speculation particularly among the Kenyan students. Students seem to speculate on what caused the many UDEs that they had raised. For instance, 'Why are lecturers not available? Why are there incidents of missing marks? Why is the public address system not being used by lecturers? So ideally, they could only speculate. Lecturers and the senior administrative staff on the other hand, seemed to be convinced of the causes of the UDEs that they raised. However, both speculation and convictions can lead to erroneous explanations.

(viii) Negative questions? Most questions in the guide were 'negative' in the sense that they asked about those issues that were not desirable. While this did not seem to bother some especially in Kenya, and it actually looked like a good way of 'letting off steam', others, particularly in NZ did note that the interview was a bit too negative. Sometimes, some participants expressed this through some deep breaths. When I noted such signals, I warned the participants that it was getting negative but explained the purpose is to identify those things that are not working well in an effort to seek solution for improvement. But quite often, as if to mitigate the negativity, some revisited the positive aspects. Likewise, I was personally affected by the negative data during the preanalysis. The Kenyan case almost broke me completely. So pathetic was the situation that I saw the students as 'academic orphans'. To mitigate the negative feelings, I searched for empirical data on those negative issues and realised that they were more or less global issues, which made me become more rational.

(ix) Participants' reflection? The interviewing process also seemed to challenge the participants to reflect on their practices. One participant indicated: 'Do we even know what our goals are?' (LK 03), another one wondered, 'Do we even know what our graduate attributes are, do we even know where we can find them? (VL 09)'. Another one indicated, 'Well, I would like to do more cases and move away from traditional lecturing 
but I do not have time this year...But essentially I want to move towards more use of case studies. That is what I want to do and that is my plan for next year for both courses (VL 02)'.

(x) Challenge to 'lines of thinking'? Going through the questionnaire with my participants challenged my line of thought. Did this interfere with the 'objective' analysis and interpretation of data/analysis? Not by any means. It only opened my mind to other frames of mind or wider perspectives.

\subsubsection{Comparative perspective of the data collection process}

Looking back at the data collection process in Kenya and NZ, it is worth noting the following issues:

1. Authorisation process: The authorisation process in Kenya involves many bureaucratic layers. This is not the case in NZ. But I attribute the quick authorisation at national and institutional levels to the perceived benefit of the research outcome to the institutions involved. Indeed, in Kenya, this authorisation was on condition that I will share the findings by providing hard and soft copies to NACOSTI and to UoN library.

2. Ease of data collection: Collecting data from the two business schools was relatively easy given the amount of data that I collected from each group of the participants in each case. Each case took three months. I would attribute this ease to the research topic, which I consider to be relevant, interesting, and important to participants. Moreover, as a researcher, I was well prepared with sufficient background information about the two cases.

3. Data collation, storage and analysis: I needed to have a good system to collate all data from all participant groups. The pre-coded nature of the interview/discussion guide allowed data to be organised and compared as it continued to be collected.

4. Time-rich vs time-poor: In Kenya, interviews and focus group discussions took relatively long compared to NZ. Indeed, one FG took almost 3hrs. This might emphasise the notion of 'socialised African time' whereby time is programmed into events and where social duties and human relations are not sacrificed at the expense of time. The clock-focused European time on the other hand depicted NZ participants as time poor. 
5. Privacy issues: In Kenya, it is culturally acceptable to give out individual mobile phone numbers. This is not the case in NZ. The implication of this is the need for a researcher to be very conscious of the legal implications of breaches of privacy.

6. Contact media: The easiest ways to reach the Kenyan participants is through mobile phones (calls and/or texts) while in NZ it is through emails.

7. Member checking: Although there were delays in sending transcripts to Kenya, comparatively, NZ (lecturers \& admin) responded particularly well. The response from both the Kenyan \& NZ students was poor. All participants in the two cases were also emailed preliminary findings of the two cases. Some responded with valuable comments that helped to improve the reporting of the findings.

\subsection{Data analysis}

The TOC framework guided the data analysis strategy. This framework was based on the purpose of the study. The framework guided the within-case analysis as well as the cross-case analysis providing the replication logic, which is recommended in multiple case analysis (Eisenhardt, 1989). The comparative analysis involved examination of data for similarities and differences within and across the cases. This process continued during data gathering process, transcription and until the final analysis.

One unique aspect of this study is the high level of triangulation involved. There is a combination of face-to-face interviews, focus group interviews, and mixed purposeful sampling in various categories of participants in the two diverse contexts (Patton, 1999). To achieve this level of triangulation, an extended field budget and time was required; however, the benefits of deeper insights into the research problem, and the credibility of the results far outweighed such costs. The triangulation also helps to draw similarities and differences. Thus, the use of triangulation in this study provided a fuller picture of the experiences of L\&T.

I presented data using multiple methods such as the TOC tree diagrams, figures, and tables. Such kinds of data display techniques are recommended for managing and presenting qualitative data (Eisenhardt, 1989). To construct the diagrams, I used two specialist software programs: Flying Logic and Transformation Logic Tree that are specifically designed for constructing the TOC Thinking Processes logic trees. To validate the causes of effects shown 
in the logic trees, I used verbatim narratives in addition to categories of legitimate reservations (CLR).

The use of CLR ensured clarity and completeness of statements, that the statements did not contain other embedded meanings, that the stated causes actually led to stated effects and that these causes were enough to produce the stated effects or if other causes could actually cause a similar effect. The CLR also helped to check whether the stated causes were actual causes and not indicators of the causes and that there were no other unstated causes that could cause the same effect. My supervisors, who are TOC experts, checked all the TOC diagrams to confirm cause-effect logic. Moreover, throughout the whole research process, I consistently adhered to the canons of scientific research to ensure credibility, dependability and confirmability of the findings. These issues are discussed in the next sub-section.

\subsection{Trustworthiness and rigour of the study}

Different criteria exist for judging the trustworthiness and rigour of qualitative studies. These criteria generally fall under four themes: credibility, transferability, dependability and confirmability (Guba \& Lincoln, 1982). Under each of these themes, researchers have used various strategies to establish trustworthiness. For instance, Guba and Lincoln (1982) indicates that triangulation and member checking have been used to ascertain credibility, comparisons, and transferability. Furthermore, Guba and Lincoln (1982) notes that dependability audit and dense descriptions of research methods, confirmability audit, reflexivity, and triangulation are used to ascertain confirmability. Although debate surrounds the use of criteria for judging qualitative studies (Denzin \& Lincoln, 2011, p.121; Rolfe, 2006), some of these criteria (such as triangulation, member checking, and dense descriptions of methods) have been applied in this study as the report indicates so far. But Lincoln, Lynham and Guba, (in Denzin \& Lincoln, 2011, p. 120) argue that it is not just the criteria in the methods applied in the research but that the interpretations should be rigorous. This implies that the rigour of the research should reside in the whole report (Rolfe, 2006).

More importantly, the discussion here revolves around the question: 'Are these findings sufficiently authentic that I may trust myself in acting on their implications? More to the point, would I feel sufficiently secure about these findings to construct social policy or legislation based on them?' (Lincoln, Lynham \& Guba, in Denzin \& Lincoln, 2011, p. 120). To the best of my knowledge, the answers to these questions are 'yes'. While acknowledging that there are many approaches to judging trustworthiness and rigour of any research, my judgement is based 
on the meticulous approach that I used to handle the research data, transparency of coding (e.g. CSF, NC), transparency of logic and my honesty in reporting the findings.

Nevertheless, it is important to address the question of whether another researcher would or would not produce the same results from the same data. The answer to this question may involve methodological and ontological issues. From a methodological perspective, the issue is whether or not the researcher adhered to the canons of scientific qualitative design and TOC methodology that have been used in this study. The TOC methodology, for instance is clear on how to articulate, say, a well-defined UDE. Nevertheless, differences may still be found on how UDE statements are structured. On the issue of CSFs, TOC fails to offer a clear guidance on how to delimit the CSFs to 3-5 or the required number of NCs. This and other issues may therefore cause differences in the results.

From an ontological perspective, differences may exist based on how, say, the CSF and NCs are specified by a researcher based on their view of reality and their understanding of the L\&T environment.

\subsection{Summary}

This chapter started with a justification of the pragmatic research philosophy that underpins the qualitative research method and the case study design adopted in this study. It then provided a detailed description of the field procedures followed in Kenya and NZ. These rigorous procedures enhance the credibility of the research (Patton, 1999). The next two chapters provide detailed data analysis of the two cases using the TOC tools. 


\section{Chapter 5}

\section{DATA ANALYSIS AND FINDINGS (KENYAN CASE)}

If you want to go fast, go alone; if you want to go far, go together (African proverb).

\subsection{Introduction}

For ease of understanding, this chapter is divided into six subsections. The first subsection (5.2) provides some background information about Kenya and its education system. General background information about the University of Nairobi (UoN), which hosts the School of Business (where this study was conducted), is then provided. Specific information about the School of Business is provided. Then, three sub-sections $(5.3,5.4 \& 5.5)$ present findings from three groups of participants, namely the students, the lecturers, and the senior administrative staff. A within-case analysis (5.6) of the three groups is finally provided.

\subsection{Contextual background}

The main purpose of this contextual background is to provide the reader with some clarification of the Kenyan case study.

\subsubsection{Background information about Kenya}

In order to help the reader make sense of the Kenyan context of this study, some general background information about the country is provided as well as some brief historical background of the Kenyan system of education. My argument is that historical forces of the education system still continue to shape the discourse of L\&T in HE today.

Kenya was colonised by Britain and remained a British protectorate until 1920 when it officially became a British colony. In 1964, Kenya became a republic. After independence Kenya remained a one-party state. From 1992, multiparty elections were held but the ruling party retained power until 2002 when the opposition won through the National Rainbow Coalition. Today, Kenya is a democratic republic and operates under a new constitution that was endorsed in a referendum in 2010. The President is both the head of state and the head of government. 
Since independence, Kenya has remained relatively stable despite changes in the political system and recent insecurity posed by its neighbour Somali. Kenya has recently moved to lowmiddle income range with a per capita income of US \$1,256 and is the fifth largest economy in Sub-Saharan Africa behind South-Africa, Nigeria, Angola and Sudan. According to the latest Kenya Economic Update (KEU) published by the World Bank, it one of the fastest-growing economies in Sub-Saharan Africa (Worldbank, 2015).

Agriculture is the mainstay of Kenya's economy and contributes about $20 \%$ of the GDP and about $65 \%$ of all exports (UK trade \& investment, 2015).

Kenya has a population of 39.2 million people and a total area of $582,646 \mathrm{~km}^{2}$. There are 42 tribes in Kenya who are united with a national language called 'Kiswahili'. Kiswahili and English are the two official languages. There are four religions: Protestants, Catholics, Muslims and Traditional believers ) (Kenya National Bureau of Statistics, 2012).

\subsubsection{History of Education System in Kenya}

Prior to the modern form of education in Kenya, traditional African societies had their own systems of education whereby members of a community were not only involved in educating the children, the young men and women but also the old. This education was passed on from the old to the young through fire-place stories, riddles, proverbs, idioms, and expressions as well as through involvement in community activities such as farming, fishing, and grazing. Moreover, the initiation ceremonies and the rites-of-passage ensured that the desired knowledge, skills, attitudes, and societal values were upheld.

The foundation of modern education in Kenya goes back to the early Christian missionaries of the $19^{\text {th }}$ and $20^{\text {th }}$ century who combined the introduction of Christianity with education (Barasa \& Misati, 2012; Buchmann, 1999). During the First World War period (1900-1920), missionaries introduced early low-cost primary schools for Africans called the bush schools. It was not until 1910 that the colonial government got involved in education. In 1908, the Government invited Professor Nelson Fraser to provide expert opinion on education in Kenya. The Fraser report of 1909 recommended the establishment of separate education systems for Africans, Asians, and Europeans. Furthermore, the missionary societies were to provide the education facilities for Africans. Fraser's argument was that through Christian instructions, Africans would have good moral foundations to obey the colonial authority. This system was upheld until 1963 (Buchmann, 1999). 
The period following the Second World War (1945-1960) marked the establishment of missionary secondary schools in Kenya and after the attainment of independence, universities were established (Barasa \& Misati, 2012).

After independence (1964-1984) Kenya adopted a 7-4-2-3 system of education with the aim of getting skilled workers and expanding education to its citizens. The system provided seven years of primary school, four years of secondary school, two years of high school and three years in university (Buchmann, 1999). Since 1985, the 8-4-4 system of education was introduced with a basic focus on vocational education with eight years designed for primary school, four years in secondary, and four years in university. The system is operative to date.

\subsubsection{Structure of Education in Kenya}

The education structure in Kenya is depicted in Figure 5.1 Education starts in pre-primary with children aged between 3-6 years. Primary education caters for learners aged 7-14 years while secondary caters for young adults of 15-18 years. After secondary school, learners would either join vocational training in the middle level colleges or HE in universities.

Figure 5.1: Structure of Kenyan Education

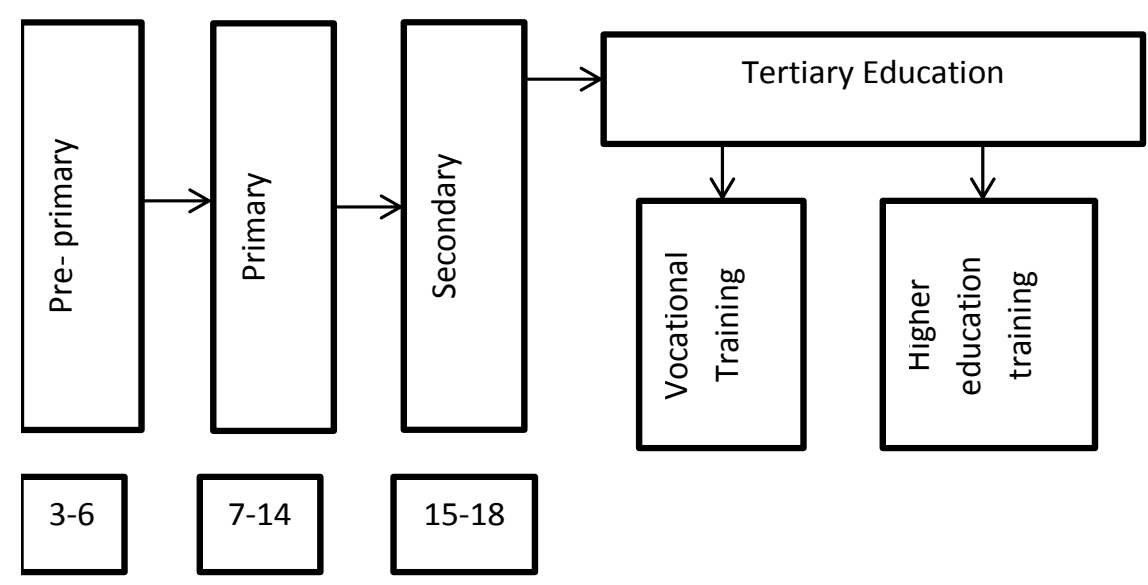

A point to note is that Kenya's education has not been free. It was not until January 2003 that Kenyan government introduced free primary education.

\subsubsection{The HE system in Kenya}

Kenya has a total of 65 universities (Commission for University Education, 2015) operating under six categories: public universities (22), public university constituent colleges (9), 
chartered private universities (17), private university constituent colleges (4), private universities with Letter of Interim Authority (11), and registered private universities (2). The total number of university students is 324,560 (Economic Survey Report, 2014). The Commission for University Education (CUE) is the body charged with accreditation and quality assurance of university education.

Accreditation in Kenya means 'public acceptance and confirmation of qualifications as evidenced by an award of a Charter.' It indicates that a university meets, and continues to meet the standards of academic quality set by the CUE (Commission for University Education, 2015).

\subsubsection{Background of the University of Nairobi}

The University of Nairobi was established in 1956 as the Royal Technical College. It was later transformed into the second University College in East Africa in 1961 under the name Royal College Nairobi. The college had special relations with the University of London in that while the college prepared students in the faculties of Arts, Science, and Engineering, the University of London awarded degrees. Meanwhile, other faculties such as the Faculty of Special Professional Studies (later renamed Faculty of Commerce) and the Faculty of Architecture continued to offer diplomas for qualifications of professional bodies.

In 1964, the Royal College Nairobi was renamed University College Nairobi, a constituent college of inter-territorial, Federal University of East Africa. From this time, it enrolled students to study for degrees of the University of East Africa and not London as was the case before. In 1970, the University College Nairobi became the first national university in Kenya and was renamed the University of Nairobi.

With rapid expansion and administrative challenges, the University underwent major restructuring in 1983 resulting in decentralisation of the administration. Six colleges headed by principals were created, operating in seven campus locations.

At its strategic apex, the university is functionally structured with divisions responsible for finance and administration, students' affairs, knowledge creation and dissemination, and academic affairs. The academic affairs division, which is headed by the Deputy Vice Chancellor (Academic Affairs), oversees the university curricula and new curricular initiatives, academic staff hiring and promotions, teaching support, and the administration of all academic departments and programs including the library. Therefore, this division has the responsibility 
of preparing the syllabi and regulations, coordination of examinations, admission of undergraduate students, research supervision, academic staff development, and all teaching and learning activities (Univerity of Nairobi, 2015, node 767).

\subsubsection{UoN School of Business}

The University of Nairobi School of Business (hereafter, UNSB) formerly known as the Faculty of Commerce was established in 1964. The School is under the College of Humanities and Social Sciences (CHSS) whose headquarters are at the main campus of the University of Nairobi. The School currently offers the Bachelor of Commerce, Master of Science in various management specialisation areas, Masters and Doctor of Philosophy in Business Administration with a wide range of concentration areas. This study was concerned with the Bachelor of Commerce (BCom) program.

The School is headed by a Dean, who is assisted by two Associate Deans for undergraduate studies and graduate studies (see Figure 4.2). For administrative support functions, the Dean is assisted by an assistant registrar, and a senior administrative assistant in coordinating administrative support functions. The School is organised in three departments, namely: the departments of Business Administration, Finance and Accounting, and Management Science. The departments are headed by chairpersons who are supported by coordinators of various departmental academic functions and academic advisers.

The School runs its programs in five different locations: (1) Lower Kabete campus, where the school's management and administrative staff are based. (2) The Main campus, where the parttime coordination office is located and where the evening graduate classes are conducted, (3) Chiromo campus, where the evening undergraduate classes are conducted. Other campuses located outside Nairobi city are Kisumu and Mombasa. The present study was conducted at Lower Kabete, Main, and Chiromo campuses.

\section{The Bachelor of Commerce Program}

The (BCom) degree program is one of the flagship programs of the University of Nairobi. The UNSB has a current student population of 7750, 102 academic staff, 20 administrative staff, and 150 support staff as shown in Table 5.1. 
Table 5.1: Student and staff population

\begin{tabular}{|l|l|l|}
\hline & Category & Numbers \\
\hline Students & Module I & 1200 \\
\hline & Module II (Day) & 3000 \\
\hline & Module II (Part-Time) & 3500 \\
\hline & Internship & 50 \\
\hline & Total & $\mathbf{7 7 5 0}$ \\
\hline Staff & Academic & 102 \\
\hline & Adminis trative & 20 \\
\hline & Support & 150 \\
\hline & Total & $\mathbf{2 7 2}$ \\
\hline
\end{tabular}

Since its inception in 1964, the BCom program has developed from a program of three (3) specialisations into the current eight (8). These are Accounting, Finance, Marketing, Risk Management and Insurance, Human Resources Management, Business Information Systems, Procurement and Supply Chain Management, and Operations Management.

\section{Objectives of the program}

The objectives of the BCom program are:

a) To introduce students to general issues and approaches to management.

b) To enhance self-confidence and ability to critically evaluate management issues from academic and practical perspectives.

c) To develop awareness of the changing local and international business contexts.

d) To prepare students for advancement in their field of specialisation.

e) To instil problem-solving attitudes and business ethics in the practice of management.

f) To inculcate entrepreneurial and self-reliance attitudes and habits in students so that they may be active participants in the creation of wealth.

\section{Admission to the program}

The admission requirements for the program are varied. The Module I (government sponsored) students are admitted through the Kenya Universities and Colleges Central Placement Services (KUCCPS - formerly the Joint Admission Board). The minimum 'cut off' point for government sponsored students is normally determined on an annual basis by the KUCCPS. The grading system (points) varies according to overall performance of candidates in the national exam called the Kenya Certificate of Secondary Education (KCSE). 


\section{Program modes}

The BCom program is offered in three modes:

- Module I: Government sponsored full-time students.

- Module II: Self-sponsored students who either attend full-time (day) or part-time (evening) classes.

- Module III: Self-sponsored distance-learning students (this group was not part of this study).

Most of Module II \& III students' admissions fall below the KUCCPS 'cut off' points. Their admission requirements vary but are guided by common regulations of the bachelors' degrees of the University of Nairobi as approved by the senate.

Modules I \& II are similar in terms of the structure of the program and the courses within the program. Each course unit has a loading of a minimum 45 hours in all modules. Differences occur in the duration and fee structures of the modules. While Module I is structured using an eight semester period of 15 weeks each and two semesters per academic year, Module II is structured in three trimesters of 15 weeks each per year. This implies that, assuming that there are no semesters' interruptions, Module II day students who study on all the three trimesters without a break would finish the course one year earlier than their Module I counterparts as shown in Figure 5.2 that is based on UoN's schedule of semester/trimester dates for the 2013/2014 academic year (University of Nairobi, 2015, node 977).

Figure 5.2: Degree completion periods

Gantt Chart showing the completion periods for Module I \& II

\begin{tabular}{|l|l|l|l|l|l|l|l|l|l|l|l|l|}
\hline & Year 1 & & & Year 2 & & & Year 3 & & & Year 4 & & \\
\hline & SEM 1 & SEM 2 & SEM 3 & SEM 1 & SEM 2 & SEM 3 & SEM 1 & SEM 2 & SEM 3 & SEM 1 & SEM 2 & SEM 3 \\
\hline & Sept-Dec & Jan-April & May-Aug & Sept-Dec & Jan-April & May-Aug & Sept-Dec Jan-April & May-Aug & Sept-Dec & Jan-April & May-Aug \\
\hline Module I & & & & & & & & & & & & \\
\hline & & & & & & & & & & & & \\
\hline Module 2 & & & & & & & & & & & & \\
\hline & & & & & & & & & & & & \\
\hline
\end{tabular}

\section{Structure of the program}

The BCom program is organised in two part: Part 1 consists of years I \& II while part 2 consists of years III \& IV. To qualify for the award of BCom degree, a candidate must successfully complete a minimum of 46 course units. These course units are divided into common, core, specialisation, and elective course units organised as shown in Table 5.2. 
Table 5.2: The program course structure

\begin{tabular}{|c|c|c|c|c|c|c|}
\hline Year & Semester & Common & Core & $\begin{array}{c}\text { Specialis- } \\
\text { ation }\end{array}$ & Elective & Total \\
\hline I & I & 2 & 4 & & & 6 \\
\hline & II & 1 & 5 & & & 6 \\
\hline II & I & & 6 & & & 6 \\
\hline & II & & 6 & & & 6 \\
\hline III & I & & 4 & 2 & & 6 \\
\hline & II & & 2 & 3 & 1 & 6 \\
\hline IV & I & & 2 & 2 & 1 & 5 \\
\hline & II & & 1 & 3 & 1 & 5 \\
\hline Total & & $\mathbf{3}$ & $\mathbf{3 0}$ & $\mathbf{1 0}$ & $\mathbf{3}$ & $\mathbf{4 6}$ \\
\hline
\end{tabular}

\section{Grading}

Each course unit is graded out of 100 marks: the final exam constitutes $70 \%$ and the course work the remaining $30 \%$. A management research paper (MRP) taken in the final semester is graded out of $100 \%$. The grading system in each course unit is as follows:

$\begin{array}{ll}\text { Marks \% } & \text { Grade } \\ 70-100 & \text { A } \\ 60-69 & \text { B } \\ 50-59 & \text { C } \\ \mathbf{4 0 - 4 9} & \text { D } \\ 00-39 & \text { E }\end{array}$

The pass mark in a course unit is $40 \%$. The classification of the degree award is based on an aggregate score. This score is derived from assessment of candidate performance in years I to IV with $10 \%, 20 \%, 30 \%$, and $40 \%$ weights respectively.

\section{First Class Honours \\ Second Class Honours (Upper Division) \\ Second Class Honours (Lower Division) \\ Pass}

$70-100 \%$

$60-69 \%$

$50-59 \%$

$40-49 \%$

\section{Fee structure}

The fee structure varies across the two modules. Table 5.3 provides a comparison of the two modules based on a 6 course unit load per semester for year 1 to year 3 and on a 5 course unit load per semester in year 4 , totalling a minimum of 46 course units required for a Bachelor of Commerce award. For international students, a 20\% surcharge applies on fees. 
Table 5.3: The fee structure $\&$ accommodation charges

\begin{tabular}{|l|r|r|r|r|}
\hline Year & Module I & & Module II & \\
\hline & KES & NZ\$ & KES & NZ\$ \\
\hline Year 1 & 28,500 & 381.01 & 153,500 & 2052.11 \\
\hline Year 2 & 25,500 & 340.9 & 148,500 & 1985.27 \\
\hline Year 3 & 25,500 & 340.9 & 140,000 & 1871.63 \\
\hline Year 4 & 25,500 & 340.9 & 126,500 & 1691.16 \\
\hline Sub-total & $\mathbf{1 0 5 , 0 0 0}$ & $\mathbf{1 4 0 3 . 7 1}$ & $\mathbf{5 6 8 , 5 0 0}$ & $\mathbf{7 6 0 0 . 1 7}$ \\
\hline Accommodation & 7,000 & 93.58 & N/A & N/A \\
\hline Books & 9,000 & 120.32 & N/A & N/A \\
\hline Catering & 18,000 & 240.64 & N/A & N/A \\
\hline Total & $\mathbf{1 3 9 , 0 0 0}$ & $\mathbf{1 8 5 8 . 2 5}$ & $\mathbf{5 6 8 , 5 0 0}$ & $\mathbf{7 6 0 0 . 1 7}$ \\
\hline
\end{tabular}

(http://www.convertmymoney.com) (11/4/14) @ 1KES=0.01NZ\$)

Table 5.3 shows that Module I students are provided with university accommodation, books, and catering allowances. These services are not available for other modules.

\subsubsection{Summary of the background}

This subsection has presented background information of the Kenyan case by providing general information about the historical development of the education system, the University of Nairobi, and the School of Business.

With this background, the next sub-sections present analysis of students', lecturers', and senior administrators' perceptions of the quality of their learning and teaching experiences. It is important at this point to note the operationalisation of the words 'context' and 'situation' that feature prominently in the subsequent analysis. 'Context' is taken to imply the learning and/or the teaching in a business school while 'situation' would imply what is constituted when students, lecturers or administrative staff enter into the teaching and learning context. Thus, the next sub-section starts with analysis from the students, lecturers, and administrators in that order. 


\subsection{UNSB students' data analysis}

This sub-section presents students' views of the teaching and learning. It starts by describing the students' participation in the focus group discussions. The data collected facilitated the identification of the learning goals and the issues affecting the quality of their learning experiences.

\subsubsection{Description of student participants (UNSB)}

A total of 33 students participated in this case study. They represented modules I \& II. These participants are distributed across five different focus groups. The first FG comprised Module I (the government-sponsored domestic students) full time students. The second comprised Module II (self-sponsored domestic students) full-time students. The third group comprised international students (they are also Module II in that they are self-sponsored) and are full-time (FT) students. They came from three different African countries. The fourth comprise student leaders who represented two student bodies: the Students of University of Nairobi Organisation (SONU) and the School of Business Organisation (SOBO). There are two SONU faculty representatives for Modules I \& II and three representatives of SOBO namely the Vice Chairman, Secretary General and Secretary for sports and entertainment. The fifth group comprised Module II part-time (PT) students who attend classes in the evening. Unlike the other four focus groups that were held during week days, the fifth FG for evening (PT) was held on a Saturday. The Table 5.4 and 5.5 shows gender and years of study representation across the five groups while Table 5.6 depicts the representation across the two modules. The FG students were not categorised according to subject specialisation or departments because such a classification would leave out first and second year students who start specialising in third year.

Table 5.4: Gender representations in the UNSB focus groups

\begin{tabular}{|l|l|c|c|c|}
\hline Focus Group & Symbol & Male & Female & Total \\
\hline Module I (government sponsored ) & KM1 & 4 & 3 & $\mathbf{7}$ \\
\hline Module II (day or full-time) & KM2-FT & 5 & 4 & $\mathbf{9}$ \\
\hline International students & KIS & 3 & 0 & $\mathbf{3}$ \\
\hline Student leaders & KSL & 5 & 0 & $\mathbf{5}$ \\
\hline Module II (evening or part-time) & KM2-PT & 4 & 5 & $\mathbf{9}$ \\
\hline Total & & $\mathbf{2 1}$ & $\mathbf{1 2}$ & $\mathbf{3 3}$ \\
\hline
\end{tabular}


As indicated in chapter 4 section 4.4, the focus groups (FGs) sizes ranged from 3 to 9 in a group. This is perceived to be within the normal FG range as noted by Wilkinson (in Silverman, 2004, p. 178) of between two to twelve depending on the context.

Table 5.5: Year of study representations across UNSB focus groups

\begin{tabular}{|l|c|c|c|c|c|}
\hline Focus Group & Year 1 & Year 2 & Year 3 & Year 4 & Total \\
\hline $\begin{array}{l}\text { Module I (government } \\
\text { sponsored ) }\end{array}$ & 2 & 2 & $\mathbf{0}$ & 3 & $\mathbf{7}$ \\
\hline Module II (day or full-time) & 0 & 0 & $\mathbf{3}$ & 6 & $\mathbf{9}$ \\
\hline International students & 0 & 0 & $\mathbf{0}$ & 3 & $\mathbf{3}$ \\
\hline Student leaders & 0 & 1 & $\mathbf{0}$ & 4 & $\mathbf{5}$ \\
\hline $\begin{array}{l}\text { Module II (evening or part- } \\
\text { time) }\end{array}$ & 0 & 9 & $\mathbf{0}$ & 0 & $\mathbf{9}$ \\
\hline Total & $\mathbf{2}$ & $\mathbf{1 2}$ & $\mathbf{3}$ & $\mathbf{1 6}$ & $\mathbf{3 3}$ \\
\hline
\end{tabular}

Table 5.6: Gender representations across UNSB modules

\begin{tabular}{|l|c|c|c|}
\hline Module & Male & Female & Total \\
\hline Module I & 6 & 3 & $\mathbf{9}$ \\
\hline Module II & 15 & 9 & $\mathbf{2 4}$ \\
\hline Total & $\mathbf{2 1}$ & $\mathbf{1 2}$ & $\mathbf{3 3}$ \\
\hline
\end{tabular}

Most students in the focus group were self-sponsored students (Module II) who attended either the day or evening program. The international students were full-time. In the student leaders' group, three leaders were in Module II while two were in Module I.

Figure 5.3: UNSB focus group discussion interview time

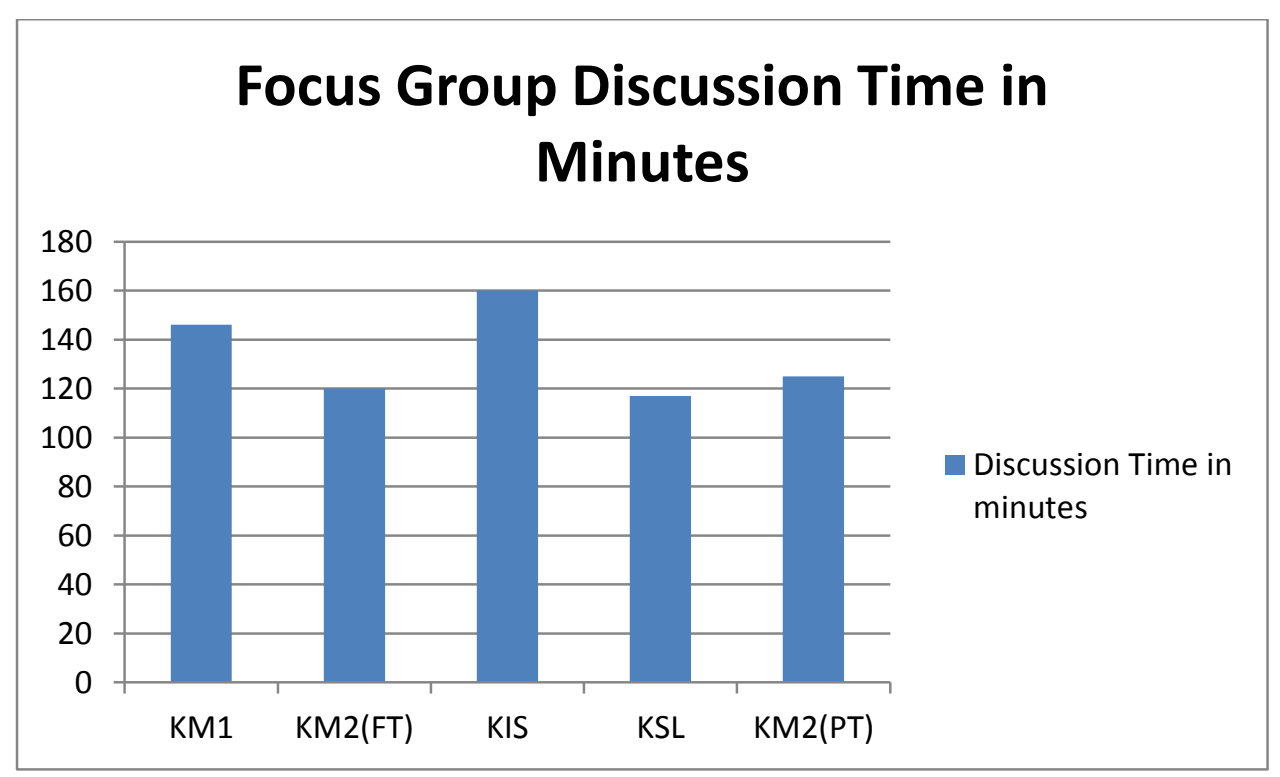


The five FG discussions were conducted within a total time period of 11 hours 13 mins and an average recorded time of 134 minutes ( $2 \mathrm{hrs} .15 \mathrm{~min})$. Although the group discussions were expected to take 1.5 hours, the time extension could be attributed to the research questions being important and pertinent to the students. They therefore provided rich descriptions of their understanding of the L\&T situation without fear since the confidentiality requirements were clearly spelt out. In addition, as most of them testified, it was a great opportunity for them to participate in a 'focus group' research, 'we have enjoyed the discussion, it was good learning for us' (KM1), which they had not done before. They also hoped that through the study findings, their concerns could reach the decision makers, 'We wish that you could share the findings with the administrators of UNSB' (KSL). Their enthusiasm and the in-depth information that they provided could be considered as the truth value or the confidence of their lived L\&T experiences (Guba \& Lincoln, 1982).

\subsubsection{Identifying UNSB's students learning goal(s), CSFs, and NCs}

The basic purpose of identifying the learning goal, the critical success factors (CSFs), and the necessary condition (NCs) is to answer the first research question and to depict it in the form of a goal tree. Another purpose is to relate the identified goals with those defined by the business school. This relationship is discussed in Chapter 8, section 8.2.

Thus, in order to identify the learning goal, during the focus group (FG) discussions, each of the students in the FGs identified their individual learning goals. But some students' goals coincided with others. And to move to the next step of identifying the (CSF) and subsequent (NCs) for each factor, a consensus goal was first sought in each FG (shown in the last row of Table 5.7). Indeed after finding a consensus goal, each of the five FGs constructed its own goal tree. The process of analysis by the researcher then involved consolidating these five goal trees into one. Two major steps were involved:

\section{Unitisation of the consensus goal}

The first step in the consolidation process was the unitisation of the separate consensus goals drawn from each group shown in Table 5.7. As explained in chapter 3, unitisation is an analytical process that attaches units of data into appropriate categories or labels with the aim of reducing the data into comprehensible form. A unit of data may be a number of words, a line of transcript, a sentence, a number of sentences, a complete paragraph that fits the defined category (Saunders et al., 2007, p. 480). Thus, unitisation analysis of the five consensus goals 
yielded a common goal of 'acquisition of business knowledge and skills'. An important issue to note is the emphasis on 'societal or social responsibility' whereby students seem conscious that their learning should help them to get self-employment and self-reliance skills, and at the same time benefit the society.

Table 5.7: Identifying UNSB's students learning goal(s)

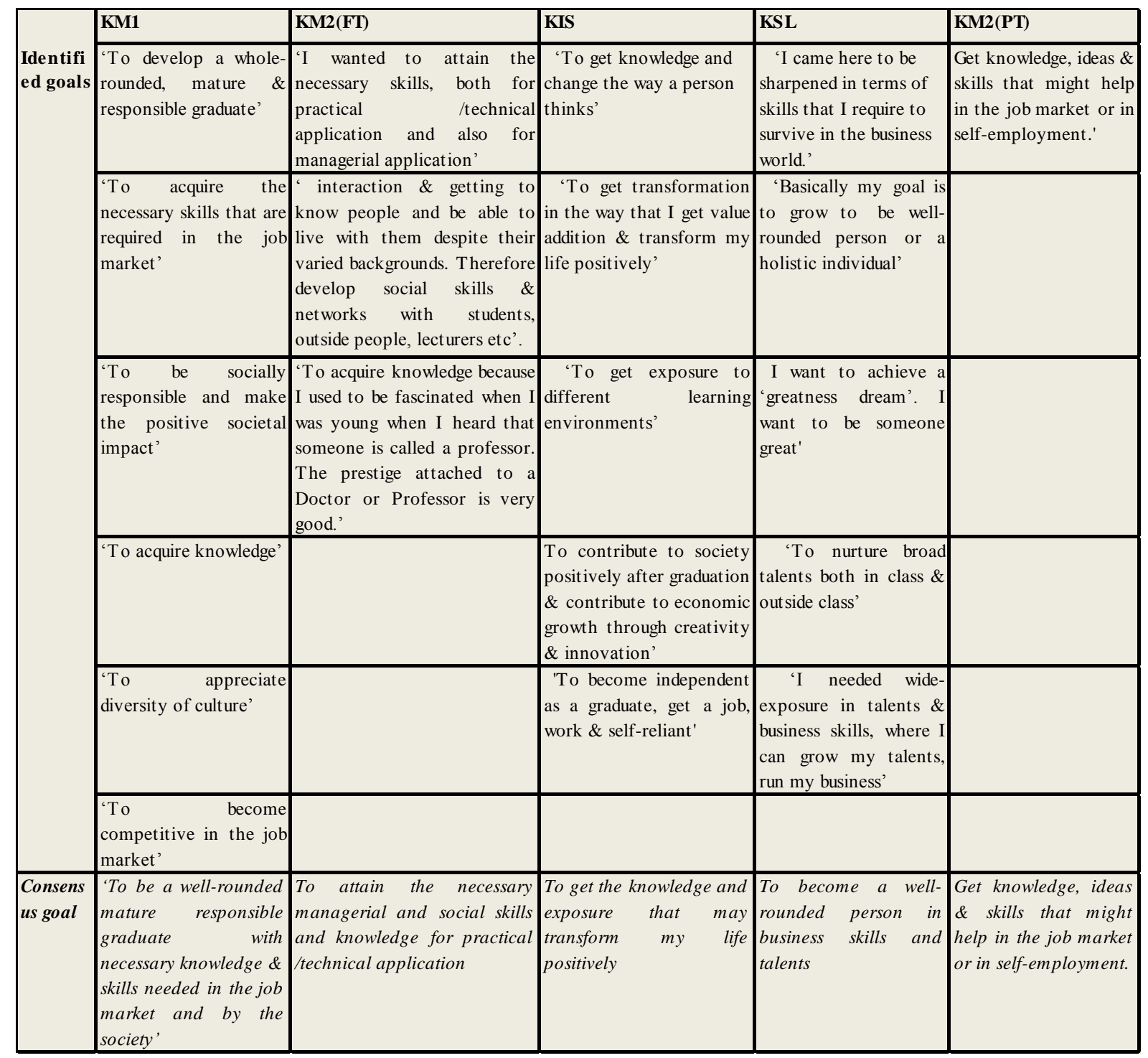

\section{Unitisation of the CSFs and the NCs}

After identifying a common goal for all five groups, the next step involved unitisation of the many CSFs and the NCs for all groups (Table 5.8). The process of unitisation started with a first CSF as mentioned by, for instance, FG KM1 - up to date learning resources is CSF1. The researcher went through all the other CSFs and NCs of all the groups searching for phrases that are related or implied learning resources. Then specific equipment or learning resources 
mentioned or related tasks or activities would then fall under the NCs under CSF1. Such NCs would include phrases that mention specific learning resources such as computer facilities, and finance labs. This process continued until most phrases were absorbed into either CSFs or NCs.

Table 5.8: Unitising UNSB students' CSFs \& NCs

\begin{tabular}{|c|c|c|}
\hline \multirow{15}{*}{ KM1 } & Critical Success Factors (CSF) & Necessary conditions (NCs) \\
\hline & \multirow[t]{4}{*}{ Up-to-date learning resources (CSF1) } & Capacity in terms of books (NC3) \\
\hline & & University needs finances to update the resources (CSF1) \\
\hline & & Internet (NC2) \\
\hline & & Right accommodation \\
\hline & \multirow[t]{7}{*}{ Committed lecturers \& tutors (CSF2) } & Commitment (CSF2) \\
\hline & & Hardworking (CSF2) \\
\hline & & Wide-knowledge in their field of specialisation (CSF2) \\
\hline & & $\begin{array}{l}\text { Good teaching methodologies which include practical learning } \\
\text { (CSF2) }\end{array}$ \\
\hline & & Appreciate technology (CSF2) \\
\hline & & Moral integrity of lecturers (CSF2) \\
\hline & & Honesty \& professionalism (CSF2) \\
\hline & \multirow[t]{3}{*}{ Self-disciplined \& hard-working student (CSF3) } & Self-discipline (CSF3) \\
\hline & & Right learning attitude (CSF3) \\
\hline & & Group/team work (NC5) \\
\hline \multirow[t]{16}{*}{$\mathrm{KM} 2(\mathrm{FT})$} & \multirow[t]{2}{*}{$\begin{array}{l}\text { Teamwork between students \& students, and students \& } \\
\text { lecturers (NC5) }\end{array}$} & Through use of class assignments \\
\hline & & Hold social contexts such as team building \\
\hline & \multirow[t]{3}{*}{ Maintaining a positive attitude as students (CSF3) } & Attending motivational talks (NC6) \\
\hline & & Approach challenges \& opportunities more courageously (CSF3) \\
\hline & & Reading widely (CSF3) \\
\hline & \multirow[t]{2}{*}{ Having mentors (such as lecturers) (NC6) } & Choose right company of students/peers (CSF3) \\
\hline & & $\begin{array}{l}\text { Having interactive sessions with lecturers and corporate world } \\
\text { (NC6) }\end{array}$ \\
\hline & \multirow[t]{8}{*}{ Good leadership from the administration. (NC) } & $\begin{array}{l}\text { The selection of the various heads of departments should be based } \\
\text { on merit. }\end{array}$ \\
\hline & & Have competent teachers (CSF2) \\
\hline & & No corruption in resource allocation (NC) \\
\hline & & Selection and recruitment that is merit based \\
\hline & & Effective \& efficient communication both top-down \& down-up \\
\hline & & Democratic voting of student leaders should be fair \& transparent. \\
\hline & & Serious performance evaluation of lecturers (CSF2) \\
\hline & & $\begin{array}{l}\text { Lecturers to be motivated through promotions and high salaries } \\
\text { (NC7) }\end{array}$ \\
\hline & Structure of UNSB & $\begin{array}{l}\text { Friendly structure with ease of reach of administrators (e.g. dean) } \\
\text { (NC7) }\end{array}$ \\
\hline \multirow[t]{3}{*}{ KIS } & \multirow[t]{3}{*}{ Creativity \& hard-work (CSF3) } & Action plan of activities to help achieve the goal or targets (CSF3) \\
\hline & & $\begin{array}{l}\text { Use 6Ps-proper prior planning prevents poor performance } \\
\text { (CSF3) }\end{array}$ \\
\hline & & Critical analysis of events, situations \& circumstances (CSF3) \\
\hline
\end{tabular}




\begin{tabular}{|c|c|c|}
\hline & Critical Success Factors (CSF) & Necessary conditions (NCs) \\
\hline & & Critical thinking of whatever undertaking (CSF3) \\
\hline & & Desire to achieve (CSF3) \\
\hline & & Self-confidence (CSF3) \\
\hline & Interaction, socialisation \& team-play (NC5) & Self-confidence, don't be shy or fear to socialise (NC5) \\
\hline & & Student socialisation \& interactive forums (NC6) \\
\hline & & Inter-classroom competition (NC6) \\
\hline & & Sports events (NC6) \\
\hline & & Incorporate/involvement in CSR activities (NC5) \\
\hline & & Teamwork \& group work (NC5) \\
\hline & & Inter-university forums (NC6) \\
\hline & $\begin{array}{l}\text { Motivation from UoN stakeholders, peers, parents \& } \\
\text { self (NC6) }\end{array}$ & $\begin{array}{l}\text { Moral support, guidance \& counselling- to provide help in } \\
\text { life(NC6) }\end{array}$ \\
\hline & & Rewards for bright students \\
\hline & & Scholarships or financial help for needy students \\
\hline & & $\begin{array}{l}\text { Role models \& mentors such as corporate world employees \& } \\
\text { politicians (NC6) }\end{array}$ \\
\hline & $\begin{array}{l}\text { UoN to have a vision that is aligned to the goal of } \\
\text { 'building the whole-man'. }\end{array}$ & School to set SMART goals \\
\hline & & UoN policies to reflect on 'building the whole-man' \\
\hline & & UoN to stipulate the role of each stakeholder achieving the goal. \\
\hline & Technology \& innovation (NC2) & $\begin{array}{l}\text { UoN to embrace new technological advancements or changes } \\
\text { (NC2) }\end{array}$ \\
\hline & & $\begin{array}{l}\text { Open-session between UoN and students to understand students' } \\
\text { problems }\end{array}$ \\
\hline & & $\begin{array}{l}\text { Management to take responsibility of technological problems } \\
\text { affecting students (NC2) }\end{array}$ \\
\hline & & $\begin{array}{l}\text { Synchronise the portal to make it more efficient \& effective } \\
\text { (NC2) }\end{array}$ \\
\hline & & $\begin{array}{l}\text { UoN to embark on talent search e.g. those students good at IT } \\
\text { (NC2) }\end{array}$ \\
\hline & & $\begin{array}{l}\text { Embark on frequent improvement of IT in new or global ways of } \\
\text { addressing IT issues. (NC2) }\end{array}$ \\
\hline & & $\begin{array}{l}\text { UoN to look at current innovation in the business world \& } \\
\text { integrate it in the syllabus (NC5) }\end{array}$ \\
\hline KSL & Access to info (NC2) & More computer facilities (NC2) \\
\hline & & Strong \& fast internet connectivity ( $\mathrm{NC} 2)$ \\
\hline & & library \& online resources ( $\mathrm{NC} 3)$ \\
\hline & More recreational facilities $(\mathrm{NC} 1)$ & State of art gym, basket-ball court and swimming pool) (NC1) \\
\hline & Academic discipline (CSF3) & Attend classes (CSF3) \\
\hline & & Motivation to learn (CSF3) \\
\hline & & Conducive learning environment (CSF1) \\
\hline & Practical experience (NC6) & Formal or organised Internships by the school (NC6) \\
\hline & & Industrial visits (NC6) \\
\hline & & Class trips (NC6) \\
\hline & & Finance-labs (NC1) \\
\hline & & Integrate extensive research (NC5) \\
\hline
\end{tabular}




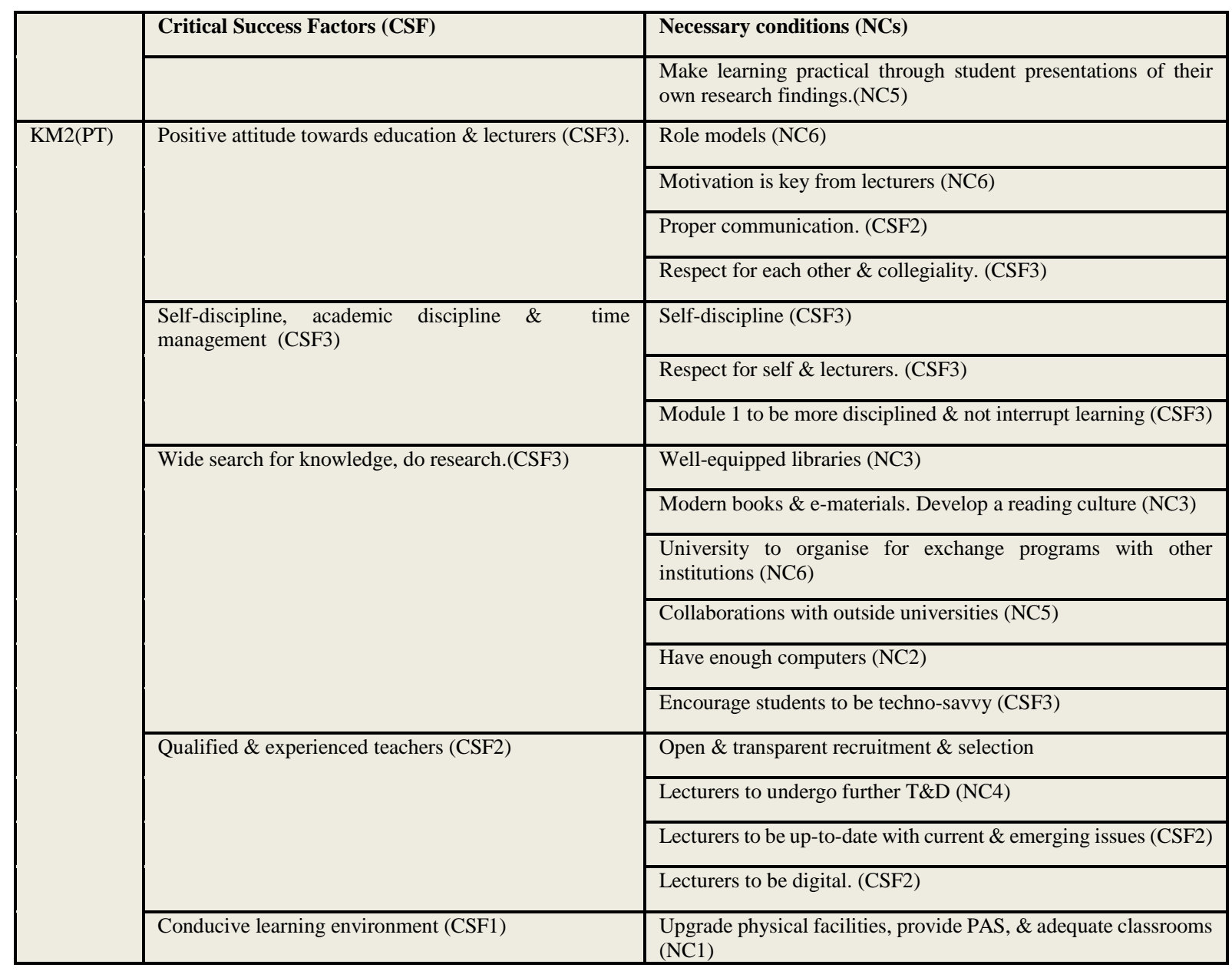

The unitisation of the CSFs resulted in three critical success factors namely: (a) Adequate L\&T facilities and structures, (b) qualified committed and 'techno-savvy' lecturers, and (c) selfdisciplined and hard-working students. Similarly, seven necessary conditions (NC) were identified: (1) modern L\&T classrooms, labs, lecture theatres, sporting and recreational facilities, (2) computer technology \& innovation and internet facilities, (3) well-equipped library and e-resources, (4) staff development \& training, (5) teamwork \& collaborations, (6) student engagement and support, and (7) good leadership of the school. To construct the goal tree, necessary condition logic that describes the requirements or prerequisites needed to have the desired outcome is used. The above CSFs and NCs are logically connected to form a goal tree (Figure 5.4).

It is important to note that some factors might have been identified as CSFs in one focus group but as NCs in another (see Table 5.8). But the necessary condition logic reduced the factors to only a few as shown in Figure 5.4. Moreover, not all data were unitised within these three factors or the seven NCs because some data were perceived to fall outside the zones of 'span 
of control' and 'sphere of influence' of the L\&T system of the UNSB. Nevertheless, students' data supported these factors. For instance, on the CSFs Module II full-time and part-time discussions were largely on CSF2 and CSF3. Student leaders' discussions concentrated more on CSF1 and CSF3. The international students dealt mainly with CSF3 with the rest of their discussions focusing on the university administrative issues.

\section{Figure 5.4: UNSB's students' goal tree}

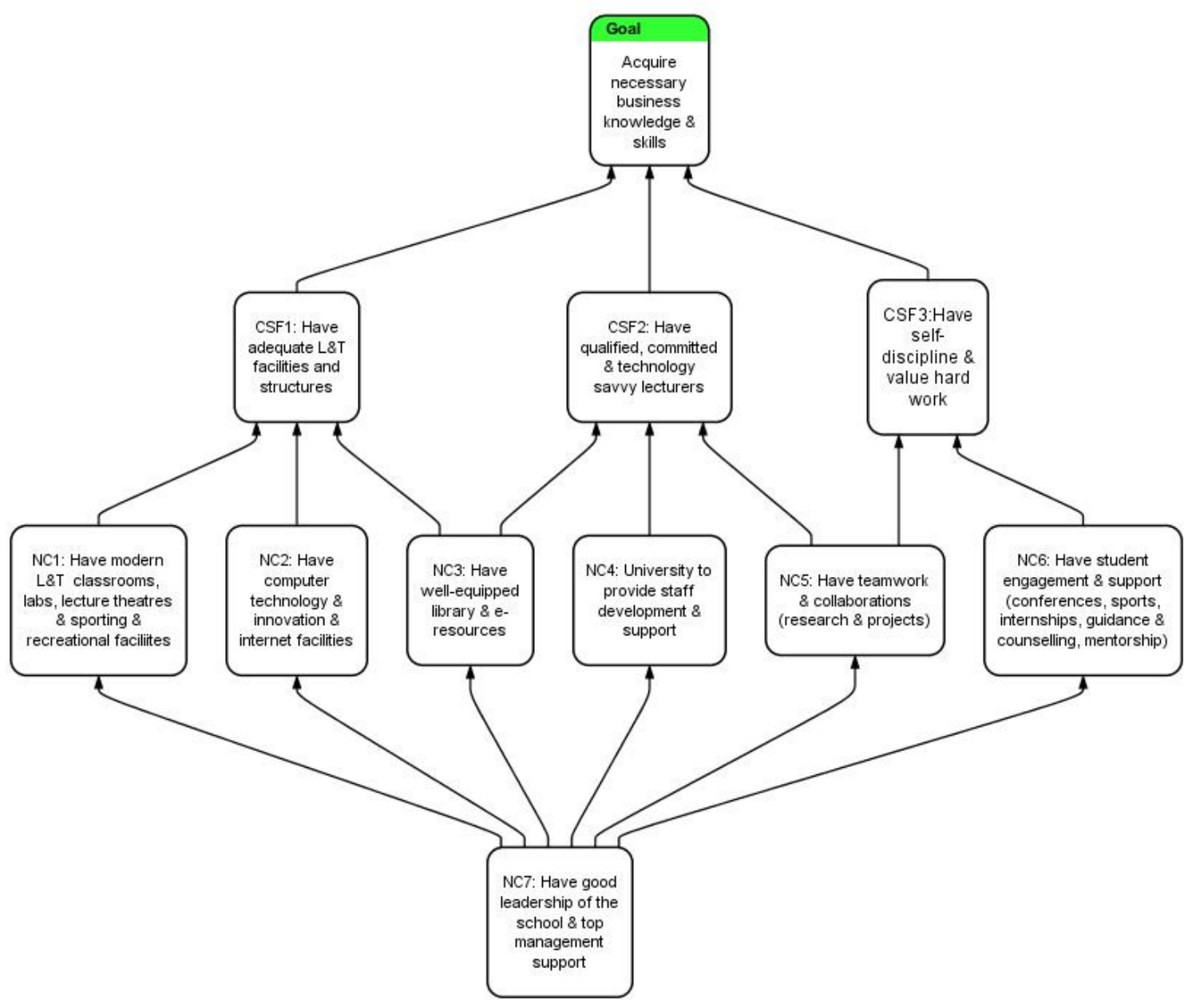

Module I students identified all the three factors as important to the achievement of the goal.

The CSF3 (self-discipline and hard-working student) seems important to all the five groups where it becomes apparent that students understand their own roles in their goal achievement. The following phrases feature prominently as NCs:

Respect for self and lecturers. Do not bring assignments late without a genuine reason (KM2-PT), Use 6Ps- 'proper prior planning prevents poor performance' (FIK), 'Choose right company of students and peers' (KM2-FT) and '... self-discipline and right learning attitude' (KM1). 
How well students practised or fulfilled these roles is not clear because what students say might be different from what they do or the way they behave. But the mere presence of the constraints within the system may well limit their good intentions related to L\&T. In TOC terms, a constraint is interpreted as a factor that limits the achievement of a goal (Goldratt, 1990, p. 4). The constraints that students identified are discussed in the next section where they are labelled 'undesirable effects (UDEs)'.

\subsubsection{Identifying UDEs that affect quality of learning experiences (UNSB)}

The analysis of students' undesirable factors and dislikes within their learning context identified a long list of issues impacting on their goal achievements as shown in Table 5.9. Not every issue is a problem but it is a symptom that indicates that there is a problem. These issues have been listed to simplify the identification of the actual UDEs that indicate that there are conflicts or dilemmas within the L\&T system.

Table 5.9: Issues impacting on UNSB students' quality of learning experiences

\begin{tabular}{|c|c|}
\hline & Issues impacting on UNSB students' quality of learning experiences \\
\hline & Teaching \& learning issues \\
\hline 1 & There is rigidity in teaching (no open-minded learning) \\
\hline 2 & There are no wide explanations of facts \\
\hline 3 & Many times, there are no Q\&A sessions in class \\
\hline 4 & Learning is exam-oriented \\
\hline 5 & The use of projectors and power-point notes limits interactions with students \\
\hline 6 & Most teaching is irrelevant/expired \\
\hline 7 & Some lecturers are not committed to supervising project research paper \\
\hline 8 & Teaching lacks a practical approach \\
\hline 9 & Teaching is more theoretical than practical \\
\hline 10 & There is no use of case studies in teaching \\
\hline 11 & There is no student involvement or engagement in learning \\
\hline 12 & There is an absence of holistic learning \\
\hline 13 & There is rote learning \\
\hline \multirow[t]{2}{*}{14} & There are no field trips for learning \\
\hline & Lecturer-issues \\
\hline 15 & Some lecturers miss module 1 classes \\
\hline 16 & Many lecturers do not keep class time \\
\hline 17 & Many lecturers do not apologise for their lateness in class \\
\hline 18 & Some lecturers tend to develop a bad attitude towards a class \\
\hline 19 & Some lecturers do not clearly explain new concepts to students. \\
\hline 20 & Some lecturers are harsh to students \\
\hline 21 & Some lecturers have not embraced technology. \\
\hline
\end{tabular}




\begin{tabular}{|c|c|}
\hline & Issues impacting on UNSB students' quality of learning experiences \\
\hline 22 & Some lecturers answer phones in class \\
\hline 23 & Many lecturers do not inform students that they will miss class(es) \\
\hline 24 & Many lecturers assume that students know some concepts \\
\hline 25 & Many lecturers do not clarify issues in class \\
\hline 26 & Some lecturers are not audible and their writing is not legible \\
\hline 27 & Some lecturers lose students' assignments \\
\hline 28 & Many times lecturers just read the notes in class \\
\hline 29 & Some lecturers do not go with mike (Public Address System) to class \\
\hline 30 & Most lecturers are not available to students \\
\hline 31 & Some lecturers are lazy \\
\hline 32 & Some lecturers only provide hand-outs \\
\hline \multirow[t]{2}{*}{33} & Some lecturers lack first-hand information in their teaching \\
\hline & Students \\
\hline 34 & There is no value for our money \\
\hline 35 & There is discrepancy in the performance of Module I \& II \\
\hline 36 & There is no appreciation of students as customers of UoN \\
\hline 37 & There is lack of transparency in the management of finance (student fees) \\
\hline \multirow[t]{2}{*}{38} & There is poor customer/student service from the non-academic staff \\
\hline & Interactions \\
\hline 39 & There are no interactions with senior administrative staff of the school \\
\hline \multirow[t]{2}{*}{40} & There is limited interactions between students and lecturers \\
\hline & Exams, grades \& missing marks \\
\hline 41 & Students think that some lecturers do not mark exams \\
\hline 42 & There are incidents of 'Harambee ${ }^{7}$ degrees' (team-work degrees) in exams \\
\hline 43 & There are incidents of 'purchasing of grades' \\
\hline 44 & There is poor invigilation of exams. \\
\hline 45 & Missing marks delay the graduation of some students \\
\hline \multirow[t]{2}{*}{46} & There are many cases of missing marks \\
\hline & Curricular \\
\hline 47 & There is no flow of knowledge acquired to the next level i.e. $1^{\text {st }}-2^{\text {nd }}-3^{\text {rd }}-4^{\text {th }}$ year (lack of coherence) \\
\hline 48 & Curricula does not integrate emerging industrial issues and practices \\
\hline \multirow[t]{2}{*}{49} & There is inadequate integration between learning and industrial practice \\
\hline & Student support \\
\hline 50 & There is no guidance for freshmen about university life \\
\hline 51 & There is lack of training on how to use the portal \\
\hline 52 & Signing at door (to enter class) is time wasting \\
\hline 53 & There are negative influences from senior to junior students \\
\hline 54 & There are incidents of student-lecturer affairs \\
\hline
\end{tabular}

7 The term harambee refers to the traditional Kenyan community self-help events. In this context, it refers to teamwork or community in exams which is a malpractice. 


\begin{tabular}{|c|c|}
\hline & Issues impacting on UNSB students' quality of learning experiences \\
\hline 55 & Module II are not provided with residential services \\
\hline 56 & Some students are forced to attend evening classes at the main campus \\
\hline 57 & Module I students take too long to graduate \\
\hline 58 & The long holidays for module1disrupt learning \\
\hline 59 & The registration procedure in first year or for new students is not well coordinated \\
\hline \multirow[t]{2}{*}{60} & The separation of Module I \&II causes disharmony/rifts \\
\hline & Facilities \& resources \\
\hline 61 & The public address system in large classes (200+) is poor/not there \\
\hline 62 & Library lacks detective system for theft \\
\hline 63 & There is lack of contextual learning materials \\
\hline 64 & Computer facilities are not sufficient for the evening students \\
\hline 65 & Many classes conducted in science laboratories in Chiromo are uncomfortable \\
\hline 66 & There are inadequate sporting facilities \\
\hline 67 & Some lecture halls in Chiromo are in poor condition \\
\hline 68 & Residential halls of residence are poorly maintained \\
\hline \multirow[t]{2}{*}{69} & There are no automatic teller machines (ATM) services \& shopping facilities in Lower Kabete \\
\hline & Fees \& other charges \\
\hline 70 & Fees are high compared to other universities \\
\hline 71 & Computer charges are very high \\
\hline 72 & Medical charges are not optional for employed students \\
\hline 73 & There is no patience to allow students to settle fees within the stipulated grace period of 6 weeks \\
\hline \multirow[t]{2}{*}{74} & Students pay for services that they do not use (such as the bus and computer services) \\
\hline & Structure \\
\hline 75 & The structure and management of the school is bureaucratic \\
\hline
\end{tabular}

The above issues are then analysed for their validity as UDEs based on Cox, et al., (2012) protocol for articulating UDEs (refer to chapter 3). The validation process then reduced the above 75 issues into 15 UDEs as shown in Table 5.10. 


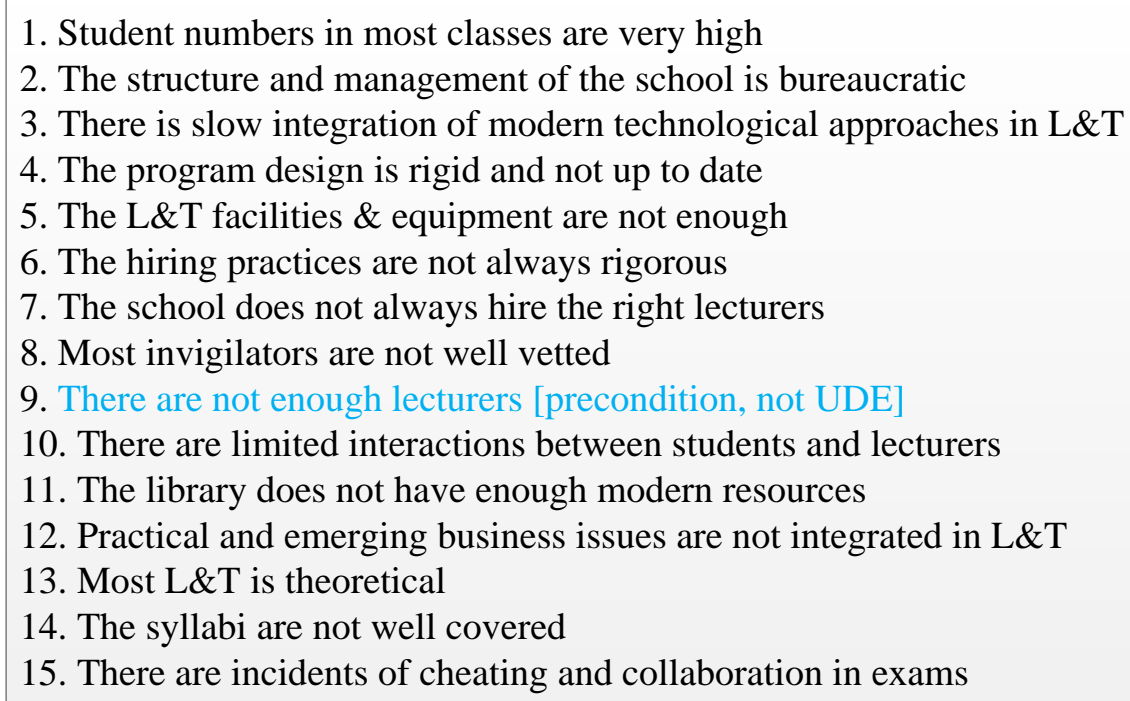

To identify the 'root cause(s)' of the undesirable issues in learning, a focused current reality tree $(f C R T)$ that depicts the logical connections of the above UDEs is constructed.

\subsubsection{Identifying the 'root causes' of UDEs}

The analysis of students' fCRT identified two critical root causes that contribute to students' undesirable experiences: The structure and management of the school is bureaucratic (UDE 2) and the student numbers in most classes are high (UDE 1) (Figure 5.5). The numbering of the UDEs is done by the Flying Logic Software but is used here for the flow of logic in explanation. The logic in explanation is made more robust by use of supporting statements from the students.

The fCRT is read from bottom to top using the 'If... then... logic. For instance, if the structure and management of the school is bureaucratic, then there is slow integration of modern technological approaches to L\&T, the program design is slow to update, the library lacks modern resources, and the hiring practices are not always rigorous. If there is slow integration of modern technological approaches to L\&T, then there is limited interaction in L\&T, and practical and emerging business issues are not always integrated into L\&T. [The entire CRT is read in that order]. What follows is a description of the fCRT (Figure 5.5) based on each of the two root causes, from bottom up to the undesirable outcome. 


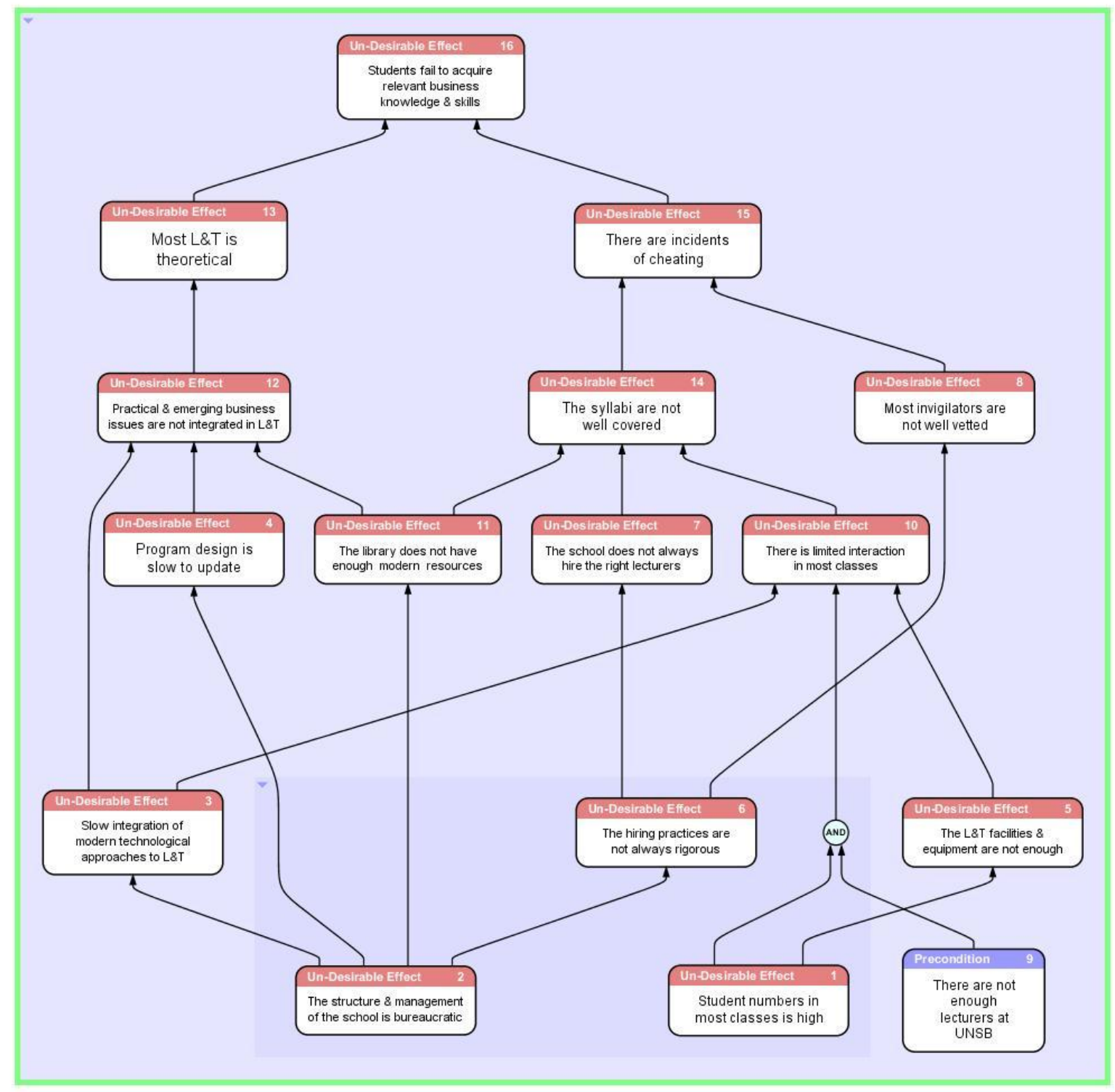

\section{The structure and management of the school is bureaucratic}

The bureaucratic structure and management of the school (UDE 2) seems to contribute to most of the UDEs that impact on students' learning experiences. On the one hand, students blame the management for the rigid program design (UDE4). Students complain about theoretical or book-based approaches to L\&T, a lack of engaged learning, industrial exposure or involvement of practitioners in their classes. Their concern is demonstrated by the following expressions.

It should be practical, what I mean is that, you can get into a university, you go through your 4 year course, you perform very well in your papers, but when you go to the company, you cannot be able to be productive. You have the skills but you do not know how to apply them or put them into practice. So we should integrate industrial exposure with classroom. If it is a business, we should visit companies and see how they do things. Here we learn but we never get to see how it is done out there. This is the reason 
why some people have done a degree in business but they cannot start their own business, as a result, you find so many people who are not employed (KM2-PT).

... learning should be more practical than theoretical. The BCom degree course is full of theory. When you reach fourth year, you have all these theories but we need to practice them. So I wish we have a situation where after we learn a theory, we go into the practical aspect of it. Visit organisations and see how the theory works. The university could invite some of these managers so that we can interact with them and know the problems they face in management (KM1).

Basically what we learn here we don't get to know what exactly happens out there in the business world. Teaching should therefore relate more to the business world. Teaching should be more application than theoretical (KM2-FT).

Students also blame the bureaucratic structure for the slow way in which the school adapts to students' changing needs. They feel that their innovative ideas are delayed and are eventually killed through red-tape. The following FG sentiments attest to this.

Bureaucracy is bad when you are told that this has to go through this process. So there are long bureaucracies in attending to students' needs/concerns... The process is that students have to complain to student leaders who then go to the immediate relevant department, who then write letters to the Dean of School, who writes to the school-principal $\{$ College of Humanities \& Social Sciences-CHSS $\}-\{$ to $\}$ relevant DVC- $\{$ to $\}$ senate $-\{$ to $\}$ government. By the time it goes through this process, the student is doing Masters (KSL).

Sometimes as a student we can be having very brilliant ideas, this being a school of business as we are saying, but you might not be able to nurture it to where it can because your idea is killed somewhere through the bureaucracies and protocols... because they think that, we, the young people, do not have the ideas. They are not people who are receptive, so if we have managers who are receptive, they'd tend to accommodate students' ideas (KM1).

In addition, students blame bureaucracy for the slow integration of modern technology in L\&T

(UDE 3). They complain that the slow integration impacts on their classroom experiences negatively because they do not clearly hear their lecturers. They also experience poor visibility of lecturers' presentations particularly in large classes.

Poor uptake of technology makes learning process to be very slow, making the communication between students and lecturers very slow as well as the grading system. Limited use of technologically enabled illustrations/diagrams limits understanding. It Limits opportunity to create discussion forums... (KM1).

Sometimes in class, we are like 200 students, and then we do not have public address system... Most of the lecturers do not come with a mike (KIS).

Students also blame the management for the poorly resourced library (UDE 11).

The poorly equipped library is caused by negligence by administrative staff and it is not given priority (KM2-PT). 
Together, these issues tend to contribute to poor integration of practical and emerging business issues in L\&T (UDE 12), which implies that most L\&T tends to be theoretical (UDE 13). As a result, students feel that they do not effectively achieve their goal of 'acquiring relevant business knowledge and skills (UDE 16).

On the other hand, the bureaucratic structure and management tends to harbour hiring practices that are not always rigorous (UDE 6). As a result, some invigilators are not well vetted. Students blame such invigilators for encouraging examination malpractices.

You find that there are also emerging trends and cultures where students hire or bribe invigilators during exams causing cheating to flourish (KM2-PT).

... because there is a lot of 'harambee' or team work in exams, where you give somebody to copy your paper... We call this 'degree harambee' (KM1)

They also indicate that those students who engage in such practices lack confidence and fear to fail. The lack of confidence is therefore attributed to lack of effective coverage of the syllabi (UDE 14). But the reason behind poor coverage of the syllabi is attributed to lecturers' behaviour.

So some lecturers miss classes for the regular \{module 1$\}$...they never keep time, they come like after an hour, they can come like for $2 \mathrm{hrs}$ late (if they have communicated that they are coming, students keep waiting for them), then stays for $30 \mathrm{~min}$ and... no apologies. Then they give assignments (KM1).

Lecturers should be monitored on how they cover the syllabus (KM2-PT).

Moreover the poor hiring practices tend to bring in some lecturers who are not always rightly qualified to teach (UDE 7). The poor teaching causes dilemmas for students.

I experienced one major dilemma because of the teachers ... to give you a more realistic perspective of this, the teachers of accounting in first years and second years, don't really emphasise teaching us the correct things. As such we found ourselves failing. If you ask all of us here, I think $95 \%$ of the students had D's in accounting for assets and accounting for equities. Most of us failed, not because we didn't know what we were doing, but simply because of poor teaching (KM2-FT).

Relatedly, students express concern that their lecturers lack commitment and are not always available for consultation.

Unavailability of lecturers for consultation... This affects me in that maybe I need some guidance from the lecturer but I cannot find him on time (KIS). 
Poor time keeping by lecturers demotivates students from attending classes. If a lecturer is late for 2 hours, the next lecture you might fail to attend and that might affect your learning. Learning is delayed so you lag behind in curriculum...Increases stress levels of students in that during the end of semester you are bombarded with lots of hand outs, assignments, and yet there was time to do all that... It sets bad example to students yet lecturers should act as role models to us. Now when they come to class late, we also start doing the same... hinders students' concentration in that you came prepared for a lesson and then the lecturer delays, so you switch off to other things like internet...It compromises their professionalism (KM1).

Thus, if students lack confidence, then they tend to engage in exam cheating. As a result, students fail to gain relevant business knowledge and skills (UDE 16).

\section{The student numbers in most classes are high}

Most classes have high student numbers (UDE 1). Yet, the L\&T facilities and equipment are not always enough (UDE 5).

The library books are not enough. For instance the lecturer refers you to a book to go and read but there are only one or two copies in the library yet you are over 200 (KM2-FT).

The computer labs are mostly filled with day time students, so it becomes difficult for us to use the facility. These computers are very few (KM2-PT).

A course like Information Systems, you don't even have a desk-top computer in front of you. So we should have hands-on experience type of learning that provides application of knowledge learnt such as more use of computers in learning if it is a computer-related course (KIS).

Also, lecturers are inadequate (precondition 9). As a result, interactions between students and lecturers are limited (UDE 10) and in some cases, poor. Indeed, students complain over the harsh way in which some lecturers treated them.

The attitude of lecturers needs to change especially those with PhDs, even before they speak they let you know that they have 4 or 5 degrees. All lecturers who are PhDs have an attitude because they are doctors. Sometimes they do not use respectable language, for example, there is one that we have, people have complained even at higher authority, even to the dean, even the vice chancellor (VC) is aware, but nothing is done to that person. ... But these people feel that because they have $3 \mathrm{PhDs}$, you make it an issue to people. You talk arrogantly, when asked a question you tell them 'you can go and report to whoever you want, even if you want to go to the VC, this is his number you can call him'. Such kind of an attitude, they shout at us and tell us off ... Such a lecturer is always absent ... (KM2-PT).

Lecturers are too difficult to deal with... they always frustrate (KIS).

In public universities, there should be disciplinary action for lecturers because even after you report to the VC, or the dean, they do not take disciplinary actions on them because this is a public university. That's why lecturers behave the way they do. They say they are permanent and pensionable (KM2-PT).

There is something about attitude whereby some lecturers develop an attitude towards a specific class and you really face a rough time. Because a lecturer comes to your class and says 'this is the class that said you do this, you miss class ... or this is the class I have been trying to know'. So already that lecturer has bad attitude towards the class (KM1).

The slow integration of modern technology allegedly contributes to the limited interactions. 
...Limits opportunity to create discussion forums. Lecturers should embrace technology in social media like Twitter and Facebook. This will reduce the gap between the lecturer and students significantly (KM1).

The limited and poor interactions then tend to contribute to the ineffective coverage of the syllabi and to ineffective acquisition of business knowledge and skills as discussed under (i).

\subsubsection{Synthesis of UNSB's students $f$ CRT}

While acknowledging that there are various ways of experiencing $L \& T$, the synthesis of students views of their learning experiences brings to the fore five basic issues:

i. Students tend to be clear about what they want to achieve (i.e. acquire necessary/relevant business knowledge and skills). Moreover, in the achievement of their goal, they stipulate clearly the need for adequate L\&T infrastructure and qualified staff. It is particularly interesting to note how students emphasise their own role of 'self-discipline and hardwork', 'teamwork and collaborations', and 'good leadership' of the school.

ii. The purportedly clear understanding of their role in the achievement of their goals might imply that they could perhaps adopt a deep approach towards learning. On the contrary, students descriptions of their experiences and practices depict a surface approach towards learning where they wait until exam time to read...for many students doing the theoretical units, they just wait for the last minute to read for exam (KM1). This contradicts their concerns or their goal of learning. It seems their concern is to pass exams with good grades. Moreover, despite students' expressed desire for a more practical approach towards learning as well as greater engagement and involvement, the learning context tends to afford them a surface and theoretical approach towards learning environment with passive student involvement and limited student engagement. This might perhaps explain why students adopt a surface approach to enable them to achieve the goal of 'passing exams with good grades'. Furthermore, they perceive good grades as highly demanded in the market and they can therefore give them a competitive edge. This might also explain why some of them engage in academic malpractices so as to get good certificates. Such approaches and practices to learning not only tell us about students' experiences of learning but also about the quality of the L\&T outcome.

iii. Closely related to the issue of involvement and engagement, students express a need for teamwork, not only amongst themselves but also between themselves and their lecturers. 
However, their complaints indicate that their lecturers might not be ready for teamwork. Most lecturers are not available to them.

iv. The blame game. Students tended to blame others for not doing their roles effectively and pointed fingers to lecturers and administrative staff who purportedly failed to provide what they desire. Indeed, they perceive themselves as 'customers' and tended to blame the institution for 'lack of appreciation of students as customers of UoN (KM1)'. In this respect, they tend to perceive education as a service but perhaps not as an on-going transformation process, which could bring about conceptual change and intellectual development in their lives. Nevertheless, despite seeing themselves as customers, their 'customer-role' or 'involvement' as co-creator and co-producer of knowledge is perhaps not well played.

v. In line with the blame game, students also perceive the need for 'monitoring' or close supervision of lecturers hoping that this would make lecturers' work better. However, they did not perceive the need to monitor their 'own-selves' on the aspect of 'self-disciplined and hard-working students', which they perceive as important in their goal achievement. Indeed, if they monitored themselves, they would probably not engage in, for instance, 'cheating in exams' or just 'reading for exams'.

vi. Their desire for integration of modern technology and current business issues and practises in their L\&T contexts is apparent. Students perceive the need for both the lecturers and themselves to be apt with modern technology and current and emerging business issues. Their concern for the need for technological advances in L\&T may be valid on the basis of technological potential enriching L\&T experiences but such advances are not without some drawbacks such as depersonalisation/dehumanisation of learning.

\subsubsection{Summary of UNSB's student analysis}

In this subsection students' goal of learning, the critical success factors and the necessary conditions are identified. A common goal of 'acquisition of business knowledge and skills' is identified. Three critical success factors are identified, namely: adequate L\&T facilities and structures, qualified and committed lecturers, and self-disciplined and hard-working students. Seven necessary conditions identified were: (1) modern L\&T classrooms labs, lecture theatres, sporting and recreational facilities, (2) computer technology \& innovation and internet 
facilities, (3) well-equipped library and e-resources, (4) staff development and training, (5) teamwork and collaborations, (6) student engagement and support, and (7) good leadership of the school.

It is particularly interesting to find that students clearly understood what they wanted to achieve during their stay at the university (i.e. the goal). Moreover, students clearly understood their role in the achievement of the goal. But the L\&T context perhaps fail to enable them to play their roles effectively so as to achieve their desired goal more effectively. Nevertheless, two critical root causes of undesirable students' experiences are identified: the bureaucratic structure of the school and high student numbers in class. These critical root causes are treated as dilemmas and their resolutions are demonstrated using evaporating clouds (ECs) in Chapter 8.

Since students' learning experiences are largely shaped by the teaching approaches, for a more comprehensive understanding of the experiences of L\&T, the next sub-section presents lecturers' perspectives of the L\&T context and their experiences therefrom. 


\subsection{UNSB lecturers data analysis}

This sub-section presents findings from the lecturers. The description of lecturer participants is presented. Lecturers' goal of teaching is identified. The issues impacting on their teaching experiences are explored and presented in the form of fCRT. A description and synthesis of fCRT is also provided.

\subsubsection{Description of UNSB lecturers participants}

The sampling strategy of UNSB lecturers yielded a heterogeneous group of twelve participants who are diverse in terms of areas of specialisation and years of teaching experiences. These lecturers hold parallel administrative positions in the school. The lecturers sample was drawn from the three departments of UNSB namely: Department of Business Administration (DBA), Department of Finance and Accounting (DFA), and Department of Management Science (DMS). A deliberate effort was made to ensure gender representation from each department as shown in Table 5.11.

Table 5.11: Composition of UNSB lecturer participants

\begin{tabular}{|l|c|c|c|}
\hline DEPT & Male & Female & Total \\
\hline DBA & 3 & 1 & 4 \\
\hline DFA & 4 & 1 & 5 \\
\hline DMS & 2 & 1 & 3 \\
\hline Total & 9 & 3 & 12 \\
\hline
\end{tabular}

A total of 12 interviews were conducted. The recorded time ranged between 23 to 100 minutes, with an average interview time of 50 minutes.

Figure 5.6: Interview time for UNSB lecturers

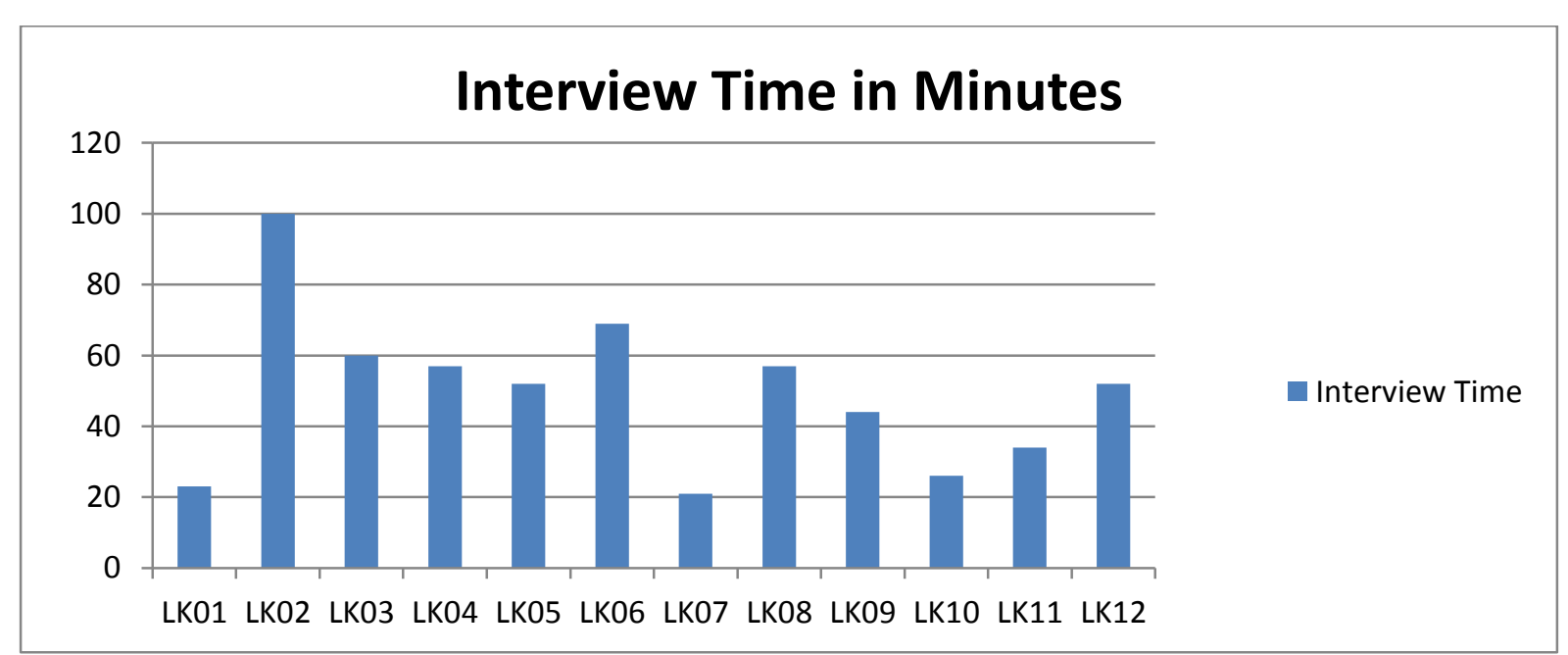


This range is due to the fact that few lecturers gave straight-forward answers and a few also gave long-wounded answers. For those who gave long-wounded answers, it was difficult to interrupt because in an African context it is rude to interrupt, particularly the elderly. The lecturers' years of experience range between 2 to 37 years as shown in the Figure 5.7.

Figure 5.7: Years of experience of UNSB lecturers

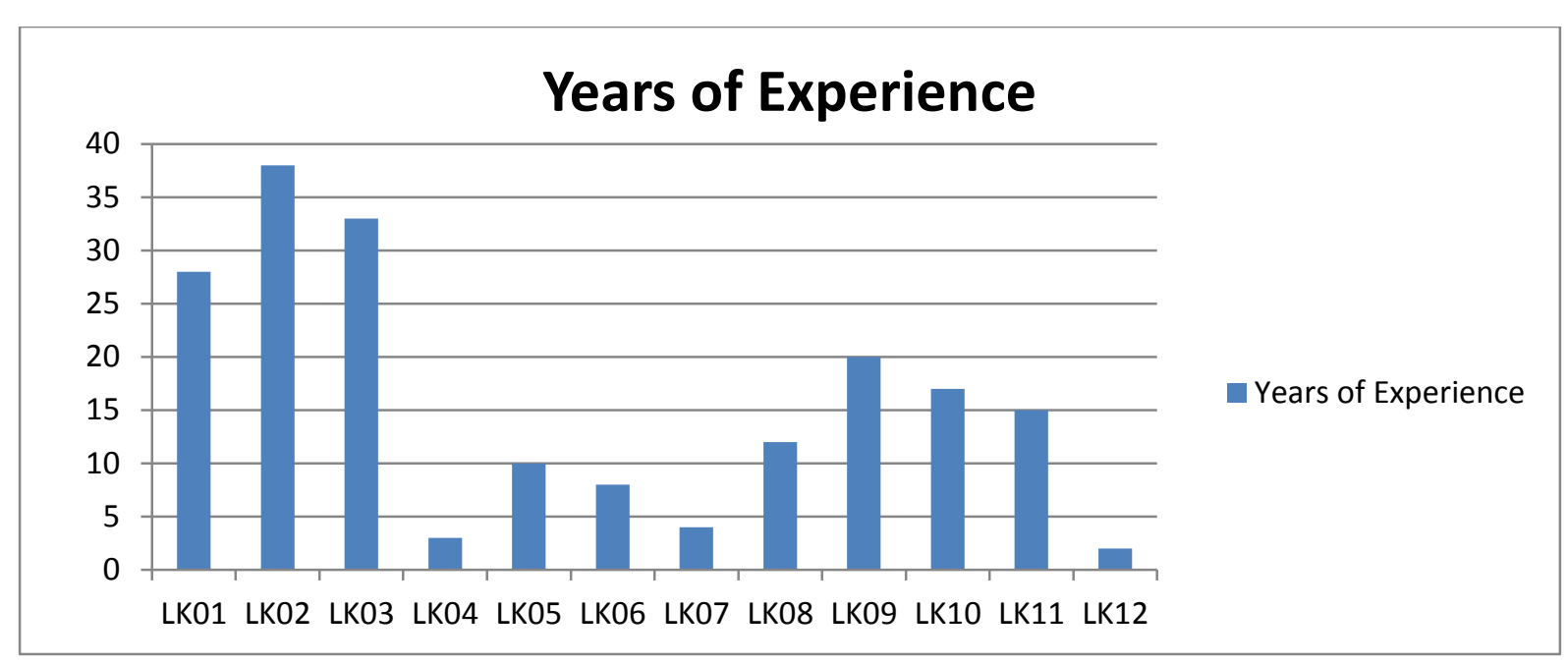

During their tenure the interviewed lecturers have held parallel positions of chair of departments, coordinators of programs and/or examination officers. Five lecturers have $\mathrm{PhD}$ qualifications. One lecturer has held the position of a principal and deputy principal in the college of humanities and social sciences, dean, and chair of a department. The lecturers have various specialisations that are hosted in their respective departments. One lecturer has won the 'lecturer of the year award' from the school.

\section{Identifying the 'gap'}

The first step in any improvement initiative is the identification of the gap between the 'actual' and 'desired' states of any system. To understand whether any gaps existed within UNSB's L\&T system, lecturers were asked to explain 'how they desired that L\&T context be like'. This was then followed by a question on 'how the desired situation compared with the actual L\&T context'. Responses to these two questions indicate gaps that provided evidence that the L\&T system is not performing as well as desired. The following statements are examples of the verbalisations of the gaps.

There is a big difference. The actual position is that we are far away from where we would want to be. For example the facilities are not available; we have a high number of students who do not want to do a lot of their work ... That desire for knowledge is not there (LK09). 
Teacher- student ratio is not good. In some classes, students are very many, until they actually get lost.

... not much training on pedagogical skills. There is some gap (LK07).

There is a gap between industry and academia, therefore need for industrial linkage. There is need for more interaction to allow for quality learning (LK12).

Occasionally there is a lack of teaching facilities and some classes do not have appropriate facilities. Sometimes there is power outage that makes it difficult to use the equipment that may be there. Therefore, these issues interfere with the desired teaching situation (LK01).

\subsubsection{Identifying teaching goal, CSFs, and NCs}

\section{Articulating a common goal}

Interviews with lecturers about their goal of teaching indicated a common purpose of teaching in the school of business. Table 5.12 provides a description of their goals.

Table 5.12: UNSB lecturers' goal descriptions

\begin{tabular}{|c|c|}
\hline Lecturer & Goal descriptions \\
\hline LK01 & $\begin{array}{l}\text { To impart knowledge, skills \& attitudes desirable in a good society: this } \\
\text { should be ideally in line with national developmental goals. }\end{array}$ \\
\hline LK02 & $\begin{array}{l}\text { Provide/produce high level man power especially at the policy making level } \\
\text { because at top level we lack skilled manpower with conceptual skills. }\end{array}$ \\
\hline LK03 & $\begin{array}{l}\text { To prepare students to be responsible adults and imparting broad } \\
\text { knowledge. }\end{array}$ \\
\hline LK04 & $\begin{array}{l}\text { Offer quality education - the best/excellence to produce the best students } \\
\text { who can work globally and perform excellently to improve the whole world. }\end{array}$ \\
\hline LK05 & $\begin{array}{l}\text { Mentor students as I impart practical knowledge and allow them to explore } \\
\text { knowledge broadly \& creatively. }\end{array}$ \\
\hline LK06 & Transformation of society. \\
\hline LK07 & $\begin{array}{l}\text { To impart knowledge, prepare students for the market and to help students } \\
\text { to meet their own objectives. }\end{array}$ \\
\hline LK08 & $\begin{array}{l}\text { Impart knowledge \& students change of attitude towards themselves, } \\
\text { community \& environment. }\end{array}$ \\
\hline LK09 & Communicating \& imparting knowledge. \\
\hline LK10 & Impart knowledge to learners. \\
\hline LK11 & $\begin{array}{l}\text { To make students to acquire knowledge \& techniques of acquiring } \\
\text { knowledge-knowledge is out there! }\end{array}$ \\
\hline LK12 & $\begin{array}{l}\text { Ensure that students are acquainted with concepts \& ensure that they } \\
\text { appreciate learning outcomes- master/appreciate objectives of the course. }\end{array}$ \\
\hline
\end{tabular}

The analysis of the above goals then provided a well-articulated consensus goal of 'imparting knowledge, skills, and attitudinal change to learners'. The consensus goal is derived from examination of the recurrence of the key phrases or words (in italics). 


\section{Determining CSFs and NCs}

After identifying the goal, the next step is to determine CSFs and NCs. These are presented in

Table 5.13. To determine common CSFs, 'unitisation' of the identified CSFs is performed.

Table 5.13: Unitising CSFs \& NCs of UNSB lecturers

\begin{tabular}{|c|c|c|}
\hline Lecturer & Critical success factors & Necessary conditions \\
\hline LK01 & $\begin{array}{l}\text { Adequate research facilities \& funds } \\
\text { Appropriate teaching load (CSF2) }\end{array}$ & $\begin{array}{l}\text { Get funding from government, NGOs \& other sources (NC1) } \\
\text { Adequate lecturers \& adequate funds for their salaries (CSF1) }\end{array}$ \\
\hline LK02 & $\begin{array}{l}\text { Adequate government funding }(\mathrm{NC} 1) \\
\text { Adequate research funds }(\mathrm{NC} 1) \\
\text { Adequate staffing }(\mathrm{NC})\end{array}$ & $\begin{array}{l}\text { Allow universities to increase fees paid by government funded students }(\mathrm{NC1}) \\
\text { Internal generation of funds }(\mathrm{NC} 1) \\
\text { University to engage vigorously in consultancy work (NC7) } \\
\text { Availability of teaching resources \& facilities (CSF1) }\end{array}$ \\
\hline LK03 & $\begin{array}{l}\text { Lecturers as role models (CSF2) } \\
\text { Lecturer consultation } \\
\text { Student involvement (NC5) }\end{array}$ & $\begin{array}{l}\text { Lecturer behaviour } \\
\text { Low student numbers (NC4) } \\
\text { Classroom \& course-work design (NC3) }\end{array}$ \\
\hline LK04 & $\begin{array}{l}\text { Quality of students admitted (CSF3) } \\
\text { Lecturers capabilities (CSF2) } \\
\text { Relevant content (NC2) } \\
\text { Student as sessment \& feedback (NC4) }\end{array}$ & $\begin{array}{l}\text { Quality \& ranking of university to ensure 'choice by students'. } \\
\text { University competitiveness } \\
\text { Industrial linkages (NC9) } \\
\text { Exchange programmes (NC9) } \\
\text { Carry out research (NC7) } \\
\text { Develop case studies (NC9) } \\
\text { Continuous assessment \& feedback (NC4) }\end{array}$ \\
\hline LK05 & $\begin{array}{l}\text { Practical learning (NC3) } \\
\text { Simulate learning problems (NC3) } \\
\text { Create solutions (NC3) }\end{array}$ & $\begin{array}{l}\text { Environment that encourages participative learning (NC5) } \\
\text { View students as co-participants (CSF3) } \\
\text { Exposure lecturer to industrial environment (NC9) } \\
\text { Participative problem solution }\end{array}$ \\
\hline LK06 & $\begin{array}{l}\text { Right instructors (CSF2) } \\
\text { Willing learners (CSF3) } \\
\text { Infrastructure that facilitates L\&T (CSF1) }\end{array}$ & $\begin{array}{l}\text { Up to date lecturers on societal \& emerging issues (CSF2) } \\
\text { Well motivated lecturers (CSF2) } \\
\text { Teaching \& examination style to invoke critical thinking (CSF2) } \\
\text { Remove commercial learners (CSF3) } \\
\text { Team work among learners (CSF3) } \\
\text { Interaction between learners \& teachers \& communities (NC5) } \\
\text { Access \& use of appropriate L\&T technology (NC1) }\end{array}$ \\
\hline LK07 & $\begin{array}{l}\text { Availability \& adequacy of L\&T resources } \\
\text { Conducive reading environment (CSF1) } \\
\text { Hire qualified lecturers (CSF2) }\end{array}$ & $\begin{array}{l}\text { Allocate funds to buy the needed resources (NC1) } \\
\text { Upgrade (modernise) L\&T facilities (NC1) } \\
\text { Funds availability \& top management support (NC1) }\end{array}$ \\
\hline LK08 & $\begin{array}{l}\text { Inspiring lecturers (CSF2) } \\
\text { Remove suspicious uni culture } \\
\text { Purposeful learners (CSF3) }\end{array}$ & $\begin{array}{l}\text { Vet best lecturers (NC2) } \\
\text { Use tenure system (NC: } \\
\text { Provide incentives (NC5) } \\
\text { Focus on positives } \\
\text { Take learning responsibility (NC5) }\end{array}$ \\
\hline LK09 & $\begin{array}{l}\text { Lecturer capability (CSF2) } \\
\text { Willing students (CSF3) } \\
\text { Availability \& enabling L\&T facilities }\end{array}$ & $\begin{array}{l}\text { Training on Communication \& pedagogical skills (NC9) } \\
\text { Change current education system } \\
\text { Student involvement (NC5) } \\
\text { Prioritise acquisition of L\&T facilities (NC1) } \\
\text { Create centres of excellence (NC) }\end{array}$ \\
\hline LK10 & $\begin{array}{l}\text { Conducive L\&T facilities (CSF1) } \\
\text { Appropriate lecturer/student ratio (NC) } \\
\text { Adequate pay for lecturers (NC) }\end{array}$ & $\begin{array}{l}\text { Modernise L\&T facilities (NC1) } \\
\text { Lecturer incentives from the government }(\mathrm{NC} 1) \\
\text { Policy towards lecturer pay to change }(\mathrm{NC} 2)\end{array}$ \\
\hline LK11 & $\begin{array}{l}\text { Class meetings } \\
\text { Students time to research (CSF3) } \\
\text { Student progress assessment (CSF2) }\end{array}$ & $\begin{array}{l}\text { Availability of L\&T materials (CSF1) } \\
\text { Teacher preparedness (CSF2) } \\
\text { Industrial arrangements (CSF3) } \\
\text { Ability to use appropriate technology (CSF3) } \\
\text { Devote time for library (CSF3) } \\
\text { Lecturers time to check progression (CSF2) } \\
\text { Tutors to check progression (NC2) }\end{array}$ \\
\hline LK12 & $\begin{array}{l}\text { Course delivery (CSF2) } \\
\text { Class participation (CSF2) } \\
\text { L\&T resource availability (CSF1) }\end{array}$ & $\begin{array}{l}\text { Appropriate illustrations \& good classroom atmosphere (CSF2) } \\
\text { Lecturer approachability (CSF2) } \\
\text { Engage students (CSF2) } \\
\text { Availability of Library resources (CSF1) }\end{array}$ \\
\hline
\end{tabular}


After the identification of the CSF, the NCs factors were determined for each CSF and/or NC. Again, the unitisation process leads to the cross-examination of the constructs and phrases related to a particular CSF and labelled as NC under that CSF. For instance, for CSF1, the phrases related to it would be labelled NC1. Similarly, for CSF2, the NCs under it would be labelled NC2, in that order. Further unitisations of the NCs were done where related ideas were categorised under one NC.

\section{Figure 5.8: UNSB lecturers' goal tree}

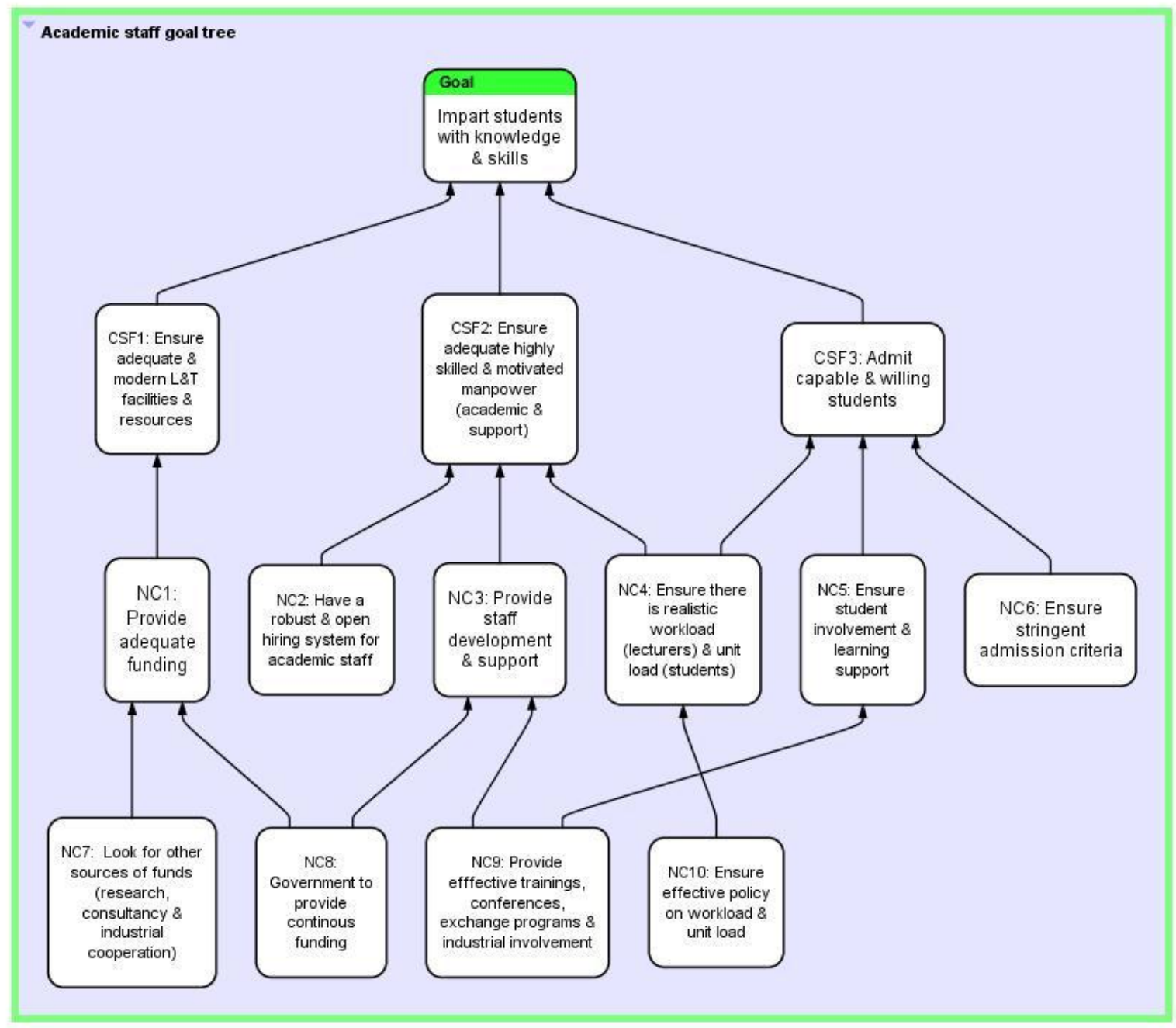

The lecturers' goal tree is a necessary condition tree and not a sufficiency tree. The tree therefore provides only two levels of NCs. The first level indicates need for adequate funding, robust and open hiring system for academic staff, staff development and support, realistic workload, student involvement and support, and stringent admission criteria. The second level indicates need for increment of government funding, attraction of other funds, effectiveness of trainings (including conferences and exchange programs), industrial involvement, and change of policy on workload. 


\subsubsection{Identifying UDEs that affect quality of teaching experiences (UNSB)}

The analysis of what lecturers 'disliked' about their teaching experiences and the undesirable issues that they encountered in their teaching identified a number of factors that negatively affected the quality of their teaching experiences. These issues are listed in Table 5.14

Table 5.14: Issues impacting on UNSB lecturers' quality of L\&T experiences

\begin{tabular}{|c|c|}
\hline 1 & There is no team-work among lecturers \\
\hline 2 & There is mistrust between senior administrators and lecturers \\
\hline 3 & Personal progression for most lecturers is checked \\
\hline 4 & There is suspicion amongst academics \\
\hline 5 & There is laxity in teaching \\
\hline 6 & Most teaching is without interaction \\
\hline 7 & There is low level of corporate sector participation in L\&T \\
\hline 8 & There are incidents of 'sex-for-marks' grades \\
\hline 9 & The student-lecturer ratio is not appropriate \\
\hline 10 & There is no practical learning; most teaching is theoretical \\
\hline 11 & There are no industrial linkages brought into class(es) \\
\hline 12 & Research has not been integrated in teaching \\
\hline 13 & Student numbers in a class are very high \\
\hline 14 & Some students are undisciplined \\
\hline 15 & Some students are immature \\
\hline 16 & Many students are not willing to learn \\
\hline 17 & Some students want to get favours for marks or grades \\
\hline 18 & There is lack of student involvement \& initiative \\
\hline 19 & There is gender-bias in managerial positions \\
\hline 20 & There is gender-blindness in decision making \\
\hline 21 & There is an inside-looking perspective within the school \\
\hline 22 & The numerous courses offered in the school are not manageable \\
\hline 23 & Quality personal contact time with students is missing \\
\hline 24 & There are insufficient teaching assistants and tutorial fellows \\
\hline 25 & The performance of Module I \&II is totally different \\
\hline 26 & The discrepancy in admission criteria affects teaching \& learning \\
\hline 27 & There is lack of student involvement in curriculum development \\
\hline 28 & The curriculum is too centralised; it limits academic freedom \\
\hline 29 & There is poor monitoring of students' performances \\
\hline 30 & Teaching well is not considered in promotions \\
\hline 31 & $\begin{array}{l}\text { There is lack of training for lecturers on using cases and interactive methods, teaching, preparing } \\
\text { content, marking exams and distributing marks }\end{array}$ \\
\hline 32 & Specific teaching goals are lacking \\
\hline 33 & Lecturers are not made aware of the specific teaching goals \\
\hline 34 & There is no consultation unit for students \\
\hline 35 & Students do not have counselling unit \\
\hline 36 & There is inadequate remuneration for lecturers \\
\hline 37 & There is lack of rigorous and uniform assessment of students \\
\hline 38 & There are discrepancies in setting of exams among lecturers \\
\hline 39 & Many lecturers are not trained in pedagogy \\
\hline 40 & There is no reward for achievements \\
\hline 41 & There is no appreciation for teaching well \\
\hline 42 & There is stagnation in academic progress \\
\hline 43 & Lecturers are not getting breaks \\
\hline 44 & There is lack of effective engagement of lecturers in conferences \\
\hline 45 & The L\&T equipment \& facilities are inadequate \\
\hline 46 & There is overcrowding in some classes \\
\hline 47 & There are no 'model-facilities' of teaching \\
\hline 48 & There are not enough lecturers \\
\hline
\end{tabular}


The analysis of what lecturers 'disliked' about their teaching experiences and the undesirable issues that they encountered in their teaching identified 48 factors that negatively affected the quality of their teaching experiences. Using the protocols for stating (demonstrating) an UDE (Cox et al., 2012) as provided in Table 3.3, these factors were reduced into few undesirable effects (UDEs) shown in Table 5.15.

Table 5.15: UNSB lecturers' UDEs

\begin{tabular}{|l|l|}
\hline 1 & There is limited government funding \\
\hline 2 & There are inadequate lecturers \\
\hline 3 & Salaries for all lecturers are low \\
\hline 4 & Most lecturers take extra teaching [intermediate effect] \\
\hline 6 & $\begin{array}{l}\text { Most lecturers are busy with teaching every semester [intermediate } \\
\text { effect] }\end{array}$ \\
\hline 7 & There is lack of trust among staff \\
\hline 8 & There is lack of team work among staff \\
\hline 9 & There are high numbers of module II admissions every trimester \\
\hline 10 & There are no trimester breaks \\
\hline 11 & The L\&T facilities are not adequate \\
\hline 12 & There is limited staff development \\
\hline 13 & Most lecturers have no training in pedagogy \\
\hline 14 & Most students are not effectively engaged in learning \\
\hline 15 & There is limited engagement in conferences \\
\hline 16 & There are inadequate teaching assistants \\
\hline 17 & There is limited student learning support \\
\hline 18 & There are no tutorials at UNSB \\
\hline 19 & Many students perform poorly [intermediate effect] \\
\hline 20 & There are high number of students in most classes \\
\hline 21 & All lecturers are overworked \\
\hline 22 & Most lecturers fail to engage in research \\
\hline 23 & There is lack of quality time with students \\
\hline 24 & There is poor monitoring of student performance \\
\hline 25 & The program objectives are not always met \\
\hline 26 & Most L\&T is theoretical \\
\hline 27 & Most students are not imparted with knowledge and skills \\
\hline 28 & UNSB limits the number of lecturers and teaching assistants it can hire \\
\hline
\end{tabular}

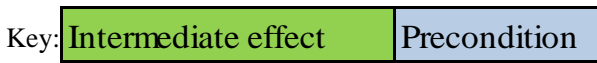




\subsubsection{Identifying the 'root causes' of UNSB's lecturers UDEs}

The identification of the UDEs, led to the construct a current reality tree (CRT) shown in Figure 5.9 .

Figure 5.9: UNSB Lecturers' $f$ CRT

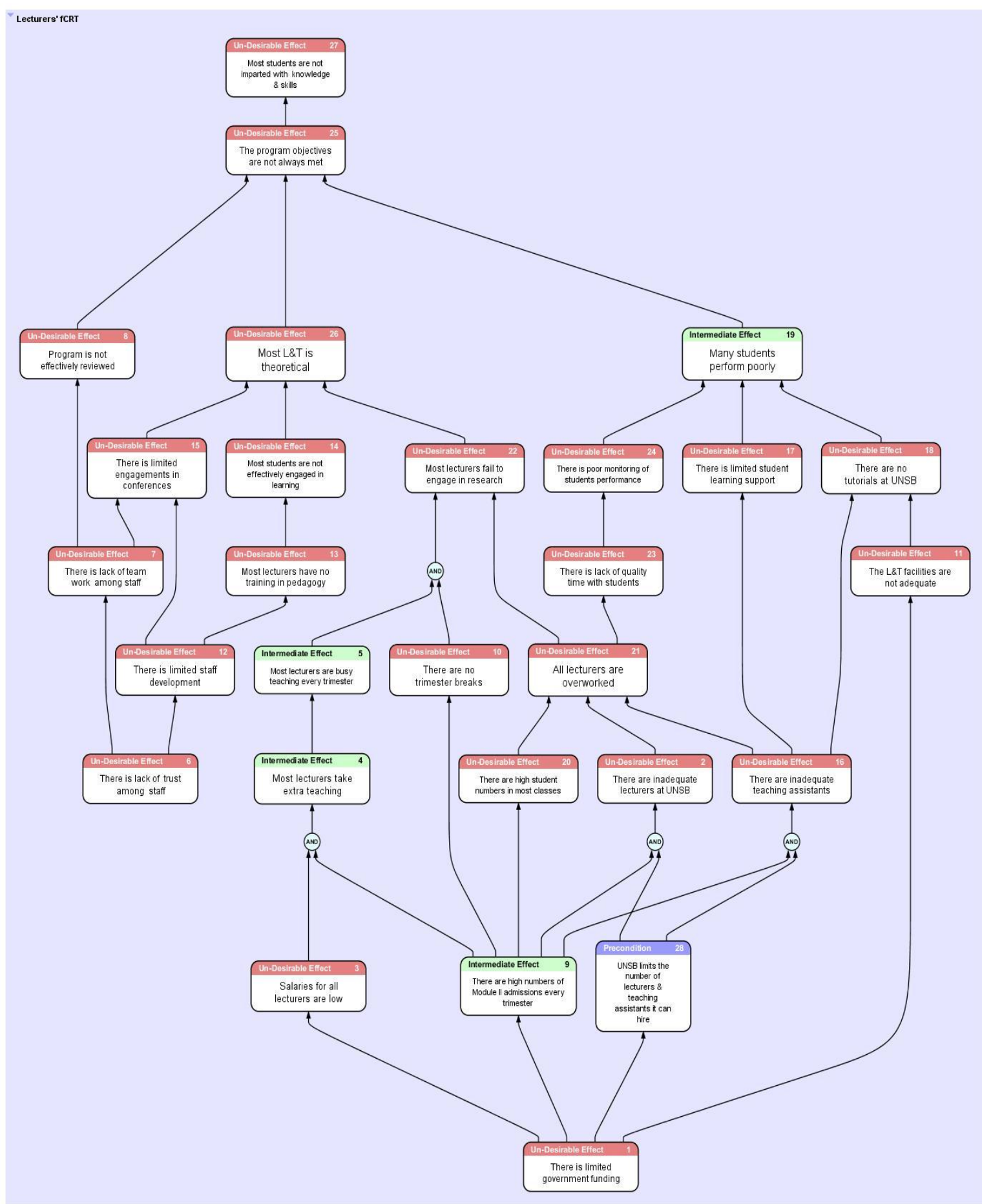

The figure depicts a logical connection of the UDEs to the root causes, as will be explained below. The analysis identified two critical root causes of less than desirable experiences of 
teaching in the Business School: limited government funding and lack of necessary coordination within the school. What follows is a discussion based on Figure 5.9, describing the effect of the root causes on the achievement of the teaching goal.

\section{There is limited government funding}

The limited government funding (UDE 01) causes the school to admit a high number of fee paying students every trimester (Intermediate Effect 09). The challenge is that there appear to be no commensurate human and physical resources to support the high student numbers.

Since the school is a sub-system within a government owned university, like many other such systems, the school does not have the autonomy to expand its human and physical resources. The limited government funding also limits recruitment of lecturers (UDE 02) and teaching assistants, tutors, and other resource persons (UDE 16).

Thus, with inadequate lecturers compared with the high number of students coupled with inadequate teaching assistants/tutors, the result is a situation where lecturers get overworked (UDE 21). Moreover, the limited government funding does not ensure good salaries for lecturers (UDE 03). Therefore, most lecturers felt the need to teach extra classes in order to earn an adequate income (Intermediate Effect 04). Furthermore, since students are admitted every trimester, this ensures a continuous stream of extra classes for the lecturers. But this means lecturers are busy teaching throughout the year without a break (UDE 10). The lack of a break then tends to interfere with the quality of L\&T as noted below.

We no longer have long vacation that we used to have ... to rest. Nowadays it is throughout the year. Those teaching undergraduate ... have to teach throughout the year, this has a toll on their health. They don't improve or care about quality, recycle notes from year to year... They have no time to go for depth... (LK02).

In a situation where lecturers are overworked (UDE 21) then they would fail to engage effectively with research and industrial consultations (UDE 22). (This issue is explored further under the second root cause). Such lecturers would also tend to lack quality time with the students (UDE 23), which might also lead to poor monitoring of students' performance (UDE 24). The lecturers confirmed this as follows.

Sometimes classes are too big thus making quality personal contact time with students to be missed. Provision of this personal quality time might aid the learning process. Class-size is very large, it becomes hard to engage students and monitor their performance closely (LK12).

Especially where teachers are teaching a large group of students, majority of the students score C or D grade (LK04). 
The poor monitoring could also be caused by lack of tutorials (UDE 18). The school no longer conducts tutorials due to the high student numbers, and inadequate classrooms and tutors (UDE 16). This seemed to have a big negative effect especially on quantitative courses where students perhaps needed closer consultations. One accounting lecturer emphasised this as follows:

All I would like to have is to have relevant tutorials; a situation where every lecture is followed by tutorials to back up lectures (LK11).

In addition to the lack of tutorials, the school lacked a consultation unit to support students with learning (UDE17). Despite that, the school continued to admit what lecturers perceived as academically weak students (due to varied admission criteria, perhaps driven by the need for more funds). Indeed, such students would be seen as 'academic orphans' whose search for academic help is not welcome even by their lecturers. Indeed, lecturers avoided them as the following comment affirms.

The large number of students limits interactions, causing you to feel detached from them. However, we do not encourage the interaction because due to large numbers, you would be overwhelmed (LK 03).

Thus, failure to provide learning support for students would cause some students to indulge in academic malpractices. As a result, many students fail to perform their academic work effectively (UDE 19) and consequently they failed to get the necessary knowledge and skills (UDE 25). Eventually, the lecturers' goal of imparting students with relevant knowledge and skills (UDE 27) is not always achieved, as is summarised by the following statement.

\begin{abstract}
We will be producing half-baked graduates. Because when I give an assignment to a student, when I mark, I am assuming that that is that student's work. The exam at least will be supervised to ensure that whatever you have written is your work. But you see there is the component of the course work. Student then scores very high course-work, which can boost the grade. Some students even hire people to come and do for them the exam, so we have caught very many. We have caught people and taken them to police station for coming to impersonate others. So these are lazy students. So ideally, what this does is that at the end of the day you have not achieved your objective, which was to impart knowledge and yet you have certified somebody that s/he has a grade and yet s/he doesn't (LK09).
\end{abstract}

\title{
2. There is lack of necessary coordination within the school
}

The lack of necessary coordination within the school (UDE 29) is identified as the second root cause. It leads to a lack of trust amongst academic staff themselves, and amongst academic staff and administrators (UDE 6). This then leads to a situation where there is no teamwork within the school. The lack of coordination together with the limited government funding then leads to a situation where there is little staff development and support (UDE 12). The lack of 
teamwork is attributed to suspicion amongst the academic staff themselves, and amongst academic staff and administrators. One lecturer had this to say:

The greatest problem with HE in Africa is that there is a lot of suspicion. People do not seem to believe that if I am left to grade, I will be objective. Somebody else must come around and make sure that I am doing the right thing and so on. That suspicion is what I'm against. We should believe that people are responsible. There should be more trust. That is one change that I would really want. More trust. (LK08).

Another lecturer observed that:

Administration causes this. They do not want to see lecturers walking together as a block talking the same thing, singing the same song. No! They want to see everybody walking this way that way in total disarray! They want to set you \{lecturers\} against one another! (LK05).

Yet another felt that:

Departmental chairs have not made an effort to help lecturers work as a team (LK04).

The lack of teamwork and the institutional culture might also indicate a lack of effective engagement with research and practice (UDE 22) leading to a lack of integration between theory and practice (UDE 26$)^{8}$, as the following statements confirm:

In teaching, we need to make research an integral part of teaching and disseminate that research knowledge to parties or audiences of that research. There is also the need for engaging lecturers in conferences and other areas where they can share ideas with fellow researchers, which, I think is not very effectively done (LK10).

...institutional culture of teaching that does not promote research, meaning that it is not easy to generate knowledge because anybody brought in is inducted into teaching many classes (LK06).

Thus, the lack of effective integration between theory and practice in teaching is attributed to a lack of effective engagement with research and limited training on pedagogy (UDE 13), which are attributed to limited staff development (UDE 12) (mentioned earlier). Indeed, in addition to high student numbers and limited facilities, the lack of pedagogical training for lecturers is implicated for the ineffective involvement and engagement of students in learning. On pedagogy, lecturers observed that:

The university does not have any program to train lecturers on how to deliver, prepare content, mark exams, distribute marks, etc. Since I joined the university, I have not seen such a program (LK 04).

\footnotetext{
${ }^{8}$ Another reason could be that since there are not enough lecturers in the school, and then if lecturers are involved in industrial research, it would mean a reduction of the number of lecturers and this could worsen the situation. Perhaps involving practitioners to teach (when lecturers are involved in industrial research) could ameliorate this situation.
} 
Notwithstanding, the ineffective involvement and engagement of students in learning would also be attributed to the design of the program that is seen as 'not relevant' to the market needs and to a lack of the teaching goals that seemed unclear to lecturers. The following phrases affirm:

$\{$ There is a need to ensure the relevance of what we are teaching. Need for constant change in curricula or the course content to ensure relevance in terms of 'what the market wants'. On quality, sometimes you wonder whether students are really getting what they are supposed to get (LK 12).

We also need to know how to achieve these goals of higher learning. What we are given are the overall university goals. In teaching, there are specific ones that we should be made aware of. But here specific teaching goals are lacking (LK03).

Moreover, some lecturers felt that involving the industry would move L\&T from theoretical to practical perspectives.

...involve industry and move teaching from book based to practical teaching (LK 06)

Internships for students would allow them to internalise their classroom experiences and relate them to the industrial application (LK12).

Thus, if the program is not effectively reviewed to reflect the L\&T goals, then students might not be effectively involved and engaged leading to a lecturer-centred and to a theoretical approach to L\&T (UDE 26). Such approaches are not likely to impart students with relevant knowledge and skills (UDE 27).

\subsubsection{Synthesis of UNSB lecturers' views}

From the above discussions, we can derive four basic issues that seem to characterise the L\&T system in lecturers' views:

i. The L\&T appears to be capacity constrained in terms of L\&T facilities, equipment, infrastructure (power failure) and shortage of staff. These factors seem to limit the school's ability to achieve the L\&T system goal. As will be discussed later, some of the measures to exploit such constraints might include re-defining semester/trimester intakes (student numbers) and cross-training of staff and students.

ii. Specific sub-system level (School of Business) teaching goals are not clear. One lecturer observed... What we are given are the overall university goals. In teaching, there are specific ones that we should be made aware of. But here specific teaching 
goals are lacking (LKO3). This might imply the need for making the teaching goals more explicit at the program level.

iii. The school's culture appears to be characterised by mistrust and suspicion amongst academic staff, and amongst academic staff and the administrators of the school. Such mistrust might be attributed to a lack of training (staff development and support), which might imply that lecturers might not be 'trusted to do the right thing'. This mistrust then tends to make lecturers experience 'a lack of academic freedom'. Moreover, the culture places more emphasis on the teaching aspects of learning, without training lecturers to teach though. Research seems to have a periphery value.

iv. The level of students' participation in the generation of knowledge or as co-producers of knowledge is low. Although low level of students' participation in large classes is a common phenomenon in HE institutions across the globe, within this context, it might be attributed to two main factors: First, the lecturers' consensus goal of teaching of 'imparting knowledge, skills, and attitudinal change to learners' might imply that the teachers are the ones who deliver the knowledge. This is perhaps best expressed by one lecturer who noted that: ...but the way we teach, we are just imparting knowledge but we are not learning from the students (LK03). The teaching seems to be about transferring information from the lecturers to students. Second, the traditional African culture of seniors detesting any 'questioning of their knowledge' by the juniors would make students 'shy' away from contributing to knowledge.

v. Lecturers seem to be overworked because of teaching many extra classes for extra income. This might indicate that their personal goals are to 'make more money'. That would mean that in order for them to make more money, they would need to teach many extra classes. Needless to say, in order for them to be able to teach many classes, they would have to simplify L\&T processes through measures such as shallow coverage of syllabi, giving few simple tasks/assignments, giving group tasks rather than individual tasks, providing less time for consultation, and recycling teaching materials, tasks, and assessments. Such measures would contradict any improvement efforts.

Thus, in order to improve the performance of the L\&T system, it would be good to surface the assumptions behind such practices in an effort to resolve the dilemmas that lecturers might be facing. The assumptions might not only provide a basis for understanding the necessary 
changes that are sufficient to achieve the desired situation but might also improve alignment of the L\&T system and possibly reduce resistance to change.

\subsubsection{Summary of UNSB lecturers' analysis}

This subsection has reported on lecturers' perspectives of their teaching goal, the critical success factors for achieving the goal, and the necessary conditions needed to achieve the critical factors. A consensus goal of 'imparting knowledge, skills, and attitudinal change to learners' is identified. Three critical success factors were also identified, namely: adequate and modern L\&T facilities and resources, adequate, skilled and motivated manpower (academic \& support), and highly capable and willing students. In addition, two levels of necessary conditions were identified. The first level indicates need for adequate funding, robust and open hiring system for academic staff, staff development and support, realistic workload, student involvement and support, and stringent admission criteria. The second level indicates need for increment of government funding, attraction of other funds, effectiveness of trainings (including conferences and exchange programs) and industrial involvement, and change of policy on workload.

The subsection provides an in-depth analysis of the current reality of the undesirable effects affecting their teaching experiences. The analysis identifies two critical root causes of the undesirable situation: the limited government funding and a perceived lack of coordination within the school. The resolution of the dilemmas behind these two root causes is demonstrated in Chapter 8.

The last two sub-sections have provided the students' and lecturers' perspectives of learning and teaching experiences. In order to have a holistic view of UNSB's L\&T system, the next sub-section provides an analysis of administrators' views of the L\&T experiences. 


\subsection{UNSB administrators' data analysis}

In this sub-section, a description of administrators participants is provided. The subsection also provides an identification of the learning and teaching goal as well as undesirable issues impacting on L\&T.

\subsubsection{Description of UNSB administrator participants}

The organisational chart of UNSB was used to identify administrative participants of this study. These are: the Dean, Associate Dean-Undergraduate Studies - who is also an assistant to the Dean, the three chairs of the three departments of the school (Departments of Business Administration, Management Science, and Finance and Accounting), and the coordinator of the BCom program. Based on the specific nature of this study, other pertinent administrators were envisaged. They are: the Assistant Registrar-who is also a senior administrative assistant and compliments administrative functions of the school, the Director of Quality Assurance (DQA), and the Assistant Dean of Students (the post for Dean of Students is not there). The DQA's position is a university level position, not a school level position. By coincidence, the present director is a full time lecturer of quality management at UNSB and only works as a director on a part-time basis. Six administrators were interviewed. Their years of experience in their current administrative positions ranged from one year to ten years as shown in Figure 5.10 .

Figure 5.10: Years of administrative experience of UNSB administrators

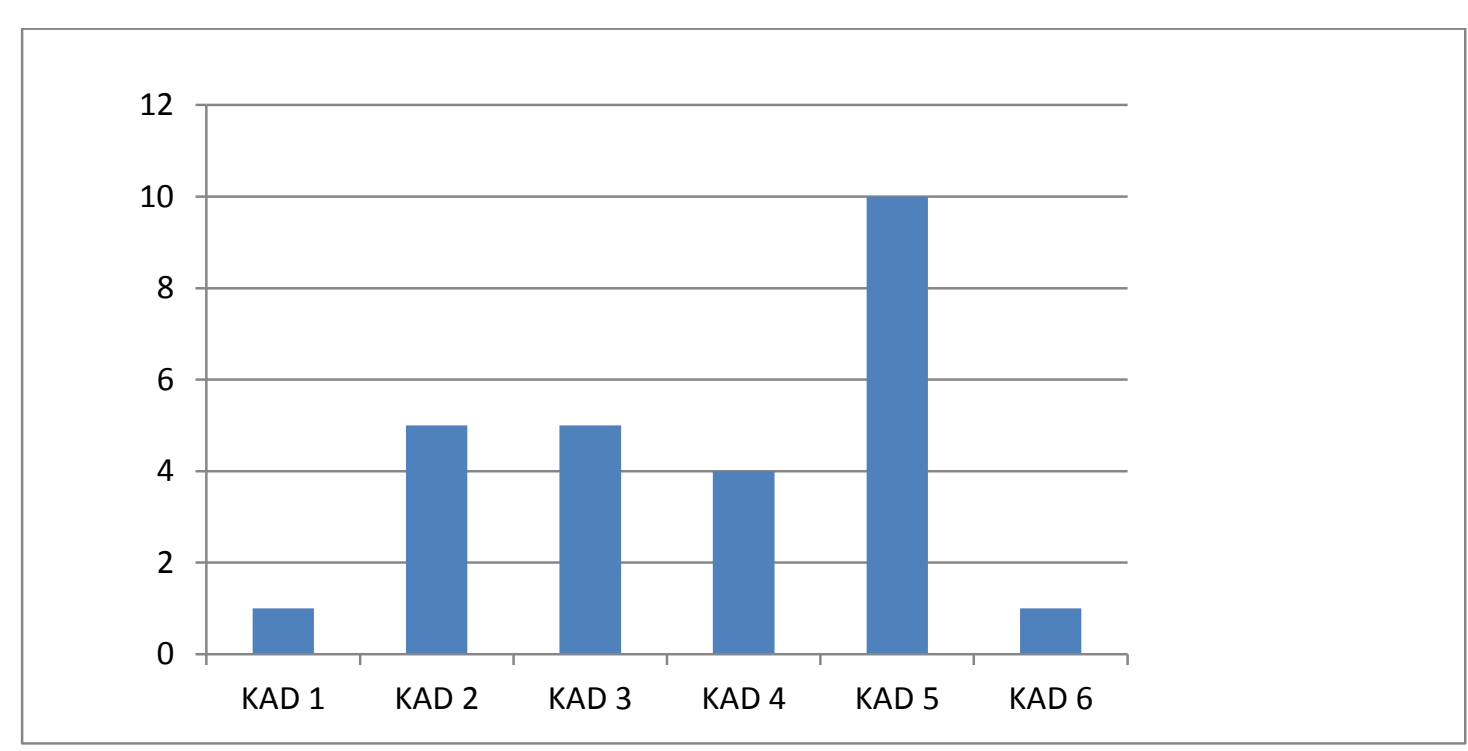


As would be expected of an educational institution, some of the administrators had combined experiences of teaching and administrative work. Interview data also reveals that their professional qualifications appear to fit well within the respective positions that they held or headed. Two of the administrators had achieved academic awards while one had achieved international profession recognition.

All interviews were conducted in the respective administrator's offices in Lower Kabete, except one for the DQA that was held in his office at Kenya Science. The interview time ranged from 36 minutes to 96 minutes.

Figure 5.11: Interview time in Minutes for UNSB administrators

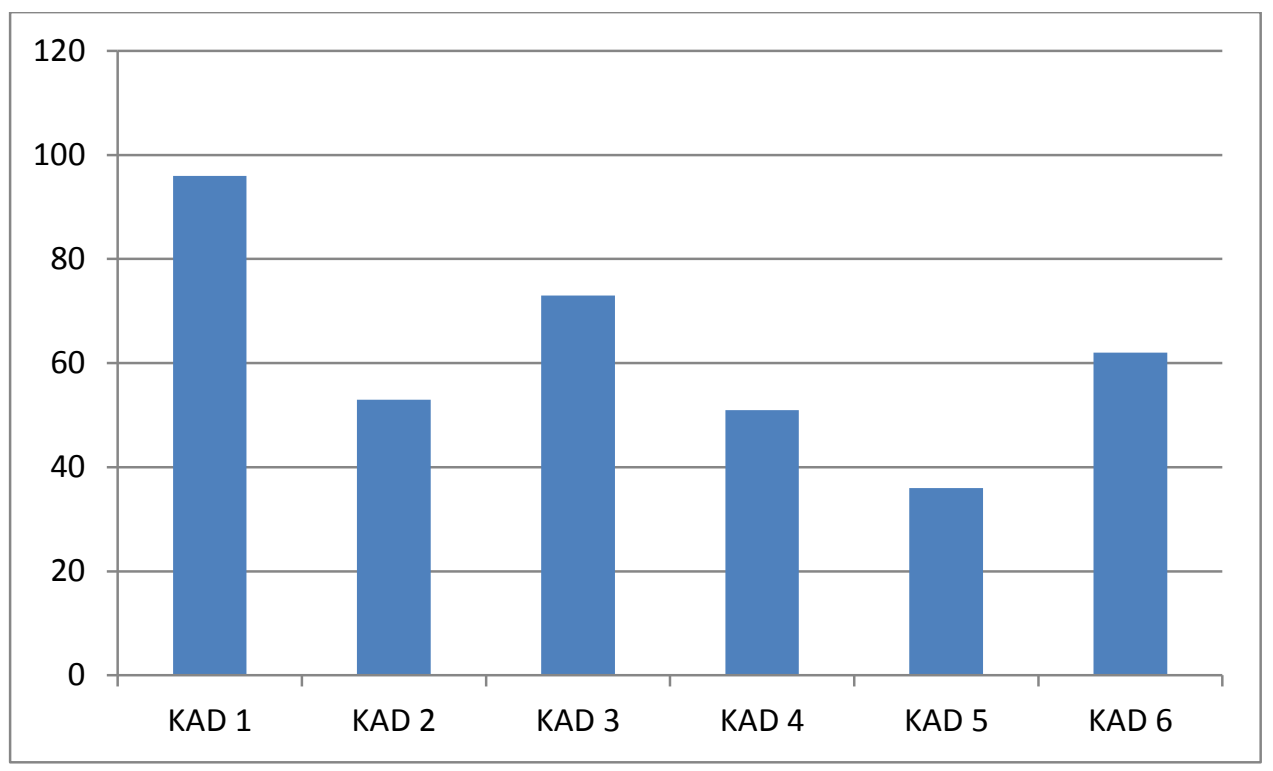

\subsubsection{Identifying UNSB administrators goal, CSFs, and NCs}

\section{Articulating a common goal}

The administrators were asked about the goal of teaching and learning in HE, specifically relating this to UNSB. Their responses seem to be largely shaped by the positions that they hold and their experiences. Table 5.16 provides their verbal descriptions of the goals. Unitisation of the italic phrases is used in order to articulate a 'common goal' of 'preparing well-rounded, knowledgeable, and productive students for modern society'. 
Table 5.16: UNSB administrators' goal descriptions

\begin{tabular}{|c|c|c|c|c|c|}
\hline KAD01 & KAD02 & KAD03 & KAD04 & KAD05 & KAD06 \\
\hline $\begin{array}{l}\text { Improving mankind. If I can } \\
\text { produce a student who can } \\
\text { go and run an industry at } \\
\text { whatever level and run it } \\
\text { productively, I will have } \\
\text { contributed to higher } \\
\text { income in the country. We } \\
\text { derive this thinking from the } \\
\text { definition of quality in terms } \\
\text { of value. Every time we } \\
\text { produce a dead-end person, } \\
\text { the society loses. Lower } \\
\text { productivity means higher } \\
\text { poverty. By teaching \& } \\
\text { designing good curricula, } \\
\text { we improve the society. }\end{array}$ & $\begin{array}{l}\text { Getting } \\
\text { appropriate } \\
\text { product or } \\
\text { output for } \\
\text { the } \\
\text { consumer } \\
\text { who is the } \\
\text { society and } \\
\text { the } \\
\text { employer. } \\
\text { The ripe } \\
\text { product, } \\
\text { somebody } \\
\text { who can do } \\
\text { it. }\end{array}$ & $\begin{array}{l}\text { One to prepare them well, one } \\
\text { to teach them well for they } \\
\text { become well-rounded } \\
\text { persons in terms of their } \\
\text { intellectual development, } \\
\text { even conceptual and } \\
\text { personal development. So } \\
\text { that they become like members } \\
\text { who understand, who are } \\
\text { comfortable with the modern } \\
\text { society. They can find their } \\
\text { way round, at good level of } \\
\text { interaction. The second one } \\
\text { will be of course to impart to } \\
\text { them knowledge and skills } \\
\text { which will be useful for } \\
\text { making a living }\end{array}$ & $\begin{array}{l}\text { I think it is } \\
\text { basically to } \\
\text { deliver the } \\
\text { knowledge, to } \\
\text { impart } \\
\text { knowledge to the } \\
\text { learners. Practical } \\
\text { knowledge that } \\
\text { can help them to } \\
\text { move to their next } \\
\text { levels. Basically. } \\
\text { Delivering } \\
\text { knowledge that is } \\
\text { practical, that is } \\
\text { relevan t to them } \\
\text { and in the } \\
\text { market. }\end{array}$ & $\begin{array}{l}\text { Basically this is } \\
\text { to disseminate } \\
\text { knowledge, } \\
\text { basically it is } \\
\text { knowledge to } \\
\text { equip people } \\
\text { with } \\
\text { knowledge so } \\
\text { that they are } \\
\text { able to use } \\
\text { that knowledge } \\
\text { either in } \\
\text { employment or } \\
\text { even in getting } \\
\text { to self- } \\
\text { employment }\end{array}$ & $\begin{array}{l}\text { To bring up a whole-round } \\
\text { formed professionals } \\
\text { because they are here to } \\
\text { receive training not only } \\
\text { academically but also teach } \\
\text { them by role models, you } \\
\text { know like by having them } \\
\text { to eat well, we are also } \\
\text { giving them some skills } \\
\text { already as they go out they } \\
\text { will be well equipped in } \\
\text { that area, if they are } \\
\text { sleeping in nice places, we } \\
\text { will be helping them to } \\
\text { learn to be organised in } \\
\text { their places. }\end{array}$ \\
\hline Common goal & \multicolumn{5}{|c|}{ To prepare well-rounded, knowledgeable and productive students for modern society } \\
\hline
\end{tabular}

\section{Determining CSFs and NCs}

The critical success factors (CSFs) and the necessary conditions (NCs) identified by the administrators are shown in Table 5.17. The CSFs are labelled as CSF1, CSF2 or CSF3 as they appear in the goal tree Figure 5.13. Most of the CSFs turned out to be NCs during the unitisation and labelling process. Three CSFs were identified as appropriate design of the academic program (CSF1), adequate academic and social support resources and standards (CSF2), and highly qualified and talented students (CSF3). These CSFs were broadly labelled to accommodate the broad goals of the administrators.

Thus in labelling and unitising the first CSF, for instance, we construe the logic as follows: In order to have an appropriate design of the academic program, then we need to [must] develop systems for communicating with industry and customer groups, develop systems for linking the voice of the customer, convert customers' needs into a curricula feature, follow appropriate processes in syllabi development, and develop policies to interact with the industry. Accordingly, administrators identified many factors, which have implications for the design of the curricula. They include limited stakeholder involvement, linkages with industry, and practical exposure. Such variables were categorised as NCs under one CSF. 
Table 5.17: Identifying CSFs and NCs of UNSB administrators

\begin{tabular}{|c|c|c|}
\hline Staff & Critical success factors & Necessary conditions \\
\hline KAD01 & $\begin{array}{l}\text { Societal need for knowledge, skills \& competence (NC1) } \\
\text { Curricula design process (NC1) } \\
\text { Measurement of what is delivered }\end{array}$ & $\begin{array}{l}\text { Develop system for communicating with industry and customer groups (CSF1) } \\
\text { Identify different customer groups (CSF1) } \\
\text { Develop system for linking hard-wiring the voice of customers (CSF1) } \\
\text { Convert customers' needs into a curricula feature (CSF1) } \\
\text { Develop sensors (e.g. on the type of data records such as pass rate) (CSF1) } \\
\text { Process capability index or measures }\end{array}$ \\
\hline KAD02 & $\begin{array}{l}\text { Appropriate syllabus (CSF1) } \\
\text { Adequate transmission standards (CSF2) } \\
\text { Involvement of stakeholders in the process of training (NC1) }\end{array}$ & $\begin{array}{l}\text { Follow appropriate process in syllabus development (NC1) } \\
\text { Proper staffing (NC2) } \\
\text { Adequate facilities (NC2) } \\
\text { Willing learners } \\
\text { Guest speakers (NC1) } \\
\text { Industrial demonstrations (NC1) } \\
\text { Attachments/ internships (NC1) }\end{array}$ \\
\hline KAD03 & $\begin{array}{l}\text { Admit right students (NC3) } \\
\text { Teaching and training (NC2) }\end{array}$ & $\begin{array}{l}\text { Admission criteria to allow for more diversity (e.g. Athletics) (CSF3) } \\
\text { Additional funding and scholarships } \\
\text { Creativity in admitting students on a case by case basis to bring in diversity (CSF3) } \\
\text { Adequate resources (by focusing and prioritising resources for classrooms) (NC2) } \\
\text { More assistants to support lecturers (NC2) } \\
\text { Better teaching and learning infrastructure (NC2) } \\
\text { Manage marking and exam process in a better way } \\
\text { Hire lecturers who like work and are specialists and like reading widely (NC2) } \\
\text { Improve salaries } \\
\text { Promotion criteria should reflect real quality } \\
\text { Lecturers need to do consultancy and research (NC2) }\end{array}$ \\
\hline KAD04 & $\begin{array}{l}\text { Linkages with the industry (NC1) } \\
\text { Learning facilities (NC2) } \\
\text { Entry criteria for students (CSF3) }\end{array}$ & $\begin{array}{l}\text { Lecturer motivation to attend conferences \& publish (NC2) } \\
\text { Facilities (computers, offices) (NC2) } \\
\text { Ensure high qualifications at hiring (NC2) } \\
\text { Develop policies to interact with the industry (CSF1) } \\
\text { Sufficient time in the academic calendar for industry attachments (CSF1) } \\
\text { Coordinator to link industry and the school (NC1) } \\
\text { Field visits } \\
\text { Proper maintenance of facilities (space, computers, classrooms) (NC2) } \\
\text { Admit sufficiently qualified students (NC3) }\end{array}$ \\
\hline KAD05 & $\begin{array}{l}\text { Theoretical Knowledge or classroom learning (NC2) } \\
\text { Practical and industrial exposure/ Knowledge (NC1) } \\
\text { Extra-Curricular activities (NC2) }\end{array}$ & $\begin{array}{l}\text { Resource persons/instructors to be knowledgeable instructors (NC2) } \\
\text { Access to library and e-materials (NC2) } \\
\text { Interactions with industries to allow for Internship opportunities (NC1) } \\
\text { Good recreational facilities (e.g. indoor/outdoor games) ((NC2) } \\
\text { Trips to other university environments (NC2) }\end{array}$ \\
\hline KAD06 & $\begin{array}{l}\text { Teamwork (NC2) } \\
\text { Students' welfare (NC2) }\end{array}$ & $\begin{array}{l}\text { Commitment (e.g. from lecturers by keeping time) (NC2) } \\
\text { Being mindful and use of appropriate words for guiding students } \\
\text { Not self centred, mindful of university wellbeing } \\
\text { Frequent joint meeting between academic and other departments (NC2). } \\
\text { Team building activities and workshops (NC2) } \\
\text { Fast procurement and payment of suppliers } \\
\text { Alternative options of supplies } \\
\text { Devolution of funds and power }\end{array}$ \\
\hline
\end{tabular}

In order to capture an 'all-rounded' aspect in the goal, CSF2, is broadened as 'Adequate academic and social support resources and standards. The 'standards' would imply the quality guidelines for those resources. For instance, in order to have qualified academic staff, then, what standards or guidelines would we follow? Moreover, the social support aspects of teamwork, students' welfare and extra-curricular activities are some of the NC variables that would perhaps fall under this factor. The third CSF is fairly simple: qualified and talented students. The administrators expressed concern for the quality of the students' admitted as follows: 'admit the right students...include additional parameters for those who have special skills such as athletics (KAD03), admit sufficiently qualified students (KAD04), willing students or a good learner, willing learner (KAD02)'. The NC under this factor is labelled as 
broad admission criteria to include the 'special skills' aspect. As in the case of CSFs, the NCs were labelled as NC1, NC2 or NC3 depending on the category under which they fit. The administrators' goal tree provides a summary of this description.

Figure 5.12: UNSB administrators' goal tree

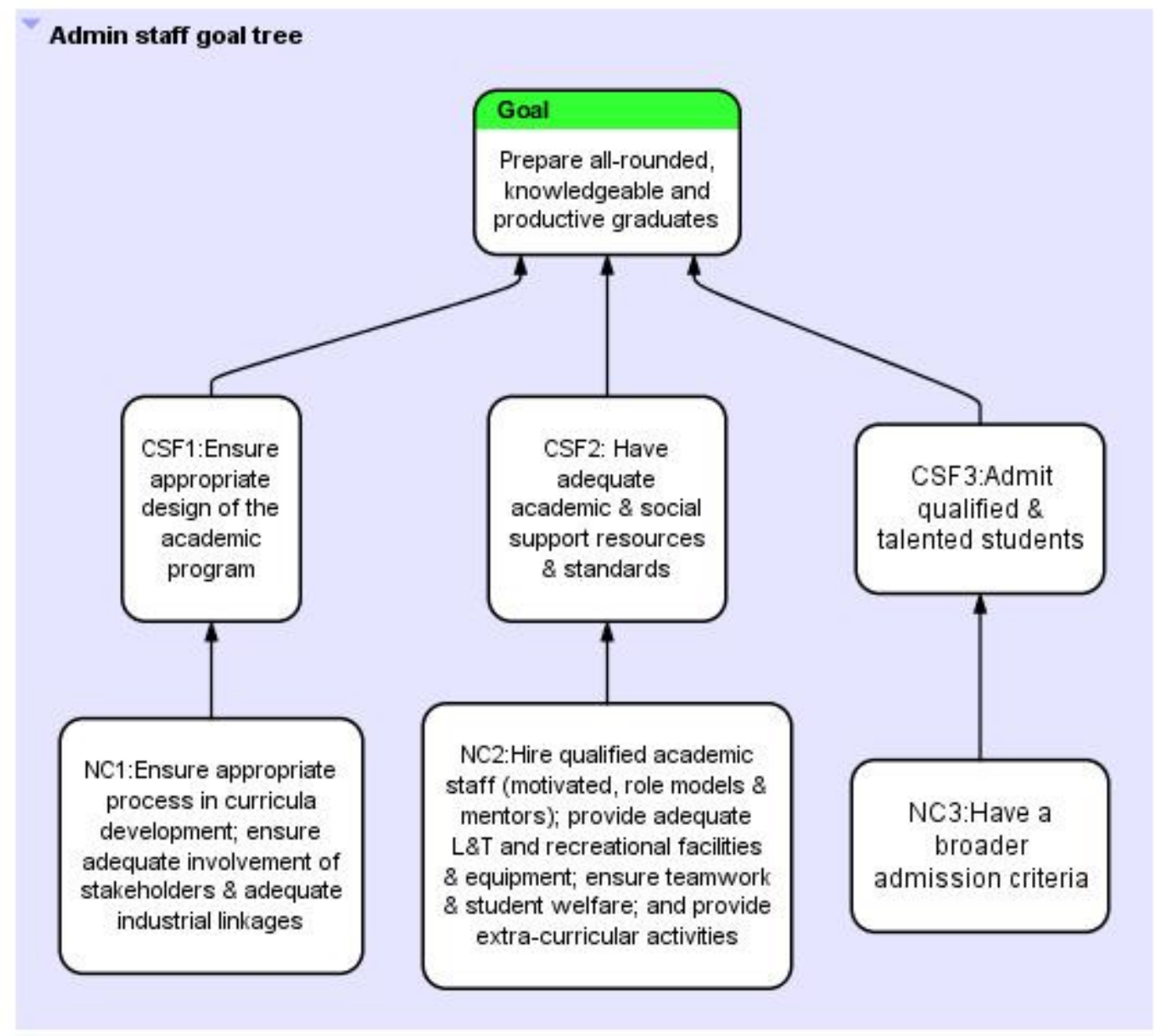

\subsubsection{Identifying UDEs that affect quality of L\&T experiences of UNSB administrators}

The analysis of administrators' data on dislikes and undesirable issues yielded many issues which in their view impacted on the quality of L\&T experiences. As indicated in earlier sections, these issues have been listed to simplify the identification of the actual UDEs whose cause-effect relationships is then depicted in the form of a focused current reality tree (fCRT). 
Table 5.18: Issues impacting on quality of L\&T experiences of UNSB administrators

\begin{tabular}{|c|c|}
\hline & Issues impacting on quality of L\&T experiences of UNSB administrators \\
\hline & Lecturer-issues \\
\hline 1 & Some lecturers are not performing well (just stay waiting retirement) \\
\hline 2 & Many lecturers are not in touch with industry \\
\hline 3 & The salaries for lecturers are low \\
\hline 4 & The school does not attract quality lecturers \\
\hline \multirow[t]{2}{*}{5} & There is a problem of staff shortage \\
\hline & Lecturer support \\
\hline 6 & The public address systems (PAS) are not there in all the lecture halls \\
\hline 7 & Financial support for participation in international conferences for lecturers is limited \\
\hline 8 & The classroom experience is not well managed \\
\hline \multirow[t]{2}{*}{9} & The support for lecturers is lacking \\
\hline & Students issues \\
\hline 10 & L\&T infrastructure (physical facilities \& library materials) are inadequate for students \\
\hline 11 & Some students are not motivated to learn (unwilling learners) \\
\hline 12 & Some students are academically weak \\
\hline 13 & Some students have poor drinking habits \\
\hline 14 & Most promises made to the students are not implemented \\
\hline \multirow[t]{2}{*}{15} & Most student leaders are demoralised \\
\hline & Student services \\
\hline 16 & Students' food lacks variety \\
\hline \multirow[t]{2}{*}{17} & The students' Shopping Centre 'comrades' does not offer a variety and quality products and services \\
\hline & Examination \& marking processes \\
\hline 18 & The marking process is not well managed \\
\hline 19 & There are cases where students complaining about their marks \\
\hline 20 & The exam process is not well managed \\
\hline \multirow[t]{2}{*}{21} & Sometimes marking is delayed \\
\hline & Malpractices \\
\hline 22 & There are some incidents of plagiarism \\
\hline \multirow[t]{2}{*}{23} & There are some incidents of cheating \\
\hline & Industrial involvement $\&$ linkages \\
\hline 24 & There are no industrial attachments \\
\hline 25 & There are no industrial linkages \\
\hline \multirow[t]{2}{*}{26} & There is no practitioners' involvement in the training of the learner \\
\hline & Bureaucracy \\
\hline 27 & The procurement processes are slow \\
\hline 28 & The recruitment process is extremely bureaucratic \\
\hline 29 & The approval process for curriculum review is slow (it does kill morale of people) \\
\hline 30 & The bureaucratic structure delays revision of our curriculum \\
\hline
\end{tabular}




\begin{tabular}{|c|c|}
\hline & Issues impacting on quality of L\&T experiences of UNSB administrators \\
\hline \multirow[t]{2}{*}{31} & The school is not autonomous \\
\hline & Structure \& policies \\
\hline 32 & The institutional structure does not have a mechanism for vetting lecturers who are not performing \\
\hline 33 & The committee system of hiring is not effective \\
\hline 34 & There is poor monitoring of students' performances \\
\hline 35 & There is no system of vetting the quality of papers published \\
\hline 36 & Policies and guidelines for linking up with the industry are not there \\
\hline 37 & The university calendar does not allow for breaks \\
\hline 38 & The admission criteria is not stringent \\
\hline 39 & The student-lecturer ratio is not good \\
\hline \multirow[t]{2}{*}{40} & The Module II program creates unbalanced life for the lecturer \\
\hline & Fire-fighting meeting \& top management \\
\hline 41 & The senior university management are not available at school level \\
\hline 42 & There are too many unscheduled meetings \\
\hline 43 & Senior management is doing a lot of fire fighting \\
\hline 44 & The meetings are not productive (they make us tired all the time for very little output) \\
\hline \multirow[t]{2}{*}{45} & $\begin{array}{l}\text { The meetings divert our energy (I would be planning for a workshop for lecturers); any developmental effort } \\
\text { is extremely difficult (e.g. curriculum review) }\end{array}$ \\
\hline & Culture \\
\hline 46 & There is laxity of some employees in implementing ideas \\
\hline 47 & There is disgruntlement amongst employees \\
\hline \multirow[t]{2}{*}{48} & The culture of excellence or a desire for excellence is not there \\
\hline & Time poor \\
\hline 49 & There is not sufficient time to mark \\
\hline \multirow[t]{2}{*}{50} & The is no sufficient time to prepare for classes \\
\hline & Interactions \\
\hline \multirow[t]{2}{*}{51} & There is no close interaction between academic staff $\&$ the administrative support staff \\
\hline & Quality assurance \\
\hline 52 & ISO does not focus on the unique work of a university \\
\hline 53 & We are working more like a production line than an academic institution \\
\hline 54 & ISO does not focus on accreditations \\
\hline \multirow[t]{2}{*}{55} & The skills level on quality is low \\
\hline & Maintenance \\
\hline 56 & Some facilities are not well maintained \\
\hline 57 & Some breakages take a long time to be fixed \\
\hline
\end{tabular}

Similar to earlier sections, the following UDEs were identified using protocols for stating UDEs. 
Table 5.19: UNSB administrators' UDEs

\begin{tabular}{|c|c|}
\hline 1 & There are delays in hiring lecturers \\
\hline 2 & Bureaucratic system of UoN \\
\hline 3 & Bureaucratic delays \\
\hline 4 & There are delays in establishing memoranda of understanding with stakeholders \\
\hline 5 & Industrial linkages are not effectively created \\
\hline 6 & The approval of curricula review often takes long or is not granted \\
\hline 7 & There is limited government funding \\
\hline 8 & The school admits high number of Module II students every trimester \\
\hline 9 & The salaries for lecturers are not attractive \\
\hline 10 & It is difficult to attract quality academic staff \\
\hline 11 & There is shortage of academic staff \\
\hline 12 & Most lecturers have heavy teaching \& marking load \\
\hline 13 & Some L\&T facilities \& equipment are not adequate \\
\hline 14 & There is no program requirement for industrial attachment or internship \\
\hline 15 & There are no semester breaks \\
\hline 16 & Most students do not go for internships \\
\hline 17 & Most lecturers are not in touch with industry \\
\hline 18 & External stakeholders are not adequately involved in the curriculum review $\&$ training \\
\hline 19 & The curricula is not up to date \\
\hline 20 & Most lecturers feel overworked \\
\hline 21 & Some lecturers' perform their teaching work is less effectively \\
\hline 22 & Many lecturers stagnate in their PhD work \\
\hline 23 & The quality of L\&T is not adequately improved \\
\hline 24 & Most lecturers do not engage in research \\
\hline 25 & Theory \& practice are not effectively linked in L\&T \\
\hline 26 & Most students do not get practical knowledge \& skills \\
\hline 27 & Some unproductive or unripe graduates are produced \\
\hline
\end{tabular}

Key: \begin{tabular}{|l|l|}
\hline Intermediate effect & Precondition \\
\hline
\end{tabular}

\subsubsection{Identifying 'root causes' of UNSB administrators UDEs}

In order to identify the root causes, the UDEs in Table 5.19 are logically connected to form a $f C R T$ (Figure 5.13). The analyses using the fCRT revealed two critical root causes of the undesirable situation at UNSB, in administrators' views. These are:

1. Bureaucratic system of the university

2. Limited government funding

\section{Bureaucratic system of the university}

The bureaucratic system of the university (UDE 2) appears to affect the school in two ways. First, it causes delays (UDE 3 ) that affect the academic, administrative, and social welfare of 
students. From an academic standpoint, the bureaucratic processes delay the approval process of the program review (UDE 6) causing the program to be very slow to update (UDE 19).

Last year we were to do a workshop to revise our curriculum... but were told that we couldn't go ahead because of some constraints in central administration ...we couldn't do the workshop. If the approval process for curriculum is slow, it does kill morale of people (KAD 03).

\section{Figure 5.13: UNSB administrators' $f$ CRT}

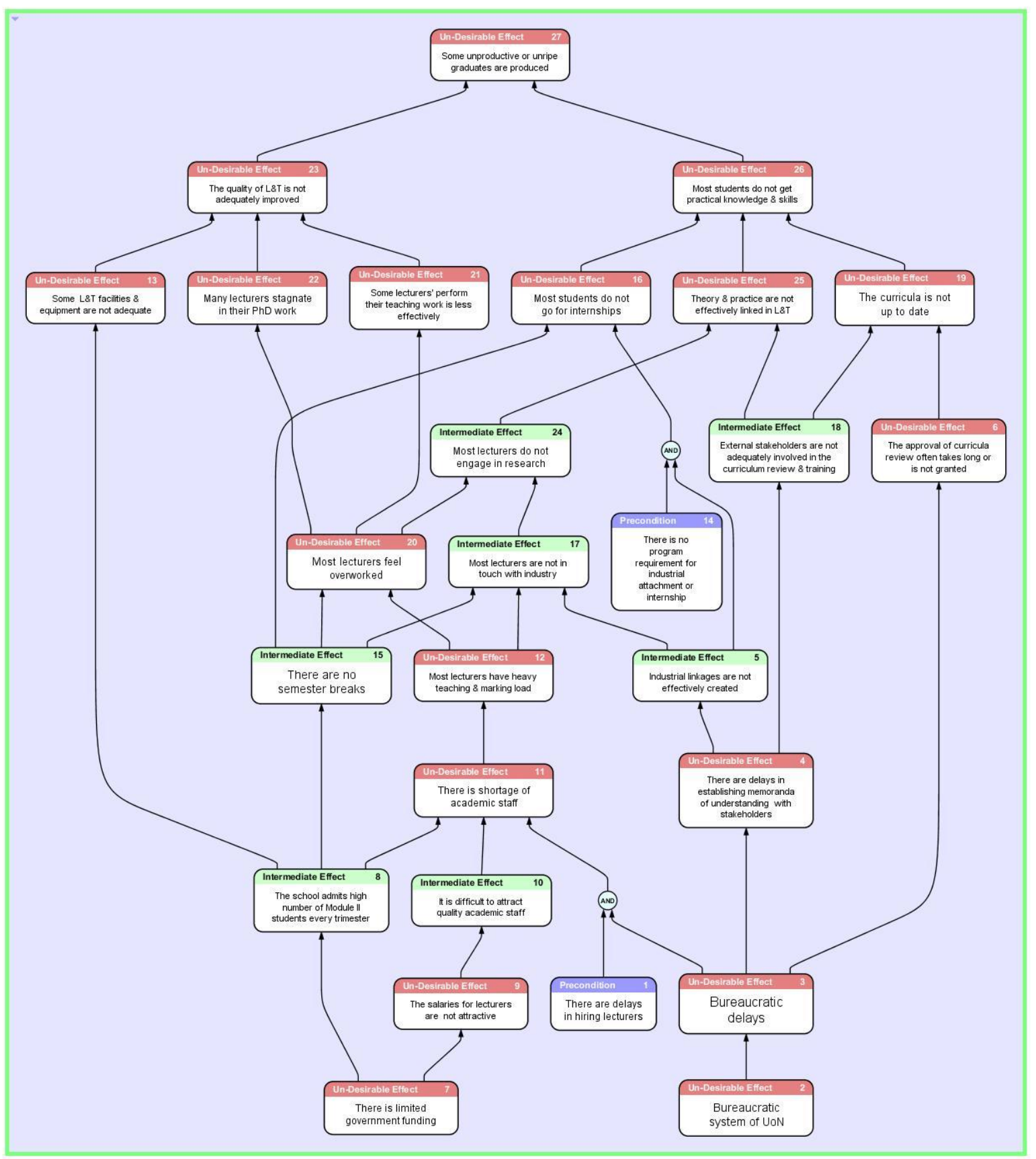

On the administrative aspect, bureaucracy appears to cause delays and inefficient delivery of the L\&T service.

... you find that in our case the college of humanities is quite big in terms of student numbers, staff, and also the geographical spread so that it brings issues of bureaucracy. When you want something done and 
done immediately you would have to make a few trips to the Main campus where our central office is, to the principal's office. That has been a quite a challenge...Like now if you needed some money for whatever use in this school you would have to liaise with the Main campus... Making the school autonomous or independent to enable those services of finance, administration much faster...Because of the challenges of bureaucracy in procurement, procurement has always been a challenge (KAD 05).

... the rigidity in terms of processing say financial commitments where you want something and then bureaucracy is very rigorous. As a school, let's say we generate funds but the funds are not with us, they are out there. And therefore I may need a very basic thing, although my (department or school) accounts have money, but I cannot use that money. It will take a long time and all that... There is a lot of bureaucracy. It is very difficult to get... it has to go through a lot of endorsements... before it eventually gets here it will be a month or later. So slow processing basically (KAD 04).

On the social aspects, bureaucracy appears to affect the health and well-being of students.

The major gap at the moment is that we have a problem with our catering and accommodation departments. The food that students are getting right now is not good. By not good I mean no variety. For example I know for some time they have lacked meat in the students' cafeteria, which is being associated with the procurement process. And in the hostels breakages can stay for long before they are fixed. That is an unhealthy environment where sanitations have poor maintenance... we need reduction of bureaucracy to enable efficient supply of what is needed. Sometimes, we are told that the suppliers have not supplied because they have not been paid. So we need faster procurement payment services to suppliers (KAD 06).

Secondly, bureaucracy tends to cause delays in establishing memoranda of understanding with stakeholders (UDE 4). As a result, external stakeholders are not effectively involved (Intermediate Effect 18). This might also explain why industrial linkages are not effectively created (IE 5).

And then the stakeholder involvement is almost not there... We need to have stakeholder meetings and seminars of some kind where we discuss and highlight the need of getting the students to do or be involved in practical work before they complete their degree programs. ... Because the stakeholders themselves do not take any initiative, then the initiative has to be from us (KAD 02).

The ineffective industrial linkages might also explain why many lecturers are not involved with industry (IE 17). Moreover, because the stakeholders are not involved in teaching, then the theory and practice do not seem to be effectively integrated in L\&T (UDE 25) and the critical factor of designing appropriate program is not met (UDE 19).

Stakeholder involvement has been met in the syllabus development because we involve them but not in the training of the learner. It is almost very little extent. So it is not met (KAD 02).

Moreover, there are no requirements for industrial attachment or internship for students (Precondition14). Furthermore, without semester breaks (IE 15), there would be no time for internship (UDE 16). This would therefore imply that students do not get practical experience.

The policies and guidelines should be put in place that enables us to link up with the industry. Because some of them really touch on us on memorandum of understanding $\{\mathrm{MoU}\}$ with those organisations. Sometimes we may not interact the way we would like because we do not have a laid down MoU on how we relate with the students. So MoU needs to be there but at a higher level. At a lower level providing for time for that is important. We may want interactivity but do we have the time allocated to the students to be able to interact with the industry? Let's say like our BCom, just like it was when you were here $\{18$ 
years ago , it is still the same, that we do not have any time, because we are left with only two weeks in a year, to allow students to go and stay out there. What we call industrial attachment. That one is out completely. So we have been trying to see if it is possible to allow for that officially (KAD 04).

Consequently, most students do not acquire the practical knowledge and skills (UDE 26) that administrators' desire that they would.

Practical knowledge that can help them to move to their next levels... We should be able to link the students with the industry so that they are practice-oriented (KAD 04).

The institution to have interactions with industries to allow for internship opportunities... for practical knowledge (KAD 05).

\section{Limited government funding}

Limited government funding would imply that UNSB does not provide attractive salaries for academic staff (UDE 9). Low salaries would explain why it is difficult to attract quality academic staff (IE, 10).

The salary it is not really good. For the beginning level it is poor. I have tried to recruit people and they refuse (KAD 03).

Limited funding also causes UNSB to admit high numbers of fee-paying students (module II) (IE 8) so as to cater for the deficit, yet facilities at UNSB are not adequate (UDE 13).

Occasionally facilities are inadequate; they are not enough for everybody (KAD 04)

In a situation where there are high numbers of students and few lecturers, lecturers would have a heavy workload (UDE 12). And since there are no semester breaks, such lecturers would be overworked (UDE 20) and inevitably have an unbalanced work-life. Although it is not mandatory to teach extra courses, lecturers feel the need to supplement their low incomes. However, they could also consider industrial consultations or research which could also enhance their academic careers. But, as the following comment affirms, the culture of research is not there.

One could do research and get the same benefits but that support for research is very weak institutionally so that if you are going to do research you will be really on your own largely and I think also School of Business culture has not been research oriented (KAD 03).

Without a research orientation within the school, most lecturers would not integrate the theory they teach with practice. Although the nexus between research and teaching is not always clear or positive (Hattie \& Marsh, 1996), a lecturer who conducts research would perhaps be more involved in the construction of knowledge and there would be some possibility of sharing that knowledge during teaching. Thus, where most lecturers are not engaged in research (IE 24) and others have remained stagnant in their PhD work (UDE 22) perhaps due to heavy workload, the quality of teaching suffers (UDE 23). Moreover, there are other lecturers within the system 
who would tend to perform less effectively (UDE 21) but the system tends to protect them through their terms of service, namely, permanent and pensionable.

\begin{abstract}
We need to also cultivate a culture of discipline in people who are not measuring up. We should not be afraid to sack people who are not performing or tell somebody this is bad. Right now it is not easy. It is now interpreted as tribal or personal and then the institutional structure doesn't really have a mechanism for vetting lecturers who are not performing. The permanent pensionable terms of service mean that some lecturers just stay waiting to retire but they are not performing. So they are like dead wood, they are very many. We need a way to somehow make them work or make them get out \{of the system \} in a nice way (KAD 03).
\end{abstract}

With such lecturers who are like 'dead wood', a program that is not up to date, without adequate academic support and with no practical exposure for students (UDE 26), then the school would tend to produce graduates who are not fully productive for the job market or 'half-baked graduates' (UDE 27).

\title{
5.5.5 Synthesis of UNSB's administrators $f$ CRT
}

The synthesis of administrators' $f$ CRT points to two basic issues within the system: bureaucracy and central administration. These issues appear to frustrate the administrators and leave them 'helpless'. Despite their efforts to make things effective, bureaucracy tends to slow the L\&T processes. Yet the central administration of UoN tends to have the final say in the operations of UNSB. Thus, although administrators see that some things are not working as desired; their hands seem to be tied. For instance, administrators desire that the BCom program is well linked with industry. But due to a bureaucratic need for memoranda of understanding with industrial partners, the process is delayed. They desire that the program is up to date to reflect the current and emerging practices; however, the program review is often delayed due to some constraints in the central administration.

The other dilemma that seems to frustrate administrators is the terms of employment: 'permanent and pensionable'. Even where employees tend to perform less well than expected, they are often protected by their terms of service.

... the permanent pensionable terms of service mean that some lecturers just stay waiting to retire but they are not performing... we will have to change the terms of employment to make sure people don't just decay... (KAD 03).

Other issues that seem to be beyond the administrators' control are the trimester system that seems to create 'unbalanced lives' of academic staff, the admission criteria that appears to bring in academically weak students and the limited staff development support within the school. These issues seem to make administrators empathetic but helpless about the situation in the school. 


\subsubsection{Summary of UNSB administrators analysis}

This sub-section has presented administrators' views of experiences of L\&T. The goal of L\&T is identified as 'to prepare all-rounded knowledgeable and productive students'. Administrators perceive appropriate design of academic program, adequate academic and social support services, and broader admission criteria as critical success factors for the achievement of L\&T goal. Moreover, they identify a vibrant curricular development process, qualified academic staff, adequate L\&T resources, and qualified and talented students as necessary conditions for the perceived critical success factors.

Various undesirable issues are identified as impacting on the experiences of L\&T. They include inadequate lecturers and academic infrastructure, and poor program linkages with industry. The analysis of undesirable effects identified two root causes: the bureaucratic system of the university and limited government funding. 


\subsection{UNSB within-case analysis}

This subsection provides a within-case analysis of the above three sub-sections. An amalgamation of the goal is provided. Similarities and differences impacting on the quality of experiences of L\&T from the three groups are drawn.

\subsubsection{Identifying L\&T goal, CSFs, and NCs of UNSB}

Figure 5.14 attempts to combine the goals of the UNSB students, lecturers, and senior administrative staff. The analysis of the goals indicates some similarities. The lecturers' goal has indications of 'imparting students with knowledge and skills', and the students' goals indicate the need for 'acquiring necessary business knowledge and skills'. Similarly, the need to develop a 'well-rounded' person is emphasised by students and administrative staff.

Interestingly, the three CSFs identified by lecturers and students are similar. The lecturers identified need to provide: (1) adequate and modern L\&T facilities and resources, (2) adequate, skilled and motivated manpower (academic \& support), and (3) highly capable \& willing students, while students identified need to provide: (1) adequate L\&T facilities and structures, (2) qualified committed and technology-savvy lecturers, and (3) self-disciplined and hardworking students. Likewise, one CSF of the administrative staff is similar to those identified by lecturers and students: adequate academic and social support resources and standards. A second CSF for administrative staff of qualified and talented students is absorbed under the CSF for 'capable and willing students' while the third is included as a fourth CSF in the common goal- appropriate design of the academic program. The high coincidence in articulation of the CSF indicates a common agreement on the parts of L\&T that are required.

Some of the NC factors included in the common goal tree are also identified as root causes in the CRTs. This might suggest that despite their perceived importance in achieving the L\&T goal, they are not presently being met. In a nutshell, a common agreement on the importance of the CSFs and the NCs among the three groups might suggest that any improvement efforts by school related to these factors could easily be supported though it would not necessarily be easy to decide on implementation. 
Figure 5.15: Combined goal tree of UNSB

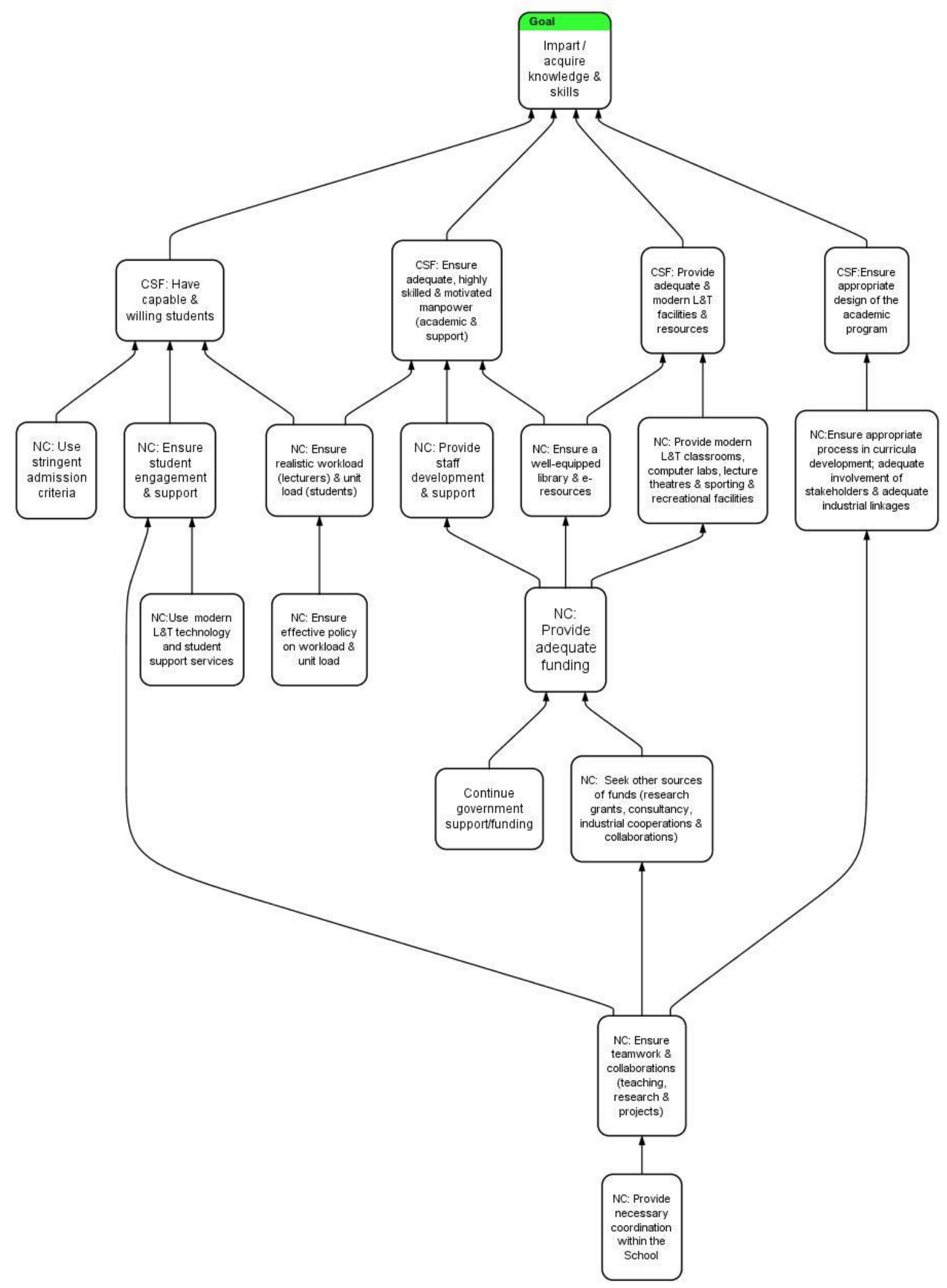




\subsubsection{Common issues affecting quality of L\&T at UNSB}

The analysis of students, lecturers, and senior administrative staff views indicate common issues, most of which are used to construct the fCRTs. Table 5.20 shows these issues. The tick $(\sqrt{ })$ indicates that the issue is enlisted by the respective group.

Table 5.20: Common issues at UNSB

\begin{tabular}{|c|c|c|c|c|}
\hline & Common Issues & Students & Lecturers & $\begin{array}{l}\text { Admin } \\
\text { Staff } \\
\end{array}$ \\
\hline 1 & There is discrepancy in performance of module $1 \& 2$ & $\sqrt{ }$ & $\sqrt{ }$ & $\sqrt{ }$ \\
\hline 2 & Most teaching is without interaction & $\sqrt{ }$ & $\sqrt{ }$ & $\sqrt{ }$ \\
\hline 3 & $\begin{array}{l}\text { There is limited interaction between students \& lecturers } \\
\text { outside classroom }\end{array}$ & $\sqrt{ }$ & $\sqrt{ }$ & $\sqrt{ }$ \\
\hline 4 & $\begin{array}{l}\text { There is low level of corporate (industrial) sector } \\
\text { participation in L\&T }\end{array}$ & $\sqrt{ }$ & $\sqrt{ }$ & $\sqrt{ }$ \\
\hline 5 & The student-lecturer ratio is not appropriate & $\sqrt{ }$ & $\sqrt{ }$ & $\sqrt{ }$ \\
\hline 6 & Teaching is more theoretical than practical & $\sqrt{ }$ & $\sqrt{ }$ & $\sqrt{ }$ \\
\hline 7 & Most lecturers are not available to students & $\sqrt{ }$ & $\sqrt{ }$ & \\
\hline 8 & Research has not been integrated in teaching & $\sqrt{ }$ & $\sqrt{ }$ & \\
\hline 9 & $\begin{array}{l}\text { Curricula do not adequately integrate current and } \\
\text { emerging business issues \& practices }\end{array}$ & $\sqrt{ }$ & $\sqrt{ }$ & $\sqrt{ }$ \\
\hline 10 & $\begin{array}{l}\text { The lack of adequate semester breaks affects teaching \& } \\
\text { learning }\end{array}$ & & $\sqrt{ }$ & $\sqrt{ }$ \\
\hline 11 & Many students are not willing to learn & & $\sqrt{ }$ & $\sqrt{ }$ \\
\hline 12 & $\begin{array}{l}\begin{array}{l}\text { Most lecturers are not effectively engaged in } \\
\text { conferences }\end{array} \\
\end{array}$ & & $\sqrt{ }$ & $\sqrt{ }$ \\
\hline 13 & $\begin{array}{l}\text { There is lack of full student involvement or engagement } \\
\text { in learning }\end{array}$ & $\sqrt{ }$ & $\sqrt{ }$ & $\sqrt{ }$ \\
\hline 14 & L\&T equipment $\&$ facilities are inadequate & $\sqrt{ }$ & $\sqrt{ }$ & $\sqrt{ }$ \\
\hline 15 & $\begin{array}{l}\text { There are inadequate teaching assistants and tutorial } \\
\text { fellows }\end{array}$ & & $\sqrt{ }$ & $\sqrt{ }$ \\
\hline 16 & Insufficient lecturers & $\sqrt{ }$ & $\sqrt{ }$ & $\sqrt{ }$ \\
\hline 17 & $\begin{array}{l}\text { The discrepancy in admission criteria affects teaching \& } \\
\text { learning negatively }\end{array}$ & & $\sqrt{ }$ & $\sqrt{ }$ \\
\hline 18 & There are incidents of mis sing marks & $\sqrt{ }$ & $\sqrt{ }$ & $\sqrt{ }$ \\
\hline 19 & There is no use of case studies in teaching & $\sqrt{ }$ & $\sqrt{ }$ & \\
\hline 20 & Many lecturers are not in touch with industry & $\sqrt{ }$ & $\sqrt{ }$ & $\sqrt{ }$ \\
\hline 21 & There are some incidents of plagiaris $m$ & $\sqrt{ }$ & $\sqrt{ }$ & $\sqrt{ }$ \\
\hline 22 & There are some incidents of cheating & $\sqrt{ }$ & $\sqrt{ }$ & $\sqrt{ }$ \\
\hline 23 & Most students do not go for internship & $\sqrt{ }$ & $\sqrt{ }$ & $\sqrt{ }$ \\
\hline 24 & There is poor monitoring of students' performances & & $\sqrt{ }$ & $\sqrt{ }$ \\
\hline 25 & Some students are academically weak & & $\sqrt{ }$ & $\sqrt{ }$ \\
\hline 26 & The salaries for lecturers are generally low & $\sqrt{ }$ & $\sqrt{ }$ & $\sqrt{ }$ \\
\hline 27 & The school does not always attract quality lecturers & $\sqrt{ }$ & & $\sqrt{ }$ \\
\hline
\end{tabular}


Table 5.20 shows that, students, lecturers, and administrative staff agree that the L\&T system is constrained by human and physical resources. They all perceive the need to move L\&T from a theoretical perspective to a more practical approach with greater interaction between students and lecturers and more student engagement and involvement. Moreover they indicate the need for more industrial linkages, and greater need for participation of industrial/corporate practitioners not only in curricular development, but also in teaching and other activities.

In the same vein, they all expressed the need for lecturers and students to be in touch with industry. Furthermore, they perceive lecturers' salaries to be generally low compared to market rates for similar qualifications. They are all discontented over discrepancies in the performance of Module I\&II students, incidents of missing marks, cheating, and plagiarism.

For their part, UNSB lecturers and academic administrators perceive the need for semester breaks and greater involvement in conferences. They are disgruntled over the discrepancy in student admission criteria and the poor monitoring of student performances. Moreover, they express concern over the rising numbers of academically weak students who are purportedly unwilling to learn. Although decline in academic ability of students at admission tends to be a global issue that has its roots in the massification of the HE sector (Ramsden, 1998) and the 'unwillingness syndrome' is a characteristic that tends to be associated with the millennials (born from 1980 through 2000) (Stewart, Houghton, \& Rogers, 2012), nevertheless, the L\&T environment has a big role in enhancing their academic ability and willingness to learn.

UNSB students and lecturers on the other hand perceive the need for students' consultation or learning support and the need to integrate research in teaching as well as more use of case studies in L\&T. Moreover, both UNSB students and administrators perceive the need to attract qualified lecturers.

\subsubsection{Diverging issues}

Let us see how the three groups of participants view each other in relation to the L\&T situation at UNSB.

i) How do students and lecturers see each other?

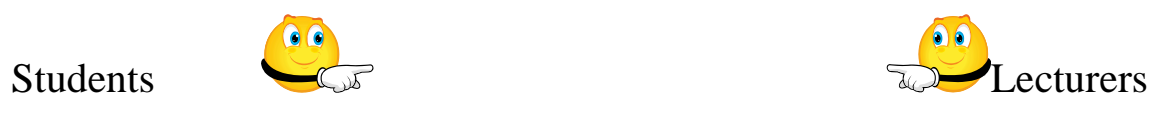

It is interesting that both students and lecturers hold various assumptions, and tend to blame each other for undesirable L\&T experiences. For instance, students presume that lecturers are: 
(1) Not always qualified teachers, no wonder some students fail ...95\% of the students had D's in accounting $1 \& 2$, assets \& equities, most of us failed, simply not because we didn't know what we were doing, but because of poor teaching (KM2-FT).

(2) Feeding them with irrelevant materials... And you expect to get information from your lecturers. So the first-hand information is just not there from most lecturers. The information that lecturers provide is very stale, outdated. It is expired. Some of it is irrelevant (KSL). And theoretical learning as opposed to practical... The learning is rote. There is inadequate learning effect. There is no practicality in it (KSL).

(3) Poor time keepers... Poor time keeping on the side of lecturers probably because they are multitasking, negligent, lack commitment, have superiority complex and due to traffic jam! (KM1).

(4) Technologically not savvy... 'Some lecturers have not embraced technology. They come to class, they have a lot of theory, there is a projector there to help explain the concept such as a diagram but they don't project or draw the diagram, so students just imagine how the diagram might be like. Even when the lecturer uses Power Point, some do not put the diagram, they just dictate notes. You are not sure what the lecturer says (KM1).

(5) Arrogant... The attitude of lecturers needs to change especially those with PhDs; even before they speak they let you know that they have 4 or 5 degrees. All lecturers with PhD have an attitude. Sometimes they do not use respectable language (KM2-PT).

(6) Poor role models... It sets bad example to students yet lecturers should act as role models to us. Now when they come to class late, we also start doing the same (KM1).

(7) Unavailable... In most of the cases, the lecturers are not usually available (KM1).

And worst of all, students doubt that lecturers mark their work... We also doubt, they do not mark the exams, they just give out grades (KM2-FT).

This dilemma is very common and all of us go through it. Sometimes you do course work and get 25/30. The last paper, you do it very well but at the end of the day you find yourself getting a C or a D. The final exam you guess that you could get something like 40/70 that adds to a B. But you end up getting a D grade. To make it worse you cannot do anything, you cannot report to anyone, the scripts are not brought back, and you can't petition anyone (KIS).

Lecturers on the other hand presume that most students, particularly those in Module II, are academically weak and unwilling to learn. ... Students' unwillingness to go an extra mile... 'Students' willingness can do marvellous things! For the unwilling and arrogant, there is nothing to do (LK11). Unprepared students make me spend a lot of time talking about simple/routine issues (LK 08).

But the dilemma is, for instance, even when lecturers make an effort to bring practicality into the course, students still do not want to do it...Like last week I gave students an assignment to go to the stock exchange to collect data and analyse, fourth year students, and they were up in arms, protesting (LK09). So 
the question is: 'Do students and lecturers clearly understand their role expectations? Are these roles clearly spelt out in the program handbook? Are the roles emphasised through clear communication? If so, how well do lecturers and students play their roles?

ii) How do UNSB lecturers and administrators see each other?

Lecturers

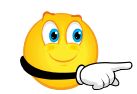

Administrators

Lecturers tend to point fingers to administration. They argue that their leaders fail to foster a collegial spirit at the school.

Department chairs have not made an effort to help lecturers work as a team (LK 04)

Administration causes this. They do not want to see lecturers walking together as a block talking the same thing, singing the same song. No! They want to see everybody walking this way that way in total disarray! They want to set you (lecturers) against one another! (LK 05)

They also fail to facilitate training of lecturers.

The university does not have any program to train lecturers on how to deliver, prepare content, mark exams, and distribute marks. Since I joined the university, I have not seen such a program... Department has not come up with a training program (LK 04).

Who has ever taught us how to come up with a case study? (LK 03)

These views point to a need for managerial intervention in order to improve the L\&T system. For their part, UNSB administrators point fingers to senior administrators of the university.

iii) How do UNSB students and administrators see each other?

Students
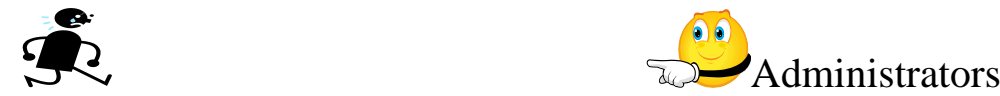

While administrators feel that most students are unwilling to learn, students on the other hand feel that administrators do not listen to their brilliant ideas.

They want free certificates. They don't want to work hard. If you are able to follow them, they are forced to 'be willing', but they complain. And if the lecturer is very strict they say 'that one, we avoid his class' (KAD 02).

They think that we, the young people, do not have the ideas. They are not people who are receptive, so if we have managers \{senior administrators\} who are receptive, they'd tend to accommodate students' ideas (KM1)

Here, there seem to be more questions than answers: What is it that students are unwilling to learn? Are they forced to learn it? Have they contributed to it? Are they learning the way they 
want to learn or the way administrators want them to learn? The two clearly need to sit down and listen to each other.

\subsubsection{Identifying common root causes of UDEs at UNSB}

The analysis of students, lecturers, and administrators staff fCRTs identified a number of critical root causes of the UDEs as shown in the Table 5.21.

Table 5.21: Critical root causes at UNSB

\begin{tabular}{|l|l|l|l|l|}
\hline & Critical root causes & Students & Lecturers & $\begin{array}{l}\text { Admin } \\
\text { Staff }\end{array}$ \\
\hline 1 & The structure and management of the school is bureaucratic & $\sqrt{ }$ & & $\sqrt{ }$ \\
\hline 2 & Student numbers in most classes are high & $\sqrt{ }$ & & \\
\hline 3 & There is limited government funding & & $\sqrt{ }$ & $\sqrt{ }$ \\
\hline 4 & There is lack of necessary coordination within the school & & $\sqrt{ }$ & \\
\hline
\end{tabular}

Note: Out of 5 FGs, 3 mentioned bureaucracy within the university and 3 mentioned limited interactions in classes due to high student numbers. Out of 12 lecturers, 3 mentioned limited funding and 5 mentioned issues to do with lack of necessary coordination. Out of 6 admin staff, 4 mentioned bureaucracy within the university and 4 mentioned limited government funding.

A similar root cause among students and administrative staff is the bureaucratic structure. Likewise, limited government funding is similar to both lecturers and administrative staff. Notably, the inadequate L\&T facilities and lack of enough qualified lecturers are identified as root-causes as well as UDEs across the three groups. The lack of enrolment limit is also commonly identified among the three groups as the cause of high student numbers. The hiring practices that are perceived as not rigorous are identified by both the students and the administrative staff. While the process may seem to be rigorous, if the decision criteria are faulty or data inadequate, then the decision will not be the most appropriate. Indeed, students feel that some invigilators are not well vetted, while administrators feel that the lecturers hired are not the best candidates.

... the recruitment process in the university is extremely bureaucratic, so that although the process is objective it can lead to funny outcomes whereby you rank people and all that, but $\{$ the $\}$ committee that ranks people (recruits) are in a hurry and are not that conversant. The committee system of hiring to me I find it almost guest work (KAD 03).

Thus, all the root causes from the three groups are then combined at the root levels in order to trace as far back as possible the critical root causes of all the UDEs. This also provides a holistic view of the whole L\&T system. The combined root cause tree is shown in Figure 5.15. 
Figure 5.16: Combined $f$ CRT of root causes at UNSB

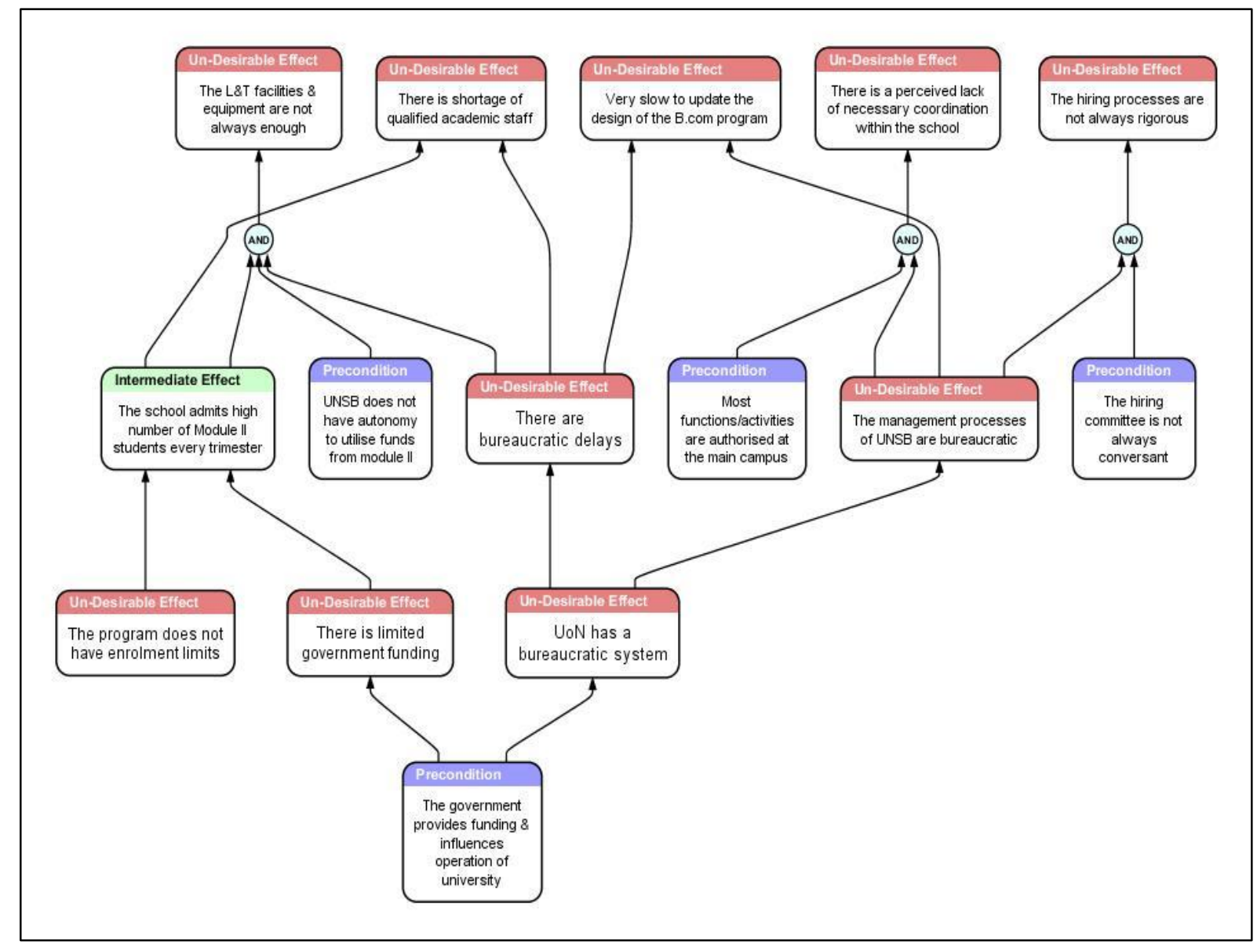

Combined root-cause analysis indicates that the bureaucratic system of the university and limited government funding are the critical root causes leading to all the undesirable issues facing UNSB. The lack of enrolment limit also contributes to the undesirable experiences. Avenues for resolution of the dilemmas associated with the critical root causes are proposed in Chapter 8.

\subsection{Summary}

Analysis of the views of three stakeholders of UNSB depicts a complex and dynamic subsystem whose L\&T processes have a goal of imparting students with knowledge and skills. But these goals and desires are apparently not sufficiently met. Despite its best intentions, UNSB appears to experience many undesirable effects (UDEs) that impact negatively on effective achievement of the desired goals. Common UDEs across the three stakeholders are identified. Critical root causes are identified: the bureaucratic system of the university and limited government funding. Resolutions of dilemmas behind these critical root causes are proposed 
Chapter 5: Data analysis and findings (Kenyan case)

in Chapter 8. The next chapter provides a similar structure of analysis based on Victoria business school (VBS). 


\section{Chapter 6}

\section{DATA ANALYSIS AND FINDINGS (NZ CASE)}

He aha te mea nui? He tangata. He tangata. He tangata. What is the most important thing? It is people. It is people. It is people (Māori proverb).

\subsection{Introduction}

This chapter is divided into six subsections. The first subsection (6.2) provides some background information about NZ and its education system. Then, brief background information about Victoria University of Wellington is provided. Specific information about the Victoria Business School (VBS) programs is then provided. What follows after are three sub-sections $(6.3,6.4 \& 6.5)$ that present findings from three groups of participants namely students, lecturers, and senior administrative staff. Section 6.6 provides a within-case analysis of the three groups.

\subsection{Contextual background}

The purpose of this contextual background is to provide the reader with some understanding of the NZ case study.

\subsubsection{Background information of New Zealand (NZ)}

New Zealand is also known as Aotearoa, a Māori name that means 'land of the long white cloud'. The ancestral people of NZ are the Māori. They settled in NZ between 950-1130 AD (www.history-nz.org). In 1642, the Dutch explorer, Abel Tasman discovered Aotearoa and named it Nieuw Zeeland (after a province in Holland) but it was not until 1769 when the first European Captain James Cook claimed New Zealand for Britain (www.fourcorners.co.nz).

From 1790s, European settlers continued to migrate to NZ. The vast majority were of British descent. In 1840, 500 Māori chiefs signed the Treaty of Waitangi, ceding governance to Britain. In the following year, 1841, NZ was declared a British colony. Today, NZ is an independent multicultural nation governed by a democratically elected government (www.stats.govt.nz). 
NZ has a market economy heavily dependent on international trade. In previous years, NZ earnings were mainly from agricultural products. Today, there are new economic developments in tourism, film production, and wine-making (www.stats.govt.nz).

In 2014, NZ's estimated population is 4.471 million in a total area of $269,652 \mathrm{sqkm}$. The major ethnic groups are Europeans, Māori, Asian, and Pacific people. English, Māori, and NZ sign language are the official languages (www.stats.govt.nz).

\subsubsection{History of education in NZ}

Prior to the 1877 Education Act of NZ, there existed early schools for 'natives' and 'settlers' children. The first missionary school for Māori (natives) was established at Rangihoua in 1816, and by 1867, the Native Schools Act was established (Simon, 1994). The settlers' schools on the other hand were established from 1840 through to 1853 . These schools were run by churches or private individuals. In Auckland, the first school was opened in 1843, a Roman Catholic School (Simon, 1994).

Until 1870, not more than half of NZ children aged between 5-13 went to school because there were no compulsory attendance laws (Simon, 1994). There were however campaigns for universal schooling as early as 1849. These campaigns, which were also shaped by Britain's universal education at that time, advocated for the formation of the moral character of a child (Simon, 1994).

The Constitution Act of 1852 heralded the beginning of self-governance in NZ. The Act divided NZ into six provinces and saw the birth of a provincial system of education. This system apparently created inequalities particularly in access to education. Thus, the Education Act of 1877 sought to bring about equal access to primary school for all children (Simon, 1994).

Since 1877, NZ has had a national education system, which is guided by egalitarian and racial harmony principles (Simon, 1994). This education system has undergone various reforms over the years. Between 2002 and 2004 the National Certificate of Education Achievement (NCEA) became the main secondary school qualification (www.teara.govt.nz). The government sets the national policies and frameworks for regulation and guidance, and requirements and funding arrangements for primary and secondary school education (www.minedu.govt.nz). 


\subsubsection{Structure of Education in NZ}

The NZ education system has 3 levels: early childhood education (ECE), school education, and tertiary education (Figure 6.1). ECE is not compulsory but has high participation rates of $95 \%$. It covers the years from birth to school entry age. School education is compulsory from age 519. It comprises 13 year levels. Tertiary education includes all post-secondary education including higher and vocational education. Students can follow a variety of flexible pathways (www.minedu.govt.nz).

Figure 6.1: Structure of Education system in NZ

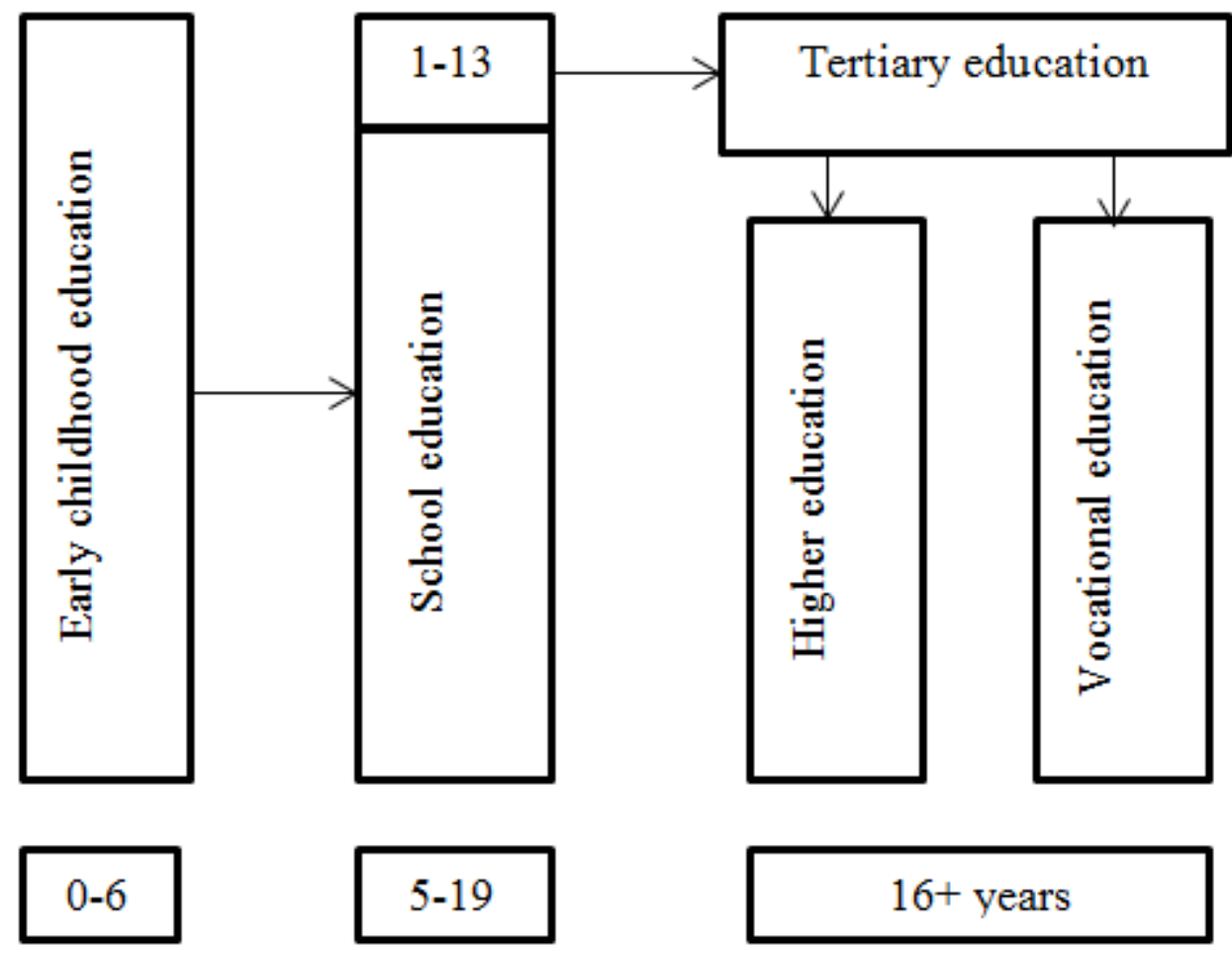

\subsubsection{The HE system in NZ}

NZ has 8 public state-funded universities. There are no privately owned universities. The quality assurance for university qualifications is provided by Universities New Zealand (UNZ) (Te Pōkai Tara) through the Committee on University Academic Programs (CUAP), and through the independent Academic Quality Agency for New Zealand Universities (AQA) (www.minedu.govt.nz).

The CUAP is charged with setting up and applying qualification and regulation approval, accreditation and program moderation procedures across universities while the AQA supports universities in their achievement of standards of excellence in research and teaching. The AQA 
achieves this objective through regular institutional audits and promotion of quality enhancement practices across the university sector (www.minedu.govt.nz).

\subsubsection{Background of Victoria University of Wellington}

Victoria University of Wellington started as Victoria College in 1897, named in honour of Queen Victoria. Victoria College remained a teaching college until 1899 when research began following the arrival of four pioneering professors: Thomas Easterfield, Hugh Mackenzie, Richard Maclaurin and John Rankine Brown (www.vuw.ac.nz).

In 1962, Victoria College was renamed Victoria University of Wellington (VUW). Over the years, VUW has grown to become NZ's top ranked university in research quality. It is home to nine Faculties and 24 research institutes and centres. It operates on four campuses namely: Kelburn, Karori, Te Aro, and Pipitea (www.vuw.ac.nz).

VUW is governed by a council and is led by a Vice-Chancellor who is the University's Chief Executive and oversees academic and administrative management. The Vice-Provost (Academic \& Equity) heads the academic office that supports faculties, schools, and services related to learning and teaching. The office is responsible for learning and teaching strategy, academic quality assurance, equity and diversity, and student experience strategy.

\subsubsection{Victoria Business School (VBS)}

VBS started as the Bachelor of Commerce in 1909 . In 1939, the Faculty of Commerce was established and in 1964, the Faculty name was changed to Faculty of Commerce and Administration. The Bachelor of Commerce degree was also changed to Bachelor of Commerce and Administration. In 2012, the Faculty of Commerce and Administration name changed to VBS and the degree name changed back to Bachelor of Commerce (http://www.victoria.ac.nz/vbs).

VBS is headed by the ProVice-Chancellor and the Dean of Commerce. It has six schools that contribute to its degree and programs at undergraduate, post-graduate, and post-experience levels. The six schools are: School of Information Management (SIM), School of Economics and Finance (SEF), School of Accounting and Commercial Law (SACL), School of Management (SoM), School of Marketing and International Business (SMIB), and the School of Government (SoG). Each school is led by a Head of School (http://www.victoria.ac.nz/vbs). 
In addition to the six schools, VBS has two research institutes, three centres and five externally funded chairs with specialist research expertise.

VBS offers undergraduate and post graduate programs in all areas of business including: Accounting, Actuarial Science, Commercial Law, Economics, Finance, Human Resource Management and Industrial relations, Information systems, International Business, Marketing, Public policy, Taxation, and Tourism Management (www.victoria.ac.nz/vbs).

\section{Admission to the program}

Admission to the business program follows the VUW admission criteria. As in many other universities, there are varied admission requirements. The reader is referred to http://www.victoria.ac.nz/study/apply-enrol/admissions for more details. However, for those seeking admission using the National Certificate of Education Achievement (NCEA), the guarantee undergraduate entry score for 2015 is 150 points at level three.

\section{Undergraduate program structure}

In its undergraduate program, VBS offers two major qualifications: Bachelor of Commerce and Bachelor of Tourism Management

\section{i. Bachelor of Commerce structure}

The BCom degree consists of courses worth at least 360 points (mostly 24 courses $\times 15$ points because all BCom courses are 15 points each) required for a major in Accounting, Commercial Law, e-Commerce, Economics, Finance, Human Resource Management and Industrial Relations, Information Systems, International Business, Management, Marketing, Public Policy, and Taxation. The courses are offered at 100-level, 200-level and 300-level. Along with the 360 points requirement, at least 180 points (12 courses) should be at 200 -level or above and at least 9 courses must be at 300-level (Undergraduate prospectus, 2015).

The program has 7 core courses, 6 or 7 major requirements and several electives within and outside Commerce. Students also have a choice of graduating with a major and a minor, double majors, or even conjoint and double degrees (combining a Commerce degree with another like Bachelor of Arts-BA). Whatever the case, there are specific requirements that a student must meet. 


\section{ii. Bachelor of Tourism Management (BTM) structure}

The BTM degree consists of three parts with a total value of 360 points. Part I consists of 6 compulsory Tourism courses offered at 100 and 200 levels. A practicum is done at 300 level, plus a selection of 3 Tourism electives at 300-level. Part II consists of 5 Commerce courses (3 at 100-level and 2 at 200-level). Part III comprises the remaining 90 points (either 5 or 6 courses) required to complete the degree. These courses can be chosen from either other Tourism courses not included in Part I, other BCom courses (not already taken in Part II), courses from BA or other BA subjects (Undergraduate prospectus, 2015).

\section{The learning goals}

The learning goals as defined by VBS Bachelor of Commerce degree are:

- Critical and creative thinking: Graduates are able to demonstrate application of critical and creative thinking skills to practical and theoretical problems

- Communication: Graduates are effective communicators

- Global and multicultural perspective: Graduates have a global and multicultural perspective

- Leadership: Graduates recognise, support and display leadership skills

- Specific knowledge skills: Graduates develop specific knowledge and skills in their majors.

At the time of the study, program learning goals were in a state of flux to realign them with the new Victoria Graduate Profile which was approved in 2013. The new graduate profile can be found in the website (www.victoria.ac.nz/vbs/teaching/publication/BCom-Learning-Goalsand-Objectives). The new BCom Learning Goals were formally approved in November, 2014.

\section{Assessments and mandatory course requirement}

Assessments vary with each course. Exams and internal assessments (tests, assignments or projects) can range from 0\%-100\%. For instance: exam 50\%, internal 50\%; exam 60\%, internal $40 \%$; internal $70 \%$, case competition assignment/presentation $30 \%$; assignments $70 \%$, tutorial briefs $30 \%$; exam $100 \%$. To pass a course, a student must obtain a course mark of at least $50 \%$. But many courses have additional requirements that must be met. For example, a student must obtain a minimum mark in a test or examination, or carrying out some specific tasks, like attending a minimum number of tutorials. Failure to meet the requirements means that a student fails the course, even if the student's course mark is $50 \%$ or more. In such a case, the student gets a $\mathrm{K}$ grade that is still a fail (Undergraduate prospectus, 2015). The grading system in force from the first trimester of 2014 is depicted in Table 6.1. 
Table 6.1: Standard pass/fail grades

\begin{tabular}{|l|l|l|l|}
\hline Grade & Range & Midpoint & Indicative Characterisation \\
\hline A + & $90-100$ & 95 & Outstanding performance \\
\hline A & $85-89$ & 87 & Excellent performance \\
\hline A- & $80-84$ & 82 & Excellent performance in most respects \\
\hline B + & $75-79$ & 77 & Very good performance \\
\hline B & $70-74$ & 72 & Good performance \\
\hline B- & $65-69$ & 67 & Good performance overall, but some weaknesses \\
\hline C+ & $60-64$ & 62 & Satisfactory to good performance \\
\hline C & $55-59$ & 57 & Satisfactory performance \\
\hline C- & $50-54$ & 52 & Adequate evidence of learning \\
\hline D & $40-49$ & 45 & Poor performance overall, some evidence of learning. Fail. \\
\hline E & $0-39$ & 20 & Well below the required standard. Fail. \\
\hline
\end{tabular}

Source: http://www.victoria.ac.nz/students/study/progress/grades

\section{i. Other pass grades}

H: Pass (for some Practicum courses)

M: Overall Pass with Merit (used only for Teacher Education courses)

P: Overall Pass (for a course classified as Pass/Fail)

G: Aegrotat Pass

$\mathbf{J}$ : Pass in recognition of prior learning

L: Compensation Pass

Z: Special Pass

\section{ii. Other fail grades}

F: Fail (for a course classified as Pass/Fail; also used for an unsuccessful Special Pass application)

K: Fail due to not satisfying mandatory course requirements, even though the student's course mark reached the level specified for a pass, usually 50 percent.

\section{Fee structure}

The 2015 fee structure for domestic students is $\$ 48.10$ per point in the BCom. For instance, the cost of a full year 120 point in the BCom is $\$ 5,772$. Other fees are $\$ 714$ per year that covers student support services such as counselling, health services, financial support and advice, careers guidance, student advocacy, student publications, and student representation (www.victoria.ac.nz/fees).

\subsubsection{Summary of the background}

This foregoing section has provided the reader with brief background information about NZ history of the education system, and a summary of the structure of education. The subsection also outlines the historical background of Victoria University of Wellington. Then, a brief description of VBS is provided with special emphasis of the Bachelor of Commerce program. 


\subsection{VBS students' data analysis}

This subsection discusses students' views of their learning goal. Next, the critical success factors and the necessary conditions to help achieve the goal are depicted in the form of a goal tree and are discussed. Then, the less than desirable issues that impact negatively on the achievement of the learning goals are analysed and their root causes identified.

\subsubsection{Description of the students' participants}

A total of 32 students participated in this case study. This number is comparable to other studies that have used students in focus group interviews (Lea \& Callaghan, 2008; McLafferty, 2004; Lea, Stephenson \& Troy, 2003). These students represented five different categories of students at VBS, capturing their levels of study, and diversity. Categories represented are level 100, 200, and 300 comprising domestic students, Māori \& Pasifika students, and international students. International students comprised students from China, Hong Kong, Indonesia, and Vietnam. Table 6.2 shows gender representation across the five categories.

Table 6.2: Gender representation of VBS focus groups

\begin{tabular}{|c|c|c|c|c|}
\hline \multicolumn{5}{|c|}{ Gender representation across the groups } \\
\hline Category & Symbol & Male & Female & Total \\
\hline Level 100 (Domestic students) & VD 1 & 2 & 3 & 5 \\
\hline Level 200 (Domestic students) & VD 2 & 0 & 7 & 7 \\
\hline Level 300 (Domestic students) & VD 3 & 1 & 7 & 8 \\
\hline Maori \& Pasifika & VMP & 1 & 2 & 3 \\
\hline International students & VI & 4 & 5 & 9 \\
\hline Total & & 8 & 24 & 32 \\
\hline
\end{tabular}

A total of 8 males and 24 females participated. This difference might be due to the fact that nowadays more women in Anglophone countries (Australia \& New Zealand) are participating in undergraduate studies than men (Blackmore, 2014). Table 6.3 shows gender distribution of all student participants across three levels of study. 
Table 6.3: VBS students gender representation across levels of study

\begin{tabular}{|l|c|c|c|}
\hline \multicolumn{4}{|c|}{ Gender across the levels of study } \\
\hline Category & Male & Female & Total \\
\hline Level 100 & 4 & 4 & $\mathbf{8}$ \\
\hline Level 200 & 1 & 10 & $\mathbf{1 1}$ \\
\hline Level 300 & 3 & 10 & $\mathbf{1 3}$ \\
\hline Total & $\mathbf{8}$ & $\mathbf{2 4}$ & $\mathbf{3 2}$ \\
\hline
\end{tabular}

The host schools of the 200-level and 300-level students who were already specialising in their majors are shown in Table 6.4. However, two students* indicated that they were hosted in two schools [(SACL \& SEF) and (SoM \& SACL)]

Table 6.4: Students' representation across VBS schools

\begin{tabular}{|l|c|}
\hline SACL & 6 \\
\hline SIM & 1 \\
\hline SMIB & 8 \\
\hline SEF & 3 \\
\hline SoM & 4 \\
\hline Total & $\mathbf{2 2 *}$ \\
\hline
\end{tabular}

Seven focus groups (FGs) were used in this case. The group sizes ranged from 3-7 participants. [There were two different FGs for level 300 (domestic students) and the international students]. These are labelled VD3a \& VD3b and VIa \& VIb respectively (see Figure 6.1). 
Figure 6.1: VBS students focus groups' discussions/interview time

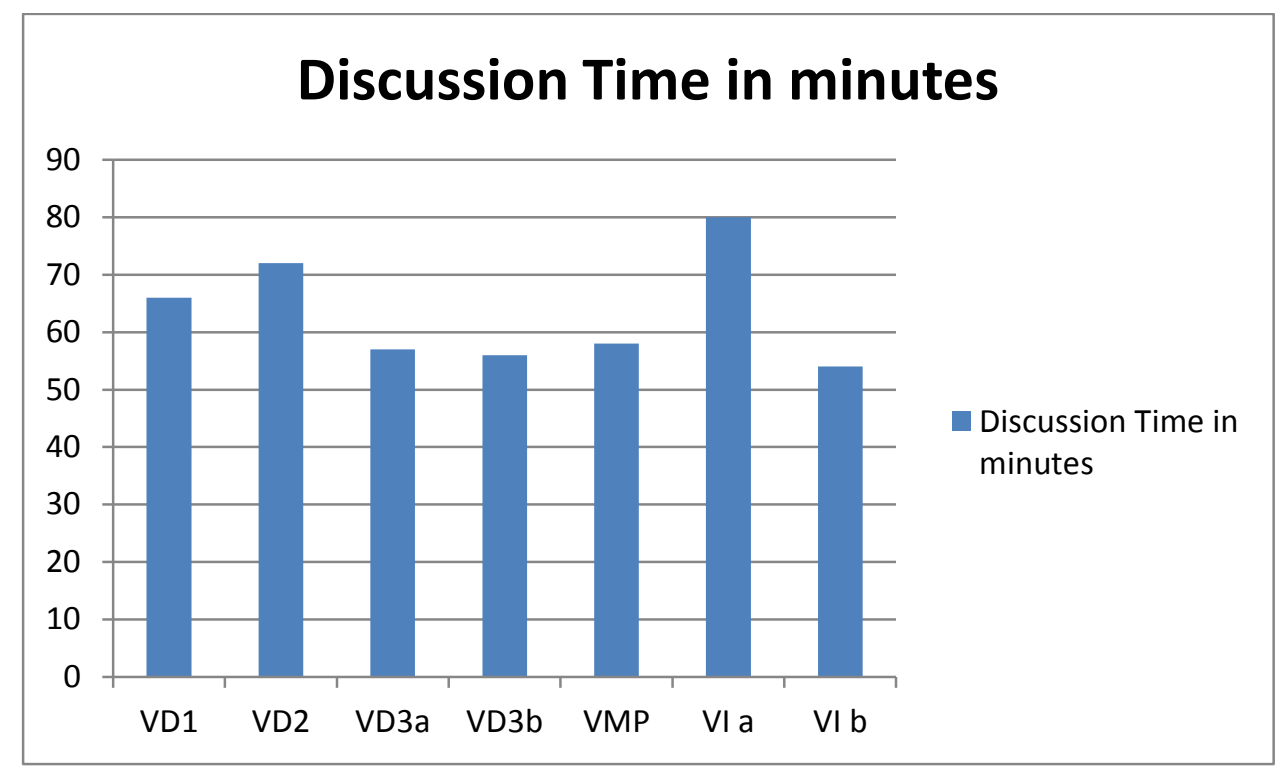

In the first FG of level 300, there were only 3 participants, justifying the need for a second group. For international students, the first FG was 6 but there were very many students willing to participate. A second group consisting of 3 was conducted. The total recorded time for all the 7 groups was $7 \mathrm{hrs} 38$ min averaging $1 \mathrm{hr} 5$ minutes.

\subsubsection{Identifying VBS students' learning goal(s), CSFs, and NCs}

There were many goals identified by each FG (see Table 6.5). The goals for the separate groups of level 300 (VD 3) and international students (VI) are combined for ease of analysis in Table 6.5. As explained in section 5.3.2. the purpose of identifying students goals is to relate them with those officially defined by the business school. This relationship is discussed in Chapter 8 , section 8.2.

\section{Articulating a common goal}

The unitisation of common words or phrases (in italics) leads to a common goal of 'getting a qualification with applicable and employable skills'. In order to get a qualification that could get them a job, students stress the need for applicable skills and provide examples of the skills they need including problem-solving; communication; negotiation; and interviewing. It is important to note the Māori and Pasifika students in particular emphasise the need to 'provide for the family'. 
Table 6.5: Identifying VBS students learning goal(s)

\begin{tabular}{|c|c|c|c|c|c|}
\hline & VD 1 & VD 2 & VD 3 & VMP & VI \\
\hline $\begin{array}{l}\text { Goals } \\
\text { identified }\end{array}$ & $\begin{array}{l}\text { 'My goal is just to } \\
\text { get a degree'. 'To } \\
\text { be able to get a job'. } \\
\text { 'Get a relevant } \\
\text { degree to get a job'. } \\
\text { 'Get the most out of } \\
\text { university } \\
\text { experience'. 'Draw } \\
\text { the links between } \\
\text { the knowledge from } \\
\text { the various courses, } \\
\text { so that you can } \\
\text { develop further and } \\
\text { further on what you } \\
\text { know and so } \\
\text { personally I just } \\
\text { want to join the } \\
\text { little dots' }\end{array}$ & $\begin{array}{l}\text { 'To be well } \\
\text { prepared for the } \\
\text { working } \\
\text { environment, so be } \\
\text { employable'. 'Get } \\
\text { competitive } \\
\text { advantage } \\
\text { compared to other } \\
\text { people at job } \\
\text { market'. 'Getting } \\
\text { social skills', 'Get } \\
\text { specific knowledge } \\
\text { in my field of study } \\
\text { and general } \\
\text { knowledge', 'have } \\
\text { exposure to great } \\
\text { diversity'. }\end{array}$ & $\begin{array}{l}\text { 'To get a job', 'A qualification to } \\
\text { get a job', 'Have a university } \\
\text { experience', 'Find yourself', Get all } \\
\text { the kind of the university } \\
\text { experience which you cannot get } \\
\text { unless you go to a university'. 'To } \\
\text { come out of university with a } \\
\text { degree that I can use, a useful } \\
\text { degree to help me get a career out } \\
\text { of it' 'Get applicable skills, skills } \\
\text { in writing, professionalism, } \\
\text { interviewing \& debating \& } \\
\text { negotiation skills', 'have superior } \\
\text { knowledge, new ideas, and things } \\
\text { that other people have not been } \\
\text { exposed to as much, also modern } \\
\text { ideas like when new management } \\
\text { research is released, I want to know } \\
\text { more about it'. }\end{array}$ & $\begin{array}{l}\text { 'Get a good job and } \\
\text { provide for your } \\
\text { family', 'Get self- } \\
\text { improvement \& get a } \\
\text { preparation for the } \\
\text { future'. Have a wider } \\
\text { understanding of } \\
\text { what is going on in the } \\
\text { economy. }\end{array}$ & $\begin{array}{l}\text { 'Have enough skills', 'develop } \\
\text { a way of self-learning, learn } \\
\text { how to learn', 'have problem } \\
\text { solving skills', 'time } \\
\text { management skills', 'project } \\
\text { management', 'have some } \\
\text { people skills \& ability to work } \\
\text { with others', 'communication } \\
\& \text { social skills', group } \\
\text { presentations, team spirit skills } \\
\text { and cooperation'. 'Get a } \\
\text { qualification \& get a job'. } \\
\text { 'Have ability to solve } \\
\text { problems, not just knowledge } \\
\text { from the text book but } \\
\text { practical knowledge', } \\
\text { networking \& communication } \\
\text { skills. }\end{array}$ \\
\hline $\begin{array}{l}\text { Consensus } \\
\text { goal }\end{array}$ & $\begin{array}{l}\text { Get a degree, get a } \\
\text { job, have wide } \\
\text { university } \\
\text { experience, link/ } \\
\text { connection the } \\
\text { knowledge across } \\
\text { the courses. }\end{array}$ & $\begin{array}{l}\text { To be well } \\
\text { prepared for the } \\
\text { work environment, } \\
\text { be employable } \\
\text { have competitive } \\
\text { advantage in the } \\
\text { job market, have } \\
\text { social skills, } \\
\text { specific and general } \\
\text { knowledgeable, \& } \\
\text { exposure to great } \\
\text { diversity }\end{array}$ & $\begin{array}{l}\text { Get a qualification to get a job and } \\
\text { get a university experience and } \\
\text { applicable skills, and superior and } \\
\text { modern knowledge. }\end{array}$ & $\begin{array}{l}\text { Have wider } \\
\text { understanding } \text { or } \\
\text { knowledge; be able to } \\
\text { get a good job as well } \\
\text { as self-improvement } \\
\& \text { a preparation for } \\
\text { the future }\end{array}$ & $\begin{array}{lr}\text { Get a qualification that can } \\
\text { help me get a job, have } \\
\text { problem solving } r \text { skills, } \\
\text { practical knowledge, } & \text { time } \\
\text { management skills, project } \\
\text { management, people } & \text { skills \& } \\
\text { team spirit } & \text { skills, } \\
\text { communication skills, social } \\
\text { skills \& networking skills, and } \\
\text { learn how to learn. }\end{array}$ \\
\hline
\end{tabular}

But from Table 6.5, we can see that some students' goals emphasise getting a qualification or a degree that could help them get a job while others emphasise getting skills and practical knowledge.

Next is the unitisation process that involves coding some words or phrases so that they fit well under a CSF or NC. Table 6.6 shows the CSFs, and the NCs identified by each FG. 
Table 6.6: Unitising VBS students' CSFs \& NCs

\begin{tabular}{|c|c|c|}
\hline & $\begin{array}{l}\text { Critical success factors } \\
\text { (CSFs) }\end{array}$ & Necessary Conditions (NCs) \\
\hline \multirow[t]{4}{*}{ VD1 } & Motivation to learn $\{$ CSF 1$\}$ & Passion to learn (NC 2) \\
\hline & Supporting guardians (NC 9) & Passion from guardians (NC 9) \\
\hline & learning resources $\{\mathrm{CSF} 3\}$ & Books, facilities (NC 7) \\
\hline & Qualified lecturers (NC 12) & 'know how to teach' (NC 12) \\
\hline \multirow[t]{8}{*}{ VD2 } & \multirow[t]{3}{*}{ Good grades } & Apply oneself to study, (NC 2) \\
\hline & & Take responsibility, (NC 2) \\
\hline & & Motivation $\{$ CSF 1$\}$ \\
\hline & \multirow[t]{4}{*}{ Dedication to study $\{\mathrm{CSF} 1\}$} & Treat learning as a job, (NC 2) \\
\hline & & show up for classes, (NC 2) \\
\hline & & passion for learning, (NC 2) \\
\hline & & make lectures exciting \& engaging (NC 1) \\
\hline & $\begin{array}{l}\text { Interaction with other students } \\
\{\mathrm{CSF} 2\}\end{array}$ & $\begin{array}{l}\text { Get out of the small cliques, Confidence to face other people, Use } \\
\text { opportunities in group work \& tutorials, Seeking other opportunity (clubs), } \\
\text { Seeing the big picture (after graduation) (NC } 3,5,9)\end{array}$ \\
\hline \multirow[t]{4}{*}{ VD3a } & \multirow[t]{3}{*}{ Relevant skills } & Working with the industry or alongside the industry (NC 11) \\
\hline & & Up to date technology \& programmes (NC 6) \\
\hline & & Different online databases to be able to research (NC 7) \\
\hline & Passionate lecturers (NC 1) & $\begin{array}{l}\text { Qualified in their fields, Practical experience in their fields, Ability to } \\
\text { communicate knowledge, Passionate with students, Encouraging students } \\
(\mathrm{NC} 1,11,13)\end{array}$ \\
\hline \multirow[t]{5}{*}{ VD3b } & \multirow{2}{*}{$\begin{array}{l}\text { Motivation \& practical } \\
\text { learning/vocational skills }\{\mathrm{CSF}\end{array}$} & Practical \& hands on assignments (NC $1,11,12)$ \\
\hline & & Practical tests (NC 12) \\
\hline & Student support & Student learning support services (SLSS) (NC 9) \\
\hline & Flexibility in the program & Accommodate students' needs \\
\hline & Choice of courses & A range of courses within specialisations \\
\hline \multirow[t]{2}{*}{ VMP } & Motivation to learn $\{$ CSF 1$\}$ & $\begin{array}{l}\text { Family support, socialising, helping each other, team-players in a group (NC } \\
3,9)\end{array}$ \\
\hline & Self-dis cipline (NC 2) & Prioritising learning (NC 2) \\
\hline \multirow[t]{6}{*}{ VIa } & \multirow{2}{*}{$\begin{array}{l}\text { Adequate time allocated to } \\
\text { studies (NC 2) }\end{array}$} & Devote time to develop the skills (NC 2) \\
\hline & & $\begin{array}{l}\text { Making right choices, } \& \text { balance the cost-benefit } \& \text { the opportunity cost to } \\
\text { arrive at the best choice. (NC 2) }\end{array}$ \\
\hline & \multirow[t]{2}{*}{$\begin{array}{l}\text { Participation in group work \& } \\
\text { research (NC 3) }\end{array}$} & $\begin{array}{l}\text { Have positive attitude towards participation \& contributing towards the } \\
\text { group. (NC 3) }\end{array}$ \\
\hline & & Connect with smart world like space/online participation (NC 3, 7) \\
\hline & \multirow{2}{*}{$\begin{array}{l}\text { Resources (workshops, online } \\
\text { resources, \& intangible } \\
\text { resources) (NC 7) }\end{array}$} & Having positive attitude to take advantage of available opportunities, (NC2) \\
\hline & & $\begin{array}{l}\text { Being optimistic, positive mind, patient, eager to learn \& share, do not give } \\
\text { up (NC 2) }\end{array}$ \\
\hline \multirow[t]{7}{*}{$\mathrm{VIb}$} & \multirow[t]{2}{*}{ Good friends (NC 9) } & $\begin{array}{l}\text { Mix the international students with domestic students through some } \\
\text { activities hosted by the university (NC 3) }\end{array}$ \\
\hline & & $\begin{array}{l}\text { Be around people who want to study and with whom we have similar } \\
\text { personality \& interests (NC 9) }\end{array}$ \\
\hline & \multirow[t]{3}{*}{ Good tutors (NC 4) } & Bubbly tutors \& more approachable (NC 8) \\
\hline & & Able to explain issues (NC 8) \\
\hline & & High quality tutors with teaching ability (NC 8) \\
\hline & \multirow[t]{2}{*}{ Good lecturers (NC 1) } & $\begin{array}{l}\text { Able to communicate clearly and provide more examples outside the text } \\
\text { books relating to the real world- real company or real industry. (NC 11) }\end{array}$ \\
\hline & & Lecturers who not just reading the lecture slides. (NC 12) \\
\hline
\end{tabular}




\section{Determining CSFs and NCs}

The unitisation process identified 3 CSFs and 13 NCs that are connected using the necessitybased logic to form a goal tree (Figure. 6.2). Students identify motivation and dedication, interactions and learning resources as the most important factors that can help them to achieve their goal of 'getting a qualification with applicable and employable skills'. These CSF are explained below.

Figure 6.2: VBS students' goal tree

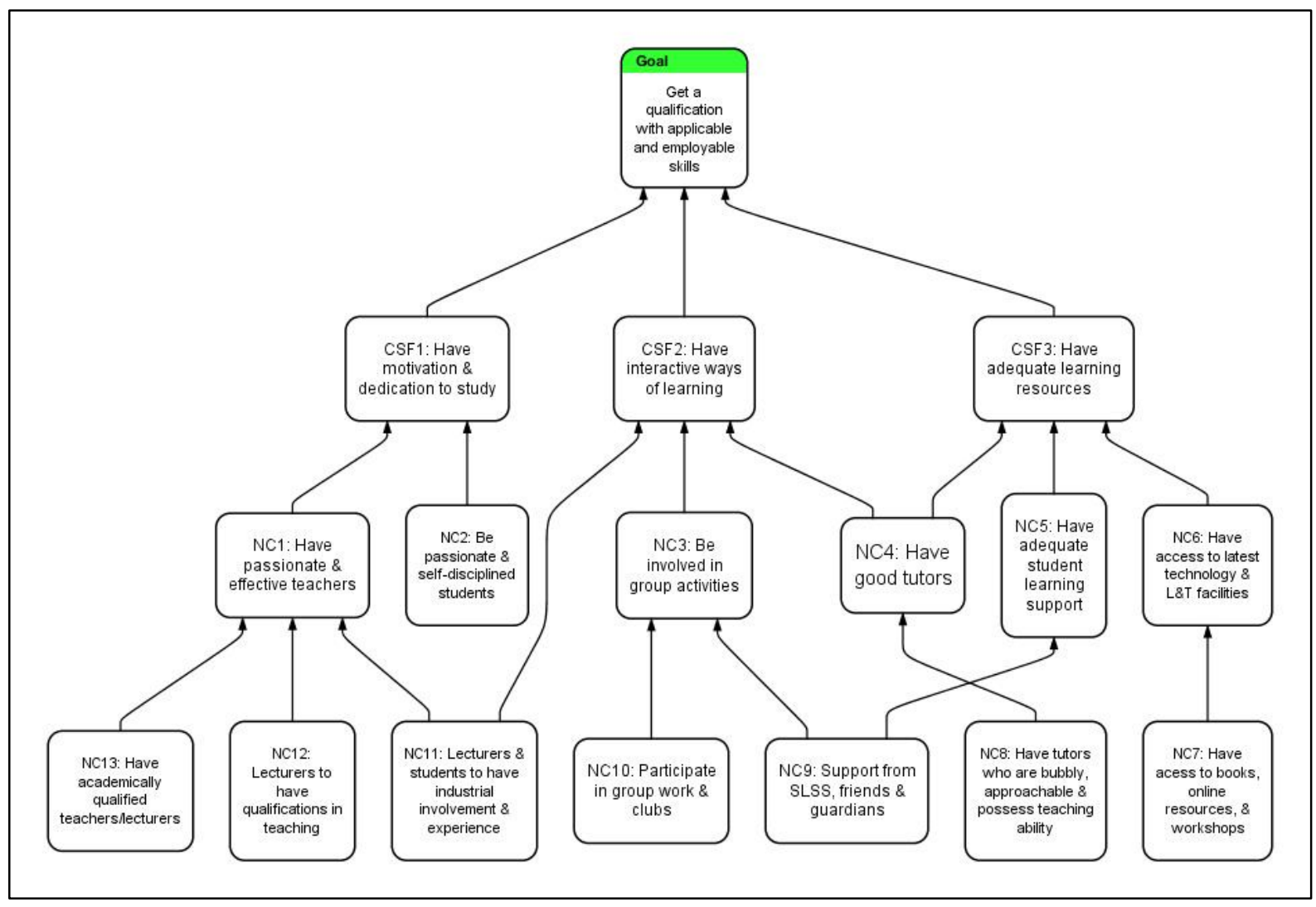

i) Motivation and dedication

Students feel that both they and the lecturers need to have motivation. For their part, students feel that they need to remain motivated and focused on their learning.

'...keep myself motivated, stay focused and understand the importance of staying focused (VMP)', 'have passion to do what you going to do (VD1)', make right choices... having positive attitude to take advantage of available opportunities (VIa).

Students also express the need for their lecturers to be motivated and enthusiastic. The issue of lecturer motivation was a heated one in all the groups. Students express disappointment with some of their lecturers and many indicate that they fail to attend lectures because they did not derive much value from them.

There are lecturers who are really not there, lecturers who are not really enthusiastic about their course. It is like they are a little out of touch. Just like when they speak most of the time, they are boring. It is 
like standing at a podium and they just read, and read and read, and then we have their notes and it's not what they have in the slides and it is a monotone. And we wonder why, rather than studying on your own, you are wondering why you are at a lecture (VD1).

Some talk in monotone, yes, it just sends you falling asleep; some in accents you can hardly understand, some of them the class is very quiet. And some of them are not engaging, some lecturers just stay there like a statute and they just talk non-stop. It is like some of them do not have confidence. It is like they are very knowledgeable but they are not just expressing it, they are just reading the slides. Yes I just stay at home and read the slides (VD3b).

But some lecturers, their tone is very flat, it is like a robot. So you sleep in class (VIb).

Based on the fact that students do not seem to derive much value, is there any need for lectures? Why is the university spending a lot of money on lectures, yet, students do not seem to derive much value from them? Evidently, students prefer tutorials to lectures.

Honestly between lectures and tutorials, I find tutorials more important because the tutor, even though they might not be as knowledgeable as the lecturer, but they know how to teach or they intend to teach at least and it is easier to have a discussion in a tutorial. And you can tell that some lecturers just focus on their research and kind of take teaching like a part-time job (VIa).

And though lecturing and teaching might entail different roles, the importance of teaching skills in lecturing is emphasised in all the groups. Surprisingly, some tutors seem to do a better job than some lecturers.

And I know a lot of lecturers in the university are researchers but a lot of tutors do not have a degree or masters but they have teaching skills. When they \{tutors\} teach it is easy to understand and can develop group discussions in class and also can create a desire to study in class but not the lecturers (VIa).

Thus, students express need for lecturers to be qualified both academically and in teaching. Researcher's reflection: But are lecturers hired as lecturers, teachers or researchers? Is the role of a lecturer similar to that of a teacher? Do students understand this difference? Do they need to understand it? Do lecturers understand students' preference for being taught and not being lectured?

ii) More positive interactions

Students express the need for interactions in lectures, tutorials, group assignments and within the wider university community. They seem to appreciate the interactions in their tutorials indicating satisfaction with their tutors, particularly those who were bubbly and charismatic. With regard to group assignments, students express concern that in some cases when they are given a written group assignment they still break it up into parts, and still do it individually. As such they express the need for group assignments to be practice-oriented.

If you got some group work whereby we are shooting like a YouTube video, which is better, that is more practical and you can learn as a group and you can do different aspects. But when they are sitting you down and you have to try and just write it, really, a basic report, it is a lot easier and better to kind of do that stuff by yourself. So I think group work needs to be practical and hands on. That way, you interact with people better and that is the whole point to be able to work with people when you get out of university (VD3b). 
iii) Adequate resources

In many cases, students feel that they have many opportunities because of good resources (clubs, workshops, seminars, student learning support services [SLSS], Victoria international leadership program [VILP], Vic-Plus) available within the wider university. Some indicate that their interactions with these resources help them to build confidence to face people. In contrast, the high cost of text-books is seen as a barrier to learning.

\begin{abstract}
'A brand new book costs $\$ 120-\$ 200$, which is ridiculous (VD1). I just came back from an exchange program in England and I bought four text-books for all my four courses, equivalent of about $\$ 150$ for all four of them while one of my textbooks this year costs me $\$ 190$ here. So I cannot understand how there is such a difference in prices. When I was in Japan as well, my textbooks cost me like $\$ 10-\$ 15$ each (VD3a).
\end{abstract}

\title{
6.3.3 Identifying UDEs that affect the quality of learning experiences (VBS)
}

This subsection identifies issues which students feel impact negatively on their learning. The issues touch on lecturers and their teaching styles, the relationship between lecturers and students, as well as tutors.

Table 6.7: Issues impacting on VBS students' learning experiences

\begin{tabular}{|c|c|}
\hline & Issues impacting on VBS students' learning experiences \\
\hline & Lecturer issues \\
\hline 1. & Many lecturers are not enthusiastic, lack passion \& motivation to teach and are boring \\
\hline 2. & Many lecturers lack teaching skills (ability to teach), they do not engage students in lectures \\
\hline 3 & Many lecturers are not passionate about their topics \\
\hline 4 & Some lecturers take teaching as a 'part-time job' \\
\hline 5 & Many lecturers are not passionate with students, 'they are there to click a wage' \\
\hline 6 & Some lecturers do not use technology consistently (posting notes on blackboard) \\
\hline 7 & Students feedback on lecturers is not taken seriously \\
\hline 8 & Some lecturers do not relate experiences of the real world to teaching \\
\hline 9 & Some lecturers do not have real world experiences in their field of specialisation \\
\hline 10 & Many lecturers do not change their teaching styles \\
\hline 11 & Some lecturers have strong accents (difficult to understand) \\
\hline 12 & Some lecturers are not willing to help; always saying 'I am not free at that time' \\
\hline 13 & Some lecturers do not 'honour their office hours' \\
\hline \multirow[t]{2}{*}{14} & Some lecturers use the same teaching style each year \\
\hline & Teaching style \& assessments \\
\hline 15 & There is subjectivity in some lecturing and marking (rubrics \& tutors are subjective) \\
\hline 16 & $\begin{array}{l}\text { There is lack of practical learning in some courses (no hands-on assignments/test or exams- Exams } \\
\text { involve cramming) }\end{array}$ \\
\hline 17 & Many lecturers 'just read their slides'; Some talk in monotone, their tone is very flat, it is like a robot \\
\hline 18 & $\begin{array}{l}\text { There is lack of consistency in some teaching (within a particular lecturer and between lecturers teaching } \\
\text { a common course) }\end{array}$ \\
\hline 19 & There is a lot of weight put on end of semester exams \\
\hline 20 & $\begin{array}{l}\text { Some marking styles are quite specific; you have to state specific things in a specific order, in a specific } \\
\text { way }\end{array}$ \\
\hline \multirow[t]{2}{*}{21} & Some exams and assignments are ambiguous \\
\hline & Courses \\
\hline 22 & There is lack of proper linkage between assignments and course content \\
\hline \multirow[t]{2}{*}{23} & There is much overlap (repetition) between courses-adding nothing of value \\
\hline & Relationship between lecturers and students \\
\hline 24 & Personal interaction between lecturers and students is not there \\
\hline 25 & Most learning is impersonal \\
\hline
\end{tabular}




\begin{tabular}{|l|l|}
\hline 26 & Issues impacting on VBS students' learning experiences \\
& $\begin{array}{l}\text { First year students are not taken seriously; they are not given enough work to motivate them. Basically, } \\
\text { not much is expected of us }\end{array}$ \\
\hline & Tutors \\
\hline 27 & Some tutors do not back their lecturers, they criticise them in tutorials \\
\hline 28 & Some tutors do not communicate well with their lecturers; they do not have a relationship \\
\hline 29 & Some tutors are not confident, some lack ability to communicate \\
\hline 30 & Some tutors are not qualified \\
\hline 31 & $\begin{array}{l}\text { Some tutors do not build classroom environment, they are impersonal and lack interaction skills; they } \\
\text { lack charisma }\end{array}$ \\
\hline 32 & Some tutorials are 'like baby-sitting sessions' \\
\hline 33 & Text-books \\
\hline 34 & The cost of text-books is high \\
\hline & Some text-books do not link well with the course but they buy some lecturers 'best lunches in town' \\
\hline 35 & Living costs \\
\hline
\end{tabular}

The above issues are then analysed for their validity as UDEs based on Cox et al. (2012) protocol for articulating UDEs (refer to Table 3.3). The validation process then reduced the above 35 issues into 12 UDEs as shown in Table 6.8.

Table 6.8: VBS students UDEs

\begin{tabular}{|l|l|}
\hline & UDEs identified by students \\
\hline 1 & Most lecturers are here for research \\
\hline 2 & Many Lecturers do not have passion/motivation/enthusiasm to teach \\
\hline 3 & Many lecturers do not enhance teaching and communication skills \\
\hline 4 & Many lecturers do not use active engagement teaching methods \\
\hline 5 & Many lecturers are not genuinely available for students \\
\hline 6 & There are limited interactions between students and lecturers \\
\hline 7 & Many students do not feel a connection with the course or lecturer \\
\hline 8 & Many lectures are very boring \\
\hline 9 & Many students fail to go to class/lectures \\
\hline 10 & Many lecturers place more emphasis on theoretical skills \\
\hline 11 & There are limited practical activities built into courses \\
\hline 12 & Many students fail to get applicable \& employable skills \\
\hline
\end{tabular}

To identify the 'root cause(s)' of the undesirable issues at VBS learning environment, a focused current reality tree (fCRT) that depicts the logical connections of the above UDEs is constructed. 


\subsubsection{Identifying the 'root causes' of UDEs}

The analysis of students' $f$ CRT identified one critical root cause that seems to contribute to VBS students' undesirable experiences. This is 'lecturers are here [VBS] for research' (Figure $6.3)$.

Figure 6.3: VBS students' $f$ CRT

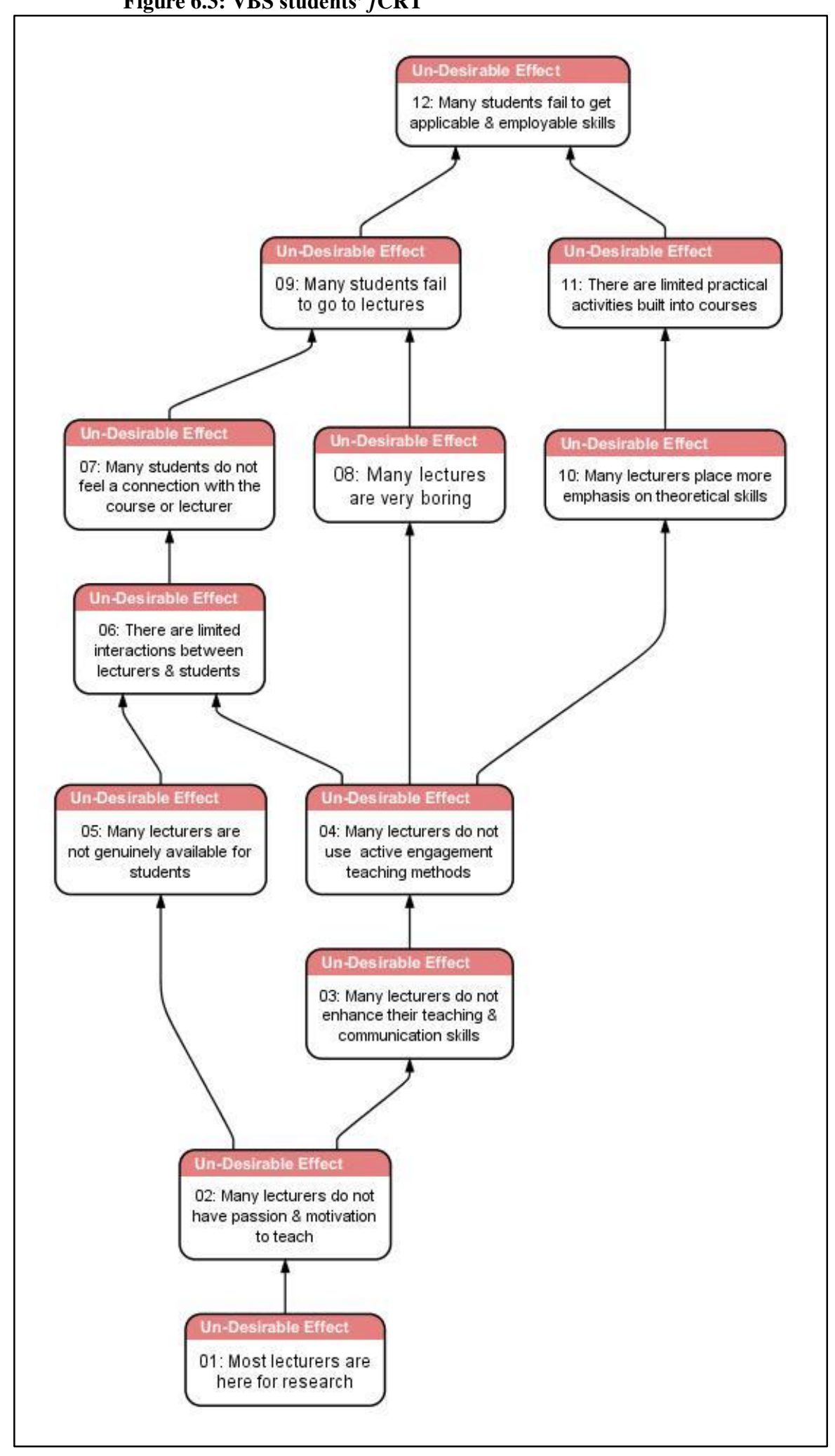


Students perceive that the basic problem causing their less desirable experiences is that 'most lecturers are at VBS for research' and not to teach (UDE 01). As a result, many lecturers focus on their research and do not have passion and motivation to teach (UDE 02).

I find I lose motivation when I find that there aren't any assignments and the lectures are not motivating enough (VD1).

They are academics and some of them are just boring, I am sorry but some of them are really boring people, ooh man. Some of them genuinely don't care. They have been here for research, you can tell. You can tell that they have no passion for teaching and they just don't care at all (VD2).

Because of lack of passion and motivation to teach, many lecturers do not enhance their teaching and communication skills (UDE 03). [The issues of motivation and interactions are discussed in section 6.3.2 above under the goal tree]. Consequently, they (lecturers) do not use active engagement teaching methods (UDE 04) and practical approaches to teaching.

What we have right now is a lot of learning, which we haven't actually tried out. The practical approach to assignments and exams is not being done at the moment (VD3b).

They are also not available for students (UDE 05). This then limits interactions between lecturers and students.

Some are always saying 'I am not free at that moment' always saying that. So it is like an excuse not to help (VIb).

Because of limited interactions, students feel that they do not connect with the lecturer or the course (UDE 07). It is sort of a mechanistic relationship.

Well I know it is a bit weird to impart knowledge about yourself about where you live, your family, kids, but that kind of humanises you. XXX put a picture of his kids when we were studying and stuff like that makes them seem normal, not just weird people you do not know. It definitely brings some level of connection between the lecturer and students (VD2).

Moreover, because many lecturers do not actively engage students in their lectures, lectures become very boring (UDE 08) as discussed above. This makes many students not go to lectures (UDE 09). And because many lecturers place more emphasis on theoretical skills (UDE 10), there are limited practical activities built into courses (UDE 11). Consequently, many students fail to reach their goal of learning, which is to have 'applicable and employable skills (UDE 12).

So you are just thinking 'do I really need to be at University' (VD1).

\section{Other pertinent issues}

Other pertinent issues revolve around the role of lecturer and accent as a barrier to communication. The role of lecturers has changed. Students seem to recognise this quickly. 
I think most lecturers spend a lot of time with the slides so they do not have time to create a positive atmosphere for the students. So they do not create enthusiasm for the students. Because there is a lot of information that we can get from the internet, so lecturers should help students to develop critical thinking, not with a lot of knowledge, which we can Google. If we can have critical thinking, we can create more knowledge (VIa).

Students indicate that the role of lecturers is to develop critical thinking but not to give out knowledge that is available online. But the question is, do lecturers realise that their roles have changed? Are they reflecting on their delivery in view of this need (critical thinking)?

Students also complain about accents as a communication barrier in learning. This is probably because of the diversity of VBS academic staff. This issue affects both domestic and international students in that it hinders their understanding and so it calls for attention.

The lecturers' way of explanation is not well understood. Some lecturers have got very strong accents (VIb).

Some speak in accents you can hardly understand (VD3b).

The fact is that many people are not always conscious of how they speak, but they care a great deal how others speak. This is probably because they want to understand others. But often people assume they are being understood. Perhaps being keen to enhance students' understanding can make lecturers become more conscious of their accents. They can then make a deliberate effort to improve their accents through courses on accent learning. Likewise, students should learn to appreciate other accents as societies across the globe continue to become widely multicultural.

\subsubsection{Synthesis of VBS students' $f$ CRT}

The above discussion simply indicates that students want changes in order to improve their L\&T experiences. So what exactly do students want?

Basically, students suggest very simple changes to help resolve their problems. They are summarised in Table 6.9. 
Table 6.9: What changes do students want?

\section{The changes students want?}

\section{Lecturers}

- $\quad$ Exciting, animated, enthusiastic \& motivated about their courses

- Lecturers 'who know how to teach'

- $\quad$ Passionate about their subjects and concerned about students

- Know students by name

Teaching style \& assessment

- $\quad$ More feedback on students' work (critique)

- $\quad$ More practically oriented teaching (use practical examples)

- $\quad$ Practical assignments \& practical group work

- $\quad$ Get rid of slides \& focus on developing critical thinking

- Give participation marks in lectures

- Bring additional information, expertise, own experience (offer diversity)

- Use right body language

- $\quad$ Link course content \& text-books

- Tie course content to assignments

- Use guest speakers

- Ongoing feedback of teaching

- $\quad$ Make feedback on teaching online \& available to students

- Change teaching styles

- Objective lecture notes

- $\quad$ More emphasis on internal assessments, not exams

- $\quad$ Exam setting (mix essay and choice questions)

- More instructions

- $\quad$ More revision resources (past exams)

Tutorials

- $\quad$ More tutorials \& fewer lectures

- $\quad$ More participation in tutorials

- Good relationships between lecturers \& tutors

\subsubsection{Summary of students' analysis}

This subsection has discussed students' views of their learning goal that is identified as 'getting a qualification with applicable and employable skills'. Three critical success factors are identified: (1) motivation and dedication, (2) interactions, (3) and resources. The necessary conditions are also identified. Then, the less than desirable issues that impact negatively on the achievement of the learning goal are discussed and their root cause is identified as lecturers are here for research'. The resolution of this dilemma is discussed in Chapter 8. 


\subsection{VBS lecturers' data analysis}

This subsection discusses lecturers' views of their goal(s) of teaching. The critical success factors and the necessary conditions to help achieve the goal(s) are also discussed. Then, the less than desirable issues that impact negatively on the achievement of the teaching goals are analysed and their root causes identified. The lecturers' view of the resolution of the problems ailing the L\&T system is finally highlighted.

\subsubsection{Description of VBS lecturers}

There are twelve lecturers who participated in this case. These lecturers were selected using purposive, and convenience techniques. The lecturers were selected from five out of the six schools of VBS. The School of Government ( $\mathrm{SoG}$ ) was purposely excluded because it did not closely match the characteristics of the first case (Kenyan Business School). The composition is shown in Table 6.10. Coincidentally, the sample is gender balanced.

Table 6.10: Composition of VBS lecturer
\begin{tabular}{|l|c|c|c|}
\hline School & Male & Female & Total \\
\hline SIM & 0 & 1 & $\mathbf{1}$ \\
\hline SEF & 1 & 1 & $\mathbf{2}$ \\
\hline SACL & 1 & 2 & $\mathbf{3}$ \\
\hline SoM & 3 & 0 & $\mathbf{3}$ \\
\hline SMIB & 1 & 2 & $\mathbf{3}$ \\
\hline Total & $\mathbf{6}$ & $\mathbf{6}$ & $\mathbf{1 2}$ \\
\hline
\end{tabular}

There were 12 face-to-face interviews. The recorded time ranged from 25 to 64 minutes with an average of 47 minutes (Figure 6.4).

Figure 6.4: VBS lecturers' interview time

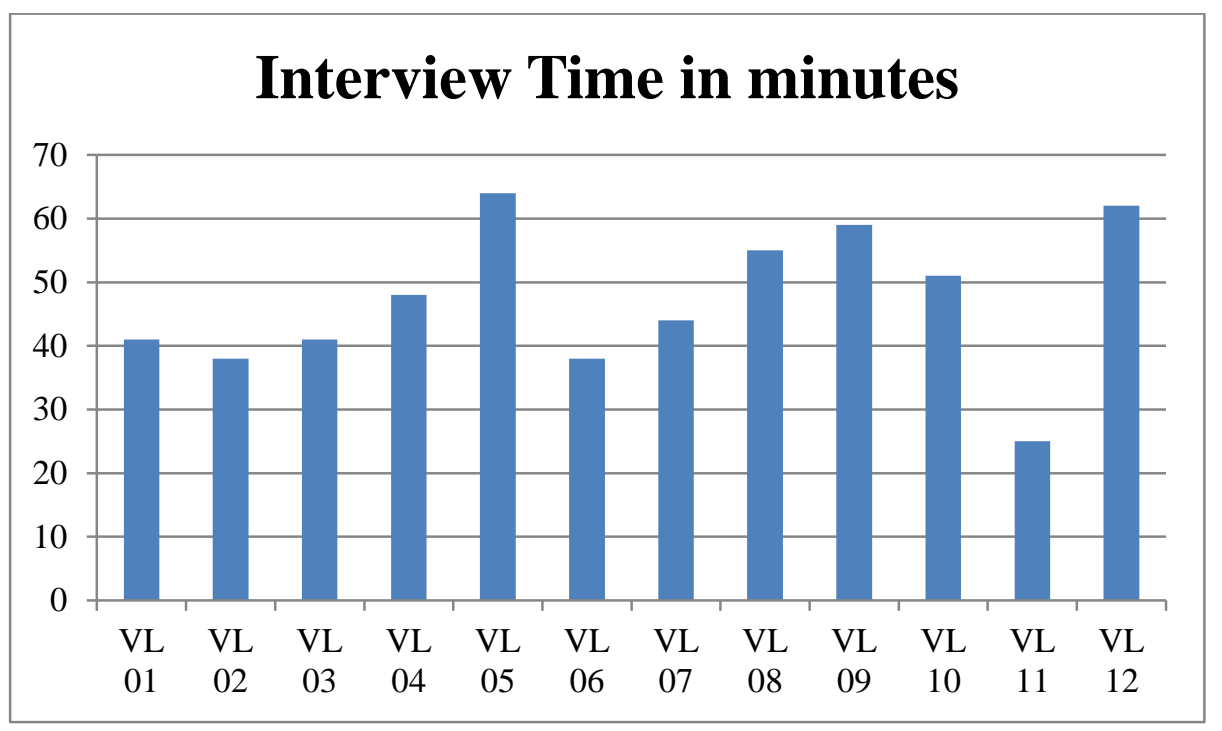


The lecturers interviewed had a wide range of experience from 3 to 28 years (Figure 6.5). All of them had PhD qualifications, and their positions ranged from lecturers to senior lecturers to associate professors. In addition to their teaching and research work, some lecturers hold parallel administrative positions. Three lecturers have won teaching or teaching-related awards.

Figure 6.5: Teaching experience of VBS lecturers

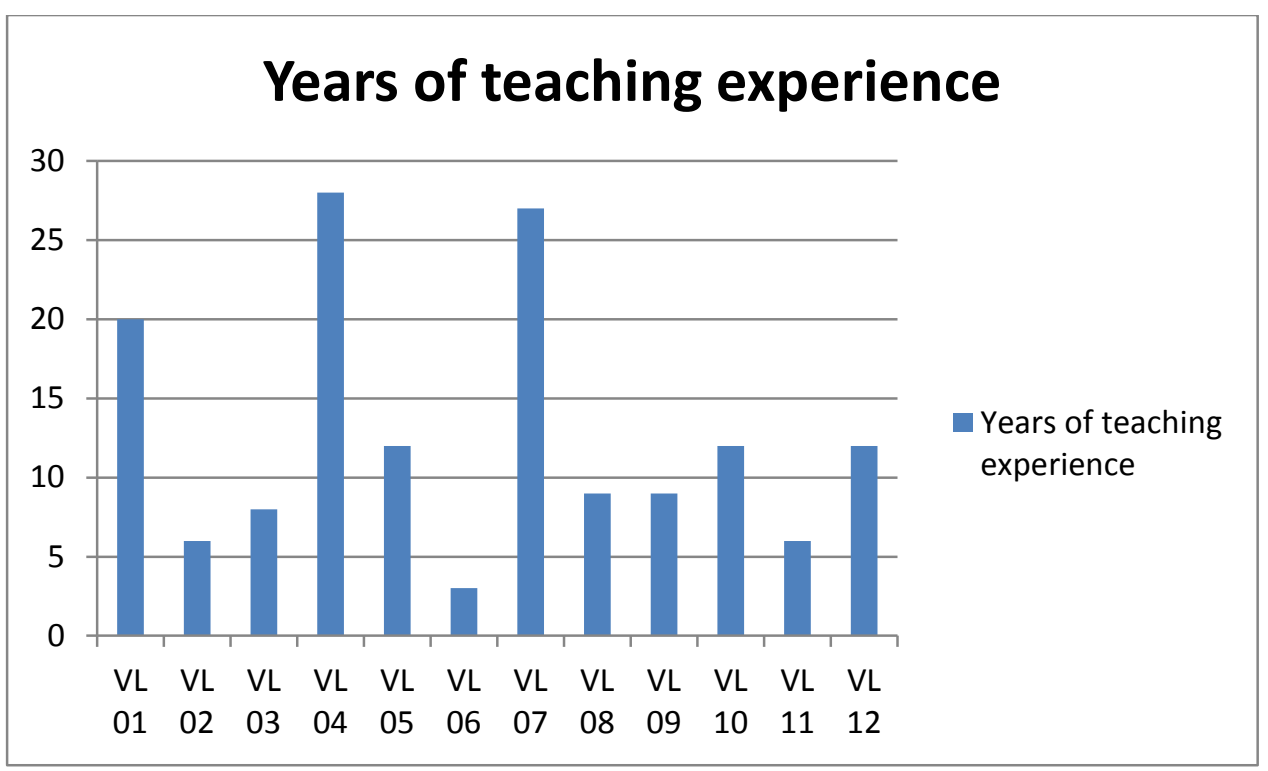

\subsubsection{Identifying VBS teaching goal, CSFs, and NCs}

\section{Identifying a common goal}

The unitisation of lecturers' descriptions of their teaching goals yielded a common goal of 'helping students to develop competence in thinking and/or cultivate intellectual independence in students'. The common phrases used in the unitisation are in italics in Table 6.11. They include: analytical, internalise, make connections, solve problems, understand, and think. As suggested in Table 6.11, not all participants expressed their goal of teaching in those common phrases. 
Table 6.11: VBS lecturers' goal descriptions

\begin{tabular}{|c|c|}
\hline Lecturer & Goal description \\
\hline VL01 & $\begin{array}{l}\text { Change what the students think, help them change their mental models, new } \\
\text { information, and different information, challenge what they know already \& reinforce } \\
\text { what they know already. }\end{array}$ \\
\hline VLO2 & $\begin{array}{l}\text { I would like people to go out and do jobs competently, people taking entry level jobs } \\
\text { after they finish their studies and do it competently. That to me is the core of what we } \\
\text { are about. My dream is to prepare students for the labour market. }\end{array}$ \\
\hline VL03 & $\begin{array}{l}\text { The primary role of the university is to cultivate intellectual independence. That is } \\
\text { the number one goal. To help students get intellectual independence. }\end{array}$ \\
\hline VL04 & $\begin{array}{l}\text { I want to help students understand. The first objective is to keep them awake. I have } \\
\text { to keep them interested, engaged and I want them to say at the end of the lecture 'hey, } \\
\text { that was interesting' 'hey, that was good'. }\end{array}$ \\
\hline VL05 & $\begin{array}{l}\text { My goal is the university's goal. The university's goal is to retain students to } \\
\text { completion. My goal as a lecturer is to meet the university's strategic guidelines of } \\
85 \% \text { retention for completion. As a teacher, my goal or my role is to try and get the } \\
\text { best out of the students. My goal is to teach good students and make them better, get } \\
\text { the best. Equivalent idea would be to get a student and see if I can help them get a } \\
\text { Nobel prize. Very few students would be able to do that. But that should be the } \\
\text { lecturer's goal. To get the best. }\end{array}$ \\
\hline VL06 & $\begin{array}{l}\text { Overall my goal is to turn out some really good graduates who are analytical, who are } \\
\text { able to foot it anywhere against any other university graduate. We want highly } \\
\text { analytical graduates who can be leaders, who can take their place in the working } \\
\text { world and are able to create their options. }\end{array}$ \\
\hline VL07 & $\begin{array}{l}\text { I would say that what I am teaching them to do most of the time is solve problems in } \\
\text { the real world... So it is trying to make them appreciate some of the is sues that are out } \\
\text { there. }\end{array}$ \\
\hline VL08 & $\begin{array}{l}\text { And obviously, what people learn in class is not necessarily what they do when they } \\
\text { get out there... And so I believe it is important to have them understand the } \\
\text { arguments that go on...I suppose the goal of teaching in HE as Victoria people would } \\
\text { say, is to make people think. }\end{array}$ \\
\hline VL09 & $\begin{array}{l}\text { To have the students achieve their learning goals... by clearing away the barriers } \\
\text { related to learning. }\end{array}$ \\
\hline VL10 & $\begin{array}{l}\text { I want the students to internalise what we are talking about... truly understand and } \\
\text { make connections. }\end{array}$ \\
\hline VL11 & $\begin{array}{l}\text { My personal goal of teaching is to help students achieve what they want to achieve in } \\
\text { life... If we do a good job of teaching them, hopefully they will be able to go on and try } \\
\text { to achieve that. }\end{array}$ \\
\hline VL12 & $\begin{array}{l}\text { To help students to deepen their insights of the subjects and understand better } \\
\text { about their ideas. }\end{array}$ \\
\hline
\end{tabular}

Some indicated that their goals are to help students to achieve their own learning goals (VL 09, VL 11) although it is not clear whether they understood what the students' 'learning goals' are. Moreover, the responses also indicate different levels of interpretations of the goals.

Some interpretations appear to be at a specific course level, a general undergraduate level, university level and individual levels. This indicates that there is no common understanding of 
the goal of teaching at VBS. In support of this, one participant indicated that the first important factor to achieve the goal of teaching is to have 'a general understanding by academics of VBS of what it is that we are trying to achieve. A general commitment to the thought, 'this is the goal' (VL 02).

\section{Determining CSFs and NCs}

VBS lecturers identified a number of CSFs and NCs that they deem as important in the achievement of their goals of teaching. Table 6.12 provides a list of these factors.

To determine the CSFs and NCs to be included in the goal tree, similar to previous sections, 'unitisation' is used. In this particular process, only one CSF is identified; motivated \& passionate students. The other CSFs turned out to be NCs in the strict sense of prerequisites; otherwise they can still be termed as CSFs. Indeed, Dettmer (2007, p.72) notes that the only real difference between a CSF and NC is their degree of specificity. Many of CSFs identified by lecturers ended up as NCs during the unitisation process. The number labelling (e.g. NC3) of the CSF and NCs in Table 6.12 indicate the factor under which the phrase is unitised in the goal tree. A few success factors are unitised under the goal. 
Table 6.12: CSFs \& NCs (VBS lecturers)

\begin{tabular}{|c|c|c|}
\hline Lecturer & Critical Success factor & Necessary conditions \\
\hline \multirow[t]{4}{*}{ VL 01} & Sufficient time (NC6) & Less adminis trative work \\
\hline & Incentives \& rewards (NC8) & $\begin{array}{l}\text { Allocate time to prepare \& create teaching materials } \\
\text { (NC6) }\end{array}$ \\
\hline & & Allocate time for PHELT course (NC6) \\
\hline & & Reward good teachers (NC8) \\
\hline \multirow[t]{3}{*}{ VL 02} & Common understanding of the goal (NC5) & Leadership sets common understanding (NC9) \\
\hline & Common set of expectations (NC5) & $\begin{array}{l}\text { Commitment of VBS staff, discussions \& feedback on the } \\
\text { process (NC7) }\end{array}$ \\
\hline & Employer feedback & Get employers' views through research \\
\hline VL 03 & $\begin{array}{l}\text { Expose students to different ideas (NC2) } \\
\text { critical thinking (goal) }\end{array}$ & $\begin{array}{l}\text { Creativity \& diversity, academic freedom, alternative } \\
\text { perspectives, less structured curriculum, less structured } \\
\text { approach to teaching (NC2) }\end{array}$ \\
\hline \multirow[t]{2}{*}{ VL 04} & Relevant materials (NC3) & Contextualised materials (NC3) \\
\hline & Eas y to understand materials (NC3) & Practise the skills \\
\hline VL 05 & Students' definitions of their goals & Understand students' goal \\
\hline \multirow[t]{3}{*}{ VL 06} & Motivated staff (NC8) & Employ motivated staff \\
\hline & Promote student engagement (NC2) & Motivated students (CSF) \\
\hline & Improved lecture rooms & \\
\hline \multirow[t]{4}{*}{ VL 07} & Motivated students (CSF) & $\begin{array}{l}\text { Relevant examples, practical work, feedback, provide } \\
\text { diverse resources (NC3) }\end{array}$ \\
\hline & Develop problem solving skills (goal) & Ability to learn on own, on-going learning (CSF) \\
\hline & Communication skills (goal) & \\
\hline & Research skills (goal) & Differentiate reliable information \& sources (goal) \\
\hline VL 08 & Understand arguments (goal) & $\begin{array}{l}\text { Relevant examples, practice-based learning, encourage } \\
\text { critical thinking (NC3), (goal) }\end{array}$ \\
\hline VL 09 & Remove barriers related to learning & $\begin{array}{l}\text { Provide learning resources, set expectations, set high } \\
\text { goals (NC1), (NC3) }\end{array}$ \\
\hline VL 10 & $\begin{array}{l}\text { Students take ownership, passionate about } \\
\text { learning, students learn the way that suits } \\
\text { them best (flexible learning), students are } \\
\text { passionate (CSF) }\end{array}$ & $\begin{array}{l}\text { Create scenarios \& activities, use innovative teaching } \\
\text { styles, make connections, reflective learning, appeal to } \\
\text { students' sense of maturity (NC2) }\end{array}$ \\
\hline \multirow[t]{3}{*}{ VL 11} & Effective teaching (NC4) & PHELT course \\
\hline & Effective communication (NC4) & Understand students' expectations \\
\hline & Student facilities (NC3) & $\begin{array}{l}\text { Peer assisted study sessions (PASS), mentoring } \\
\text { schemes, student learning support services (SLSS) (NC3) }\end{array}$ \\
\hline VL 12 & $\begin{array}{l}\text { Students to have a holistic approach to } \\
\text { learning (goal) }\end{array}$ & $\begin{array}{l}\text { Analyse \& understand issues, check understanding, } \\
\text { challenging questions (goal) }\end{array}$ \\
\hline
\end{tabular}

\section{VBS lecturers' goal tree}

As indicated earlier, a goal tree uses necessary condition logic because it describes the requirements or prerequisites needed to achieve a desired outcome. We can read the goal tree (Figure 6.6) as follows: in order to help students to develop intellectual independence (goal), 
students must be motivated and passionate about learning (CSF). And in order to have motivation and passion among students, the teaching staff must set high expectations (NC1), must engage students through creative and diverse teaching methods (NC2), and must use contextualised and relevant materials that students can identify with, and must provide diverse learning resources (NC3).

Figure 6.6: VBS lecturers' goal tree

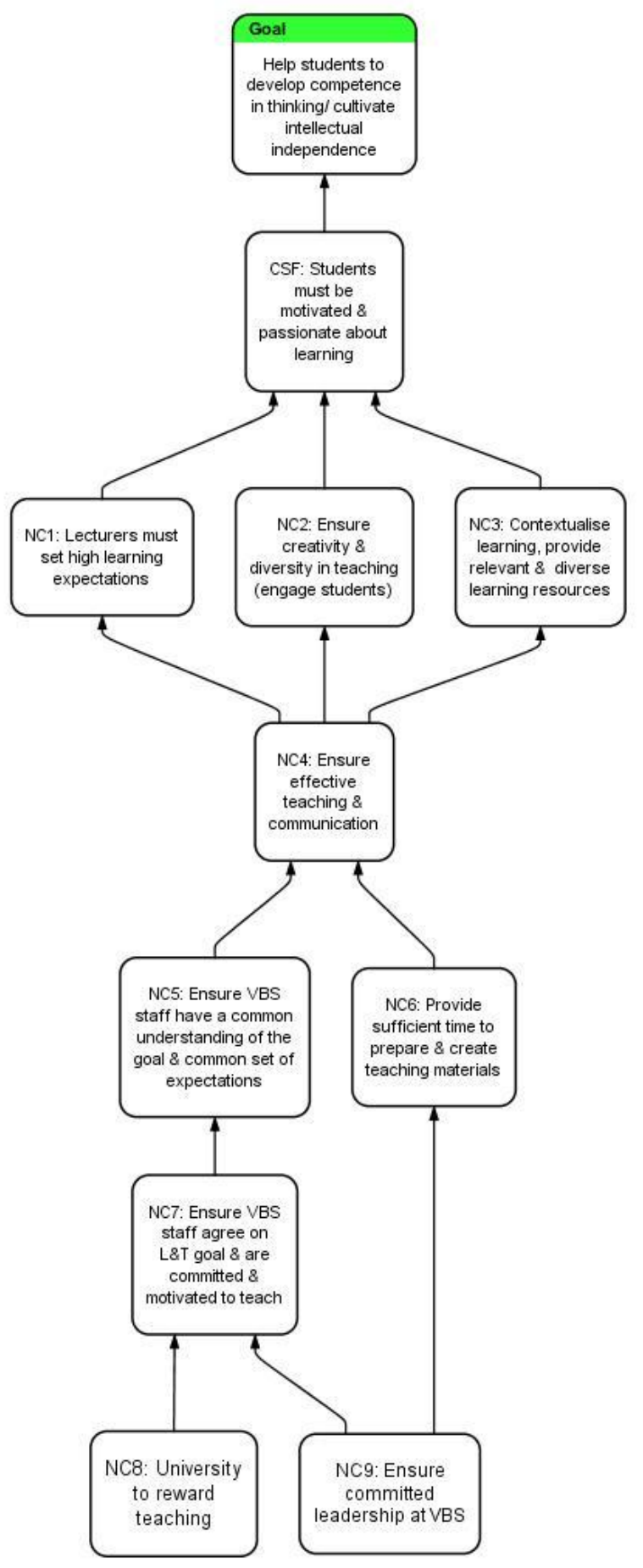


Furthermore, in order for staff to be able to set high expectations, engage students and provide appropriate learning resources, teaching staff must be effective in teaching and in communicating (NC4). And in order for teaching staff to be effective in teaching and communicating, on the one hand, VBS staff must have a common understanding of the goal of teaching, and a common set of expectations (NC5). Indeed, it is apparent from the responses that participants do not have an explicit goal of teaching. This point is best expressed by the following comment:

\begin{abstract}
I do not think students are taught a lot of stuff looking at the list of graduate attributes \{profile\}, which stuns me because, in many other institutions you have to know what they are. You have to be able to say in class, 'this is addressing graduate attribute $\mathrm{X}$ or $\mathrm{Y}$ '. But here, do I even know what our graduate attributes \{profile\} are? Would I know where to find them? ${ }^{9}$ (VL 09).
\end{abstract}

Thus, in order for VBS to have a common understanding of the 'goal' and 'set of expectations' (NC5), VBS staff must commit themselves to agree on a common 'goal' and 'set of expectations' (NC7). Moreover, VBS leadership must drive the commitment (NC9) and university must reward teaching (NC8).

Moreover, in order for teaching staff to be effective in teaching and communicating, the teaching staff must have sufficient time to prepare and create teaching materials (NC6). And in order for the teaching staff to have sufficient time to prepare and create teaching materials, there must be committed leadership (NC9). Apparently, participants feel that the university does not value teaching as much as research. Teaching is not seen as a good thing.

\footnotetext{
'It is not a career enhancing move. It is not seen as a good thing spending too much time on teaching ...if you are too keen on your teaching, it is seen as a bad thing. You should spend more time doing research (VL 01)'.

'...comments like 'oh well, we do not employ people who say that they are good teachers' (VL 06)'
}

In order for teaching to be rewarded, the university and VBS leadership must be committed to rewarding teaching. But why should teaching be rewarded? What value does it add? One participant felt that:

Failure to spend quality time with students leads to loss of reputation, which cannot be bought by money... \{spending more \} time with students, can help students to be more creative, who can then be a great asset in future as alumni of VIC (VL 12).

\footnotetext{
${ }^{9}$ This may be partially explained by the fact that graduate attributes/learning goals were in a state of flux at the time of the study to realign them with the new Victoria Graduate Profile. They were therefore not clearly displayed.
} 
Another one indicates:

I worry whether the quality of our education that the current students are getting, whether the students in 10 years' time will look back and say how much value they got. I think that is a real strain for Victoria. I often see people who were at this business school who say they see no value or they did not get any value for their time (VL 01).

So people look at value from different perspectives. Lecturers seem to perceive it differently from the university management. But what are the performance measures that the university has set? Research output! Does this pose a dilemma for L\&T? This question leads us to the next section that explores more dilemmas related to L\&T. Chapter 8 demonstrates how the university might tackle the dilemmas, including the tensions between research and teaching.

\subsubsection{Identifying UDEs that affect quality of teaching experiences (VBS)}

Lecturers identify many issues that impact undesirably on their teaching experiences. Table 6.13 provides a list of these factors. The long list points to the areas that might need attention but does not necessarily indicate that lecturers are unhappy with their teaching jobs. Indeed, many indicate that they enjoy their work

So I do not want you to think that am unhappy, I enjoy my work. I feel very fortunate that I am doing a job that I like doing' (VL 04).

Table 6.13: Issues impacting on VBS lecturers' quality of experiences of L\&T

\begin{tabular}{|c|c|}
\hline & Issues impacting on VBS lecturers' quality of experiences of L\&T \\
\hline & Management issues \\
\hline 1 & University structure is risk averse \\
\hline 2 & The university bureaucracy overlays teaching \\
\hline 3 & University has chosen to reward research more than teaching \\
\hline 4 & University does not recognise good teaching \\
\hline 5 & University has over-played a number of rules \\
\hline 6 & $\begin{array}{l}\text { The senior management of VBS and university do not understand the purpose of the university- to } \\
\text { inculcate intellectual independence }\end{array}$ \\
\hline 7 & The split campus makes it difficult for students to consult with lecturers \\
\hline 8 & Some schools are intentionally short-staffed \\
\hline 9 & Rules change all the time, we do not always know what the rules are \\
\hline 10 & $\begin{array}{l}\text { With IT, some things work, others do not. 'this does not work if you are using Firefox, this does not } \\
\text { work if you are using Explorer' }\end{array}$ \\
\hline 11 & Sometimes you spend much time filling in forms that a secretary can fill in \\
\hline 12 & $\begin{array}{l}\text { There is a lot of paper work involved if you want to do teaching that is not the norm. It is very time } \\
\text { consuming }\end{array}$ \\
\hline 13 & Administratively, it is frustrating to find out the effectiveness of teaching \\
\hline 14 & There is no focus on the graduate attributes/profiles \\
\hline 15 & There is lack of training on how to handle an earthquake situation in a lecture \\
\hline 16 & $\begin{array}{l}\text { Lecturers have many administrative duties: organise workshops, attend committees, teach post-graduate } \\
\text { courses, post-graduate supervision, develop new courses from time to time, yet there is no reduction of } \\
\text { course loads }\end{array}$ \\
\hline 17 & $\begin{array}{l}\text { Lecturers get paid academic salaries and part of what they do is administrative jobs that could be done } \\
\text { by people who are not paid academic salaries }\end{array}$ \\
\hline 18 & Top management do not understand the amount of work that academic staff have \\
\hline \multirow[t]{2}{*}{19} & Human capital is not valued \\
\hline & Teaching issues \\
\hline
\end{tabular}




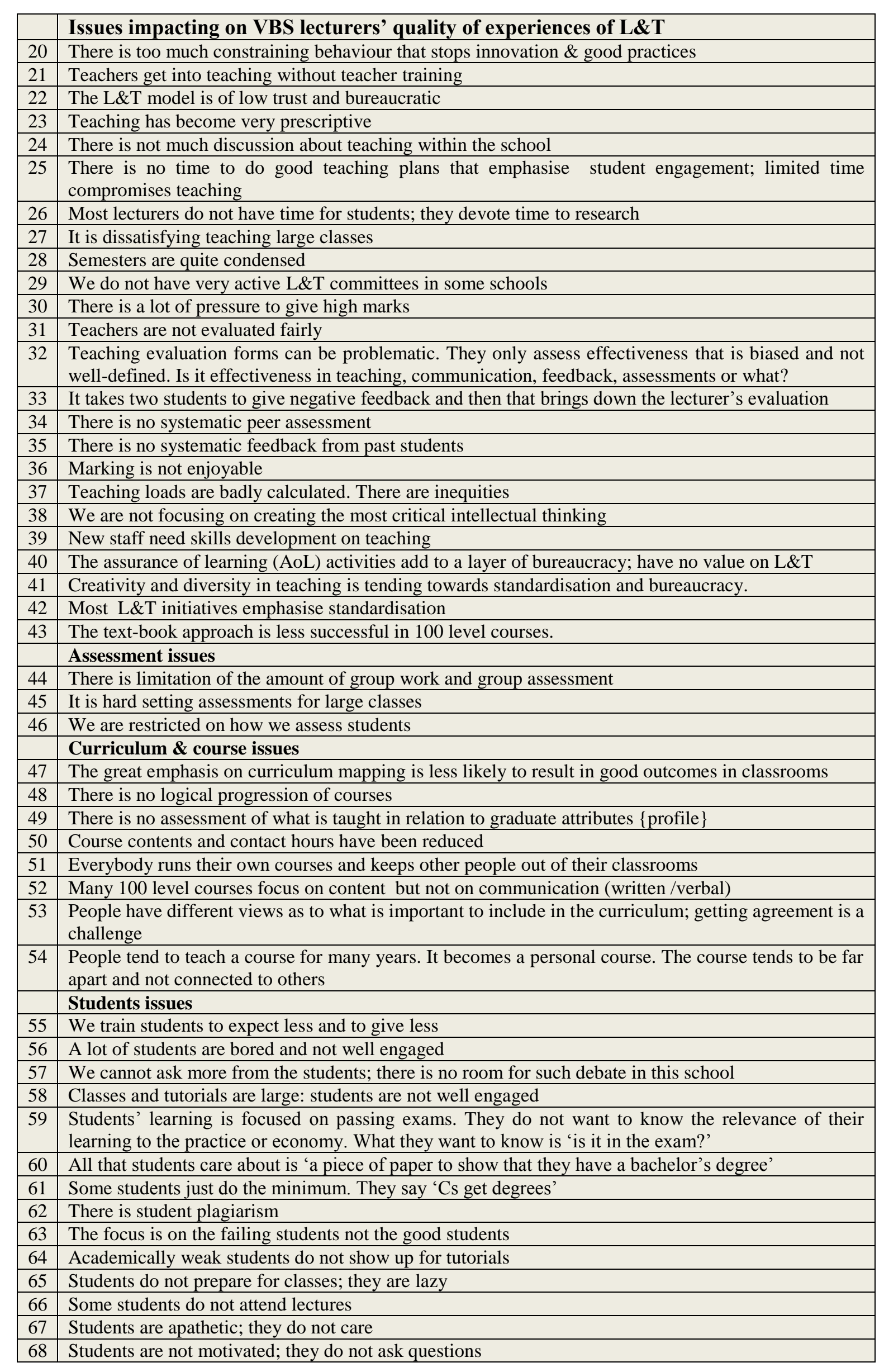




\begin{tabular}{|l|l|}
\hline & Issues impacting on VBS lecturers' quality of experiences of L\&T \\
\hline 69 & Most students in $1^{\text {st }}$ year are bored; they just look at you \\
\hline 70 & There is a growing rude helplessness among $1^{\text {st }}$ years; they want to be spoon-fed. \\
\hline 71 & Students do not take education seriously \\
\hline 72 & Students are given too much voice \\
\hline 73 & The system does not really care about students \\
\hline 74 & Most staff do not have patience with students \\
\hline 75 & Students expect to be told everything they need to know to pass exams \\
\hline 76 & Our students have terrible communication skills \\
\hline 77 & I do not like not knowing students' names \\
\hline & Teaching \& research \\
\hline 78 & Teaching is largely inferior to research \\
\hline 79 & We do not get rewarded for teaching \\
\hline 80 & Teaching work is quite heavy; it compromises the amount you can put into research \\
\hline 81 & People do not genuinely think that teaching is as important as research \\
\hline 82 & Spending too much time on teaching is not seen as a good thing \\
\hline & Tutors \\
\hline 83 & Tutors are not qualified to be teachers \\
\hline 84 & Some tutors are a bit removed from the lecturers \\
\hline 85 & Sometimes lecturers do not have contacts with all tutors \\
\hline 86 & Tutors spend all their time explaining things to academically weak students \\
\hline
\end{tabular}

The above issues do indicate that there is a part of the L\&T system at VBS that is not operating as might be desired by the participants. A common reaction might be to attempt to tackle each of the symptoms individually/in isolation or to prioritise some without realising that are they all connected, and there is an easier way if this is exploited. The next step involves identifying the UDEs. The process of identifying is guided by a protocol that specifies the characteristics of well-articulated UDEs (see Table 3.3 in Chapter 3). The following UDEs are identified. 
Table 6.14: VBS lecturers' UDEs.

\begin{tabular}{|c|c|}
\hline 1 & Teaching is not rewarded at the university \\
\hline 2 & Teaching is not prioritised at the school \\
\hline 3 & Teaching skills are not emphasised \\
\hline 4 & Many lecturers are hired with inadequate teaching skills \\
\hline 5 & Some schools within the business school do not have active L\&T committees \\
\hline 6 & $\begin{array}{l}\text { There is no sytematic planning on teaching load \& administrative duties in some } \\
\text { schools }\end{array}$ \\
\hline 7 & Many lecturers have many admin duties \\
\hline 8 & Many lecturers have heavy teaching load \\
\hline 9 & Many lecturers have insufficient time to engage with teaching materials \\
\hline 10 & Many lecturers have insufficient time to train for PHELT \\
\hline 11 & Many lecturers have inadequate teaching skills \\
\hline 12 & There is little formal support for L\&T dialogue \\
\hline 13 & Everybody runs their own courses \\
\hline 14 & There is no common understanding of teaching goal among teaching staff \\
\hline 15 & There is no common set of expectations on courses among teaching staff \\
\hline 16 & There is no systematic focus on graduate profile \\
\hline 17 & Many lecturers have low expectations (from students) on the courses \\
\hline 18 & Many lecturers spend teaching time doing research \\
\hline 19 & Many lecturers do not raise students expectations \\
\hline 20 & There is inadequate integration of creativity \& innovation in L\&T \\
\hline 21 & There is limited diversity in L\&T styles \\
\hline 22 & Many students are not motivated to learn \\
\hline 23 & Many students are not fully engaged in learning \\
\hline 24 & Many students fail to gain full intellectual independence \\
\hline 25 & Many lecturers concentrate on doing research \\
\hline
\end{tabular}

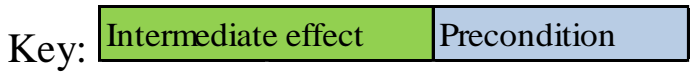

\subsubsection{Identifying 'root causes' of UDEs}

After the identification of the UDEs, the next step involves analysis of logical connections of the UDEs to form a focused fCRT (Figure 6.7). The basic aim is to identify the root causes of all the UDEs. 
Figure 6.7: VBS lecturers' $f C R T$

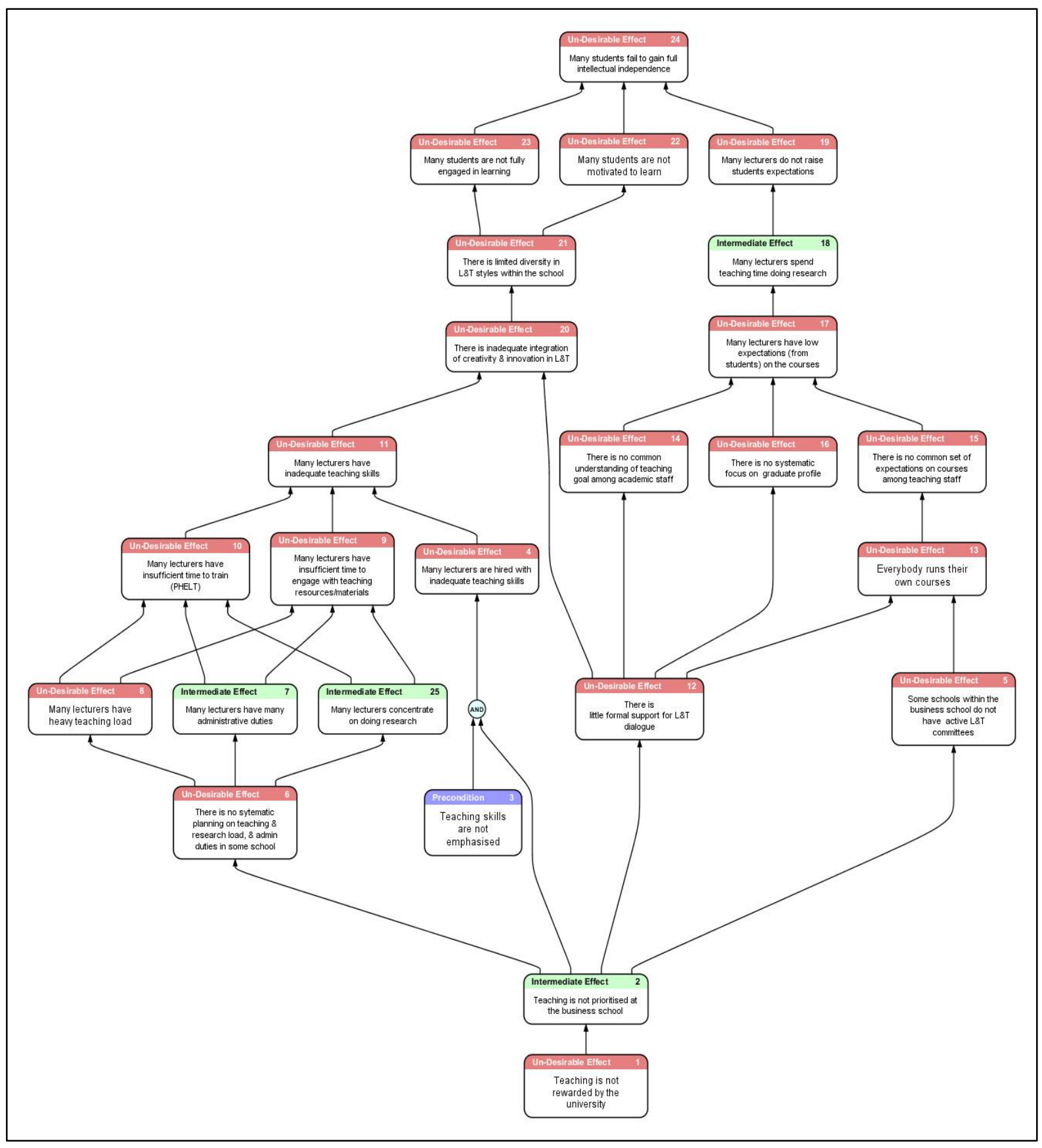

The $f$ CRT identifies lack of teaching rewards (UDE 1) as the critical root cause of undesirable experiences of teaching. If teaching is not rewarded, then it means that people do not give it priority (UDE 2). This is because people will generally tend to work towards what is valued and what is rewarded. The lack of prioritisation of teaching then gives rise to two main issues discussed below: 


\section{Leadership-related issues}

People tend to point to management regarding lack of prioritisation of teaching within the university in general.

The university has multiple objectives and so it does essentially choose one over the other. There are two main ones: research and teaching. It has chosen one over the other. It has chosen to reward one more than the other. If you don't reward people to do better, then people go for the minimum. And that does not get high quality teaching. It just goes for the lowest common denominator. So if you feel that minimum teaching is enough, so you are going to get minimum from everybody (VL 01).

As a result, even the leaders within the school do not seem to encourage discussions on L\&T (UDE 12) or strong and active committees of L\&T in some schools (UDE 05).

I think it is much to do with how you agree with people and that will take some discussion and it takes the leadership as well about what to achieve as a group. It will also require some sort of peer review or feedback on teaching that you can get, but it is very informal and done very loosely. And there is not much discussion about teaching within the school (VL 02).

We do not have a very active L\&T committee in our school. I think we need a better functioning L\&T committee (VL 08)

Consequently, everybody runs their own courses (UDE 13), which means that there is no common set of expectations on course content and design (UDE 15).

Everybody runs their own courses and keeps other people outside your own classroom... But we can't do that if we just do it on one course and a whole bunch of others are not. And really there is no such room for such debate in this school (VL 02).

So it becomes a personal course and so the course tends to be far apart from each other and they are not connected (VL 07).

It means to me that the content has been removed and the academic standards have been lowered (VL 04).

Another one would be a common set of expectations and teaching techniques. So that the students would really know that if they do this, this is what is expected of you regardless of the course (VL 02).

The lack of much discussion on L\&T then implies that there is no systematic focus on integrating graduate attributes/profile in course designs (UDE 16) and that there is no common understanding of the goal of teaching (UDE 14).

I do not think students are taught a lot of stuff looking at the list of graduate attributes \{profile\}, which stuns me because in many other institutions you have to know what they were. You have to be up to say in class, 'this is addressing graduate attribute $\mathrm{X}$ or $\mathrm{Y}$ '. But here, do I even know what our graduate attributes \{profile\} are? Would I know where to find them? So I suspect there is no focus on it (VL 09).

Consequently, there are lower expectations from the courses (UDE 17).

I think we train students to expect less and to give less back to us. I think they work harder in high school than students here do. And I think we try to train them to behave like that. 'Ooh go get jobs to manage your time', then we do not have to deliver as much. But I think we are sending messages to them that 
'well, don't worry about that'. This is something I do not see for example in the law school. Law students are still made to work hard. I do think School of Business students work a lot less than the Law students, and students who do the bachelor's degree know that. We see that all the time. But it's because they get away with it by doing very little (VL 01).

Moreover, the lower expectations from courses implies that most lecturers spend most of their time doing research (UDE 18) and that they do not ask much from the students so that they can have enough time for research.

And if you can stop spending an hour on teaching that means an hour of research, then you are doing a better job. And if you tell people that you are spending lots of time on teaching, they will say you are wasting your time... And so that is helpful for us because they\{students $\}$ do not do so much, so we can spend their time on other/our things (VL 01).

\section{Lecturer-related issues}

Because teaching is not prioritised, (UDE 2) then, there is no systematic planning of teaching loads and administrative duties (UDE 6).

The teaching loads are very badly calculated. If you look at how they are allocated, there is no relationship between how much people complain about their teaching load and how much of the teaching they do. And I think there are a lot of inequities in the system really (VL 02).

As a result, many lecturers have many unnecessary administrative duties (UDE 7) as well as heavy teaching load (UDE 8).

The situation is that lecturers have many administrative duties, have to organise workshops, attend committees, have post-graduate courses to teach, post-graduate supervision, develop new courses from time to time, yet there is no reduction of course loads (VL 12).

The number of hours allocated for teaching is something that needs to be logically thought out and regarded so that we do not have unbearable workload on people. In this school we have some staff who teach overload because of the number of students and I think that is not a very good position for us to be in. Some people feel that they must have been made to be in that position where there is no one else to teach the course in that particular trimester, so basically you have to do it. Now you get to be paid for it but I do not want this money. I do not want to be paid for it. I want a normal workload. I want the workload to be fair across everyone and not to have this school intentionally short-staffed and saying, well we do not know if we are going to need someone (VL 08).

Subsequently, many lecturers do not have sufficient time to engage with teaching materials

(UDE 9) or even to undertake a Postgraduate Certificate on Higher Education Learning and

Teaching (PHELT) course that is offered free to staff at VUW.

I think the other thing that would probably make a lot of difference is the PHELT course. In terms of becoming a better teacher, that's really important but it is time consuming. It is good if you want to improve your teaching but not if you want to get a university career that is about publishing (VL 01).

Well there is a HE certificate but there is time constraint as well, you have to go for some years-PHELT, I would like to do but I just do not have time at the moment (VL 06).

And because teaching is not prioritised by the university, why should lecturers prioritise it either? Yet, even at the hiring stage, teaching skills are not always emphasised (UDE $3 \& 4$ ).

I would like to see far more emphasis on skills development in teaching particularly with the new people coming through (VL 06). 
Consequently, many lecturers have inadequate teaching skills (UDE 11), which means that they do not integrate creativity and innovations in teaching (UDE 20). As a result, they do not provide diverse teaching styles (UDE 21).

And so we need innovation and management and administrators who understand how to give that innovation (VL 01).

But, there are those lecturers who feel that creativity and innovation are being curtailed by the university management.

I think the university has over-played a number of roles. I think there are too many constraints on teachers doing good jobs. There are lots of rules that stop things from happening. The obvious example is the limitation on the amount of group work and group assessment that you can do (VL 01).

We are restricted on how we assess students. We are limited in use of multiple choice questions as an example, which to me is totally wrong because assessment should be related to pedagogy. So having those rules is almost a view that this institution does not trust us as lecturers (VL 05).

In my view, creativity and diversity in teaching is tending towards standardisation and bureaucracy (VL03).

If you want to find out if teaching is more effective, you have to deal with administration, that is what I find frustrating and you want to leave a lot of time to be able to do it. If you want to do a field trip you need to do an off-site, risk-assessment form. So you need to do a lot of paper work to be able to take students off campus. If I want to find out what the students like when I am doing my teaching, I have to do a lot of paper work. The same way you did for this $\{\mathrm{PhD}$ research $\}$ to get approval from the human ethics committee (HEC), every year and all of that needs to be planned months ahead because all those committees don't meet all the time, they aren't that flexible. So it takes a lot of effort and it has nothing to do with teaching... but that is very frustrating and very time consuming and if you do not do it on time you might not be able to do it at all. It is just all the paper work... (VL10).

Limited creativity and innovation together with limited skills on teaching lead to a situation where students are neither motivated to learn, (UDE 22) nor well-engaged in learning (UDE

23). But views on student motivation are two-sided. Some lecturers feel that the context of VBS contributes to students' apathy.

To be honest, there are a lot of students who are quite bored. Not well engaged. The current deal is that we do not ask that much effort from them and they do not give much of it. That is the deal. It is not the right deal but it is the one now. If we ask more of the students, then they would give more. And they want to give more (VL 02).

Others blame the tertiary education system for enrolling students who purportedly do not care about learning.

So as we get our students into tertiary education who don't care about learning. All they care about is 'give me that piece of paper to show that I have got my Bachelor's degree' (VL 05).

Some students say 'Cs get degrees'. So some students will be looking to just do the minimum and they are happy, they do not care (VL 07).

Students do not really want to know the relevance of their learning to the practice or economy, what they want to know is 'is it in the exam?' (VL 08). 
When I ask a question some time at the end of the lecture, students will say to me, will this topic be in the exams and I am only in the second week of the course (VL 04).

And to enable such kinds of students to go through the program, some feel that standards have been lowered.

There is a lot of pressure to give high marks and that leads to grade inflation and that keeps going on (VL 02).

Courses have been dumbed down and many of my colleagues share this concern (VL 04).

So, some lecturers feel disappointed that their valuable time is wasted on such students.

We spend our time trying to get failing students to pass a course instead of focusing on the good students and making them even better. So we spend more of our time on the bottom students than on the top students. And that is not the way a good tertiary education system should work. I am sad and disappointed because of that (VL 05).

And besides, many lecturers do not seem to raise students' learning expectations, as discussed in (i) above. The situation then culminates in failure by the students to gain their full potential in intellectual independence (UDE 24). Based on this, many lecturers feel that the university is not only failing the student body and the public but also ruining its future reputation.

Failure to spend quality time with students leads to a loss of reputation, which cannot be bought by money (VL 12).

And the acknowledgement if we fail at that teaching interface, then, that is the public perception of what we are doing (VL 06).

I worry whether the quality of our education that the current students are getting, whether the students in 10 years' time will look back and say how much value they got. I think that is a real strain for Victoria. I often see people who were at this business school who say they see no value or they didn't get any value for their time (VL 01).

And this leads us to a big question:

The university and everybody should ask themselves this question: why should students come here?(VL 12).

\subsubsection{Synthesis of VBS lecturers' $f$ CRT}

The fCRT depicts a situation where lecturers' seem to be in a dilemma. This dilemma tends to be propagated by the actions of the management of VUW. Lecturers do indicate that their great interest is to teach well. However, their responses show that good teaching is not the management's priority.

These people don't genuinely think that teaching is as important as research (VL 06). The university has multiple objectives and so it does essentially choose one over the other (VL 01). 
Thus, it is quite clear that the university has prioritised research over teaching. And although there are those lecturers who indicate that their interest is in research, they also make it clear that if they have to teach, then they have to do it well 'if I have to do it \{teaching\}, then, I have to do it well (VL 01)'. Many lecturers, want to pursue both research and teaching, yet the VUW management does not seem to recognise their needs.

\begin{abstract}
But those of us who are here because we like teaching as well as research, I think in this stage you can follow your teaching kind of career, you can't do that here and I think there should be an acknowledgement that even if you are a good teacher, and you are not the high flying researcher, that you are not a failure. And that is a perfectly legitimate way of being employed and that makes part of the institution (VL 06).

There are many teachers here who do OK research but it doesn't matter whether we get $90 \%$ of our income from teaching, it does not matter, they are the ones who get promotion. So what does that tell me? Actually I was talking to somebody who is highly successful in his area and I said 'you know I am 15 years after my PhD and I am still a senior lecturer', and he said, 'why is that?' And I said, 'I have not got the research performance'. And he said, 'why is that?' I said, because 'I have got a lot of teaching', and he said, 'there you go'. But it is a good process for me because it made me realise why I am a senior lecturer, and what is important to me and teaching is important to me but I will forever remain a senior lecturer. I will not get to that prof because I do not care enough about research...I just take pleasure from what I achieve in teaching and I have come to accept that promotion-wise I am not going to go there (VL 09).
\end{abstract}

In addition to a lack of recognition and reward of teaching, the management seems to bring in rules and procedures that constrain efforts to do good and innovative teaching. Moreover, at VBS, discussions or debates related to best practices of L\&T do not happen.

\title{
And what do VBS lecturers think is the answer to the above problems?
}

The state of L\&T at VBS seems to worry many lecturers. We have seen their genuine concern in the foregoing discussion. Their suggestions indicate three issues that the university and the management of VBS in particular must show commitment to:

1. A clear communication of the goal of L\&T

2. A balance in the rewards of teaching and research

3. Remove bureaucratic processes that interfere with L\&T autonomy 


\section{The university must clearly communicate its goal of $L \& T$}

Many lecturers find it unfortunate that VBS in particular does not communicate or even encourage discussions on L\&T. And at a broader level, they feel that the university is not committed to the goal of L\&T.

I want to achieve that goal \{change what the students think\} but I don't think the university does. To be honest I do not see evidence of that. It is a conscious decision on how much effort it wants to put on high quality teaching. If you put lots of effort on high quality teaching it will bring the rest up (VL 01).

\section{The university must balance the rewards for teaching and research}

Lecturers also feel that people concentrate more on research because that is what is rewarded. They therefore feel the need to balance the two.

I do not blame those in teaching for not setting their own expectations because in this university, we don't get rewarded on teaching, we get rewarded on research, so you don't blame them for going that way, they don't care, they won't do it (VL 09).

Because most people are connecting at the teaching level, so you do have to have a balance (VL 06).

World-wide rankings of universities are based predominantly on research and there are those who think they are important to get students. It is really ironic. Those students \{undergraduate\} do not come here for research, they come here for teaching. So the obstacles are those of applying the ranking games that are focused on research. But do we need rankings to get students who want to be taught? (VL 01).

\section{Bureaucratic processes and interference with L\&T autonomy}

As explained earlier, lecturers are uncomfortable with the bureaucratic processes they have to go through in order to do good teaching. The university seems to interfere with the L\&T autonomy in various ways including restrictions on group work and assessments.

\subsubsection{Summary}

This subsection has discussed lecturers' views of their goals of teaching. Critical success factors and necessary conditions to help achieve the goal are discussed. Then, the less than desirable issues that impact negatively on the achievement of the teaching goals are identified. The less than desirable issues seem to revolve around two issues: leadership-related issues and lecturer-related issues. But the root cause is identified as 'teaching is not rewarded'. The resolution of this dilemma is discussed in Chapter 8. 


\subsection{VBS administrators' analysis}

This subsection provides a description of the administrators' views on the goal of L\&T and on the undesirable effects that tend to hinder the effective achievement of the goal. The root causes of the less desirable factors are identified.

\subsubsection{Description of VBS administrators}

The senior managers/administrators (hereafter referred to as administrators) were selected based on the direct relevance of their roles to L\&T (undergraduate). They totalled eight. They are the Associate Dean (L\&T), Manager-Academic Program Accreditation, 3 Heads of Schools (HoS), Deputy Associate Dean (Students), Manager-Student Academic Services, and Equity Coordinator. The administrators have varied years of experience in their roles that range from 8 months to over 6 years. The interview times ranged from $46 \mathrm{~min}$ to $84 \mathrm{~min}$.

\subsubsection{Identifying L\&T goal, CSFs, and NCs}

Administrators verbalised a number of goals as shown in Table 6.15. In order to arrive at a synthesised goal, similar to the previous sections, the unitisation of italic phrases is done.

Table 6.15: VBS administrators' goal descriptions

\begin{tabular}{|c|c|}
\hline Admin & Goal descriptions \\
\hline VAD 01 & $\begin{array}{l}\text { A combination of acquisition of knowledge, use of it and dissemination of it, so the students can } \\
\text { know stuff, but also have the so-called 'soft skills', so they can actually use the skills and adapt } \\
\text { their knowledge to the changing situations that they are going to find themselves in. }\end{array}$ \\
\hline VAD 02 & To produce highly skilled graduates and also researchers \\
\hline VAD 03 & $\begin{array}{l}\text { To provide opportunity for the students to develop new skills, new knowledge, and be able to } \\
\text { apply the skills and knowledge to situations that they may face when they leave university. By } \\
\text { the time they finish their undergraduate degree, they should be able to critique work, to have their } \\
\text { own opinions, and be able to communicate those with others in verbal or written form. Have } \\
\text { confidence, which should grow within themselves as a person, so they should be able to interact } \\
\text { with a variety of people in different circumstances at the correct level. And underlying all that is } \\
\text { the knowledge of particular disciplines. }\end{array}$ \\
\hline VAD 04 & $\begin{array}{l}\text { The ultimate goal would be some sort of transformation of the students who come here. Well } \\
\text { students come in with some X-amount of knowledge or X-attributes \{profile\} and come out with } \\
\text { several knowledge and attributes. So the overall goal would actually have to be that you transform } \\
\text { those students along the lines outlined by your overall L\&T strategy that would be based around } \\
\text { several particular graduate attributes \{profile\}. So you have some notions of what you want your } \\
\text { students to look like when they come out, so the ultimate goal of L\&T is to accomplish that. }\end{array}$ \\
\hline VAD 05 & $\begin{array}{l}\text { We want people who are going to cope in situations, which we have not even taught them how } \\
\text { to cope with. To prepare them for everything else, for life as an employee, as an economic agent, } \\
\text { as someone making decisions on behalf of a family, decisions on being good citizens, and } \\
\text { university is a place where people can be encouraged to think about more than just themselves } \\
\text { but other perspectives, analyse situations, that they have never come across before and do so } \\
\text { accurately and thoughtfully. And sort of deconstructing a problem to understand the most } \\
\text { appropriate method or technique to solve it. So I would like to produce graduates who are able to }\end{array}$ \\
\hline
\end{tabular}




\begin{tabular}{|c|c|}
\hline & $\begin{array}{l}\text { tackle problems that we have not taught them how to tackle. So I would say that generally a } \\
\text { university makes you think. }\end{array}$ \\
\hline VAD 06 & $\begin{array}{l}\text { Well big part of L\&T is driven by those graduate attributes \{profile\}. I think from a bigger picture } \\
\text { perspective an important objective too is to inspire students to life-long learning. So the graduate } \\
\text { attributes \{profile\} play a very important role in terms of the construction of the courses and the } \\
\text { course outlines. But I think taking an even bigger picture perspective on L\&T what we really } \\
\text { need to do in an academic environment is instil a desire for life-long learning. So I think that is a } \\
\text { much higher level objective. }\end{array}$ \\
\hline VAD 07 & $\begin{array}{l}\text { Well every school has the goal of providing students with the best education. But I think the goal } \\
\text { of quality L\&T from the point of view of students is to provide students with the best practical } \\
\text { knowledge so that they can understand the markets and economy better. }\end{array}$ \\
\hline VAD 08 & $\begin{array}{l}\text { The goal is to produce graduates who are best equipped to make the progression from study to } \\
\text { employment or from study at a particular level to a higher level of study. So the goal of L\&T is } \\
\text { to equip those people so that when they present themselves to an employer they are well } \\
\text { positioned in terms of not just what they know, not just the skills and competences that are } \\
\text { required but also the softer skills. And this comes back to graduate profiles and graduate } \\
\text { attributes: so the capacity to be a creative thinker, a critical thinker, and to communicate } \\
\text { effectively, whether in writing or orally. But also in some respects a degree of emotional } \\
\text { intelligence so that they also have the capability to work with others. }\end{array}$ \\
\hline
\end{tabular}

A synthesis of the above goals indicates that administrators perceive the L\&T goal as 'a process of transformation whereby students develop an ability to think critically and creatively, and communicate effectively as they apply the knowledge and skills in changing situations. The administrators also underscore the importance of the VUW graduate profile/attributes in shaping the L\&T goal at VBS.

\section{Determining CSF and NCs}

The CSFs and the NCs identified by the administrators are presented in Table 6.16. To determine the common CSFs, the 'unitisation' is performed. Three CSFs are identified: lecturers' capability to deliver the program (CSF1), students' capability to be transformed (CSF2), and program design (CSF3). 
Table 6.16: Unitising VBS administrators' CSFs and NCs

\begin{tabular}{|c|c|c|}
\hline & Critical success factors & Necess ary conditions \\
\hline \multirow[t]{5}{*}{ VAD 01} & High quality staff (CSF1) & Knowledgeable \& enthusiastic staff (CSF1) \\
\hline & & Professional development (NC1) \\
\hline & & Technologically engaged staff (NC4) \\
\hline & Technology (NC4) & Effective \& reliable technology \\
\hline & High quality students (CSF2) & Creative \& critical thinkers (goal) \\
\hline \multirow[t]{4}{*}{ VAD 02} & 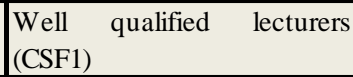 & On-going researchers $(\mathrm{CSF} 1)$ \\
\hline & & Ongoing development of teaching skills (NC1) \\
\hline & General staff & Well trained \& networked \\
\hline & Good funding (NC8) & Alumni \& business networks, government funding (NC8) \\
\hline \multirow[t]{3}{*}{ VAD 03} & $\begin{array}{l}\text { Non-threatening } \\
\text { environment (NC5) }\end{array}$ & $\begin{array}{l}\text { Appropriate class sizes, student groups \& student support } \\
\text { (NC5) }\end{array}$ \\
\hline & Students resources (NC5) & $\begin{array}{l}\text { Library, cyber commons, study spaces, ongoing } \\
\text { development of facilities (NC5) }\end{array}$ \\
\hline & $\begin{array}{l}\text { Passionate academic staff } \\
(\mathrm{CSF} 1)\end{array}$ & $\begin{array}{l}\text { Learning from best practices, mentoring, training on } \\
\text { pedagogy }(\mathrm{NC} 1)\end{array}$ \\
\hline \multirow[t]{4}{*}{ VAD 04} & $\begin{array}{l}\text { Clear understanding of } \\
\text { transformation (NC9) }\end{array}$ & Communication (NC9) \\
\hline & $\begin{array}{l}\text { Teachers' capacity to deliver } \\
\text { (CSF1) }\end{array}$ & Recruit right staff (NC3) \\
\hline & $\begin{array}{l}\text { Students' capacity to be } \\
\text { transformed (CSF2) }\end{array}$ & Recruit right students (NC3) \\
\hline & Resources (NC5) & $\begin{array}{l}\text { Building, technology \& conducive learning environmen } \\
\text { (NC5) }\end{array}$ \\
\hline \multirow[t]{5}{*}{ VAD 05} & $\begin{array}{l}\text { Offering students variety of } \\
\text { choices }\end{array}$ & Different fields of learning (CSF3) \\
\hline & & Different types of skills (CSF3) \\
\hline & & Different opportunities to excel \\
\hline & & Flexibility over own development \\
\hline & $\begin{array}{ll}\text { One-on-one relationship } \\
\text { (NC5) }\end{array}$ & Care for students \\
\hline \multirow[t]{6}{*}{ VAD 06} & \begin{tabular}{|l} 
Dedicated \& excellent \\
teachers $(\mathrm{CSF} 1)$
\end{tabular} & Hire good teachers (NC3) \\
\hline & & Good orientation of teaching approach (NC1) \\
\hline & & Acknowledgement \& rewards (NC6) \\
\hline & & Strong adminis trative support (NC2) \\
\hline & Small classes (NC5) & Resources (NC5) \\
\hline & \begin{tabular}{|l} 
Exposure to best global \\
practices
\end{tabular} & Experiential \& application based learning practices (CSF3) \\
\hline \multirow[t]{3}{*}{ VAD 07} & $\begin{array}{l}\text { Proper linkages } \& \\
\text { coordination of courses } \\
(\mathrm{CSF} 3)\end{array}$ & Proper linkage of the program design (CSF3) \\
\hline & Program design (CSF3) & General astute of core courses (CSF3) \\
\hline & Capable lecturers (CSF1) & Hire right lecturers (NC3) \\
\hline \multirow[t]{3}{*}{ VAD 08} & $\begin{array}{l}\text { Graduate profile \& attributes } \\
\text { (goal) }\end{array}$ & Group work (CSF3) \\
\hline & Resources (NC5) & Ongoing development of resources (NC8) \\
\hline & & Professional development (NC1) \\
\hline
\end{tabular}

After identifying the CSFs, related NCs are determined under each CSF and/or under each NC. The unitisation process identifies 9 NCs. These are: 
- Professional development

- Strong administrative support

- Good recruitment and hiring practices

- IT support and technological skills

- Resources

- Motivation (acknowledgments \& rewards)

- Accessibility and meaningfulness of professional development

- Clear understanding and communication of the goal

- Adequate funding for on-going facilities' developments

Figure 6.8: VBS administrators' goal tree

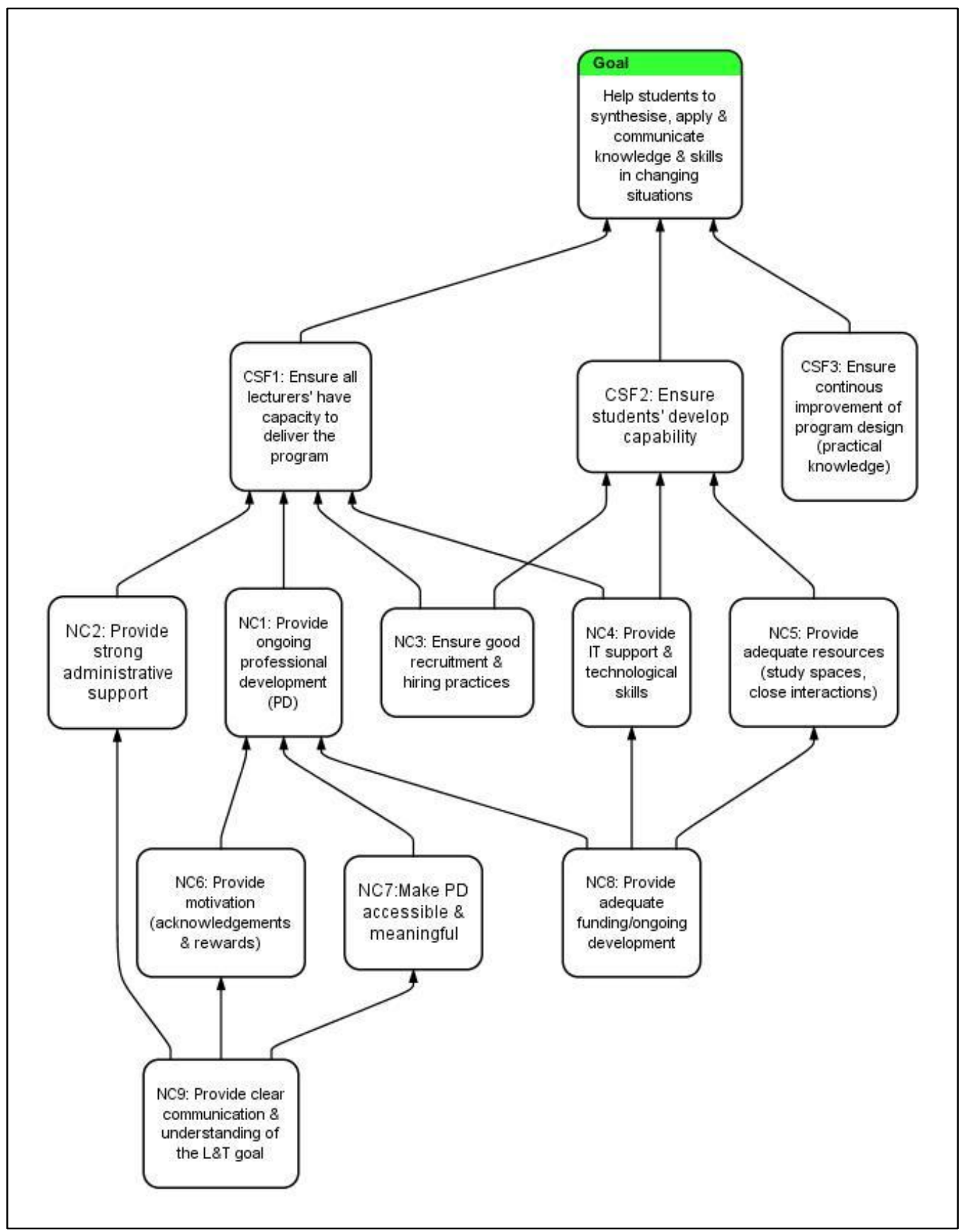




\subsubsection{Identifying UDEs that affect quality of L\&T experiences of VBS}

\section{administrators}

Several issues were identified as impacting on the quality of L\&T experiences (Table 6.17).

These issues relate to academic staff, students, assurance of learning (AoL), teaching and research, and technology.

Table 6.17: Issues impacting on quality of L\&T experiences of VBS administrators

\begin{tabular}{|c|c|}
\hline & Issues impacting on quality of L\&T experiences of VBS administrators \\
\hline & Academic staff \\
\hline 1 & Academic staff are not as technologically engaged as students. \\
\hline 2 & There is a 'digital divide' among the staff. \\
\hline 3 & There is little emphasis on teaching skills while selecting and hiring lecturers. \\
\hline 4 & Some lecturers are not flexible with students' needs. \\
\hline 5 & Academic staff do not provide feedback on physical developmental plans. \\
\hline 6 & Academic staff criticise proposed developmental plans and do not provide solutions. \\
\hline 7 & Most teaching staff do not have qualifications in teaching. \\
\hline 8 & Orientation for new staff is not as good as it should be. \\
\hline 9 & Some academics do not engage well with L\&T. They are more interested in research. \\
\hline 10 & Lecturers do not always buy into the institutional view of transforming students. \\
\hline 11 & Lecturers often resist change. \\
\hline 12 & Academic staff do not offer much support to heads of schools. \\
\hline 13 & The opportunity cost of undertaking PHELT course is quite significant to many staff. \\
\hline & Assurance of learning (AoL) \& accreditation \\
\hline 14 & AoL has the risk of becoming bureaucratic and degenerating into compliance. \\
\hline 15 & AoL does not have an effective way of ensuring that courses have learning outcomes. \\
\hline 16 & $\begin{array}{l}\text { It is not clear what the AoL activities lead to. Does it affect improvement in course completions? Does it } \\
\text { affect placement of graduates? }\end{array}$ \\
\hline 17 & AoL is generally perceived as an imposition \& a matter of compliance. \\
\hline 18 & $\begin{array}{l}\text { Sometimes AoL can constrain academics in terms of what they can teach \& how they teach it. It might limit } \\
\text { academic freedom. }\end{array}$ \\
\hline 19 & Accreditation is sometimes seen as a form of standardisation. \\
\hline & Students \\
\hline 20 & The basic purpose of students gaining graduate attributes \{profile\} tends to be overlooked. \\
\hline 21 & Students do not have strong critical thinking skills. \\
\hline 22 & The biggest obstacle in L\&T is student engagement; students are failing through non-engagement. \\
\hline 23 & Unimaginative Power Point presentations bore students and encourage disruptive behaviour. \\
\hline 24 & Some students are intimidated in large classes; they do not feel a connection with their lecturers. \\
\hline 25 & Some students are not motivated to succeed. \\
\hline 26 & Some students do not have the capability. \\
\hline 27 & Some students do not know what their goals are or their purpose of learning. \\
\hline 28 & $\begin{array}{l}\text { Not much advice is given to first year students on how to manage the transition from high school to } \\
\text { university. }\end{array}$ \\
\hline 29 & Pastoral care; should we be doing it? \\
\hline
\end{tabular}




\begin{tabular}{|c|c|}
\hline & Issues impacting on quality of L\&T experiences of VBS administrators \\
\hline 30 & Students' failure rate is high in some courses. \\
\hline 31 & There is not enough focus on students' well-being. \\
\hline 32 & There is a lack of awareness \& training on students' issues/problems. \\
\hline 33 & Students are not well engaged with their study buddies and with VICom Association. \\
\hline 34 & Students have poor time management. \\
\hline 35 & Students are full of apathy. They do not want to be involved in learning experiences. \\
\hline 36 & Students are not concerned about their best teachers whom they could nominate for awards. \\
\hline \multirow[t]{2}{*}{37} & Students do not provide feedback into the system. \\
\hline & Course evaluations \\
\hline 38 & Course evaluations are summative rather than formative. They do not benefit the present cohort. \\
\hline 39 & Heads of schools have limited information on actual quality of teaching. Evaluations are problematic. \\
\hline 40 & Course evaluations and teaching evaluations are not done in an organised way. \\
\hline \multirow[t]{2}{*}{41} & We do not pay enough attention to drop out rates. \\
\hline & Group work \\
\hline 42 & $\begin{array}{l}\text { Restrictions on group work put students at a competitive disadvantage globally. It goes against the global } \\
\text { trend. }\end{array}$ \\
\hline \multirow[t]{2}{*}{43} & Restrictions on group work impact on the achievement of graduate attributes. \\
\hline & Class sizes \\
\hline 44 & Class sizes are large; lecturers do not have full control of their classes. \\
\hline \multirow[t]{2}{*}{45} & There is a lot of grading/marking due to large class sizes. \\
\hline & Teaching \& research \\
\hline 46 & $\begin{array}{l}\text { We do not have school meetings where teachers share teaching practices amongst themselves or where they } \\
\text { reflect on their teaching. }\end{array}$ \\
\hline 47 & We do not have systems in place to address challenges posed by poor teaching performance. \\
\hline 48 & $\begin{array}{l}\text { There is a lot of emphasis on performance based research funding (PBRF). Research enjoys greater } \\
\text { prominence \& higher status than teaching. }\end{array}$ \\
\hline 49 & Managers make assumptions that everyone should be able to do research \& teach. \\
\hline \multirow[t]{2}{*}{50} & We have many great researchers who cannot teach. This destroys or undermines the basis of the university. \\
\hline & Course structure/program structure \\
\hline 51 & The structure of some courses is not fair to all students. \\
\hline \multirow[t]{2}{*}{52} & $\begin{array}{l}\text { Some prerequisite courses are taught in the same semester as the next level course. Students are not able to } \\
\text { do the next level course until 8-9 months later. }\end{array}$ \\
\hline & IT \& Technology \\
\hline 53 & Social media \& digital technologies are not currently very effective in getting students engaged with content. \\
\hline 54 & IT support is not designed in a way that maximises student learning experience. \\
\hline 55 & IT is not always reliable. It is under-resourced. \\
\hline 56 & We do not have up to date technology for teaching support. \\
\hline 57 & Rooms are not always designed appropriately to support technology. \\
\hline \multirow[t]{2}{*}{58} & Monitoring academic performance is not technologically enhanced. \\
\hline & Complaints \\
\hline 59 & Students' complaints often do not reach lecturers or Heads of schools. \\
\hline 60 & Students' complaint system is very random; it often does not work. \\
\hline 61 & The complaints from Heads of Schools are not always acted upon. \\
\hline
\end{tabular}




\begin{tabular}{|l|l|}
\hline & Issues impacting on quality of L\&T experiences of VBS administrators \\
\hline & Interactions/relationships \\
\hline 62 & There is not much interaction between teachers \& students. \\
\hline 63 & There is no opportunity for students to engage with lecturers. \\
\hline 64 & We do not build a relationship with students one-to-one. \\
\hline 65 & Bureaucracy \\
\hline 66 & Sometimes, it takes a long time to get things done. \\
\hline & Communication \\
\hline 67 & There is not enough communication between academic staff \& general staff. \\
\hline 68 & Communication between academic staff \& students are not always open. \\
\hline 69 & Sometimes lecturers' communication with students is downright rude. Academics are arrogant. \\
\hline 70 & $\begin{array}{l}\text { Communication from students is opinionated. It reflects largely on student leaders and not the wider student } \\
\text { community. }\end{array}$ \\
\hline 71 & $\begin{array}{l}\text { Poor communication from academics causes a lot of administrative issues including refund of course fees, } \\
\text { poor academic progress and health of students. }\end{array}$ \\
\hline & Strategic alignment \\
\hline 72 & Sometimes we have difficulty aligning the VBS strategic plan with the University's. \\
\hline 73 & VUW strategic plan does not discuss much about L\&T. \\
\hline & Equity \\
\hline 74 & There is a lack of appreciation of the importance of addressing equity in terms of learning outcomes. \\
\hline
\end{tabular}

In order to understand the root causes of the above undesirable issues, the UDEs are first identified using the protocol for articulating UDEs mentioned in the previous sections. The validation process then reduced the above 74 issues into 18UDEs (24-6) shown in Table 6.18. 
Table 6.18: VBS administrators' UDEs

\begin{tabular}{|c|c|}
\hline 1 & A lot of paper work is needed to engage students outside classes \\
\hline 2 & Many lecturers do not have teaching skills \\
\hline 3 & For some lecturers, English is not their first language \\
\hline 4 & Some academic staff perceive AoL as standardisation \& bureaucratic; top-down \\
\hline 5 & Some academic staff perceive AoL as more concerned with processes (not with LO) \\
\hline 6 & Some academic staff perceive AoL exercises as not generating actual data on L\&T practice \\
\hline 7 & Some academic staff perceive that AoL interferes with academic freedom; it is seen as imposition \\
\hline 8 & There is some academic staff resistance to AoL initiatives \\
\hline 9 & Lecturers performance is not measured on teaching output \\
\hline 10 & Many lecturers do not spend much time on teaching matters \\
\hline 11 & There are limited forums at VBS for sharing best L\&T practices \\
\hline 12 & Learning outcomes (LO) are not effectively designed in course contents \\
\hline 13 & Many lecturers spend most of their time in research \\
\hline 14 & Many lecturers do not have time to undertake PD courses on teaching \& communication \\
\hline 15 & Many lecturers do not have teaching \& communication skills \\
\hline 16 & Some lecturers do not effectively communicate \& engage students (particularly in large classes) \\
\hline 17 & Many lecturers often choose low contact methods of teaching (eg lectures) \\
\hline 18 & Many lecturers do not have enough time to understand students' learning needs \\
\hline 19 & Some students feel intimidated to engage in class \\
\hline 20 & There are limited interactions between students \& lecturers \\
\hline 21 & Some lecturers do not effectively deliver the course content \\
\hline 22 & Some students are not well engaged in \& outside classes \\
\hline 23 & Some graduate attributes (critical \& creative thinking) tend to be overlooked \\
\hline 24 & The VBS L\&T efforts often do not develop strong critical thinking skills in our students \\
\hline & Intermediate effect \\
\hline
\end{tabular}

\subsubsection{Identifying the 'root causes' of UDEs}

From the above UDEs, a fCRT is constructed (Figure 6.9) by logically connecting the UDEs using cause-effect logic until a root cause is identifed. Analysis of VBS administrators' fCRT identified two critical root causes: (a) lecturers' performance is based on research output and not on teaching output, and (b) the assurance of learning (AoL) is concerned with processes and not learning outcomes (LO). 
Figure 6.9: VBS administrators' $f$ CRT

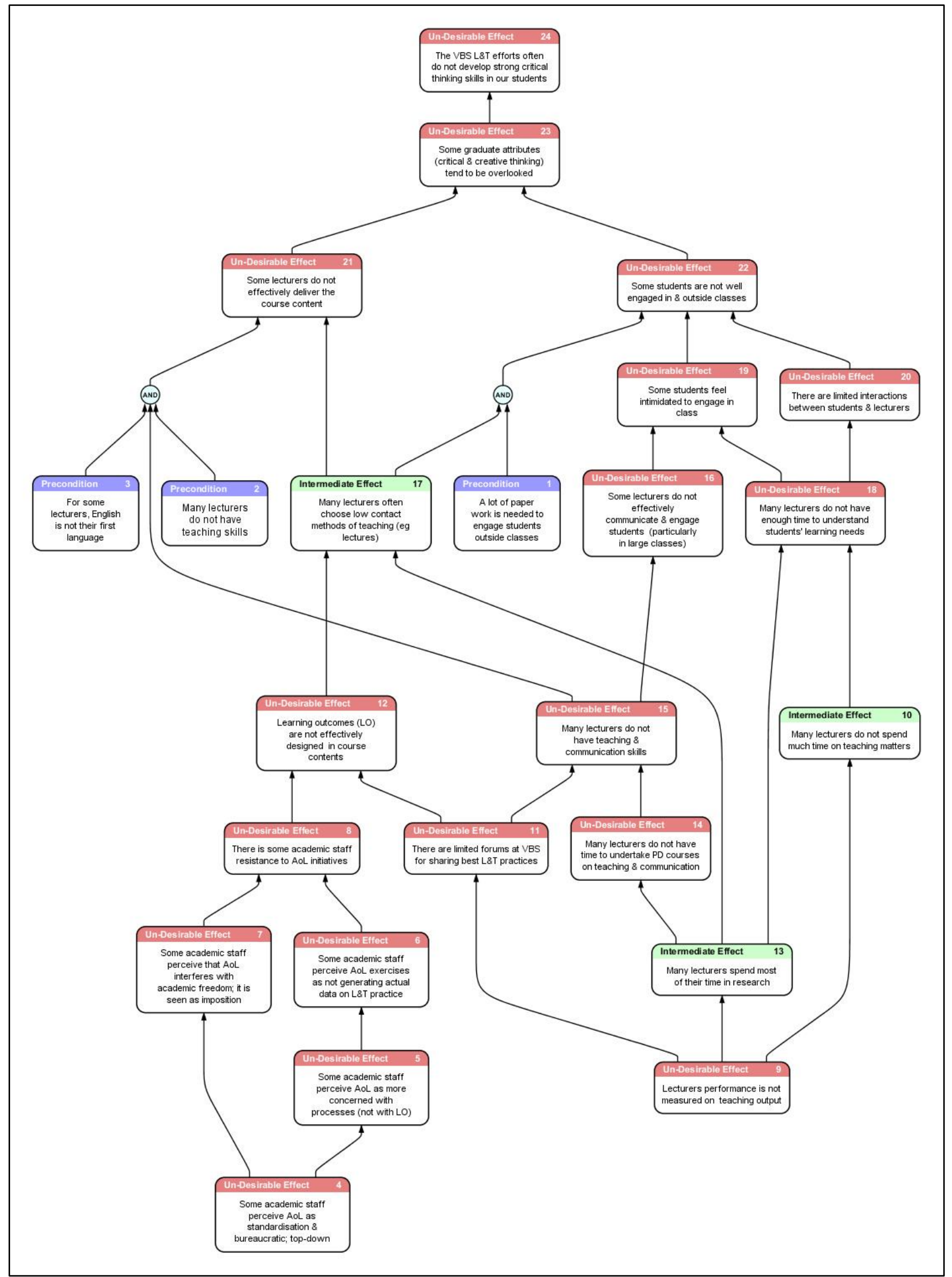




\section{Lecturers' performance is based on research output and not teaching output}

Lecturers' performance at VBS and at VUW in general is measured on quality of research output (UDE 09).

Research has tended to enjoy greater prominence and higher status than teaching (VAD 08).

A lot of emphasis is on the PBRF (VAD 07).

As a result, many lecturers spend most of their time on research related issues (IE 13) because that is what rewards them. Thus, if many lecturers spend most of their time on research matters, then they do not have enough time for students (UDE 18) and they do not have time to undertake professional development (PD) courses on teaching and communication (UDE 14).

Have professional development so that staff can improve the way they communicate with students and engage with them (VAD 01).

If lecturers fail to undertake PD, and if most of them do not have teaching qualifications, and if they do not engage in forums for sharing best practices in L\&T (UDE 11), \{We do not have those kinds of school meetings where the meetings are meetings of teachers who are talking about teaching practice within their particular school or talking about some aspect of teaching (VAD 08)\}, then many lecturers do not possess teaching and communication skills (UDE 15) and this affects students' learning experiences.

The poor communication from the academic has impacted on the whole student body. It causes a lot of issues around administrative problems around refunding courses, and the health of the students, their academic progress (VAD 03).

But there is no opportunity for the students to engage with the person. And sometimes it can be a downright rude... So it is the whole communication... And so the student feels that I can't go back and question this or find more opportunity... And we often find that a student failing in that course and you can go back and find that it is communication between the academic and the student (VAD 03).

If many lecturers do not have adequate teaching and communication skills, then some lecturers do not know how to engage students effectively, particularly in large classes (UDE 16). This then affects some students who fail to engage because they feel intimidated in large classes (UDE 19).

So students, because classes are so big, are so intimidated. They do not feel a connection with their teachers (VAD 02).

And since many lecturers do not have time for these students (UDE 18) then such students do not get well engaged in learning (UDE 22) ${ }^{10}$. Moreover, because many lecturers have limited teaching skills, they do not always deliver the course content effectively (UDE 21).

$10 \mathrm{It}$ is acknowledged that some students might engage in other endeavours on their own, but this explanation relates to those that VBS may endear its students to have. 
Professional development has to be made accessible and meaningful to all so that the staff can engage with it and update their knowledge and skills, particularly in delivery of content (VAD 01).

As a result, students fail to acquire strong critical thinking skills (UDE 24).

And they are much more likely to achieve that outcome if there is a strong connection between the students and the lecturers. And in this sort of environment it is much more difficult to achieve (VAD 06).

\section{The $\mathrm{AoL}^{11}$ is perceived to be concerned with processes and not learning outcomes}

AoL tends to contribute to ineffective achievement of critical thinking skills in that it is perceived by some academic staff as a standardisation, and as a bureaucratic process (UDE 04). As a result, some academic staff perceive it to be more concerned with processes than learning outcomes (UDE 05).

The AoL as a process has a risk of getting bureaucratic. They get so concerned about the process, conducting assessments, entering the results into data bases and those sorts of things, that the purpose of it all of identifying whether students are gaining the attributes \{profile\} appears to be overlooked! (VAD $01)$.

It has become very bureaucratic because it has a lot of compliance involved in L\&T (VAD 04).

Consequently it is perceived to interfere with academic freedom (UDE 07) and is seen as an imposition.

The negative side for academics is that their academic freedom is curtailed to some extent (VAD 04)

The AoL arrangements are generally perceived as an imposition and a matter of compliance (VAD 08).

As a result, it is resisted by some academic staff (UDE 08) because they feel that, AoL exercises fail to generate actual data on L\&T practice (UDE 06).

Particularly with the AoL, that is only going to work if we actually get the data that is generated from an AoL exercise and you close the loop by taking that data back to your teachers, your teachers' groups and you discuss it (VAD 08).

And since there are few forums for sharing best practices of L\&T (UDE 11) then learning outcomes are not effectively designed into the BCom program (UDE 12).

\{We are $\}$ not creating those places where teachers come together and reflect on the program goals, the courses that make up the program, and how to improve (VAD 08).

Moreover, many lecturers often choose low contact methods of teaching (such as lectures) IE 17. And because for some lecturers English is not their first language (precondition 3), and they do not have adequate teaching skills (precondition 2) they may fail to deliver course content

\footnotetext{
${ }^{11}$ It is important to note that the issue of AoL was mentioned by 4 out of 8 administrators. One administrator expressed satisfaction indicating how s/he has applied it in his/her course; the second expressed both the positive and negative aspects of AoL. The third expressed his/her opinion of the perception of AoL within the faculty but maintained a neutral position. The fourth was adamant that AoL was not achieving its potential benefits for effective learning outcomes.
} 
effectively (UDE 21). Consequently, if graduate attributes \{profile\} are overlooked (UDE 23), then students may fail to develop strong critical thinking skills (UDE 24).

\subsubsection{Synthesis of VBS administrators $f$ CRT}

The administrators' fCRT identifies the statement that 'lecturers' performance is measured based on research output' as the critical root cause of undesirable L\&T experiences at VBS. And although AoL is depicted as another root cause, it seems to be like a tassel bobbling in the deep problem of the performance as measured by research output. Indeed, the fact that AoL aims to enhance quality of L\&T might be perceived as a burden by some academics who might be more interested in research output. What is clear is the matters of L\&T tend to be given less priority by the institution than research. The basic message here is that unless there is a balance of performance measures of L\&T and research outputs, the experiences of L\&T will continue to be less desirable. The consequence is that students may fail to achieve appropriate graduate profiles.

The administrators' fCRT indicate that the dilemma facing VBS is balancing research and teaching. The resolution to this dilemma is demonstrated in Chapter 8.

\subsubsection{Summary}

In this subsection admin's views of the L\&T goals are discussed. The critical success factors and the necessary conditions to help achieve the L\&T goal are discussed. Then, the less than desirable issues that impact negatively on the achievement of the L\&T goals are identified. Two root causes are identified: (a) lecturers' performance is based on research output and not on teaching output, and (b) assurance of learning (AoL) is perceived to be concerned with processes and not learning outcomes (LO). But the critical root cause is identified as 'lecturers' performance is based on research output and not on teaching output'. The next subsection provides a within-case analysis of the students', lecturers' and administrators' views of VBS L\&T system. 


\subsection{VBS within-case analysis}

This subsection provides a within-case analysis of the above three sub-sections. An amalgamation of the goal is provided. Similarities and differences impacting on the quality experiences of L\&T from the three groups are drawn.

\subsubsection{The L\&T goals, CSFs, and NCs}

The analysis of the three goals (Table 6.19) indicates some common views as well as different ones. But, there is more convergence than divergence. The convergence of views on the importance of the CSF and the NCs would point to the fact that the three groups are heading in the same direction and that they could easily buy-in to any improvement efforts geared towards these issues.

Table 6.19: VBS goals

\begin{tabular}{|c|c|c|}
\hline Students' learning goal & Lecturers' teaching goal & Administrators' L\&T goal \\
\hline $\begin{array}{l}\text { Get a qualification with } \\
\text { applicable and employ able skills }\end{array}$ & $\begin{array}{l}\text { Help students to develop } \\
\text { competence in thinking and/or } \\
\text { cultivate intellectual } \\
\text { independence in students }\end{array}$ & $\begin{array}{l}\text { A process of transformation whereby students acquire new knowledge and skills } \\
\text { (including the soft skills), develop an ability to think critically and creatively as } \\
\text { they apply the knowledge and skills in changing situations (including markets, } \\
\text { economy and social) as well as an ability to communicate effectively in varying } \\
\text { situations. }\end{array}$ \\
\hline
\end{tabular}

Table 6.19 shows that the students' and administrators' goals tend to emphasise applicable skills, while lecturers' and administrators' goals tend to emphasise competence in critical thinking. Although students' individual goals might imply the need for competence in problem solving skills at work places (see Table 6.5 in subsection 6.3.2), the focus tends to be more on getting jobs than acquiring knowledge for the sake of it. And this does not seem to augur well with lecturers who express concern that the goal of a university is not to train students for jobs and that the training for jobs is the work of polytechnics or Wanangas. So those students should actually be in Wanangas.

The university should not be providing students for the market place. Polytechnics do that. That is not the role of the university. So universities have the wrong mixture. We are not focused on creating the best, strongest and the most critical intellectual thinking. For some reason we are now focused on getting people jobs. I always thought that was the position for the polytechnics. Universities are always considered to be institutions of higher learning, which is, learning for learning sake, learning to learn, learning how to learn; be interested in the subject matter, not being interested in the piece of paper (e.g. the degree) (VL 05).

If you look at the Education Act in NZ, about what distinguishes universities from polytechnics, the Wananga and other private training establishments, there is nothing in there about the role of the university being to train people for jobs. Training and jobs does not get mentioned. The primary role of the university is to cultivate intellectual independence. That is the number one goal. To help students get intellectual independence (VL 03). 
But is the job market looking for polytechnic graduates or for university graduates? Where is the misalignment?

Returning to the converging issues on the goal of L\&T, the effort to consolidate the three yields a common goal of 'Transforming students to develop critical thinking, application and communication skills'.

Further analysis of CSFs and NCs (Table 6.20) indicates common factors such as motivation. All three groups indicated the need for motivation of students and academic staff as well as effective teaching. Students indicate the need for passionate and effective teachers. Likewise, lecturers indicate the need for effective teaching and communication, and administrators also indicate need for capable lecturers who can deliver the program. The three groups also agree on the need for diverse learning resources. In particular, lecturers and administrators indicate the need for IT support in L\&T.

Lecturers and administrators do emphasise the need for common understanding and clear communication of the goal of L\&T.

Table 6.20: VBS CSFs \& NCs

\begin{tabular}{|c|c|c|c|}
\hline & Students & Lecturers & Admin \\
\hline CSFs & $\begin{array}{ll}\text {. } & \begin{array}{l}\text { Motivation \& dedication } \\
\text { (lecturers \& students) }\end{array} \\
\text {. } & \text { Interactions } \\
\text {. } & \text { Learning resources }\end{array}$ & $\begin{array}{ll}\text { Motivated students } & \& \\
\text { passionate learners } & \\
\text { Effective teaching } & \text { \& } \\
\text { communication }\end{array}$ & $\begin{array}{l}\text { - Lecturers' capability to deliver the } \\
\text { program } \\
\text { Students capability to be } \\
\text { transformed } \\
\text { Program design }\end{array}$ \\
\hline $\mathrm{NCs}$ & $\begin{array}{ll}\text {. } & \text { Passionate \& effective } \\
& \text { teachers } \\
\text {. } & \text { Passion \& self-discipline } \\
\text {. } & \text { Group activities } \\
\text {. } & \text { Good tutors } \\
\text {. } & \text { Student support } \\
\text {. } & \text { Technology \& facilities } \\
\text {. } & \text { Academic qualifications } \\
\text {. } & \text { Qualifications in teaching } \\
\text {. } & \text { Industrial involvement \& } \\
& \text { experience } \\
\text {. } & \text { Group work }\end{array}$ & $\begin{array}{l}\text { Setting high expectations } \\
\text { Creativity \& diversity in } \\
\text { teaching \& student engagement } \\
\text { Contextualised, relevant \& } \\
\text { diverse learning resources } \\
\text { Common understanding of goal } \\
\text { \& common set of expectations } \\
\text { Sufficient time to prepare \& } \\
\text { create teaching materials } \\
\text { Commitment \& motivation } \\
\text { Reward teaching } \\
\text { Committed leadership }\end{array}$ & 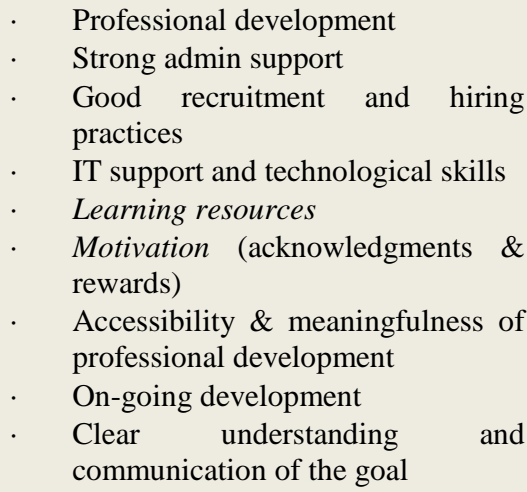 \\
\hline
\end{tabular}

The consolidation of the above CSFs and NCs then yield a goal tree depicted in Figure 6.10. The figure depicts three CSFs: (a) capable and motivated lecturers, (b) capable and motivated students, and (c) appropriate program design and six NCs. The NCs are teaching rewards, professional development in teaching and communication, common understanding of L\&T goals, appropriate learning resources, self-discipline, and committed leadership. 
We read the goal tree as follows:

In order to have capable and motivated lecturers, VBS must have teaching rewards, professional development in teaching and communication, and a common understanding and clear communication of the goal of L\&T.

Figure 6.10: Combined VBS goal tree

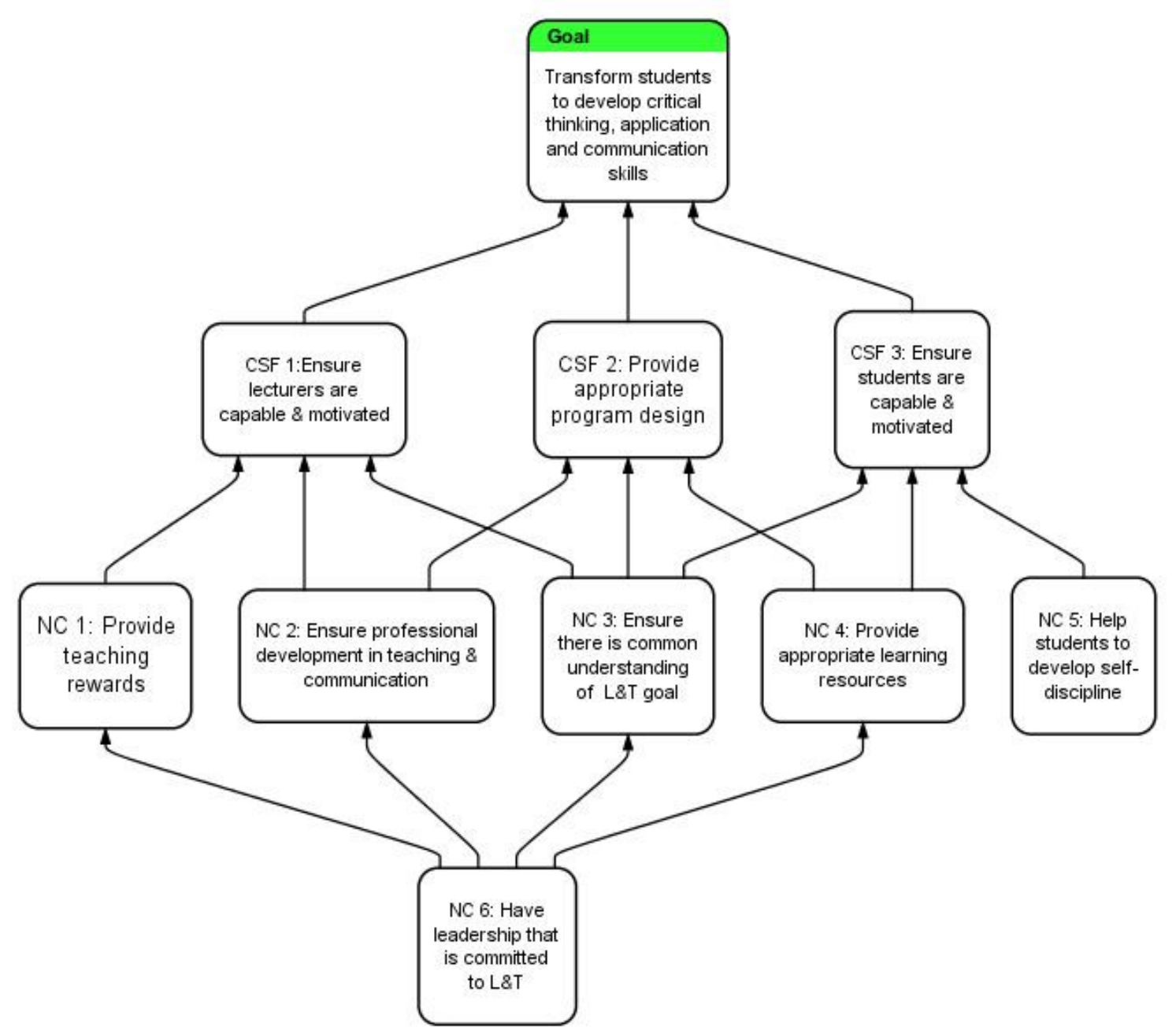

Moreover, in order to have capable and motivated students, VBS must provide a common understanding and clear communication of the goal of L\&T, and provide appropriate learning resources. Students for their part must have self-discipline. But the most important factor is that VBS must have committed leadership to L\&T. 


\subsubsection{Common issues affecting quality of L\&T at VBS}

There are very many common issues among the three groups. This confirms further that the three are heading in the same direction. The ticks $(\sqrt{ })$ indicate whether the issue is common either among the three groups or among any two of them.

Table 6.21: Common issues at VBS

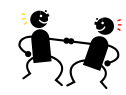

\begin{tabular}{|c|c|c|c|c|}
\hline & Common Issues & Students & Lecturers & Admin \\
\hline 1 & Interactions between students and lecturers are often limited & $\sqrt{ }$ & $\sqrt{ }$ & $\sqrt{ }$ \\
\hline 2 & Lecturers are not motivated to teach large classes & $\sqrt{ }$ & $\sqrt{ }$ & \\
\hline 3 & $\begin{array}{l}\text { Most lecturers do not have time for students; they devote time to } \\
\text { research }\end{array}$ & $\sqrt{ }$ & $\sqrt{ }$ & $\sqrt{ }$ \\
\hline 4 & Many lecturers lack teaching skills & $\sqrt{ }$ & $\sqrt{ }$ & $\sqrt{ }$ \\
\hline 5 & There is lack of practical learning in some courses & $\sqrt{ }$ & $\sqrt{ }$ & \\
\hline 6 & Many lecturers are here for research & $\sqrt{ }$ & $\sqrt{ }$ & $\sqrt{ }$ \\
\hline 7 & We are not focusing on creating the most critical intellectual thinking & $\sqrt{ }$ & $\sqrt{ }$ & $\sqrt{ }$ \\
\hline 8 & There is no logical progression of courses/ repetition within courses & $\sqrt{ }$ & $\sqrt{ }$ & $\sqrt{ }$ \\
\hline 9 & Everybody runs their own courses & $\sqrt{ }$ & $\sqrt{ }$ & \\
\hline 10 & People tend to teach a course for many years & $\sqrt{ }$ & $\sqrt{ }$ & \\
\hline 11 & Students expect less and give less & $\sqrt{ }$ & $\sqrt{ }$ & \\
\hline 12 & A lot of students are bored and not well engaged & $\sqrt{ }$ & $\sqrt{ }$ & \\
\hline 13 & Classes and tutorials are large & $\sqrt{ }$ & $\sqrt{ }$ & \\
\hline 14 & Some students do not attend lectures & $\sqrt{ }$ & $\sqrt{ }$ & \\
\hline 15 & We have many great researchers who cannot teach & $\sqrt{ }$ & & $\sqrt{ }$ \\
\hline 16 & Some tutors are a bit removed from the lecturers & $\sqrt{ }$ & $\sqrt{ }$ & \\
\hline 17 & The opportunity cost of undertaking PHELT course is quite significant & & $\sqrt{ }$ & $\sqrt{ }$ \\
\hline 18 & $\begin{array}{l}\text { AoL has the risk of becoming bureaucratic and degenerating into } \\
\text { compliance }\end{array}$ & & $\sqrt{ }$ & $\sqrt{ }$ \\
\hline 19 & $\begin{array}{l}\text { AoL does not have an effective way of ensuring that courses have } \\
\text { learning outcomes }\end{array}$ & & $\sqrt{ }$ & $\sqrt{ }$ \\
\hline 20 & $\begin{array}{l}\text { Sometimes AoL can constrain academics in terms of what they can } \\
\text { teach \& how they teach it. It can limit academic freedom }\end{array}$ & & $\sqrt{ }$ & $\sqrt{ }$ \\
\hline 21 & Accreditation is sometimes seen as a form of standardisation & & $\sqrt{ }$ & $\sqrt{ }$ \\
\hline 22 & Unimaginative Power Point presentations bore students & $\sqrt{ }$ & $\sqrt{ }$ & \\
\hline 23 & Some students do not have capability to learn & & $\sqrt{ }$ & $\sqrt{ }$ \\
\hline 24 & $\begin{array}{l}\text { We do not have school meetings where teachers share teaching practices } \\
\text { amongst themselves or where they reflect on their teaching. }\end{array}$ & & $\sqrt{ }$ & $\sqrt{ }$ \\
\hline 25 & $\begin{array}{l}\text { There is a lot of emphasis on performance based research funding } \\
\text { (PBRF). Research enjoys greater prominence \& higher status than } \\
\text { teaching. }\end{array}$ & $\sqrt{ }$ & $\sqrt{ }$ & $\sqrt{ }$ \\
\hline 26 & $\begin{array}{l}\text { IT support is not designed in a way that maximises student learning } \\
\text { experience. }\end{array}$ & & $\sqrt{ }$ & $\sqrt{ }$ \\
\hline 27 & IT is not always reliable. It is under-resourced. & & $\sqrt{ }$ & $\sqrt{ }$ \\
\hline
\end{tabular}


All three groups agree that there are limited interactions between students and lecturers, because many lecturers do not have time for students. They also agree that many lecturers do not have enough teaching skills; there is not much focus on graduate attributes; and program is not coherent.

VBS lecturers and students agree on many things including the fact that there is lack of coherence of the courses and that some lecturers teach the same course materials year after year. They also agreed that students are bored and not well engaged and that many of them fail to attend lectures. Table 6.22 provides other converging views.

Table 6.22: Some converging views (VBS students \& lecturers)

\begin{tabular}{|c|c|c|}
\hline Issue & What do students say? & What do lecturers say? \\
\hline Pay/cheque & $\begin{array}{l}\text { For lecturers are they just there because they are clicking a wage } \\
\text { (VD1). }\end{array}$ & $\begin{array}{l}\text { If someone came and said XXX, do you want to give up teaching completely and just do } \\
\text { research? I'd say, yes. I hate it. \{But what keeps you going? Pay cheque. \{What? Pay?\} } \\
\text { Yes (VL 02). }\end{array}$ \\
\hline $\begin{array}{l}\text { Logical } \\
\text { sequence \& } \\
\text { linkages }\end{array}$ & $\begin{array}{l}\text { The assignments were pointless and they did not relate to } \\
\text { anything. The pop quizzes did not relate to the lectures. So the } \\
\text { assignments did not link well with the course content. That } \\
\text { course was really a big shame (VD1). }\end{array}$ & Everybody runs their own courses (VL 02). \\
\hline repetition & $\begin{array}{l}\text { There is so much repetitiveness between papers that I get really } \\
\text { angry that am paying } \$ 700 \text { and something per paper and I have } \\
\text { actually learnt } 90 \% \text { of that already (VD3b). }\end{array}$ & $\begin{array}{l}\text { This university is also taking out the logical progression of subjects so as to give students } \\
\text { flexibility (VL 09). }\end{array}$ \\
\hline Expectations & $\begin{array}{l}\text { Basically not much is expected of us. So we won't do anything. } \\
\text { So basically we are all treated like a whole bunch of us come } \\
\text { here in and a lot of us \{are going\} drop next year, so we are not } \\
\text { expected much and we are not really treated seriously... At } \\
\text { times there are not enough assignments (VD1). }\end{array}$ & $\begin{array}{l}\text { We train students to expect less and to give less back to us (VL 01). To be honest, there are } \\
\text { a lot of students who are quite bored. Not well engaged. If we ask more of the students, then } \\
\text { they would give it. And they want to give it (VL 02). }\end{array}$ \\
\hline $\begin{array}{l}\text { Genuine } \\
\text { availability? }\end{array}$ & $\begin{array}{l}\text { Some are always saying 'am not free at that moment' always } \\
\text { saying that. So it is like an excuse not to help (VIb). }\end{array}$ & $\begin{array}{l}\text { But really the lecturer should be genuinely available (VL 04). 'Ooh go get jobs to manage } \\
\text { your time', then we do not have to deliver as much... And so that is helpful for us because } \\
\text { they do not do so much, so we can spend their time on other/our things (VL 01). }\end{array}$ \\
\hline Easier way? & I take business degree because it is easy to pass (VIa). & $\begin{array}{l}\text { I do think School of Business students they work lot less than the law students, and } \\
\text { students who do bachelor degree know that (VL 01). }\end{array}$ \\
\hline
\end{tabular}

VBS lecturers and administrators agree that the opportunity cost of taking PHELT is quite significant, and that AoL tends to be bureaucratic and therefore tends to limit academic freedom. Moreover, the two agree that there is a lot of emphasis on research and that forums for sharing of L\&T are not there. It is no wonder that the program does not link well. They also agree on the need for reliable IT to support L\&T. Table 6.23 provides another common view.

Table 6.23: Convergence of views (VBS lecturers \& administrators)

\begin{tabular}{|l|l|l|}
\hline Issue & What do lecturers say? & What do admin say? \\
\hline Logical & This university is also taking out & So part of the problem with our system is that prerequisites for example XYZ 201 \\
sequence & $\begin{array}{l}\text { the logical progression of } \\
\text { subjects so as to give students } \\
\text { flexibility (VL 09). }\end{array}$ & $\begin{array}{l}\text { \& XZ 203 are both taught the same semester, trimester two, so not all XYZ 203 } \\
\text { that time most of the stuff is lost in their memory (VAD 05) }\end{array}$ \\
\hline
\end{tabular}


VBS students and administrators agree that some lecturers have poor teaching skills and that Power Point slides are boring (Table 6.24). Indeed, students have suggested that lecturers should get rid of their boring slides and do a little more.

They should get rid of slides. Bring additional information, expertise, offer a bit of diversity as opposed to just reading information on the slides, bring their own experience, and relate it back to real world (VD2).

But does getting rid of slides imply that students prefer traditional teaching using chalk/white board? Or does it imply the need for creativity in teaching? So what brings the boredom, is it the slides or the lecturer or the teaching style? These issues need serious deliberations between staff and students. How can VBS attend to them? There are many models out there including one suggested by Higher Education Academy (2014) on partnership learning communities where students and staff can partner in co-learning, co-designing, and co-developing learning and teaching assessments, and in curriculum design and pedagogy. But in order for such partnerships to work, there must be trust. Engaging in open and honest dialogue between staff and students would help to constructively critique and challenge practices and approaches in L\&T that seem less effective.

Returning to the converging issues at VBS, Table 6.24 indicates convergence of students' and administrators' issues on teaching and researching, less useful lectures and intimidated students.

Table 6.24: Convergence of views (VBS students \& administrators)

\begin{tabular}{|l|l|l|}
\hline Issue & What do students say? & What do administrators say? \\
\hline $\begin{array}{l}\text { Teachers } \\
\text { and } \\
\text { researchers? }\end{array}$ & $\begin{array}{l}\text { Just because they are teachers and have a PhD } \\
\text { and have a lot of knowledge about the area, } \\
\text { does not mean they are good at teaching or } \\
\text { explaining it to someone (VD3b). }\end{array}$ & $\begin{array}{l}\text { Some people who are very good researchers are actually } \\
\text { lousy teachers. And sometimes we have very good } \\
\text { researchers who are very good teachers as well. But in } \\
\text { many cases, we do not have that. Some of our worst } \\
\text { teachers are very good researchers (VAD 07). }\end{array}$ \\
\hline $\begin{array}{l}\text { Not useful } \\
\text { lectures }\end{array}$ & $\begin{array}{l}\text { But when we attend his lectures he is just } \\
\text { reading his slides. So it is not useful. But I do } \\
\text { prefer the lecturer who teaches everything on } \\
\text { the board but of course he is very neat in } \\
\text { writing and so we actually learn as we write } \\
\text { notes, instead of reading the Power Point slides } \\
\text { (VI b). }\end{array}$ & $\begin{array}{l}\text { 'alk to students using examples, do things with students, } \\
\text { lecturers can be boring and can encourage disruptive in- } \\
\text { class behaviour, especially in large lecture theatres. So just } \\
\text { talk to them. Bring your insights, examples, etc.; include } \\
\text { images, objects, pictures, but not the unimaginative Power } \\
\text { Point presentations (VAD 01). }\end{array}$ \\
\hline Intimidation & $\begin{array}{l}\text { I am not very comfortable putting up my hand } \\
\text { to ask a question (VMP) } \\
\text { In large classes, it is very hard to ask a a } \\
\text { question, I dare not raise my hand amongst over } \\
300 \text { students. I do not have the courage (VIb). }\end{array}$ & $\begin{array}{l}\text { So students, because classes are so big, are so intimidated. } \\
\text { They do not feel a connection with their teachers (VAD } \\
\text { 02). }\end{array}$ \\
\hline
\end{tabular}

The above converging issues indicate common concerns on L\&T issues. They point towards the need for a transformed way of thinking about L\&T practices and for a deeper understanding of how the L\&T practices are perceived by students, lecturers and admin. Perhaps these 
common issues would be easier to address in an effort to improve the L\&T system than the diverging ones. Let's now turn the leaf to the diverging issues.

\title{
6.6.3 Diverging views
}

How do the three different groups of participants view each other?

\section{Diverging views (Students \& lecturers)}
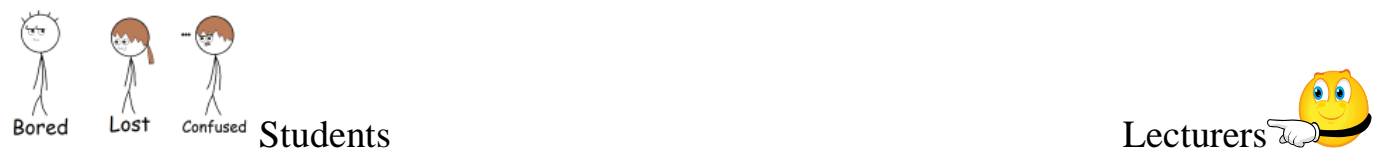

Students' attribute most of their less desirable experiences to their lecturers. They feel that even though lecturers are highly qualified in their fields, they do not always teach and communicate to them clearly. They see their lecturers as:

1. Lacking teaching skills; indeed, many prefer tutors claiming that tutors have better teaching skills.

\begin{abstract}
And I know a lot of lecturers in the university are researchers but a lot of tutors do not have a degree or masters but they have teaching skills. When they teach it is easy to understand and can develop group discussions in class and also can create a desire to study in class but not the lecturers. They just read their slides and I do not discuss that (VIa). They are just reading the slides instead of looking up at students and delivering and in tutorials; sometimes the lecturer is the tutor. So I feel like I want more from them (VMP).
\end{abstract}

2. Boring; most lecturers are boring and send students to slumber land. Students wonder why they should attend such lectures, yet they can read the slides on their own since they have reading skills.

It was like a class of 100 and it went down to about 30 people... And there are times when you notice students come back for one lecture to see whether there has been an improvement. Just like me, I sometimes think, oh this one is likely to be better and I will force myself to go. Then I go and find they are still talking over my head, and they are still talking rubbish then I will not go again for another 3 weeks. So I keep coming back and checking... Yes I just stay at home and read the slides (VD3b). Yet, because I have the reading skills, I can read at home (VIa).

3. Not motivated to teach.

Some of them genuinely don't care. They have been here for research, you can tell (VD2). They just want to do research and they do not want to teach (VIa).

4. Uncaring, not eager to develop relationships with students and not genuinely available for students.

Some are always saying 'am not free at that moment' always saying that. So it is like an excuse not to help (VIb). 
5. Out to exploit them; Students feel that their lecturers do not care enough for them and that, they just there because they are clicking a wage (VD1). Indeed some indicate that the reason why there is lack of linkages between some course and text books is because some textbooks bought some lecturers the best lunch in town.

The lecturer said to us, which really shocked me, he was like, and the reason why you've got the text-books is because they bought me best lunch (VD3a).

And so students cannot wait to see change in teaching. They cannot wait to have value for their money. And this is what students are asking their lecturers:

It is the same teaching style each year and we have to pay more and more each year, so where does the money go. So what's the point paying that much, are you going to improve or not or is it just going to stay the same? (VD3b).

On the other hand, lecturers feel that students:

1. Are not concerned about learning but are only interested in degree certificates and in passing exams.

And students are coming here and all they want is a piece of paper and they don't care about learning (VL 05). When I ask a question some time at the end of the lecture, students will say to me, will this topic be in the exams (VL 04).

2. Want to be spoon-fed, particularly the first years.

I sort of suspect that with the first year level there is a kind of growing helplessness with them. It is almost like you have to spoon-feed them (VL 06).

3. Those who do not attend lectures are a big problem.

There are students who do not turn up \{for lectures\}. They are a big problem here. They don't turn up for any lectures because lectures are not compulsory and typically those students do not do very well (VL 07).

4. In the same vein, lecturers complain about the weak students claiming that they take up most of their time.

What we spend our time on is trying to get failing students to pass a course instead of focusing on the good students and making them even better. So we spend more of our time on the bottom students than on the top students. And that is not the way good tertiary education system should work. I am sad and disappointed because of that (VL 05).

But how about those students who feel uncomfortable in classes?...I am not very comfortable putting up my hand to ask a question (VMP). What do we do with such students? Actually some lecturers express concern for those students who learn in different styles and exemplified the need to recognise that: 
'Not everybody learns particularly well by reading a book chapter. So it is having more opportunities for the students so that they can choose the medium for the learning that works best for their needs (VL 10).

And what is the parting word to fellow lecturers?

Some \{students \} might sit down and discuss a book chapter, some might actually like to visualise the book chapter as for example a virtual game where it is illustrated. And some might like to listen to the book chapter read out and that might help them. And some of them might want to do something that might start to get them involved. In all of those scenarios I can just facilitate it rather than being the "sage on the stage' (VL 10).

The diverging issues between students and lecturers bring to the fore pertinent issues relating to the roles of lecturers and students. What exactly is the role of a university lecturer in today's universities? Some would argue it is to facilitate, to direct learning, to partner, which way? What is the role of a student? Some would say it is to learn, to teach themselves, to partner in learning, yet others would say it is to get a service (because they feel that they are customers)? Whatever role each undertakes, which one facilitates the best way to achieve the goal of learning?

\section{Diverging views (VBS lecturers \& administrators)}

VBS lecturers and administrators

Lecturers

Lecturers feel that generally VUW management is putting pressure on them and interfering with their academic freedom in some ways. They also feel that:

1. They are overloaded with teaching and administrative duties and the management does not seem to realise it. Lecturers have many administrative duties, have to organise workshops, attend committees, have post-graduate courses to teach, post-graduate supervision, develop new courses from time to time, yet there is no reduction of course loads. So the top management do not understand the amount of work that academic staff have (VL 12).

2. Management lack trust in them, no wonder they overplay their roles and put restrictions on assessment. We are restricted on how we assess students. We are limited use of multiple choice questions... So having those rules is almost a view that this institution does not trust us as lecturers (VL 05). I think the university has over-played a number of roles, I think there are too many constraints on teachers doing good jobs. There are lots of rules that stop things from happening. There are lots of rules to stop bad behaviour... University stops it because some people could do it badly. They will stop people doing good things because somebody will do something wrong (VL 01). It's quite a low trust model. It is based on an assumption that some teachers have been abusing their positions. So, I would prefer to trust the academics (VL 03).

3. The institution is not keen to reward teaching and they see the university as having different goals. The university has multiple objectives and so it does essentially choose one over the 
other. There are two main ones: research \& teaching (VL 01). The university's goal is to retain students to completion (VL 05).

4. Management do not seem to understand the role of the university. I don't think the organisation understands what the role of universities is because the role of university is to cultivate intellectual independence. But I will say that most people in the business school wouldn't think that is the role of the business school. So I don't basically trust, I don't have faith in senior management of the business school or the university because I don't think they understand the purpose of the university (VL $05)$.

Management on the other hand feel that lecturers do not always try to understand students' learning needs and do not provide the senior administrators with feedback. We provide a lot of opportunities for feedback mainly from the academic staff and they do not take it up... So they don't engage right from the start. They wait until it is just about to finish. Then they will come in and start criticising you. They do not give you solutions, they just criticise you (VAD 03).

\section{VBS students and administrators}

Students feel sad that their feedback on teaching is not taken seriously. They also indicate that some lecturers are arrogant about the feedback.

I think VBS does not read feedback because in lots of courses we write feedback for the lecturer, but they still come back to teach... the lecturer was the only lecturer, and she even said at the end of the lecture when we have the evaluation, just say what you want to say, if you fail this course I am going to return next year anyway, so just write whatever you want'(VIa).

The lecturer was horrible but he has been teaching for so many years the same subject, so really they do not take the forms seriously. Because even past students used to talk about the course and would say he was horrible so I don't think they look at the feedback. With lecturers, it does not seem to have so much of an impact. And they have taught the same course for 15 years, so why would they get someone else (VD2).

Because each year we have those evaluation forms, but I don't think they are actually followed up (VD3b).

Students are surprised that a drop in student numbers in many classes does not seem to mean anything to VBS management.

It was like a class of 100 and it went down to about 30 people... I think there need to be consideration in the fact that yes numbers will drop and that's a significant drop, then there is something wrong and something needs to be made better... But they $\{$ lecturers\} are not going to go back to the head of school and say, oh everybody has stopped turning up to my lecture (VD3b).

But administrators actually agree with the students that they do not pay enough attention to drop out rates. 
We do not pay enough attention to drop out rates. If you have a class that started off with about 150 students, and after the first mid-term it is only 60 students, then there could be a big problem. But you find that attention isn't paid to that (VAD 07). So, who should pay this attention?

Indeed, administrators indicate that students' complaints never get to their doors. They put the blame on the way 'students' feedback on teaching' is handled. Administrators tend to blame the senior university management because of the flaws with the 'students' feedback on teaching' system. Administrators agree with the students that some people do not take 'students' feedback on teaching' seriously.

In this university, the way \{student feedback on teaching and courses $\}$ are done to my mind is very very very very problematic because it is carried out in class by the so-called class representatives, and the teacher concerned is responsible for setting everything up. So people forget to do it or people pretend to forget to do it... \{As for complaints\} I might hear rumours about a class, that lecturer X is a real idiot in teaching, he teaches horribly, but if people do not report to me directly, I can't do anything. Students might complain to the class reps, but a lot of class reps just don't do anything. If the Head of School does not hear officially, they can't do anything. (VAD 07).

\section{So what do administrators suggest could be done with the student feedback?}

Well mostly in universities around the world, course evaluations \{student feedback\} are done through central administration. So it is seen to be more serious. It is done, no excuses, the results are published, and they become public information. And because it is also done centrally it is well coordinated (VAD 07).

Does the fact that most universities use central administration make student feedback effective? But whether effective or not, the top management is to blame for blocking such proposals.

\section{Then, what prevents such a change happening here at VBS?}

It's obvious, institutional politics. Different people have different invested interests (VAD 04).

Within the university any change requires a lot of consultation. A lot of people to agree to it and in the end you can get through a multitude steps coming through various committees and it can be shut down in the very end by the council or the vice chancellor. Everyone could agree to it, but will be shut down at the very end (VAD 03).

In a nutshell, the contentions with student feedback tend to point to the following issues:

- Effectiveness of how and when student feedback is administered. Does student feedback benefit the present cohort of students? Does it benefit the next cohort? How is that ensured?

- Effectiveness of what is measured (is it achievement of learning outcomes, teaching style, assessment, teaching communication) and how effectively can that be measured?

- Who eventually provides feedback? If in a class of 150 students, most students miss lectures and perhaps only 60 remain to provide feedback on teaching. Then it might 
imply that the 60 are the ones who are most likely satisfied with a lecturer. How about the 90 who miss out due to dissatisfaction and who never provide their feedback?

- What improvements in L\&T have these feedbacks brought at VBS so far?

The issue of feedback on teaching is discussed in Chapters 8 and 9.

\subsubsection{The root causes of VBS UDEs}

The root cause of VBS less desirable experiences point to one thing: prioritising research over teaching. This root cause cuts across the three groups (Table 6.25).

Table 6.25: Common critical root causes at VBS

\begin{tabular}{|l|l|l|}
\hline Students & lecturers & Admin \\
\hline Lecturers are here for research & Teaching is not rewarded & Lecturers performance is based on research output \\
\hline
\end{tabular}

Note: Out of 7 FGs, 2 mentioned that lecturers were more enthusiastic with research than teaching. And out of 12 lecturers, 6 expressed strong concern over the emphasis that research gets relative to teaching. Two expressed concern that much teaching interfered with their research output while four did not mention effect of research on teaching or vice versa. Among the administrators, 5 out of 8 indicated that emphasis on research compromised teaching and that academic staff are more interested in research than teaching. One indicated that research tended to compete with his/her time for admin work, one mentioned research but not its negative impact on teaching while one did not mention anything to do with research.

The issue of prioritising research over teaching at VBS, however, might appear to be consistent with VUWs positioning strategy of a 'research university'. But, if VUW has positioned itself as such, why does VUW's current strategic plan emphasise increasing student numbers? Is this strategy in line with its positioning? Or does VUW target research students?

The dilemmas surrounding the above three critical root causes point to one basic issue: research versus teaching. The resolution to this dilemma is explored in Chapter 8.

\subsection{Summary}

The analysis of the views of students, lecturers, and administrators of VBS depicts a situation where people are put in a dilemma because of research and teaching. It is clear that the university rewards research and not teaching. Therefore, the natural thing for lecturers to do is to prioritise research. Studies on the relationship between good researchers and good teachers are inconclusive. But in the case of VBS, prioritising of research by lecturers tends to impact undesirably to students who may not effectively achieve their goals of learning. Lecturers also tend to agree that they do not effectively help students to achieve the goals of getting intellectual independence. The administrators seem to be thrown into a sea of confusion. They do not seem to communicate a clear understanding of a common goal of L\&T. As a result, 
everybody tends to do their own thing. Lack of focus or consensus on a common goal leads to underachievement of the L\&T goal. 
Chapter 6: Data analysis and findings (New Zealand case) 


\section{Chapter 7}

\section{CROSS-CASE ANALYSIS}

Resemblances are the shadows of differences. Different people see different similarities and similar differences (Vladimir Vladimirovich Nabokov, 1899-1977).

\subsection{Introduction}

This chapter provides a comparative analysis of UNSB and VBS students', lecturers', and administrators' views of their goals of learning and teaching drawing on similarities and perceived differences of critical success factors and necessary conditions. Similarities and differences are explored focusing on less-than-desirable issues that impact on quality of learning and teaching experiences. Critical root causes are highlighted. Then, comparisons are drawn from similar groups of participants in each country (such as UNSB students vs VBS students). Similar to the previous sections, the order of comparison is students, then move on to lecturers and administrators.

\subsection{Students' comparisons}

This subsection discusses some similarities and differences between UNSB and VBS students' views of their goals of learning and the less than desirable experiences of their learning.

\section{The students' goals, CSFs, and NCs}

The analysis of UNSB and VBS students' goals indicates that both groups of students are interested in acquiring knowledge and skills (required in the job market or in self-employment).

Table 7.1: Comparing students' goals

\begin{tabular}{|l|l|l|}
\hline & UNSB & VBS \\
\hline Goal & $\begin{array}{l}\text { Acquiring business } \\
\text { knowledge and skills }\end{array}$ & $\begin{array}{l}\text { Getting a qualification with applicable and } \\
\text { employ able skills }\end{array}$ \\
\hline
\end{tabular}

Both the groups indicate the need for social skills, networking, and exposure. The difference is that at VBS there is much more emphasis on 'getting a qualification to get a job'. This is not as emphasised by UNSB students' goal statements. Does this mean that getting a job is not a priority for many UNSB students? Well, some of the students interviewed were already in employment, while others emphasised skills for self-employment. This lack of emphasis on employment could also be explained by the fact that getting a job in Kenya is not always easy. 
Many Kenyans appreciate self-employment due to limited jobs opportunities in formal employment. VBS students' goals also emphasise applicable skills that are not emphasised by their UNSB counterparts.

Table 7.2: Comparison of CSFs and NCs

\begin{tabular}{|c|c|c|}
\hline & UNSB & VBS \\
\hline CSFs & $\begin{array}{l}\text { Adequate T\&L facilities \& structures } \\
\text { Qualified, committed \& 'techno-savvy' } \\
\text { lecturers } \\
\text { Self-discipline \& hard-work (students) }\end{array}$ & $\begin{array}{ll}\text { Motivation and dedication } \\
\text { Interactions } \\
\text { Resources }\end{array}$ \\
\hline NCs & $\begin{array}{l}\text { Modem T\&L classrooms, labs, lecture } \\
\text { theatres, sporting and recreational facilities } \\
\text { Computer technology \& innovation and } \\
\text { internet facilities } \\
\text { Well-equipped library and e-resources } \\
\text { Staff development \& training } \\
\text { Teamwork \& collaborations } \\
\text { Student engagement and support } \\
\text { Good leadership of the School }\end{array}$ & $\begin{array}{l}\text { Passionate \& effective teachers } \\
\text { Passion \& self-discipline (students) } \\
\text { Group activities \& clubs } \\
\text { Student support (SLSS, peers) } \\
\text { Good tutors (teaching ability \& bubbly) } \\
\text { Technology \& facilities (books, e-resources \& } \\
\text { workshops) } \\
\text { Academic qualifications (lecturers) } \\
\text { Qualifications in teaching (lecturers) } \\
\text { Industrial involvement \& experiences }\end{array}$ \\
\hline
\end{tabular}

The comparisons of the CSFs and the NCs show many similarities between UNSB and VBS students. We find similar needs in terms of commitment (dedication), facilities and resources, group work, academic qualifications, and student support. There are few differences. For instance, UNSB students emphasise the need for their lecturers to be technology savvy and for good leadership of UNSB that are not indicated as needs of VBS students.

\section{Issues impacting on the achievement of the goal}

The common issues impacting negatively on the achievement of the goals of UNSB and VBS students are depicted in Table 7. 3.

\section{Table 7.3: Similar UDEs}

- Limited interactions between students \& lecturers

- $\quad$ Lack of a practical approach to L\&T

- Inadequate student involvement \& engagement

- Lack of genuine availability of lecturers

- Most lecturers lack teaching skills

- Most lecturers 'just read their slides/notes'

- Lecturer evaluations are not 'acted upon'

Both the groups of students insist on the need for more interactions, more involvement and engagement in learning and for a practical approach to L\&T. They want their lecturers to have teaching skills perhaps to be able to deliver in a better way. They feel that if lecturers' feedback is acted upon, they could perhaps improve the teaching function. Other similar verbatim views are depicted in Table 7.4. 
Table 7.4: Similar views

\begin{tabular}{|c|c|c|}
\hline Issue & What the UNSB students say & What the VBS students say \\
\hline Lecturing & $\begin{array}{l}\text { The situation here is that a lecturer comes and } \\
\text { just reads for us those words without any } \\
\text { explanations (KM1). } \\
\text { They read their notes, so we do not get } \\
\text { anything from them because it is the same as } \\
\text { reading the hand-out for yourself (KM2-FT). }\end{array}$ & $\begin{array}{l}\text { Some lecturers just stay there like a statute and they just talk non-stop. } \\
\text { They are just reading the slides. Yes I just stay at home and read the } \\
\text { slides (VD3b). } \\
\text { It is like standing at a podium and they just read, and read and read, and } \\
\text { it is a monotone. And we wonder why, rather than studying on your } \\
\text { own, you are wondering why you are at a lecture (VD1). }\end{array}$ \\
\hline $\begin{array}{l}\text { Rote } \\
\text { learning \& } \\
\text { Curricula } \\
\text { design }\end{array}$ & $\begin{array}{l}\text { When you come to first year, there are some } \\
\text { units you read, do exams, forget about those } \\
\text { things, delete them in your mind, then you go } \\
\text { to another unit, you delete, so at the end of it } \\
\text { all you do not remember anything that you } \\
\text { learnt in first year. So on the way there is no } \\
\text { other unit that will make you remember the } \\
\text { concepts you learnt earlier. There is lack of } \\
\text { flow of acquired knowledge from first year on } \\
\text { to other years, one level to the other (KM } 1 \text { ). }\end{array}$ & $\begin{array}{l}\text { But sometimes, the topic is still hard. So after we learn it, after the } \\
\text { exams, we just forget every thing (VIb). }\end{array}$ \\
\hline $\begin{array}{l}\text { Lecturer } \\
\text { evaluations }\end{array}$ & $\begin{array}{l}\text { Even if you evaluate the lecturers, evaluations } \\
\text { \{feedback }\} \text { do not work (KM } 1) \text {. }\end{array}$ & $\begin{array}{l}\text { Those feedback sheets that they give us at the end of the semester } \\
\text { aren't taken seriously enough at all (VD3b). }\end{array}$ \\
\hline Assessment & $\begin{array}{l}\text { You find that } 70 \% \text { of assessment is done at the } \\
\text { end of the semester while } 30 \% \text { constitutes the } \\
\text { course work. The current trend is that when } \\
\text { exams are just around the corner, that's when } \\
\text { students start struggling to read, which } \\
\text { accounts to } 70 \% \text { of the score. So this is not } \\
\text { realistic reflection of what I have been doing } \\
\text { around. This is an imbalance, So the ratio can } \\
\text { be } 50 \%-50 \% \text { or } 40 \%-60 \% \text { (KM } 2-\mathrm{FT}) \text {. }\end{array}$ & $\begin{array}{l}\text { They make the course } 50 \% \text { is test. On average it is } 50 \%: 50 \% \text {. I think } \\
\text { it should be like } 30 \%: 70 \% \text {. At the end of semester you work for only } \\
3 \text { hrs for } 50 \% \text {, and with all the classes. All the effort is put to end of } \\
\text { semester exam (VD3b). }\end{array}$ \\
\hline Poor scores & $\begin{array}{l}\text { If you ask all of us here, I think } 95 \% \text { of the } \\
\text { students had D's in accounting } 1 \& 2 \text {, assets \& } \\
\text { equities, most of us failed (KM2-FT). }\end{array}$ & $\begin{array}{l}\text { I had a test last trimester that had a } 13 \% \text { pass rate. The highest mark I } \\
\text { heard was } 10 / 30 . . . \text { It was terrifying. I also did two tests that had a } \\
\text { median grade of } 19 \% \text {...I did a test that was so difficult and one of the } \\
\text { girls actually started crying after sitting the test. She thought that all } \\
\text { her hope is gone, I am going to fail, every one was scared (VD2). }\end{array}$ \\
\hline Customer & $\begin{array}{l}\text { Lack of appreciation of students as customers } \\
\text { of University of Nairobi (KM2-FT). }\end{array}$ & $\begin{array}{l}\text { Because we are customers of Vic University, but Vic University does } \\
\text { not respect us (VIa). }\end{array}$ \\
\hline
\end{tabular}

\section{Dissimilar views}

Many of UNSB and VBS students' views on the L\&T tend to be similar. But differences arise due to contextual issues. For instance, at UNSB, there are no tutorial classes and not all large classrooms/lecture halls are fitted with microphones. The point to note is that the issues raised 
below are not necessarily opposing views but are emphasised more by one group and not the other, depending on their contextual needs.

- Missing classes/lectures: UNSB lecturers miss classes, while at VBS it is the students who miss classes.

- Program: At UNSB, students complain about 'outdated program' while at VBS students complain about a lack of coherence and overlaps/repetitions within the program.

- Unavailability of lecturers: At UNSB most lecturers are unavailable to students because of the many classes that they are teaching (sometimes in distant campuses) and because there are not enough lecturers while at VBS lecturers are busy with research.

- Resources: UNSB students complain about basic resources such as inadequate books in the library, inadequate computers, classrooms, and other facilities. VBS students do not complain about such resources. They complain about high cost of text-books.

- Student support: UNSB students express great need for student support in terms of guidance and counselling about university life and other forms of training (such as using a portal). This need is not expressed by VBS students.

- Marking, assessments and grades: UNSB students complain a great deal about missing marks, the invigilation process and grades. VBS students complain that some marking is quite specific and not broad enough. VBS students also indicate that some exams and assignments are ambiguous.

Moreover, VBS students complain about:

- Accents: Students do not understand accents of some academic staff.

- Course lecturers: Because the same lecturer teachers a course from one semester to another, they express the need for a change.

- Tutors: Students would want their tutors to be qualified with ability to communicate well. They want charismatic and bubbly tutors.

\section{Root causes of the less desirable experiences}

The root causes of the two groups are different (Table 7.5). At UNSB, the less desirable issues tend to be propagated by high student numbers in classes which allegedly limits interactions during lectures. In addition, the bureaucratic structure tends to obstruct the changes that students desire. 
Table 7.5: Root causes

\begin{tabular}{|l|l|}
\hline UNS B & VBS \\
\hline There are high student numbers in most classes & Most lecturers are at the VBS for research \\
The structure of the UNSB is bureaucratic & \\
\hline
\end{tabular}

At VBS, most lecturers feel priority is research work and this tends to cause most of the less than desirable experiences of students. It is not surprising that even the VBS lecturers indicate that great importance placed on research. Prioritising research has placed a de facto greater emphasis on research at the expense of time devoted to teaching. As a result, most of VBS lecturers concentrate more on their research than on teaching because research is what is rewarded. The negative effects of this emphasis on teaching are evident from the previous chapters. Other studies conducted in NZ such as Willis (2009) corroborate indicate that emphasis on research has made the scholarship of L\&T increasingly invisible.

\section{Conclusion}

The views of UNSB and VBS students tend to converge more on the needs for interactive and active learning. In order to achieve this level of interaction and active learning, students want more interaction with their lecturers. This might point to a need to design programs to deliver and support active learning. 


\subsection{Lecturers' comparisons}

This subsection discusses some similarities and differences between UNSB and VBS lecturers' views of teaching goals, CSFs and NCs. Comparisons are also drawn on the less than desirable experiences of teaching as well as the root causes of the undesirable experiences.

\section{The lecturers' goals, CSF, and NCs}

The UNSB and VBS lecturers' goals point to a need to improve students' competence in knowledge and skills (Table 7.6). But the process of helping students to attain the competence tends to differ.

Table 7. 6: Comparing lecturers' goals

\begin{tabular}{|l|l|l|}
\hline & UNSB & VBS \\
\hline Goal & $\begin{array}{l}\text { Imparting knowledge, skills and } \\
\text { attitudinal change to learners. }\end{array}$ & $\begin{array}{l}\text { Helping students to develop competence } \\
\text { in thinking and/or cultivate intellectual } \\
\text { independence in students }\end{array}$ \\
\hline
\end{tabular}

In VBS, lecturers 'help students to develop and cultivate' intelligence while at UNSB, lecturers 'impart' knowledge. The terms 'develop and cultivate' and 'impart' might point to how UNSB and VBS lecturers perceive the 'conception of teaching'. In both cases the conceptions seem to contradict current recommended good teaching practices (This issue is discussed further in Chapter 8).

On the CSFs and the NCs (Table 7.7), both UNSB and VBS lecturers find it critical to have motivated (willing) learners. They also agree on the need for student involvement (engagement) and motivated staff. On the learning resources, UNSB lecturers are concerned about 'adequacy' while VBS lecturers are concerned about 'diversity'. 
Table 7. 7: Comparison of CSFs and NCs

\begin{tabular}{|c|c|c|}
\hline & UNSB & VBS \\
\hline CSFs & $\begin{array}{l}\text { Adequate \& modem L\&T facilities \& } \\
\text { resources } \\
\text { Adequate, skilled \& motivated manpower } \\
\text { (academic \& support) } \\
\text { Highly capable \& willing students }\end{array}$ & $\begin{array}{l}\text { Motivated students \& passionate leamers } \\
\text { Effective teaching \& communication }\end{array}$ \\
\hline $\mathrm{NCs}$ & $\begin{array}{l}\text { Adequate funding } \\
\text { Robust and open hiring system for academic } \\
\text { staff } \\
\text { Staff development and support } \\
\text { Realistic workload } \\
\text { Student involvement and support } \\
\text { Stringent admission criteria } \\
\text { Sufficient government funding } \\
\text { Ability to attract other funds } \\
\text { Effective trainings, conferences, \& exchange } \\
\text { programs } \\
\text { Industrial involvement }\end{array}$ & $\begin{array}{l}\text { Set high expectations } \\
\text { Student engagement } \\
\text { Creative and diverse teaching methods } \\
\text { Contextualised and relevant materials } \\
\text { Diverse learning resources } \\
\text { Common understanding of goal \& common set of } \\
\text { expectations } \\
\text { Sufficient time to prepare \& create teaching materials } \\
\text { Commitment \& motivation } \\
\text { Reward teaching } \\
\text { Committed leadership }\end{array}$ \\
\hline
\end{tabular}

A closer look at NCs indicates that VBS NCs are more aligned to classroom issues while UNSB NCs are not. UNSB NCs tend to focus on funding, admission, hiring, and staff development but not on classroom issues, per se.

\section{Issues impacting on the achievement of the teaching goals}

Table 7.8 depicts the common issues that impact negatively on the achievement of the teaching goals at UNSB and VBS. Lecturers at UNSB and VBS complain that management lacks trust in them. They feel that their expertise is not respected. They feel bad that good teaching is not rewarded. Moreover, there is no common understanding of the goal of teaching. Other common issues are limited interactions with students and limited involvement and engagement of students in learning.

\section{Table 7. 8: Common UDEs}

- Marking is not enjoyable

- Most lecturers do not have teacher training

- There is low trust of the profession

- There is no common understanding of the goals of teaching / are not well known

- There are limited interactions with students

- Good teaching is not rewarded

- Many students are not motivated to learn

- Many students want 'certificates'

- Some students are academically weak

- The student population has diverse needs

- There is limited student involvement \& engagement

- The teaching load is heavy

- Lecturers are not genuinely available to students

- It is difficult to engage students in large classes 
Table 7.9 depicts some of the similar phrases from UNSB and VBS that touch on the above

UDEs.

Table 7. 9: Lecturers' similar views

\begin{tabular}{|c|c|c|}
\hline Issue & What UNSB lecturers' say & What VBS lecturers say \\
\hline $\begin{array}{l}\text { Goal/ } \\
\text { graduate } \\
\text { profile }\end{array}$ & $\begin{array}{l}\text { But here specific teaching goals are lacking and } \\
\text { lecturers are not made aware of them (LK 03). }\end{array}$ & $\begin{array}{l}\text { But here, do I even know what our graduate } \\
\text { attributes are? Would I know where to find them? } \\
\text { (VL 09). }\end{array}$ \\
\hline $\begin{array}{l}\text { Unwilling } \\
\text { learners }\end{array}$ & $\begin{array}{l}\text { Unprepared students make me to spend a lot of time } \\
\text { talking about simple/routine issues such as how to do } \\
\text { homework, how to read, instead of inspiring students } \\
\text { and discussing big things affecting the globe (LK 08). }\end{array}$ & $\begin{array}{l}\text { So what happens is I spend my time on most of } \\
\text { those students and the top students get nothing } \\
\text { (VL 05). } \\
\text { So it is just frustrating when you go to a class and } \\
\text { you know half of the students are prepared and } \\
\text { they want to talk but again half of them have not } \\
\text { done anything. So that is quite demotivating (VL } \\
\text { 07). }\end{array}$ \\
\hline $\begin{array}{l}\text { Training on } \\
\text { handling } \\
\text { students }\end{array}$ & We do not know how to handle students (LK 03). & $\begin{array}{l}\text { But really there are no guidelines and they do not } \\
\text { tell us what to do. Nobody addresses that kind of } \\
\text { stuff or how to deal with alcoholics in class. So I } \\
\text { feel that they need to train people on these things } \\
\text { (VL 09). }\end{array}$ \\
\hline $\begin{array}{l}\text { Teacher } \\
\text { training }\end{array}$ & $\begin{array}{l}\text { The university does not have any program to train } \\
\text { lecturers on how to deliver, prepare content, mark } \\
\text { exams, and distribute marks (LK 04). } \\
\text { We do not know, you just do it your way. Who has } \\
\text { ever taught us how to come up with a case study? We } \\
\text { just finish university then we are employed (LK 03). }\end{array}$ & $\begin{array}{l}\text { We get to go from the PhD into teaching. We } \\
\text { haven't got any teacher training (VL 09). }\end{array}$ \\
\hline Marking & $\begin{array}{l}\text { I don't enjoy marking. I wish I had an assistant (LK } \\
\text { 09). }\end{array}$ & Well I hate marking. I don't like marking (VL 02). \\
\hline Certificates & $\begin{array}{l}\text { According to them... they are just looking for } \\
\text { certificates (LK 06). } \\
\text { And the issue that the system started demand of those } \\
\text { certificates it is a pressure to get a certificate, a good } \\
\text { no of students we have are there because they are } \\
\text { being pushed. When you finish high school you must } \\
\text { go to university and get a certificate. That desire for } \\
\text { knowledge is not there (LK 09). }\end{array}$ & $\begin{array}{l}\text { All they care about is 'give me that piece of paper } \\
\text { to show that I have got my Bachelor's degree (VL } \\
\text { 05). } \\
\text { Some students say 'Cs get their degrees'. So some } \\
\text { students will be looking to just do the minimum } \\
\text { and they are happy, they do not care (VL07). }\end{array}$ \\
\hline $\begin{array}{l}\text { Academic } \\
\text { freedom \& } \\
\text { trust }\end{array}$ & $\begin{array}{l}\text { I don't think the lecturers or professors have enough } \\
\text { freedom... Once you have been hired as an expert, } \\
\text { then you should be left to do it on your own... } \\
\text { People do not seem to believe that if am left to grade } \\
\text { I would be objective, somebody else must come } \\
\text { around and make sure that am doing the right thing } \\
\text { and so on. That suspicion is what I am against. We } \\
\text { should believe that people are responsible. There } \\
\text { should be more trust (LK 08). }\end{array}$ & $\begin{array}{l}\text { I think increasingly there are attempts to constrain } \\
\text { academic freedom ...It's quite a low trust model. } \\
\ldots \text { And for me you are a profession that am going } \\
\text { to trust to make a professional judgement. And am } \\
\text { going to trust that you make the best decisions for } \\
\text { your students and that you have the outcomes of } \\
\text { your students at heart (VL 03). } \\
\ldots \text { So having those rules is almost a view that this } \\
\text { institution does not trust us as lecturers (VL 05). }\end{array}$ \\
\hline $\begin{array}{l}\text { Student } \\
\text { diversity }\end{array}$ & $\begin{array}{l}\text { The nature of our students; part of them are working, } \\
\text { their availability is limited and when they come, they } \\
\text { are tired. Then, we are mixing them with very young } \\
\text { students fresh from high school, all with varying } \\
\text { ages. The nature of some of our courses requires that } \\
\text { students have work experience in order to understand } \\
\text { them well. In that case, those students with working } \\
\text { experience or knowledge about business are likely to } \\
\text { do better because they can be able to relate to their } \\
\text { work than their counterparts without it. So this brings } \\
\text { a problem to the lecturer when you are teaching. } \\
\text { Whom do you address? This is a very heterogeneous } \\
\text { group of students; working, not working, with } \\
\text { experience, without, and age differences (LK 09). }\end{array}$ & $\begin{array}{l}\text { We have a very diverse group of learners, we have } \\
\text { people with physical impairments, we have } \\
\text { students who have come through the schooling } \\
\text { system and can now go to university even though } \\
\text { they are not good textual learners, we have people } \\
\text { who have come from different cultural } \\
\text { backgrounds and can relate to different cultural } \\
\text { stuff and they are also learning different cultural } \\
\text { experiences (VL 10). }\end{array}$ \\
\hline
\end{tabular}




\section{Dissimilar views}

The issues discussed here are those that are perhaps more emphasised by one party than the other. They are not necessarily opposing views.

- Managerial interferences: Although both UNSB and VBS lecturers express a need for more trust from senior management, VBS lecturers are more disgruntled about the rules that management have put on assessments. They also perceive the assurance of learning (AoL) as an imposition that is not likely to yield good outcomes. VBS lecturers also challenge senior management to understand 'the purpose of a university'.

- Bureaucratic processes: VBS lecturers perceive red tape within the L\&T system as frustrating to any creative initiative related to good teaching. On the contrary, UNSB administrative processes do not seem to constrain lecturers in their teaching initiatives.

- Administrative duties: VBS lecturers complain about excessive administrative duties yet they get paid 'academic salaries'. They feel that such duties could be done by people who are not paid academic salaries.

- Lecturer evaluation: VBS lecturers feel that teaching evaluations are problematic, not always fair and can easily be manipulated (by the lecturers themselves). 'With a de-brief, you psychologically affect the students and so you can manipulate it [the evaluation] easily (VL 09)'. They also express fear that poor lecturer evaluations can cause punishments such as demotion (VL 12).

- Semesters: VBS lecturers feel that semesters are quite condensed while UNSB lecturers indicate a need for semester breaks. UNSB lecturers indicate that semester breaks could help them to reflect on their teaching.

- Curricula: VBS lecturers complain about a lack of logical progression of courses and 'personal ownership' of courses that characterise the curricula. UNSB counterparts complain that the curricula are not up-to-date and do not integrate current business practices. We pause here and ask ourselves 'what is the role of curricula design?'

In view of the above dissimilarities we find commonality on how lecturers respond to the contextual issues in L\&T. At VBS, effort to align and organise curricula is met by complaints. At UNSB, they complain that the curricula are not aligned and up to date. So they complain if you try to align and organise and they complain if you do not. So, which way?

\section{Root causes of less desirable experiences}

The root causes of less desirable experiences of teaching at UNSB are limited government funding and lack of necessary coordination within the school. The issue of government funding is reflected in the above NCs (Table 7.7) that indicate lecturers' concern for sufficient funding to enable the L\&T system to operate more effectively. The lack of necessary coordination is 
also reflected by concerns for a coordinated approach to staff development and other L\&T functions within the school. These root causes are related to those of VBS.

Table 7.10: Root causes

\begin{tabular}{|l|l|}
\hline UNS B & VBS \\
\hline Limited government funding & Teaching is not rewarded \\
Lack of necessary coordination within the school & Emphasis is research funding \\
\hline
\end{tabular}

VBS lecturers are concerned that teaching is not rewarded. This is because research is more emphasised because of research funds that it brings to the institution. Thus in both cases, funding is the key driver. This root cause resonates clearly with their CSFs and the NCs (Table 7.3.2) that they perceive to be necessary to improve the L\&T (classroom issues) function. The common problem here is that lecturers are in situations which result in them having limited time and incentive for innovative course development and student engagement. The causes of this are different, but this is potentially the common "core problem".

\section{Conclusion}

UNSB and VBS lecturers' views of the goals of teaching and of undesirable issues tend to converge on the need for active learning approaches. However, there appears to be divergence and contradictions on the conceptions of teaching as reflected in each party's goal statements and teaching practices (as reflected on the L\&T issues). Similar and dissimilar issues are drawn. The dissimilar issues tend to be shaped by the contexts of the L\&T environment. 


\subsection{Administrators' comparisons}

This subsection presents some similarities and differences between UNSB and VBS administrators' views of the L\&T system in terms of the L\&T goals, undesirable effects on the goal achievement, and on the critical root causes of the undesirable effects.

\section{The administrators' goals, CSF, and NCs}

The goals of UNSB and VBS administrators are similar in that they tend to emphasise equipping students with knowledge (Table 7.11).

Table 7. 11: Comparison of administrators' goals

\begin{tabular}{|l|l|l|}
\hline & UNSB & VBS \\
\hline Goal & $\begin{array}{l}\text { Prepare well-rounded, knowledgeable } \\
\text { and productive students for modern } \\
\text { society. }\end{array}$ & $\begin{array}{l}\text { A process of transformation whereby students acquire new knowledge } \\
\text { and skills (including the soft skills), develop an ability to think critically } \\
\text { and creatively as they apply the knowledge and skills in changing } \\
\text { situations (including markets, economy and social) as well as an ability } \\
\text { to communicate effectively in varying situations. }\end{array}$ \\
\hline
\end{tabular}

But UNSB's goal is more summarised compared to the VBS one. VBS goal tends to expound more on specific skills that students need in order to cope with the changing situations that they may face.

The CSFs and NCs (Table 7.12) of UNSB and VBS tend to agree on the importance of appropriate program design as well as on the capability of lecturers and students.

Table 7. 12: Comparison of CSFs and NCs

\begin{tabular}{|c|c|c|}
\hline & UNSB & VBS \\
\hline CSFs & $\begin{array}{l}\text { Appropriate program design } \\
\text { Adequate academic, social support, } \\
\text { resources \& standards } \\
\text { Broad admission criteria }\end{array}$ & $\begin{array}{l}\text { Lecturers' capability to deliver the program } \\
\text { Students' capability to be transformed } \\
\text { Program design }\end{array}$ \\
\hline $\mathrm{NCs}$ & $\begin{array}{l}\text { Appropriate curricular development } \\
\text { process } \\
\text { Qualified \& motivated academic staff } \\
\text { Qualified \& talented students } \\
\text { Adequate L\&T facilities \& equipment } \\
\text { Team work } \\
\text { Involvement of stakeholders } \\
\text { Adequate industrial linkages } \\
\text { Student welfare } \\
\text { Extra-curricular activities }\end{array}$ & $\begin{array}{l}\text { Professional development } \\
\text { Strong admin support } \\
\text { Good recruitment and hiring practices } \\
\text { IT support and technological skills } \\
\text { Leaming resources } \\
\text { Motivation (acknowledgments \& rewards) } \\
\text { Accessibility \& meaningfulness of professional } \\
\text { development } \\
\text { On-going development } \\
\text { Clear understanding and communication of the goal }\end{array}$ \\
\hline
\end{tabular}


The UNSB's NCs also emphasise the need for adequate academic and L\&T facilities and equipment. In addition, teamwork, stakeholder involvement, and industrial linkages are not overlooked. VBS counterparts do not seem to emphasise these issues. Instead, VBS administrators emphasise the need for clear understanding and communication of the goal, professional development, good recruitment and hiring practices, and administrative support. Thus, it is apparent that the need for 'adequate' resources is paramount for achievement of UNSB's goal of L\&T.

\subsubsection{Issues impacting on the L\&T goals}

The common issues that impact negatively on the achievement of L\&T goals include limited interactions between students and lecturers, inadequate communication between academic staff and general staff, and allegedly, academically weak students.

\section{Table 7. 13: Similar UDEs}

- There is not enough communication between academic staff and general staff

- Some students are academically weak

- Things take a long time to get done

- There is not much interactions between lecturers and students

- The class sizes are large; lecturers do not have full control

- Students are not fully engaged

- There is not enough focus on students well-being

Other similar views are depicted in Table 7.14. They include bureaucracy, lack of student participation and engagement, and poor teaching performances. 


\begin{tabular}{|c|c|c|c|}
\hline & Issue & UNSB & VBS \\
\hline 1. & Bureaucracy & $\begin{array}{l}\text { And therefore I may need a very basic thing, although } \\
\text { my (department or school account) accounts have } \\
\text { money, but I cannot use that money. It will take a } \\
\text { long time and all that. Most of our (department) } \\
\text { money is controlled by the school. But that money is } \\
\text { not readily available. There is a lot of bureaucracy. It } \\
\text { is very difficult to get because the money may not be } \\
\text { available at Kabete itself, so it has to go through a lot } \\
\text { of endorsements before, it eventually get here it will } \\
\text { be a month or later (KAD 04). }\end{array}$ & $\begin{array}{l}\text { Something that I do not like, how long it takes } \\
\text { to get things done (VAD 02). } \\
\text { And so it is the process that we have to go } \\
\text { through to get any funding. So the process is } \\
\text { very long-winded. Within the university any } \\
\text { change requires a lot of consultation. A lot of } \\
\text { people to agree to it and in the end you can } \\
\text { through a multitude steps coming through } \\
\text { various committees and it can be shut down in } \\
\text { the very end by the council of the vice } \\
\text { chancellor (VAD 03). }\end{array}$ \\
\hline 2. & $\begin{array}{l}\text { Addressing } \\
\text { poor } \\
\text { teaching }\end{array}$ & $\begin{array}{l}\text { The institutional structure doesn't really have a } \\
\text { mechanism for vetting lecturers who are not } \\
\text { performing (KAD 03). }\end{array}$ & $\begin{array}{l}\text { We do not have the kind of systems in place to } \\
\text { address challenges posed by poor teaching } \\
\text { performance (VAD 08). }\end{array}$ \\
\hline 3. & $\begin{array}{l}\text { Communica } \\
\text { tion between } \\
\text { academic } \\
\text { staff \& } \\
\text { general staff }\end{array}$ & $\begin{array}{l}\text { I would desire change in the management, where if } \\
\text { there could be close interaction like between } \\
\text { academic staff \& the administrative support staff. In } \\
\text { our case here the lecturers find themselves to be very } \\
\text { high and they have nothing to do with administrators } \\
\text { (KAD 06). }\end{array}$ & $\begin{array}{l}\text { The lack of communication between academic } \\
\text { staff and general staff. We do not } \\
\text { communicate as well with each other (VAD } \\
\text { 02). }\end{array}$ \\
\hline 4. & Monitoring & $\begin{array}{l}\text { Maybe because of being so many we are not able to } \\
\text { monitor them \{students\} (KAD 02). }\end{array}$ & $\begin{array}{l}\text { So things like monitoring academic } \\
\text { progression for each student or groups of } \\
\text { students become time consuming (VAD 02). }\end{array}$ \\
\hline 5. & $\begin{array}{l}\text { Student } \\
\text { participation } \\
\text { /engagement }\end{array}$ & $\begin{array}{l}\text { The students' dormancy where they just look at you } \\
\text { and they don't talk, lack of participation by } \\
\text { students... the need of getting the students do } \\
\text { practical or be involved in practical work (KAD 02). }\end{array}$ & $\begin{array}{l}\text { Some of the students aren't engaging with } \\
\text { their studies (VAD 05). }\end{array}$ \\
\hline 6. & $\begin{array}{l}\text { Student } \\
\text { motivation/ } \\
\text { willingness }\end{array}$ & I wish I could have willing learmers (KAD 02). & $\begin{array}{l}\text { They never meet you half-way, sometimes you } \\
\text { end up wanting them to succeed more than } \\
\text { they want to succeed. When it becomes that I } \\
\text { am more motivated for them to succeed than } \\
\text { they are (VAD 02). }\end{array}$ \\
\hline 7. & $\begin{array}{l}\text { Student } \\
\text { capability }\end{array}$ & $\begin{array}{l}\text { To have the right students in the program in terms of } \\
\text { entry criteria, qualifications and all that. Right means } \\
\text { sufficiently qualified students (KAD 04). }\end{array}$ & $\begin{array}{l}\text { Some of the students are clearly not up to it. } \\
\text { Some clearly don't have the capability (VAD } \\
\text { 04). }\end{array}$ \\
\hline
\end{tabular}

\section{Dissimilar views}

The following issues are not necessarily opposing views but are perhaps uniquely shaped by the contextual issues affecting administrators in the two business schools.

Adequate resources: As indicated above, there is a dire need for adequate resources that are basic for the L\&T at UNSB. At VBS it is not much emphasised though it can be traced back through funding.

- Academic staff: UNSB administrators are concerned about the adequacy and quality (qualifications) of their academic staff. They worry that their academic staff are not in touch with industry and about the low salaries that academic staff get. At VBS, concerns are about the digital divide, teaching skills and that academic staff are less engaged with L\&T issues than research.

- Teaching and research: VBS administrators state that they do not have in-house forums where they could discuss L\&T issues. They are also concerned that research enjoys greater 
prominence and higher status than teaching. UNSB administrators on the other hand are concerned that their academic staff are not well supported to engage in research.

- Student issues: At UNSB, the main administrative issue is that students outnumber resources. Some facilities such as science labs are improvised into classrooms for business students. The limited resources cause disillusionment to UNSB students. At VBS, administrators are concerned about students' non-engagement, lack of strong critical thinking skills, and there is a lack of focus on their well-being (the students' problems/issues).

- Industrial involvement and linkages: UNSB administrators desire more industrial involvement and linkages in their program. However, they are constrained by bureaucratic process in their effort to get memoranda of understanding with industrial players. Industrial involvement and linkages do not seem to concern VBS administrators.

- Fire-fighting: UNSB administrators are disgruntled about fire-fighting meetings, which they claim only exhaust their energy. VBS counterparts do not seem to have any fires to fight perhaps because there is a perceived lack of discussions of L\&T issues.

- Assurance of learning/ISO 900: VBS administrators fear that the AoL has the risk of becoming bureaucratic and being merely compliant about rules and standards. A related concern by UNSB counterparts is that ISO 9000 certification processes do not focus on the unique work of the university but force people to work like a production line.

\subsubsection{Root causes of the less desirable experiences}

The root causes of the less desirable issues impacting on the L\&T systems at UNSB and VBS are different. At UNSB, limited government funding seems to cause inadequacies in most resources needed by the school. In addition, bureaucratic processes tend to impact on the effectiveness of the L\&T system.

Table 7. 15: Root causes

\begin{tabular}{|l|l|}
\hline UNS B & VBS \\
\hline Bureaucratic system & Lecturers' performance is based on research output \\
Limited government funding & Assurance of Learning is concerned with processes \\
\hline
\end{tabular}

At VBS, the main problem is that research output is the measure of performance for lecturers. As such, lecturers tend to concentrate more on their research than teaching. Embedded therein is the AoL that seems to concern itself with processes more than with learning outcomes. 


\subsubsection{Conclusion}

The section has presented views of administrators of UNSB and VBS on their goals of L\&T. Despite the administrators' best intentions, there exist constraints that tend to limit the L\&T goal achievement. Some of these constraints are contextual. There are similarities and perceived differences in some aspects of goals, and the less desirable issues that impact negatively on goal achievement. The similar aspects may imply global challenges that are affecting L\&T while the different aspects may imply contextual challenges. The next subsection offers a synthesis of the two cases. 


\subsection{Cross-case synthesis}

This subsection brings together the case synthesis of UNSB and VBS in brief. It reviews the composite goals, CSFs, and NCs. The section also provides a recap of the common UDEs in each case as well as the root causes.

\subsubsection{The goals, CSF, and NCs (UNSB \& VBS)}

The UNSB and VBS goals are compared in Table 7.16. As noted in the previous sub-sections, UNSB's goal emphasises imparting knowledge while the VBS emphasises transforming students' thinking. The aim is not to expound on the issues that are already explained in the previous subsections but to summarise the synthesis.

Table 7. 16: Comparison of composite goals (UNSB \& VBS)

\begin{tabular}{|l|l|l|}
\hline & UNSB & VBS \\
\hline Goal & Impart/acquire knowledge \& skills & $\begin{array}{l}\text { Transform students to acquire critical thinking, } \\
\text { application and communication skills }\end{array}$ \\
\hline
\end{tabular}

The CSFs in both the schools point to the need for capable and motivated lecturers and students, and appropriate program design. Other CSFs emphasised at UNSB are adequacy of L\&T facilities and manpower.

Table 7. 17: Comparison of CSFs and NCs (UNSB \& VBS)

\begin{tabular}{|c|c|c|}
\hline & UNSB & VBS \\
\hline CSFs & $\begin{array}{l}\text { Appropriate design of the academic } \\
\text { programme } \\
\text { Adequate \& modem T\&L facilities \& } \\
\text { resources; } \\
\text { Adequate, skilled \& motivated } \\
\text { manpower (academic \& support) } \\
\text { Highly capable \& willing students }\end{array}$ & $\begin{array}{l}\text { Capable \& motivated lecturers } \\
\text { Appropriate programme design } \\
\text { Capable \& motivated students }\end{array}$ \\
\hline $\mathrm{NCs}$ & $\begin{array}{ll} & \text { Adequate funding } \\
\text { Robust hiring system } \\
\text { Staff development \& support } \\
\text { Realistic workload } \\
\text { Student engagement \& support } \\
\text { Stringent admission criteria } \\
\text { Teamwork \& collaborations } \\
\text { Necessary coordination (leadership) }\end{array}$ & $\begin{array}{l}\text { Common understanding of the L\&T goal } \\
\text { Teaching rewards } \\
\text { Professional development in teaching \& communication } \\
\text { Appropriate training resources } \\
\text { Self-discipline (students) } \\
\text { Leadership committed to L\&T }\end{array}$ \\
\hline
\end{tabular}

The NCs indicate two common factors: professional development and leadership. The other important factors emphasised at UNSB are adequate funding, robust hiring system, student engagement and support, and teamwork and collaborations. At VBS, common understanding of the L\&T goal, teaching rewards, appropriate training resources, and self-discipline (students) are emphasised. 
The common factors needed in the two business schools are capable and motivated lectures, capable and motivated students, resources for L\&T and committed leadership.

\subsubsection{Issues impacting on the L\&T goals}

The common issues impacting on the achievement of the L\&T goals are shown in Table 7.18. These issues point to the current trends in HE on the need for partnership in L\&T (The Higher Education Academy, 2014) and engagement in learning (NSSE, 2006).

\section{Table 7. 18: Common UDEs (UNSB \& VBS)}

- Interactions between students and lecturers are limited

- Lecturers are not genuinely available for students

- Many lecturers lack teaching skills

- Many courses lack a practical component

- Some students are academically weak

- There are limited interactions in most lectures/classes

- Students are not fully engaged in learning

- Many students are not willing/motivated to learn

\subsubsection{Root causes}

The root causes of the less-than-desirable L\&T experiences at each school are shown in Table 7.19. These root causes indicate some of the dilemmas that many managers of HE institutions are facing in today's changing HE landscape. Some of these issues are explored in chapter 2.

Table 7. 19: Root causes (UNSB \& VBS)

\begin{tabular}{|l|l|}
\hline UNS B & VBS \\
\hline Bureaucratic sy stem & Lecturers' performance is based on research output \\
Limited government funding & Teaching is not rewarded \\
$\quad$ Student numbers in most classes are high & Lecturers are at VBS for research, not teaching \\
There is lack of necessary coordination & \\
within the school & \\
\hline
\end{tabular}

\subsection{Summary}

This subsection has briefly provided recapitulation of the two business schools where common and differing factors affecting quality of L\&T experiences were identified across similar groups of participants. Common factors are attributable to global trends in the HE landscape 
while differing issues are attributable to the contextual environment where each business school operates. Although further comparisons could be drawn across different groups (such as UNSB Students vs VBS lecturers) this was avoided due to limitations on the word count of this thesis. The next chapter discusses these factors relating them to the current studies. 


\section{Chapter 8}

\section{DISCUSSION OF FINDINGS}

A teaching philosophy is always accompanied, whether one is aware of it or not, by a philosophy of knowledge (Joy du Plessis \& Irfan Muzaffar, 2010, in Vavrus, Thomas, \& Bartlett, 2011).

\subsection{Introduction}

This study set out to identify goal(s) of L\&T, factors that impact on the quality of L\&T experiences as well as critical root causes of the less-than-desirable experiences in two business schools. The chapter discusses findings presented and analysed in earlier chapters. The purpose is to relate the findings to other studies on L\&T in the HE sector and to demonstrate the efficacy of the TOC methodology in exploration of the experiences of L\&T within HEIs. The chapter starts with a discussion of the goals and then provides a detailed discussion that integrates the TOC methodological tools (Dettmer's goal tree and the current reality tree) with Biggs' 3P (presage-process-product) model. The chapter ends with proposals of improvement strategies that may not only resolve dilemmas associated with experiences of L\&T but also enhance the quality of L\&T experiences. The structure of the chapter is consistent with earlier chapters on data analysis.

\subsection{The goals of learning and teaching}

A system must have an aim. Without an aim, there is no system (W. Edwards Deming, 1994 as cited by Seddon 2008, p.82).

This subsection discusses the goals of students, lecturers and senior managers of UNSB and VBS in the context of extant literature. It highlights how a lack of a clear and common understanding of the goals of L\&T impacts negatively on learning outcomes.

\section{The goal of learning (UNSB \& VBS students)}

The findings identify the goal of UNSB students as 'acquisition of business knowledge and skills', and that of VBS students as 'getting a qualification with applicable and employable skills'. These findings indicate that there is some level of congruence and some differences between the students' verbalised goals and those stated in their respective institutions.

At UNSB, the learning objectives of the BCom program include ability to exercise a critical mind, problem-solving skills, entrepreneurial and self-reliance skills, and an awareness of the local and global business environments. The objectives of entrepreneurial and self-reliance 
skills, and problem-solving skills, are uniquely demonstrated in UNSB students' goals, but not so the goals of critical thinking and global awareness. This suggests that whilst the entrepreneurial and self-reliance skills are actually emphasised at UNSB, UNSB students indicate that they also need business knowledge and skills not just for seeking employment but also for self-employment.

At VBS, at the time of this study, the learning goals included an ability to apply critical and creative thinking skills, effective communication, global and multicultural awareness, leadership skills ${ }^{12}$, and specific knowledge skills. However, most VBS students who participated in this study place more emphasis on application and employability skills than other skills. It is only the international students (focus group) who emphasised the need for communication skills. But this emphasis might be attributed to the fact that most international students do not initially communicate effectively because they are not native English speakers. As an aside, Dave and Noel (2003) observe that NZ employers express concern over the performance gap in graduate communication skills.

The feedback received following presentation of conference papers (Kimani, Mabin, \& Davies, $2014 \mathrm{a} ; 2014 \mathrm{~b} ; 2014 \mathrm{c} ; 2015)$ relate to appreciation of the importance of knowing the L\&T goals.

\section{The goals of teaching (UNSB \& VBS lecturers)}

The goal of UNSB lecturers is to 'impart knowledge, skills, and attitudinal change to learners' while that of VBS lecturers is to 'help students to develop competencies in thinking and/or cultivate intellectual independence in students'. These goals point to differences in how UNSB and VBS lecturers practise teaching, and perhaps conceive L\&T.

UNSB lecturers indicate that they 'impart' knowledge and skills to learners. This conception is associated with transmission of knowledge and it tends to be a teacher-centred strategy (Prosser \& Trigwell, 2014). It appears that many UNSB lecturers' approach to teaching is largely teacher-centred; although there are examples of attempting to encourage student engagement, such as where an assignment requires students to engage with members of a Stock Exchange. Such an assignment indicates lecturer's desire for high levels of student involvement and engagement, which is consistent with the global trends in HE (Zepke \& Leach, 2010). The findings therefore imply that some lecturers do more than 'imparting knowledge and skills',

\footnotetext{
${ }^{12}$ Leadership skills have been downplayed in the revised Learning Goals
} 
seeking to use different ways of engaging students to impact their attitude to learners regardless of whether the goals of learning are achieved.

Indeed, the importance of lecturers understanding their goals of teaching was acknowledged by conference participants in Seville, Spain, where a paper, based on parts of this thesis, was presented (Kimani, Mabin, \& Davies, 2014b).

We note again the observation made in section 6.4.4 that VBS lecturers' teaching approach tends to be more teacher-centred/content-oriented than student-centred/learning-oriented. This approach is contrary to lecturers' stated goal of intellectual independence, which is associated with a more student-centred approach.

However, what UNSB and VBS lecturers have in common is that the approaches to teaching they adopt are clearly influenced by constraints surfacing within their institutions. At UNSB, lecturers cited inadequate L\&T resources, and limited academic freedom. Lecturers feel that they do not have full control over how they teach and examine students. But issues of inadequate resources and limited academic freedom are not uncommon in Africa. Indeed, in their analysis of $21^{\text {st }}$ century challenges facing the African HE sector, Teferra and Altbach, (2004) observe that there is a constant decline in resources allocated to HEIs by governments. In Kenya, Teferra and Altbach, (2004) note that interference and abuse of academic freedom have eroded the autonomy and quality of the HEIs.

At VBS, lecturers indicate that great importance placed on research, citing the requirement to provide evidence of research, a research performance for evaluation within the PerformanceBased Research Fund (PBRF) evaluation framework. The PBRF has placed a de facto greater emphasis on research at the expense of time devoted to teaching. As a result, most of VBS lecturers concentrate more on their research than on teaching because research is what is rewarded. The negative effect of PBRF on teaching resonates with findings of other studies conducted in NZ such as Willis (2009). In the same vein, there is a perceived lack of full control of teaching activities. Lecturers note with concern that restrictions on assessments and bureaucratic processes involved in field trips limit their freedom to use creative and innovative teaching approaches. Thus, when VBS lecturers tend to place their emphasis on research and to comply with university teaching-related restrictions, this is seen as what Blackmore refers to as 'a way of self-regulation where [lecturers] try to align themselves with university priorities' (Blackmore, 2014, p.285). 
Closely related is the fear of poor student feedback that sometimes leads to promotions being delayed and salary being affected. Kohn (1999, p.135) indicates that such punitive strategies are intrinsically offensive to employees and do not lead to improvement in quality. Nevertheless, Blackmore (2014) points out that student feedback is now more about accountability than improving quality. However, in my opinion, lecturers who are keen on improving their teaching effectiveness and building their teaching portfolio, would, regardless, seek feedback on their teaching, not only from students but also from other sources. They would also be dissatisfied with just the end-of-semester feedback and would seek to augment their teaching portfolios with quantitative and qualitative evidence collected at different times of the course period (such as weekly and mid-semester feedback).

The above constraints need to be addressed by the two participant case schools in order to improve teaching effectiveness. Although the resource constraints might not be within their full control, both schools remain able to influence the culture of academic freedom and curriculum design. Encouraging open discussions and tolerance to criticism may go a long way to improving the experiences of L\&T, whereby curricula, for instance, could be re-designed to help students to engage in the construction of knowledge for the sake of addressing complex, global societal challenges rather than helping students gain knowledge for knowledge's sake (Clayton-Pedersen, 2005, p. $9.6^{13}$ ). As noted earlier in chapter 7, a common problem is that lecturers are in situations which result in them having limited time and incentive for innovative course development and student engagement. The causes of this are different, but this is potentially the common 'core problem' that the two business schools should strive to resolve.

\section{The goals of learning and teaching (UNSB \& VBS administrators)}

The goal of UNSB academic administrators is to 'prepare well-rounded, knowledgeable and productive students for modern society'. The VBS counterparts indicate their goal as 'a process of transformation whereby students acquire new knowledge and skills (including soft skills), develop an ability to think critically as they apply the knowledge and skills in changing situations (including markets, economy, and social) as well as an ability to communicate effectively in varying situations'. While acknowledging such noble goals, the findings here indicate that they are not commonly understood, and teaching staff may not be fully aware of them. The senior administrators therefore have a role to clearly and consistently communicate

\footnotetext{
13 This page reference is correct and is in line with the page numbering of the referred document.
} 
these goals in their respective schools, and to ensure that these goals are well integrated and effectively achieved in the program courses.

Relatedly, taking some steps back to students' goals, we find that students readily or easily state their goals. However, some issues remain unclear. One is whether students' goals are congruent with their teachers'. Although some may argue that students are their own learning agents and they are able to achieve their goals on their own (Yorke \& Knight, 2004), having a shared understanding of goals with their teachers would yield better outcomes in that both will work towards their achievement. A second issue is whether the officially stated goals are clearly communicated to students, and if so, what are the media of such communication? Assuming that one medium is the course outline, do students clearly see the relationship between their goals and the courses that they are undertaking? Do students clearly understand what learning outcomes/objective/goal the course(s) helps them to achieve? Do students care to know the goals? If they do, how well do they know that they are achieving their goals? How are the gains in knowledge and skills measured? What measures are most reliable and valid? Most importantly, are the skills, knowledge and competencies stated by the institution as learning objectives/goals/outcomes for the degree programs the ones needed in the $21^{\text {st }}$ century? These are important questions that the respective schools could address.

In a nutshell, we find that the various goals of L\&T held by stakeholders emphasise different things. At VBS for instance, students emphasise the goal of getting a job. However, the question arises whether students are aware of the graduate competencies required in the job market. The findings of this study also indicate that L\&T goals are not sufficiently emphasised by the respective business schools despite their perceived importance in academic achievement. Such importance is manifest in the work of Lizzio, Wilson, and Simons (2002), who, in a study that included business and commerce students, found that providing clear goals impacted positively on academic achievement. Thus in order to achieve better academic outcomes, L\&T goals should be emphasised and recognised.

\subsection{The CSFs, NCs, UDEs, and critical root causes}

A detailed and systematic discussion of the CSFs, NCs, the UDEs, and the critical root causes identified as important in this study is facilitated by factors that are mapped out with reference to Biggs' 3P model in Appendix G. This mapping is shown in Figure 8.1. 
Figure 8. 1: Integration of goal tree (Dettmer), and fCRT (Ronen) with the 3P model (Biggs)

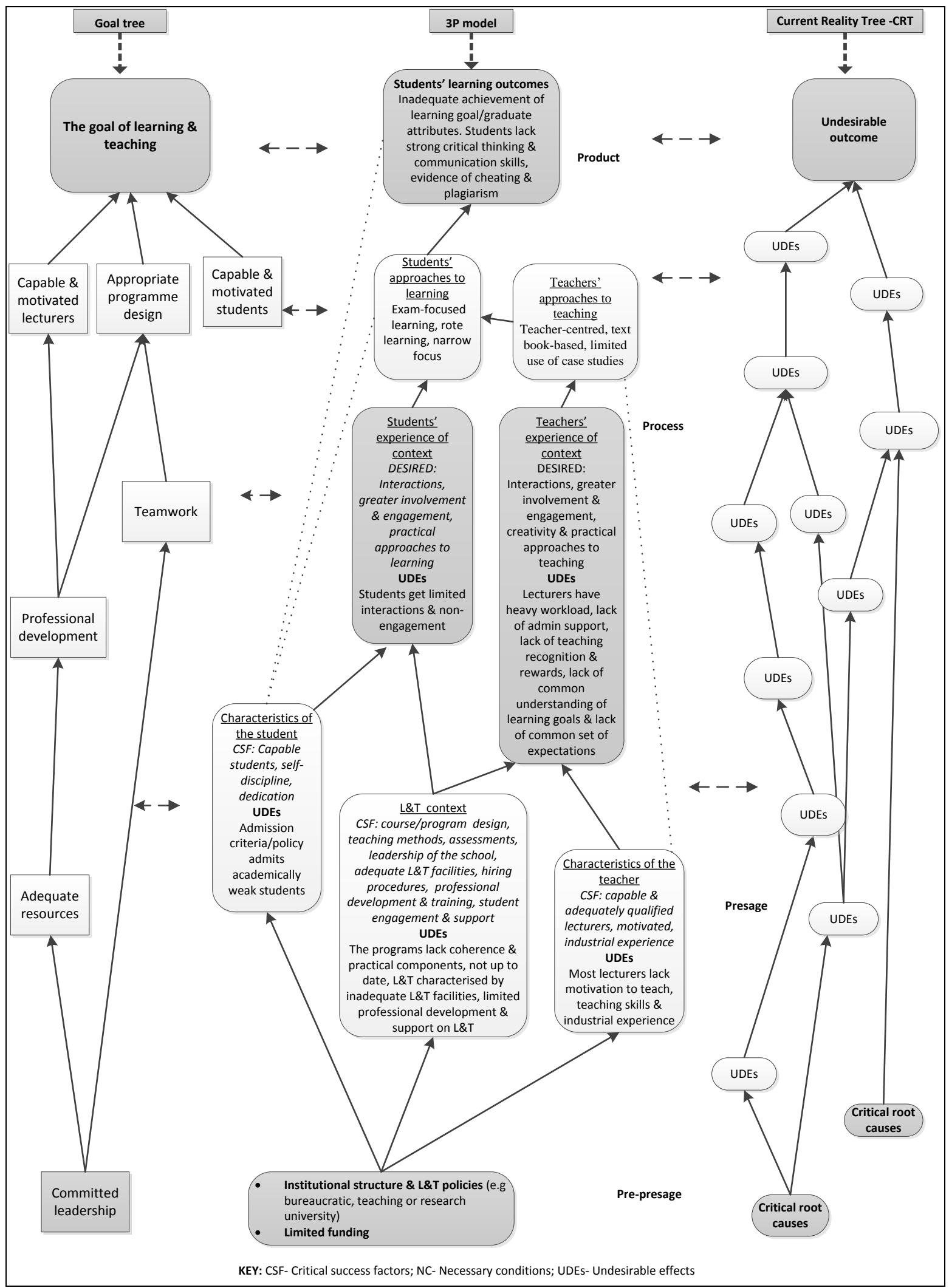

The purpose of this mapping is to show consonance between this well-known model in HE research on learning and teaching, and this study's findings. The discussion of the causal 
relationships of these factors attempt to address the third objective of this study that aims to determine how these factors affect each other and their impact on learning outcomes.

The 3P model represents a dynamic L\&T system where interactions between components of the model affect L\&T. This means that a change to any part of the system affects other parts (Dart et al., 2000; Reeves \& Freeth, 2006).

The nature of this model is therefore consistent with the systems approach of this study. Prosser and Trigwell, (1999b, p.13) also indicate that the 3P model can accommodate different interpretations, including systemic and causal perspectives. The cause-effect interpretation of the 3P model is then consistent with the cause-effect analytical approach of this study, and with other HE studies (Gibbs, 2010). Figure 8.1 provides a way of integrating HE literature and this study's findings. It does this by relating experiences of L\&T expressing the goal tree and current reality tree (TOC methodological tools), and Biggs' 3P model. This integration introduces a fourth variable in the Biggs presage dimension that normally comprises student characteristics, teacher characteristics, and learning context based factors.

The findings add institutional-based factors as a precursor to the presage dimensions (refer to Appendix G), which it identifies as critical for effective performance of the L\&T systems in the two business schools. A point to note is that in the 3P model, the L\&T context has institutional variables that are related to curriculum and methods of assessments. The institutional factors identified here, on the other hand, relate to managerial aspects in the institution. These factors herald the 3P model's presage factor. They are therefore referred to here as pre-presage dimensions. In discussing the integrated model (Figure 8.1), the focus is on exploring the impact of the pre-presage, presage and process factors on the experiences of L\&T and the learning outcome (goal of learning).

\section{The pre-presage dimensions (institutional-based)}

This study identifies two critical root causes of less than desirable experiences of L\&T. These are institutional structure and limited government funding. Moreover, effective leadership is identified as a common necessary condition for achievement of goals in the two business schools. This subsection first discusses the effective leadership necessary condition and then the two critical root causes. 


\section{i. Effective leadership}

This study identifies certain dimensions of effective leadership as lacking in the two business schools. For example, at UNSB there is a lack of coordinated effort necessary to meet a range of L\&T goals while at VBS there is insufficient and inadequate communication of a clearly understood goal.

These findings corroborate those of Alberta Consortium for the Development of Leadership in Education (ACDLE) that identifies a lack of common vision in understanding the expectations of schools as one of the issues limiting effective educational leadership (Burger, Webber, \& Klinck, 2007). An earlier study conducted in Australia indicated similar concerns of lack of vision and direction at the university level (Ramsden, 1998). Based on research work on management and leadership in Australia, New Zealand and UK, Ramsden found that effective leaders bring new ideas about teaching into departments/schools; inspire and encourage initiatives; and provide guidance, clear goals and vision for the department/school. Ramsden (1998) does state that effective leadership (encompasses good interpersonal skills); delegates effectively; provides support for L\&T; and provides feedback on improvement. One question is whether these characteristics also apply to lecturers as leaders in their courses? Should they not have vision, goals, strategies, and a deep sense of what they are delivering in classrooms? Perhaps, school leaders should take part in leadership courses together with their lecturers. But, according to Burger et al. (2007, p. 32), such courses are completely useless unless they are used in a 'self-and-group reflective manner'.

\section{iii. $\quad$ The institutional structure (bureaucratic)}

Bureaucratic structures are common in many public institutions (TheCentre, 2002). Although such structures often ensure guidance for standards, control over promotions and tenure, and coordination and regulation, they also create inefficiencies (TheCentre, 2002). The bureaucratic structures at VUW and UoN may harbour some policies that tend to make VBS and UNSB less effective in their L\&T functions. At VBS, policies on group work and assessment may interfere with creative and innovative teaching approaches. Others, like the promotional policies may be perceived as emphasising research more than teaching. As a consequence, most lecturers tend to concentrate more on their research than teaching.

At UNSB, some aspects of bureaucracy tend to delay curriculum review processes, limit academic freedom and limit involvement of other stakeholders, due to bureaucratic processes 
behind the memoranda of understanding (MoU), under which the university operates. The structure also tends to frustrate UNSB students who feel that their ideas get lost through red tape.

The bureaucratic structures of many HE institutions may therefore tend to challenge their effective operations. As a result, many business schools tend to adopt different structures that tend to afford them competitiveness and effectiveness of their operations (Fernando \& Beatrice, 2011).

\section{iv. Limited government funding}

With the massification of higher education, limited or shrinking government funding has become a common phenomenon globally (Altbach et al., 2009). At UNSB, limited government funding has been identified as a critical root cause of most UDEs. Although in a number of countries, including NZ, government funding is a contested fund pegged on specific performance, this is not the case in Kenya. Each individual university prepares its budget and identifies other sources of income in addition to the capitation expected from the Ministry of Finance (www.cue.or.ke).

Nevertheless, the level of government funding affects UNSB students' and lecturers' experiences in that it influences the number and calibre of students who can be admitted, the number and quality of lecturers, and the number of support staff. Indeed, the limited funding causes the school to admit a high number of self-sponsored students (who are not always adequately qualified) to be supported by inadequate physical resources (L\&T facilities \& equipment), and inadequate lecturers and support staff. This impacts negatively on the learning experiences in that some classes become congested and the large number of students in most classes limits interactions. The limited funding causes the school not to attract high quality lecturers. Similar effects of limited funding on the quality of undergraduate education in the UK are noted by Gibbs (2010).

\section{Presage dimensions}

In the presage process, three variables are discussed: characteristics of students; L\&T context and characteristics of the teacher.

\section{i. $\quad$ Characteristics of students}

As the clock reaches 2:50 the rustle of students packing up their bags fills the room. Our teacher tries his best to ignore it and continues lecturing about ... and the importance of double-checking our work. He then stands up to call the attendance of all those students that didn't turn in homework the day before. He proceeds to name every person currently in the classroom. In this particular class the homework grade doesn't matter, but our teacher has told us many times that if we actually want to learn the material the homework is necessary, but no one is too concerned about that. We all leave the room remembering very little of the past fifty minutes, and...completely content in this fact. I wish 
I could say that I was not a part of this apathy, but we all have become [apathetic] in some way, and once it has begun it is almost impossible to stop. -James 'Trap' Jervey (as quoted by Cardon, 2014).

Academic and administrative staff in the two schools indicate the desire and need for capable students. In Kenya, the varied admission criteria are blamed for the academically weak students who are admitted. It is alleged that students who are admitted through the government stream (Module I) are academically stronger than self-sponsored students (Module II). The obvious reason is that Module I students are admitted with higher marks than Module II. At VBS, there are also varied admission criteria for different categories of students (see for example www.victoria.ac.nz/study/apply-enrol/admissions). The domestic students usually meet a minimum university entrance requirement (www.nzqa.govt.nz). Nevertheless, administrative and academic staff at UNSB and VBS indicate that the varied admission criteria do not always ensure that 'learners who want to learn' are admitted. Often, staff believe that learners are unwilling and demotivated. On the other hand, students seem to have high confidence in themselves. Indeed, in both institutions, students also clearly indicate the need for selfdiscipline and hard-work. Nevertheless, these students do exhibit the millennial or the Netgeneration characteristics of requiring specific instructions and guidance in their academic work (Stewart, Houghton, \& Rogers, 2012). The view of lecturers who participated in this study is that 'They want to be told everything. Some want to be spoon-fed'.

In addition, millennials are said to prefer the use of modern technology in learning (Feiertag \& Berge, 2008). However, the challenge is that there appears to be a digital divide between them and most of their lecturers. This digital divide frustrates UNSB students in particular, who feel that their lecturers should use latest technologies/web resources in classes/lectures. Such students also want active engagement even outside classrooms. At VBS, students do not complain about the use of technology, per se, but they indicate that they prefer learning and group-work that is activity-based. The need for active learning is supported by many researchers and has been found to increase student performance (Freeman et al., 2014; Zepke, 2009). Thus, my view is that the contemporary needs of millennials should not be interpreted as addressing students' problems but as evolving teaching issues. Nevertheless, students must be willing and motivated to learn. It is only then that they can exhibit what Hattie (2009, p. 22) refers to as the self-regulatory attributes of self-monitoring, self-evaluation, self-assessment and self-teaching. If students exhibit these characteristics, then Hattie suggests they will able to achieve better outcomes (if they are in a supportive learning environment). More 
importantly, Hattie argues that the most successful outcomes are achieved when students 'become their own teachers' (p. 25).

\section{ii. $\quad$ The L\&T context}

The basic issues that seem to impact negatively within the L\&T contexts are fragmented/ disjointed curricula, inadequate L\&T facilities, less desirable experiences of teaching, inadequate student support and engagement, and limited professional development of teaching.

\section{a. Curricula}

UNSB curricula are not always up-to-date while that of VBS are not always seen as a coherent package. Either situation implies that the intended curricula may not always be implemented effectively to achieve the desired goals/learning outcomes. Additionally, because there is not always effective communication about program goals ${ }^{14}$, it can become difficult for the lecturers to integrate goals clearly in the syllabi. Students claim that it is unclear to them what skills and knowledge they are expected to have at the completion of the degree. At VBS for instance, perceived lack of program coherence seems to be caused by 'individual ownership' of courses. This is a clear indication of lack of teamwork and/or participative leadership within the teaching function. The lack of teamwork may be explained by the fact that lecturers are busy trying to publish — the standard performance measure/reward. Kohn $(1999$, p.137) argues that such rewards/compensation systems destroy teamwork and reduce the possibility that people will cooperate.

There are also indications of a perceived 'resentment' of the AoL activities that seem to be seen as another layer of bureaucracy. Yet, as Mabin and Marshall (2011) indicate, the wider AoL framework should bring about constructive alignment of components of the program. A lack of coherence can lead to unnecessary repetition within and between courses, and to other disjointed elements, which cause students to be disgruntled. This finding is in line with Biggs (in Kandlbinder \& Peseta, 2011) who contends that systems that are not constructively-aligned, internally or externally, lead to poor quality learning, and students end up learning things that are not required. At UNSB, the students, lecturers, and senior administrators express concern over the perceived lack of relevance of curricula, to the needs of stakeholders. This implies that curricula are not constructively aligned to stakeholder needs. Although UNSB leadership blame the top management at the university level for delay in curricula review, as Ramsden

\footnotetext{
${ }^{14}$ Note also that the Victoria graduate attributes and BCom learning goals were under review during 2012-2014.
} 
(1998) notes, as effective academic leaders at middle level management, they should be able to filter out bureaucratic demands causing delays.

b. L\&T facilities, equipment \& resources

At UNSB, low government funding limits the expansion of L\&T facilities and equipment. To compensate for the limited funding, a high number of self-sponsored students are admitted every trimester. As a result, L\&T facilities become even more inadequate, giving rise to congestion and competition for resources (library and computer labs). The large student numbers are stated to limit student interactions in classes while the unavailability of books and other resources may encourage some students to engage in academic malpractices such as plagiarism. Limited learning resources also encourage many students to rely on lecturers' notes, thus limiting independent research. Other issues such as overcrowded lectures, insufficient and outdated library resources, and limited computing and internet connectivity are common in many developing countries (Altbach et al., 2009), and in Kenya in particular (Ndirangu \& Udoto, 2011; Oyelaran-Oyeyinka \& Nyaki, 2004). At UNSB, such inadequacies tend to limit the quality of L\&T experiences.

c. Quality of teaching

At UNSB, most teaching staff have a Master's degree, which is the minimum qualification to teach in any university in Kenya (www.cue.or.ke). Whilst a Master's qualification is a common requirement for the appointment of lecturers of HEIs across the globe (Altbach et al., 2009), UNSB students are nevertheless disgruntled about the quality of teaching that is offered by some of such lecturers. At VBS, most lecturers have $\mathrm{PhD}$ qualifications but the emphasis in hiring is on an academic research track record, not necessarily teaching prowess. VBS students complain about lecturers' teaching styles, preferring tutors to lecturers. So the challenge at VBS is not just to boost academic qualifications but teaching expertise. Relatedly, participant lecturers at UNSB and VBS acknowledge that they have limited pedagogical skills and limited knowledge on 'how to handle students'. Although perceived limitations in pedagogical skills are not uncommon in business schools (Johnston \& Watson, 2004), the mere absence of acceptance of a need for common understanding of the goal of L\&T implies that critical factors such as teaching skills are perhaps not prioritised sufficiently. Moreover, the emphasis on 
research rewards at VBS has caused academic staff to focus on research and not teaching. As a result, the quality of teaching is affected negatively.

It is interesting to note the ambivalence about the level of qualifications required for effective delivery of teaching. At UNSB, for example, most lecturers do not hold PhD qualifications. At VBS, most lecturers are PhD holders. Yet, in the two schools, the quality of teaching continues to be capable of improvement. An implication may be that to enhance quality of teaching, focus should not be entirely on $\mathrm{PhD}$ qualifications but on other dimensions such as passion, talents and creativity in teaching (http://www.victoria.ac.nz/vbs/teaching/steps-to-teachingsuccess/successful-teaching-learning)

d. Professional development (PD)

However, lecturers at VBS and UNSB recognise the importance of skills in teaching. Yet, few seek to engage in programs to improve those skills. There are plenty of professional development courses related to teaching available within universities and beyond. But, at UNSB for instance, professional training on teaching is not readily available within UoN perhaps due to limited funding and a lack of priority on professional development in teaching. However, these courses are available online. At VBS, the Postgraduate Higher Education Learning and Teaching (PHELT) program, and its courses, are freely available but many lecturers say they do not have time for it because they are busy with research and other administrative duties. Yet, my view is that good university teaching is critical. Ramsden and Martin (1996) indicate that good teaching improves not only the quality of learning in terms of development of specialist knowledge and general competences, but also in helping graduates to contribute positively to the well-being of society. My opinion is that some lecturers might not be as focused on fostering graduate contribution to wider society as they are with their own personal rewards. Perhaps this explains why some lecturers at VBS, for instance, do not perceive PD in teaching as a priority in the current reward system. Therefore, in order for lecturers to commit themselves to PD related to good teaching, there must be greater recognition and rewards in teaching. This implies that university leadership must prioritise teaching and show commitment to it by rewarding and recognising efforts to improve teaching skills. 
e. Student learning support

None of the students at VBS surfaced concern about student support. If anything, all students were particularly happy with the student learning support services. At UNSB, there is no student support in terms of tutorials, academic writing or study skills. When students lack such kinds of support for their studies, they may resolve to engage in or resort to academic malpractices such as plagiarism and cheating in exams. Although the lack of learning support services is attributed to limited government funding, my view is that it is possible that UNSB could support students' learning through other means that do not necessarily require much extra funding, although there may be some coordination costs. Such support could be in the form of improving orientation processes, providing online study skill resources, peer mentoring, study buddies, matching junior students with senior students, and encouraging group learning (Zepke \& Leach, 2010). Other forms of support might include integrating high impact practices such as internships, field-based experiential learning, and student involvement in seminars and workshops (LEAP, 2015).

\section{f. Student engagement}

The need to boost student engagement at VBS and UNSB is evident. Whilst many lecturers tend to think that it is difficult to engage students in large classes, empirical evidence indicates otherwise. A recent study conducted in NZ (Exeter et al., 2010) indicates that teaching techniques that are associated with small-class teaching can effectively be used to engage students in very large classes of more than 1000 students. Moreover, support for student engagement has continued to grow. The National Survey of Student Engagement (NSSE) indicates that student engagement is correlated with student interactions with lecturers, which enhances active and collaborative learning. These, in turn, enrich educational experiences (www.celt.iastate.edu). The Australasian Survey of Student Engagement (AUSSE) used in NZ and Australia, indicates that student engagement and interactions with lecturers increases students' sense of belonging within their institutions (Australian Council for Educational Research (ACER), 2011).

Relatedly, there are many types of active learning strategies that can engage students including modified lectures, drama, and debates (Bonwell \& Eison, 1991), and team teaching (Yellowley \& Marilyn, 2006). Other modern strategies include virtual learning (Schott \& Sutherland, 2009), partnership learning communities (The Higher Education Academy, 2014), Facebook (Dougherty \& Andercheck, 2014), and a host of 'high impact practices' that include 
internships (Baker, Hansen, \& Johnson, 2013). Moreover, there is now evidence that actively engaged students achieve high performances (Freeman et al., 2014; Stewart et al., 2012). This begs the question of why, with lots of online resources on active learning and classroom management techniques, many lecturers do not seem to use them to engage students. The answer to this question may be straightforward and is well expressed in one comment made in this study: 'Good teaching requires a lot of time to prepare'. Yet, senior leadership of universities does not always appear to recognise or reward good teaching. So, as it were, it is not necessarily about an ignorance of the teaching strategies that could bring about improvements in L\&T, but about perhaps rewards for the extra effort of good teaching.

\section{iii. $\quad$ Characteristics of teachers}

Within the two business schools, not only is there a common agreement on the need for capable and adequately qualified lecturers, but also on the need for motivated and passionate lecturers. In this study, students indicate that they need lecturers who are passionate, highly knowledgeable (possess relevant \& current information in their fields), technologically savvy (ability to use modern technology in teaching), available for consultations, professional in teaching, role models, and friendly to them. These findings resonate with Yair (2008) who indicates that passion in instruction and student-lecturer relationships in HE have been neglected. Hattie (2009) echoes this view arguing that 'we rarely talk about passion in education', yet, passion is at the heart of good teaching and learning (p. 23). Indeed, Hattie (2009, p. 24) indicates that passion requires the love of content and an ethical, caring stance that makes students like the discipline being taught, while demonstrating that the teacher is not only teaching but also learning.

Many characteristics are associated with good teachers and/or with excellent teaching. Hattie (2009, p. 24) argues that excellent teachers set learning goals and set tasks structured to attain such goals; plan and intentionally transfer experiences, knowledge and decisions from earlier learning experiences to later ones; increase the amount and quality of feedback; and understand the appropriate coping strategies for individual learners. Others (Yair, 2008) indicate that content knowledge, pedagogical knowledge, and practical skills to implement the instruction, and a mastery of the curriculum are important characteristics. But Hattie (2009) emphasises that the pedagogical knowledge that is needed is not just 'teacher training' but training that relates to learning and teaching strategies, develops teachers' conceptions of teaching and 
learning, develops understanding of different ways to teach deep, surface and conceptual knowledge, and ways of building positive relationships with students (p.126).

Other good teaching practices are propounded by Chickering and Gamson (1999). They include engagement, encouraging contact between students and faculty, and developing reciprocity and cooperation among students; encouraging active learning, giving prompt feedback; emphasising time on task (proper usage of time); communicating high expectations; and respecting diverse talents and ways of learning. As such, the centrality of the role of the teacher becomes evident. But what exact role should a lecturer play in an undergraduate business course? One lecturer participant in this study indicated that teachers should facilitate learning through the 'clearing away of barriers related to learning'. For his part, Hattie (2009, p.25) argues that teachers should be activators, change agents, and directors of learning. Because learning and teaching are related but different, sometimes the teacher may take up the role of a facilitator while other times they may be catalyst or directors of learning. However, what determines whether lecturers will play the role of catalysts or facilitators is largely determined by the conception of teaching that a lecturer has, and the demands of the teaching and learning environment. The bottom line is that a lecturer's performance affects learning. In Hattie's words, 'what teachers do matters' (2009, p. 22). Indeed, what lecturers do to make learning possible matters. Do they motivate, inspire, and create exciting classroom environments or do they create anxiety by threatening students with poor grades? In Ramsden's words 'changing students' understanding can only be done by shaping experiences that encourage them to learn' (Ramsden, 1998, p.353). The next subsection examines more closely the interactive process in the teaching and learning context.

\section{Process dimension}

The process dimension of the 3P model deals with students' and teachers' interactions with L\&T contexts. These interactions form the experiences of the L\&T contexts. The presage factors influence these interactions. This subsection explores these interactions while embedding the effects of learning and teaching approaches.

\section{i. $\quad$ Students' experiences of context}

Students desire to have more interaction and greater involvement and engagement in learning. They also prefer an active and a practical-based learning approach as opposed to a theory-based one. Studies such as those of Stewart et al., (2012) have demonstrated that active learning 
improves student performance. In order for active learning to occur, Stewart et al. (2012) argue for use of an integrated instructional design, which comprises clear learning goals, active L\&T activities (including information and ideas, experiences of students doing things, and students' reflections based on those activities); and feedback and assessment (where students participate in self-assessment and where assessment is forward-looking aiming at continuous improvements throughout the semester). Students also indicate that lecturers should 'get rid of slides'. This view is similar to other students' views who indicate that they are sick of PowerPoint' and refer to lecturers who overuse PowerPoint as 'death by PowerPoint' (Gedera, 2014). Stewart et al. (2012) also agree that lectures and PowerPoint slides fail to engage students in learning.

The other important element is passion from both students and lecturers. The need for passionate lecturers is highlighted in (iii) above. Such passion would allow interactions and greater involvement to flow smoothly as students and lecturers engage virtuously within the academic discipline. This leads us to the question of how students should approach learning. Many propositions have been put forward about surface, deep and strategic approaches to learning (Keith, Michael, \& Fiona, 1999; Prosser \& Trigwell, 2014; Richardson, 2005). Prosser and Trigwell (2014) suggest that students will always use a pragmatic approach in the situation that they face, where one learning situation may require them to use a surface approach, while another may call for a deep or even a strategic approach. But in all these situations, the kind of expectations that the teacher sets, and the type of tasks that lecturers design, contribute greatly to the approaches that students adopt. In the case of VBS and UNSB, students largely use an exam-oriented approach to learning that focuses on passing exams. It is no wonder, as evidenced in this study, that oftentimes students want to know, 'Is it in the exam?' These approaches do not help students to meet their learning goals. The 'focus on exam' implies a need for change on how students are examined because to some students it may mean that, as Kohn (1999) puts it, 'anything learned in the absence of [exam] is not worth knowing' (p.120). At VBS, the students' goal is to 'get a qualification that can get them a job'. At UNSB, students' goal is to 'gain knowledge and skills'. The goals of 'getting a job' may not help students to develop skills to cope with different life situations.

\section{ii. $\quad$ Teachers' experiences of context}

The lecturers in the two schools indicate that they desire more interactions in classes, greater student involvement, as well as being able to use more creative approaches to teaching. But the 
challenge in integrating these desires is that lecturers in the two business schools believe they have heavy workloads and lack administrative support. But increasing workload is a global academic feature. Blackmore (2014) indicates that recently, the scope, scale and depth of academic workload has increased whereby academics are expected to teach, research, do university and community service, form partnerships, market courses, mentor colleagues and students, and inform policy. Nevertheless, since there is no common understanding or even common set of expectations in these schools, lecturers' desire for more interactions and student involvement are not acted upon or emphasised. Furthermore, putting in extra effort to enhance interactions and student involvement goes unrecognised and is not rewarded. Therefore, only those teachers who are motivated and passionate about their work will go out of their way, such as working extra hours to prepare for good teaching. But how has the heavy workload affected L\&T?

At VBS, heavy workloads cause many lecturers to adopt coping strategies such as working long hours, including weekends, so as to prepare good teaching materials. This means that they do not have good time for themselves and their families. Some indicate that it becomes difficult to conduct research during their teaching semesters. They therefore leave it till the summer semester. But this raises the question of when they get to reflect on their own teaching. For those who are not particularly motivated to teach well, they may recycle their teaching materials year after year. Others simply provide the minimal requirements, asking the least from the students so that they have enough time for their research. Many are seldom available to students. They keep saying, 'I am not free at that time'.

At UNSB, coping strategies used by lecturers include missing lectures, going late for lectures, leaving earlier than scheduled, giving group assignments (to reduce marking load), recycling teaching materials and avoiding student interactions to avoid getting overwhelmed. And because the Module II (self-sponsored) program is run without a semester break, it means that lecturers do not have semester breaks. Moreover, the part-time self-sponsored students study in the evenings and weekends. This not only creates unbalanced lives for lecturers but also limits their opportunities for reflection and dialogue related to teaching.

Similar coping strategies to those used at VBS and UNSB have been identified in other studies (Hemer, 2014). However, the issue of missing lectures and going to lectures late is seldom 
evident at VBS. It is noted that similar cases of missing lectures have been reported in developing countries such as Kenya (Lim, 1999).

Clearly, the issues shaping teaching and learning experiences and some of the coping strategies for lecturers and students are largely contextual. With respect to the core issues driving teaching experiences, at VBS, research is the key. It is recognised and rewarded. Many lecturers direct their efforts towards it. At UNSB, the key driver is extra income. The more courses a lecturer teaches, the more extra income s/he gets. Thus confirming Goldratt's claim of "tell me how you measure me and that is how I will behave". We could add: "If you measure me in an unbalanced way then don't be surprised to find me prioritising only part of my responsibilities".

Contextual factors seem to contribute to the teaching approaches that lecturers use. At VBS, lecturing is largely teacher-centred and many lecturers also use a text-book based approach. Such approaches tend not to encourage interactive and diverse learning styles. At UNSB, teaching is also teacher-centred with minimal use of case studies. This limits interaction and critical thinking. Research associates those teaching approaches that involve low student interactions and engagements with surface learning, which tends to be less desirable (Devlin, 2006; Prosser \& Trigwell, 2014). Thus, the causal linkages of contextual variables suggest that the L\&T environment contributes to the process of learning, which adversely affects the quality of the outcomes.

\section{Product dimension (learning outcomes)}

As noted earlier, the teaching approaches at VBS and UNSB tend to limit students' interactions and engagements. As a result, students adopt learning approaches that tend to be more focused on passing exams and getting good grades (particularly at UNSB). Arguably, students' approaches to learning are affected by their teachers' approaches to teaching. This argument is supported by Prosser and Trigwell (2014) who contend that the relationship between teachers' approaches to teaching and students' approaches to learning is substantial and powerful. In the same vein, Hattie (2009, p. 34) argues that teachers make the difference in learning and more often, the teacher directs the learning.

My argument is that in order to achieve the desired learning outcomes, both students and lecturers must clearly understand what their goals are. Thus, in any course unit situation, this would imply that at the beginning of the course, lecturers and students could first establish a 
common goal, (which is perhaps driven by the graduate attributes/profile or objectives of the program) and articulate the CSFs and the NCs needed to achieve their goals. During this

process, expectations are clearly communicated. During a course, the close interactions between lecturers and students could enhance greater student involvement and engagement. Moreover, understanding that different students have different learning styles would help to create classroom climates that are conducive for all students. The aim is to move together towards the achievement of the goal. The process would also involve evaluations and reflections of what works well and what does not.

The purpose of the above discussion is to link this study's findings with the HE literature. However, we note that in HE, researchers have not come up with ways of focusing effort. For instance, they have not indicated what, out of all the above recommendations, is needed in order to ameliorate any lack of quality of L\&T experiences. There are still ongoing concerns, which, in TOC have been conceptualised as dilemmas. So we turn to TOC to explore further these dilemmas and develop recommendations on how to deal with them.

\subsection{Dilemmas}

Several ongoing concerns were identified in this study that result from interactions with the L\&T contexts and from the nature of L\&T approaches. These concerns tend to create experiences of L\&T that are not always desirable. They relate to bureaucratic structures, limited interactions in large classes, limited government funding, coordination within the school (UNSB) and research and teaching (VBS). This subsection explores resolutions of these dilemmas using the TOC tool referred to as an evaporating cloud (EC). These resolutions represent a process of progression from less desirable situations to more desirable states in a way that is designed to achieve the best leverage from a few focused actions.

As indicated in Chapter 3, the purpose of the EC process and the EC diagram is to resolve a conflicting situation or 'evaporate' a dilemma. In the TOC view, conflicts are not always visible or confrontational. Indeed, within an organisation, conflicting forces can reside at different levels such as operational or strategic and may originate from policies or from human relationships (Dettmer, 2007, p. 159). The exploration of such ideas is in line with the fourth objective of this study that proposes improvement ideas to enhance quality of L\&T experiences and the performance of L\&T systems. 
The EC diagrams below aim to demonstrate how constraints within a business school can be exploited to achieve the goal of learning with the available resources.

\section{The structure and management of the school is bureaucratic}

The dilemma of bureaucratic structure is identified at UNSB as one of the critical root causes of less than desirable experiences of L\&T. Participants reported delays in program review, lecturer recruitment, procurement, repair and maintenance, and establishment of MoUs with external stakeholders. This dilemma is depicted in Figure 8.2 as an EC.

Figure 8.2: Bureaucratic Structure (UNSB)

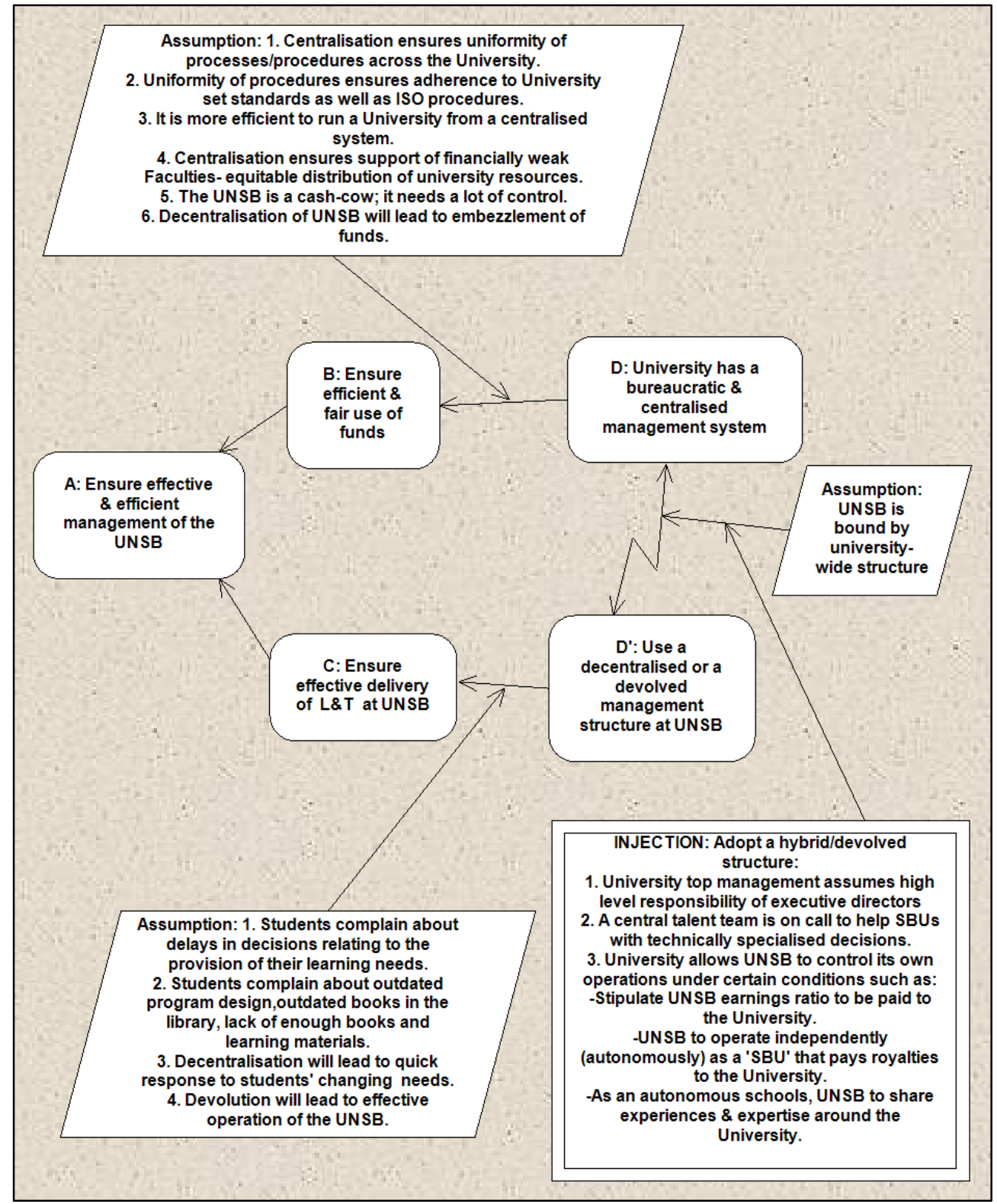


This EC is created in the following steps:

1. Identify the undesirable action that is currently forcing students to be in the dilemma situation. In this case, it is 'University has a bureaucratic and centralised management structure'. This is put in box D.

2. Identify the desired opposite of the complaint. In this case, 'Use a decentralised management system at the UNSB'. This is put in box D'

3. Identify the need that is satisfied by the action in box D or the reason why we put up with action D. This is identified as 'Ensure efficient \& fair use of funds within the university'. This is put in box B.

4. Identify the need that is satisfied by action in box D' or what does D jeopardise? This is identified as 'Ensure effective $L \& T$ delivery at UNSB'. This is put in box C.

5. Identify a common objective of having BOTH B and $\mathrm{C}$. This is identified as 'Ensure effective \& efficient management of the UNSB'.

The EC is read, from left to right, and in doing so, provides a process by which logic can be checked in a systematic and systemic manner:

In order to ensure effective and efficient management of UNSB, University must ensure it has efficient and fair use of funds across the university.

... and in order for the university to have efficient and fair use of funds across the university, it must have a centralised management structure.

On the other hand, in order to ensure effective and efficient management of UNSB, University must ensure effective $L \& T$ delivery at UNSB,

$\ldots$ and in order to ensure effective $L \& T$ delivery at $U N S B$, University must use a devolved management structure for UNSB. Hence, the conflict arises.

Assumptions underpinning each of the arrows are then surfaced as shown in Figure 8.2. They will include both valid assumptions, and invalid ones, which can be challenged (Cox et al.

2005). For example, for arrow B-D, we read,

... In order for the university to have efficient and fair use of funds across the university, it must have a centralised management structure, because (assumptions):

1. Centralisation ensures uniformity of processes/procedures across the University.

2. Uniformity of procedures ensures adherence to University set standards as well as to ISO procedures.

3. It is more efficient to run a University from a centralised system.

4. Centralisation ensures support of financially weak faculties leading to equitable distribution of university resources.

5. The UNSB is a cash-cow; it needs a lot of control.

6. Decentralisation of UNSB will lead to embezzlement of funds.

\section{At the same time for C-D',}

In order to ensure effective L\&T delivery at UNSB, University must use a devolved management structure for UNSB, because:

1. Students complain about delays in decisions relating to the provision of their learning needs. 
2. Students complain about outdated program design, outdated books in the library, lack of enough books and learning materials.

3. UNSB is unable to address these complaints quickly and effectively with the centralised management structure.

4. Decentralisation will lead to quick response to students' changing needs.

5. Devolution will lead to effective operation of UNSB.

We then generate ideas or injections that challenge or break these assumptions, which can then be explored as solutions to resolve the dilemma. The injection suggested here is to have a devolved management process where the various schools of the university could be empowered to operate autonomously (or semi-autonomously) as Strategic Business Units (SBUs) whilst working together to share experiences, expertise, and best practices across the university. For example,

- University top management could assume the high level responsibility of executive directors.

- UNSB could be allowed to operate independently (autonomously) as a 'SBU' that pays dividends or royalties to the University; or that UNSB could pay an earnings tax to the University.

Thus, the many aspects of the UNSB's operations could be reported directly through a board to the executive directors of the university (who would include the Finance director). Such reporting could be through monthly board meetings where senior management of UNSB could share experiences and best practices about UNSB operations. Moreover, other meetings could take place (weekly, monthly, and bi-annual) between UNSB and senior university managers responsible for the key centralised functions to look at pan-university synergies and growth opportunities. These and other ideas could be evaluated as a way of resolving the conflict, with a possible win-win solution.

\section{There are limited interactions due to high student numbers in class}

Initially, it was thought that high student numbers were the issue and low student numbers would be preferred. But on constructing the EC, it was concluded that actually high student numbers in classes might not be a problem, per se. The problem is instead recognised as the limited interactions. Indeed, students express a dire need for interactions as expressed in the following phrase.

The L\&T experience should be more interactive between the students and the teachers. We don't even know each other with the lecturer... for example today we have completed the course work for one course whereby, no question has ever been asked since the lecturer started lecturing. The lecturer usually asks 'is there any question?' but no question has ever been asked. So I do not know if the students are the problem or the nature of the course work or they understand more... (KM2-FT). 
The EC created in a similar way to the above, to depict this dilemma is shown in Figure 8.3.

Figure 8. 3: Limited interactions in large classes (UNSB)

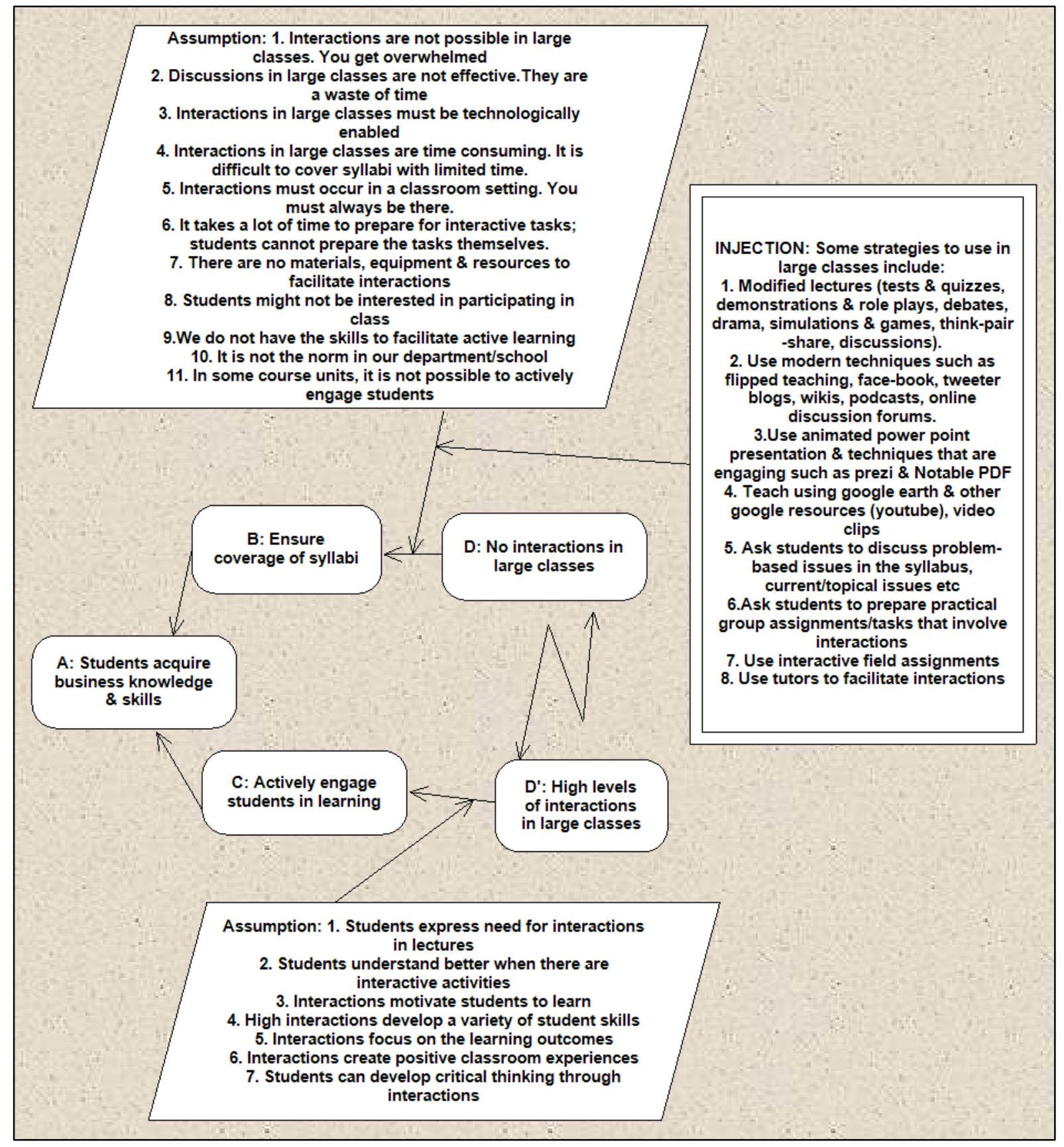

The EC read as follows:

In order to ensure students acquire business knowledge and skills (A), lecturers must ensure full coverage of syllabi $(B)$.

... and in order for the lecturers to ensure full coverage of syllabi $(B)$, they must have no interactions in large classes (D).

On the other hand, in order to ensure students acquire business knowledge and skills (A), lectures must ensure active engagement of students in learning $(C)$, 
$\ldots$ and in order to ensure active engagement of students in learning $(C)$, lecturers must have high levels of interactions in large classes $\left(D^{\prime}\right)$. Hence, the conflict arises.

Assumptions underpinning each of the arrows are shown in Figure 8.3. They will include both valid assumptions, and invalid ones, which can be challenged. For example, for arrow B-D, we read, In order for the lecturers to ensure full coverage of syllabi, they must have no interactions in large classes, because (assumptions):

1. Interactions are not possible in large classes. The teacher will not be able to control discussions.

2. Discussions in large classes are not effective. They are a waste of time.

3. Interactions in large classes must be technologically enabled.

4. Preparing tasks for interactions in large classes is time consuming- it is difficult to cover syllabi with limited time... (continued in Figure 8.3).

\section{At the same time for C-D',}

... in order to ensure active engagement of students in learning, lecturers must have high levels of interactions in large classes, because:

1. Students express the need for interactions in lectures.

2. Students understand better when there are interactive activities.

3. Interactions motivate students to learn...(continued in Figure 8.3).

We then generate ideas or injections that challenge or break these assumptions, and which can then be honed into solutions to resolve the dilemma. The injection suggested here involves giving students activities that develop their critical thinking skills (Bonwell \& Eison, 1991). Such activities can be designed as in-lecture activities such as group presentations, think-pairshare, demonstrations, and role plays. The activities could also include field assignments (individual or group) where students could write reports related to activities such as interviewing and observations, or involve them in organising and participating in events related to the course. Moreover, engagement through social media could help to create social forums where lecturers and students could share course-related debates outside classrooms. However, my view is that just like in lectures, the level of online engagement and involvement must be driven by the lecturer, based on the nature of comments, thoughts and activities a lecturer posts or blogs. Thus, these and other ideas could be evaluated as a way of resolving the interaction dilemma with a possible win-win solution.

\section{Limited government funding}

A core issue/problem that seems to challenge UNSB is limited funding. To overcome this challenge, the school can adopt the strategy of increasing student numbers (high enrolment) of fee paying students so as to cater for the deficit in funding through the tuition fee. The strategy 
of using tuition fees to finance some university operations is a common strategy globally (Altbach et al., 2009; Marginson, 2006). At UNSB, however, the strategy of high enrolments tends to put strain on the limited physical and human resources of the school. And despite its high enrolments and supposedly high tuition revenue, the school does not have the autonomy to use the revenue to increase its physical and human resources. This is because the public university that hosts the school has a centralised fund management system. This dilemma is demonstrated in Figure 8.4.

Figure 8.4: High enrolments (UNSB)

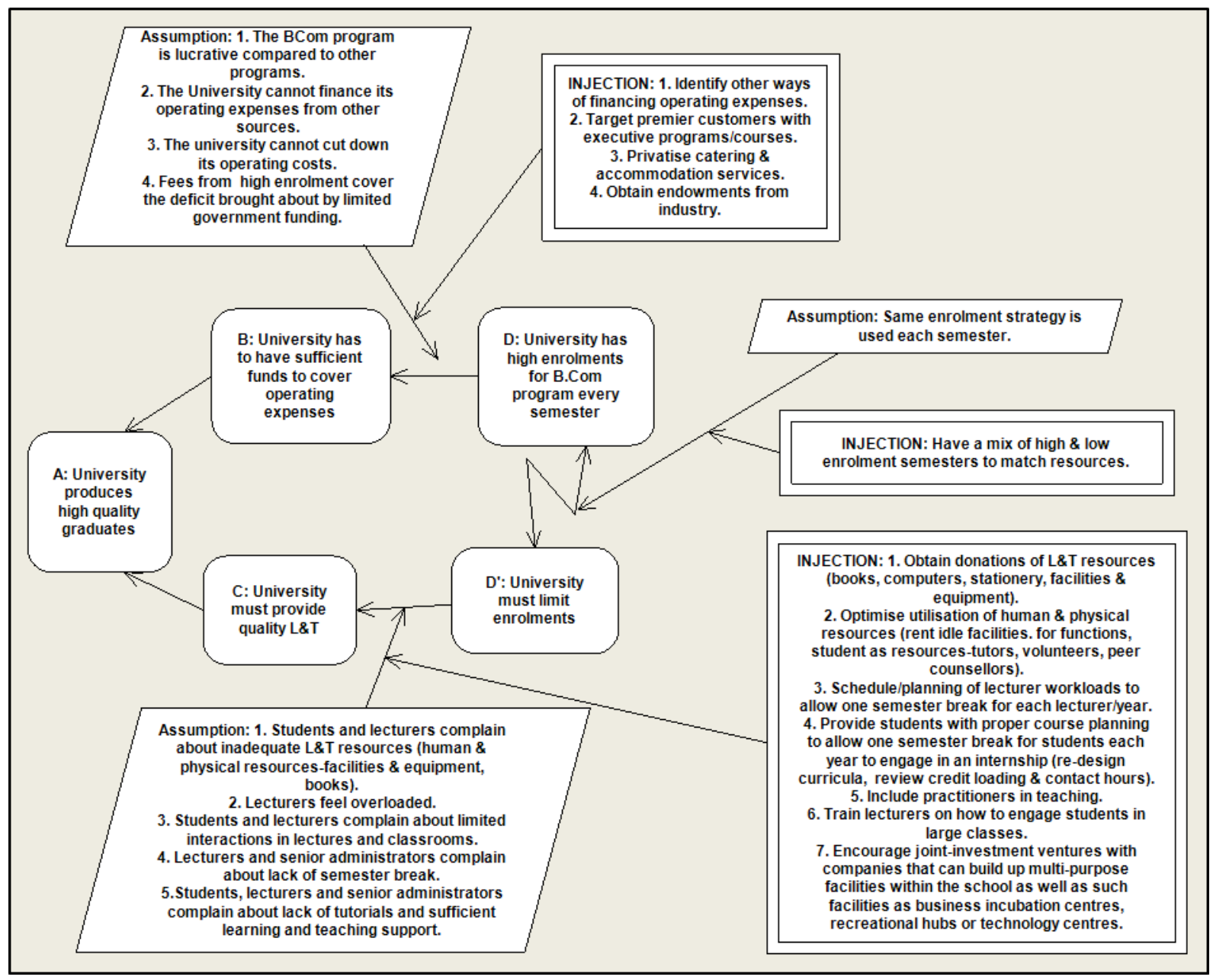

We read the EC as follows:

In order for University to produce high quality graduates, it must have sufficient funds to cover operating expenses.

.... and in order for the university to have sufficient funds to cover operating expenses, it must have high enrolments for the BCom program.

On the other hand, in order for the University to produce high quality graduates, it must provide quality $L \& T$.

....and in order to provide quality $L \& T$, the University must limit enrolment. Hence, the conflict arises. 
Assumptions for B-D and C- D' are then surfaced. They will include both valid assumptions, and invalid ones, which can be challenged. We read arrow B-D, in order for the University to have sufficient funds to cover operating expenses, it must have high enrolments for BCom program because (assumptions):

1. The BCom program is lucrative compared to other programs.

2. The University cannot finance its operating expenses from other sources.

3. The university cannot cut down its operating costs.

4. Fees from high enrolment cover the deficit brought about by limited government funding.

At the same time $\mathbf{C}-\mathbf{D}^{\prime}$, in order to provide quality L\&T, the University must limit enrolment, because:

1. Students and lecturers complain about inadequate L\&T resources (human \& physical resourcesfacilities \& equipment, books).

2. Lecturers feel overloaded.

3. Students and lecturers complain about limited interactions in lectures and classrooms.

4. Lecturers and senior administrators complain about lack of semester break.

5. Students, lecturers and senior administrators complain about lack of tutorials and sufficient learning and teaching support.

We then generate injections or ideas that could be explored as solutions to resolve the dilemma, such as the ideas below, as shown on Figure 8.4:

1. Identify other ways of financing operating expenses

2. Target premier customers with executive programs/courses

3. Privatise catering \& accommodation services

4. Obtain endowments from industry

5. Obtain donations of L\&T resources (books, computers, stationery, facilities \& equipment)

6. Optimise utilisation of human \& physical resources (rent idle facilities for functions, student as resources-tutors, volunteers, peer counsellors)

7. Schedule/planning of lecturer workloads to allow one semester break for each lecturer/year

8. Provide students with proper course planning to allow one semester break for students each year to engage in an internship (re-design curricula, review credit loading \& contact hours)

9. Include practitioners in teaching

10. Train lecturers on how to engage students in large classes

11. Encourage joint-investment ventures with companies that can build up multi-purpose facilities within the school as well as such facilities as business incubation centres, recreational hubs or technology centres.

The above injections or ideas can generally be clustered around resources, policies, and program design. They are not exhaustive. Nevertheless, they might indicate areas where the school can 'exploit' its current resources for optimal performance. Furthermore, these ideas provide opportunities for the school to question the validity of its policies relative to its goal(s). Other dilemmas such as lack of necessary coordination within the school can be tackled in a similar manner. 


\section{Resolving the research and teaching dilemma}

The core dilemma facing VBS is balancing research and teaching. Figure 8.5 demonstrates this dilemma. The fact is that under PBRF, universities' research performance is closely monitored, it is no wonder then that research enjoys greater privilege than teaching. Moreover, since personal and institutional performance measures are based on research output, then academic staff tend to concentrate more on their research output than teaching.

Figure 8. 5: Dilemma on performance measure of research output (VBS)

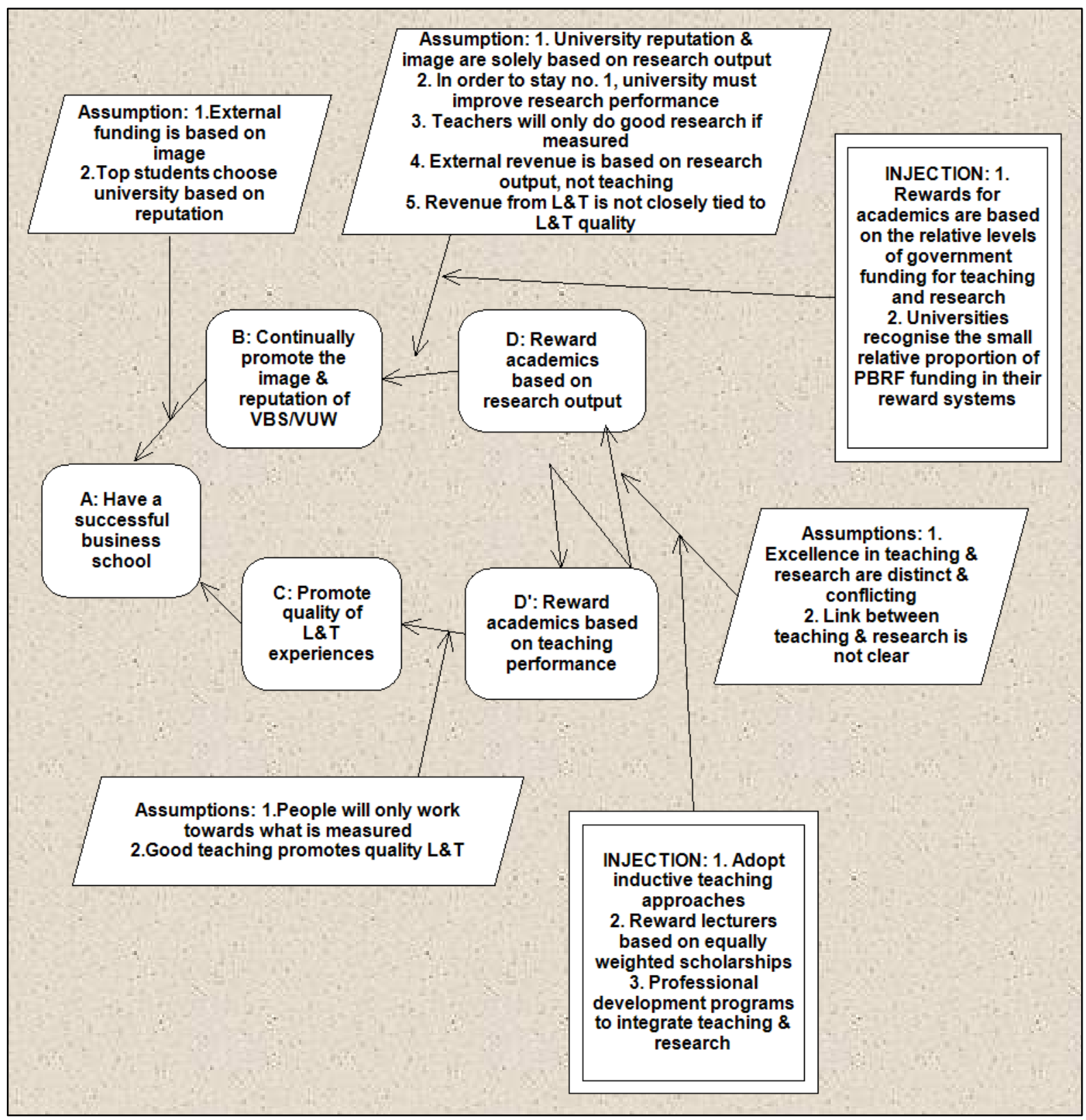


Since we might not be interested in antagonising the 'positioning' of VUW as a research institution \{at the moment we can take pride in that 'we are the NZ leading research university' VAD 08$\}$, then in this context we ask ourselves, how can VBS's research activities enhance the experiences of L\&T? The ideas suggested here are (Prince et al., 2007; Boyer, 1990):

i. Provide professional development programs that integrate teaching and research: These programs are particularly important for new academic staff where induction process could advise on how academic staff can integrate the two in their academic activities early enough.

At the National University of Singapore, NUS teaching academy promotes L\&T professional development including offering yearly induction programs for new academic staff. The academy has the vision of pursuing L\&T innovation and fostering a balanced culture of education and research excellence. In pursuing this vision, the academy actively engages NUS community in transforming the educational landscape of the university. (http://www.nus.edu.sg/teachingacademy). Many other universities in UK, USA and Australia have similar centres.

ii. Reward faculty based on equally weighted scholarships of (1) discovery, (2) integration, (3) application, and (4) teaching: Since most people have a tendency to pursue what is rewarded and recognised, VUW could set reward and promotion based on the four scholarships or a related criteria that is balanced.

Some universities base their promotions on a balanced weighting of research, teaching and service. For instance, University of Melbourne asks candidates for promotion to specify weights of at least three of the following four criteria: contribution to teaching and learning, research and research training, engagement, and leadership and service (http://hr.unimelb.edu.au). Such flexibility in choice of weighting promotes/facilitates a balance between research, teaching, and service. However, a simple fix like borrowing another university's promotion system, is unlikely to work as desired. The roles of the unions and collective employment agreements should not be overlooked.

iii. Adopt inductive teaching approaches (inquiry-based, problem-based, \& project-based approach to teaching): A balanced promotion would imply that the scholarship of discovery, integration, application, and teaching could be achieved simultaneously particularly when inductive approaches to teaching are adopted (Boyer, 1990). 
The University Of Sheffield (UK) has an Inquiry-based learning (IBL) centre. The centre that uses student-centred approaches to learning and teaching that are driven by inquiry or research. Students conduct small or large-scale inquiries that enable them to engage actively with the concepts and questions of their discipline, often in collaboration with each other. Learning takes place through an emergent process of exploration and discovery (https://www.sheffield.ac.uk/ibl).

Many examples can be offered on how L\&T can be improved. But any solution needs to be checked for fit, taking on board feedback that signifies 'resistance to change' to achieve desired aims and does not introduce undesired side effects. Subsection 8.6 expounds resistance to change. We now focus attention on how the future would be, at the participant schools, if proposed ideas were implemented.

\subsection{The Future Reality}

'Even if you're on the right track, you'll get run over if you just sit there'. Will Rogers (1879-1935) Native American cowboy and actor.

'What you have to do, and the way you have to do it, is incredibly simple; whether you are willing to do it, that's another matter'. Peter F. Drucker

'The most problematic challenges in business these days are associated with getting organisations to change the way they operate. It's not enough to clearly identify a problem and lay out an effective solution, expecting that people will be immediately persuaded by the common sense of it all. Most change agents have been frustrated to find perfectly good proposals greeted with skepticism or indifference... Why does this happen? The reason that this happens is that logic is not enough to persuade people. Human emotion, motivation and behavior enter into the equation, and these factors are likely to be even more decisive than logic'. William Dettmer

As alluded in chapter 3, the TOC methodology is not just a problem solving methodology; it embraces problem identification/structuring through to implementation and review. Thus, after identifying the various ways of resolving dilemmas facing the case schools, the next step is to predict how changes (brought about by proposed injections) could produce the desired effects. This is achieved through the use of a future reality tree (FRT). This subsection presents two tentative FRTs for each business school that are illustrative in nature and will need honing by participants in the system to strengthen the logic and deal with reservations that emerge in this process (resistance to change). Indeed, it is expected that the FRTs will prompt responses from system participants: 'yes, but...' The system participants are in the best position to scrutinise the FRTs, and firm them up with additional actions to ensure that they result in the desired end effects. Nevertheless, the tentative FRTs illustrate the future that would result if the core problems were dealt with leading to progress towards the achievement of the L\&T goals. 


\subsubsection{Future Reality at UNSB}

In relation to UNSB, the major proposition is that its operations should be decentralised to some extent in order to help it effectively raise its performance and therefore achieve the L\&T goal. The extent of decentralisation or autonomy may vary depending on many factors within the broader UoN. However, there are those operational processes that cause delays and tend to adversely affect the achievement of L\&T goals. As indicated earlier, participants complained about delays in program review, lecturer recruitment, procurement, and in repair and maintenance. Other delays relate to the MoU arrangements with external stakeholders.

The global environment in which UNSB is operating creates pressure to become more responsive to the needs of diverse constituents. Indeed, as a supplier of labour, UNSB should not only respond to students' needs but also to employers' needs. As a result, UNSB should be able to help students to develop critical knowledge and skills that are relevant in the market. In relation to this, Hawawini (2005) and Hitt (1998) posit that today there is emphasis on designing innovative programs and moving them quickly to the market place. Allowing UNSB to operate autonomously (or semi-autonomously) is likely to contribute to this form of quick response.

Figure 8.6 demonstrates that with greater autonomy, UNSB could have agility to deal with external stakeholders (through MoUs) to easily form industrial linkages. Such linkages could not only help students with industrial attachments or internships but would also help lecturers and students to become involved in industrial collaborations (such as research projects). The industrial experiences of lecturers and students, together with practitioners' involvement in the program design and delivery, could bring about perspectives of current business practices in classrooms.

The involvement of external stakeholders would also help UNSB to continuously update its program offerings in line with market needs. In an effort to respond to market needs, UNSB could perhaps broaden its program offerings thus broadening its client-base. Offering executive programs, for instance, could prove lucrative. This would mean that UNSB could offer competitive salaries and therefore be able to attract better qualified lecturers and/or professionals to deliver the program. 
Figure 8. 6: Future reality tree for UNSB

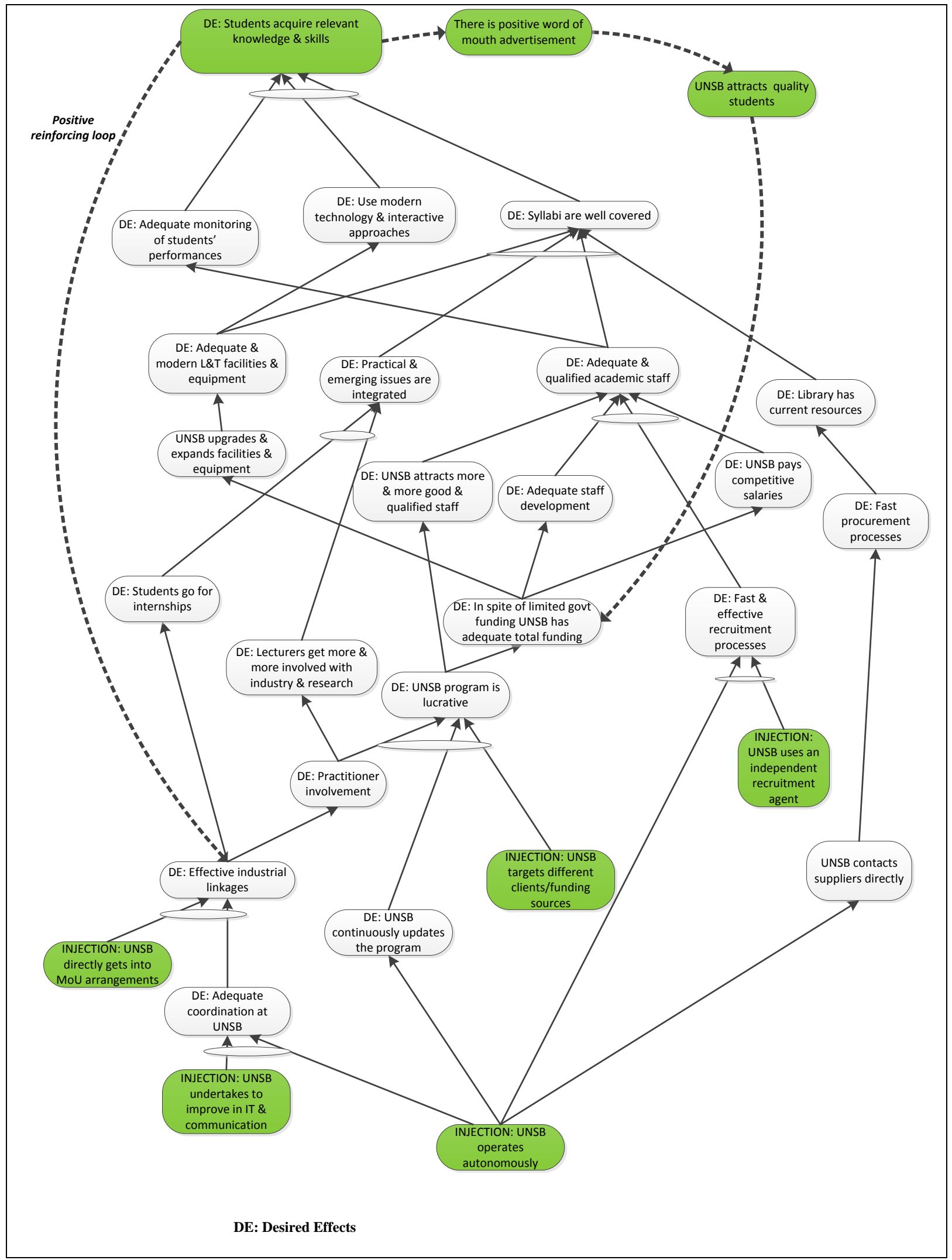

The challenge of getting $\mathrm{PhD}$ trained lecturers is, however, not understated. One approach to alleviate the faculty shortage would be to attract a mix of diverse skills and knowledge from 
fields such as economics, statistics, computer science, and psychology that have close relationship with business education (Hawawini, 2005). Other approaches include mentoring one's own students into $\mathrm{PhD}$ programs, encouraging more visiting lecturers (on sabbatical), and attracting qualified practitioners. The exhaustive process of hiring lecturers could be made easier, faster, and more credible through the use of an experienced, independent academic recruitment agency.

Liaising with external stakeholders could also enhance the use of information technology (IT) and communication within the school whereby there could be reciprocal relationships of IT training to UNSB staff and students, while UNSB could provide blended programs that allow students to learn while they are in their workplaces (Hawawini, 2005). In other words, UNSB would take the service to where clients are. If integrated properly, such reciprocal relationships can help streamline UNSB's operations, control administrative costs, and leverage the limited L\&T resources (Hawawini, 2005).

Limited funding is another big challenge at UNSB. To overcome this challenge, UNSB has launched new programs to attract students. It also admits high numbers of self-sponsored students. As explained earlier, the result is that lecturers are overworked and do not have time to do research. But without highly qualified academic staff, it will become increasingly difficult for UNSB to attract top students (Hawawini, 2005). To resolve this dilemma, UNSB might need to source funds externally from alumni and corporates in the form of donations, scholarships, endowed gifts, and endowed positions (Fernando \& Beatrice, 2011; Hawawini, 2005). In order to do so, UNSB may involve alumni and corporates in the school's governance or advisory boards. The involvement could be serving various UNSB boards and/or committees (such as audit and finance), and could be arranged through MoUs with corporates. Involving experienced business people could also benefit the school with diverse knowledge and opportunities for classroom enrichment.

Other forms of external funds might be in the form of event sponsorship, which could release more funds for operating expenses. UNSB could also offer comprehensive leadership programs, focused programs and custom made programs and consultancy services targeting premier clients (such as sports people and executives). Such programs would perhaps help UNSB to 'achieve more with less' as they free academic staff of some workload. In addition to consultancy funds available from business organisations, a number of research funds are available from institutions such as NACOSTI and Ministry of Higher Education, Science and 
Technology (MOHEST). There are other forms of research funds in collaborative networks such as Council for the Development of Social Science Research in Africa (CODESRIA), Emerald African Management Research Fund, and other regional and global networks.

As indicated above, successful use of information communication technology (ICT) may also reduce administrative costs. Moreover, outsourcing services such as cleaning, catering, and accommodation could make efficient use of operating funds. Employing students is another option. UNSB can engage students in part-time work (in library, clinic, and other administrative work). This would provide students with work experience and can be costeffective for the university. When lecturers have a more manageable workload, they could then be expected to undertake more research and perhaps attract research funds for the school.

Having more manageable workloads could also allow lecturers to have more time for students, and to develop better relationships. Such relationships might evolve into further collaborative research and consultancy work. Indeed, with such a diverse student body, it would not be surprising to get collaborative corporate funds from organisations where students work. When students graduate from UNSB with valuable experiences, they would be more supportive of alumni networks. Indeed, the FRT shows a number of positive reinforcing loops, which suggest that, for instance, when students graduate with relevant business knowledge and skills, UNSB could be able to attract more and better quality students. Such students could come through recommendations from former students, employers, and partners. The systems behaviour of positive reinforcing loops in HE is corroborated by Owlia and Aspinwall (1997) who, while using a system dynamics approach to analyse HE quality, indicate as an example, that if a university is educating better quality graduates than it previously did, then it would result in higher job performance for graduates in industry, which, in turn, improves the university's reputation. They further indicate that the enhanced reputation would increase the number of applicants to the university enabling it to select more capable students, which in turn leads to higher quality graduates (p.528).

As indicated earlier, this FRT may raise many queries or reservations, for instance: do we have facilities for executive programs? By privatising accommodation, would we not disadvantage students from poor backgrounds? By outsourcing cleaning and catering services will we not put people out of jobs? Research funds come in bits and pieces compared to a continuous stream of revenue from high student intakes. Developing MoUs can take a long time. Why should we change? 
These and other questions are valid reservations that people may have about the proposed changes. For changes to be successful, leadership needs to appreciate the need for change, take full ownership of the change process, and use a proper process to support changes, taking account of any reservations (Mabin et al., 2001). TOC tools and processes are available to assist right through this process.

\subsubsection{Future Reality at VBS}

At VBS, findings indicate a common root cause of all the UDEs: that research is given de facto priority over teaching. The previous section provided a direction for resolving this dilemma. This subsection provides a 'what if scenario' building from the proposed suggestions.

Figure 8.7 suggests what would perhaps happen if VUW, for instance, adopted practices from other universities (e.g where academic promotions are based on four work-focus categories as already discussed). Such an approach to promotion would be consistent with the desires expressed by academic staff interviewed for this research who indicate the need for more balance between research and teaching. It also provides them with a choice (and greater control) to pursue either teaching, research or both, based on their individual needs and strength, thus promoting greater work satisfaction. It is envisioned that such an approach would also promote the goals of L\&T and may lead to reputational gains for VUW in general.

Even though many academic staff may still choose a research focus, the fact that they have a choice is a powerful motivator. The importance of choice is emphasised by Kohn (1999) who argues that 'managers need to take affirmative steps to make sure that employees have real choices about how they do their jobs' (p. 192).

However, with greater choice of what to pursue, a more favourable working environment is created whereby those in leadership, teaching specialisations, and teaching and research focus categories are likely to have more commitment to L\&T. This commitment would then create an environment in which a shared understanding of the common goal of L\&T could be identified.

The shared goal would then create a situation whereby the L\&T committees would be keen to ensure (with the support of motivated lecturers) that the learning outcomes are effectively designed into the program. 
Figure 8. 7: FRT at VBS

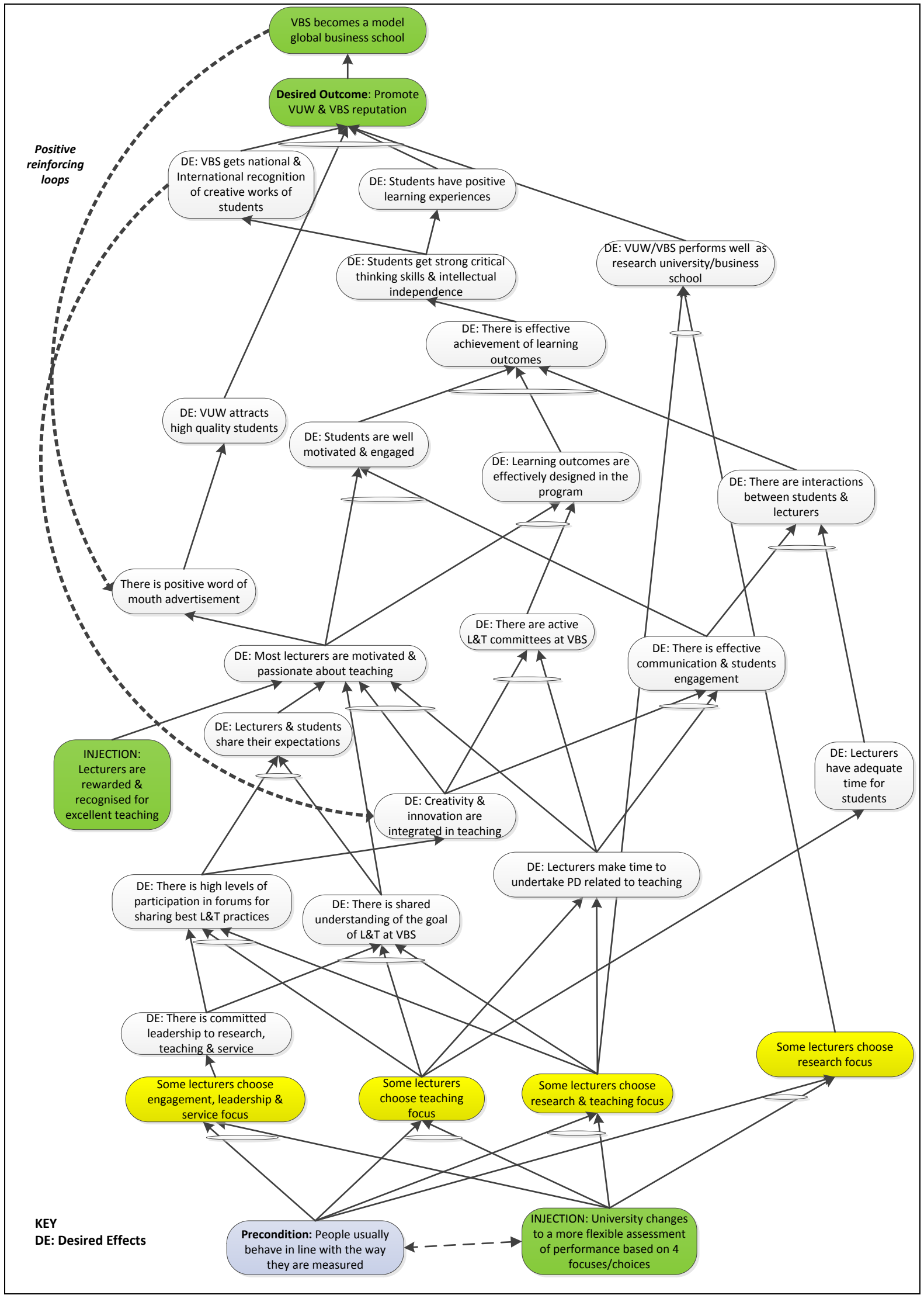


The increased commitment to L\&T would perhaps create sharing forums for best practices in L\&T as well as enhanced participation in such forums. These forums would help lecturers to learn from each other and probably lead to enhanced integration of creative and innovative teaching approaches (Freeman et al., 2014; Zepke, 2009).

The forums could also help lecturers and students to understand each other's expectations. In such an environment, lecturers may more likely become motivated and passionate about teaching. Consequently, students become motivated as they actively engage in learning (Hattie, 2003, p.24).

Similarly, those pursuing a teaching focus, and presenting research and teaching categories for promotion, would be more likely to undertake professional development related to teaching. This would enhance their teaching and communication skills. The result would be effective communication and engagement with students, even in large classes. Moreover, lecturers would then tend to have more time for student consultations. This would then lead to more interactions between lecturers and students, as they both try to explore creative ways of L\&T.

In a situation where the learning outcomes are well designed and integrated within the program, students would become motivated and better engaged in learning (Mabin \& Marshall, 2011). Moreover, if there are high levels of interactions between lecturers and students, then the learning outcomes would effectively be achieved. Subsequently, students would develop strong critical thinking, and intellectual independence, which would be demonstrated through national and international recognition of their creative and collaborative work with businesses, as well as opportunities for scholarships for further studies. The national and international recognition together with the work of those lecturers pursuing the research focus, could generate reputational gains for VBS and VUW. Meanwhile, the recognition of students' creative work becomes part of a positive reinforcement loop, which encourages lecturers to innovate more in teaching. Another reinforcement loop is evident: as VBS and VUW reputation increases, VBS attracts more high quality students, which in turn leads to more motivated and engaged students and so on. This creates a virtuous cycle of improvement.

The above discussions propose improvement ideas that could enhance quality of L\&T experiences and overall performance of L\&T systems. However, challenges in implementing change should not be overlooked. 


\subsection{Designing and implementing the change}

This study proposes a number of changes. At VBS for instance, the study urges changes to the promotion and reward system. This is the first step in the change process, identifying what to change. The changes should however be approached with care. Kohn (1999, p.119) cautions that reward systems can bring about perverse effects in organisations. He argues that rewards neither enhance performance (especially in tasks that require creativity, such as teaching) nor lead to long-term improvements in quality of work (p.122). In this regard, at VBS performance targets could perhaps be discussed and agreed upon among lecturers and senior academic management of the school on key areas (particularly teaching and research) that seem to impact negatively quality of L\&T. Such performance targets may relate to class attendance, number of students consulting with a lecturer, course materials and course review, course load (term papers, assignments, and exams) and industrial visits. Here, the leadership role would be to provide as much information as possible about, say promotion and reward systems, or the proposed change/idea. The leadership should also encourage others to share their ideas as much as possible.

The next step should aim at getting agreement. But getting agreement on any change initiative is not always easy. As noted in chapter 2, there is a general high resistance to change in $\mathrm{HE}$ (Abdous, 2011). The leadership of the schools should expect some resistance. Being aware of the various forms of resistance to change may help leadership understand how to deal with resistance to change. The TOC's change questions are designed, not only to identify layers of resistance to change but also to provide ways of harnessing resistance to change (Mabin et al., 2001). Extant TOC literature identifies layers of resistance to change as shown in Table 9.1 (Goldratt-Ashlag, 2010 p.574-584).

Knowledge of layers of resistance may help leadership to understand the systematic way to address each layer. Indeed, going through each layer would help them to identify various causes of resistance such as fear of the unknown, loss of control, loss of face, loss of competence, loss of comfortable habits, need for security, poor timing, lack of support, lack of confidence and lingering resentment (Mabin et al., 2001). These forms of resistance can occur at any stage through the change process. 
Table 8. 1: Layers of resistance to change

\begin{tabular}{|c|c|c|}
\hline Layers of resistance & Purpose of peeling the layer & TOC tool applied \\
\hline $\begin{array}{l}\text { Disagreement on the problem } \\
0 . \text { The problem does not exist or } \\
1 \text {. We do not agree on the problem } \\
2 \text {. The problem is out of our } \\
\text { control }\end{array}$ & $\begin{array}{l}\text { Gain agreement on the problem } \\
0 \text {. Identify gaps in the achievement } \\
\text { of the goal or undesirable effects } \\
\text { that are symptoms that a problem } \\
\text { exists } \\
\text { 1. Get a consensus on the core } \\
\text { problem } \\
\text { 2. Uncover erroneous assumptions } \\
\text { (see the problem as solvable \& } \\
\text { within control) }\end{array}$ & $\begin{array}{l}\text { Goal tree } \\
\text { List of UDEs } \\
\text { Current reality tree (CRT) } \\
\text { Evaporating cloud (EC) }\end{array}$ \\
\hline $\begin{array}{l}\text { Disagreeing on the solution } \\
\text { 3. Disagreeing on the direction of } \\
\text { the solution } \\
\text { 4. Disagreeing on the details of the } \\
\text { solution } \\
5 \text {. The solution has negative } \\
\text { consequences }\end{array}$ & $\begin{array}{l}\text { Gain agreement on the solution } \\
\text { 3. Verify \& agree on the right } \\
\text { direction for the solution } \\
\text { 4. Verify that agreed solutions will } \\
\text { properly address the problem } \\
\text { 5. Take care of negative } \\
\text { ramifications }\end{array}$ & $\begin{array}{l}\text { EC } \\
\text { Future reality tree (FRT) } \\
\text { Negative branch reservations } \\
\text { (NBRs) }\end{array}$ \\
\hline $\begin{array}{l}\text { Disagreeing on the } \\
\text { implementation } \\
\text { 6. We cannot implement the } \\
\text { solution } \\
\text { 7. Disagreeing on the details of the } \\
\text { implementation } \\
\text { 8. The solution holds risks } \\
\text { 9. Social and psychological barriers }\end{array}$ & $\begin{array}{l}\text { Gain agreement on the } \\
\text { implementation } \\
\text { 6. Identify \& agree on obstacles to } \\
\text { implementation } \\
\text { 7. Agree details of the } \\
\text { implementation } \\
\text { 8. Identify \& address possible } \\
\text { risks of change } \\
\text { 9. Identify \& address external } \\
\text { reasons for resisting change }\end{array}$ & $\begin{array}{l}\text { Prerequisite tree }(\mathrm{PRT}) \\
\text { Transition tree }(\operatorname{Tr} \mathrm{T})\end{array}$ \\
\hline
\end{tabular}

Other than identifying causes of resistance, the process of going through the layers of resistance would help the leadership to identify likely undesirable consequences that may result from well-intentioned actions (Scheinkopf, 2010, p.737). Nevertheless, regardless of which change initiative, leadership should still expect some resistance. But if they view change as necessary and urgent, and view contributions, reservations and resistance to proposals in a positive light, then more robust plans can be developed.

To harnessing resistance to change, getting buy in is a strategy that leadership may use. The process of buy in not only helps to address pertinent questions of what is to be gained by change in terms of its benefits (and getting rid of problems and issues in the current system); but also what will be lost by the change (e.g. comfortable habits learnt under the old system); and the risks or costs of changing (fear of unknown, transition issues, etc). The aim of the process of harnessing resistance is to arrive at a co-designed system (Mabin et al., 2001) that will bring about the desired behaviours and cultural changes. The process of buy in should therefore make 
everybody involved feel that they have something to win. Questions such as 'what needs to happen to make teaching more satisfying?' should feature prominently. The process of buy in should be conducted in a sincere manner, having honest dialogues with people, which focus on common goals. Mabin et al. (2001) note that the process of harnessing resistance requires ability of leaders to not only identify resistance to change but also to engage people in using this resistance, testing and honing change strategies and action plans. This view of engaging others is consistent with Seddon who emphasise the need of 'putting people in control' as an intrinsic way of motivating them to change (Seddon, 2008, p. 67). Thus engaging people, delegating responsibility and authority to them is critical in the change management process.

Another strategy related to buy in is building a critical mass - 'a small segment of the population that chooses to make big contributions to the collective action while the majority do little or nothing' (Oliver, Marwell, \& Teixeira, 1985). The critical mass are the supporters of the ideas who are willing to listen and advocate for change. In order to build this critical mass, communication about change should be done in ways that appeal to people.

Moreover, leadership must recognise that they have to trust people and refrain from interfering, or micro-managing those to whom they have delegated responsibility. More trust can be created with enhanced relationships which can be created in team building activities, workshops and seminars. The deans and the heads of schools should be at the forefront in supporting these activities.

Leaders must also perform and fulfil their leadership roles. They must communicate the vision, goals and provide leadership. In addition, they must understand the expectations of the various stakeholders and fulfil those expectations where they can. They must also recognise the importance of their visibility within their schools. They have to be visible to students, academic staff and the broader school community. Having open forums is one of the strategies of bringing about visibility. In such forums, more ideas about implementing changes could be sought. Asking questions such as can we really do this, do it well and do it sustainably, is important. In TOC, the Negative Branch Reservations (NBRs) process helps to identify undesirable effects that are likely to emanate from an idea so that the undesirable effects may be avoided by timely preventive steps (Scheinkopf, 2010).

Once the reservations have been addressed, then agreement on direction of change becomes feasible. For instance, academic staff may agree on the performance targets and then, they can develop official work plans on how to achieve them. At each stage of the process, new 
reservations are likely and at each stage of the process, these reservations need to be taken on board to enhance the solution.

In a nutshell, to bring about effective changes that may lead to quality improvements, TOC advocates that leaders should create an environment of trust where people feel that change is required and where they feel a commitment to the change process (Mabin et al., 2001).

\subsection{The use of the TOC tools}

If we revisit the limitations of the TOC in Chapter 2, section 2.7.1, we recall that Ronen (2005) calls for rigor in the use of tools while Mabin and Davies (2010) call for research in TOC that address multi-methodological issues, methodological consistency and rigor in using TOC-TP tools. Watson et al. (2007) discussed subjectivity element on the one hand and non-user friendly on the other. On the balance, my view is that TOC methodological tools provide logic and rigor which helps and/or supports the qualitative research designs. The tools allow collection and analysis of data and provides a narrative that provides a chain of logic. The categories of legitimate reservations (CLR) (discussed in Chapter 3) offers critique of the chain of logic and encourages open debate and scrutiny while evaluating the tools. The CLR also helps to challenge the representation of TOC diagrams without challenging the researcher. As such, the CLR offers objective rules of logic. The process of organising the TOC diagrams forces the analyst to put things in a clearer and more logical framework that is easier for other people to critique. Table 8.2 provides a summary of my take on the use of five TOC tools used in this study.

Table 8. 2: Evaluating the use of the TOC diagrams

\begin{tabular}{|c|c|c|c|c|c|}
\hline & Goal tree (GT) & CRT & $f$ CRT & EC & FRT \\
\hline $\begin{array}{l}\text { Usefulness of } \\
\text { tool in the } \\
\text { data } \\
\text { collection } \\
\text { stage }\end{array}$ & $\begin{array}{l}\text { It is easy to } \\
\text { construct with } \\
\text { participants. } \\
\text {. It makes } \\
\text { participants think of } \\
\text { what their goals, } \\
\text { CSFs and NCs are. } \\
\text {. It helps participants } \\
\text { to make logical } \\
\text { connections between } \\
\text { the goal, CSFs and } \\
\text { NCs. } \\
\text {. The process of } \\
\text { constructing the goal } \\
\text { tree is engaging and } \\
\text { helps participants to } \\
\text { reflect on their } \\
\text { goals. }\end{array}$ & $\begin{array}{l}\text { Focuses attention on } \\
\text { surfacing the } \\
\text { symptoms that indicate } \\
\text { that the system is not } \\
\text { currently performing } \\
\text { as well as desired, and } \\
\text { on the factors that are } \\
\text { causing this situation. } \\
\text { Participants have } \\
\text { high enthusiasm in } \\
\text { raising unfavourable } \\
\text { issues (perhaps in the } \\
\text { hope that the system } \\
\text { could be improved). }\end{array}$ & $\begin{array}{l}\text { Focuses } \\
\text { attention on } \\
\text { surfacing the } \\
\text { symptoms that } \\
\text { indicate that the } \\
\text { system is not } \\
\text { currently } \\
\text { performing as } \\
\text { well as desired, } \\
\text { and on the } \\
\text { factors that are } \\
\text { causing this } \\
\text { situation. }\end{array}$ & $\begin{array}{l}\text { It helps to raise issues } \\
\text { that are perceived as } \\
\text { conflicts/dilemmas. } \\
\text { It greatly clarifies the } \\
\text { reasons why the } \\
\text { problematic situation } \\
\text { exists. } \\
\text {. By following the } \\
\text { process, ideas to } \\
\text { resolve the dilemma } \\
\text { readily come to light. } \\
\text { It allows participants } \\
\text { to reflect on how they } \\
\text { can resolve their own } \\
\text { dilemmas. }\end{array}$ & $\begin{array}{l}\text { Easy to identify data } \\
\text { about what people } \\
\text { like/prefer the system } \\
\text { to be-that is can be } \\
\text { included or used in } \\
\text { constructing a FRT. } \\
\text { Easy to solicit } \\
\text { ideas/proposals for } \\
\text { improvements. }\end{array}$ \\
\hline
\end{tabular}




\begin{tabular}{|c|c|c|c|c|c|}
\hline & Goal tree (GT) & CRT & $f$ CRT & EC & FRT \\
\hline $\begin{array}{l}\text { Usefulness of } \\
\text { tool in the } \\
\text { data analysis } \\
\text { stage }\end{array}$ & $\begin{array}{l}\text { Helps analyst to } \\
\text { understand what is } \\
\text { perceived to be } \\
\text { critical/important in } \\
\text { the goal } \\
\text { achievement by the } \\
\text { stakeholders. } \\
\text {. Helps the analyst } \\
\text { to establish the } \\
\text { extent to which the } \\
\text { goals of the system } \\
\text { are commonly } \\
\text { understood. }\end{array}$ & $\begin{array}{l}\text {. It is easy to construct } \\
\text { a CRT by relating it to } \\
\text { a GT because UDEs } \\
\text { represent deviations } \\
\text { from the goal } \\
\text { (Dettmer, 2007, } \\
\text { p.107). } \\
\text {. Working through } \\
\text { logical connections } \\
\text { allows an analyst to } \\
\text { think deeply about the } \\
\text { system. } \\
\text {. The process of } \\
\text { constructing the CRT } \\
\text { raises many } \\
\text { assumptions about the } \\
\text { system } \\
\text {. Diagramming the } \\
\text { CRT illustrates the } \\
\text { complexity of the } \\
\text { system which, } \\
\text { however, is simplified } \\
\text { by identifying the few } \\
\text { critical root causes. }\end{array}$ & $\begin{array}{l}\text { It starts with a } \\
\text { leading UDE } \\
\text { which is often } \\
\text { opposite of the } \\
\text { goal statement. } \\
\text { The } f C R T \text { is } \\
\text { viewed as the } \\
\text { opposite of the } \\
\text { goal tree in the } \\
\text { sense that it } \\
\text { connects the } \\
\text { negative factors } \\
\text { (UDEs), mainly } \\
\text { related to the } \\
\text { goal (Ronen \& } \\
\text { Pass, 2008, p. } \\
121 \text { ). } \\
\text {. It is therefore } \\
\text { easier to } \\
\text { construct and } \\
\text { describe. }\end{array}$ & $\begin{array}{l}\text { It is easy to construct } \\
\text { an EC using an EC } \\
\text { template or a web } \\
\text { application such as the } \\
\text { one available at } \\
\text { www.evaporatingclou } \\
\text { ds.com. } \\
\text {. The process of } \\
\text { constructing an EC } \\
\text { helps an analyst to } \\
\text { surface and question } \\
\text { the assumptions (valid } \\
\text { and invalid) related to } \\
\text { the dilemma at hand. } \\
\text {. It helps an analyst to } \\
\text { understand the system } \\
\text { better. } \\
\text {. It helps an analyst to } \\
\text { search for information } \\
\text { or ideas to resolve the } \\
\text { dilemma by focusing } \\
\text { questions on the points } \\
\text { where the dilemma } \\
\text { can most effectively } \\
\text { be resolved. }\end{array}$ & $\begin{array}{l}\text { Its construction starts } \\
\text { with an injection(s), at } \\
\text { the bottom moving up } \\
\text { to the top. } \\
\text {. It allows the tree } \\
\text { builder to think } \\
\text { critically about the } \\
\text { proposed ideas and } \\
\text { whether they may } \\
\text { bring about not only } \\
\text { the desired goal, but } \\
\text { also any form of } \\
\text { undesired effects. } \\
\text { Its construction is a } \\
\text { motivation to the tree } \\
\text { builder. }\end{array}$ \\
\hline $\begin{array}{l}\text { Practical } \\
\text { application } \\
\& \\
\text { implication }\end{array}$ & $\begin{array}{l}\text { A very simple tool } \\
\text { to describe to other } \\
\text { people, using simple } \\
\text { practical } \\
\text { illustrations. } \\
\text {. Can be useful in } \\
\text { setting up a course } \\
\text { at the start and } \\
\text { check with students } \\
\text { what they want from } \\
\text { the course. This } \\
\text { might also apply to } \\
\text { help students when } \\
\text { forming groups. } \\
\text { Can be used as an } \\
\text { evaluation/review } \\
\text { tool where half way } \\
\text { through the course, } \\
\text { can be used to do a } \\
\text { mid-course review, } \\
\text { checking how } \\
\text { people are going } \\
\text { compared to their } \\
\text { goal. } \\
\text {. It can help an } \\
\text { organisation assess } \\
\text { how well its goal(s) } \\
\text { are understood by its } \\
\text { stakeholders. } \\
\text {. The process of } \\
\text { constructing the goal } \\
\text { tree may help an } \\
\text { organisation to } \\
\text { reflect and/or realign } \\
\text { its goals, have a } \\
\text { clear understanding } \\
\text { of the CSFs and } \\
\text { NCs needed to } \\
\text { achieve its goal. } \\
\text { The GT is a good } \\
\text { entry point for the } \\
\text { CRT as it clarifies } \\
\text { what is needed for } \\
\text { the desired goal, } \\
\text { against which helps } \\
\text { to identify } \\
\text { shortcomings in the } \\
\text { current reality. }\end{array}$ & $\begin{array}{l}\text {. It provides the } \\
\text { mechanism for the } \\
\text { analyst to search for } \\
\text { connectedness and } \\
\text { simplicity within } \\
\text { complexity of a } \\
\text { system } \\
\text {. It is a unique tool } \\
\text { that has the capability } \\
\text { of adopting a systemic } \\
\text { view, yet be able to } \\
\text { isolate few critical } \\
\text { factors that } \\
\text { management may } \\
\text { focus on. } \\
\text {. It raises issues that } \\
\text { points to direction of } \\
\text { changes and those that } \\
\text { may be 'disturbing' to } \\
\text { management. }\end{array}$ & $\begin{array}{l}\text { The } f \text { CRT uses } \\
\text { few or fewer } \\
\text { UDEs } \\
\text { compared to a } \\
\text { CRT but is still } \\
\text { able to identify } \\
\text { the critical root } \\
\text { causes - where } \\
\text { management } \\
\text { should focus } \\
\text { effort. }\end{array}$ & $\begin{array}{l}\text {. A great tool that } \\
\text { opens a dialogue. } \\
\text {. It allows people to } \\
\text { see the other side of } \\
\text { the situation. } \\
\text {. It brings better } \\
\text { understanding among } \\
\text { people when they } \\
\text { understand others } \\
\text { assumptions. } \\
\text {. It enables people to } \\
\text { see what is within their } \\
\text { span of control and } \\
\text { sphere of influence. } \\
\text {. It allows people to } \\
\text { think about direction } \\
\text { of change. } \\
\text {. It broadens an } \\
\text { analyst's thinking } \\
\text { process. } \\
\text {. In reality, the } \\
\text { construction of EC } \\
\text { should involve all the } \\
\text { parties involved in the } \\
\text { dilemma situation, } \\
\text { whereby they would } \\
\text { first agree that a } \\
\text { dilemma exists and } \\
\text { then raise their } \\
\text { assumptions, and } \\
\text { provide ideas of how } \\
\text { they could resolve } \\
\text { their dilemmas. }\end{array}$ & $\begin{array}{l}\text {.It is a good tool 'test } \\
\text { drive' allowing a } \\
\text { system, to predict how } \\
\text { future may look like. } \\
\text {.It seeks inputs from } \\
\text { participants as to what } \\
\text { as to what conditions } \\
\text { or future ideas and } \\
\text { actions are needed to } \\
\text { make changes that } \\
\text { may deliver desired } \\
\text { effects. } \\
\text {. It spells out the } \\
\text { advantages that } \\
\text { proposed changes may } \\
\text { bring into the system. } \\
\text {. It is a great tool to } \\
\text { use where proposed } \\
\text { changes are internal } \\
\text { and within the span of } \\
\text { control of the } \\
\text { implementers. } \\
\text {. It allows } \\
\text { management to see } \\
\text { how the system would } \\
\text { look like if changes } \\
\text { were implemented. } \\
\text {. It can be used as a } \\
\text { vehicle to facilitate } \\
\text { focused and robust } \\
\text { dialogue/debate of } \\
\text { other conditions or } \\
\text { actions that are needed } \\
\text { to support primary } \\
\text { injections/ideas. }\end{array}$ \\
\hline
\end{tabular}




\begin{tabular}{|c|c|c|c|c|c|}
\hline & Goal tree (GT) & CRT & $f$ CRT & EC & FRT \\
\hline Limitation & $\begin{array}{l}\text { The process of } \\
\text { constructing the goal } \\
\text { tree requires } \\
\text { participants to put } \\
\text { aside their normal } \\
\text { activities and } \\
\text { verbalise overall } \\
\text { goals that we do not } \\
\text { normally stop to } \\
\text { think about, which } \\
\text { involves the ability } \\
\text { to 'see the wood for } \\
\text { the trees' and may } \\
\text { put some } \\
\text { participants in } \\
\text { discomfort. } \\
\text {. TOC methodology } \\
\text { fails to provide a } \\
\text { clear guidance on } \\
\text { how to delimit the } \\
\text { CSFs to 3-5 or the } \\
\text { required number of } \\
\text { NCs needed to } \\
\text { construct the goal } \\
\text { tree. As such, goal } \\
\text { trees may vary in } \\
\text { size and shape. } \\
\text {. Within the same } \\
\text { system, different } \\
\text { participants may } \\
\text { define and classify } \\
\text { CSFs and NCs } \\
\text { differently. The tree } \\
\text { builder must use } \\
\text { necessity logic and } \\
\text { knowledge of the } \\
\text { system to construct } \\
\text { a GT that best } \\
\text { represents } \\
\text { participants' views. }\end{array}$ & $\begin{array}{l}\text { Constructing a CRT } \\
\text { is a time consuming } \\
\text { process and involves } \\
\text { great cognitive effort. } \\
\text {. To construct a CRT, } \\
\text { a tree builder must } \\
\text { first sort out the UDEs } \\
\text { (using protocol for } \\
\text { identifying well- } \\
\text { articulated UDEs) } \\
\text { from the many } \\
\text { unfavourable issues } \\
\text { raised. } \\
\text { The identified UDEs } \\
\text { may need scrutinising } \\
\text { by someone } \\
\text { knowledgeable in } \\
\text { TOC logic. } \\
\text {. The causes of effects } \\
\text { are not always explicit. } \\
\text { It needs a good } \\
\text { understanding of the } \\
\text { system. } \\
\text { A CRT diagram can } \\
\text { become very complex } \\
\text { in seeking to become } \\
\text { comprehensive and/or } \\
\text { in response to use of } \\
\text { the CLR rules. } \\
\text {. Constructing a CRT } \\
\text { needs someone who } \\
\text { knows how to write } \\
\text { the logic. } \\
\text {. It may dampen a tree } \\
\text { builder's spirit if they } \\
\text { think the process stops } \\
\text { here or they feel the } \\
\text { root causes are } \\
\text { insurmountable. } \\
\text { (Trained users know } \\
\text { that in this case we go } \\
\text { back up the tree to a } \\
\text { point within the span } \\
\text { of control). }\end{array}$ & $\begin{array}{l}\text { The } f \text { CRT } \\
\text { attracts } \\
\text { additional } \\
\text { reservations } \\
\text { because of its } \\
\text { inherent } \\
\text { simplification/o } \\
\mathrm{r} \\
\text { incompleteness } \\
\text { and its failure to } \\
\text { adhere to the } \\
\text { full CLR } \\
\text { process. } \\
\text { To establish } \\
\text { the core } \\
\text { problem the } \\
\text { analyst must } \\
\text { always follow } \\
\text { causal logic and } \\
\text { keep posing and } \\
\text { answering the } \\
\text { question 'why', } \\
\text { until he/she } \\
\text { connects the } \\
\text { effect(s) down } \\
\text { to the root } \\
\text { cause(s). } \\
\text { Without } \\
\text { adhering to the } \\
\text { causal logic, the } \\
\text { results in form } \\
\text { of 'root causes' } \\
\text { are confounded. }\end{array}$ & $\begin{array}{l}\text { People may not } \\
\text { always agree on what } \\
\text { constitutes a dilemma. } \\
\text {. Bringing people } \\
\text { together to construct } \\
\text { an EC is not always } \\
\text { easy. } \\
\text { ECs may frustrate } \\
\text { people when proposed } \\
\text { ideas may be beyond } \\
\text { their span of control or } \\
\text { spheres of influence. }\end{array}$ & $\begin{array}{l}\text { The FRT needs to be } \\
\text { scrutinised by key } \\
\text { stakeholders can } \\
\text { question the } \\
\text { practicality of the } \\
\text { proposed ideas to help } \\
\text { make the plan more } \\
\text { workable. }\end{array}$ \\
\hline
\end{tabular}

\subsection{Summary}

This chapter has discussed the goals of L\&T as identified by students, lecturers, and senior administrators of the two business schools involved in this study; together with related impacts and implications. Then, for such goals, critical success factors and necessary conditions are mapped out in an adaptation of Biggs' 3P model. In addition, the critical root causes of the less-than-desirable experiences of L\&T are discussed. The purpose of using the $3 \mathrm{P}$ model is to show how the analysis of L\&T experiences using the TOC methodological tools mirrors the HE literature corroborating this study's findings. Resolutions of the dilemmas associated with the root causes are proposed. Finally, future scenarios for UNSB and VBS of the core problems are illustrated using FRTs. The next chapter draws conclusions from the research findings visa-vis research objectives, and provides recommendations for actions. 
Chapter 8: Discussion of findings 


\section{Chapter 9}

\section{CONCLUSIONS AND RECOMMENDATIONS}

Cultures do not change by mandate; they change by the specific displacement of existing norms, structures and processes by others; the processes of cultural change depend fundamentally on modelling the new values and behaviour that you expect to displace the existing ones (Richard Elmore, Harvard Professor).

\subsection{Introduction}

The purpose of this study is to explore the quality of L\&T experiences within the HE sector and to determine the impact of the less-than-desirable experiences of L\&T on the performance of the L\&T systems' goals. This chapter first provides a brief evaluation of how effectively this purpose has been achieved and relates this to the four research objectives. Secondly, it reflects on the contribution of this thesis to the existing body of knowledge. In particular it argues that TOC is in itself useful as a qualitative research methodology. Thirdly it highlights the limitations of the study. Fourthly, it discusses the implications of the findings to HE students, lecturers, and to senior management. Finally, proposals for future research are provided, before closing with a personal reflection, and final remarks.

\subsection{Evaluating the research outcomes}

This subsection summarises, evaluates, and reflects on the research outcome. The subsection is divided into four:

1. Research objective one: To identify the $L \& T$ goal(s) with a view to identifying the critical success factors and necessary conditions for goal achievement.

This research has found that the two business schools do not have commonly understood goals of L\&T. Yet, from a systems thinking perspective, the goal or the purpose should drive measures and methods used to achieve that purpose (p.82) (Senge, 1990; Goldratt \& Cox, 1992; Seddon, 2008). In this study, the TOC goal tree has been used to identify the L\&T goal(s), the critical success factors, and the necessary conditions. This tool has proved to be particularly useful where the process of identifying the goal(s) prompted many participants to reflect on the goals of learning and teaching. In particular, lecturers and administrative staff reflected on the need to have a common understanding of the goal of the L\&T system as well as clear communication about goals. 
At UNSB and VBS, students, lecturers, and senior administrators were tasked to articulate their goals and the important factors needed to achieve those goals. The goals identified appear to be pragmatic in nature for each of these groups in each business school context. In addition, factors perceived by the participants to be important for effective performance of the L\&T systems in each of the two schools were identified. These factors have not only been identified as critical in these two schools but also in other L\&T systems in the HE sector. For instance, appropriate curriculum design, adequate L\&T facilities and resources, and adequately qualified academic staff and students have been identified as important dimensions that enhance quality of L\&T in the HE sector (Gibbs, 2010; Mabin, 2010). However, three important related factors that are uniquely and commonly emphasised across the two business schools are the need for 1) motivated lecturers and students, 2) committed leadership of the school, and [the need for] 3) professional development of academic staff.

One conclusion from this research regarding this objective is that the goal tree is a critical tool that can guide the thinking of the L\&T system at a system level, at individual course level and at a personal level. At the system level, as has been demonstrated, the tool prompted users to express their desire for a common understanding of the goal, and identification of the important factors that are needed to achieve the goal. These are then the factors that the L\&T system could focus attention on. At individual course unit level, the goal tree can guide the efforts of a lecturer and students to understand what goal to pursue in that course. They can then identify the important factors that are needed in order to achieve that goal. At a personal level, a lecturer can identify a personal goal related to teaching, such as excel in my teaching, and/or identify the important factors s/he needs in order to achieve the goal and work towards that goal. The goal tree demonstrates that the specification of the factors is crucial because they act as the building blocks in the achievement of the goal.

In attempting to address this objective, this research has also addressed concerns raised by Mabin and Davies (2010, p.649) over 'whether the system goal can be objectively defined...or whether its definition and description varies according to questioner/observer'. The findings demonstrate that even though the various stakeholders may express the goal and NCs differently, there is enough consensus for system goals to be collectively defined by system owners. 
2. Research objective two: To identify the factors that affect the quality of experiences of $L \& T$ with a view to identifying critical root causes of less-than-desirable L\&T experiences.

This study found that there are many less-than-desirable factors that affect the quality of experiences of L\&T but very few critical root causes in each school. At UNSB, two critical root causes were identified: the bureaucratic system of the university and limited government funding. At VBS, one critical root cause is identified: prioritising research over teaching.

The identification of less-than-desirable factors that impact negatively on the L\&T systems is a relevant milestone of this study. Many studies addressing quality issues tend to focus more on the so-called 'satisfying factors' than the less satisfying ones. But this begs the question of 'why devote effort where it cannot have much effect on improving?' The approach of this study is underpinned by the assumption that the L\&T systems of UNSB and VBS are operating less than optimally and therefore can be improved. In order to effect this improvement, there is a need to identify the undesirable factors that limit the effective performance of these L\&T systems.

Many factors have been identified by participants as inhibiting the effective performance of L\&T systems. They include limited interactions between lecturers and students, inadequate teaching skills, academically weak students, inadequate student engagement and limited active learning. The need for lecturer/student interaction and active learning, for instance, has also been identified in other studies as some of the needs of the recent generation of students (Feiertag \& Berge, 2008; Zepke \& Leach, 2010). However, we note from this study that in order to achieve the active engagement that students need, lecturers ought to have appropriate teaching skills, that is, there is a relationship between these two factors. As such, treating each factor in isolation will do little to improve the situation. It is therefore imperative to see these factors as a whole, not in isolation.

The focused current reality tree (fCRT) proposed by Ronen and Pass (2008, p. 115) is a TOC tool that is used to map out the causal relationships between the undesirable factors (UDEs). This tool not only depicts the causal relationships between these factors but it can also identify the critical root cause(s) of the undesirable factors. This study has identified the fCRT as an effective tool that points to the factors that the business school leaders could pay attention to. 
The $f$ CRT can therefore help leadership to focus on the few critical factors to address them at the root, rather than attempting to deal with symptoms or simply add more 'bells and whistles' that will not actively lead to improvement. Moreover, focusing on the 'causes' of the undesirable effects implies that once the causes have been addressed, then flow-on negative effects will be eliminated. This study lays bare the root causes of undesirable experiences of L\&T for these two business schools. The critical root causes identified are bureaucratic systems, promotion policies, and limited government funding. Although these factors are common in many HE institutions, the fact that they are the core causes of less than optimal performances of these two L\&T systems indicates that they need to be addressed by the respective institutions.

3. Research objective three: To determine the impact of less-than-desirable experiences of L\&T on L\&T goals.

The impact of less-than-desirable experiences of L\&T on L\&T goals can partly be deduced from cause-effect logic implicit in the research data. Such impact would limit effective achievement of the L\&T goals implying that the quality of graduates would not always be satisfactory. At UNSB, there is fear, for example, of producing 'half-baked' graduates. Such fear has also been expressed in other studies such as Waswa and Katana (2008). In NZ, employers express concern over performance gaps in graduate communication skills (Dave \& Noel, 2003). Other negative impacts are demonstrated by lecturers and students. Lecturers, for instance, may lack motivation in their teaching, some miss lectures, arrive late for lectures and leave early, or are not freely available to students. Such teachers are not always good role models to students. Students, on the other hand, also miss lectures, and engage in academic malpractices identified as plagiarism and cheating in exams, and may be demotivated or unwilling to learn. Senior administrators seem to observe the situations in their schools, feeling unable to help.

The impact is evident. At VBS, more than half the students in a class miss lectures in some courses, while at UNSB, more than half the students in basic courses score poor grades such as $\mathrm{C}$ or D. Lecturers and administrators point to policies that tend to limit improvement of L\&T systems. These policies relate to terms of service, rewards and promotions, and course and program design. 
4. Research objective four: To propose improvements to enhance the quality of $L \& T$ experiences and performance of $L \& T$ systems.

In terms of TOC thinking, the presence of critical root causes in L\&T systems indicates that there are unresolved dilemmas. To resolve these dilemmas, the applicable TOC tool that has been used is the evaporating cloud. Conceptualising critical root causes as dilemmas, this study has been able to demonstrate how seemingly complex situations can be resolved with a winwin outcome. The dilemmas associated with interactions in large classes, with bureaucratic structures, and with limited resources have all been demonstrated in this study. But for effective resolution, there must be appropriate change to the policy framework to support the ideas. However, change in policy needs the support of top leadership. The ultimate responsibility (and authority) rests with the top leadership of the two universities that host the two business schools.

\subsection{Strengths and contributions of the study}

The strengths and major contributions of this study are fivefold: research design, TOC methodology, theoretical knowledge, international perspective, and openness.

1. On research design, there are four main contributions from this study: the systemic approach, triangulation of data collection methods and sources, use of causal logic, and the comparative approach.

a. This research is underpinned by first, a systemic design that is used in collecting and analysing data within and across the two cases, as called for by Krause (2007).

b. Secondly, triangulation is used in research settings (two cases), and a range of data collection methods (focus group discussions and personal interviews) and sources (students, lecturers and senior administrators) are used in each case. The analysis also uses several TOC tools for each group of participants before combining the findings of each case. Separate analysis of the three groups in each case provides a comprehensive analysis of each group, before combining them. This triangulation therefore facilitates a more complete picture of the experiences of L\&T in each business school and across the schools. Moreover, triangulation provides cross-verification within and across the schools (Guba \& Lincoln, 1982). 
c. Thirdly, this study contributes its demonstration of the explicit use of causal logic to determine critical root causes of the less-than-desirable factors that negatively impact on the achievement of L\&T goals. This causal logic has provided an empirical way of understanding and explaining the causes of undesirable experiences in L\&T systems in the HE sector. Through causal logic, this research has been able to weave separate pieces of evidence together into a logical whole, and then offer coherent explanation, rich description, attribution and interpretation supported with verbatim evidence. This study has therefore bridged the gap in the literature that called for 'causal analysts to use more systemic and rigorous use of narrative and process analysis for causal explanations' (Maxwell, 2004). Indeed, Maxwell (2004, p. 8) in relaying Abbott's (1992) concern for a need to 'tell a real story' has argued that 'a social science expressed in terms of typical stories would provide far better access for policy intervention...' Previously, Abbott had indicated that he was unaware of any discussions about the relationship between causal analysis and attributions of responsibility (Abbott, 1998, p.172).

d. A fourth contribution is the case-oriented comparative approach. This approach has produced evidence that has face validity and that is verifiable by natural comparability, and is to some extent generalisable to other HE contexts based on the high level of convergence with other studies in HE contexts.

2. With regard to TOC methodology, this study has undertaken a rigorous application of TOC methodology to explore experiences of L\&T in two diverse HE sectors. The study is the first of its kind in Kenya and NZ to address such broad L\&T issues using the TOC-Thinking processes. It therefore produces a platform for further studies. The results of this study have demonstrated the value of TOC methodology in producing useful insights about the perceived quality of L\&T in the HE sector. The TOC methodological tools have not only proven to be rigorous and effective in application but the impact of applying the methodology is also evident from the participants' reflections.

a. Rigour of the TOC methodology: Ronen (2005) called for academic rigor to research in TOC research while Mabin and Davies (2010) called for future reseach that focuses on multi-methodological issues, and philosophical and methodological assumptions underpin methodological consistency and rigor in using TOC-TP tools. Through the 
use of causal logic, this study has shown that TOC methodological tools (Goal Tree, CRT, and EC) contribute to qualitative analysis via schematic depiction of cause-effect logic, and separate necessary condition and sufficient condition logic. Although we cannot say for certain that the causes, for instance, identified here are the only causes, in the tradition of qualitative research, the causes identified are based on the perceptions of participants, which for them, creates/forms/shapes their reality. Reality, as they perceive it, shapes their actions and behaviour. Thus, if we need to change their behaviour, we need to change their perceptions. Based on this reasoning, we find that the use of TOC tools results in rich findings within each category (e.g. students) and within each case (e.g. Kenyan business school). Indeed, the use of TOC methodology allowed separate full analysis of each group of participants (students, lecturers and administrators) before combining the analysis of each case. The tools also allowed comparisons to be drawn within each case and across cases. This approach is different from other TOC studies.

b. Effectiveness of TOC tools: This study identifies the goal tree as an effective tool which can identify not only the goal(s) of L\&T, but also CSFs and NCs. However, the distinctiveness, similarities or overlap between CSF and NCs depends on how they have been specified. As a result, the goal tree can take many forms in demonstrating the embedded logic. The CSFs in the goal trees of this study range from as few as one to four. To logically incorporate common CSFs and NCs identified by a group of participants, sometimes two or three logical levels of NCs are depicted in the trees. This study also attends to calls for research related to CSFs and NCs by Kim et al. (2008). Thus, in judging the effectiveness of the goal tree, this study demonstrates its usefulness in promoting a dialogue among participants in the schools where this study is conducted and among the TOC practitioners.

c. This study has introduced a new concept of unitisation to TOC. In the process of constructing goal trees, this study has woven together a notion often used in qualitative research (unitisation) with TOC methodology.

d. The TOC literature indicates that goals and CSFs are unique to each system (Dettmer, 2007, p. 68). However, this study demonstrates that different systems can indeed exhibit similar and/or shared features relating to goals, CSFs and UDEs. 
$e$. This study also supports the use of the fCRT in preference to the full CRT (as in Dettmer, 2007, p. 91). The $f$ CRT generates a simpler current reality tree whose causal logic is easier to construct, describe, and understand. Thus, its presentation is often more meaningful to the reader than a more complex CRT (see appendix $\mathrm{H}$ ), even though it may be more rigorous. Indeed, the CRT by Dettmer can lead to a complex diagram that requires great cognitive effort to understand through its rigorous depiction of logic (one example is the CRT of a legal case that runs up to nine pages in Dettmer, 2007, p. 384-392). It is also because the CRT is a sufficiency logic tree. The fCRT on the other hand is a necessity-based logic tree that displays logical connections of the few UDEs within a system. Thus, after identifying the UDEs, using the logic process, the fCRT connects them in what appears to be a more simplified representation than the CRT. For example, the $f$ CRT starts with a leading UDE at the top of the page, which indicates that the system is not achieving the goal (Ronen \& Pass, 2008, p. 121). The $f$ CRT is viewed as the opposite of the goal tree in the sense that it connects the negative factors (UDEs), mainly related to the goal, but from top to bottom in the logic tree until the root cause is reached (the UDEs are essentially perceived as gaps between goal, CSFs or NCs and actual performance). The causal links are identified by posing and answering the question 'why', you connect the effect(s) down to the cause(s). However, the $f$ CRT is not fully sufficient because it connects only a few UDEs and may not include other possible entities that could contribute to the logic, or effect. Thus, the logic of $f$ CRT is not sufficiently 'tight'. The process of making each connection of the UDEs 'sufficient' could then form a voluminous CRT. For example, CRTs constructed by the author early in the analysis process needed to be printed on A1 paper to be legible (Appendix H). With $f$ CRT, we are able to see the 'big picture'.

f. Impact of the interviewing process using a TOC-designed interview guide: As discussed in my reflections in section 4.6.3, the process of gathering data for this study involved many participants in reflecting on their own practices. Students reflected on their goals of learning (with some thanking me for making them to reflect on their 'goals of learning'). Lecturers reflected on their goals of teaching, with some explicitly wondering if they even know what their goals are. The administrators feared that they neither had a common understanding of the goal nor clear communication of the goals of L\&T in their schools. The interviewing process was quite comprehensive in that it 
covered goals (as well as the critical success factors and necessary conditions), UDEs, causes and effects. The process also allowed the researcher to dig deeper into conflicts and assumptions behind UDEs, that is, the basis of the dilemmas represented by ECs. Although a few participants were not comfortable with some aspects of interviewing and/or design of the interview guide, repetition of questions, asked in a different way ensured thoroughness/cross-checking.

g. Taking all the above together, this study has weaved together the TOC methodology and the qualitative methods of validity. Weaving the two frameworks together complements the strength of each other.

h. Integration of TOC models with existing HE models: The use of TOC methodology in exploring quality of experiences of L\&T has identified many factors that impact on L\&T experiences, which are similar to those identified in other quality studies in HE. Indeed, the UDEs identified in this study match the HE factors that impact on quality as identified by Gibbs (2010), and Owlia and Aspinwall (1996, 1998). The convergence of the findings might indicate the authenticity of the TOC in exploring critical factors for improving quality of L\&T in HEIs. But unlike other approaches, TOC uses a systemic approach to identify very few critical factors where management could productively focus attention. Moreover, TOC goes beyond this identification to provide a focus on key root causes (and searches for a different direction of addressing these few root causes) rather than providing general endorsements to do everything better. Relatedly, this study has shown that the TOC models, particularly the goal tree and the current reality tree models, embed assumptions, variables, and relationships that are in harmony/consonant with existing HE models of L\&T experiences. The study has used a causal interpretation of Biggs 3P model to map out the cause-effect relationships of the undesirable effects of L\&T experiences. The integration of the TOC models with the 3P model provides a comprehensive analysis of the L\&T system. Based on this, it is recommended that TOC methodological tools can be used with other theoretical models of the HE sector to effectively analyse HE systems.

$i$. Finally, the study has taken the TOC beyond its usage in a predominantly industrial setting into the HE sector, and positioned it as an effective methodology for exploring 
quality improvement imperatives. The study has expanded the knowledge base relating to the TOC methodology and to the experiences of L\&T in the HE sector.

3. In terms of theoretical contribution, the findings of this study first connect well to the existing body of knowledge on experiences of L\&T in the HE sector. The findings resonate strongly with research work on experiences of HE (such as Gibbs, 2010; Prosser \& Trigwell, 2014) (see Figure 8.1). Secondly, the findings corroborate recent work addressing students' needs for engagement and active learning (Stewart et al., 2012, p. 2014; Zepke \& Leach, 2010). Its third major contribution to the theoretical work on L\&T rests with its emphasis on the goal(s) of learning and teaching in the HE sector. This study places high importance on understanding the goal of the L\&T system. This goal then becomes the benchmark against which efforts are measured. The study has demonstrated, in particular, the negative effects of a lack of clear and common understanding and communication of L\&T goals to learning outcomes. In an effort to achieve the goal, we note expectations and roles of teachers and students need to be clear and well understood by each other. Fourthly, this study contributes to the literature through identifying the critical factors of less-thandesirable effects that impact the quality of experiences of L\&T in HEIs. Its major contribution is the identification of a small set of one or two of critical root causes that are specific to each business school. Fifthly, exploring L\&T experiences with a seemingly negative lens (the less-than-desirable perspective) provides an alternative view of reality that is not often used. This lens has exposed many 'critical' views that may otherwise not have emerged. The exposition of these critically-derived and logically-derived views could perhaps prompt action by the schools, allowing them to 'take the bull by its horns' and initiate change that can really make a difference. Finally, this study contributes to TOC literature by exploring quality of L\&T experiences through three phases of TOCs problemsolving process vis-à-vis: why change, what to change, and what to change to.

4. Fourthly, the use of two diverse cases brings to the fore an international perspective of the experiences of L\&T in the HE sector. The study has broadened the understanding of the goals of L\&T, developing complementary perspectives in different contexts, and of the negative factors that impact on the achievement of these goals. This implies that other HE institutions can gain insights from the findings of this study. 
5. This study provides frank and candid views from the participants. This openness is valuable in that it has exposed deep insights, ('if somewhat disturbing' as one senior administrator put it after reading the draft chapters of the findings), that would have otherwise remained hidden. Presumably, voicing these 'disturbing issues' might prompt school leadership to re-think more deeply about how to address and improve the L\&T system. It is important to note that although this study does not guarantee the anonymity of the role/position of participants within the institutions, all quotes used codes to preserve anonymity.

\subsection{Implications of the findings and recommendations}

'I have been impressed with the urgency of doing. Knowing is not enough; we must apply. Being willing is not enough; we must do'. Leonardo da Vinci (1452-1519)

The results of this study have implications for the senior leadership of universities and business schools, their lecturers and students. The findings indicate that each group has a clear and different impact on the perceived experiences of L\&T.

The senior leadership teams of the two universities have major indirect impact on experiences of L\&T dependent on what behaviours and activities they emphasise as 'valued and rewarded'. Lecturers' responses indicate their willingness to teach well. Unfortunately, they perceive that teaching well is not recognised or rewarded. There exist many academic promotion criteria/models that leadership can review. However, based on the results of the findings, at senior university leadership level, this study recommends the following:

a. Teaching \& research

- Teaching should be recognised at the same level as research with commensurate recognition and rewards. Leadership could develop and use rewards for good teaching/pedagogy that academics value and understand. But as Kohn (1999, p.41) indicates, the objective of such rewards should not lead to mere compliance with reward criteria but should lead to long-term quality improvement. Kohn suggests that such improvements could be achieved through collaborations (learning together), content (what are people busy about?), and choice (autonomy) (p.213). To provide schools/faculties with choice/autonomy for instance, good teaching could be defined at school/faculty level and criteria for promotion on good teaching made explicit at that level. At Harvard University, for instance, each school has its own set of guidelines that articulate procedures and policies 
related to teaching and advising (http://www.faculty.harvard.edu/teaching-andadvising/teaching-policies-and-resources).

- At the lecturer hiring stage, good teachers who possess good communication skills could be sought and rated more highly. Teaching statements, teaching philosophies and other documentation of teaching effectiveness are becoming the norm in the hiring process for lecturers, in addition to research statements. To indicate a commitment to quality teaching, and where appropriate, new lecturers could be required to undertake a certificate of teacher training perhaps within one calendar year upon employment. Relatedly, at VUW, with the PHELT program, each completed paper $(501,503 \& 504)$ could be treated as equivalent to an academic journal article that contributes to promotion merit in its own right. This might encourage more staff to recognise the value placed on teaching by the university. Qualifications in university teaching could therefore be made prerequisites for tenure, promotions and appointments. Indeed, ongoing developments of and reflections on teaching could be genuinely incorporated into the annual review and promotion processes.

- How to measure effective teaching is important. This is because different indicators may carry different meanings and at times can be misunderstood, while tools for measuring teaching effectiveness must be seen to be authentic and not biased (Henard \& LeprinceRinguet, 2008). At VBS however, for effective feedback and documentation of teaching, a shift in the administration of evaluation of teaching is needed. Lecturers could take centre stage to collect a variety of feedback to their teaching. If university leadership could ask for yearly documentation of teaching effectiveness, perhaps lecturers could generate and compile various types of evidence of their teaching effectiveness from students and nonstudents (peers, advisors, and other faculty members). In this way, the responsibility of administering student feedback processes and getting feedback shifts from the administrative arm of the university to lecturers. Lecturers could then become responsible for documenting their teaching effectiveness using valid methods/sources (such as end-ofsemester feedback, mid-semester, qualitative and quantitative, formative and summative, peer observation by other staff, as well as their own reflections). This responsibility of documenting could make lecturers become more accountable and reflective regarding their teaching. However, lecturers would need not to see it as mere compliance or a burden but as a means of building an evidential teaching portfolio (collecting evidence and 
documenting teaching records) and as the basis for sharing good teaching practice. The feedback collected should help to identify issues to fix and/or valued and not used against the lecturer. VBS could broaden the base for the evaluation of teaching and not rely wholly on student feedback.

- Good teaching could be embraced as a collegial responsibility, which could be be shared by a teaching group at a program or curriculum level and include developing curriculum coherence. To improve quality of teaching, good teaching should also tolerate criticism. Indeed, Teferra and Altbach, (2004) note that an academic community with a legitimate culture of academic freedom should be tolerant to criticisms and open to different views (including those related to teaching). Collegiality could be promoted through more teamteaching, which could perhaps facilitate sharing of views, thus increasing trust among teachers. Teamwork could be one of the criteria for judging good teaching.

- Encourage and reward research on pedagogy and other teaching matters.

\section{b. Supporting L\&T functions}

A restructuring of learning and teaching functions to support L\&T experiences is needed. At VBS, most lecturers could be relieved of some administrative and coordination tasks related to L\&T that can be done by administrative assistants. This might easily be achieved by simplifying lines of authority and reporting, and improving communication such that people clearly understand their roles. If teaching staff are enabled and encouraged to spend freed-up time on developing better teaching strategies, this will improve teaching. The aim of restructuring should be to send the message that L\&T experience is being highly regarded by the top management not just research performance. At UNSB, the development and provision of student learning support services could be initiated, even if on a small scale. Involving senior students in tutoring and mentoring junior students, for instance, might lead to more effective ways of supporting students.

\section{c. Committed leadership}

Committed leadership is identified as a necessary condition for effective achievement of the goals of L\&T in the participant schools. Senior management of the two universities could be at the forefront in supporting teaching effectiveness. Ramsden (1998) indicates that university leaders should be enabling, coherent, honest, firm, and competent people, who seek to understand how academics work by entering into their world. To develop ways of leading 
collaboratively, participation in leadership development programs could play an effective role. The aim is to improve schools through the change of individuals and school cultures.

\section{d. Structure of the schools}

Different models of business schools exist across the world. Some operate as a unit of a university; as stand-alone brands, but fully financed by a parent university; as stand-alone brands but partially financed by a parent university; as stand-alone brands owned by a parent university but fully financing own their operations; not related to a parent university and as independent schools and promoting the creation of a university (Fernando \& Beatrice, 2011). The parent universities of UNSB and VBS could allow the business schools to develop organisational structures and processes that could help them to achieve the goals of L\&T more effectively.

The findings indicate an imperative that the leadership of the business schools should communicate a clear and common understanding of each school's goals of L\&T. Likewise, the roles of each party (lecturers, students, and administrators) in the achievement of the goal could be clearly stipulated.

Other supporting recommendations related to L\&T that have emerged from the research, are as follows:

- Formal and informal forums where staff discuss teaching and learning could be regularly timetabled and promoted. These forums would not only create more awareness of students' experiences but would also help to break teaching and teacher isolation but also 'course ownership' mentality. These practices may help staff develop productive, trusting relationships.

- Open sharing forums between lecturers and students could also be included in the School calendar. Such forums could aim at clarifying and understanding each party's roles and expectations in the learning process. These forums might lead to better understanding of the goals, critical success factors and necessary conditions (among lecturers, students and senior administrators) for achieving those goals.

- Formal mentoring programs for new lecturers and tutors to develop better teaching skills could be initiated. 
- The findings suggest that programs at the participating schools, would benefit from greater relevance and coherence respectively. Thus, program curricula and courses could be redesigned to ensure coherence and relevance. In order to do this, teamwork within specialised fields of study could be encouraged and upheld. The teams could stipulate how the learning goals would be achieved within each course and within each specialisation. In the redesigning of the courses, student engagement activities could be incorporated.

- UNSB and VBS could have regular teaching-related workshops. Such workshops would help academic staff to reflect and explore ideas related to good teaching. Moreover, workshops designed to help teachers understand the needs of the Netgeneration students, and other issues related to the L\&T environment, could be programed in the school calendars. Relatedly, because of intergenerational differences, students could be equipped with an understanding and appreciation of the expectations of older generation lecturers.

The findings indicate that lecturers have a great impact on students' experiences of learning. In this study, to some extent, students tended to blame lecturers for most of their undesirable experiences. It would be beneficial for lecturers to make an effort to understand the generation of students that they are dealing with, for example, adopting a more friendly approach towards students, and with a heightened interest on students' needs. In order to continually improve teaching, lecturers could embrace and earnestly seek feedback as appropriate. Such feedback could be both formal (such as end-of-semester feedback) and informal (from interactions with students and peers). Peer sharing (could also generate both formal \& informal feedback) of teaching information and practices could be embraced as a culture. Finally, the way in which student feedback is used (at VBS) for promotion purposes should be reviewed. Indeed, participants were keen that this should happen.

\subsection{Limitations of the study}

This study has four main limitations: transferability/generalisability, representation, implementation, and testability of the results. The first limitation, transferability, relates to case and sample selection. It was initially conceded that the focus of this study would be limited to two cases; one from each country, Kenya and NZ. Though it was accepted that a two case approach might limit the transferability of the findings, it was in line with the focus of the 
study, which was to collect rich data to help understand the L\&T system rather than generate generalisable findings. Nevertheless, the fact that the findings from the two diverse business cases share a lot in common might suggest that the results may provide a platform for generalisability. This will need to be tested in other cases. What cannot be generalised is the fact that this study is carried out in business school settings. Thus, further research in more case studies including different kinds of schools will be needed to validate the transferability of findings to other HE settings. There was a purposive element of sample bias in selecting Kenyan students. Relatedly, the inclusion/selection of lecturers in both cases was based on their perceived willingness to participate. In addition, a bigger sample size of students and lecturers could perhaps provide wider views. Nevertheless, as discussed in chapter 4 , the fact that this study had pre-coded themes for analysis, which implies that as data collection progressed, it became clear how well the themes were being addressed. Once one finds many similarities and voices echoing each other (saturation, see section 4.6.1), the smaller the benefit of increasing sample size. Indeed, much commonality is evidenced in data analysis, within and across different groups. Moreover, the triangulation of data (students, lecturers, and senior administrators) provides a means of corroborating evidence on experiences of L\&T. The corroboration of each individuals' evidence through 'repeated' questions was another level of validation. The findings are also consistent with others as discussed in Chapter 8.

A second limitation pertains to representation across the groups of participants. While great effort was made to ensure that the different categories of participants in the two schools were appropriately representative of the schools, some categories had wider representation than others. For instance, in the VBS case, only 3 Māori and Pasifika students participated. Although such representation might reflect the demographics of such categories, a larger sample of such students could be appropriate in other circumstances. At UNSB, efforts to have a heterogeneous group of previously defined, Module II part-time student representatives in terms of years of study bore no fruit and this sub-group comprised only year 2 students. Nevertheless, further analysis of the data is required to determine for instance whether there are any similarities or differences between students' mode of study (particularly in Kenya) and between the year of study (e.g. $2^{\text {nd }}$ year $\&$ final year).

A third limitation relates to the implementation of the proposed ideas on how to overcome dilemmas associated with the critical root causes. This study was not able to, and did not test whether the implementation of proposed ideas could bring about the desired changes without 
creating other undesirable side effects. This is because further discussions were needed with the respective schools. Without the testing of proposed ideas and implementation, it might become difficult to persuade policy makers to support the full implementation of the suggestions. The testing of the implementation will perhaps form the next phase of a future study. Notwithstanding, the study fills a gap in understanding the goals of L\&T, the constraints that limit effective achievements of the goals, and the core causes of undesirable experiences of L\&T in HE institutions.

The fourth limitation relates to testability of the results. Because of limitation of time and the fact that this research was not designed as an action research, it was not possible to go back to participants to confirm their views about the goal(s), the CSF and NCs of their systems, and the root causes of the undesirable effects. Neither did this research allow participants to discuss the resolutions of dilemmas (here designed as ECs) nor the future reality under the proposed changes (FRT). As a result, the ECs and the FRTs are only illustrative.

\subsection{Future research}

As suggested elsewhere, more research opportunities exist that relate to the use of the TOC methodology in HE; the goal(s) of L\&T in HE institutions; to issues impacting on L\&T experiences; and to dilemmas associated with L\&T in HE institutions.

In relation to the use of TOC methodology in a wider range of the HE sector, more research opportunities are available. A larger research base could provide more opportunity to consider the efficacy of TOC. At the beginning of this research, the work of Nagarkatte and Oley (2010) on mathematics student attrition at Medgar Evers College, the City University of New York, was the major study situated in a HE institution using the TOC methodology. Through this study, improvements were made to curriculum content and process, tutorial services, assessment procedures, and in the use of technology. These improvements led to a remarkable increase in retention of students in the mathematics department. TOC has also been successfully applied in setting up an assurance of learning system at VBS, and has yielded positive results such as meeting the requirements for good practice of the Association to Advance Collegiate Schools of Business (AACSB). More importantly, the use of learning goals, learning objectives, and their corresponding rubrics have, where used, made the learning objectives of assignments clearer to VBS students (Mabin, 2014; Mabin \& Marshall, 2011). This thesis has not gone to the same practical level of resolving the dilemmas facing the two 
business schools involved in this study. Thus, future research could focus on developing TOC guidelines/plans for resolving the identified dilemmas to effect on-going improvement.

Regarding the goal(s) of L\&T in HE institutions, more research is needed not only in other business schools but also in other HE institutions. In order to guide HE institutions along different pathways in the process of continuous improvement, a clear understanding and agreement of the goals of the various systems within HE institutions is needed. Further study may clarify such goals.

The findings of this study indicate that there are many dilemmas facing business schools. They also indicate that further understanding is needed about the dilemmas facing the major stakeholders of business schools and HE institutions in general. The exposition of these dilemmas, and the development of subsequent proposals for their resolutions might help provide focus to wider ongoing improvement initiatives.

Finally, this research work has surfaced undesirable matters related to L\&T experiences. The purpose is not to 'whistle blow', or to put the participant schools in a negative light. Rather, this study attempts to give an accurate and truthful description of experiences of L\&T, in the hope that the results might provoke debate and critical re-thinking about those experiences, and how they may be improved.

\subsection{Personal reflection}

\section{Coming to NZ}

The decision to come to NZ was not easy to make. With a seven year old, a 15 year old teenager, and a husband, the decision was a tough one. But a time had come when I felt that I needed to do something new in my career. I had taught as a university lecturer for 10 years. Despite great student feedback on my teaching, I still felt that I was not delivering consistently excellent quality of teaching. Like an eagle, I knew I needed to renew my strength. This is how the story of an eagle unfolds:

The eagle has the longest life-span of its species. It can live up to 70 years. But to reach this age, the eagle must make a hard decision. In its 40's its long and flexible talons can no longer grab prey, which serves as food. Its long and sharp beak becomes bent. Its old-aged and heavy wings, due to their thick feathers, become stuck to its chest and make it difficult to fly. Then, the eagle is left with only two options: die or go through a painful process of change, which lasts 150 days. The process requires that the eagle fly to a mountaintop and sit on its nest. There the eagle knocks its beak against a rock until it plucks it out. After plucking it out, the eagle will wait for a new beak to grow back and then it will pluck out its talons. When its new talons grow back, the eagle starts plucking its old-aged feathers. And after five months, the eagle takes its famous flight of rebirth and lives for 30 more years (http://www.slideshare.net/targetseo/rebirth-of-the-eagle-photo-presentation). 
Whether fact or fiction, the story motivated me to take bold steps to leave my dear family and move to the farthest part of the world (relative to Kenya). But one most important thing that prompted my strong desire to come to $\mathrm{NZ}$ was the hope of getting a quality $\mathrm{PhD}$ with an international perspective of HE environments.

\section{The start of my PhD journey}

When I started my PhD journey in July 2012 at VBS, I was provided with the basic resources that I needed: a spacious office, a line up of postgraduate workshops and all sorts of learning support. Above all things, I got great supervisors. With all this support, I knew I was the driver of my $\mathrm{PhD}$ journey and that my own speed was a critical determinant of my finishing time.

$\mathrm{NZ}$, in general, offers great opportunities to learn about new cultures and integrate with nature. Victoria University of Wellington in particular offered me a different work place to learn new things. Running up and down to classes, getting to grips with Kiwi and other accents, workshops, participating in events, working with different groups and committees, all provided a stimulating life in NZ. And like any other $\mathrm{PhD}$ journey, it has been a cocktail of joys and tears.

\section{What have I learnt?}

One important thing that $\mathrm{PhD}$ has given me is the confidence to see through complexities. $\mathrm{My}$ interactions with different participants have helped me to understand complexity and to learn tolerance for ambiguity. The TOC methodological tools have taught me to find connectedness within complexity. The tools have also helped me to see the manageability of the complexity by focusing on a few key constraints. The confidence that I have found is to take time to explore complex things, focus attention on a few things that matter, explore possible solutions and the possible negative consequences of such solutions.

In relation to my research, I have learnt critical and valuable knowledge related to L\&T. I have interacted with TOC experts and I have learnt how to apply the TOC tools. Indeed, upon going back to teaching, I look forward to using TOC tools. I hope to start my classes with construction of a goal tree. This will perhaps to make explicit the goal we want to achieve as a class and what we need to have in order to achieve the goal. The reason I am very enthusiastic about using the TOC tools is because when I used the goal tree during my data collection, students enjoyed the sessions and indicated that the tool helped them to reflect on their learning goals. But it is not just using the tools in class; it is also about applying them to solve organisational 
problems. One important thing that I have learnt from my supervisor, Professor Vicky Mabin, who has also been my mentor throughout this process, is how she has supported her students (MBA especially) to learn and use the TOC tools to help solve organisational problems where those students work.

But not everyone might be receptive to TOC ideas, perhaps not even my colleagues! However, as George Berkeley put it, 'The same principles that at first view lead to scepticism, pursued to a certain point, bring men back to common sense'. The TOC is about common sense. But again, this common sense is very uncommon, as put more precisely by Professor Vicky Mabin in her inaugural lecture on $12^{\text {th }}$ November 2013, 'It's just common sense, right? So why is it so uncommon?' (https://www.youtube.com/watch?v=Req_BuwwABA). With the continued use of TOC logic, I can only hope that with time, people will see the common sense that comes with it.

\section{Back to class}

What will I change in my teaching? Previously, I taught with limited theoretical knowledge of teaching itself. Now that I have the knowledge will it make me a better teacher? Definitely, it will. One important change that I got from one of my participants and I want to embrace is: 'When students cannot learn the way we teach, we have to teach the way they learn'. In my view, recognising that learners of today are a lot different from my time as a 'learner in university' is important. Today's learners are diverse in many ways: some are practical, textual, visual, online etc. I also look at my role more as a facilitator and a 'guide on the side' rather than 'a sage on the stage'.

I now have a broad understanding of the complexity of learning and teaching contexts. My $\mathrm{PhD}$ has provided me with a different eye to view and understand the complexity. My stint on the VBS Faculty Board, and interactions with senior managers and lecturers in the two schools have given me valuable insights of management issues related to L\&T contexts. I believe that this broad knowledge that I have gained will help me to improve my delivery in class and make an impact in my students' lives. I also believe that I will make great contributions within the university community.

But I wonder...

Will the findings of this study convince people of the need to change L\&T systems? 


\subsection{Conclusion}

This chapter draws together the findings of the study, which offer a number of useful outcomes. Through the use of the TOC methodology, some important aspects of L\&T have been brought to the fore: understanding the goals of L\&T, the undesirable effects that impact on effective achievement of goal(s), and the critical root causes of the undesirable effects. This study points to specific factors where each of the two business schools studied could focus attention on, in order to improve experiences of L\&T. Furthermore, the study depicts what the future reality of the L\&T systems in the two schools could be, if the proposed ideas were implemented, although much input would be needed from each school to make feasible those future realities.

This thesis provides useful insights of the problems impacting on experiences of L\&T from the perspectives of three key stakeholders: students, lecturers and administrators. As such, it provides a better rounded perspective of the experiences of L\&T. Through the use of TOC logic tools, the study provides causal linkages of the problems impacting on experiences of L\&T, and offers verbatim explanations. To provide a clear and deep understanding of the problems impacting on experiences of L\&T, the study uses within-groups, within-case and cross-case analysis. This means that different views of each group of stakeholders are analysed separately and then brought together as one in each case. Thus, while the within-case analyses provide contextual understanding of the issues that impact on experiences of L\&T, the crosscase analyses provides an international dimension to the understanding. The contextual knowledge might perhaps be more significant for each separate school if each was treated as a standalone project. From an international perspective, this study sheds light on some of the global issues that impact on L\&T within the HE sector. It shows how these issues, though global in nature, can affect specific HEIs differently in different HE settings.

As I reflect on my thesis, the process of developing it has provided me with a very broad understanding of complexities of L\&T issues in HEIs. While I am happy that I have adequately addressed the research objectives of this study and satisfied my earlier curiosity for such knowledge, my strong belief is that true improvement of L\&T can only happen when university top managers (policy makers) step back, listen to and support what students, lecturers, and administrators are saying is impacting the quality of experiences of L\&T. Borrowing a leaf from the Ministry of Education, NZ, where two years ago, confidence was at a low ebb, but has turned around and achieved '2014 Justice Sector Award for Integrity and Trust', [an award that recognises agencies that demonstrate the highest standards of integrity, and a commitment 
to building trust with the people and communities they serve], Peter Hughes, the Secretary for Education, points out that '...we determined that schools would be more likely to accept the guidelines if their representatives could lead the design. We stepped back and let them get on with developing the guidelines themselves, moving ourselves into a supporting role' (IPANZ, 2015). Testimonies from the sector (education) indicate that there is improved communication, more interactions, increased levels of confidence, and signs that the Ministry is more open to new approaches (IPANZ, 2015). By the same token, there might be need for the senior management of the two business schools to work more closely with their teachers and students, in order to understand the unique L\&T challenges that impact on their day to day practices and then step back and allow them to design processes that are more effective.

Finally, this thesis has demonstrated an alternative methodological approach to the exploration of the quality of L\&T in HE. For example, it has developed related understanding of stakeholder perspectives of the quality of L\&T experiences. As such, this thesis has value not only to the HE fraternity/community, in terms of how quality can be improved, or how experiences of L\&T can be impacted, but also to the TOC community, in terms of affirming the efficacy of the TOC methodology and tools in non-traditional domains.

\section{DISCLAIMER}

The findings of this study relate to a subset of HE L\&T systems where the quality of L\&T experienced by students could be impacted by engagement with continuous improvement processes. As such, the findings do not portray, and are not meant to portray a wide-spread malaise in the quality of L\&T in these HE institutions. 


\section{References}

Abbott, A. (1998). The causal devolution. Sociological Methods \& Research. 27(2), 148-181.

Abdous, M. (2011). Towards a framework for business process reengineering in higher education. Journal of Higher Education Policy and Management, 33(4), 427-433. doi:10.1080/1360080X.2011.585741.

Abdullah, F. (2006). Measuring service quality in higher education: HEdPERF versus SERVPERF. Marketing Intelligence \& Planning, 24(1), 31-47. doi:10.1108/02634500610641543.

Abili, K., Thani, F. N., Mokhtarian, F., \& Rashidi, M. M. (2011). Assessing quality gap of university services. Asian Journal on Quality, 12(2), 167-175. doi:10.1108/15982681111158724.

Abouchedid, K., \& Nasser, R. (2002). Assuring quality service in higher education: registration and advising attitudes in a private university in Lebanon. Quality Assurance in Education, 10(4), 198-206. doi:10.1108/09684880210446866.

Ahmad, H., Francis, A., \& Zairi, M. (2007). Business process reengineering: critical success factors in higher education. Business Process Management Journal, 13(3), 451-469. doi:10.1108/14637150710752344.

Allen, D., \& Harrison, N. (1999). Re-engineering change in higher education. Retrieved August 27, 2012, from http://informationr.net/ir/4-3/paper56.

Altbach, P., G., Reisberg, L., \& Rumbley, L. E. (2009). Trends in global higher education: Tracking an academic revolution (pp. 1-278). Paris: UNESCO.

Australian Council for Educational Research (ACER). (2011). The AUSSE research briefings. Australasian Survey of Student Engagement, 12(September), 18.

Baker, S., Hansen, M., \& Johnson, K. (2013, April). Implementing and assessing high impact practices. Conference Proceedings. Learning Outcomes Assessment, Toronto.

Barasa, F., \& Misati, J. (2012). The role of the church in the development of education in Kenya: Expanding education through evangelization. International Journal of Current Research, 4(12), 97-102.

Barnard, A. (2010). Continuous improvement and auditing. In J. Cox \& J. Schleier (Eds.), Theory of constraints handbook (pp. 403-454). NY: New York: McGraw Hill.

Barr \& Tagg (2000). From teaching to learning - a new paradigm for undergraduate education. in DeZure, D. (Eds). Learning from change: Landmarks in teaching and learning in higher education from change magazine, 1969-1999. Stylus Publishing LLC.

Bayraktaroglu, G., \& Atrek, B. (2010). Testing the Superiority and Dimensionality of SERVQUAL vs. SERVPERF in Higher Education. Quality Management Journal, 17(1), 47-59.

Becket, N., \& Brookes, M. (2008). Quality management practice in higher education: What quality are we actually enhancing? Journal of Hospitality, Leisure, Sports \& Tourism Education, 7(1), 4054. doi:10.3794/johlste.71.174.

Bennett, S. (2004). Supporting collaborative project teams using computer-based technologies. In T. S. Roberts (Ed.), Online Collaborative Learning: Theory and practice. Covent Garden, London: Information Science Publishing. Retrieved from http://books.google.co.nz/books. 
Bennis, W., G., \& O’Toole, J. (2005). How business schools lost their way. Harvard Business Review, (May).

Berg, L. D., \& Roche, M. M. (1997). Market metaphors, neo-liberalism and the construction of academic landscapes in Aotearoa/New Zealand. Journal of Geography in Higher Education, 2l(2), 147-161. doi:10.1080/03098269708725421.

Biggs, J. (2001). The reflective institution: Assuring and enhancing the quality of teaching and learning. Higher Education, 41(3), 221-238. doi:10.1023/A:1004181331049.

Black, B., \& Stanley, N. (Eds.). (1998). Do distance students get value for their HECS dollar? In The Proceedings of the 7th Annual Teaching Learning Forum (pp. 39-43). The University of Western Australia: Centre for Staff Development.

Blackmore, J. (2014). Still hanging off the edge. In N. P. Stromquist \& K. Monkman (Eds.), Globalisation and Education: Integration and Contestation across Cultures (pp. 285-303). Lanham, MD: R\&L Education.

Bolton, A. (1995). A rose by any other name: TQM in higher education. Quality Assurance in Education, 3(2), 13-18. doi:10.1108/09684889510087809.

Bonwell, C. C., \& Eison, J. A. (1991). Active learning: Creating excitement in the classroom. ASHEERIC Higher Education Reports. Retrieved from http://eric.ed.gov/?id=ED336049.

Bower, M., \& Richards, D. (2006). Collaborative learning: Some possibilities and limitations for students and teachers. In Who's learning? Whose technology? (pp. 79-89). The University of Sydney. Retrieved from http://ascilite.org/conference/past-proceedings/.

Boyer, E. L. (1990). Scholarship reconsidered: Priorities of the professoriate. New York. NY. Carnegie Foundation

Brochado, A. (2009). Comparing alternative instruments to measure service quality in higher education. Quality Assurance in Education, 17(2), 174-190. doi:10.1108/09684880910951381.

Buchmann, C. (1999). The state and schooling in Kenya: Historical developments and current challenges. Africa Today, 46(1), 95-117. doi:10.1353/at.2003.0072.

Bulpitt, G. (2012). Leading the student experience: Super-convergence of organisation, structure and business processes (No. Series 3: Publication 5) (pp. 1-51). UK: Leadership Foundation for Higher Education. Retrieved from www.lfhe.ac.uk.

Burger, J. M., Webber, C. F., \& Klinck (Eds.). (2007). Intelligent leadership: Constructs for thinking educational leaders (Vol. 6). Dordrecht: Springer.

Buttle, F. (1996). SERVQUAL: review, critique, research agenda. European Journal of Marketing, 30(1), 8-32. doi:10.1108/03090569610105762.

Calvo-Mora, A., Leal, A., \& Roldán, J. L. (2006). Using enablers of the EFQM model to manage institutions of higher education. Quality Assurance in Education, 14(2), 99-122. doi:10.1108/09684880610662006.

Cardon, L. S. (2014, December). Diagnosing and treating millennial student disillusionment [Change: The Magazine for Higher Education]. Retrieved from http://www.changemag.org. 
Carrillat, F. A., Jaramillo, F., \& Mulki, J. P. (2007). The validity of the SERVQUAL and SERVPERF scales. International Journal of Service Industry Management, 18(5), 472-490. doi:10.1108/09564230710826250.

Chalmers, D. (2008). Teaching and learning quality indicators in Australian Universities. Paris: OECD.

Chalmers, D., \& Johnson, S. (2012). Quality assurance and accreditation in higher education. In I. Jung, C. Latchem, \& J. Herrington (Eds.), Quality Assurance and Accreditation in Distance Education: Models, Policies and Research. Oxford, England: Routledge.

Cheng, H., Trietsch, D., \& Balakrishnan. (2008). The theory of constraints in academia: Its evolution, influence, controversies, and lessons. Operations Management Education Review, 2, 97-114.

Chickering, A. W., \& Gamson, Z. F. (1999). Development and adaptations of the seven principles for good practice in undergraduate education. New Directions for Teaching and Learning, 1999(80), 75-81. doi:10.1002/tl.8006.

Clayton-Pedersen. (2005). Curricula designed to meet $21^{\text {st }}$ century expectations. In D. Oblinger, J. Oblinger, \& J. Lippincott (Eds.), Educating the Net Generation. Retrieved from http://digitalcommons.brockport.edu/bookshelf/272.

Coates, H. 2010. Development of the Australasian Survey of Student Engagement (AUSSE). Higher Education. 60 (1) 1-17.

Cohen, O. (2010). Daily management with TOC. In J. Cox \& J. Schleier (Eds.), Theory of constraints handbook (pp. 671-727). NY: New York: McGraw Hill.

Commission for University Education (2015). Retrieved on 31/03/15 from http://www.cue.or.ke.

Cooper, M. J., \& Loe, T. W. (2000). Using the theory of constraints' thinking process to improve problem solving skills in marketing. Journal of Marketing Education, 22(2), 137-146.

Cox, J., Blackstone, J. H. Jr \& Schleier, J. (2003). Managing operations: A focus on excellence. Vol. 1. Great Barrington, MA. North River Press Publishing Corporation.

Cox, J., Boyd, L., Sullivan, T., Reid, R., \& Cartier, B. (2012). TOCICO dictionary by Theory of Constraints International Certification Organisation, (TOCICO). Retrieved November 12, 2012, from http://www.tocico.org/dictionary.

Cox, J., Mabin, V., \& Davies, J. (2005). A case of personal productivity: Illustrating methodological developments in TOC. Human Systems Management, 24(1), 39-65.

Cox, J., \& Schleier, J. (Eds.). (2010). Theory of constraints handbook. New York, NY: McGraw-Hill.

Crawford, L. E. D., \& Shutler, P. (1999). Total quality management in education: problems and issues for the classroom teacher. International Journal of Educational Management, 13(2), 67-73. doi:10.1108/09513549910261122.

Creswell, J., W. (2007). Qualitative inquiry \& research design: Choosing among five approaches ( $2^{\text {nd }}$ ed.). Lincoln: Sage Publications Inc.

Cuthbert, P. F. (1996). Managing service quality in HE: Is SERVQUAL the answer? Part 1. Managing Service Quality, 6(2), 11-16. doi:10.1108/09604529610109701.

Danilo, S. (2002a). Using graphic organisers to improve the teaching of business statistics. Journal of Education for Business, 78(1), 33-37. 
Danilo, S. (2002b). Writing MIS mini- cases to enhance cooperative learning; A theory of constraints approach. Journal of Information Systems Education, 13(4), 351-356.

Darke, P., Shanks, G., \& Broadbent, M. (1998). Successfully completing case study research: combining rigour, relevance and pragmatism. Information Systems Journal, 8(4), 273-289. doi:10.1046/j.1365-2575.1998.00040.x.

Dart, B. C., Burnett, P. C., Purdie, N., Boulton-Lewis, G., Campbell, J., \& Smith, D. (2000). Students' conceptions of learning, the classroom environment, and approaches to learning. The Journal of Educational Research, 93(4), 262-270. doi:10.1080/00220670009598715..

Dave, H., \& Noel, B. (2003). Business graduate competencies: Employers' views on importance and performance. Asia-Pacific Journal of Cooperative Education, 16-22.

Davenport, T. H., \& Stoddard, D. B. (1994). Reengineering: Business change of mythic proportions? MIS Quarterly, 18(2), 121-127. doi:10.2307/249760.

Davies, J. (2001). The emergence of entrepreneurial cultures in European universities. Journal of the Program on Institutional Management in Higher Education, 3(2), 25-41.

Davies, J., Hides, M. T., \& Casey, S. (2001). Leadership in higher education. Total Quality Management, 12(7-8), 1025-1030. doi:10.1080/09544120120096197.

Davies, J., \& Mabin, V. (2009). Theory of constraints. Research Issues, Decision line (March), 9-15.

Davies, J., Mabin, V., \& Balderstone, S. J. (2005). The theory of constraints: a methodology apart?-a comparison with selected OR/MS methodologies. Omega, 33(6), 506-524. doi:10.1016/j.omega.2004.07.015.

Davis, H. C., \& Fill, K. (2007). Embedding blended learning in a university's teaching culture: Experiences and reflections. British Journal of Educational Technology, 38(5), 817-828. doi:10.1111/j.1467-8535.2007.00756.x.

Denyer, D., Tranfield, D., \& van Aken, J. E. van. (2008). Developing design propositions through research synthesis. Organisation Studies, 29(3), 393-413. doi:10.1177/0170840607088020.

Denzin, N. K., \& Lincoln, Y. S. (Eds.). (2011). The Sage handbook of qualitative research (4 ${ }^{\text {th }}$ ed.). Thousand Oak, CA: Sage Publishing Inc.

Dettmer, H. W. (2007). The logical thinking process. Milwaukee, Wisconsin: American Society for Quality; Quality Press.

Dettmer, H. W. (2011). Our goal is...What is our goal? Goal Systems International. http://www.goalsys.com/books/documents/WhatisOurGoal-v5.pdf.

De Vita, G., \& Case, P. (2003). Rethinking the internationalisation agenda in UK higher education. Journal of Further and Higher Education, 27(4), 383-398.

Devlin, M. (2006). Challenging accepted wisdom about the place of conception of teaching in university teaching improvement. International Journal of Teaching and Learning in Higher Education, 18(2). Retrieved from www.isetl.org/ijtlhe.

Dill, D. D. (2000). Capacity building as an instrument of institutional reform: Improving the quality of higher education through academic audits in the UK, New Zealand, Sweden, and Hong Kong. 
Journal of Comparative Policy Analysis: Research and Practice, 2(2), 211-234. doi:10.1080/13876980008412643.

Dill, D. D., Massy, W., Williams, P., \& Cook, C. (1996). Accreditation and academic quality assurance: Can we get there from here? The Magazine of Higher Education, 28(5), 17-24.

Dougherty, K. D., \& Andercheck, B. (2014). Using Facebook to engage learners in a large introductory course. Teaching Sociology, 42(2), 95-104. doi:10.1177/0092055X14521022.

Douglas, J., McClelland, R., \& Davies, J. (2008). The development of a conceptual model of student satisfaction with their experience in higher education. Quality Assurance in Education, 16(1), 19-35. doi:10.1108/09684880810848396.

Economic Survey Report (2014) Retrieved June 28, 2014, from http://www.scribd.com/doc/220912290/Economic-Survey-Report-2014-pdf.

EFQM. (2012). An overview of the EFQM Excellence Model. EFQM. Retrieved from www.efqm.org

Eisenhardt, K. (1989). Building theories from case study research. Academy of Management, 14(4), $532-550$.

Elmuti, D., Kathawala, Y., \& Manippallil, M. (1996). Are total quality management program in higher education worth the effort? International Journal of Quality \& Reliability Management, 13(6), 29-44. doi:10.1108/02656719610124244.

ENQA. (2003). Quality procedures in European higher education (The Danish Evaluation Institute No. ENQA Occasional Papers 5). Helsinki, Finland.

Ernst \& Young. (2012). University of the future: A thousand year old industry on the cusp of profound change (pp. 1-31). Adelaide: Ernst \& Young. Retrieved from http://www.ey.com/Publication/vwLUAssets/University_of_the_future/\$FILE/University_of_ the_future_2012.pdf.

Exeter, D. J., Ameratunga, S., Ratima, M., Morton, S., Dickson, M., Hsu, D., \& Jackson, R. (2010). Student engagement in very large classes: The teachers' perspective. Studies in Higher Education, 35(7), 761-775. doi:10.1080/03075070903545058.

Fedurko, J. (2013). Through cloud to solutions: Working with UDEs and UDE clouds. Tallinn, Estonia: TOC Strategic Solutions, Ltd.

Feiertag, J., \& Berge, Z. L. (2008). Training generation N: How educators should approach the Net Generation. Education + Training, 50(6), 457-464. doi:10.1108/00400910810901782.

Fernando, D., \& Beatrice, A. (2011). Business schools and resources constraints: A task for deans or magicians? Research in Higher Education Journal, 13. Retrieved from www.aabri.com/rhej.html.

Fielden, K., \& Malcolm, P. (2005). Aligning academic activities: Implications for teaching and research in a New Zealand Institute of Technology. Systemic Practice and Action Research, 18(3), 275301.

Ford, J. B., Joseph, M., \& Joseph, B. (1999). Importance-performance analysis as a strategic tool for service marketers: the case of service quality perceptions of business students in New Zealand and the USA. Journal of Services Marketing, 13(2), 171-186. doi:10.1108/08876049910266068. 
Freeman, S., Eddy, S. L., McDonough, M., Smith, M. K., Okoroafor, N., Jordt, H., \& Wenderoth, M. P. (2014). Active learning increases student performance in science, engineering, and mathematics. Proceedings of the National Academy of Sciences, 201319030. doi:10.1073/pnas.1319030111.

Gamage, D. T., Suwanabroma, J., Ueyama, T., Hada, S., \& Sekikawa, E. (2008). The impact of quality assurance measures on student services at the Japanese and Thai private universities. Quality Assurance in Education, 16(2), 181-198. doi:10.1108/09684880810868457.

Garrison, R. H., Noreen, E. W., \& Brewer, P. C. (2012). Managerial accounting (14 ${ }^{\text {th }}$ ed.). New York, NY: McGraw- Hill Irwin.

Gedera, D. (2014). Tool mediation and learner engagement: An activity theory perspective. In Rhetoric \& Reality: Critical Perspectives on Educational Technology (pp. 1-7). Dunedin: Ascilite. Retrieved from http://ascilite.org/conferences/dunedin2014.

Gibbs, G. (2010). Dimensions of quality (pp. 1-60). The Higher Education Academy. Retrieved from www.heacademy.ac.uk.

Gill, R. (2011). Theory and practice of leadership (2nd ed.). London: Sage Publications.

Goldratt-Ashlag, E. (2010). The layers of resistance: the buy-in process according to TOC. In J. Cox \& J. Schleier (Eds.), Theory of constraints handbook (pp. 571-585). NY: New York: McGraw Hill.

Goldratt, E. M. (2010). Introduction to TOC-My perspective. In J. Cox \& J. Schleier (Eds.), Theory of constraints handbook (pp. 3-9). NY: New York: McGraw Hill.

Goldratt, E., \& Cox, J. (1992). The goal : A process of ongoing improvement. Great Barrington, MA: North River Press.

Goldratt, E. M. (1990). What is this thing called theory of constraints and how should it be implemented?. Croton-on-Hudson, NY.: North River Press.

Goldratt, E. M., \& Fox, R. E. (1986). The race. Croton-on-Hudson, NY: North River Press.

Goldratt, R., \& Weiss, N. (2005). Significant enhancement of academic achievement through application of the theory of constraints (TOC). Human Systems Management, 24(1), 13-19.

Greene, F. \& Loughridge, B. (1996). Investigating the management information needs of academic heads of departments: a critical success factors approach. Information Research, 1(3) Available at:http://informationR.net/ir/1-3/papers8.html.

Guba E. \& Lincoln Y. (1982) Epistemological and methodological bases of naturalistic inquiry. ECTJ, 30 (4) 233-252. ISSN 0148-5806.

Guba, E. \& Lincoln, Y. (1994). Competing paradigms in qualitative research. In N.K. Denzin \& Y.S. Lincoln (Eds.). Handbook of qualitative research (pp. 105-117). Thousand Oaks, CA: Sage

Harasim, L. (2012). Learning theory and online technologies. New York, NY: Routledge.

Harvey, L., \& Green, D. (1993). Defining quality. Assessment \& Evaluation in Higher Education, 18(1), 9-34. doi:10.1080/0260293930180102. 
Harvey, L., \& Newton, J. (2004). Transforming quality evaluation. Quality in Higher Education, 10(2), 149-165. doi:10.1080/1353832042000230635.

Hattie, J. (2003). Teachers make a difference: What is the research evidence? Professional Learning and Leadership Development, NSW DET.

Hattie, J. (2009). Visible learning: a synthesis of over 800 meta-analyses relating to achievement. New York, NY: Routledge.

Hattie, J., \& Marsh, H. W. (1996). The relationship between research and teaching: A meta-analysis. Review of Educational Research, 66, 507-542. doi:10.3102/00346543066004507.

Hawawini, G. (2005). The future of business schools. INSEAD. Retrieved from http://mpra.ub.unimuenchen.de/44888/7/MPRA_paper_44888.pdf.

Healey, M. (2000). Developing the scholarship of teaching in higher education: A discipline-based approach. Higher Education Research \& Development, 19(2), 169-189. doi:10.1080/072943600445637.

Healey, M., \& Jenkins, A. (2006). Strengthening the teaching-research linkage in undergraduate courses and programs. New Directions for Teaching and Learning, 2006(107), 43-53. doi:10.1002/tl.244.

Hemer, S. R. (2014). Finding time for quality teaching: An ethnographic study of academic workloads in the social sciences and their impact on teaching practices. Higher Education Research \&amp; Development, 33(3), 483-495. doi:10.1080/07294360.2013.841647.

Henard, F., \& Leprince-Ringuet, S. (2008). The path to quality teaching in higher education. OECD. Retrieved from www.oecd.org.

Hides, M. T., Davies, J., \& Jackson, S. (2004). Implementation of EFQM excellence model selfassessment in the UK higher education sector - lessons learned from other sectors. The TQM Magazine, 16(3), 194-201. doi:10.1108/09544780410532936.

Hitt, M. A. (1998). 1997 Presidential Address: Twenty-First-Century Organisations: Business Firms, Business Schools, and the Academy. The Academy of Management Review, 23(2), 218-224. doi:10.2307/259371.

Houston, D. (2007). TQM and higher education: A critical systems perspective on fitness for purpose. Quality in Higher Education, 13(1), 3-17. doi:10.1080/13538320701272672.

IPANZ. (2015). Leading by backing others to win. Journal of the Institute of Public Administration, New Zealand, 38(1), 15-17.

Jenkins, A. (2004). A guide to the research evidence on teaching-research relations. The Higher Education Academy. Retrieved from www.heacademy.ac.uk.

Johnston, B., \& Watson, A. (2004). Participation, reflection and integration for business and lifelong learning. Journal of Workplace Learning, 16(1/2), 53-62. doi:10.1108/13665620410521512.

Jongbloed, B., \& Vossensteyn, H. (2001). Keeping up performances: An international survey of performance-based funding in higher education. Journal of Higher Education Policy and Management, 23(2), 127-145. 
Kandlbinder, P., \& Peseta, T. (Eds.). (2011). Higher education research and development anthology. Milperra, NSW: HERDSA. Retrieved from www.herdsa.org.au.

Kaplan, R., S., \& Norton, D., P. (2001). Transforming the balanced scorecard from performance measurement to strategic management: Part I. American Accounting Association, Accounting Horizons, 15(1), 87-104.

Keith, T., Michael, P., \& Fiona, W. (1999). Relations between teachers' approaches to teaching and students' approaches to learning. Higher Education, 37(1), 57-70.

Kelly-Weekes, R. (2012). Thinking critically about conflicts: Educators' perception of the cloud cognitive process. Virtual Conference, Saginaw Valley State University. Retrieved from www.TOCforEducation.

Kenya National Bureau of Statistics (2012). Retrieved on 15/03/15 from www.mfa.go.ke

Kimani, S., Mabin, V., \& Davies, J. (2014a). Exploring the impact of undesirable student and staff experiences on the performance of a business school in Kenya. In International conference on teaching and learning in higher education. Singapore: National University of Singapore. Retrieved from http://www.cdtl.nus.edu.sg/tlhe/tlhe2014/abstracts/kimanisw.pdf.

Kimani, S., Mabin, V., \& Davies, J. (2014b). Understanding the causes of undesirable experiences of teaching in a business school: The theory of constraints thinking processes (TOC-TP) approach. ICERI2014 Proceedings, 3160-3170.

Kimani, S., Mabin, V., \& Davies, J. (2014c). Using the Theory of Constraints-Thinking Processes to explore business school students' learning experiences. Proceedings of the 48th Annual Conference of the ORSNZ (Joint NZSA+ORSNZ Conference) 23-26 November, 2014. Wellington, New Zealand. (orsnz.org.nz/conf48).

Kimani, S., Mabin, V., \& Davies, J. (2015). Exploring business school students' learning experiences - A TOC systems-based approach. In J. Bell, (Ed.), Proceedings of the 44th Annual Meeting of Western Decision Sciences Institute (pp. 24201 - 24208). Maui, USA: Western Decision Sciences Institute.

Kimani, S. W., Kagira, E. K., \& Kendi, L. (2011). Comparative analysis of business students' perceptions of service quality offered in Kenyan universities. International Journal of Business Administration, 2(1). doi:10.5430/ijba.v2n1p98.

Kim, S., Mabin, V., \& Davies, J. (2008). The theory of constraints thinking processes: Retrospect and prospect. International Journal of Operations \& Production Management, 28(2), 155-184. doi:10.1108/01443570810846883.

Kis, V. (2005). Quality assurance in tertiary education: current practices in OECD Countries and a literature review on potential effects (pp. 1-47). Retrieved from www.oecd.org/edu/tertiary/review.

Knight, P. T., \& Trowler, P. R. (2000). Department-level cultures and the improvement of learning and teaching. Studies in Higher Education, 25(1), 69-83. doi:10.1080/030750700116028.

Koch, J. (2003).TQM: why is its impact in higher education so small? The TQM Magazine. (5) $325-333$.

Koch, J., \& Fisher, J. (1998). Higher education and total quality management. Total Quality Management, 9(8), 659-668. doi:10.1080/0954412988136. 
Koehler, M., \& Mishra, P. (2009). What is technological pedagogical content knowledge? Contemporary Issues in Technology and Teacher Education, 9(1), 60-70.

Kohn, A. (1999). Punished by rewards: the trouble with gold stars, incentive plans, A's, praise, and other bribes. New York, NY: Houghton Mifflin Company.

Krause, K.-L. (2012). Addressing the wicked problem of quality in higher education: theoretical approaches and implications. Higher Education Research \& Development, 31(3), 285-297. doi:10.1080/07294360.2011.634381.

Kulski, M., \& Groombridge, B. (2004). Aligning teaching quality indicators with university reward mechanisms. Tertiary Education and Management, 10(1), 45-59.

Lattuca, L. R., \& Stark, J. S. (1994). Will disciplinary perspectives impede curricular reform? The Journal of Higher Education, 65(4), 401-426. doi:10.2307/2943853.

Lawrence, S., \& Sharma, U. (2002). Commodification of education and academic labour-Using the balanced scorecard in a University Setting. Critical Perspectives on Accounting, 13(5-6), 661677. doi:10.1006/cpac.2002.0562.

LEAP. (2015). High-impact educational practices [organisation]. Retrieved January 16, 2015, from https://www.aacu.org/leap.

Lea, S., \& Callaghan, L. (2008). Lecturers on teaching within the "supercomplexity" of Higher Education. Higher Education, 55(2), 171-187. doi:http://dx.doi.org/10.1007/s10734-0069041-5.

Lea, S., Stephenson, D. \& Troy J. (2003) Higher Education Students' Attitudes to Studentcentred Learning: Beyond 'educational bulimia'? Studies in Higher Education, 28:3, 321-334, DOI: 10.1080/03075070309293

Lim, D. (1999). Quality assurance in higher education in developing countries. Assessment and Evaluation in Higher Education, 24(4), 379-390.

Lizzio, A., Wilson, K., \& Simons, R. (2002). University students' perceptions of the learning environment and academic outcomes: Implications for theory and practice. Studies in Higher Education, 27(1), 27-52. doi:10.1080/03075070120099359.

Lovelock, C. H., \& Wirtz, J. (2007). Services marketing: people, technology, strategy (6th ed.). Upper Saddle River, NJ: Pearson/Prentice Hall.

Lucheli, I. (2012, December 25). ERB accused of failing to honour court order. Standard Digital News. Retrieved from http://standardmedia.co.ke.

Lundquist, R. (1997). Quality systems and ISO 9000 in higher education. Assessment \& Evaluation in Higher Education, 22(2), 159-172. doi:10.1080/0260293970220205.

Mabin, V. (2014). Using systems thinking tools to guide the establishment of an "assurance of learning" system. In 7th International Conference of Education, Research and Innovation. Seville, Spain: IATED. Retrieved from http://iated.org/iceri/publications.

Mabin, V., \& Balderstone, S. (2000). The world of the theory of constraints. Boca Raton, FL: CRC Press LLC. 
Mabin, V., \& Balderstone, S. J. (2003). The performance of the theory of constraints methodology: Analysis and discussion of successful TOC applications. International Journal of Operations \& Production Management, 23(6), 568-595. doi:10.1108/01443570310476636.

Mabin, V., \& Davies, J. (2010). The TOC thinking processes: Their nature and use: Reflections and consolidation. In J. Cox \& J. Schleier (Eds.), Theory of constraints handbook (pp. 631-669). NY: New York: McGraw Hill.

Mabin, V., Davies, J., \& Cox, J. (2006). Using the theory of constraints thinking processes to complement system dynamics' causal loop diagrams in developing fundamental solutions. International Transactions in Operational Research, 13(1), 33-57. doi:10.1111/j.14753995.2006.00532.x.

Mabin, V., Davies, J., \& Kim, S. (2009). Rethinking tradeoffs and OR/MS methodology. The Journal of the Operational Research Society, 60(10), 1384-1395. doi:http://dx.doi.org/10.1057/jors.2008.90.

Mabin, V., Forgeson, S., \& Green, L. (2001). Harnessing resistance: Using the theory of constraints to assist change management. Journal of European Industrial Training, 25(2/3/4), 168-191.

Mabin, V. J. (2010). Eating the elephant! Using the theory of constraints for assurance of learning. In Proceedings of the 41st Annual Meeting of the Decision Sciences Institute. San Diego. Retrieved from http://www.victoria.ac.nz/vbs/teaching.

Mabin, V., \& Marshall, S. (2011). Beyond Assessment: Assuring Student Learning in Higher Education. In Proceedings of the Symposium on Assessment and Learner Outcomes,. Victoria University of Wellington. Retrieved from www.victoria.ac.nz/vbs.

Maglio, P., Kieliszewski, C., \& Spohrer (Eds.). (2010). Handbook of service science. New York, NY: Springer. Retrieved from www.springer.com.

Mahoney, J. (2008). Toward a unified theory of causality. Comparative Political Studies. doi:10.1177/0010414007313115.

Mahoney, J., \& Goertz, G. (2006). A tale of two cultures: Contrasting quantitative and qualitative research. Political Analysis, 14(3), 227-249.

Marginson, S. (2006). Dynamics of national and global competition in higher education. Higher Education, 52(1), 1-39. doi:10.1007/s10734-004-7649-x.

Martens, E., \& Prosser, M. (1998). What constitutes high quality teaching and learning and how to assure it. Quality Assurance in Education, 6(1), 28-36.

Mason, M. (2010). Sample size and saturation in PhD studies using qualitative interviews. Forum: Qualitative Social Research, 11(3).

Maxwell, J. A. (2004). Causal explanation, qualitative research, and scientific inquiry in education. Educational Researcher, 33(2), 3-11. doi:10.3102/0013189X033002003.

McCuen@aacu.org. (2014, June 24). High-Impact educational practices [Text]. Retrieved January 16, 2015, from https://www.aacu.org/leap/hips.

McLafferty, I. (2004). Focus group interviews as a data collecting strategy. Methodological issues in nursing research. Blackwell Publishing Ltd. Journal of Advanced Nursing, 48(2), 187-194 
Mehralizadeh, Y., \& Safaeemoghaddam, M. (2010). The applicability of quality management systems and models to higher education: A new perspective. TQM Journal, 22(2), 175-187. doi:http://dx.doi.org/10.1108/17542731011024282.

Middleton, S. (2009). Becoming PBRF-able: Research assessment and education in New Zealand. University of Waikato Research Commons. Retrieved from http://researchcommons.waikato.ac.nz/handle/10289/2133.

Mok, K. H. (2000). Impact of globalization: A study of quality assurance systems of higher education in Hong Kong and Singapore. Comparative Education Review, 44(2), 148-174.

Nagarkatte, U., \& Oley, N. (2010). Theory of constraints (TOC) and thinking process (TP) tools in academia. Medgar Evers College, CUNY. Retrieved from www.tocforcollege.com.

Nair, M. (2004). Essentials of balanced scorecard. Hoboken, NJ: John Wiley \& Sons.

Ndirangu, M., \& Udoto, M. (2011). Quality of learning facilities and learning environment: challenges for teaching and learning in Kenya's public universities. Quality Assurance in Education, 19(3), 208-223. doi:10.1108/09684881111158036.

Neumann, R., \& Becher, T. (2002). Teaching and learning in their disciplinary contexts: A conceptual analysis. Studies in Higher Education, 27(4), 405-417. doi:10.1080/0307507022000011525.

Nganga, G. (2011, July 8). Kenya: Professional bodies reject degreees. University Worldnews. Retrieved from http://www.universityworldnews.com.

Nganga, G., \& Kigotho, W. (2011, July 18). Kenyan engineering degrees rejected. Research. Retrieved from http://researchresearch.com.

Ngigi, G. (2011, August 28). Graduates to take extra courses in degree row. Business Daily. Retrieved from http://www.businessdailyafrica.com.

NSSE. (2006). Engaged learning: Fostering success for all students (Annual Report). Bloomington: Centre for Postsecondary research, Indiana University Bloomington.

Oliver P., Marwell, G. \& Teixeira, R. (1985) A Theory of the Critical Mass. interdependence, group heterogeneity, and the production of collective action. American Journal of Sociology. 91(3) $522-556$.

Osseo-Asare, A. E., \& Longbottom, D. (2002). The need for education and training in the use of the EFQM model for quality management in UK higher education institutions. Quality Assurance in Education, 10(1), 26-36. doi:10.1108/09684880210416085.

Owlia, M. S., \& Aspinwall, E. M. (1996). A framework for the dimensions of quality in higher education. Quality Assurance in Education, 4(2), 12-20. doi:10.1108/09684889610116012.

Owlia, M. S., \& Aspinwall, E. M. (1997). TQM in higher education. International Journal of Quality \& Reliability Management, 14(5), 527-543.

Owlia, M. S., \& Aspinwall, E. M. (1998). A framework for measuring quality in engineering education. Total Quality Management, 9(6), 501-518. doi:10.1080/0954412988433.

Oyelaran-Oyeyinka, B., \& Nyaki, C., A. (2004). Internet access in Africa: Empirical evidence from Kenya and Nigeria. Telematics and Informatics, 21(1), 67-81. doi:10.1016/S07365853(03)00023-6. 
Pannirselvam, G. P., \& Ferguson, L. A. (2001). A study of the relationships between the Baldrige categories. International Journal of Quality \& Reliability Management, 18(1), 14-37. doi:10.1108/02656710110364468.

Parasuraman, A., Zeithaml, V. A., \& Berry, L. L. (1985). A conceptual model of service quality and its implications for future research. Journal of Marketing, 49(4), 41-50. doi:10.2307/1251430.

Parasuraman, A., Zeithaml, V. A., \& Berry, L. L. (1994). Reassessment of expectations as a comparison standard in measuring service quality: Implications for further research. Journal of Marketing, 58(1), 111-124. doi:10.2307/1252255.

Patton, M. Q. (1999). Enhancing the quality and credibility of qualitative analysis. Health Services Research, 34(5), 1189-1208.

Pongsart, G. (2005). Postgraduate students' constraints in doing a masters degree thesis (Masters Thesis). Wellington: Victoria University of Wellington.

Pongsart, G. (2015). Theory of constraints (TOC) and Appreciative inquiry (AI): A comparative study of their effectiveness inimproving master's thesis students' performance. ( $\mathrm{PhD}$ Thesis). Wellington: Victoria University of Wellington.

Powell, T. C. (1995). Total quality management as competitive advantage: A review and empirical study. Strategic Management Journal, 16(1), 15-37. doi:10.1002/smj.4250160105.

Prince, M. J., Felder, R. M., \& Brent, R. (2007). Does faculty research improve undergraduate teaching? An analysis of existing and potential synergies. Journal of Engineering Education, 96(4), $283-$ 294. doi:10.1002/j.2168-9830.2007.tb00939.x.

Prosser, M., \& Trigwell, K. (1999). Understanding Learning And Teaching: The Experience in Higher Education. Buckingham: The Society for Research into Higher Education \& Open University Press.

Prosser, M., \& Trigwell, K. (2014). Qualitative variation in approaches to university teaching and learning in large first-year classes. Higher Education, 67(6), 783-795. doi:10.1007/s10734013-9690-0.

Rae, D. (2007). Connecting enterprise and graduate employability: Challenges to the higher education culture and curriculum? Education + Training, 49(8/9), 605-619. doi:10.1108/00400910710834049.

Ramsden, P. (1998). Managing the effective university. Higher Education Research \& Development, 17(3), 347-370.

Ramsden, P., \& Martin, E. (1996). Recognition of good university teaching: Policies from an Australian study. Studies in Higheer Education, 21(3), 299-315.

Rao, A., Carr, L., Dampolena, 1, Kopp, R., Martin, J., Rafii, F., \& Schlesinger, P. (1996). Total quality management: A cross-functional perspective. New York, NY: John Wiley \& Sons.

Reeves, S., \& Freeth, D. (2006). Re-examining the evaluation of interprofessional education for community mental health teams with a different lens: understanding presage, process and product factors. Journal of Psychiatric and Mental Health Nursing, 13(6), 765-770. doi:10.1111/j.1365-2850.2006.01032.x. 
Retna, K., Chong, E., \& Cavana, R., Y. (2009). Tutors and tutorials: Students' perception in a New Zealand University. Journal of Higher Education Policy and Management, 31(3), 251-260.

Richardson, J. (2005). Students' approaches to learning and teachers' approaches to teaching in higher education. Education Psychology, 25(6), 673-680.

Ricketts, J. A. (2008). Reaching the goal: How managers improve a service business using Goldratt's theory of constraints. Upper Saddle River, NJ: IBM Press, Pearson Plc. Retrieved from www.ibmpressbooks.com.

Rigotti, S., \& Pitt, L. (1992). SERVQUAL as a measuring instrument for service provider gaps in business schools. Management Research News, 15(3), 9-17. doi:10.1108/eb028197.

Roberts, P. (1999). The future of the university: Reflections from New Zealand. International Review of Education, 45(1), 65-85.

Rockart, J. (1979). Chief executives define their own data needs. New systems approach, based on the identification of 'critical success factors' supports attainment of organisational goals. HBR March-April 1979, 81-93.

Rolfe, G. (2006). Validity, trustworthiness and rigour: Quality and the idea of qualitative research. Journal of Advanced Nursing, 53(3), 304-310. doi:10.1111/j.1365-2648.2006.03727.x.

Ronen, B. (2005). Guest editorial: Special issue on the theory of constraints-practice and research. Human Systems Management, 24(1), 1-2.

Ronen, B., \& Pass, S. (2008). Focused Operations management: Achieving more with existing resources. New Jersey, NJ: John Wiley \& Sons, Inc.

Ross, J. E. (1993). Total quality management: Text, cases, and readings. Boca Raton, FL: St. Lucie Press.

Rowland, S. (2002). Overcoming fragmentation in professional life: The challenge for academic development. Higher Education Quarterly, 56(1), 52-64. doi:10.1111/1468-2273.00202.

Ruben, B. D. (2007). Higher education assessment: Linking accreditation standards and the Malcolm Baldrige criteria. New Directions for Higher Education, 2007(137), 59-83. doi:10.1002/he.246.

Ruben, B. D., Russ, T., Smulowitz, S. M., \& Connaughton, S. L. (2007). Evaluating the impact of organisational self-assessment in higher education: The Malcolm Baldrige/Excellence in Higher Education framework. Leadership \& Organisation Development Journal, 28(3), 230250. doi:10.1108/01437730710739657.

Sahney, S., Banwet, D., \& Karunes, S. (2004). Conceptualizing total quality management in higher education. The TQM Magazine, 16(2), 145-159. doi:10.1108/09544780410523044.

Saunders, M., Lewis, P., \& Thornhill, A. (2007). Research methods for business students (4 ${ }^{\text {th }}$ ed.). London: Prentice Hall.

Sayers, N. (2013). Internationalising the curriculum: Design delivery and depth (No. Series 4: Publication 1) (pp. 1-19). UK: Leadership Foundation for Higher Education. Retrieved from www.lfhe.ac.uk.

Scheinkopf, J. (1999). Thinking for a change. Boca Raton, FL: CRC Press LLC. 
Schott, C., \& Sutherland, K. A. (2009). Engaging tourism students through multimedia teaching and active learning. Journal of Teaching in Travel \& Tourism, 8(4), 351-371. doi:10.1080/15313220903047987.

Scott, D. J. (2009). A closer look at completion in higher education in New Zealand. Journal of Higher Education Policy and Management, 31(2), 101-108. doi:10.1080/13600800902825819.

Seddon, J. (2008). Systems thinking in the public sector. Station Yard: Axminster: Triarchy Press.

Senge, P.M. (1990). The Fifth Discipline. New York: Doubleday/Currency.

Silverman, D. (Ed.). (2004). Qualitative Research: Theory, methods and practice ( $2^{\text {nd }}$ ed.). London: Sage Publications.

Simon, J. (1994). The historical perspectives on schooling. In (E) Coxon, (K.) Jenkins, (J.) Marshall, \& L. Massey (Eds.), The politics of Learning and Teaching in Aotearoa- New Zealand (pp. 3781). Palmerston North: Dunmore Press.

Skiba, D., \& Barton, A. (2006). Adapting your teaching to accommodate the Net-generation of learners. The Online Journal of Isssues in Nursing, 11(2). doi:10.3912/ojin.vol11no02Man04.

Smit, D. (1994). Some difficulties with collaborative learning. In Composition Theory for the Postmodern Classroom. Albany, NY: State University of New York Press.

Srikanthan, G., \& Dalrymple, J. (2003). Developing alternative perspectives for quality in higher education. International Journal of Educational Management, 17(3), 126-136. doi:10.1108/09513540310467804.

Stewart, A. C., Houghton, S. M., \& Rogers, P. R. (2012). Instructional design, active learning, and student performance using a trading room to teach strategy. Journal of Management Education, 36(6), 753-776. doi:10.1177/1052562912456295.

Tam, M. (2001). Measuring quality and performance in higher education. Quality in Higher Education, 7(1), 47-54. doi:10.1080/13538320120045076.

Teferra, D., \& Altbach, P., G. (2004). African higher education: Challenges for the 21st century. Higher Education, 47(1), 21-50. doi:10.1023/B:HIGH.0000009822.49980.30.

TheCentre. (2002). University organisation, governance and competitiveness (Annual Report). TheCentre. http://mup.asu.edu/UniversityOrganisation.pdf.

The Higher Education Academy. (2014). Framework for partnership in learning and teaching in higher education. https://www.heacademy.ac.uk

Trigwell, K., \& Prosser, M. (1991). Improving the quality of student learning: The influence of learning context and student approaches to learning on learning outcomes. Higher Education, 22(3), 251-266. doi:10.2307/3447175.

Trow, M. (1997). The development of information technology in American higher education. Daedalus, 126(4), 293-314. doi:10.2307/20027469.

Trow, M. (2000). From mass higher education to universal access: The American advantage. Minerva, 37(4), 303-328. doi:10.1023/A:1004708520977. 
Tsinidou, M., Gerogiannis, V., \& Fitsilis, P. (2010). Evaluation of the factors that determine quality in higher education: an empirical study. Quality Assurance in Education, 18(3), 227-244. doi:10.1108/09684881011058669.

UK trade \& investment (2015). Guidance on exporting to Kenya. Retrieved on 2015/03/05/ from (https://www.gov.uk) .

University of Nairobi (2015, node 767). Historical background of the Academic Division. Retrieved on 31/03/15 from www.uonbi.ac.ke/node/767

University of Nairobi (2015, node 977) Information to New Students and the Joining Instructions 2013/2014 Academic Year. Retrieved from 31/03/15 from http://www.uonbi.ac.ke/node/977

Van Gelder, A., \& Urban, B. (2010). The theory of constraints as applied to solid waste management (SWM) in four cities in Africa- A case study. Retrieved from www.tocico.org.

Vavrus, F., Thomas, M., \& Bartlett, L. (2011). Ensuring quality by attending to enquiry: Learnercentered pedagogy in Sub-Saharan Africa. UNESCO-IICBA. http://unesdoc.unesco.org/images/0021/002160/216063e.pdf.

Venkatraman, S. (2007). A framework for implementing TQM in higher education programs, 15(1), 92-112. doi:10.1108/09684880710723052.

Vesper, K. H., \& Gartner, W. B. (1997). Measuring progress in entrepreneurship education. Journal of Business Venturing, 12(5), 403-421. doi:10.1016/S0883-9026(97)00009-8.

Waswa, F., \& Katana, G. (2008). Academic staff perspectives on operating beyond industrial actions for sustainable quality assurance in public universities in Kenya. International Journal of Environment, Workplace and Employment, 4(1), 45-58. doi:10.1504/IJEWE.2008.022257.

Watson, K. J., Blackstone, J. H., \& Gardiner, S. C. (2007). The evolution of a management philosophy: The theory of constraints. Journal of Operations Management, 25, 387-402.

Weigert, K. M. (1998). Academic service learning: Its meaning and relevance. New Directions for Teaching and Learning, 1998(73), 3-10. doi:10.1002/tl.7301.

Willis, D. (2009). Disciplines, institutions and the performance-based research fund: The scholarship of teaching and learning from a New Zealand Perspective. International Journal for the Scholarship of Teaching and Learning, 3(2). Retrieved from http://digitalcommons.georgiasouthern.edu/ij-sotl/vol3/iss2/7.

Winn, B., \& Cameron, K. (1998). Organisational quality: an examination of the Malcolm Baldrige National Quality Framework. Research in Higher Education, 39(5), 491-512.

Winter, R., Taylor, T., \& Sarros, J. (2000). Trouble at mill: Quality of academic worklife issues within a comprehensive Australian university. Studies in Higher Education, 25(3), 279-294. doi:10.1080/713696158.

World Bank (2015). Kenya among the fastest growing economies in Africa.Retrieved on 2015/03/05/ from http://www.worldbank.org/en/news/press-release.

Yair, G. (2008). Can we administer the scholarship of teaching? Lessons from outstanding professors in higher education. Higher Education, 55(4), 447-459. 
Yellowley, W., \& Marilyn, F. (2006). Team teaching: Engaging diverse student groups in higher education. Reflections on initiatives at Monash University, Australia and Buckinghamshire Chilterns University, UK. The Higher Education Academy Annual Conference Session Papers, July 2006. Retrieved from www.heacademy.ac.uk.

Yilmaz, K. (2008). Constructivism: Its theoretical underpinnings, variations and implications for classroom instruction. Educational Horizons, 86(3), 161-172.

Zepke, N. (2009). Thinking strategically in response to New Zealand's tertiary education strategy: The case of a Wananga. Journal of Management and Organisation, 15(1), 110-121.

Zepke, N., \& Leach, L. (2010). Improving student engagement: Ten proposals for action. Active Learning in Higher Education, 11(3), 167-177. doi:10.1177/1469787410379680. 


\section{Appendices}

\section{Appendix A: Interview/ discussion guide}

(Adapted from Dettmer (2007: Chapter 3) and Cox, et al (2003, p. 90)

RESEARCH TITLE: Exploring the quality of teaching and learning experiences in higher education using the theory of constraints (TOC)-thinking process (TP): New Zealand and Kenya

1. Please share what you like about your career as $15 *$ ?

2. In an ideal world, what should learning/teaching/teaching \& learning* be like in your business school?

3. In your current role, what do you enjoy/like about learning/teaching/teaching \& learning environment? a. In your current role, are there any things that you do not like learning/teaching/teaching \& learning?

4. Do you think we need any changes learning/teaching/teaching \& learning? Why?

5. In your opinion, what would you say is the goal(s) of learning/teaching/teaching \& learning?

6. What do you consider are the most important factors necessary for achieving that goal(s)?

7. What are the necessary conditions required to satisfy the important/critical success factors you just identified? a. Which (if any) of these necessary conditions are not being met?

8. What are some of the obstacles that impact your ability to achieving the learning/teaching/teaching \& learning goal?

a. In your opinion, how would you overcome these obstacles?

b. Have you developed any strategies to overcome these obstacles?

9. Are there specific problems (undesirable issues) you have encountered within your role regarding learning/teaching/teaching \& learning? (please avoid use of names)

a. Can you highlight 2 or 3 most important problems/undesirable issues? (please avoid use of names)

10. Why do you identify the issue(s) as being undesirable or bad?

a. What do you feel really causes the problem or undesirable issues?

b. How do these problems or undesirable issues affect your ability to achieve the learning/teaching/teaching \& learning related goals?

c. Why then do you still continue to put up with the problem/undesirable issues?

11. Do you experience any conflicts or dilemmas as a result of these problems or undesirable issues?

a. Please describe the conflict or the dilemma

b. What suggestions would you recommend to help alleviate the problem or eliminate the conflict?

12. What obstacles do you feel may likely serve as barrier(s) to the implementation of your proposed suggestion/solution?

13. If all of your solutions were implemented, what benefits would you expect to arise as a result of the actions?

14. How would these solutions impact your experience as * student/lecturer/administrator?

15. Is there anything else you would like to share about your experience as * student/lecturer/administrator in your school/university?

\footnotetext{
$15 *$ This question was adjusted based on whether it is the dean/head of business school, associate dean of students, director of quality assurance, associate dean teaching and learning, or heads of schools/departments. Similarly, the framing of the question was adjusted to suit the particular participant(s) with emphasis on teaching, learning or both.

*In the case of students the first question read...Please share what attracted you to do a degree in business? Subsequent adjustments emphasised learning

*In the case of lecturers the first question read... Please share what attracted you to a teaching career. Subsequent adjustments emphasised teaching
} 


\section{Appendix B: Human Ethics Approval}

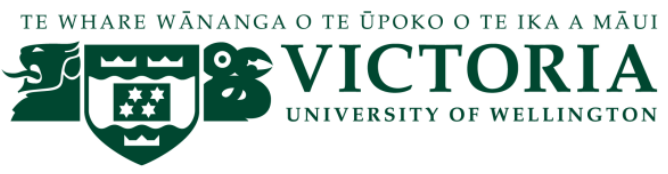

\section{HUMAN ETHICS COMMITTEE}

\section{Application for Approval of Research Projects}

Please write legibly or type if possible. Applications must be signed by supervisor (for student projects) and Head of School

Note: The Human Ethics Committee attempts to have all applications approved within three weeks but a longer period may be necessary if applications require substantial revision.

\section{NATURE OF PROPOSED RESEARCH:}

\section{Student Research}

If Student Research Degree: PhD in Management Course Code: MGMT 690

Project Title: Exploring the quality of teaching and learning experiences in higher education using the theory of constraints-thinking process: New Zealand and Kenya.

\section{INVESTIGATORS:}

\section{Principal Investigator}

Name: Sarah Kimani

Email address: sarah.kimani@vuw.ac.nz.

School of Management

Other Researchers: $\quad$ N/A

Supervisor (in the case of student research projects)

i. $\quad$ Prof. Vicky Mabin

ii. Prof. John Davies

\section{DURATION OF RESEARCH}

Proposed starting date for data collection: Immediately after HEC approval/September 2013

(Note: that $\mathrm{NO}$ part of the research requiring ethical approval may commence prior to approval being given)

Proposed date of completion of project as a whole: December 2016

\section{PROPOSED SOURCE/S OF FUNDING AND OTHER ETHICAL CONSIDERATIONS}

\section{Sources of funding for the project}

Please indicate any ethical issues or conflicts of interest that may arise because of sources of funding e.g. restrictions on publication of results 
This is a self- funded study/research

Is any professional code of ethics to be followed

If yes, name

Is ethical approval required from any other body

If yes, name and indicate when/if approval will be given

\section{No}

\section{DETAILS OF PROJECT}

\section{Briefly Outline:}

\section{The objectives of the project}

To apply the theory of constraints* tools to identify the higher education teaching and learning system goal( $(s)$ in $N Z$ and Kenya with a view to identifying the critical success factors and necessary conditions for goal achievement in each case.

(a) To apply the theory of constraints tools to identify the factors that affect the quality of higher education teaching and learning experiences in NZ and Kenya with a view to identifying the critical root causes of less than desirable teaching and learning experiences in each case

(b) To apply theory of constraints tools of analysis to determine the impact of higher education teaching and learning experiences on the performance of higher education teaching and learning systems in NZ and Kenya with a view to understanding what currently limits the higher education teaching and learning system's performance in each case.

(c)To propose improvements that might enhance the quality of teaching and learning experiences and the performance of teaching and learning systems.

*Theory of constraints is a multi-faceted systems methodology that was developed to assist people and organisations to think about problems, develop breakthrough solutions and implement those solutions successfully (Mabin \& Balderstone, 2003). While there are now many different tools, principles and methods within the methodology, it primarily provides an approach to continuous improvement of organisations based on the premise that constraints determine the performance of a system (Blackstone, 2001). The 'thinking processes' comprise a suite of logic diagrams (tools) together with protocols for constructing and checking the logic at each stage from goal identification, problem diagnosis, and solution design through to implementation.

\section{Method of data collection}

Data will be collected in form of focus group discussions with students, academic staff and administrative staff at 2 business schools (the intention is to approach one school in NZ and one in Kenya). Participants will participate in the mix of focus groups (3-10 persons /group). The following are anticipated in each business school:

2 focus groups with students -approximately 6-10 students per focus group 
1 or 2 focus group(s) with academic staff** - approximately 4-8 staff per focus group

1 focus group with administrative staff** - approximately 3-6 staff per focus group

Personal interviews will be used with academic and administrative staff:

Academic staff**-approximately 10- The number reached using the focus group discussions with academic staff will influence the number to be personally interviewed.

Administrators- approximately 5- mainly the Deans of Schools, the Deans of Students, Associate Dean Teaching \& Learning, and Quality Assurance coordinator/director

**Either focus group or personal interview will be used depending on the flexibility of the participants.

\section{Characteristics of the participants}

University undergraduate students in schools of business

University academic staff in schools of business

University administrators - mainly the Dean of each Business School, and the Associate Dean of Students,

Associate Dean Teaching \& Learning, Quality Assurance coordinator/director and heads of

schools/departmental heads (or equivalent).

\section{The benefits and scientific value of the project}

The study will bridge the gaps that exist in literature in relation to teaching and learning system goal(s), the nature of experiences of teachers and learners in higher education and the impact of their experiences on performance of teaching and learning system relative to the goal(s). The use of two diverse cases will provide deeper knowledge of the quality of teaching and learning experiences within higher education institutions that are at different stages of higher education reforms as well as contextualised knowledge within the theory of constraints framework, leading to theoretical and/or methodological developments of theory of constraints.

\section{Method of recruitment}

The following departments in each university will be contacted to seek their cooperation in recruitment:

Students: International offices, school administrators/registrar, student association or equivalent, Māori \& Pacific office.

Lecturers: Human resource departments/faculty dean's office

Administrative staff: Initial email or telephone call to book appointments will be made.

The initial contact will be either by phone or email as will be deemed appropriate requesting for voluntary participation in the interviews.

Payments that are to be made/expenses to be reimbursed to participants

N/A

Other assistance (e.g. meals, transport) that is to be given to participants

Students will be given snacks or a small token for lunch.

Any special hazards and/or inconvenience (including deception) that participants will encounter

No

State whether consent is for (delete where not applicable):

(i) The collection of data

(ii) Attribution of opinions or information 
(iii)Use for a conference report or a publication

(i) State whether consent is for:
(i) The collection of data Yes
(ii) Attribution of opinions or information Yes
(iii) Release of data to others No
(iv) Use for a conference report or a publication Yes
(v) Use for some particular purpose (specify) Yes

To propose and/or effect changes in business schools' practices as might be appropriate as a result of these findings.

Attach a copy of any questionnaire or interview schedule to the application (done)

How is informed consent to be obtained (see sections 4.1, 4.5(d) and 4.8(g) of the Human Ethics Policy?)

(i) the research is strictly anonymous, an information sheet is supplied and informed consent is implied by voluntary participation in filling out a questionnaire for example (include a copy of the information sheet)

(ii) the research is not anonymous but is confidential and informed consent No will be obtained through a signed consent form (include a copy of the consent form and information sheet)

(iii) the research is neither anonymous nor confidential and informed consent will be obtained through a signed consent form (include a copy of the consent form and information sheet)

(iv) informed consent will be obtained by some other method (please specify and provide details)

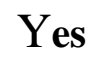

With the exception of anonymous research as in (i), if it is proposed that written consent will not be obtained, please explain why N/A

If the research will not be conducted on a strictly anonymous basis state how issues of confidentiality of participants are to be ensured if this is intended. (See section 4..1(e) of the Human Ethics Policy). (E.g. who will listen to tapes, see questionnaires or have access to data). Please ensure that you distinguish clearly between anonymity and confidentiality. Indicate which of these are applicable.

(i) access to the research data will be restricted to the investigator

No

(ii) access to the research data will be restricted to the investigator and their Yes supervisor (student research) 
(iii) all opinions and data will be reported in aggregated form in such a way No that individual persons are not identifiable

(iv) Other (please specify)

Procedure for the storage of, access to and disposal of data, both during and at the conclusion of the research. (see section 4.12 of the Human Ethics Policy). Indicate which are applicable:

(i) all written material (questionnaires, interview notes, etc.) will be kept Yes in a locked file and access is restricted to the investigator

(ii) all electronic information will be kept in a password-protected file and Yes access will be restricted to the investigator

(iii) all questionnaires, interview notes and similar materials will be destroyed:

(a) at the conclusion of the research

No

(b) five (5) years after the conclusion of the research; or

(iv) any audio or video recordings will be returned to participants and/or Yes electronically wiped

(v) other procedures (please specify):

If data and material are not to be destroyed please indicate why and the procedures envisaged for on-going storage and security N/A

Feedback procedures (See section 7 of Appendix 1 of the Human Ethics Policy). You should indicate whether feedback will be provided to participants and in what form. If feedback will not be given, indicate the reasons why.

After the focus group discussions and/interviews, data will be summarised in form of aggregate graphical representations (in form of logic trees) that will be fed back to the individual interviewees and relevant groups to confirm that the trees adequately capture their views. Participants will also have opportunity to receive a written summary of the findings of this study.

Reporting and publication of results. Please indicate which of the following are appropriate. The proposed form of publications should be indicated on the information sheet and/or consent form. 
Appendices

(i) publication in academic or professional journals

(ii) dissemination at academic or professional conferences
Yes

Yes

(iii) deposit of the research paper or thesis in the University Library Yes (student research)

(iv) other (please specify)

Signature of investigators as listed on page 1 (including supervisors) and Head of School.

NB: All investigators and the Head of School must sign before an application is submitted for approval

Principal Investigator

Sarah Kimani

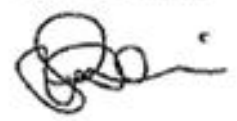

Date: 08/10/2013

Supervisors

Prof. Vicky Matin

Viatoialar.

Date: $8 / 10 / 13$

Prof. John Davies

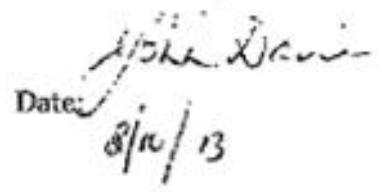

Heapofschool Relume

Date. $1 / 1 / 10 / 1.3$

325 


\section{Appendix C: Information sheet for participants}

RESEARCH TITLE: Exploring the quality of teaching and learning experiences in higher education using the theory of constraints (TOC)-thinking process (TP): New Zealand and Kenya

Dear Sir/Madam,

My name is Sarah Kimani. I would like to invite you to participate in my $\mathrm{PhD}$ research for which Human Ethics Committee approval has been granted. The research aims to explore the quality of teaching and learning experiences in higher education and determine how these experiences impact on the performance of teaching and learning systems relative to their goal(s). The research will be conducted in New Zealand and Kenya. Personal interviews and focus group interviews will be used and will cover issues related to the goals of teaching and learning; the causes and effects of less than desired quality of teaching and learning experiences; proposed changes to improve teaching and learning experiences; implementation of proposed changes and the expected benefits of the change. The research seeks participation of university students, lecturers and senior administrative staff. It is envisaged that this study will lead to a better understanding of teaching and learning experiences and their impact on the performance of teaching and learning systems relative to their goal(s).

In order to understand the above research issues, I invite you to a personal interview ${ }^{16}$ at a time suitable for you. The interview will last no longer than one hour. I might also require some of your time, some weeks later, to help in general confirmation of the accuracy of my data pre-analysis. This pre-analysis will be in form of cause-effect diagrams that will be constructed by combining administrators' interview data.

The information that you will provide will be used only for the purpose of this research project and access to this information will be strictly limited to me and my two supervisors. The information will be securely stored in locked files and in password protected files and only accessible to me. The information will be destroyed five years after completion of this research project. I will also ensure that your name or your identity is not disclosed at any time in the write ups. All write ups will be anonymised by combining the results of administrators' views in the analyses.

If you agree to be interviewed ${ }^{17}$, I will ask you to fill in a consent form which aims at adequately informing you how your rights as a participant will be respected. Informed consent is a requirement of the Victoria University of Wellington Human Ethics Committee, which ensures that all research conforms to ethical standards.

Thank you for your time and cooperation in this research endeavour. If you have any queries, please use the contact below:

\section{CONTACT INFORMATION}

Professor Vicky Mabin

Associate Dean (Teaching and Learning)

Victoria Business School Orauariki

Victoria University of Wellington,

23 Lambton Quay, Pipitea Campus

P.O. Box 600, Wellington 6140 .

Phone: +64 4 463-5140

Email: Vicky.mabin@vuw.ac.nz

$\begin{array}{lr}\begin{array}{l}\text { Sarah Kimani } \\ \text { Doctoral }\end{array} & \text { researcher } \\ \text { School } & \text { Management } \\ \text { Victoria University of Wellington } & \\ \text { P.O. Box 600, Wellington 6140. } & \\ \text { Phone: +64 223055467 } & \\ \text { Phone:+254716641262 } & \text { Email: sarah.kimani@vuw.ac.nz,swambui@ cuea.edu }\end{array}$

\footnotetext{
${ }^{16}$ In the case of students, this read: I invite you to join a focus group discussion that will comprise six to ten student participants, at a time suitable for you. The group discussion will last no longer than two hours.

17 ...Join the focus group
} 
Appendices 


\section{Appendix D: Informed consent form (for interviews)}

RESEARCH TITLE: Exploring the quality of teaching and learning experiences in higher education using the theory of constraints (TOC)-thinking process (TP): New Zealand and Kenya

I have read the research project information sheet and have understood the purpose of this study. The details of the study have been explained to me. I understand that the information that I will provide will be kept securely and is only accessible to the researcher and two supervisors. My questions about the study have been answered to my satisfaction and I understand that I may ask further questions at any time.

${ }^{18}$ Furthermore, I understand that my participation is voluntary and that I have the right to withdraw from the interview (or any information that I have provided after a maximum period of 3 days) or decline to answer particular questions without giving my reasons for such actions and at no penalty whatsoever.

Based on this, I agree to participate and to provide the information to the researcher under the conditions that no remarks made in the interview will be attributed to me.

I agree ( ) do not agree ( ) to have the interview recorded. I also understand that if at some point I am not comfortable with the recording, I can request the researcher to put off the tape recorder.

\section{Participant:}

Signed:

Institution:

Date:

I wish to receive written summary of the findings of this study. My email address is:

\footnotetext{
${ }^{18}$ The focus group read: Furthermore, I understand that my participation is voluntary and that I can withdraw from the focus group. However, my statements prior to my withdrawal cannot be removed. 


\section{Appendix E: Research Authorisation \& Clearance Permit}

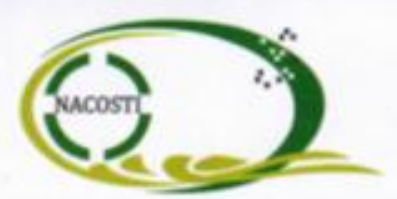

\section{NATIONAL COMMISSION FOR SCIENCE,} TECHNOLOGY AND INNOVATION

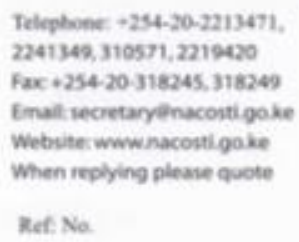

\section{RE: RESE.ARCH AUTHORIZATION}

Following your application dated $23^{\text {Nd }}$ October, 2013 for authority to carry out research on "Exploring the quality of teaching and learning experiences in higher education using the Theory of Constraint (TOC) - Thinking Process (TP): New Zealand and Kenya," I am pleased to inform you that you have been authorized to undertake research in Nairobi County for a period ending $31^{\text {"t }}$ December, 2016.

You are advised to report to the County Commissioner and the County Director of Education, Nairobi County before embarking on the research project.

On completion of the research, you are expected to submit two hard copies and one soft copy in pdf of the research report/thesis to our office.

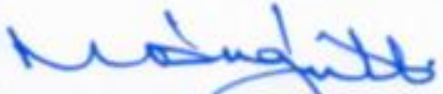

DR. M. K. RUGUT, PhD, HSC.

DEPUTY COMMISSION SECRETARY

NATIONAL COMMISSION FOR SCIENCE. TECHNOLOGY \& INVOVATION

Copy to:

The County Commissioner

The County Director of Education

Nairobi County. 
PAGE 2

THIS IS TO CERTIFY THAT:

Prof./Dr./Mr./Mrs./Miss/Institution

Sarah Kimani

of (Address) Victoria University of Wellington

New Zealand.

has been permitted to conduct research in

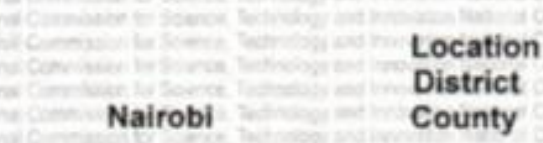

On the topic: Exploring the quality of teaching And learning experiences in higher education Using the Theory of Constraint (TOC) - Thinking Process (TP): New Zealand and Kenya.

for a period ending: 31" December, 2016.

\section{Conomiovs}

1. You must report to the County Commissioner and the County Education Officer ef the area before embarking on your research. Failure to do that may lead to the cancellation of your permit

2. Gavernment Officers will net be interviewed without prior appointment.

3. No questionaaire will be used uniess it has been approved.

4. Excavation, filming and collection of biological specimens are subject to further permission from the relevant Government Ministries.

5. You are required to subenit at least two(2) hard copies and one(1) soft copy of yeur final report.

6. The Goverament of Kenya reserves the right to modify the conditions of this permit inctuding

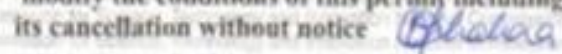

\section{PAGE 3}

Research Permit No. NACOSTVRCD/14/013/1747

$\begin{array}{ll}\text { Date of issue } & 29^{\mathrm{h}} \text { October, } 2013 \\ \text { Fee received } & \text { KSHS, 2000 }\end{array}$
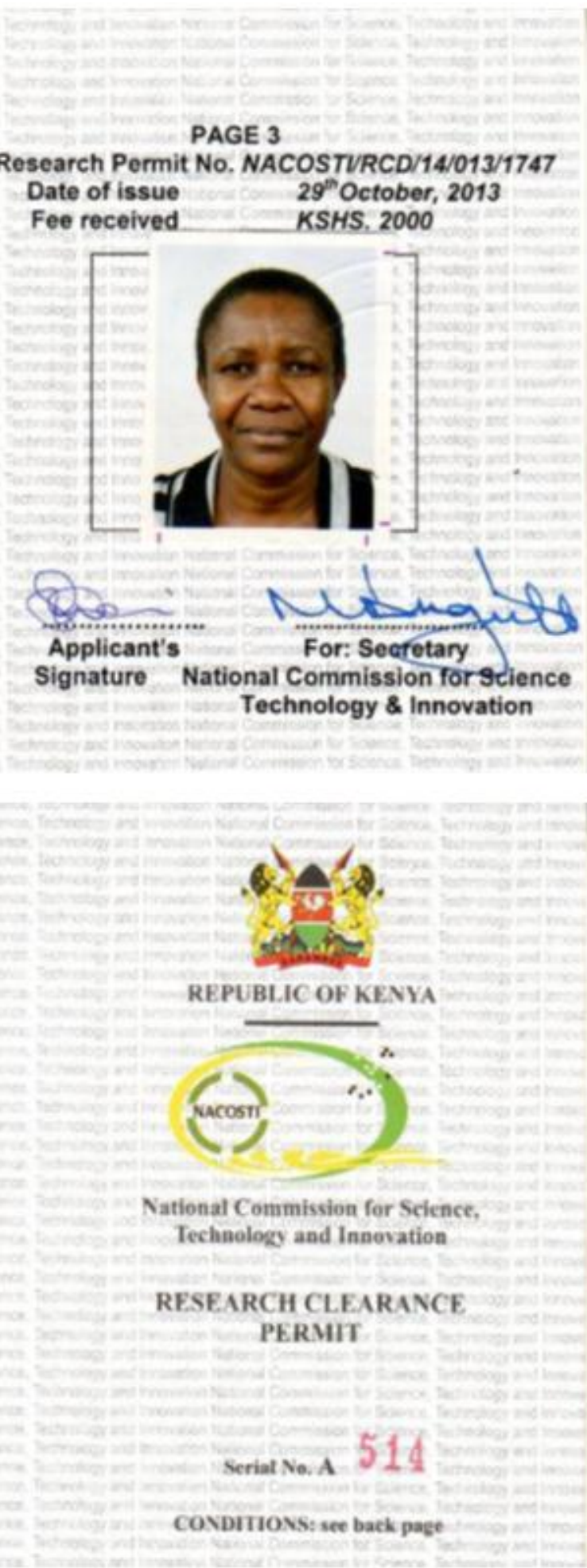


\section{Appendix F: University of Nairobi Permit}

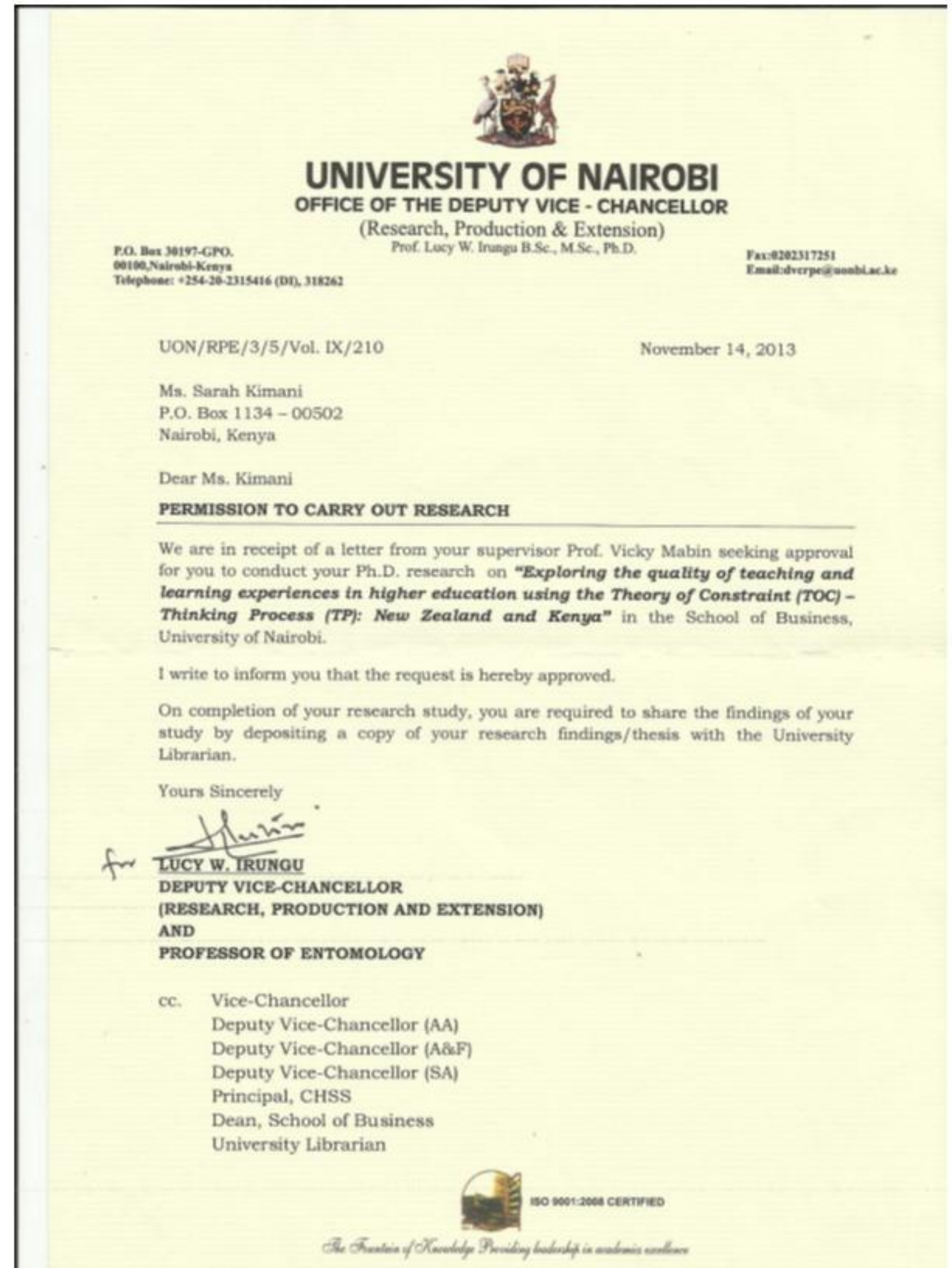




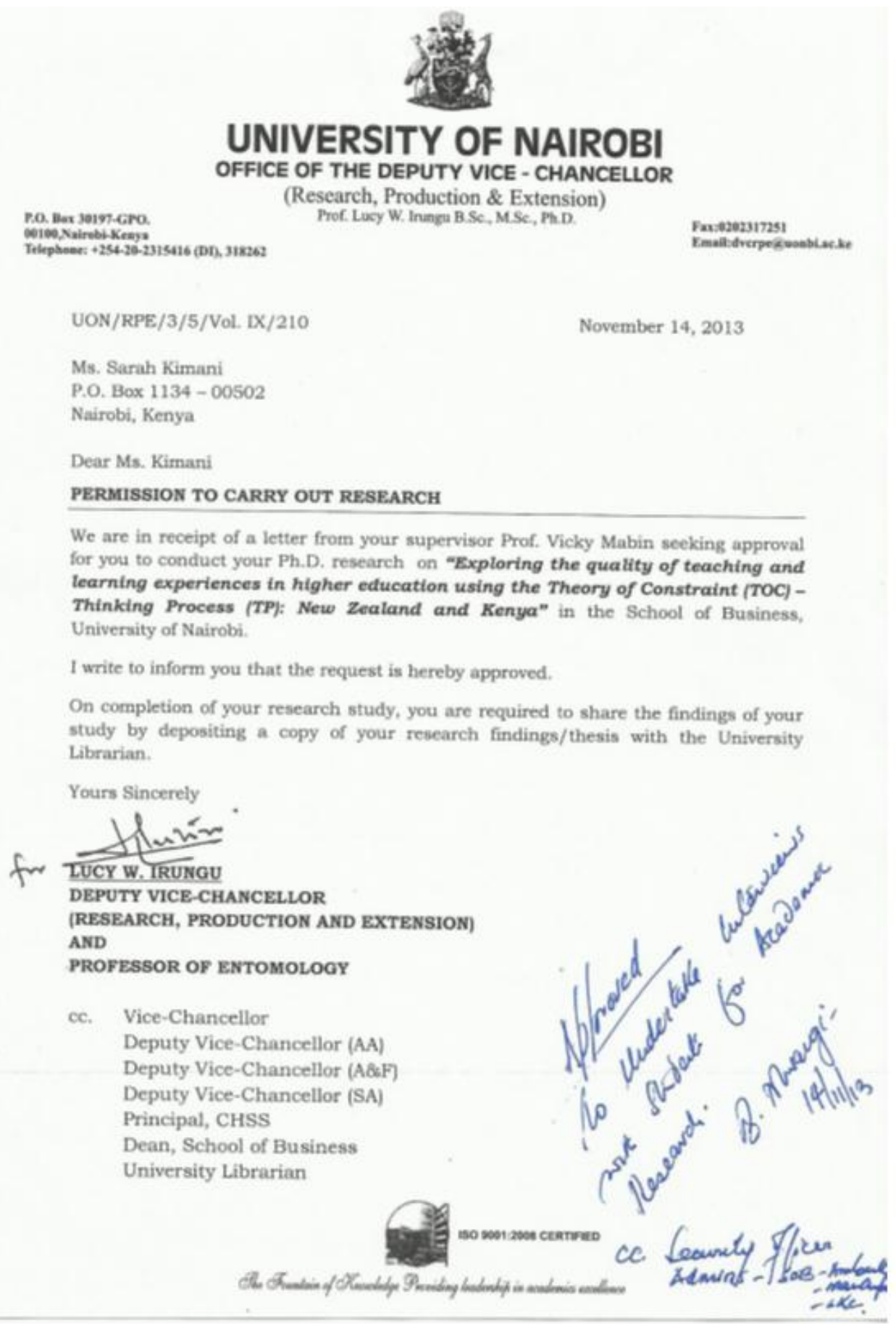




\section{Appendix G: Biggs' 3P model}

The 3P model was developed by Biggs in 1993. It conceptualises three stages in the learning and teaching (L\&T) process, and in which L\&T related factors are framed (Dart et al., 2000; Prosser \& Trigwell, 2014):

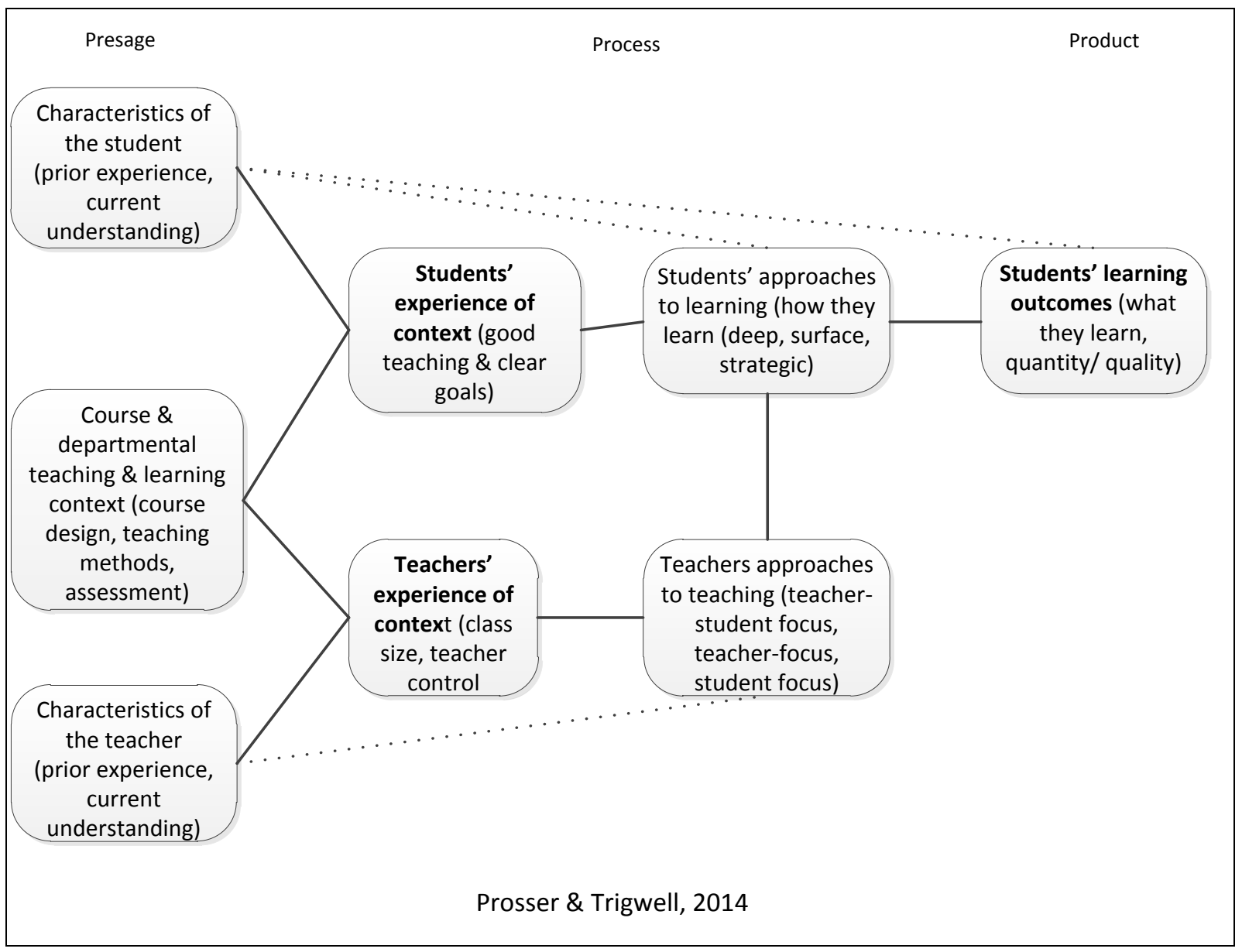


Presage variables are those that pre-exist within a university even before students start the learning process. The model identifies three aspects or dimensions. The first relates to student characteristics brought into the learning system such as prior knowledge and prior ways of learning, capabilities, values and expectations (Dart et al., 2000).

The second aspect relates to the teaching context in which $L \& T$ takes place. It includes the course structure, curricula content, the teaching methods and assessment. The interaction between students' characteristics and the teaching contexts create students' experiences of the L\&T. In particular, students approach their studies based on their perceptions of context and on the teachers' approaches to teaching (Dart et al., 2000). The student approach to study then impacts the quality of their learning outcome (Devlin, 2006).

The third aspect relates to the characteristics of teachers entering the teaching system comprising prior experiences and understanding of the L\&T context. The teacher characteristics together with the departmental L\&T contexts, impact the teaching approaches that a teacher adopts (Prosser \& Trigwell, 2014), and student approaches to learning.

In the process phase, Biggs suggests there are four basic variables which interact with the presage factors. These variables are: the students' perceived experiences of the L\&T context, student approaches to learning; teachers' perceptions of experiences of teaching context and teaching approaches. These aspects result from interactions with the presage factors.

The product variables are concerned with the outcome of the educational process and are determined by the learning approaches. They include student performance (confidence, competence and capability), retention and employability (Dart et al., 2000; Gibbs, 2010). 
Appendices

Appendix H: The CRT (attached) 